Adam R. Heinrich

ALL RIGHTS RESERVED 


\title{
A ZOOARCHAEOLOGICAL INVESTIGATION INTO THE MEAT INDUSTRY \\ ESTABLISHED AT THE CAPE OF GOOD HOPE BY THE DUTCH EAST INDIA COMPANY IN THE SEVENTEENTH AND EIGHTEENTH CENTURIES.
}

By

ADAM R. HEINRICH

\author{
A Dissertation submitted to the \\ Graduate School-New Brunswick \\ Rutgers, The State University of New Jersey \\ In partial fulfillment of the requirements \\ For the degree of \\ Doctor of Philosophy \\ Graduate Program in Anthropology \\ Written under the direction of \\ Carmel Schrire \\ And approved by
}

New Brunswick, New Jersey

May 2010 


\begin{abstract}
OF THE DISSERTATION
A Zooarchaeological Investigation Into the Meat Industry Established at the Cape of Good Hope by the Dutch East India Company in the Seventeenth and Eighteenth Centuries.
\end{abstract}

By ADAM R. HEINRICH

Dissertation Director:

Carmel Schrire

The Dutch East India Company (VOC) established their settlement at the Cape of Good Hope in 1652 in order to refresh passing trade ships with fresh water, vegetables, and meat in hopes of lessening disease and death during the long voyages around the tip of Africa between Europe and the Far East. The great demand for meat provided an impetus for Dutch-Khoehoe interactions which ultimately drained the Khoekhoe of their wealth, land, and identity. Currently, with the exception of the terrestrial faunal from Oudepost I (Cruz-Uribe and Schrire 1991), historic period faunal analyses at the Cape have been very localized, superficially descriptive, and taphonomically flawed, which has 
lead to very little understanding of the overall colonial meat market and included some implausible interpretations.

This thesis takes into account contextual evidence, applies zooarchaeological methodology, and incorporates actualistically-based research into taphonomic traces on bone surfaces and to better reconstruct the originally deposited samples. The investigation of the VOC's meat industry that was emplaced at the Cape is carried out through the investigation of five faunal samples including three sites from the Castle of Good Hope; the Moat, the Granary (F2), and Donkergat (DKG); Elsenburg; and the Dump from Oudespost I. The systemic approach provides information about livestock production, slaughter, and consumption at the Cape with information about large scale slaughter for local markets or trade ship provisioning. This thesis describes the transplanted European husbandry practices as the VOC overcame initial hardships of meeting high meat demands to become the dominant power across the landscape. 


\section{ACKNOWLEDGEMENTS}

I would foremost like to thank Carmel Schrire for sharing her guidance and critical mind, while also having great patience throughout the research and writing of this dissertation. I would also like to thank my dissertation committee, Robert Blumenschine, Robert Scott, and David Landon (University of Massachusetts- Boston), for helpful critiques and advice. I would like to additionally thank Robert Blumenschine for his instruction in faunal analysis and taphonomy.

I would like to thank Royden Yates, Graham Avery, Margaret Avery and Lalou Meltzer who were instrumental in helping me gain access and navigate the IZIKO: South African Museum, especially Graham Avery for working alongside me to help identify various bones and the birds. Thanks are also extended to the faculty at the University of Cape Town's Archaeology Department for allowing me access to various faunal assemblages kept in their store rooms. I also appreciate the help from Richard Klein (Stanford University) who had helped me with some bone specimens in addition to reviewing some portions of this work. I would also like to thank Eileen Westwig at the American Museum of Natural History for providing access to their Mammalogy Collections.

Funding for this research has been obtained from Special Opportunity Award, Bigel Grants, the Center for Human Evolutionary Studies Student Grant at Rutgers University, and Wenner-Gren.

Outside of the thesis research and writing, I would like to thank colleagues who broadened my archaeological experiences including Charles Bello, Carolyn Dillian, Matt Tomaso and crew at CRCG; Paul McEachen and Robert Lore at Richard Grubb and 
Associates; Bill Liebeknecht, Ian Burrows, Richard Hunter and crew at Hunter Research; and especially Richard Veit for education and inspiration on topics from gravestones to mansions. Zuletzt, möchte ich meiner Familie und meine liebe Alison Kepple für Liebe und Stabilität danken. 


\section{TABLE OF CONTENTS}

ABSTRACT ii

ACKNOWLEDGEMENTS iv

TABLE OF CONTENTS vi

LIST OF TABLES viii

LIST OF FIGURES $\quad$ x

CHAPTER ONE: Introduction 1

I. Research Objectives $\quad 1$

II. Historical Period Zooarchaeology 3

III. Historical Background $\quad 5$

IV. Animals at the Cape 12

V. Animals in Food from the European Homeland and the Cape 46

VI. Summary of Historical Zooarchaeology at the Cape from the

Seventeenth and Eighteenth Centuries 61

CHAPTER TWO: Methodology

I. Sampling $\quad 66$

$\begin{array}{ll}\text { II. Taphonomy } & 67 \\ \end{array}$

III. Taxonomy and Quantifications $\quad 73$

IV. Ages of the Fauna $\quad 75$

$\begin{array}{ll}\text { V. Sex } & 79\end{array}$

$\begin{array}{ll}\text { VI. Butchery } & 81\end{array}$

CHAPTER THREE: Castle of Good Hope's Moat 83

I. History $\quad 83$

II. Archaeology $\quad 85$

III. Faunal Results $\quad 93$

IV. Discussion 116

CHAPTER FOUR: Donkergat (DKG) 129

$\begin{array}{lr}\text { I. History } & 129\end{array}$

$\begin{array}{lr}\text { II. Archaeology } & 130\end{array}$

III. Faunal Results 132

IV. Discussion 146

CHAPTER FIVE: The Granary (F2) $\quad 148$

$\begin{array}{lr}\text { I. History } & 148 \\ & 148\end{array}$

$\begin{array}{ll}\text { II. Archaeology } & 149\end{array}$

III. Thackeray's Faunal Results 157

$\begin{array}{lr}\text { IV. Faunal Results } & 159\end{array}$ 
$\begin{array}{lr}\text { CHAPTER SIX: Elsenburg } & 184\end{array}$

$\begin{array}{ll}\text { I. History } & 184\end{array}$

$\begin{array}{lr}\text { II. Archaeology } & 187\end{array}$

III. Faunal Results 194

IV. Discussion $\quad 212$

CHAPTER SEVEN: Oudepost I Dump (DP) 225

$\begin{array}{ll}\text { I. History } & 225 \\ \end{array}$

II. Terrestrial Faunal Summary 225

III. Archaeological Summary of the Dump Deposit 227

$\begin{array}{ll}\text { IV. Faunal Results from DP } & 228\end{array}$

$\begin{array}{ll}\text { V. Discussion } & 240\end{array}$

CHAPTER EIGHT: Determining Breed Difference 244

$\begin{array}{ll}\text { I. Introduction } & 244\end{array}$

$\begin{array}{ll}\text { II. Sexual Dimorphism } & 246\end{array}$

III. Methodology and Materials $\quad 251$

IV. Known-Sex Results 258

V. Archaeological Results $\quad 264$

VI. Age-Related Variation in Tooth Row Lengths 275

VII. Age Variation Discussion $\quad 281$

$\begin{array}{ll}\text { VIII. Conclusion } & 282\end{array}$

CHAPTER NINE: Conclusion $\quad 285$

I. Scope of the Thesis $\quad 285$

II. Characteristics of the VOC Meat Industry 286

III. The Impact of the VOC Meat Industry on the Cape Landscape 297

IV. The VOC Meat Industry's Impact on the Cape Culture 302

V. Contributions to Slave Zooarchaeology 309

VI. In Closing $\quad 312$

$\begin{array}{ll}\text { APPENDICES } & \mathbf{3 1 5}\end{array}$

1. Analysis Coding Conventions 315

2. Osteological Coding Conventions 318

$\begin{array}{ll}\text { WORKS CITED } & 321\end{array}$

CURRICULUM VITA 
1.1 Historical references to the domestic animals kept during the VOC period at the Cape with the time of their introduction and place of origin. 15

2.1 Criteria recorded to assess bone condition 69

2.2 Criteria recorded to describe non-butchery related taphonomic traces $\quad 72$

2.3 Basic criteria recorded from specimens 76

2.4 Criteria recorded to describe butchery related taphonomic traces $\quad 82$

3.1 Tobacco pipestem mean bore diameter according to Levels 93

3.2 Sample sizes for respective columns and levels 94

3.3 Surface condition observed on all bone fragments 96

3.4 The degree of root etching on the bone fragments 96

3.5 Measures of long bone completeness 98

3.6 Taxonomic representations in the Moat samples 101

$\begin{array}{lll}3.7 & \text { Sheep postcranial epiphyseal fusion NISP } & 104\end{array}$

$\begin{array}{lll}3.8 & \text { Cattle postcranial epiphyseal fusion NISP } & 106\end{array}$

3.9 The frequencies of butchery and burning in each Level 113

4.1 Sample sizes (NISP) for each Layer in Column 1 in DKG 132

4.2 Measures of long bone completeness 133

4.3 Taxonomic representations in each respective Layer in DKG 137

4.4 Estimated meat contributions from sheep and cattle in Layer 4 137

4.5 Sheep postcranial epiphyseal fusion stages for Layer $4 \quad 138$

4.6 Cattle postcranial epiphyseal fusion stages for Layer $4 \quad 139$

4.7 Pig postcranial epiphyseal fusion stages for Layer $4 \quad 139$

$\begin{array}{lll}\text { 4.8 The frequencies of butchery and burning in each Layer } & 143\end{array}$

5.1 Hall's and Yates et al.'s pipestem bore sample sizes and mean diameters 156

5.2 Thackeray's MNI by Phase 159

5.3 Sample sizes (NISP) for Phase 1 and Phase $7 \quad 159$

5.4 Measures of long bone completeness 161

5.5 Frequencies of abrasion damage observed on bone surfaces 162

5.6 Frequencies of carnivore damage observed on bone surfaces 163

5.7 Frequencies of butchery and cooking evidence 163

$\begin{array}{lll}5.8 & \text { Bone breakage patterns } & 164\end{array}$

5.9 Taxonomic representations in Phase 1 and Phase 7 of the Granary 165

5.10 Bird taxa identified in the various Phases of the Granary 166

$\begin{array}{lll}5.11 & \text { Sheep epiphyseal fusion frequencies } & 169\end{array}$

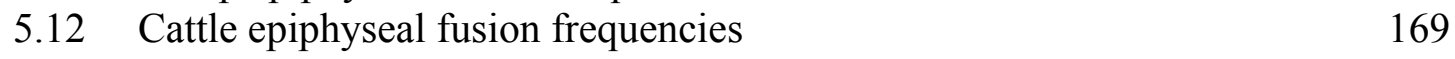

5.13 Skeletal part frequencies of Ovis aries/size 2 bovids by NISP and
compared to Thackeray's sheep-only results

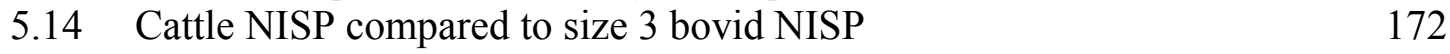

$\begin{array}{lll}5.15 & \text { Summary of Cannon's Point faunal samples } & 174\end{array}$

5.16 Summary of Monticello's faunal samples 176

$\begin{array}{lll}6.1 & \text { Sample sizes of DBYC } 6 & 194\end{array}$

6.2 Surface condition observed on the bone fragments from DBYC 6 194

$\begin{array}{lll}6.3 & \text { Bone breakage patterns } & 196\end{array}$

6.4 Measures of long bone completion 197 
6.5 Taxonomic representations in the DBYC 6 sample 199

6.6 Estimated meat contributions from sheep and cattle in DBYC 6200

6.7 Sheep postcranial epiphyseal fusion NISP 202

6.8 Cattle postcranial epiphyseal fusion NISP 203

$\begin{array}{lll}6.9 & \text { Pig postcranial epiphyseal fusion NISP } & 204\end{array}$

6.10 The frequencies of butchery and burning in DBYC 6 209

$\begin{array}{lll}7.1 & \text { Sample sizes (NISP) for both DP analyses } & 229\end{array}$

7.2 Bone fragment surface condition for DP 3-16 229

$\begin{array}{ll}7.3 & \text { Bone breakage patterns from DP 3-16 } \\ 7.42\end{array}$

$\begin{array}{lll}7.4 & \text { Measures of long bone completion } & 232\end{array}$

$\begin{array}{ll}7.5 & \text { Taxonomic representations in DP } \\ 7.6 & \text { Catle postan }\end{array}$

7.6 Cattle postcranial epiphyseal fusion stages from DP 3-16 236

$\begin{array}{lll}\text { 7.7 Pig postcranial epiphyseal fusion stages from DP 3-16 } & 237\end{array}$

7.8 Frequencies of processing damage on the bone fragments from DP 3-16 240

8.1 Sample sizes, means, normality, and skewness for each sample of the known-sex bovids 258

8.2 Mann-Whitney comparisons of the measurements for the known-sex bovid samples 262

8.3 Sample sizes, means, normality, and skewness for each archaeological sheep sample 264

8.4 Mann-Whitney comparisons of the measurements for the archaeological sheep samples 264 
1.1 A map of the Western Cape illustrating the locations of towns, sites, and geographic locales mentioned throughout the thesis.

1.2 Modern map of Cape Town illustrating the locations of archaeological sites within the urban center. 1) Van der Stel Moat, 2) Donkergat (DKG), 3) F2 the Old Granary, 4) Darling Street Moat, 5) Grand Parade, 6) Slave Lodge.

1.3 Drawings of prehistoric rock art depicting two fat-tailed sheep 20

1.4 Detail of a 1597 engraving illustrating fat-tailed sheep and cattle 20

1.5 A late seventeenth century illustration showing sheep with relatively thin tails

1.6 A late seventeenth century sketch illustrating Khoekhoe people milking an indigenous Cape cow

1.7 Lady Anne Barnard's illustration of a waterker candle maker 27

1.8 A Dutch map of the Cape settlement's shore in 1678/9 28

1.9 A mid-eighteenth century French map of the Cape settlement showing a butchery

1.10 Lady Anne Barnard's illustration of a carriage 35

1.11 Persian horses being used to thresh wheat 35

2.1 Line drawing illustrating the medial acetabular wall of the Bos taurus pelvis

2.2 Placement of calipers measuring the medial acetabular wall 81

$3.1 \quad 1710$ map of the Castle of Good Hope $\quad 84$

3.2 1767 map of the Castle of Good Hope $\quad 85$

3.3 Aerial photograph of the Castle 88

3.4 Photograph showing the excavation in relation to major architectural components of the Castle

$\begin{array}{lll}3.5 & \text { Photograph showing the area of the Moat excavation } & 89\end{array}$

3.6 The Moat stratigraphy along the length of the excavation 91

3.7 Mean measures of size 2 bone fragments from all sites 95

3.8 Mean measures of size 3 bone fragments from all sites 95

3.9 The frequencies of carnivore tooth mark damage to size 2 bone fragment surfaces

3.10a Abrasion damage frequencies observed on size 2 bone fragments $\quad 99$

$3.10 \mathrm{~b}$ Abrasion damage frequencies observed on size 3 bone fragments 99

3.11a Sheep M3 molar tooth wear profiles N-3 103

3.11b Sheep M3 molar tooth wear profiles N-4 103

3.11c Sheep M3 molar tooth wear profiles S-3 104

3.11d Sheep M3 molar tooth wear profiles S-4 104

$\begin{array}{lll}3.12 \mathrm{a} & \text { Skeletal element profiles N-3 } & 108\end{array}$

$\begin{array}{ll}3.12 b & \text { Skeletal element profiles N-4 } \\ 3.12 c & \text { Skeletal en }\end{array}$

3.12c Skeletal element profiles S-3 108

3.12d Skeletal element profiles S-4 108

3.12e Skeletal element profiles S-5 109

3.13 Histogram illustrating the distribution of medial acetabular 
measurements for sheep in the Moat

\begin{tabular}{ll}
3.14 & Locations of chop, cut, and scrape marks for N-3 \\
\hline
\end{tabular}

3.15 Locations of chop, cut, and scrape marks for S-3 115

3.16a Diagrams illustrating the relative locations of chop and cut marks on the dorsal sides of sheep crania from N-3 116

3.16b Diagrams illustrating the relative locations of chop and cut marks on the ventral sides of sheep crania from N-3

3.17 A 1678/9 map of the Cape Settlement illustrating a tannery on the beach near the Castle

4.1 Aerial photograph of the Castle illustrating the location of the DKG excavation

4.2 Mean measures of size 2 bone fragments from all sites 133

4.3 Mean measures of size 3 bone fragments from all sites 133

4.4 The frequencies of carnivore tooth mark damage to bone surfaces $\quad 134$

4.5 The frequencies of abrasion damage observed on the bone surfaces 135

4.6 Frequencies of rodent damaged bones 136

$\begin{array}{lll}4.7 & \text { Sheep skeletal element profiles } & 140\end{array}$

4.8 Cattle skeletal element profiles 141

4.9 Locations of chop, cut, and scrape marks on sheep from DKG Layer $4 \quad 144$

4.10 Sheep proximal femur showing localized burning 145

4.11 Cattle proximal tibia showing the burning on the interior shaft 145

5.1 Aerial photograph of the Castle illustrating the location of the F2 Granary excavation

5.2 Section photograph illustrating the parallel, platy strata with abrupt stratigraphic breaks

5.3 Mean measures of size 2 bone fragments from all sites $\quad 160$

5.4 Mean measures of size 3 bone fragments from all sites 160

5.5 Third molar wear stages for sheep from both Phases 168

6.1 The U-shaped Herehuis is the centerpiece of Melck's werf
surrounded by several outbuildings

$\begin{array}{ll}\text { 6.2 A plan view of the Herehuis excavations } & 189\end{array}$

6.3 Profile drawing of the kitchen Dump illustrating the stratigraphy 190

6.4 Mean measures of size 2 bone fragments from all sites 195

6.5 Mean measures of size 3 bone fragments from all sites 195

6.6 The frequencies of carnivore tooth mark damage to bone surfaces 196

6.7 The frequencies of abrasion damage observed on the bone surfaces 197

6.8 Sheep M3 molar tooth wear profiles 202

6.9 Angulate tortoise marginal xiphiplastron fragments illustrating the size variability

6.10 Sheep skeletal element profiles 206

6.11 Histogram illustrating the distribution of medial acetabular measurements for sheep in Elsenburg $\quad 207$

6.12 Locations of chop, cut, and scrape marks on sheep from DBYC6 210

6.13 Locations of chop, cut, and scrape marks on cattle from DBYC6 211

7.1 Map locating Oudepost I within the Western Cape including a plan of the three stone structures and DP on the shore of Langebaan Lagoon 226 
7.2 Illustrating flakey, powdery surface and rounding common on the bone fragments from DP

7.3 Mean measures of size 2 bone fragments from all sites 231

7.4 Mean measures of size 3 bone fragments from all sites 231

$\begin{array}{lll}7.5 & \text { Sheep first molar wear stages } & 235\end{array}$

7.6 Sheep second molar wear stages 235

$\begin{array}{lll}7.7 & \text { Sheep third molar wear stages } & 236\end{array}$

7.8 Skeletal element frequencies for sheep from DP 1-16 238

7.9 Skeletal element frequencies for cattle from DP 1-16 239

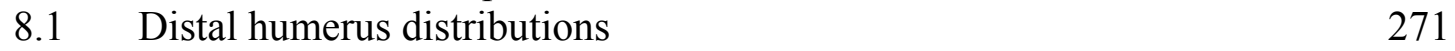

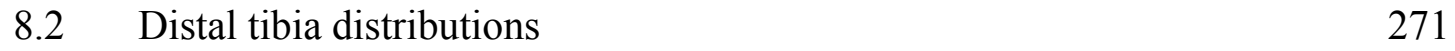

8.3 Mandibular premolar distributions 272

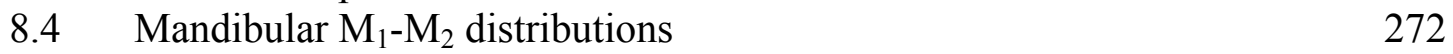

$\begin{array}{lll}8.5 & \text { Mandibular } \mathrm{M}_{1}-\mathrm{M}_{3} \text { distributions } & 273\end{array}$

8.6 Maxillary premolar distributions 273

$\begin{array}{lll}8.7 & \text { Maxillary } \mathrm{M}^{1}-\mathrm{M}^{2} \text { distributions } & 274\end{array}$

8.8 Maxillary $\mathrm{M}^{1}-\mathrm{M}^{3}$ distributions 274

8.9 Contrasting length between the molar tooth row segment between two different aged sheep mandible specimens 276

8.10 Mandibular premolar tooth row length decreases with advancing age 277

8.11 Mandibular $\mathrm{M}_{1}-\mathrm{M}_{2}$ row length decreases with advancing age 277

8.12 Mandibular $\mathrm{M}_{1}-\mathrm{M}_{3}$ row length slightly increases and then may decrease with advancing age

8.13 The mandibular molars showing the trapezoidal crown shape of the $\mathrm{M}_{1}$ and $\mathrm{M}_{2}$, and the increasing mesio-distal length of the $\mathrm{M}_{3}$ down the tooth crown's height

8.14 Maxillary premolar tooth row length shows no clear change through these two age brackets

8.15 The maxillary $\mathrm{M}^{1}-\mathrm{M}^{2}$ tooth row segment decreases slightly through advancing age

8.16 The mean maxillary $\mathrm{M}^{1}-\mathrm{M}^{3}$ tooth row segment may increase with advancing age

8.17 Maxillary molar examples showing the variably shaped crown of the $\mathrm{M}^{1}$ and $\mathrm{M}^{2}$

9.1 Diagram summarizing and comparing the taphonomic details of the major faunal samples discussed in this dissertation

9.2 Diagram summarizing and comparing the main characteristics of the major faunal samples discussed in this dissertation 


\section{CHAPTER ONE: Introduction}

\section{RESEARCH OBJECTIVES}

The Dutch East India Company's (VOC) settlement at the Cape of Good Hope was established in 1652 to support their sea-borne mercantile trade networks between Europe and Asia by provisioning their ships with fresh water, vegetables, fruits, and meat. This dissertation is the first systematic synthesis of production and consumption components of the meat industry. It analyzes the problems faced by a maturing industry, and contextualizes the local, diasporic diet of the personnel and colonists in the settlement. The incessant demands of the VOC meat industry were important causes for the colonial hegemony at the Cape that eventually dispossessed the indigenous Khoekhoe people of their land and socio-political capital.

This dissertation takes a processual approach that incorporates comparative and experimental research to identify and integrate the various aspects of the meat industry developed at the Cape of Good Hope during the seventeenth and eighteenth centuries. Chapter 2 describes the methods used in the analysis and interpretations of the various faunal examples. Chapters 3 through 7 present the data on five faunal samples analyzed. Chapter 3 discusses the fauna from the Moat of the Castle of Good Hope, dating to the second quarter of the eighteenth century. Chapter 4 discusses the fauna from a fill (c.1790s) in Donkergat, a possible torture chamber within the Castle. Chapter 5 discusses the reanalysis of the fauna from Phase 1 (c.1666-1685) and Phase 7 (c.1750s)

of the Granary deposits inside the Castle. The Granary reanalysis also serves as a critique of previous slave diet interpretations. Chapter 6 discusses the fauna from Elsenburg (c.1730-1750), an inland farm that was a site of stock production. Chapter 7 discusses 
the fauna recovered from the intertidal Dump at Oudepost (1669-1732) a coastal outpost on the northern frontier. Chapter 8 is a detailed study of the main faunal component, namely sheep. It deals with the evidence for hybridization, selective breeding, and culling. Chapter 9 integrates the faunal samples into the wider concerns of the VOC economy at the Cape of Good Hope. Figures 1.1 and 1.2 locate sites mentioned throughout the thesis found within the Cape settlement and across the Western Cape.

Figure 1.1. A map of the Western Cape illustrating the locations of towns, sites, and geographic locales mentioned throughout the thesis.

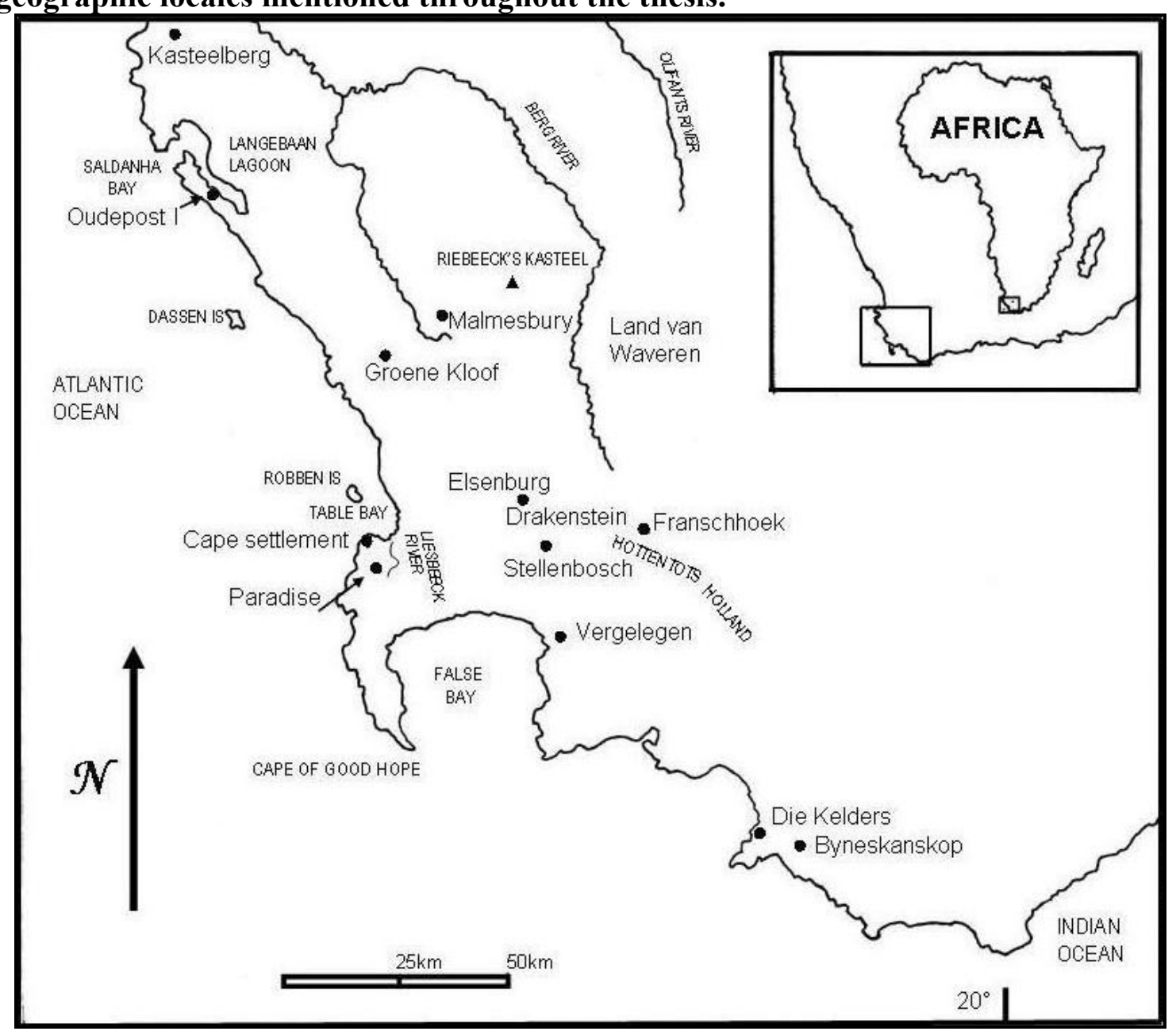


Figure 1.2. Modern map of Cape Town illustrating the locations of archaeological sites within the urban center. 1) Van der Stel Moat, 2) Donkergat (DKG), 3) F2 the Old Granary, 4) Darling Street Moat, 5) Grand Parade, 6) Slave Lodge. (Base map reproduced from Picard 1968: 17)

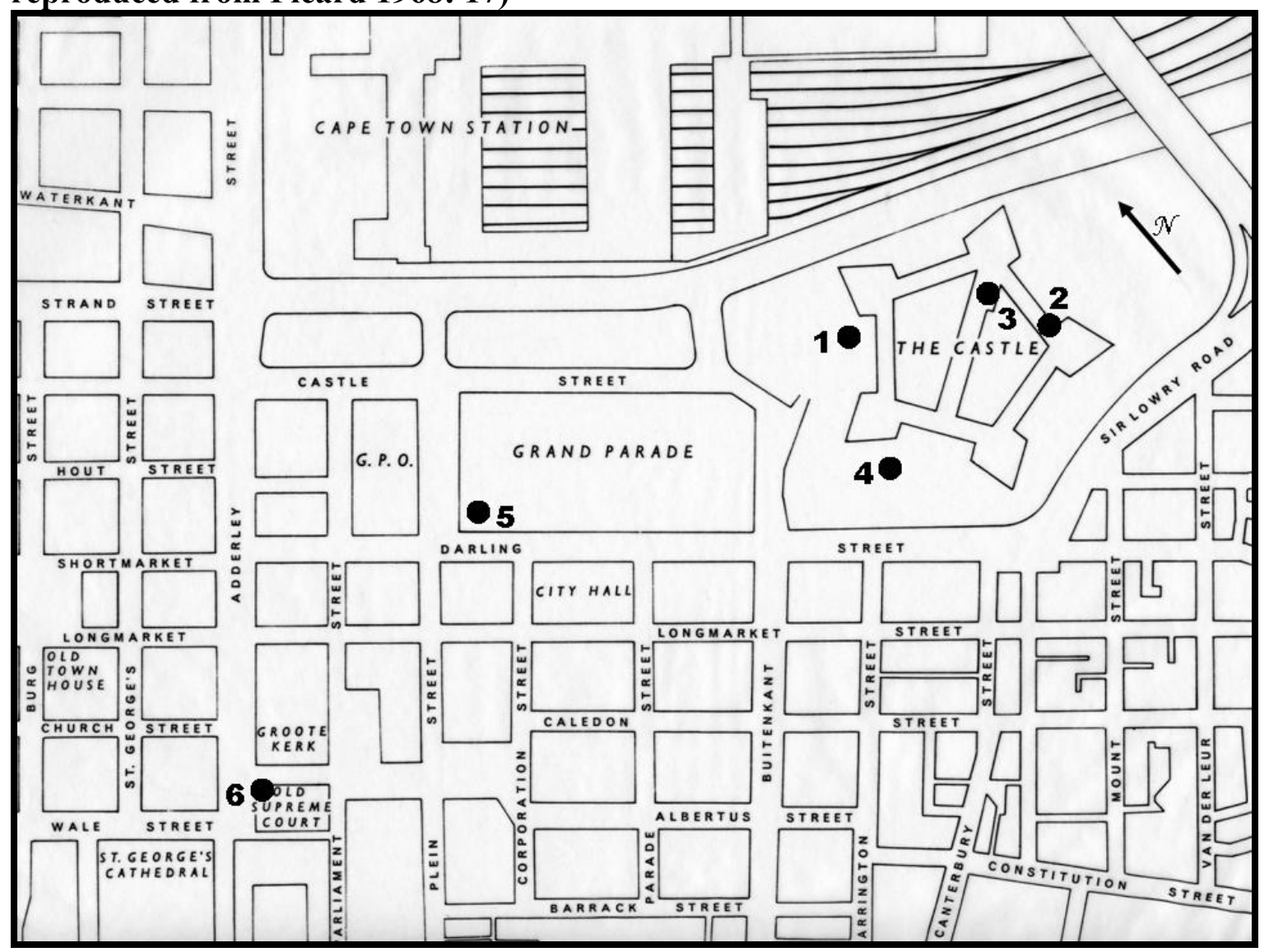

\section{HISTORICAL PERIOD ZOOARCHAEOLOGY}

In the historical period, “...most [animal] bone was disposed of at a stage of the exploitation process when it was deemed no longer worthwhile bothering with (Meadow 1978: 15)." When studied by zooarchaeologists, these faunal remains can often reveal clues to human exploitation of the animals around them (Davis 1987: 19; Klein and CruzUribe 1984: 1, 3; O’Connor 2000: 173; Reitz and Scarry 1985: 1; Reitz and Wing 1999: 3). James Deetz (1996: 73-79, 168-171) stressed the value of foodways, or the cultural practices of food, as part of the "small things forgotten" to history. Though Deetz focused on the inferences that one can make from ceramics and utensils found at 
archaeological sites, he stressed that the researcher needed to identify the patterns present in the residues as well as how these patterns fit within the clues recorded in the documentary record.

In the discipline of historical archaeology (often defined as beginning with the period of European expansion in the late fifteenth century), which is characterized by artistic and diagnostic artifacts made of ceramic, glass, metal, and other materials, zooarchaeological analyses have often been included as superficial descriptions of meat consumed and discarded at sites. Faunal analyses had often been mere appendices or relegated to a basic mention within the site's description instead of being integrated into the fuller interpretation of the site (Crabtree 1990: 188-190; Gumerman 1997: 112; Jolley 1983: 75; Landon 2005: 5, 24; Reitz et al. 1996: 4, 11). This was especially true in the colonial period settings until the late 1970s when a small group influenced by Deetz produced studies that address questions that went beyond the simple description of subsistence practices at a specific site. This research included studies on the adaptation of colonists and their animals to new environments (e.g. Bowen 1994; Bowen and Andrews 2000; Cosette and Horard-Herbin 2003; Cruz-Uribe and Schrire 1991; Martin 1991; Reitz 1991a; 1991b; 1992a; 1992b; Reitz and Honerkamp 1983; Reitz and Ruff 1994), social status disparities (e.g. Armstrong 1990; Cheek 1988; Crader 1984; 1989; 1990; Ervynk et al. 2003; Ewen 1986; Ijzereef 1988; Lev-Tov 1998; McKee 1988; 1999; Miller 1979; Otto 1977; 1984; Reitz 1987; Reitz et al. 1985; Reitz et al. 2006; Schmitt and Zeier 1993; Schulz and Gust 1983; Singer 1985; Yentsch 1994), ethnic diversity and the continuation of traditional foodways (e.g. Bostwick 1980; Crader 1984; 1989; 1990; Greenfield 1989; Janowitz 1993; Klippel 2001; McKee 1987; Reitz 1994; Scott 1996; 
2001), and contrasts between rural and urban markets (e.g. Bowen 1992; Brown 1989; Henn 1985; Landon 1996; 1997; 2008; Pendery 1984; Reitz 1986; 2007; Zierden and Reitz 2009).

\section{HISTORICAL BACKGROUND}

A. Dutch Hegemony: During the late sixteenth and seventeenth centuries, early modern Europe emerged from a feudal, tributary economy to eventually become a capitalist economic system that would wield significant influence across the globe (Wallerstein 1980: 5-6). The Dutch were in a prime situation to develop as a premier, core, hegemonic state within Europe. With the ending of their war with Catholic Spain, the Dutch were also able to reach peace with several other nations including a significant and favorable agreement with the Danes for fixed-price access to the Danish Sound, which was a key access point for transport from the Baltic region (De Vries and Van der Woude 1997: 353; Israel 1998: 544; Jones 1967: 47; Wallerstein 1980: 77). In contrast, the main Dutch rival, England, suffered under grain prices that were peaking at their highest costs in centuries. In addition, the rival core states of France and England restricted each other's imports, and the English merchants were paying the costs of the English Civil Wars through taxation as well as protection since the navy was preoccupied suppressing the conflict (Braudel 1979: 208-209; De Vries and Van der Woude 1997: 199; Jones 1967: 46-48; Wallerstein 1980: 77).

The Dutch were an apparently unlikely candidate to develop their economic dominance since they did not have the military power to match their rival states nor did they have a navy to control the seas and ports that were so important for their trade 
(Boxer 1965: 4; Wallerstein 1980: 38). In the Dutch situation, military prowess was not a prerequisite for the development of their hegemonic power. Instead, when peace was attained after the prolonged Spanish wars in the late sixteenth century, skilled artisans flowed into the Low Countries that swelled urban populations and set up industries where little experienced competition stood in the way (Israel 1998: 309-310). The newly found Dutch dominance in commodity production allowed them to produce and distribute consumables cheaply (Israel 1998: 309-310; Jones 1967: 40; Parry 1961: 133;

Wallerstein 1980: 38-39). A key to the Dutch development was with salted herring that was consumed throughout northern Europe. The Dutch herring ships used in the north seas were considered the fastest and most efficient, because they were designed to carry smaller, well-trained crews and greater amounts of cargo. Their efficient shipping was also the cheapest due to their monopoly in Baltic timber, and cost savings were passed along to all Dutch industries tied into the goods carried on their ships (Boxer 1965: 6-7, 66-67; De Vries and Van der Woude 1997: 243-244; Jones 1967: 44; Paine 1995: 46; Parry 1961: 133; Sleigh 1980: 5; Stevens 1998: 24; Unger 1980: 253; Wallerstein 1980: 55). In addition to the herring, efficient husbandry and diversified agricultural production, timber, plus other bulk trade goods shipped by the Dutch between peripheral and core nations were able to be priced so cheaply that the Dutch were able to outcompete foreign merchants in their own core nations (Boxer 1965: 6-7; Israel 1998: 319; Parry 1961: 134; Wallerstein 1980: 40-46). At the turn of the seventeenth century, the greatest economic returns came when the Dutch began carrying and distributing the luxury trade into central Europe which realized more profit per volume than herring, timber, and cloth (Israel 1998: 318, 344). Tangible products were not the only market 
controlled by the Dutch. Great amounts wealth flowed into the Netherlands due to their domination in what Wallerstein (1980: 39) calls the "invisibles" such as transport, communication, credit, and insurance.

B. Development of the Dutch East India Company: After the Portuguese rounded the Cape of Africa to reach Goa in 1498 and they initiated the seaborne mercantile potential of the Asian markets to Europe, capitalist enterprises developed in major port cities throughout Europe to distribute the new products being imported by the Portuguese. The Dutch were unable to develop their early seaborne trade to compete with Portugal in Asia because their resources were exhausted from the Eighty Years War with Spain. They were also not able to take advantage of the imported Portuguese trade, because the Portuguese circumvented Dutch merchants by only dealing with a restricted number of contracted "middle-men." Though the Dutch dominated the Northern European sea trade and fishing industries, their exclusion from the Asian trade irritated them since they were forced to pay high prices for Asian goods such as pepper due the weak and inefficient Portuguese mercantile system that was not able to keep up with the European demands (De Vries and Van der Woude 1997: 383-384; Houston 1999: 163; Sleigh 1980: 5-6; Wallerstein 1980: 47).

In the late sixteenth century, several competing Dutch mercantile companies unsuccessfully tried to tap into the Asian trade network (Boxer 1965: 22-23; De Vries and Van der Woude 1997: 383-384; Israel 1998: 318-321; Sleigh 1980: 6; Wallerstein 1980: 47). Consequently in 1602, several former rival merchant groups organized under one company, the Verenigde Oost-Indische Compagnie (VOC), or the Dutch East India 
Company. This new joint-stock enterprise was owned by private shareholders with a board of directors known as the Heeren $X V I I$ who represented the six chambers invested in the Company. The Dutch States-General granted the VOC a monopoly over Asian trade and the authority to develop its own military, navy, and fortifications to protect its interests and well as capture foreign holdings that could be sold for profit to any buyer (Boxer 1965: 46-47; De Vries and Van der Woude 1997: 385; Israel 1998: 322; Jayasena 2006: 111; Parry 1961: 100; Sleigh 1980: 7; Wallerstein 1980: 47). Unlike the Dutch West India Company, the VOC was not designed as a colonial enterprise, but instead sought to establish bases where they could monitor and develop trade. At its height, the VOC had about 300 Asian entrepots that were occupied by a subordinate of the VOC. Most were small local offices or factories that were hired to manufacture goods specified by the Heeren XVII according to tastes at the intended markets (Stevens 1998: 62, 87).

The VOC quickly gained dominance in the Asian trade markets over Portuguese and English companies. Mainly, they benefited from their expert knowledge of local market conditions, political manipulation, and an element of luck in the case of Japan's 1635 self-seclusion policies which forced them to rely on the VOC traders to import highly desired goods from China (Blusse 1996: 55, 59; Braudel 1979: 132; De Vries and Van der Woude 1997: 392-394; Israel 1998: 319). Trade generally involved the export of precious metal specie from the Dutch Republic which was used to purchase Asian spices, copper, porcelains, and textiles. During the early growth of the VOC, the major trade stayed in the intra-Asian network between China, Japan, and South Asian areas centered on the VOC's overseas home-base at Batavia, with a lesser amount of goods being 
imported back to Europe (De Vries and Van der Woude 1997: 435; Israel 1998: 941-943; Sleigh 1980: 31-33; Stevens 1998: 59).

The VOC had the advantage of being integrated into the larger Dutch shipping industry. They were able to construct their fleets at low costs due to their monopoly in Baltic timber, as well as through a system of mass production and standardization that allowed the Heeren XVII to calculate the amount of cargo that each ship was able to carry (Boxer 1965: 66-67; Jones 1967: 44; Paine 1995: 46; Sleigh 1980: 5; Stevens 1998: 24; Unger 1980: 253; Wallerstein 1980: 55). Furthermore, the VOC paid their sailors lower wages relative to the Dutch navy, and made their employees live very stringently. Though living conditions on board VOC ships were basic, the peasant class, who made up a bulk of the sailors, got two to three meat days per week onboard as opposed to one meat-based meal if they were living as a farmer (Boxer 1965: 50-51; 66-68, 75; De Vries and Van der Woude 1997: 642; Stevens 1998: 71-72).

VOC expenses were minimized through cheap construction and labor costs, but their profits were made by buying luxury goods at low prices and selling at high ones. Most goods that were imported to Europe were sold at auction, except for spices which were a tightly controlled commodity sold at fixed prices. Trade in luxury goods, compared to consumable necessities, required a careful balancing of supply and demand within a small number of available markets (Wallerstein 1980: 47). The VOC learned from the inefficient Portuguese and English competitors to limit the spice trade to meet the European demand, while at the same time not glutting the market which would deflate the high selling prices set by the Heeren XVII. This balancing act often resulted 
in the Heeren XVII ordering agents in Asia to destroy entire spice crops in order to keep the supply at a specific level (De Vries and Van der Woude 1997: 430; Sleigh 1980: 33).

The first half of the seventeenth century was a very profitable period for the VOC even though the importation of luxury Asian commodities into Europe declined because the Company was less able to distribute the luxury goods throughout the limited European markets. At this point, the Heeren XVII decided to strengthen the VOC's control over the intra-Asian trade networks (DeVries and Van der Woude 1997: 428-429; Wallerstein 1980: 39). Part of this increased focus towards the east included the establishment of Cape settlement under the command of Jan van Riebeeck at the southern tip of Africa in 1652. Strategically placed midway between Europe and Asia, the Cape settlement was unique undertaking for the VOC, because it was established as a refreshment station for passing ships instead of a typical mercantile base that would provide commodities or repositories for the intra-Asian trade (De Vries and Van der Woude 1997: 429; Israel 1998: 938; Grove 1995: 128; Robertson 1945a: 3; Schrire 1995: 13; Schrire and Merwick 1991: 12; Sleigh 1980: 49). The Cape settlement would supply VOC ships at fixed prices, while foreign ships would have to pay inflated prices for any food or materials from the Cape (Mentzel 1921: 174; Raven-Hart 1970b: 300; Robertson 1945a: 16).

The VOC settlement at the Cape supplied fresh vegetables, fruits, water, as well as meat derived from the indigenous Khoekhoe stock. The Cape settlement served a vital role in the VOC's attempt to lower the high mortality rates suffered by travelers and sailors during the long sea voyages. It had been known since the Portuguese expeditions that fresh food and water helped stave off scurvy which was a common affliction aboard 
the long distance trade ships (Boxer 1965: 75; Mentzel 1921: 47; Sleigh 1980: 49). Between 1602 and 1795, an estimated 975,000 to 1,000,000 young, often poorer, men served the VOC in its stations in Africa and Asia, and a high estimate of 600,000 died during their employment (De Vries and Van der Woude 1997: 75; Houston 1999: 165). While many of these deaths were the result of tropical diseases or conflict, a significant mortality was incurred on ships and the hospitals (Boxer 1965: 243; Elphick and Malherbe 1988: 10; Mentzel 1921: 47, 108-116; 1944: 252; Ross 1988: 243; Schrire 1988: 216). Although the Cape refreshment station was established to minimize the loss of life on the voyages, its actual effectiveness as a hospital is questionable since shipboard mortality rates actually increased in the late seventeenth and eighteenth centuries which has been attributed to the "chronic unfitness" of the men hired to serve the VOC instead of the conditions aboard the ships (Boxer 1965: 243).

In the mid-eighteenth century, the VOC entered an unprofitable period due to their weakening hold over European trade networks, and increased competition from English and French mercantile companies (De Vries and Van der Woude 1997: 449; Idenburg 1963: 8). The cheap raw material and manufacturing advantage that the Dutch held in the seventeenth century still depended on timber and grain from the Baltic region that the Dutch were unable to produce themselves. This advantage now favored the English who were now able to produce these raw materials themselves as well as being able to manufacture their own products through the advent of large scale industrialization (Sleigh 1980: 61). The intra-Asian trade also suffered to the point that the Dutch Republic had to provide subsidies to keep it functioning (De Vries and Van der Woude 1997: 450). When the VOC and the Dutch Republic economically collapsed in 1795, the 
Company was 120 million guilders in debt and lost many overseas bases including the Cape settlement to the British (Botha 1928: 3, 23; De Vries and Van der Woude 1997: 456; Idenburg 1963: 8-9; Israel 1998: 1127; Schrire 1995: 13-14).

\section{ANIMALS AT THE CAPE}

A. Precolonial Pastoralists: The preexisting archaeological paradigm argues that domestic sheep came to the Cape about 2000BP, with cattle coming in later about 1300BP (Boonzaier et al. 1996: 29; Bousman 1998: 141-142; Clutton-Brock 2000: 3233; Deacon and Deacon 1999: 181-182; Deacon et al. 1978; Henshilwood 1996: $945-$ 949; Holl 1998: 93; Klein 1986: 6-7; Klein and Cruz-Uribe 1989: 83; Sadr 1998: 101 104; Schweitzer 1979: 202-203; Schweitzer and Scott 1973: 547; Sealy and Yates 1994: 58-67; 1996: 109-110; Smith 1983: 79; 2000: 226-236; 2006: 2). Recently, direct carbon dating of a Bos taurus specimen from Byneskranskop shows that sheep and cattle arrived simultaneously at 2000BP (Horsburgh 2008). Genetic, linguistic, and archaeological evidence now suggest that the stock originated in the Middle East or Northern Africa and moved south via routes originating in Eastern Africa and then across either present day Botswana/Namibia or down through the Eastern Cape region (e. g. Bleek 1929; Boonzaier et al. 1996; Cooke 1965; Clutton-Brock 2000; Deacon and Deacon 1999; Elphick 1977; 1985; Elphick and Malherbe 1988; Hanotte et al. 2002; Henn et al. 2008; Holl 1998; Klein 1986; Parkington 1984; Robertshaw 1979; Sadr 1998; Smith 1983; 1992; 1997; 1998; 2000; 2006; Stow 1905; Theal 1910; Westphal 1963; Wilmsen 1989). A recent craniometric study suggests that the pastoralists and stockless hunters and gatherers around the Cape were part of the same biological population (Stynder 2009: 804). 
Named "Hottentots" by the Europeans, the pastoralists encountered by the visitors at the Cape were the Khoekhoe people. Many contemporary European visitors recorded observations of Khoekhoe culture as well as how they interacted with their domestic stock. They led a transhumant life leading their stock herds between suitable grazing lands throughout the Cape (Balasse and Ambrose 2002: 927-928; Boonzaier et al. 1996: 29; Klein and Cruz-Uribe 1989: 92; Elphick 1977: 58; 1985: 58; Elphick and Malherbe 1988: 8-10; Penn 1986: 63; Smith 2006: 13). This mobile lifestyle inconvenienced the earliest colonists who relied upon the stock trade in the early years to supply fresh meat to their ships and garrisons (e. g. Robertson 1945a; Thom 1952).

Stock served several purposes for the Khoekhoe. Cattle were symbols of status and capital that differentiated them from the stockless hunters and helped define the Khoekhoe society (Boonzaier et al. 1988: 42, 44-47; Elphick 1977: 57; 1985: 38, 57; Elphick and Malherbe 1988: 10; Kolben 1731a: 183, 260; Raven-Hart 1970a: 113; Schrire 1995: 64; Valentyn 1973: 77). Beyond being capital, stock provided meat, milk, hides, and defense (see figure 1.6). Historical accounts suggest that most stock, especially cattle, seem to have only been slaughtered during special ceremonial or ritual occasions (Boonzaier et al. 1988: 41-48; Elphick 1977: 60-62; 1985: 60-62; Kolben 1731a: 125, 200; Valentyn 1973: 67, 97). The excavations at Kasteelberg show that prehistoric pastoralists seasonally culled large numbers of lambs, which may have served more everyday, non-ceremonial meat purposes (Klein 1986: 10; Klein and Cruz-Uribe 1989: 90-93; Smith 2006: 45).

Accounts of herd management record that breeding was not strictly controlled in the sense that rams were allowed to run free with the ewes, which often led to lambing 
twice a year due to their shorter gestation periods compared to cattle (Balasse and Ambrose 2002: 927; Balasse et al. 2003: 208; Elphick 1985: 58-59; Klein and CruzUribe 1989: 90; Kolben 1731a: 168-169; 1731b: 64; Mentzel 1921: 56, 1944: 213). While the males and females were herded together and allowed to breed naturally, the Khoekhoe castrated the males, bulls and rams, which they did not desire to use as breeding stock (Elphick 1985: 59; Kolben 1731a: 170).

B. Historical Observations of the Animals at the Cape: Reports written by these early travelers described how the colonists traded, raised, hunted, or utilized the animals they were able to obtain. The journal kept by Van Riebeeck, the first Commander of the Cape settlement, provides valuable information about the earliest period of the settlement (Robertson 1945a; 1945b; 1945c; 1945d; Thom 1936; 1952). Peter Kolben (1731a; 1731b), who visited the Cape between 1705 and 1712, provided itemized descriptions of the various plants and fauna at the Cape and described the wild fauna in more detail than most. He inspired Otto Mentzel $(1921 ; 1925 ; 1944)$ who visited the Cape between 1733 and 1741 and described sheep and cattle rearing along with observations on wild mammals. Other firsthand accounts come from French, Dutch, German, and English visitors (Raven-Hart 1967; 1970a; 1970b; 1976; Strangman 1936; Valentyn 1971; 1973). These visitors describe how the VOC fulfilled an international demand for fresh supplies when traveling to and from the trade networks in the East. After the British gained control of the Cape, accounts by Willem Stephanus van Ryneveld (Thom 1942), Lady Anne Barnard (Robinson 1994; Wilkens 1901), and Lady Duff Gordon (Fairbridge 1927) recorded their own observations of Cape foods and animals in their journals or correspondences with friends. Finally, there are modern syntheses (Elphick 1985; 
Guelke 1988; Robertson 1945a; 1945b; 1945c; 1945d; Ross 1988; Skead 1980; 1987) and archaeological data from VOC period sites (Abrahams 1996; Avery 1989; Cruz-Uribe and Schrire 1991; Schrire 1995; Schrire et al. 1993).

Table 1.1. Historical references to the domestic animals kept during the VOC period at the Cape with the time of their introduction and place of origin.

\begin{tabular}{|l|l|l|l|}
\hline Animal & Introduced & Origin & References \\
\hline Cape sheep & indigenous & indigenous & \\
\hline Persian sheep & 1652 (hybridized) & Persia & Mentzel 1944: 210 \\
\hline English sheep & $\begin{array}{l}\text { 1699-1707 restricted to } \\
\text { Gov. A. van der Stel }\end{array}$ & England & Mentzel 1944: 210 \\
\hline Merino sheep & $1789-1790$ & Spain & $\begin{array}{l}\text { Lydekker 1912: 180; McKee } \\
1913: 2 ; \text { Mentzel 1944: 211; } \\
\text { Thom 1942: 57 }\end{array}$ \\
\hline Cape cattle & indigenous & indigenous & \\
\hline European cattle & 1652 (failed) & Netherlands & Mentzel 1921: 53 \\
\hline Friesland cattle & $1780 \mathrm{~s}$ & Netherlands & Thom 1942: 103-105 \\
\hline European pigs & 1652 & Netherlands & $\begin{array}{l}\text { Mentzel 1921: 53; Robertson } \\
1945 \mathrm{a}: 10 ; \text { Thom 1952: 121, } \\
123\end{array}$ \\
\hline $\begin{array}{l}\text { Javan/Chinese pigs } \\
\text { Persian horses }\end{array}$ & before 1712 & Java/Batavia & $\begin{array}{l}\text { Kolben 1731b: 117; Mentzel } \\
1944: 213\end{array}$ \\
\hline $\begin{array}{l}\text { Domestic fowl (ducks, } \\
\text { geese, chickens) }\end{array}$ & 1652 & $\begin{array}{l}\text { Persia, } \\
\text { Batavia/Far } \\
\text { East }\end{array}$ & $\begin{array}{l}\text { Kolben 1731b: 8, 128; } \\
\text { Robertson 1945b: 82; } \\
\text { Valentyn 1973: 119 }\end{array}$ \\
\hline
\end{tabular}

\section{Domestic Mammals}

a. Sheep (Ovis aries): Although cattle were the most sought after stock, the Dutch soon learned that obtaining cattle would be difficult, because the indigenous Khoekhoe prized their cattle as symbols of wealth and status and only willingly traded older or ill cattle. The Khoekhoe parted more freely with their sheep and since sheep were more numerous in the indigenous herds and more easily acquired through trade, they became the main meat providers for the local cuisine and provisioning (Elphick and Malherbe 1988: 10; Robertson 1945a: 5; Schrire 1995: 95, 141; Thom 1952: 105, 110). 
Initial attempts to raise European sheep were unsuccessful due to the Cape's highly seasonal and arid climate, but within a year of the settlement's founding, VOC herders were cross-breeding the indigenous ewes with imported European, Bengali, and Persian rams to produce a larger, meatier hybrid that flourished in the Cape environment (Cruz-Uribe and Schrire 1991: 97; Guelke 1988: 71; Mentzel 1921: 56; 1944: 210; Raven-Hart 1970b: 381; Thom 1936: 246, 249).

The VOC rapidly established their sheep flocks through trade, theft, confiscation, and hybridization. In 1657, the increasing numbers of stock encouraged Van Riebeeck to allow "free burghers" to raise the VOC herds in the frontier grazing lands (Elphick 1985: 110, 155; Elphick and Malherbe 1988: 11; Guelke 1988: 66, 70; Robertson 1945b: 79-80; Van der Merwe 1995: 1). By the late seventeenth century, Simon van der Stel established new towns such as Stellenbosch (1679) and Drakenstein (1687) in the prime grazing pastures further inland (Elphick and Malherbe 1988: 12; Guelke 1988: 66; Mentzel 1944: 55-56, 67-72). These settlements provided an element of protection for the burghers from any aggressive Khoekhoe as well as providing for the continuation of community functions. The meat contracts awarded to the burghers specified amounts of meat that were to be delivered to the Cape at scheduled times. When their herds were scheduled for slaughter, the herders or their slaves led the animals on hoof to the Cape. Although both indigenous and hybridized sheep retained their weight better than European breeds on these long drives, herders would often graze their cattle and sheep in order to refatten them (Fouche 1914: 19; Mentzel 1925: 55, 56; 1944: 212; Ross 1988: 247, 253). Groene Kloof, roughly $45 \mathrm{~km}$ north of the Cape settlement, was the largest 
temporary pasturage used for this purpose in the early eighteenth century (Cruz-Uribe and Schrire 1991: 97; Kolben 1731b: 62; Mentzel 1925: 55; 1944: 212).

Historical sources, together with a preliminary isotopic analysis reveal that the sheep in the Khoekhoe herds lambed twice annually since rams and ewes were herded and pastured together (Balasse and Ambrose 2002: 927; Balasse et al. 2003: 208; Elphick 1985: 58-59; Klein and Cruz-Uribe 1989: 90; Kolben 1731a: 168-169; 1731b: 64; Mentzel 1921: 56, 1944: 213). The settlers did not desire the double lambing and separated the rams from the ewes in order to control breeding. This segregation produced only one lambing season per year, extended the longevity of the ewes for breeding, and yielded more fit lambs (Kolben 1731b: 64; Mentzel 1921: 56; 1944: 213). Wethers (castrated males) were the main type of sheep used for meat, and records indicate that they were slaughtered between one and two years of age (Mentzel 1921: 56; 1944: 212). Eighteenth century records do not describe the birth or death rates unless they were the result of Khoekhoe raids (Newton-King 1999: 191). Data from twentieth century Afrikaaner sheep, the descendents of the Dutch hybrids, showed a near 50/50 ratio of male and female lambs from a breeding flock with a 59.5\% weaning success (NewtonKing 1999: 21, 191). Weaning success would have likely been lower in the eighteenth century due to more primitive husbandry techniques and greater predation.

Estimates determine that sheep outnumbered cattle from 2.3 to four in indigenous herds, and that sheep were even more dominant in the VOC holdings (Cruz-Uribe and Schrire 1991: 96; Elphick 1985: 160; Ross 1988: 251-253). In 1681, about 30 years after the founding of the Cape settlement, Elias Hesser observed a herd of over 1200 sheep belonging to a single burgher (Raven-Hart 1970b: 278). Later, in the early eighteenth 
century, Mentzel (1925: 56) recorded herds of over 6000 sheep held by each of the three official burghers contracted by the VOC. Large herds were common among the burghers, and in the early eighteenth century, Valentyn (1971: 75) recorded that even a poor burgher near the Castle still had a herd of 600 sheep and 100 cattle. Between 1700 and 1708, during the first eight years of legal open trade permitted between burghers and the Khoekhoe, the burghers' sheep herds increased by a remarkable 35,562 documented animals (Elphick and Malherbe 1988: 21). The scale of theft is apparent in a record of about 2500 sheep taken from the Inqua in 1702 (Elphick and Malherbe 1988: 21). These figures are drawn from the official documents, but undocumented sheep acquisition through trade and capture was probably even more significant (Ross 1988: 248).

Unlike the woolly-haired sheep breeds used as important fiber sources in Europe, the indigenous and hybrid sheep at the Cape had straighter, goat-like hair, which was similar to breeds from Asia and the Middle East (Raven-Hart 1967: 15, 20, 23, 70, 82, $122,152,156)$. The hybrid sheep were noted to be as "fat and as big as donkeys" (Raven-Hart 1970b: 331) and "considerably larger than those in Europe" (Raven-Hart 1970a: 213). A late seventeenth century visitor mentioned that "these sheep are as large as one of our one-year old cows" (Raven-Hart 1970a: 148). General consensus estimated the hybridized sheep carcass to weigh about 60 to 80 pounds (Mentzel 1925: 56; RavenHart 1970b: 297). Visitors during the VOC period often described the mutton to be comparable to that back in Europe (Kolben 1731b: 65; Mentzel 1925: 84, 101; 1944: 252; Raven-Hart 1967: 18, 23; Strangman 1936: 134), but Lady Anne Barnard complained that the mutton from the Cape sheep was of a white color and inferior in taste (Wilkens 
1901: 74; Robinson 1994: 182). Mentzel (1944: 211) also noted that some sheep had horns while others did not.

The tails of the sheep were particularly noteworthy. The indigenous Cape sheep were described as having heavy, fat tails; including several observations from before the Dutch began hybridization (Boonzaier et al. 1998: 41; Deacon and Deacon 1999: 181; Epstein 1971: 151; McKee 1913: 6; Raven-Hart 1967: 15, 18, 20, 26, 35, 40, 46, 58, 125, 128, 152, 156; 1970a: 160; Smith 1998: 151-152), and rock paintings across southern Africa often depict fat-tailed sheep, though these paintings remain undated and therefore could just as likely be representing colonial stock since several paintings of colonists, ships, and wagon carts exist (see figures 1.3, 1.4, 1.5) (Deacon and Deacon 1999: 180; Jerardino 1999: 64-65; Manhire et al. 1986: 22-24; Smith 1983: 82; Smith and Pheiffer 1993: 13). Supporting the fat-tailed theory of the indigenous sheep, many first-hand accounts describe these sheep before the Dutch settled permanently and started the hybridization process (Epstein 1971: 151; Lodewijcksz 1597; Raven-Hart 1967: 15, 18, $20,26,35,40,46,58,125,128,152,156)$. Figure 1.4, which depicts sheep in 1597 before hybridization occurred, may be flawed due to the common practice that these romantic, idealized depictions were often drawn from memory or second hand accounts. In these cases, the artist would draw from his memory of foreign sheep such as the fattailed Persian breed, similar to Theodore De Bry who portrayed indigenous peoples in heroic, Classical physiques and landscapes. Mentzel (1921: 56; 1944: 211) adds confusion to this topic when he contradicts these accounts by stating that the indigenous Cape sheep had long, thin tails, and that the fatty tail only developed as a result of hybridization with Persian fat-tailed rams (there may be an explanation for this in 
Chapter 8). The size of the fatty deposits was astonishing with some observers

estimating the tail's weight to be over 15 pounds (Kolben 1731b: 65; Raven-Hart 1970a: 160). Georg Meister in 1688 stated, “...these tails are also very tasty, being nothing of fat, and one of them suffices for fully 16 to 20 men" (Raven Hart 1970b: 343). Mentzel

(1944: 212) again contradicts these accounts and states that these tails were only between four and six pounds each, but that they could potentially get larger if the sheep were not slaughtered at regular schedules. All agreed that the tail was a delicacy. Tail fat was used as a substitute for butter, which was rather difficult to obtain at the Cape's urban center and will be discussed below (Abrahams 1998: 19; Botha 1970: 50, 86; Coetzee 1977: 65, 94; Kolben 1731b: 65; Mentzel 1921: 56; 1925: 101; McKee 1913: 6;

Robinson 1994: 182; Wilkens 1901: 74).

Figure 1.3. Drawings of prehistoric rock art depicting two fat-tailed sheep from Steenbokfontein Cave, Western Cape Province (from Jerardino 1999: 65).

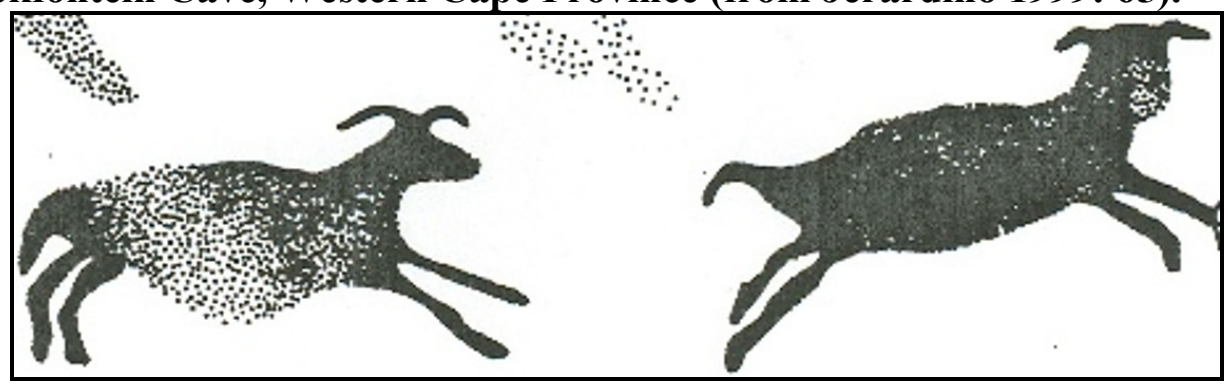

Figure 1.4. Detail of a 1597 engraving illustrating fat-tailed sheep and cattle at the Cape before any possible hybridization that could have confused later artists who may have depicted hybridized sheep instead of the pure indigenous sheep (from Lodewijcksz 1597 reprinted in Smith and Pheiffer 1993: 13).

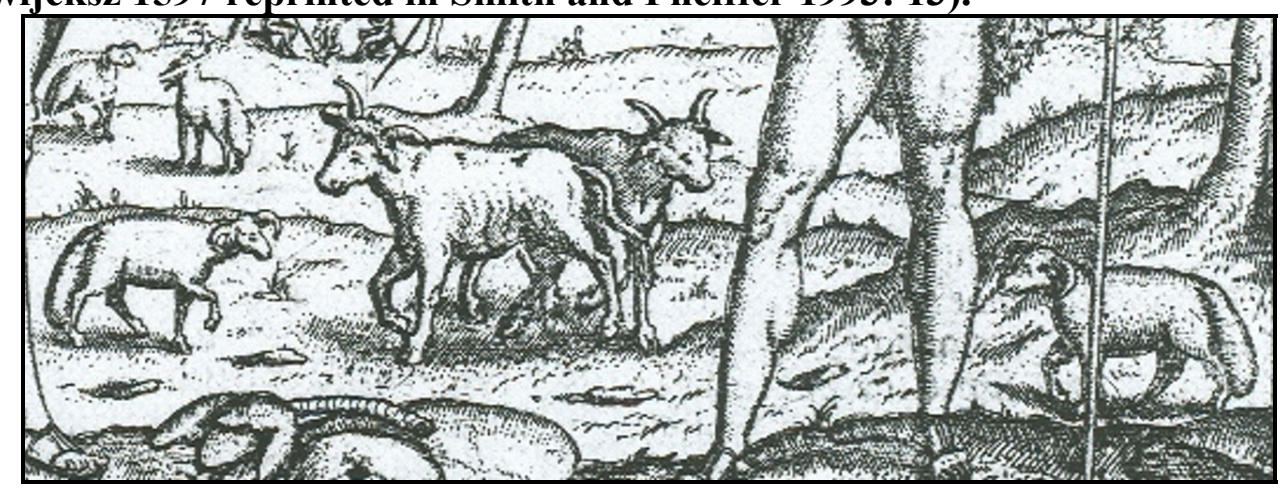


Figure 1.5. A late seventeenth century illustration showing sheep with relatively thin tails (from Smith and Pheiffer 1993: 23). It is possible that the sheep are younger and have not yet developed the large fat deposits as Mentzel (1944: 212) described for the hybrids.

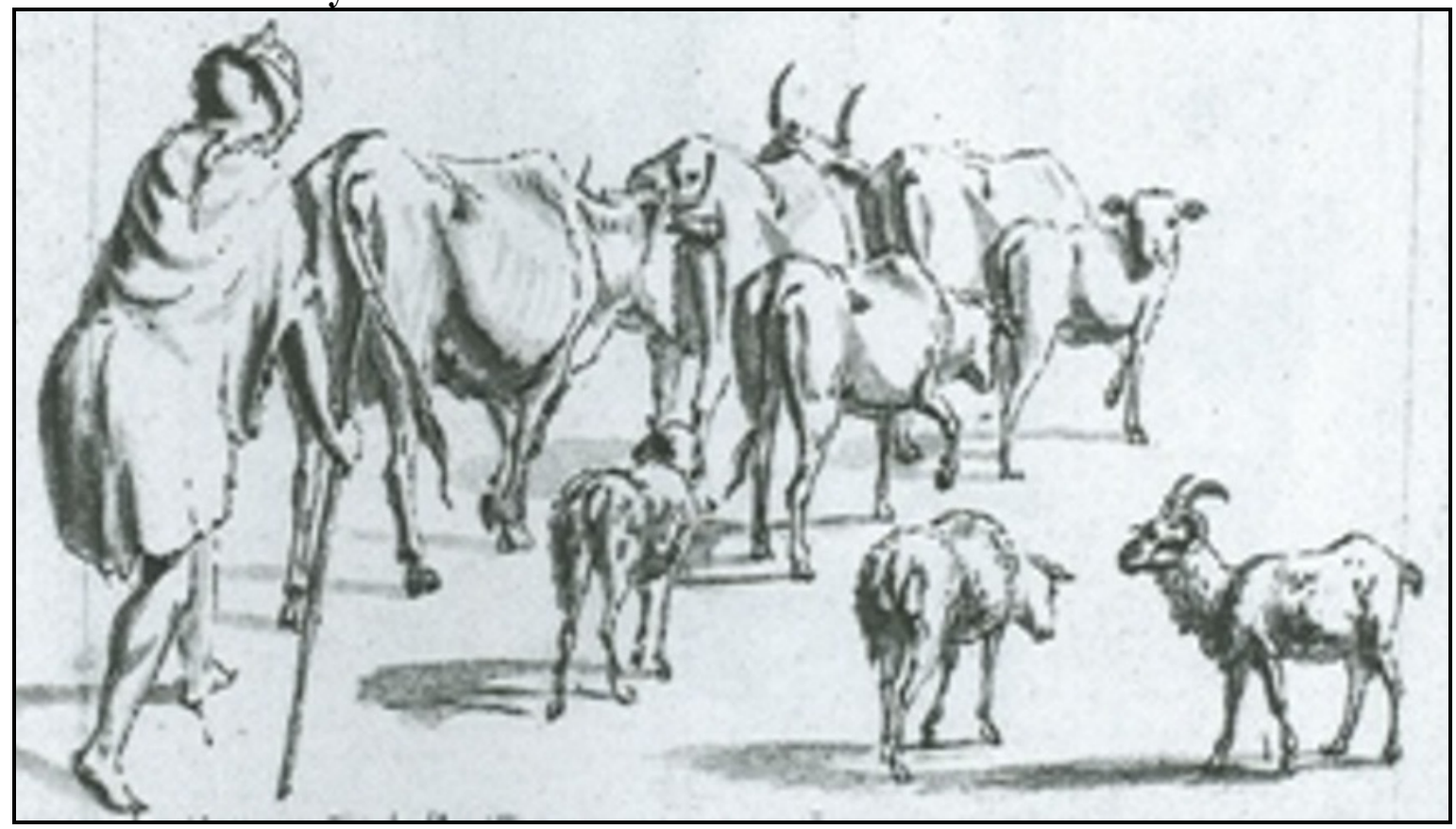

b. Cattle (Bos taurus): Cattle were important in the Khoekhoe society as sources of meat, milk, draught, and as symbols of social status (Boonzaier et al. 1988: 44-47; Elphick and Malherbe 1988: 10; Kolben 1731a: 260). Khoekhoe were often very reluctant to trade their cattle so that the cattle trade proceeded slower than with sheep (Elphick and Malherbe 1988: 10; Schrire 1995: 95, 141; Thom 1952: 105, 110). Whereas sheep could be obtained for small amounts of coiled wire, tobacco, and arrack, the VOC had to offer additional payments of copper plate, glass beads, and iron tools for the cattle (i.e. Kolben 1731a: 262-263; 1731b: 65; Mentzel 1921: 53; Raven-Hart 1970a: 103, 217; Robertson 1945b: 84; Schrire 1995: 52, 57-58, 111-112; Thom 1952). In the first years of the colony, large-scale theft of the Khoekhoe cattle was contemplated, but the VOC decided that trade would be more effective considering that they were still few in number 
and would probably be unable to repel attacks by a larger indigenous force (Thom 1952: 110).

VOC cattle herds increased more slowly than sheep through normal breeding, military raids, and trading. During the pre-colonial period, the indigenous herds were estimated to have been about 2.3 to four sheep to each cow (Cruz-Uribe and Schrire 1991: 96; Elphick 1985: 160). Robert Ross (1988: 253) estimated the VOC herd ratio in 1720 to be about 2.5 sheep to each cow, which increased to about $4: 1$ by 1770 . In the first eight years of legal open trade between the free burghers and the Khoekhoe (17001708), the burghers' cattle herds increased by 8,871 animals through this trade (Elphick and Malherbe 1988: 21). During the 1702 theft from the Inqua, the Dutch took about 2000 cattle along with the 2500 sheep mentioned earlier (Elphick and Malherbe 1988: 21). Archaeological evidence from Oudepost I and Paradise does not support these historically documented stock proportions and instead show sheep:cattle ratio between 3:1 and 8:1, suggesting that cattle were not slaughtered as frequently as sheep (CruzUribe and Schrire 1991: 94, 96; Hall et al. 1993: 52; Schrire 1995: 108-109; Schrire et al. 1993: 30).

The indigenous cattle were described as looking similar to the European breeds (Kolben 1731b: 64; Valentyn 1973: 119). A few observers who described them as having high humps on their backs (Fairbridge 1927: 38; Raven-Hart 1970a: 213), were contradicted by Kolben (1731b: 64) and Mentzel (1944: 200) who claimed the cattle had no humps except when under the yoke (see figures 1.5 and 1.6). Like sheep, some cattle were described as having horns, while others did not (Mentzel 1921: 51; 1944: 200; Raven-Hart 1970a: 213). The indigenous cattle were smaller than European breeds, 
where an ox rarely provided more than 600 pounds of meat (Mentzel 1944: 202). Cape beef was considered inferior compared to the more popular mutton (Mentzel 1925: 84, 101; 1944: 203), and Lady Ann Barnard described the beef as having little flavor with the fat melting off when roasted, while the veal was "red and ugly" (Robinson 1994: 184).

Since cattle were mainly used for meat, draught, and breeding, they would have therefore been reared to prime ages or older. Mentzel (1925: 101) claims that veal was not often consumed at the Cape except when "... something is wrong with the calf or farmer if he slaughters a cow so young." Contrary to Mentzel's statement, are occasional notes on the consumption of veal by people such as Adam Tas and Lady Anne Barnard who complained about its quality (Fouche 1914: 27; Robinson 1994: 184). Indigenous cows usually calved once a year in the rainy season when new growth was available on the pastures (Kolben 1731b: 64; Mentzel 1944: 203).

Throughout most of the VOC period, the Dutch did not try to improve the indigenous cattle by hybridizing them with imported breeds. The European cattle imported in 1652 immediately failed, possibly due to exhaustion from plowing (Mentzel 1921: 53). As a result, indigenous Cape cattle proved to be necessary at the Cape for draught, since the horses, imported in 1659-1660, were too small to pull heavy cartloads of goods, navigate the mountain passes, and to plow the sandy plains (Fouche 1914: 19, 39; Guelke 1988: 71; Kolben 1731b: 8, 73, 128; Mentzel 1925: 101; Robertson 1945b: 82; Valentyn 1973: 119). After the initial shipments of cattle with Van Riebeeck, no additional European cattle were brought to the Cape until about the 1780s (Cruz-Uribe and Schrire 1991: 96; Thom 1942: 103-105). The VOC did not continue to import European cattle or hybridize the Cape cattle. Information from Van Ryneveld's 1804 
report suggests that the imported Dutch cattle, a Friesland breed, were highly successful and were considered to be much higher in quality in terms of milk production, meat, draught, and hides at the Cape (Thom 1942: 103-111). While Dutch cattle and their hybrids were increasingly common on farmsteads across the Cape, other burghers were resistant to changing from the Cape cattle (Thom 1942: 105-111). One explanation, the red Africander, the hybrid of indigenous and Friesland cattle, were not popular due to their inferior draught performance (Newton-King 1999: 192; Thom 1942: 117). This claim suggests that Van Ryneveld had misrepresented the hybrid cattle as being a superior draught animal due to his agenda to promote cross breeding and milk production.

c. Secondary Products from Sheep and Cattle: Although meat was the primary concern for the VOC at the Cape, secondary products such as milk, butter, and cheese were also of value. Within months of landing in 1652, the VOC servants attempted to milk the stock they acquired through trade. These early attempts at milking were relatively unsuccessful, with 25 cows producing just one half of an anker (one anker is approximately 37.85 liters or 10 gallons) of milk per week, and a mere three to 3.5 pounds of butter. The butter production was quickly improved to be finer in quality and more yellow in color, but quantities and preservation caused supplies to be limited. Milking attempts were also made on the sheep, but it was discontinued because very little milk could be obtained and taking the milk severely threatened the health of the lambs (Mentzel 1944: 213; Robertson 1945b: 75; Thom 1952: 359). Mentzel (1944: 203) also 
Figure 1.6. A late seventeenth century sketch illustrating Khoekhoe people milking an indigenous Cape cow that does not have a high humped back (from Smith and Pheiffer 1993: 55). If the cow refused to give milk, one could blow air into the vulva to release the milk.

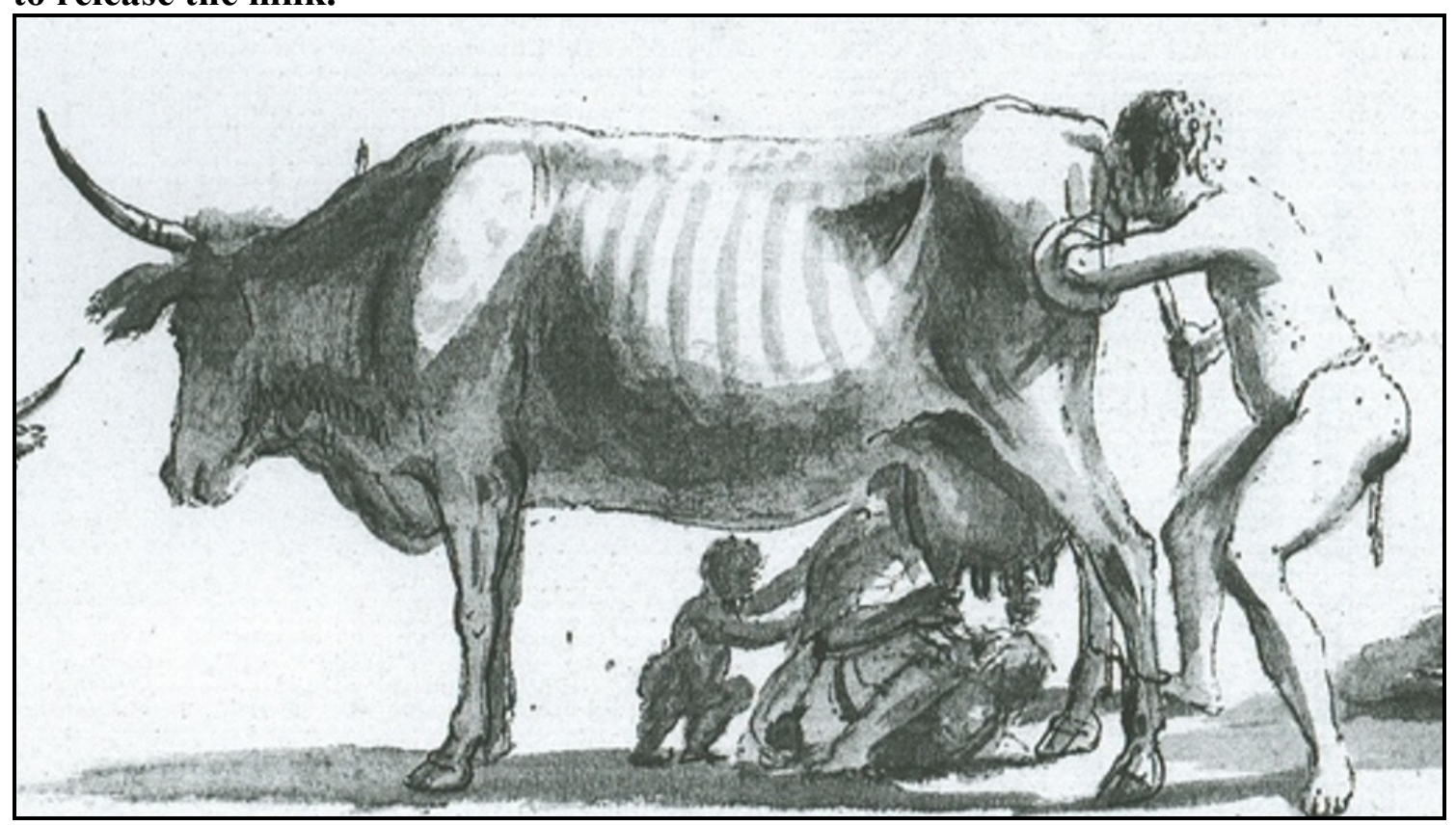

mentioned that the cows produced no milk unless the newly born calves were just suckling. The calves suckled for about eight to ten weeks after their births during the rainy season, which limited the period of time when milk and butter could be produced.

Though milk and butter were sometimes sent aboard the ships, their availability in the settlement markets was limited and expensive since they were produced on the frontier farms where the cattle were herded and then had to be brought into the settlement for trade (Coetzee 1977: 33; Mentzel 1925: 101). Though small amounts of dairy products were produced, they were described as being inferior to the comparable European products (Raven-Hart 1976: 30-31; Wilkens 1901: 74). It is unknown why the Company would not have tried to improve milk production by importing European cattle. In 1804, Van Ryneveld recorded that the first generation cow created from a Dutch bull and Cape 
cow produced five to six times the volume of milk that a purely indigenous Cape cow could produce (Thom 1942: 107).

The fat from the sheep's tails was used as a butter substitute, as well as being rendered into tallow to make candles and soap (see figure 1.7) (Botha 1970: 87; Wilkens 1901: 85).

Cattle were used for draught, and the indigenous oxen were valuable when hauling large quantities of cargo (Fouche 1914: 19, 39; Guelke 1988: 71; Kolben 1731b: 73; Valentyn 1973: 119). The cattle were used to haul stones and timber from quarries and forests near the surrounding mountains and also to plough the wheat fields (CruzUribe and Schrire 1991: 96; Guelke 1988: 71; Mentzel 1925: 101; Thom 1952: 331). With large numbers of cattle and sheep slaughtered for ship provisioning and market sale, hides were very numerous and they were purchased from the slaughterers and farmers for low prices. Only fresh hides were usable for leather manufacturing, and a sheep hide was worth one half of a stuiver while an ox hide was worth one rijksdaalder (approximately 50 stuivers) (Mentzel 1925: 55). Hides were also used on the frontier to make shoes and leather thongs for straps and to mend wooden beams (Mentzel 1944: 202). A 1678/9 map of the Cape settlement recorded a tannery along the shore near the Castle, within close proximity to where the livestock was slaughtered at the jetty (Raven-Hart 1970a: 201) (see figure 1.8). Tanning also took place at local businesses around the settlement (i.e. Mentzel 1921: 135; Picard 1968: 74) 
Figure 1.7. Lady Anne Barnard's illustration of a waterker candle maker with a pile of fatty sheep tails in the foreground (Robinson 1973: 181). A waterker candle was made by dipping wicks in tallow and water repeatedly to create a long thin candle (Botha 1970: 87).

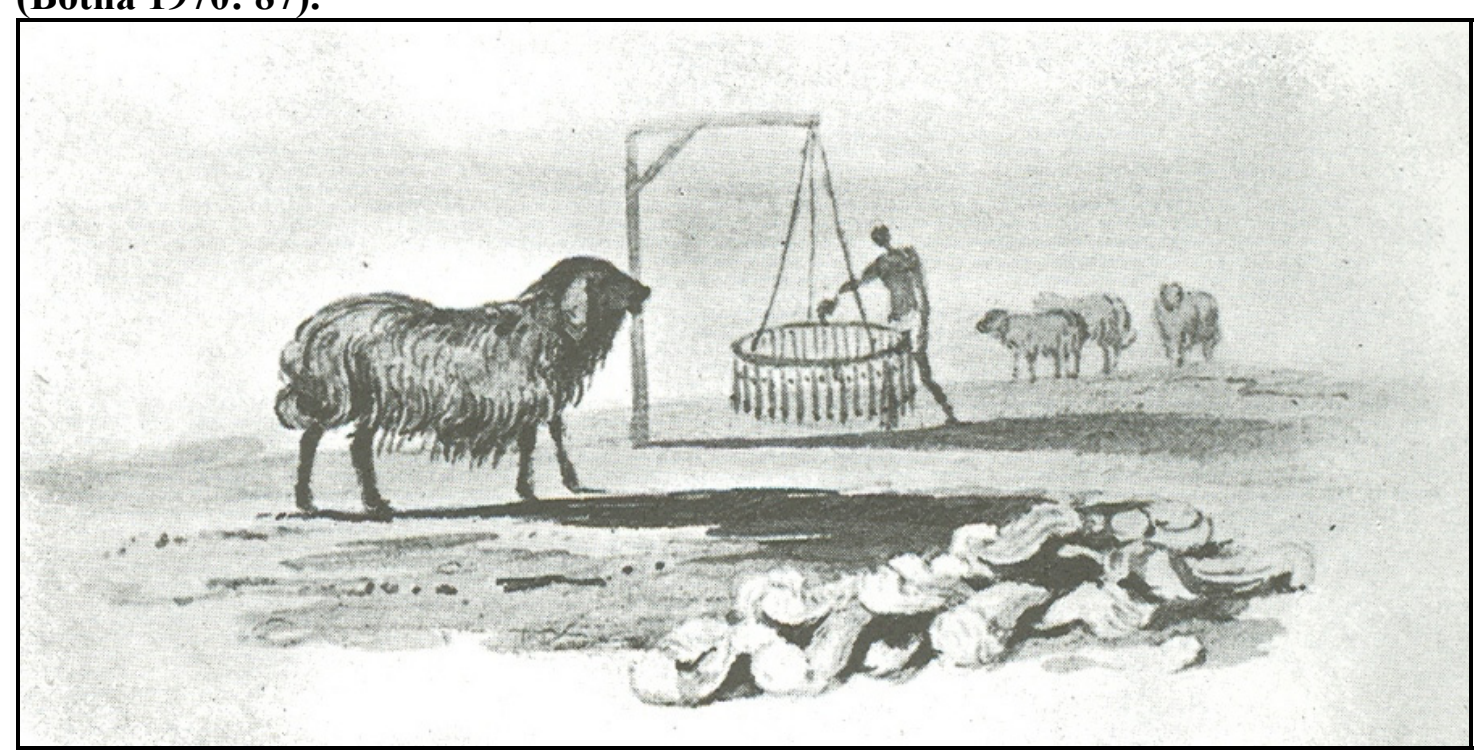

The goat-like hair of the indigenous and hybrid sheep precluded exporting wool as a commodity. Governor Willem Adriaan van der Stel imported English woolly sheep during his administration; but these sheep were restricted to his pastures and their wool producing qualities were quickly lost through hybridization after the Governor's recall in 1707. This was noteworthy, because the English did not allow the export of breeding sheep at this time (Mentzel 1944: 210). In 1782, burghers and VOC officials at the Cape petitioned the Heeren XVII to begin manufacturing wool products, but the petition failed because the Dutch government was attempting to revive their faltering textile industry in the homeland and that any competition would have been detrimental (Boxer 1965: 252). Though the VOC was initially denied the development of a wool industry, in 1789-1790, when the Spanish government lifted their embargo on exporting their merinos, the woolly, Spanish breed was imported to the Cape (Lydekker 1912: 180; Mentzel 1944: 211; McKee 1913: 2; Ross 1988: 255; 2005; Thom 1942: 57). Wool-production 
Figure 1.8. A Dutch map of the Cape settlement's shore in 1678/9. Structure "N" is identified as the tannery (Raven-Hart 1970a: 201).

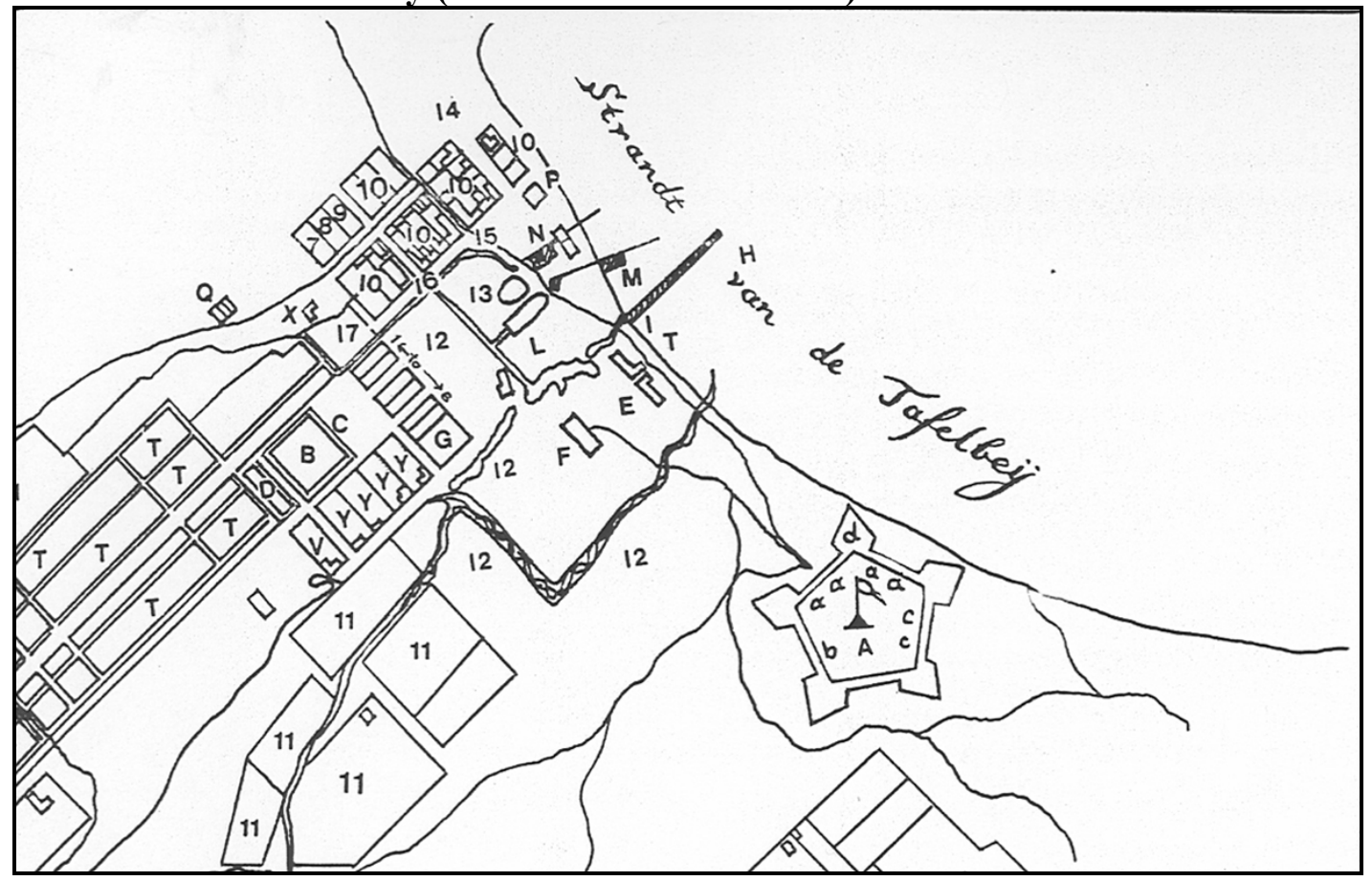

was slow with only 7000 merino sheep recorded at the Cape amongst an estimated total population of 1,250,000 sheep when the British took over in 1795 (Boxer 1965: 252).

d. Sheep and Cattle for Provisioning: Meat provisioning was contracted out to at most four official VOC slaughterers (Fouche 1914: 85; Kolben 1731b: 6; Mentzel 1925: 55-56; Robertson 1945b: 79-80; Ross 1988: 247) as well as to the free burghers (Elphick and Malherbe 1988: 11; Fouche 1914: xix; van der Merwe 1995: 1). These slaughterers were contracted for six-year periods to butcher healthy animals that were brought to the Groene Kloof pasturage station from the frontier grazing lands. About 5000 sheep were kept at Groene Kloof at all times, with a few hundred sheep at pastures closer to the Cape, so that there was an ever-ready supply of fresh meat. The freshly slaughtered meat was destined for the Governor, ships, markets, storerooms, outposts, and the hospital (Elphick 1985: 152-153; Green 1977: 45; Liebbrandt 1896: 6, 14; Mentzel 1921: 48, 171; 
1925: 55; Thom 1952: i.e. 138, 146, 158, 165). Ships' meat was delivered both slaughtered and live. In the mid-eighteenth century, the VOC contracts required a total of 390,000 pounds of meat annually, although this total did not include the weight of the live animals sent on the ships used to feed the officers and the sick (Liebbrandt 1896: 6, 14; Mentzel 1921: 171; 1925: 56). During one year of his stay of an unnoted date, Mentzel (1921: 171) recorded 88 Dutch East Indiamen that called at the Cape were provisioned with 5148 Dutch gulden (where one Dutch gulden equaled 20 stuiver) worth of live sheep. The calculation included an estimate that each of the 88 VOC ships received 15 sheep, which cost the Company 78 stuivers per sheep. This did not include the foreign ships, which would have had to pay monopolistic prices for fresh meat and other commodities (Liebbrandt 1896: 16).

Various accounts mention where the stock was slaughtered for the ships calling at the settlement. Mentzel (1921: 108) described a slaughterhouse as "an unpretentious building" near the wood storage house, but its actual location is unmapped. A mideighteenth century French map shows the Company butchery building next to the hospital along the shore (see figure 1.9). In 1677, Georg Meister also mentions a structure used as a slaughterhouse (Raven-Hart 1970a: 202). In 1677 he mentions:

At times the Dutch slaughter fully 100 sheep and some cattle for the refreshing of their ships coming from the Fatherland...then these Hottentots assemble in great numbers and make for the slaughterhouse, and take the guts of these slaughtered cattle which otherwise would be thrown away. (Meister in Raven-Hart 1970a: 202) 
Figure 1.9. A mid-eighteenth century French map of the Cape settlement showing a butchery located on the shore near the jetty. Structure " $G$ " is the butchery, which neighbors the Hospital (structure "E") (Hall 2000: 28). Also see figure 3.2 in the Moat chapter.

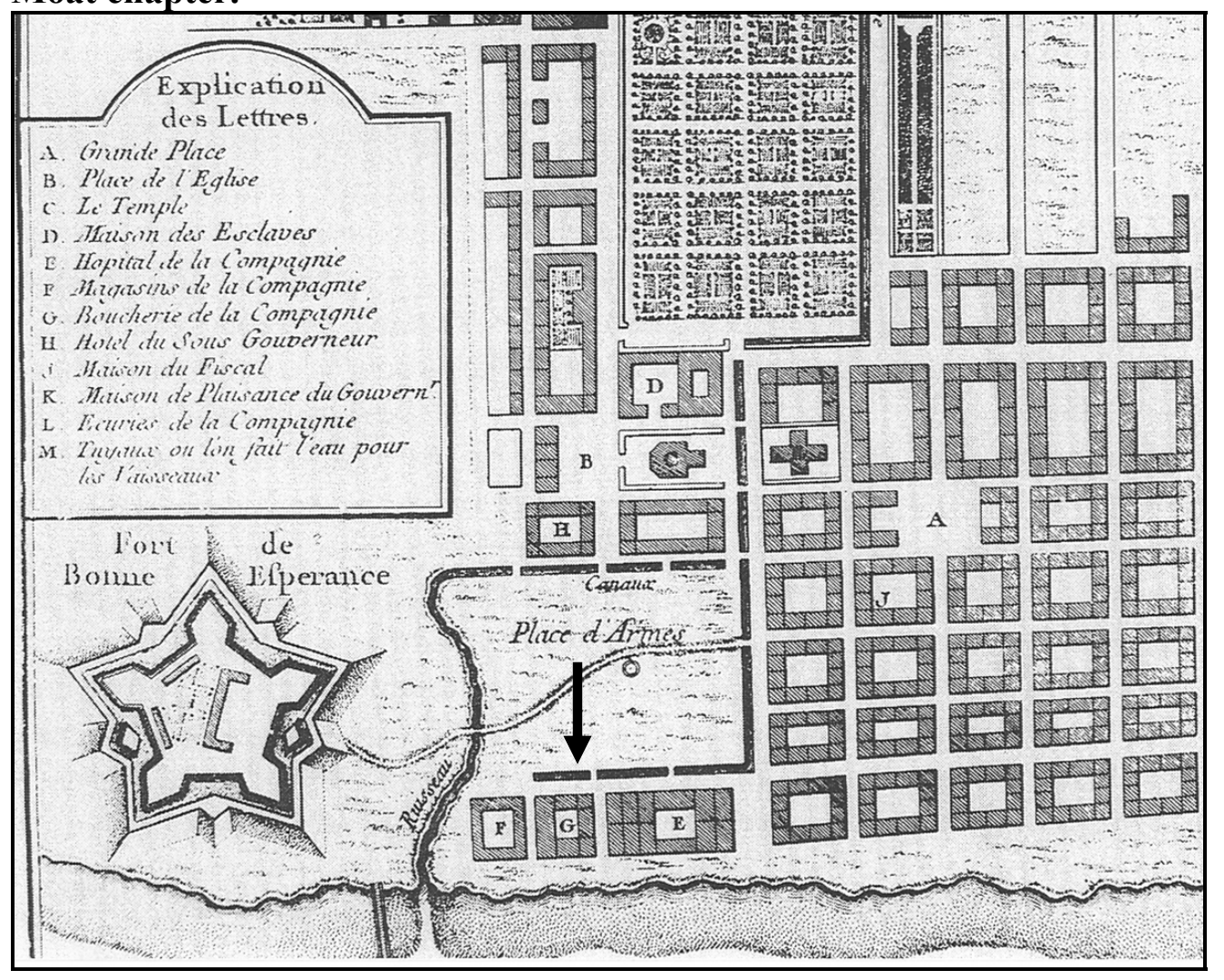

Meister described a remarkably similar scene in 1688 , but this time at the jetty instead of the slaughterhouse:

To return to the said Hottentots; When the Dutch kill cattle at the jetty many of them assemble, and squat on their heels here and there all around, like black ravens on a refuse heap; since otherwise the Dutch would throw the cuts into the sea, instead they throw them before the Hottentots, with the dung and all in them..., and it seems that these tidbits are very pleasing to them, since they gobble them up greedily. (Meister in Raven-Hart 1970b: 346)

Meister's documents are revealing about what the Dutch may have used for provisioning and what they may have discarded. According to European cultural norms, the offal was usually undesirable and, on the large scale described by Meister, fit only for the sea or the Khoekhoe who were not averse to eating the viscera and organs (i.e. Harris 
1985). While most of the offal was simply disposed of during mass slaughter episodes for provisioning (Raven-Hart 1970a: 202; Raven-Hart 1970b: 346; Robinson 1994: 185), the "pluck," which included the heart, lungs, and liver, were to be supplied to the Company free of charge (Mentzel 1925: 55). These descriptions of sea dumping are reified by Schrire's findings at Oudepost I where the VOC are inferred to have dumped the rotting organs and waste parts from the larger animals into Langebaan Lagoon (Schrire 1995: 108-109; Schrire et al. 1993: 30). In addition to the fresh meat, live and slaughtered, the VOC preserved meat for the ships. Mentzel (1925: 103) recorded the preservation of beef with smoke, salt, and spices. This process involved cutting the cattle carcasses into joints and placing them in barrels with salt and other preservatives. Possible evidence of similar cuts has been recovered from the VOC's Vergulde Draeck (1656) shipwreck off the west coast of Australia, which revealed butchered cattle and pig bones that where picked up at the Cape settlement (Green 1977: 244-246).

Slave owners provisioned mutton and beef to the slaves and herders who drove the stock to the slaughter at the Cape settlement. This was generally provided as a supplement to the staple fish (Armstrong and Worden 1988: 146; Sealy et al. 1993: 84). The use of beef and mutton as slave rations was common on farmsteads in the interior, though Markell et al. (1995: 84) claim that the slaves were fed the less desirable portions of the animals. This was supported by a visitor's account that recorded slaves being fed the offal of the sheep (Armstrong and Worden 1988: 146).

e. Pigs (Sus scrofa): Domesticated European pigs were brought to the Cape with the first contingent of VOC settlers in 1652. They started to die within months of landing, and 
early records of pig breeding mention that few of the young survived more than a few days from birth (Robertson 1945b: 10; Thom 1952: 121, 123). Pigs are generally reliable stock since they can feed on a variety of items and produce several young per pregnancy, which would have provided a greater rate of increase compared to the single or double births observed in sheep and cattle.

Two varieties of pigs were present at the Cape, the typical Dutch breed and the Chinese breed, which had "dainty" meat and claws like a dog (Kolben 1731b: 117; Mentzel 1944: 213). Though they were cheap to rear, farmers mainly kept them for personal consumption since there was no local market for pork. Though Mentzel (1944: 101, 213-214) insisted that there was no market for pork, he mentioned that they were generally slaughtered at six to eight weeks of age and that pig's heads and smoked meat were sold quickly.

Salted pork was imported to the Cape, which the European settlers enthusiastically purchased at the Company stores (Abrahams 1996: 225-226, 1998: 1517; Coetzee 1977: 65-68, 99; Mentzel 1925: 89, 102-103; 1944: 101, 107, 114; RavenHart 1976: 29). It was often brought from Europe, so that the pig bones recovered from the Vergulde Draeck shipwreck may not have come from the Cape (Green 1977: 244). Whether imported or preserved at the Cape, the pork was so heavily preserved that it could stand in storage for over a year, and sea water could be used to remove the salt from the meat. In order to make the pork edible, it had to be soaked for about 16 hours (Mentzel 1925: 102). Pig remains are present in the archaeological residues from Oudepost and Paradise, and the presence of teeth has been interpreted as live, on-site butchery rather than the consumption of preserved meat (Avery 1989: 114; Cruz-Uribe 
and Schrire 1991: 96; Schrire 1995: 108). Meat provisioning lists report dispatching more "bacon" than other meat to frontier posts such as Land van Waveren, Hottentots Holland, and Oudepost I at Saldanha Bay, but not Robben Island, which hints at their need to be somewhat self-sufficient through their own herds or hunting of wild game (Cruz-Uribe and Schrire 1991: 96; Schrire 1995: 108; VOC 4004: f. 197, 453, 591-592, 627, 633, 893-894; VOC 4008; VOC 4010: f. 547-549, 561, 568, 574, 580, 583, 587, 594, 600, 606, 611, 616, 624, 625; VOC 4047: f. 533, 547, 554, 571-572, 578, 583, 589).

f. Horses (Equus sp): Domestic horses were imported to the Cape in 1659-1660 for transportation (Kolben 1731b: 8, 128; Robertson 1945b: 82; Valentyn 1973: 119). The imported horses proved to be too small and weak, so the colonists had to rely on the indigenous oxen for the heavy draught work and plowing (Cruz-Uribe and Schrire 1991: 96; Fouche 1914: 19, 39; Guelke 1988: 71; Kolben 1731b: 67, 73, 128; Mentzel 1925: 101; Thom 1952: 331). Lady Anne Barnard confirmed that the smaller, weaker horses were still being used by the Dutch after British conquest of the settlement (Robinson 1994: 169). Though they were too small for draught or plowing, these horses were useful for travel between farmsteads and for hunting in the frontier (Cruz-Uribe and Schrire 1991: 96; Mentzel 1944: 207).

Despite many requests by the first Commander, Van Riebeeck, for European horses, VOC officials believed that the wild zebras might be tamed (Robertson 1945b: 82). Instead of European horses, the VOC imported a Persian breed by way of the Far East, which were so successful the market was soon flooded and the horses could be acquired cheaply (Kolben 1731b: 8; Mentzel 1921: 57; Robertson 1945b: 82-83). About 
the 1730s, Mentzel (1921: 58) stated that a good riding horse could be purchased for 40 to 60 rijksdaalders while a carriage with four horses could cost about 1000 florins (333 $1 / 3$ rijksdaalder) (see figure 1.10). Horses were also used to thresh wheat "in the Hungarian manner" where the horses were led around an enclosure to trample the harvest (see figure 1.11) (Kolben 1731b: 69, 73; Mentzel 1921: 57).

Despite the numerous records of horses during the VOC period, faunal remains are scarce in the archaeological sites. At Oudepost I, a site heavily dependent on the horse for transport and hunting, their presence was inferred through the discovery of a single spur and from frequent requests for fodder in the archives (Cruz-Uribe and Schrire 1991: 96).

2. Wild Fauna: The VOC Cape abounded with diverse wild fauna. Partly the reason for choosing the Cape for settlement, stock trade was expected to be lucrative, but in fact, it started quite slowly. Early during the early years of the settlement, the VOC soldiers and servants frequently faced food shortages so they supplemented their rations with the indigenous fauna (Robertson 1945a: 4; Thom 1952: 56-92). Due to advanced technologies of the horse, guns, and nets, the Dutch were able to take advantage of the fauna from all local environments such as the interior mountains and plains, the beaches, the offshore rocky islands, the sea, and the air (Avery and Underhill 1986; Cruz-Uribe 1988: 184; Cruz-Uribe and Schrire 1991: 93, 96; Skead 1980, 1987: 813-855; Thom 1952). 
Figure 1.10. Lady Anne Barnard's illustration of a carriage led by a team of eight horses (Robinson 1973: 102).

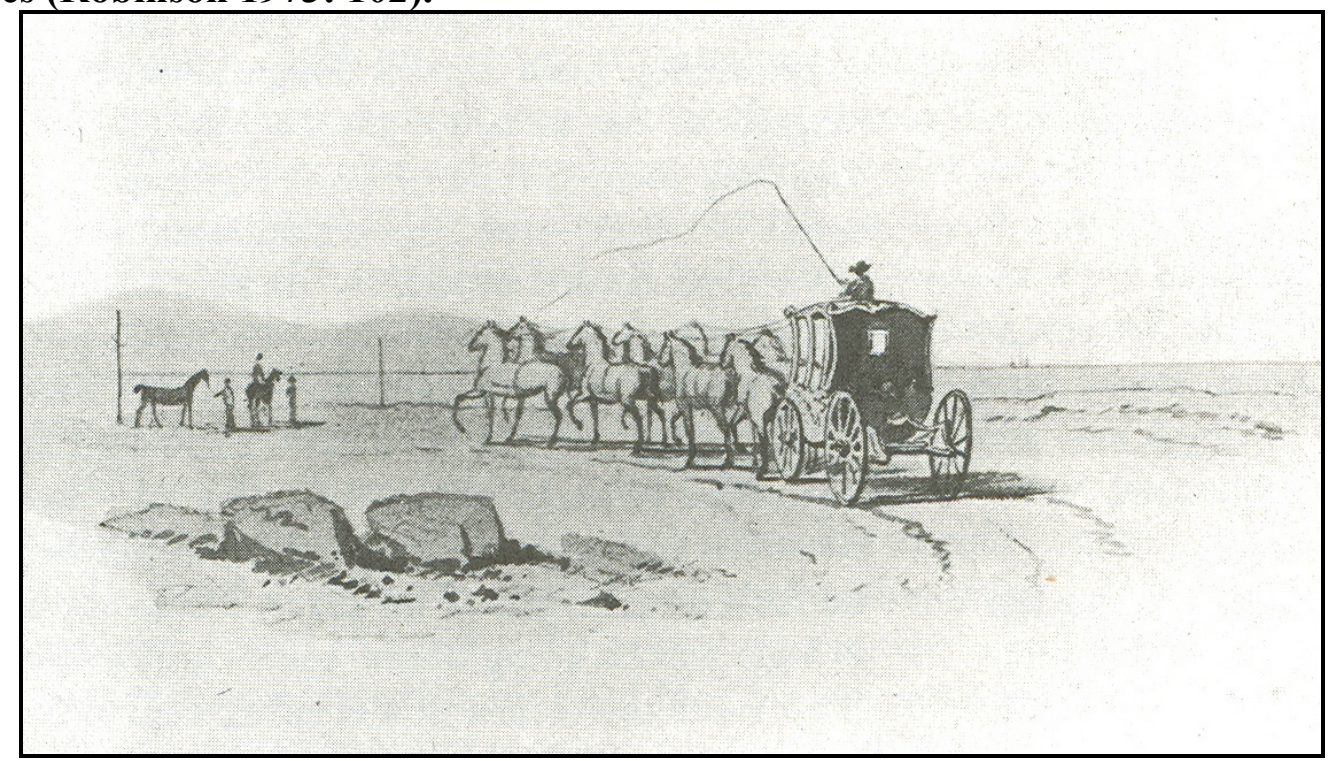

Figure 1.11. Persian horses being used to thresh wheat in the "Hungarian manner" at the Cape (from Kolben 1731b: 68).

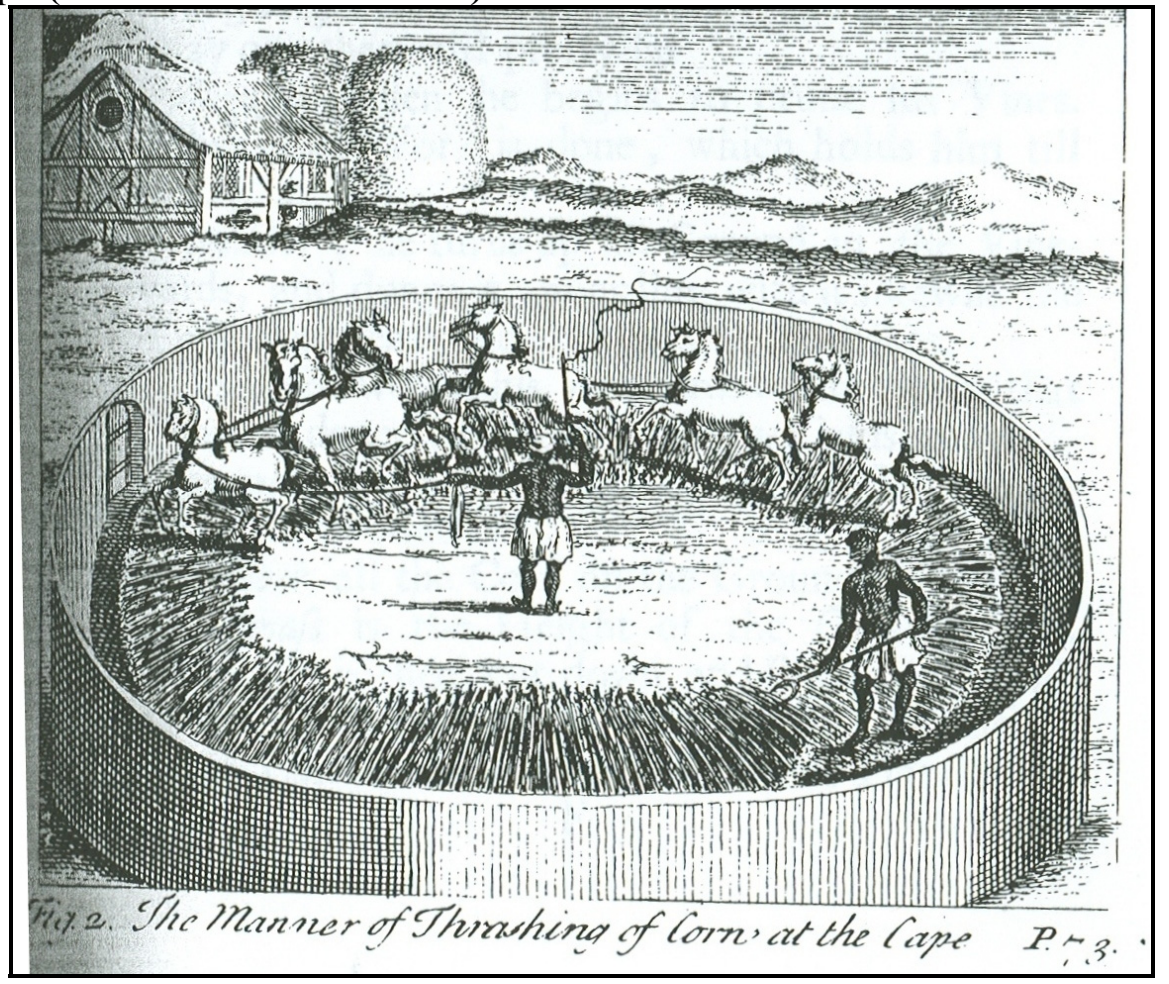

The exotic, indigenous fauna was a novelty for the callers who stopped at the Cape, and many late seventeenth and early eighteenth century visitors describe the unique fauna in their journals. Many accounts document the increasing scarcity of the wild 
fauna near the Cape settlement within a few decades of the VOC's colony's inception in 1652 was due to hunters, stock grazing, and wheat farming. This, with over-hunting for sport and food, severely decimated the local indigenous faunal populations or at the least pushed them further into the South African frontier (Jeffreys 1944: 106; Raven-Hart 1970b: 270; Mentzel 1925: 101; 1944: 77, 102; Skead 1987: 813-855). By the early eighteenth century, Mentzel (1925: 101) estimated that the wild fauna was rare within "24 German miles" (120 English miles) of the Castle. Over-hunting was facilitated by guns, horses, and boats, which allowed the Dutch to efficiently collect animals that were previously inaccessible to the Khoekhoe, as is characteristic of European colonization of foreign lands worldwide (Crosby 1986: 275; Cruz-Uribe and Schrire 1991: 96; Grove 1995: 126; Skead 1987: 813-855).

The depletion of the wild mammals prompted the VOC to issue a series of proclamations against unchartered hunting of the animals, where the only legal hunting was to be performed by the Governor's personal hunters who hunted strictly for his table. At the Governor's dinner parties, visiting dignitaries were often treated to lavish spreads that featured the wild game. It was noted that three professional hunters had to work full time in order to obtain sufficient wild game due to the sparseness of the animals and the distance needed to travel (Mentzel 1925: 101). The hunters had to consider that traveling too far inland would cause the meat to spoil before it was brought back to the Castle. Hunting still occurred on the frontier farms, but it was not registered (Mentzel 1925: 101). Frontier residents were allowed to hunt wild game if the game was injured or damaging their crops (Mentzel 1925: 101). Wild fauna is present on eighteenth century archaeological sites (Avery 1989: 114; Hall et al. 1993: 52), and in the case of Oudepost 
I, it dominated the land-based assemblage (Cruz-Uribe and Schrire 1991: 93, 96; Schrire 1995: 106-107; Schrire et al. 1993: 30). It is unsure if these animals were acquired legally according to the restrictions emplaced by the VOC, but in the case of the distant outpost at Oudepost I, it is likely that a blind eye was turned to hunting.

\section{a. Wild Game (e.g. Sylvicapra grimmia, Raphicerus melanotis, Raphicerus campestris,} Taurotragus oryx): Wild bovids were the main targets of the Dutch hunters. They ranged in size from the tiny steenbok to the large elands. European explorers did not see the largest bovid, the Cape buffalo, at the Cape, but Khoekhoe informants confirmed its presence in the region (Skead 1980: 598-599). The large herds of game were described as too timid to be hunted by guns because the hunters had to approach too closely for an accurate shot. Early attempts at snares were not strong enough to capture the animal, so the Dutch had to develop traps (Thom 1952: 50). Van Riebeeck mentioned that the Khoekhoe would offer many small bovids, or bovid parts to the Dutch for trade (Thom 1952: i.e. $77,86,96)$. Significant herds of bovids were still available near the Cape in 1668 when visitor John Schreyer mentioned, “elands, deer, steenbuck go there in great herds," and that the Dutch merely had to shoot into the herd "and hardly ever missed" (Raven-Hart 1970a: 123). The historical accounts that discuss the decreasing numbers of wild fauna most likely concern the bovids. These animals were once highly conspicuous in the landscape due to their tendency to congregate in herds, so their absence would have been noteworthy. By 1685, less than 20 years from Schreyer's account, another visitor Francois-Timoleon de Choisy stated, "all the wild beasts are moving further away as the country becomes inhabited" (Raven-Hart 1970b: 270). 
Early in the settlement's existence, wild bovid meat did not seem to be very highly desired. A price list from 1665 quotes the cost of wild bovid meat to be 2 stuivers per pound of meat, equal to the cost of beef, but cheaper than mutton and pork (Leibbrandt 1901: 151; Skead 1980: 395). Gerrit Vermeulen, in 1668, remarked that all wild bovids "in flesh and taste they are almost all similar, only that they differ in size, colour, and horns” (Vermeulen in Raven-Hart 1970a: 137). However, Mentzel (1925: 103) claimed that game meat usually had "a 'high' odor", and was therefore not the most desirable meat. The Governor's official restriction on wild game hunting seems peculiar when one considers that it prohibiting the hunting of less desirable meat. Although the meat was inferior in taste, the rarity must have changed the perception of the meat to be a novelty, especially when dining with foreigners who may have been unaccustomed to feasting on exotic animals. One must also consider that the Cape Governor had access to all the spices and cooks to make the game meat quite palatable (Mentzel 1925: 100).

b. Hyrax (Procavia capensis): These small rodents, known to the Dutch as "rock rabbits" or dassies, inhabited the rocky mountain areas and beaches, and still do today. They were plentiful and the Dutch often collected them in the dozens, which were then salted and placed in casks for transport back to the fort (Thom 1952: i.e. 84, 89, 90). These animals were most significantly used for food when the supplies were dwindling during the initial months after landing (i.e. Thom 1952). At the end of eighteenth century, the colonial secretary, John Barrow, remarked that the hyrax was still eaten occasionally, but that the meat was "black, dry, and of indifferent flavour" (Skead 1980: 244). 
c. Elephants (Proboscidean sp.): Visitors' journals note that elephants were abundant at the Cape prior to the VOC settlement in 1652, though Van Riebeeck states they were not found nearby in his earliest journals (Raven-Hart 1967: 99-100; Skead 1980: 195-197; Thom 1952: 153). Van Riebeeck's exploratory parties into the frontier encountered some elephant herds, a fair distance from the landing site (Thom 1952: 153). Elephants were important because of their ivory tusks. In fact, early trading episodes between Van Riebeeck and the Khoekhoe included the bartering of tusks for tobacco and copper (Skead 1980: 236; Thom 1952: 78, 106, 110, 153). The Vergulde Draeck shipwreck contained several elephant tusks that were likely obtained from the Cape settlement (Green 1977: 241). Elephant were occasionally sighted close to the Cape in the early eighteenth century, but by then the European encroachment had driven most of them further into the frontier. A troop of 40 elephants had been living in the Groene Kloof pastures, but were eventually driven across the river to preserve the valuable fodder for the VOC's sheep and cattle (Mentzel 1944: 77).

d. Hippopotamus (Hippopotamus amphibius): The hippopotamus, or "sea-cow", was a conspicuous animal on the landscape. It was the first animal hunted by Van Riebeeck's exploratory parties, but not without difficulty. The size of the hippopotamus was striking, described as being the size of two full sized oxen with a huge head and teeth (Skead 1980: 312; Thom 1952: 34). Its most outstanding quality was its resistance to firearms, "since it was most violent and fierce that they had their hands full to subdue it in spite of its having been hit behind the ears by a few bullets which penetrated the head, 
its skin being a good inch thick and so hard that at some places no musket-ball could penetrate it" (Thom 1952: 34). Skead believes that hippopotami were more common at the Cape than visitors' journals describe, because the Cape environment with its many freshwater streams was a favorable habitat for the large mammal. A few seventeenth and eighteenth century entries record footprints of elephants at stream mouths, which may have been misidentifications of the equally large footprints of these hippopotami (Skead 1980: 393). Though common in the earlier years of the settlement, hippopotami were not seen by Mentzel during his stay in the early eighteenth century (Mentzel 1944: 51; Skead 1980: 400). Hippopotamus meat was relatively common and eaten regularly during the second half of the seventeenth century, such that their meat was the cheapest from the local stores (Leibbrandt 1901: 151; Skead 1980: 395). This may suggest that hippopotami populations were affected by Dutch encroachment since they hunting the meat for food. Observers at the end of the seventeenth century recorded that hunters had to travel one or two days to shoot the animals (Raven-Hart 1970a: 109).

e. Cape Fur Seals (Arctocephalus pusillus): Cape fur seal colonies on offshore islands were recorded at contact "in countless numbers" (Thom 1952: 82). The VOC knew the value of these animals back in Holland for their skins and oil (Cruz-Uribe and Schrire 1991: 100; Robertson 1945d: 246; Thom 1952: 59, 175, 177). Best hunted with clubs, the skins were removed and the train oil was rendered on site. The meat was not eaten from these expeditions and the rotting carcasses were left behind. Sealers or soldiers at frontier outposts may have consumed seal meat, but it was generally considered a last resort food source during an early period of starvation caused by a lull in the livestock 
trade (Cruz-Uribe and Schrire 1991: 101; Thom 1952: i.e. 81, 84, 130, 137, 231, 287). Records do not include the transport of meat along with the oil and skins (Skead 1980: 670-675; Thom 1952: i.e. $81,84,130,137)$. Each voyage collected a couple dozens to more than a thousand skins, plus the barrels of oil (Skead 1980: 676-678; Thom 1952: i.e. 281, 297, 302). The skin and oil trade with Europe was stopped in 1657 due to its inability to compete with the Greenland sealing operations. Oil rendering was continued into the nineteenth century for the Asian trade (Roux 1975: 91ff cited in Schrire 1984: 19; Skead 1980: 683-684). Seal numbers on the islands fluctuated seasonally, and they were most numerous during the calving season between October and December (Mentzel 1921: 75; Thom 1952: 287, 330). Human encroachment affected seal numbers within three years of the VOC's settlement where seal numbers dropped at Dassen Island (Schrire 1984: 19; Thom 1954: 27). An eighteenth century mention of human encroachment affecting seal behavior was recorded by Mentzel (1921: 75) who stated that the seals no longer inhabited Robben Island, but instead had moved to the safer shore of Dassen Island.

f. Other Notable Mammals: Rabbits, both indigenous (Lepus capensis and Lepus saxatilis,) and domesticated (Oryctolagus sp.), were present at the Cape at Dutch settlement. The Dutch imported rabbits in 1654 , but mainly restricted them to the offshore islands like Robben and Dassen Islands to allow for easier trapping (Mentzel 1921: 76; Raven-Hart 1970a: 26; Robertson 1945a: 10; Skead 1980: 630-636; Thom 1952: 223). Of the two wild species, one was smaller and the other was larger in size 
compared to the intermediate domesticated European rabbit (Cruz-Uribe and Schrire 1991: 95).

The porcupine (Hystrix africae-australis) was not often used as a food source, though its meat was considered edible (Kolben 1731b: 120; Mentzel 1944: 241). The "iron pig" was perhaps most noted for its ability to kill the dangerous carnivores that threatened settlers and their stock herds. While some sources claim that the porcupine was able to shoot their spines like arrows into potential predators, a few observers correctly noticed that the porcupine simply pushed their spines into their attacker (Mentzel 1944: 241; Raven-Hart 1970a: 113; Skead 1980: 653). An early eighteenth century account described a lion's pelt pierced by porcupine quills hanging from the original Fort's gateway (Skead 1980: 653; Valentyn 1973: 117).

The large carnivores, mainly lions (Panthera leo) and leopards (Panthera pardus), also made impressions on the Europeans. During the first few months of settlement, the stock and poultry were often attacked, thus forcing the Dutch to improve their kraals (Thom 1952: i.e. 119, 127, 221, 310,315). The large carnivores were mainly dangerous at night, while they posed little threat during the daylight hours (Skead 1980: 123). In 1656, the VOC offered bounties for killing these predators (Cruz-Uribe and Schrire 1991: 95; Mentzel 1944: 244; Skead 1980: 84-86, 123). Lions were eventually exterminated or driven away from the immediate Cape settlement vicinity by the early eighteenth century, but other large cats could still be found several dozens of miles away in the frontier (Mentzel 1944: 244-245; Skead 1980: 123). The carnivores were also consumed when the opportunity was available, and Kolben (1731b: 97) states that leopard was tasty roasted or boiled, and that younger ones tasted like chicken. 
3. Birds: Wild birds were numerous throughout the coastal and inland regions of the Cape at contact (Avery and Underhill 1986: 339-341; Mentzel 1944: 248; Robertson 1945a: 4; Thom 1952: i.e. 58, 61, 84, 165). The Khoekhoe obtained birds for food, but the Dutch were able to take bird acquisition to a new level using firearms and birdshot, which allowed them to acquire the flying birds in great quantities (Cruz-Uribe and Schrire 1991: 96). Most were described by color, while others were equated to species known from Europe such as the cormorant. When the early stock trade was faltering, the hungry Dutch settlers hunted many varieties of birds, which were sometimes brought back to the fort fresh, while at other times they were salted and placed in casks (Thom 1952: i.e. 59, 297, 303). For the most part, the Cape's waterfowl were described as having fatty and tasty meat, with one exception being the pelican, whose "meat is very oily, and cannot well be eaten" (Raven-Hart 1970a: 132).

The Jackass penguin (Spheniscus demersus) caught the attention of many observers, and this flightless bird inhabited the offshore island in great numbers, and they were exploited heavily. As soon as the VOC landed at the Cape, penguins were corralled and clubbed, salted, and placed in casks for the soldiers and servants (Thom 1952: 59, 84, 229). Their eggs, which were laid around December, were collected in the hundreds and thousands from each expedition (Mentzel 1921: 77; Thom 1952: 59, 84). A late seventeenth century account remarked that penguin eggs were food for "common folk" (Raven-Hart 1970a: 133). Although, Mentzel stated that the penguin carcasses were useless, it did not keep the first starving settlers from eating the flesh. The Dutch often plucked the soft, specialized feathers from the penguin's breast for use in bed mattresses 
even though Mentzel (1921: 77) claimed that the mattresses would emit a strong fishy odor for a long period. He also favored their eggs as food, but he mentioned that they have a fishy flavor that could be diminished with the addition of imported spices (Mentzel 1921: 77).

Ostrich (Struthio camelus) eggs and feathers were often traded by the Khoekhoe for copper, rice, and tobacco (Raven-Hart 1970a: 128; Thom 1952: 75). The eggs tasted like chicken eggs and they were valuable to the Dutch because of the volume of food per egg. John Schreyer in 1668 claimed that one ostrich egg equaled 24 chicken eggs (Raven-Hart 1970a: 132). Later in 1679, another visitor, Johann Wilhelm Vogel stated that the tame birds walked through the settlement's streets and that they would consume and digest iron (Raven-Hart 1970a: 213)!

The Dutch imported the domestic birds, including geese, ducks (Anatidae dom.), turkeys (Meleagris gallopavo), and chickens (Gallus gallus), that were brought with the first contingent that settled the Cape (Robertson 1945a: 10; Schrire 1995: 63; Thom 1952: 168). They were used for both meat and eggs. The domestic fowl produced eggs successfully within the first year of landing, and this only improved the following year. Egg production was successful enough to send fresh eggs onto calling ships (Liebbrandt 1896: 14; Raven-Hart 1970a: 76; Thom 1952: 121).

Mentzel (1925: 101) remarked that chickens were mainly raised for individual consumption on local farms, and that chicken meat was difficult to find in the city. He also mentioned that chickens and their eggs were mainly obtained when a nearby farmer's wife would bring a few into the city to barter for "petty sundries". Though few in minimum numbers, chickens are the most abundant domesticated fowl identified in 
Paradise's faunal assemblage compared to turkeys and possible domestic ducks (Avery 1989: 114; Hall et al. 1993: 52).

4. Fish: Fish were very heavily harvested during the earliest time of the VOC's settlement (Robertson 1945a: 4). Most fishing was done by groups with seine nets that could be placed in the water in an extended position, and then dragged through the water capturing anything in its way. This netted hundreds of fish in each sweep of the net, and they were most often salted and placed in casks for transport back to the fort for later consumption. Van Riebeeck's accounts stated that daily hauls were generally of one or two fish varieties (Thom 1952: i.e. $69,77,78,79,88,95,97$ ). In the early eighteenth century, Mentzel noted in his report that Indian Ocean fish were often caught by hooked lines while the Atlantic Ocean fish were caught by nets (Mentzel 1921 cited in Hall n.d.c.: 2). Early VOC sites suggest that most fish were taken from colder water, while warmer water species from False Bay were more common in later sites (Poggenpoel 1996: 122).

Though fish were a common food for the earliest settlers, their importance in the Cape diet diminished when mutton and beef availability became more available. This may partly be associated with the use of fish as a staple of slave diet at the Cape creating a stigma for the food amongst Cape society (Armstrong and Worden 1988: 146; Sealy et al. 1993: 84). Hall (2000; n.d.c.: 2) states that the common fish became stigmatized as a food for the poor and subservient, and therefore were unfit for consumption by the upper social classes. Social distinctions affected how Cape consumers chose fish for themselves and their servants, perhaps regardless of taste. Hall's (2000; n.d.c.: 2) 
research from urban Cape Town archaeological sites suggests a disparity between the fish species consumed by the servants and the owners. The servants were fed the common Atlantic fish while the owners consumed the line caught Indian Ocean fish. The stable isotopic analysis of a late eighteenth/early nineteenth century, first generation, female slave burial from the Vergelegen plantation provided further archaeological evidence for the importance of fish in the slave diet. The analysis of nitrogen isotopes ratios was able to determine that the woman's diet was altered when she was moved to the Cape, from a diet of little or no fish to a diet rich in marine resources (Markell et al. 1995: 27; Sealy et al. 1993: 89). Soldiers were also provided rations of fish, and some accounts recalled soldiers fishing during their free time (Dooling 1994: 23). In post-VOC times, Lady Ann Barnard recorded that fish were very plentiful and of higher quality than the fish from her native England. She was still concerned with status when she described the "King of the Clip" (Kingklip, Genypterus capensis) fish that was plentiful and had an excellent taste, but the fish was "not the fashion" (Robinson 1994: 182).

\section{ANIMALS IN FOOD FROM THE EUROPEAN HOMELAND AND THE CAPE}

Archaeological faunal residues should be interpreted within the contexts of cultural meat supply systems and meat consumption activities. The Dutch ways of raising and eating animals had a deep inherited history aimed at maximizing meat and/or secondary products. When they settled at the Cape, the Dutch were a diasporic group who imported and adapted their husbandry and culinary practices to a new environment. 


\section{A. Animal Products and Foodways}

1. Foodways in Northern Europe: Cuisine in Medieval Northern Europe, including the Flemish/Dutch Low Countries, France, Germany, and England, differed more notably between social levels than across political boundaries (Adamson 2004: 45, 134, 142-144; Albala 2003: 116; Braudel 1973: 128-129; Mennell 1985: 18, 41-47, 50-51, Norman 1972: 120; Teuteberg 1986: 17; Woolgar et al. 2006: 275). In these regions, meat was an important component of the diet owing to long held historic traditions of widespread, intensive stock herding (i.e. Adamson 2004: 132; Bokonyi 1971; Norman 1972; Sykes 2006a; Tannahill 1973; Teuteberg 1986) and long held concepts of health by physicians who preached that meat was healthy while vegetables and fruit were to be eaten in moderation or as medicines (Norman 1972: 78, 96-99; Woolgar 2006: 198).

Europeans acquired their meat from cattle, sheep, pig, poultry, and fish, while wild game was mainly reserved for the wealthiest tables (Crossley-Holland 1996: 57-58; Mennell 1985: 42-43; Norman 1972: 75; Sykes 2006b: 163). Beef was often the most frequently consumed meat (Albala 2003: 63; Sykes 2006a: 63; Teuteberg 1986: 18), while pork was a favorite in Germany and the Low Countries where pigs were strictly raised as a meat source that required minimal tending while the meat lent itself well to the contemporary preservation methods (Adamson 2004: 30, 135, 142; Albala 2003: 62; Norman 1972: 61; Woolgar 2006: 92; Woolgar et al. 2006: 275). Fresh meat was not a perennial luxury since the highly seasonal Northern European climate required the autumn culling of animals that might have stressed fodder supplies or may not have survived the harsh winter (Braudel 1973: 132; Dyer 2006: 204; Hamerow 2002: 131; Tannahill 1973: 209; Trow-Smith 1951: 97). Consequently, a large proportion of meat 
consumed by any level of society was salted, pickled, or smoked. Cookery books show that the Medieval cuisine of Northern Europe was a menu that included large quantities of meat prepared as liquid-based stews and potages that were scooped with spoons and crusty bread trenchers, while roasts and boiled meats were only consumed occasionally (Crossley-Holland 1996: 141-147; Deetz 1996: 170; Museum Boymans van Beuningen Rotterdam 1991: 19, 35, 80; Norman 1972: 75; Schaeffer 1994: 75; Tannahill 1973: 222). The stews and potages served two important purposes. They allowed the meat to cook all day with little attention and also diluted the high salt content of the preserved meat. In addition to the fluid-based cuisine, sauces were used to both partially extract as well as mask the salt in the preserved meat, and they took prominent places in Medieval dishes (Adamson 2004: 26-27, 134, 137; Crossley-Holland 1996; 150-151; Norman 1972: 7577; Tannahill 1973: 209, 218; Thirsk 2007: 113).

The Northern European cuisine remained relatively unchanged for a millennium until the Late Medieval Period between the fourteenth and seventeenth centuries. At this period, meat dishes began to change from the dominant wet stews and potages to fuller joints of dry meats in the form of roasts (Adamson 2004: 137; Crossley-Holland 1996: 147; Norman 1972: 114; Woolgar 2006: 90). The impetus for this transition to roasted joints is often attributed to the slow, incremental, and often hesitant introduction of the fork throughout Northern Europe by way of Italy from Byzantine Turkey beginning in the fourteenth century (Adamson 2004: 124, 160; Albala 2003: 103-104; CrossleyHolland 1996: 182; Deetz 1996: 168-170; Museum Boymans van Beuningen Rotterdam 1991: 164; Norman 1972: 117; Teuteberg 1986: 19). 
An important component of the Northern European diet was dairy products of milk, cheese, and butter. Their consumption of these dairy products has a long history in Northern Europe, but dairy products were normally minor components of the diet until the Later Medieval Period. Instead, draught, wool, and meat yield were the major goals of earlier Medieval animal husbandry (Sykes 2006a: 57-58; Woolgar 2006: 94). Beginning in the thirteenth century, the development of an improved plough freed draught cattle (Sykes 2006a: 59) and intensive breeding practices allowed for increased milk production (Adamson 2004: 141). Milk consumption was normally minor because of preservation issues, but butter and cheese allowed dairy to be eaten throughout the year (Woolgar 2006: 95). Initially dairy products were considered "white meat" and were mainly the food of the poor and the rural who could not afford meat on a regular basis (Adamson 2004: 45-47, 134; Mennell 1985: 42-43, 46; Norman 1972: 120; Schaefer 1994: 140-141). Dairy products were often consumed by all groups on the religious days when flesh was forbidden (Adamson 2004: 138, 142 Crossley-Holland 1996: 102). Slowly, milk based dishes such as custards, caramels, and creams began to appear in cookery books, with cream based soups only being invented in the seventeenth century (Norman 1972: 113-114). Butter consumption was also initially slow, where butter was included in only 7 of 460 recipes from two major fifteenth century cookery books (Norman 1972: 113). Butter eventually became common additions to pastries, vegetables, sauces, and it was used as a replacement for bread and flour as a thickening agent (Norman 1972: 113).

The Flemish/Dutch Low Countries were renowned for their dairy production. The limited amount land in the swampy Low Countries caused the Dutch to import grains 
while developing an intensive animal and dairy production regime. By the Late Medieval Period, dairy products had already become significant elements in the Dutch diet, but they became dominant in the second half of the sixteenth century (Adamson 2004: 46, 141; Crossley-Holland 1996: 102; Rose 1989: 6; Schaefer 1994: 72-74; Schama 1987: 158-159, 163-164; Teuteberg 1986: 18). Dutch cuisine began to differentiate from the rest of Europe through the use of dairy products in place of other materials. The stereotypically portly Dutch were nicknamed "butter balls" by the French, because butter was used in place of the widely used animal fats in other Northern European and olive oils in the Mediterranean cuisines (Adamson 2004: 141; Boxer 1965: 61; Schama 1987: 163, 170; Thirsk 2007: 39). In fact, the practice of eating bread with a butter spread is believed to have been a Flemish invention (Adamson 2004: 46). In the seventeenth century, nationalism caused the Dutch people to identify and personify themselves as an honest, hardworking, “cheese-munching” caricature named Jan Kees ( $k a a s=$ cheese) commemorated by the poet Jacob Westerbaen (Schama 1987: 164). Recent genetic evidence shows that the modern Dutch population is nearly $100 \%$ lactose tolerant indicating the historical importance of the dairy industry in their diet (Wade 2006). The dominant Dutch presence in seaborne trade throughout the sixteenth through eighteenth centuries helped spread the importance of dairy products into the Northern European diet, especially to France, England, and New Netherland in North America (Albala 2003: 10, 117; Braudel 1973; 142, 144; Crossley-Holland: 1996: 103; Norman 1972: 122; Rose 1989: 3-35; Schama 1987: 169-170; Thirsk 2007: 38-40). 
2. Foodways at the Cape: Most knowledge of Cape cookery during the VOC period comes from the personal observations of Cape visitors and inhabitants as well as through the analyses of ceramics excavated from around the settlement. After the initial foodrelated hardships experienced by the first settlers under command of Van Riebeeck (i.e. Skead 1980, 1987: 813-855; Thom 1952: 56-92; Coetzee 1977: 25-27), the Cape diet became a mixture of imported and indigenous ingredients. The meat mainly consisted of the indigenous cattle and fish, hybridized sheep, imported pigs and poultry, plus the occasional heavily salted provisions delivered by calling ships (see the section of "Historical Incidences of Animals" for full description and citations). Indigenous, wild birds and game were less frequently consumed once the domestic stock numbers were sufficient and over-hunting depleted the amount of game near the settlement (Cruz-Uribe and Schrire 1991: 96; Raven-Hart 1970b: 270; Mentzel 1925: 101; 1944: 77, 102; Skead 1987: 813-855). As the settlement developed, the cookery acquired its own Cape identity as a creolized cuisine, sometimes called "Cape Malay" for its mixture of the European and its slave identity of East Asian, and Eastern African influences (Abrahams-Willis 1998: 6-8; Botha 1970: 49; Coetzee 1977: 28, 44-47; Elphick and Malherbe 1988: 28-35; Elphick and Shell 1988: 225).

Hilda Gerber (1959: 10) suggests that the creolization of the Cape diet was a later development in the mid-eighteenth century, and that it developed as a result of the new surroundings of the free burghers who were living throughout sparsely populated frontier. One insight from Van Riebeeck's Batavian born and raised grand-daughter who visited in 1709 tells how she retained her accompanying slave to serve as a cook since the Cape diet was unlikable to her since it was still too Dutch-like (Gerber 1959: 10). Kolben 
(1730 cited in Gerber 1959: 10) and Valentyn (1971 cited in Gerber 1959: 10), covering the period from the 1710s-1730s, do not discuss the Cape diet resembling Eastern styles, but instead refer to the Eastern ingredients as being more commonly used for the slaves. The creolization of the imported European diet mainly involved non-meat ingredients such as spices, vegetables, rice, sauces, and condiments.

Ceramics provide indirect clues about the food that was prepared at a particular site since vessel forms are generally designated as food storage vessels, food preparation vessels, or food serving vessels (i.e. Beaudry et al. 1983; Jordan 2000a; 2000b). Three main studies have been performed on ceramics from VOC Cape archaeological sites include Gabeba Abrahams-Willis’ (1994 1996, 1998) study of the coarse earthenwares from the Grand dated to 1740-1760; Jane Klose's (1997) study of all ware types from several seventeenth and eighteenth century sites including the Castle and Elsenburg; and Stacey Jordan's (2000a; 2000b) study of the typology and petrology of local and imported coarse earthenwares from the Castle and Oudepost I. The vessel forms include hollow wares such as pipkins and large, lidded cook pots for stews, roasts with drip pans to collect the juices and fat from the rotisseried meat joints, and saucepans for the characteristic Northern European meat sauces and stews (i.e. Abrahams 1994; 1996; 1998; Jordan 2000a; 2000b; Klose 1997). Communal dining may have been common among groups such as the garrison and the ill at the hospital (Abrahams 1996: 233; Mentzel 1921: 112). The Dump deposit from Elsenburg contained similar types of vessels related to food preparation, but it also contained a large proportion of vessels consistent with its wealthy owners, including flat plates and serving dishes made of expensive porcelain imported from China and Japan (Klose 1997: 133). Roasted meat is 
expected at the Cape as a result of Dutch continuation of their cuisine from the homeland. It is possible that roasted meats were consumed at places of lower social standing on plates made of different materials such as pewter or wood and therefore might not be preserved or included on discussions of ceramic finds (Abrahams 1996: 227). Though the sample of comparable sites is small, the ceramics suggest that the wealthy Elsenburg inhabitants may have consumed roasted meat on a more regular basis. Attributed as an impetus for the transition from stews to roasts as the more prominent dishes in Northern Europe in the Later Medieval Period, the fork also features at the Cape in historical documents being used at a wedding feast (Abrahams 1998: 35; Mentzel 1925: 120) and archaeological deposits where they are found at the upper-class Elsenburg (Hart and Halkett 1993: 37). An important missing component of the ceramic typology at the Cape is the characteristic milk pan which was not imported or made locally, suggesting that dairy products may not significantly factored into Cape foodways (Abrahams 1996: 228; Jordan 2000a: 175).

Ceramics lets us infer whether foods were prepared wet or roasted, and served communally or individually. Unlike the quantity published in Europe, cookery books only first appear in 1819 after the English have influenced the Cape cuisine (Abrahams 1996: 230; Coetzee 1977: 28, 106). However, contemporary observers described the cuisine with the many ingredients and help place the meals in their social contexts.

Most of the documents were made by visiting dignitaries and others who were privy to feasts and official banquets (i.e. Kolben 1731a; 1731b; Mentzel 1921; 1925; 1944; Raven-Hart 1970a; 1970b; 1976; Strangman 1936; Valentyn 1971; 1973). This privileged perspective presents a somewhat biased picture of Cape cuisine showing how 
the wealthier dined with full access to the available meats, spices, and garnishes. Descriptions of the meat dishes mainly include identifications of the meats present and sometimes if they are stewed, roasted, or served with various spices, plants, or pastries.

Fresh meat, especially mutton, was always available at the Cape since the settlers did not need to perform seasonal culling and meat preservation due to the mild Cape climate. Even though fresh meat, stock and fish, was readily available, records of meat preservation do appear in the records in regards to provisioning for calling ships (Mentzel 1925: 89, 102-104), but also to keep large amounts of meat readily available for continuation of Northern European tastes (Abrahams 1996: 225-226; 1998: 15-17; Coetzee 1977: 65-68, 99; Mentzel 1925: 102-103; 1944: 101, 107, 114; Raven-Hart 1976: 29). Mentzel (1925: 103-104) describes the preparation of large amounts of salted beef. Pickled and salted meats imported from Europe were favored by the Cape settlers as a break from the monotony of fresh meat (Mentzel 1925: 102). The meat from the stock, especially the beef, at the Cape is often described as being inferior to the same in Europe (Mentzel 1925: 101; 1944: 203; Robinson 1994: 182, 184; Wilkens 1901: 74), but the meat preserved at the Cape was described to rival the salted beef from Hamburg, Germany (Mentzel 1925: 103). The importance of the imported salted meats to the Cape inhabitants is demonstrated by the French astronomer Nicholas Louis de la Caille in the mid-eighteenth century:

Although fresh meat and fish are very cheap at the Cape, the Dutch take no pleasure but in salted or smoked meat or fish, or even dried fish which they eat lightly grilled with much pepper and bread soaked in hot water. The women are particularly fond of achards, that is to say vegetables or fruits salted and preserved in vinegar, with an abundance of spices. I was a guest at several banquets where the main dishes were hard, yellow stockfish and half putrid European ham with the fat entirely yellow and 
rancid. Everyone carefully avoided the fresh foods, which were served in profusion, but merely to make up the number of dishes... the finest gifts that can be given by the Captains of the ships that touch at the Cape are pieces of beef salted in Europe for the food of the crews; and the blacker these are, the more they are liked by the Dutch. (Raven-Hart 1976: 29)

Roasting was a common method of preparing joints of meat in the documents (Abrahams 1996: 226-227; Coetzee 1977: 87; 89, 91, 92, 94; Gerber 1959: 65; Robinson 1994: 181). Adam Tas, a prominent free burgher, described "3 fat quarters of roast mutton" at a wedding feast in 1705 (Botha 1970: 57; Fouche 1914: 75). Stews appear less often in the documentary record. The Company Hospital served a mutton stew daily, except on Friday when they were served a beef stew (Mentzel 1921: 112). A creolized Cape dish called kerri-kerri (curry) was commonly consumed and consisted of a stew with mutton or fish with spices and rice (Mentzel 1921: 112). While mutton, beef, and fish were commonly consumed meats in stews, Adam Tas mentioned receiving a stew from his neighbor, Mrs. Van der Bijl, who had just slaughtered a pig (Fouche 1914: 21). At the turn of the nineteenth century, roasting from the newly imported English cookery seemed to have replaced some of the Dutch or creolized stews common during the VOC period (Abrahams 1996: 227; 1998: 19; Malan 1993: 179; Robinson 1994: 181).

The VOC settlers consumed most parts of the sheep and cattle they slaughtered. Most of the offal was simply disposed of during mass slaughter episodes for provisioning (Raven-Hart 1970a: 202; Raven-Hart 1970b: 346; Robinson 1994: 185), but the "pluck," the heart, lungs, and liver, were to be provided by the Company slaughterers to the VOC authority at the Cape free of charge (Mentzel 1925: 55). Though it was the least favored portion of the animals, the "pluck" obtained from the smaller scale home slaughtering 
was often minced to be included in stews and hash, while the colon, tongue, and head were roasted on a grill or under hot coals (Coetzee 1977: 65-66).

Creolization through the additions of new ingredients and combinations was not the only factor that transformed the imported Dutch cookery to a more Cape cuisine. The Dutch and the other Northern European VOC servants who settled at the Cape had formerly had a diet that was dominated by dairy products. Dairy was rather unproductive at the Cape, and the products that could be made were considered inferior to the European counterparts (Raven-Hart 1976: 30-31; Wilkens 1901: 74). To compensate for the scarcity and inferiority of the Cape butter, the fat from the sheep's tail was used in place of the butter to cook vegetables, meats, and sauces by the Dutch back in Europe (Abrahams 1998: 19; Botha 1970: 50, 86; Coetzee 1977: 65, 94; Kolben 1731b: 65; Mentzel 1921: 56; 1925: 101; Robinson 1994: 182; Wilkens 1901: 74). Since dairy products were difficult to obtain, they were expensive when available. Using pork as a gauge-- being one of the most expensive meats at the Company stores-- an undated price list shows one pound of butter cost as much as three pounds of pork, while one pound of Cape cheese cost as much as two pounds of pork (Coetzee 1977: 33).

B. Animal Management in Europe: In order to study animal husbandry in the colonies, it is important to understand how these practices were developed in the homelands. The Dutch were inheritors of European husbandry traditions which they innovated to support their growing urban populations and changing demands for new animal products.

European animal management strategies were established by the Classical Period, and spread throughout Europe by the Romans (Bult and Robbers 1992: 135; Fussell 
1972: 13; Hamerow 2002: 126). Domestic animals dominated archaeological assemblages. Sheep and goats dominated herds, where they were raised for wool and milk; while pigs were raised for meat, and cattle were kept for draught and dairy though their milk yields were relatively low (Fussell 1972: 13, 33). In Northern Europe before the Romans, breeding seems to have been random where rams and bulls were not selected for beneficial qualities. The Romans placed greater control on breeding through the selection of quality stock as well as structuring schedules for breeding, except for pigs which were generally unimproved and allowed to forage in a wild state (Bokonyi 1971: 653; Fussell 1972: 32). Ewes were first bred at the earliest two years of age, though three years was considered ideal (Fussell 1972: 32). Sows were first bred between twelve to twenty months of age and they could continue to produce young until they were about seven years of age (Fussell 1972: 33). Regional cattle breeds have been distinguished though documentary descriptions of colors and size. Their cows were normally bred between four and ten years of age though it was possible to breed cows as young as two years of age if necessary (Fussell 1972: 34).

Animal management strategies from Roman to Early Medieval times were relatively similar throughout central and northern Europe. Cattle provided the greatest quantities of meat in the Medieval European diet, but sheep were often the most numerous remains in the documents and archaeological contexts (Bult and Robbers 1992: 135; Pennington 1989: 60; Stone 2005: 40; Sykes 2006: 57-59, 63; Trow-Smith 1951: 125; 1957: 173). Though pigs were common during the Roman period, they became more significant meat resources for Medieval Europeans since the cattle and sheep were more heavily relied upon for their secondary products (Bult and Robbers. 1992: 135; 
Crabtree 1989: 210; 1996: 62-64; Fehring 1991: 176; Fussell 1972: 33; Grant 2002: 18; Hamerow 2002: 131, 134, 146; Nyerges 2002: 267-268; Pennington 1989: 60; Pigiere et al. 2002: 236).

Documents reveal aspects of animal husbandry not visible in the archaeological record. With increased control over breeding, castration was practiced on male animals that were not suitable for breeding though they were still useful for meat. In France, bullcalves were castrated in the autumn when they were about two years of age, while pigs were castrated between six months to one year of age (Anonymous 1650: 95, 99). English rams were often gelded at five months of age (Trow-Smith 1957: 244). Breeding was performed by very few males, which were kept segregated from the females until scheduled breeding times in the spring (Allison 1958: 101; Kolben 1731b: 64; Mentzel 1921: 56; 1944: 213; Trow-Smith 1951: 96-9; 1959: 198). One ram, between 15 months and six years of age, was considered capable of breeding with 20 to 60 ewes annually (Allison 1958: 103; Stone 2005: 76; Trow-Smith 1957: 242; 1959: 40). Two bulls were considered sufficient to breed with 60 to 70 cows (Fussell 1972: 34). An element of superstition also played a part in Medieval animal husbandry, where it was believed that the sex of the offspring could be predicted based upon the certain weather conditions such as the direction of the wind (Anonymous 1650: 98).

Slaughter patterns reflected the products obtained from the animals during the Medieval Period. Cattle were often slaughtered at older ages after their usefulness for dairy, breeding, and draught was exhausted (Fehring 1991: 176; Hamerow 2002: 127; Sykes 2006: 57-59). Sheep were also kept older to obtain wool, lambs, and possibly milk (Fehring 1991: 176; Hamerow 2002: 132; Sykes. 2006: 58). Pigs, which only provide 
meat, were slaughtered very young except the few kept for breeding (Fehring 1991: 176). At the Early Medieval site of Ludeborg, England, $90 \%$ of the pigs were slaughtered before two years of age, while 50\% were younger than one year of age (Hamerow 2002: 128). As mentioned in the discussion on Medieval European cookery above, salted meats were major components of the diet due to the necessity to cull large numbers of animals in the autumn to reduce stress on the fodder supplies (Dyer 2006: 204; Hamerow 2002: 131; Tannahill 1973: 209; Trow-Smith 1951: 97, 125).

Medieval husbandry strategies began to change in the "sixteenth and seventeenth centuries [which was] a period of transition from senile medievalism to a vigorous and adolescent modernity" (Trow-Smith 1957: 172). Increased urbanization caused livestock producers to change their focus away from the secondary products to a greater emphasis on meat production and commercial agriculture to feed the growing demand from the towns (Davis 1997: 416; Pennington 1989: 61; Trow-Smith 1957: 172-173). Cattle became the major meat producing stock to supply the urban centers. At this time, cattle also began to lose importance as a draught animal to the horse which was able to pull the improved plows (Albarella 1997: 22; Bult and Robbers 1992: 137; Pennington 1989: 61; Trow-Smith 1957: 173). The shift towards meat production instead of secondary products saw sheep and cattle being slaughtered at younger ages. Fattened sheep were slaughtered between two to four years of age when the animals reach their maximum meat yield to feed intake efficiency (Sykes 2006: 63; Trow-Smith 1959: 199). Beef cattle were slaughtered around three to five years of age (Fehring 1991: 176; Sykes 2006: 63; Trow-Smith 1957: 239). Rural sites often contained relatively older animals compared to urban sites because the females were kept on the farms to produce offspring (Allison 
1958: 101-102; Landon 1997: 57; Sykes 2006: 62). Though very young animals were traditionally slaughtered for culling purposes to relieve stress on fodder supplies and to remove undesirable animals, younger animals were slaughtered to fulfill growing demand for tender meat. The production of lamb and veal increased in the seventeenth century, indicating that taste was a driving force in meat consumption in urban areas (Albarellla 1997: 22; Trow-Smith 1957: 244; 1959: 23).

Part of this new focus towards greater meat production was the improvement of the animal breeds. One method used to identify improved breeds in the English archaeological record is that larger skeletal measurements would indicate greater meat producing animals (Albarella 1997: 19-23; Davis and Beckett 1999: 4; Thomas 2005: 74). Using the width of various elements to judge animal size, researchers identify steady increases in mean animal size of the stock, including fowl, from as early as the fifteenth century (Albarella 1997: 19-26; Davis 1997: 418-427; Davis and Beckett 1999: 11-14; Fussell and Atwater 1933: 381; Outhwaite 1986: 3-4; Thomas 2005: 77-82). Though breed improvement occurred early, cattle were improved the earliest, while sheep, pigs, and fowl were slower to be improved (Albarella 1997: 21; Davis and Beckett 1999: 1114).

As early as the thirteenth to fourteenth centuries, the Dutch exported agricultural innovations that played key roles in the development of the Late Medieval animal husbandry in Northern Europe (i.e. Fussell 1959; Murray 1957; Plumb 1952: 86; TrowSmith 1951: 110-112, 148; 1957: 180, 235, 253; 1959: 1, 26-8). The Dutch developed the plow-wheel that allowed horses to perform draught work and freed cattle to be used for milk and meat (Fussell 1959: 621; Murray 1957: 851; Trow-Smith 1951: 111-112). 
Dutch horses were often hybridized in places like England to create large, powerful draught horses capable of performing this plow work (Fussell 1959: 619; Trow-Smith 1951: 124; 1957: 253). The wide use of Dutch clover, as well as the practice of grazing on rotated fallow fields, diversified the fodder and contributed to the improved nutrition and growth of livestock outside of the Low Countries (Fussell 1959: 614-617; Murray 1957: 851; Trow-Smith 1951: 110; 1957: 235).

Dutch cattle were highly regarded, and they were incorporated into English cattle husbandry by the seventeenth century (Fussell 1959: 619; Trow-Smith 1951: 124, 151; 1957: 180; 1959: 1, 26-28). The Dutch cattle were noted for their physical appearance such as their long legs, short horns, white markings, and greater body size (Fussell 1959: 619-620; Trow-Smith 1959: 26-28). Most importantly, with the increased urbanization leading to a greater demand for dairy products, the Dutch cattle improved the milk yield of the English breeds (Trow-Smith 1951: 151; 1959: 1, 26-28). Though the Dutch cattle were desired, the Dutch breed was rarely kept pure. The Dutch breed was mixed with the English breeds to retain the high quality of the beef produced by the English cattle (Trow-Smith 1959: 28).

\section{SUMMARY OF HISTORICAL ZOOARCHAEOLOGY AT THE CAPE IN THE SEVENTEENTH AND EIGHTEENTH CENTURIES}

Excavations of VOC period (1652-1795) sites at the Cape involve only a few zooarchaeological investigations (Hall and Markell 1993: 3-5). The few available reports rarely go further than simple taxa lists and age identifications, with the exception of the detailed systematic analysis of the terrestrial fauna at Oudepost I (Cruz-Uribe and Schrire 1991). The available sites can be divided into Cape center and frontier sites as follows: 
A. Cape Center: The meat consumed at the urban Cape settlement, which would become Cape Town, was produced throughout the outskirts and frontier controlled by the VOC. The animals were then imported on foot and slaughtered at established abattoirs before the meat was distributed to various markets for sale or provisions. Two faunal analyses are presented from the VOC period Cape settlement and both are derived from secondary fills.

1. The Grand Parade: The Grand Parade is the historic site of the earthen Fort de Goede Hoop which was in use between 1652 and 1674 when the permanent, stone Castle of Good Hope was built nearby. Excavations undertaken by Gabeba Abrahams-Willis between 1982 and 1992 were believed to reveal structures including a moat attributed to have belonged to the original Fort. Finds of glass, ceramics, and fauna suggest a palimpsest of secondary deposits. The majority of the assemblage was dated to the mideighteenth century; nearly a century after the Fort was no longer used (Abrahams 1994: 2; 1996: 245; Abrahams-Willis 1998: 3-4).

The faunal sample included 95 individuals which were dominated by mammals, followed by birds, frogs, tortoises, and fish in decreasing proportions. The mammals were mainly domestic stock dominated by sheep over cattle, while only one pig individual was identified (Abrahams 1996: 239-243). A few wild bovids were also identified, and they were only the smaller grysbok, steenbok, and duiker (Abrahams 1996: 236). This assemblage is useful in that the number of sheep allowed Avery to describe one aspect of husbandry at the Cape. The majority of the Parade sheep were slaughtered at two years of age and older, and they were interpreted to have been the 
products of local butchers who slaughtered mutton brought into town from the outskirts (Abrahams 1996: 244-245). No taphonomic traces or skeletal element frequencies were reported.

2. Slave Lodge: The Slave Lodge, less than $1 \mathrm{~km}$ from the Parade, was built in 1679 to house VOC slaves. Excavations were conducted in the Lodge's courtyard to obtain information about the VOC's slaves (Avery 1992: 1). Graham Avery (1992: 2) explicitly noted that the archaeological deposits were highly disturbed fills and the bones recovered from these fills can not be considered a confident reflection of slave diet at the Lodge.

Though the bones derive from secondary fills, the bones may be considered a product of urban consumption since the fills were heavily comprised of architectural debris and it is unlikely that refuse would be transported into the town for disposal. The faunal assemblage is dominated by sheep through NISP and MNI, followed by cattle, chicken, pigs, and a small wild bovid. Fish bones were numerous though MNI was not calculated (Avery 1992: 1, 3). Although taphonomic traces were not recorded, except for butchery, the faunal assemblage seems to have been affected by differential preservation processes since the denser, resistant skeletal portions are best represented (Avery 1992: $5)$.

B. Frontier: Within a few years of establishment at the Cape, the VOC moved beyond Table Bay into the frontier to establish trade posts and protect against other European incursions (Schrire 1988; 1990; 1995; Schrire et al. 1993; Sleigh 1987), to protect natural resources (Hall et al. 1993; Sleigh 1987; Valentyn 1973: 241), and to settle grazing lands 
for the great sheep and cattle herds (Elphick 1985: 110, 155; Elphick and Malherbe 1988: 11; Guelke 1988: 66, 70; Robertson 1945b: 79-80; Van der Merwe 1995: 1).

1. Paradise: The site of Paradise was a VOC foresting outpost dating from 1659. The outpost included a small number of structures that housed a small contingent of soldiers, overseers and their family, as well as slaves throughout the period of VOC control (see Hall et al. 1993: 40-41 and sources there).

Excavations were undertaken between 1985 and 1989 at the locations of the Main House and the two outbuildings (Hall et al. 1993: 43). Material remains were recovered from several fills that span the eighteenth and nineteenth centuries (Hall et al. 1993: 4951).

The fauna from the Main House was originally analyzed by Margaret Avery (1989), but in order to produce a larger sample size, the fauna was not separated by context disregarding the fact that the bones resulted from fills representing an extended period of time. A second analysis in 1993 split the samples into the structures they were found within and around. The sample sizes for each of these fills were very small, with the latest fill being the richest. The fauna was dominated by sheep over cattle, chicken, and pig. A small number of wild birds and mammals were identified. Interpretations about social status between the Main House and outbuildings were attempted through the proportions of skeletal parts, but no discussion of taphonomy was done (Hall et al. 1993: 52). Taphonomy seems to have been an important process at Paradise when Avery commented that sheep remains were fragmented and missing epiphyses, though she concludes stating that "it seems likely that some of the apparent inconsistencies have 
social rather than mechanical implications" (Avery 1989: 115). In the first analysis, Avery presented some information about sheep selection in the Main House sample. The sheep were mostly slaughtered between 6 months and 2 years of age, with a few individuals slaughtered older than 2 years of age (Avery 1989: 115).

2. Oudepost I: The fauna recovered from Oudepost I's terrestrial excavations is summarized in Chapter 7.

3. Vergelegen: Vergelegen was a large estate established by Governor Adriaan van der Stel who served as governor of the Cape settlement from 1699 to 1708 . Vergelegen was a contested construction, which led to Van der Stel's recall back to the Netherlands, and it included a main house and several outbuildings such as slave quarters and a water mill (Markell et al. 1995: 10-27).

A small collection of faunal remains dating from the mid-eighteenth century were recovered from the water mill. The fauna was simply quantified. Sheep and cattle were similarly represented nine to six MNI respectively, and while cattle would have provided more meat per animal, no mention is made on what portions of the animals are represented by the remains (Markell et al. 1995: 27). Smaller amounts of pig and chicken round out the domestic portion of the mill sample. Marine resources were identified in the mill sample and include fish and mollusks obtained from False Bay (Markell et al. 1995: 28). 


\section{CHAPTER TWO: Methodology}

\section{SAMPLING}

The effects of sample size on quantifications have been discussed for a variety of zooarchaeological problems such as abundance and diversity (Cannon 2001; Cruz-Uribe 1988; Grayson 1978; 1981; 1984; 1989; Kintigh 1989; Lyman and Ames 2004; 2007; Meltzer et al. 1992), skeletal part representations (Jackson 1989), and mortality profiles (Lyman 1987b; Maltby 1982). In general, larger sample sizes are more likely to represent the variability present in the full collection. In this project, time constraints necessitated sampling in order to analyze the largest possible samples from the five different sites. Site specific excavation details are presented in the appropriate site chapter. Cursory examinations of the full faunal collections were undertaken in order to determine that the selected samples confidently represented their larger, respective collection in regards to primary data such as taxa, skeletal part representations, and aging (Reitz and Wing 1999: 106-107). Since the feature deposits were excavated in square or rectangular units, the unit or units that contained the greatest amount (number of fragments) of faunal remains were selected in order to provide the largest samples possible that could be analyzed in the available time (except Oudepost I where the entire excavated portion of the Dump was analyzed).

Equal treatment was applied to each bone fragment of the selected samples from each site. Klein and Cruz-Uribe (1984: 19) argue that "it is rare that nonidentifiable bones provide any information that is not also available from the identifiable ones." While it is possible that the presence or absence of various data can be determined between identifiable and nonidentifiable bone fragments, the frequency present in the 
sample and the geographical locations of taphonomic data along the bones require that an analyst includes all bone fragments to counter the bias of what that analyst can or cannot identify in regards to taxon or skeletal element (for the importance of patterning and frequency with fragmentation see Brain 1975; for scavenging traces see Blumenschine 1988; 1995). Failing to record the data from "unidentifiable" bone fragments might lead to losing potentially relevant data (Reitz and Wing 1999: 154-155). Identification to the most specific taxonomic level and skeletal element was made for each bone fragment in the chosen samples. In addition, each bone fragment received the same attention when surveying for the taphonomic data that is outlined below. This equal treatment to all the samples presented here allows for inter- and intra-site comparison.

\section{TAPHONOMY}

One aspect of the processual paradigm calls for the identification of empirical patterns in the archaeological record in order to infer human behavior (e.g. Binford and Binford 1968; Deetz 1968, 1996; Leone 1972; O’Brien et al. 2005; Watson 2007; Watson et al. 1984). A crucial part of this approach is to identify any possible interferences or biases that can lead to equifinalities or confuse the interpretations of archaeological residues (e. g. Binford and Bertram 1977; Binford 1981; Bonnichsen and Sorg 1989; Gifford 1981; Lyman 1994; Micozzi 1991; see also references cited below). This project applies a suite of middle range theory and experimental archaeology adapted from available prehistoric and historical zooarchaeological studies to understand the processes that produced the faunal samples presented here. 
A. Depositional Context: Depositional contexts are crucial to understand how the bones were deposited if we are to impose logical behavioral and temporal on the collections. The nature of the deposits revealed whether the deposits were primary or secondary and whether they had developed over limited or extended periods of time. Understanding the time represented by the deposits then allowed the samples to be realistically compared on the intra- or inter-site levels. Field notes, photographs, and profile drawings were also useful in understanding the sedimentology and depositional history of each site. These excavation descriptions aided in determining how the sediments were deposited as a discrete unit, as well as how they relate to adjacent layers. Associated artifacts were also useful because they provided the best clues about deposition through analysis of their fragmentation and manufacture dates (Lyman 1994: 405-409; Schiffer 1987: 267-287; South 1977: 202, 291; Stein 1987: 351-353; Wood and Johnson 1978: 315).

B. Bone Condition: A number of factors can contribute to the fragmentation and degradation of deposited bone. Length and width measurements, general breakage patterns, and overall surface conditions were recorded in order to identify the timing of fragmentation and the bone's exposure before burial (table 2.1). These categories provided initial impressions of the bone collections that could be explored further through the more intense taphonomic trace analyses. Distinctions were made between green, oblique breaks, which indicate the fragmentation of fresh bones, and dry, transverse breaks, which indicate the fragmentation of bones that had undergone some loss of their organic, collagen component (Brain 1981: 15; Davis 1985: 66-67; Haynes 1983: 111 113; Johnson 1985: 160; Marshall 1989: 11-16; Morlan 1984: 161-165; Myers et al. 1980: 487-488; Villa and Mahieu 1991: 40). Weathering phases complement breakage 
Table 2.1. Criteria recorded to assess bone condition (adapted from Blumenschine 2003 with changes made to accommodate specific questions and qualities of the faunal collections).

\begin{tabular}{|c|c|}
\hline $\begin{array}{l}\text { Maximum } \\
\text { fragment length }\end{array}$ & $\mathrm{mm}$ \\
\hline $\begin{array}{l}\text { Maximum } \\
\text { fragment width }\end{array}$ & $\mathrm{mm}$ \\
\hline $\begin{array}{l}\text { Long bone shaft } \\
\text { circumference }\end{array}$ & $\begin{array}{l}0.1-1.0, \text { shafts divided by tenths to assess } \\
\text { completeness }\end{array}$ \\
\hline Surface color & Specific to specimen \\
\hline Surface condition & $\begin{array}{l}1=\text { pristine } \text {, original surface } \\
2=\text { minor exfoliation or flaking } \\
3=\text { minor chemical erosion } \\
4=\text { minor mechanical rounding } \\
5=\text { minor adhering matrix } \\
6=\text { major exfoliation or flaking that obscures } \\
\text { marks } \\
7=\text { major chemical erosion that obscures } \\
\text { marks } \\
8=\text { major mechanical rounding that obscures } \\
\text { marks } \\
9=\text { major adhering matrix that obscures } \\
\text { marks }\end{array}$ \\
\hline Weathering & 0-5, according to Behrensmeyer 1978 \\
\hline Recent breakage & $\begin{array}{l}0=\text { none } \\
1=\text { yes, but with less than } 10 \% \text { missing } \\
2=\text { yes, with more than } 10 \% \text { missing } \\
3=\text { modern breaks, but fragments can mend } \\
9=\text { indeterminate }\end{array}$ \\
\hline General breakage & $\begin{array}{l}1=\text { spiral, oblique } \\
2=\text { transverse } \\
3=\text { stepped } \\
4=1 \& 2 \\
5=1 \& 3 \\
6=2 \& 3 \\
7=\text { bone flake } \\
8=1,2 \& 3 \\
9=\text { indeterminate due to condition, modern } \\
\text { break, breakage of axial elements, or } \\
\text { breakage from butchery where no natural } \\
\text { break occurs (chop) }\end{array}$ \\
\hline
\end{tabular}

patterns by providing a rough temporal gauge to the length of time a bone had laid on an exposed surface (Andrews 1990: 10-11; Behrensmeyer 1978: 150-162; 1991: 308; 
Lyman and Fox 1989: 293-317). Surface condition was examined for various interferences such as matrix adhesion, root etching, or chemical dissolution that might obscure more detailed trace analyses (e. g. Denys 2002; White and Hannus 1983). C. Analyses of Taphonomic Traces on Bone Surfaces: Many studies have described the importance of close investigations to identify taphonomic traces, generally with some magnification (e. g. Behrensmeyer et al. 1986; Binford 1981; Blumenschine 1995; Blumenschine and Marean 1993; Blumenschine and Selvaggio 1988; Blumenschine et al. 1996; Bunn 1981; Capaldo and Blumenschine 1994; Dominguez-Rodrigo and Piqueras 2003; Egeland et al. 2004; Fiorillo 1989; Fisher 1995; Potts and Shipman 1981; Selvaggio and Wilder 2001; Shipman 1981). Taphonomic traces created by natural or human involvement with the bones are often inconspicuous and difficult to observe with the naked eye or irregular lighting. In addition, close investigation is important to correctly identify the trace present since it is possible for several processes to produce superficially similar modifications to the bone surfaces (see citations above). This project utilized the protocols described by Blumenschine et al. (1996: 494), which called for the survey of all bone surfaces under a 10x power hand lens while holding the bone specimen at a raking angle from a desk lamp in order to provide a contrast whenever a mark was encountered (table 2.2).

Mammalian carnivore interactions on bone assemblages can be significantly destructive. A large amount of attention has been paid to evidence of carnivore damage to archaeological faunas, though this research has generally focused on prehistoric scenarios such as hominid scavenging of carnivore kills or carnivore scavenging of hominid-collected fauna. While these taphonomic studies of carnivores involve the 
observation of wild animals such as wolves, leopards, and the bone-crushing hyenas, the research can also be applied to the effects of the domestic dog which has been a common component of historic period landscapes (Binford and Bertram 1977: 78-79; Brain 1981: 15; Landon 2005: 6; Munson 2000: 399; Munson and Garniewicz 2003: 408; Reitz and Wing 1999: 134-135). Scavenging carnivores consciously target fresh bones in order to consume any nutrients that may be available on the bone such as flesh scraps or within the bone such as grease or marrow. In the process of nutrient acquisition, various deletive actions occur which can include the full consumption of softer bones or bone portions, such as epiphyses, as well as rendering archaeological fauna less identifiable through fragmentation. These actions disadvantage zooarchaeologists by selectively deleting smaller sized animals, younger individuals, or bone portions useful for identification and aging (e. g. Bartram and Marean 1999: 25; Binford and Bertram 1977: 82; Blumenschine 1988: 498; Blumenschine and Madrigal 1993: 557; Blumenschine and Marean 1993: 282-289; Egeland et al. 2004: 349; Faith et al. 2007: 2028; Marean and Spencer 1991: 651-652; Marean et al. 1992: 106-111; Munson and Garniewicz 2003: 411-412; Symmons 2005: 1697). In addition to identifying these interferences, carnivore and other taphonomic traces help us to infer the depositional histories of the archaeological samples before their final disposal (table 2.2).

Other natural, destructive processes were recorded in order understand the range of processes that could have altered the faunal collections (table 2.2). Trampling or abrasion damages are preserved as shallow scratch marks that run in subparallel directions on the bone surfaces and they can vary in quantity (Behrensmeyer et al.: 1986: 770; Brain 1967: 98; Fiorillo 1989: 65; Fisher 1995: 33-36; Lyman 1994: 380-381). This 
project assumes that abrasion damage can be made on a bone surface in two ways; when the bone is pushed into the ground surface by walking people or other means, and when the bone is dumped into the ground adjacent to abrasive inclusions such as brick, mortar, or stone. More important than the scratches that trampling can leave on the bone surfaces; bones can be fragmented, crushed, and removed from the archaeological record through trampling. Generally, a weathered bone would fragment most easily, but even fresh, less dense bones or bone portions can be destroyed through trampling (Haynes 1991: 253; Lyman 1994: 379; Nicholson 1992: 89; Yellen 1991: 165). Root etching (Binford 1981: 49-50) and rodent gnawing (Lyman 1994: 193-197) damage were also recorded as part of the detailed taphonomic investigations of the bone surfaces.

Table 2.2. Criteria recorded to describe non-butchery related taphonomic traces observed on bone surfaces (adapted from Blumenschine 2003 with changes made to accommodate specific questions and qualities of the faunal collections).

\begin{tabular}{|c|c|}
\hline $\begin{array}{l}\text { Carnivore Tooth } \\
\text { Mark (TM) }\end{array}$ & $\begin{array}{l}0=\text { absent } \\
1=\text { present as isolated marks } \\
2=\text { present as punctures } \\
3=\text { present as gross gnawing } \\
4=\text { low confidence tooth marks }\end{array}$ \\
\hline TM location A & $\begin{array}{l}1=\text { cortical only } \\
2=\text { medullary only } \\
3=1 \& 2 \\
4=\text { thickness only } \\
5=1,2 \& 3 \\
6=1 \& 3 \\
7=2 \& 3 \\
9=\text { cannot see thickness or medullary surface }\end{array}$ \\
\hline TM location $\mathrm{B}$ & $\begin{array}{l}1=<2 \mathrm{~mm} \text { from fracture edge } \\
2=>2 \mathrm{~mm} \text { from fracture edge } \\
3=1 \& 2 \\
4=\text { on flake platform }\end{array}$ \\
\hline TM location $\mathrm{C}$ & $\begin{array}{l}1=\text { on or towards epiphyseal and NEFs, respectively } \\
2=\text { on or towards midshaft end for epiphyseal and } \\
\text { NEFs }\end{array}$ \\
\hline
\end{tabular}




\begin{tabular}{|c|c|}
\hline & $\begin{array}{l}3=1 \& 2 \\
4=\text { indeterminate, on midshaft fragment }\end{array}$ \\
\hline Notching & $\begin{array}{l}0=\text { absent } \\
1=\text { percussion mark } \\
2=\text { tooth notch } \\
3=\text { uncertain }\end{array}$ \\
\hline Notch associates & $\begin{array}{l}0=\text { no mark } \\
1=\text { tooth mark at notch } \\
2=\text { tooth mark opposite notch } \\
3=\text { percussion mark at notch } \\
4=\text { percussion mark opposite notch }\end{array}$ \\
\hline Multiple notches & $\begin{array}{l}0=\text { none }(\text { only } 1) \\
1=\text { on same edge } \\
2=\text { on opposite edge } \\
3=\text { on both edges }\end{array}$ \\
\hline Rodent & $\begin{array}{l}0=\text { absent } \\
1=\text { present }, \text { minor } \\
2=\text { present }, \text { major }\end{array}$ \\
\hline Root etching & $\begin{array}{l}1=\text { absent to isolated spots } \\
2=\text { minor } \\
3=\text { moderate } \\
4=\text { severe, obscuring marks }\end{array}$ \\
\hline Trampling & $\begin{array}{l}0=\text { absent } \\
1=\text { present }\end{array}$ \\
\hline
\end{tabular}

\section{TAXONOMY AND QUANTIFICATION}

Each bone specimen was identified to the most specific taxon possible (table 2.3). Taxonomic identifications for the mammals, birds, and reptiles were carried out with the aid of the IZIKO: South African Museum's comparative faunal collection. Osteological manuals were also consulted for mammals (Hillson 1992; Schmid 1972), birds (Cohen and Serjeantson 1996), and to aid in distinguishing between sheep and goats (Boessneck 1969; Halstead et al. 2002; Payne 1985; Prummel and Frisch 1986). Any fish remains were previously analyzed by Poggenpoel (1996). Biased assumptions were avoided by 
designating the more conservative, less-specific taxonomic categories and Bunn's (1982) relative body sizes for specimens that could not be identified to the species level. Though the sites presented here are from the historic period, all size 2 bovid bone fragments that were not able to be identified to the species level could not all be assumed to be from the domesticated Ovis aries, since wild size 2 bovids were accessible to VOC hunters at the Cape.

The standard number of identified specimens (NISP) is used to express the raw count of bone fragments such as when they are used in calculations of the taphonomic trace frequencies introduced above. The principle of interdependence causes NISP to be an unfit quantification when comparing taxonomic abundances since taphonomic processes may not be equal between contexts or even taxa from the same context (Grayson 1973: 432-433, 1979: 203, 1984: 20-24, 28; Klein and Cruz-Uribe 1984: 25; Lyman 1979: 536). Minimum numbers of individuals (MNI) were used to determine the abundance of each taxon while accounting for animal age and fragment interdependence. Grayson (1973: 433, 1979: 204, 1984: 30-34) warns that aggregating contexts may produce highly varied MNI calculations, which in turn makes interpretations on taxonomic abundances difficult depending on the fineness of the context being discussed. The faunal samples presented in this project were recovered from substantial, welldefined deposits that were able to be temporally controlled through analyses of material remains and/or documents. Aggregating multiple contexts was unnecessary to manufacture larger sample sizes in this research.

While MNI provides a count of complete animals represented, the age and context of the collections make them dependent on market economies. Ranked organizations 
such as the military and capitalist markets can create situations where incomplete animals are purchased or distributed to the consumers based on status, either through purchasing power or service rank (Huelsbeck 1987, 1991; Lyman 1977, 1979, 1987a; Schulz and Gust 1983). These potentially uneven distributions make MNI a potentially misleading quantification since it accounts for complete animals. Quantifications of skeletal element frequencies determined the completeness of the animals deposited in their respective contexts. Minimum numbers of elements (MNE) were determined through the MNI represented by each element. Bone side, developmental age, and landmarks were the primary factors in determining the MNI represented by each bone, while relative size was secondary and used only if the size differences were rather disparate. Interpretations of skeletal element frequencies were made in conjunction with the taphonomic investigations to encompass the various cultural and depositional processes.

\section{AGES OF THE FAUNA}

In the studies of complex societies, aging domesticated animals has provided valuable information about human management of their animal resources. Animal use in the historic period, especially in the colonial settings, has narrowly focused on site-level interpretations where aging data is mainly used to explain status differences or slaughter practices at the site or supplying market (Bowen 1994: 155). Exceptions to this criticism using aging data are studies on urban-rural meat supply systems (e. g. Crabtree 1990; Landon 1996; 1997; Reitz 1986b) as well as Bowen's (1994) analysis of Chesapeake and New England cattle systems to investigate climactic pressures on meat or dairy production. This type of regional systematic approach is applied to the Cape's VOC 
Table 2.3. Basic criteria recorded from specimens (adapted from Blumenschine 2003 with changes made to accommodate specific questions and qualities of the faunal collections).

\begin{tabular}{|c|c|}
\hline Taxon & Most specific identifiable taxon \\
\hline Animal size & Relative size, for mammals according to Bunn 1982 \\
\hline $\begin{array}{l}\text { Skeletal part } \\
\text { Skeletal portion } \\
\text { Skeletal part } \\
\text { segment }\end{array}$ & $\begin{array}{l}\text { After Blumenschine } 2003 \text { (attached Appendix 1) } \\
\text { After Blumenschine } 2003 \text { (attached Appendix 1) } \\
\text { After Blumenschine } 2003 \text { (attached Appendix 1) }\end{array}$ \\
\hline Allometry & $\begin{array}{l}\text { Sex measurements, mm (Greenfield 2002). } \\
\text { Plus measurements of tooth rows, distal humeri and } \\
\text { distal tibiae widths, mm (Von den Driesch 1976) }\end{array}$ \\
\hline Relative age & $\begin{array}{l}\mathrm{A}=\text { adult } \\
\mathrm{S}=\text { subadult } \\
\mathrm{P}=\text { subadult, but partially fused } \\
\mathrm{I}=\text { indeterminate }\end{array}$ \\
\hline $\begin{array}{l}\text { Tooth eruption } \\
\text { age }\end{array}$ & According to Bull and Payne 1982; Silver 1969 \\
\hline Side & $\begin{array}{l}\mathrm{R}=\text { right } \\
\mathrm{L}=\text { left } \\
\mathrm{I}=\text { indeterminate }\end{array}$ \\
\hline Crown height & Height of crown of formed isolated tooth (mm) \\
\hline Crown breadth & Breadth of crown of formed isolated tooth $(\mathrm{mm})$ \\
\hline $\begin{array}{l}\text { Tooth wear } \\
\text { stage }\end{array}$ & $\begin{array}{l}\text { Tooth wear stage of tooth rows as well as specific } \\
\text { tooth if isolated (Payne 1973) }\end{array}$ \\
\hline
\end{tabular}

sites where aging data is incorporated in "looking at the much broader context of the herding system and how it shapes the selection of food" (Bowen 1994: 155).

Dentition provided the best material to age the domestic stock. Modern aging data for tooth development is applied to the archaeological material using Silver (1969) and Bull and Payne (1982). Modern data is used since eruption sequences and timing has been shown to be "stable," even between domestic and wild parallels as has been demonstrated with pigs and sheep (Bull and Payne 1982: 55, 71; Deniz and Payne 1978). 
In addition, with domestic stock, timing variations between improved or archaic breeds or modern later maturing breeds and earlier maturing breeds have been demonstrated to be no more than a few months on average (Habermehl 1975 and Reiland 1978 in Bull and Payne 1982: 56; Greenfield and Arnold 2008: 848; Silver 1969: 296-297), and these ages still fit within the standard age ranges proposed by Silver (1969) and Bull and Payne (1982).

The samples presented in this project are heavily dominated by sheep remains and Payne's (1973) tooth wear stages were applied to these specimens. Tooth wear is able to work beyond the age boundaries that limit the tooth eruption or epiphyseal fusion methods of aging which can only determine whether an individual is younger or older than the age at which the tooth erupts or the bone is fused. Since hypsodont, herbivore teeth are designed to wear down throughout the animal's life, crown height measurements have been argued as an effective method of providing prey mortality profiles indicative of human hunting or slaughter patterns. Criticisms have shown that the crown height methods regularly overestimate or underestimate animal ages due to the nonlinear wear rates of tooth rows as well as the wear rates of individual teeth (e.g. Gifford-Gonzalez 1991; Greenfield and Arnold 2008; Klein and Cruz-Uribe 1983, 1984; Klein et al. 1983; Pike-Tay et al. 2000). In addition, getting access to the root of the tooth, crown height measurements would be destructive if large proportions of the teeth were still anchored in the mandible or maxilla. The dentition and partial tooth rows from the sites presented in this project comfortably fit within Payne's (1973) tooth wear series. Isolated teeth were considered reliable representations of age and used in conjunction with the intact tooth rows as well as when intact tooth rows were not preserved. Payne's 
tooth wear method provides the benefit of a quick and nondestructive observation of both relative age when observing the wear on isolated first and second molars (see Chapter 7) as well as absolute ages for more intact tooth rows and third molars. In the cases of absolute ages, Payne's method of incremental wear also allows for discrete age class intervals of one or two years in length, which are more appropriate for showing potential variations in mortality that could remain undetected through the use of coarser age class intervals such as those provided through postcranial epiphyses (Gifford-Gonzalez 1991: 44; Klein and Cruz-Uribe 1984: 43; Lyman 1987b: 128; Monk 1981: 212). An even finer tooth wear aging method has been proposed by Grant (1982) and used with promising results such as the detection of seasonal slaughtering, but this method relies on wellpreserved fuller tooth rows, amongst other criticisms (e. g. Ervynck 2005 and references therein). Actualistic taphonomic work with domestic dogs have shown that the hard teeth are lost as the dog chewed the bone, or passed relatively complete if the teeth were ingested (Munson 2000: 399; Munson and Garniewicz 2003: 408).

Aging by epiphyseal fusion was performed as a cross-check for the dental results, as well as serving as the main aging method for samples where teeth were not available (Watson 1978: 100). The use of epiphyseal fusion stages for aging has several disadvantages such as the epiphyses being susceptible to deletion by taphonomic processes and coarser, uneven age brackets than those provided by the dentition. Epiphyses are only able to show whether an individual is younger or older than the age at which the epiphysis fuses to the bone's diaphysis (e.g. Klein and Cruz-Uribe 1984: 43; Monk 1981: 212; Watson 1978: 97-100). Similar to the interdependence problems faced with NISP quantifications, one is not able to assign ages in the terms of an individual 
since the relationships between bone fragments cannot be known in a mixed deposit. In this case, it is then possible to age "the same individual from different specimens many times" (Reitz and Wing 1999: 181). For this project, epiphyseal ages are presented as NISPs and interpretations are made on the general pattern observed with an eye for outliers that would indicate an individual not represented by dentition, such as a lamb (Reitz and Wing 1999: 183). Also, epiphyseal fusion stages cannot provide the equallength age class intervals that are better achieved by using Payne's (1973) tooth wear stages for sheep (Chaplin 1968: figs 5-7; Klein and Cruz-Uribe 1984: 43; Monk 1981: 212; Watson 1978: 97). Again, Silver (1969) and Bull and Payne (1982) provided reliable and commonly accepted ages for the postcranial bone development.

\section{V.SEX}

Determining animal sex is important in order to understand herd demographics, and human management of their domesticated stock. Sex is often able to be determined through sexual dimorphism or secondary sex characteristics such as horns. Sexual dimorphism in bone structure can be identified through the shapes of skeletal parts such as the cranium and pelvis, but these elements are not regularly found in complete enough condition due to their fragile nature (Klein and Cruz-Uribe 1984: 39). Sexual dimorphism has been quantitatively demonstrated by using breadth measurements from various skeletal elements of known-sex individuals that are more resistant to destruction such as metapodials (Fock 1966; Grigson 1982; Higham 1968). A concern arises regarding the distal breadth measurements of skeletal elements since distal breadth measurements of the humerus has been previously used in South African archaeology to 
demonstrate size differences between sheep breeds (indigenous versus hybridized) (CruzUribe and Schrire 1991: 97; Klein and Cruz-Uribe 1989: 91). The confusion between sexual dimorphism and sheep breeds size differences will be addressed in Chapter 8 .

Due to the often fragmentary nature of archaeological faunal remains, Greenfield's (2002) method of sexing ungulate acetabulae can be applied to a skeletal portion frequently present in collections. This method calls for the measurement of the medial acetabular wall at the ilio-pubis juncture as seen in figures 2.1 and 2.2 , since the medial acetabular wall is wider in males than females.

Secondary sex characteristics are not common in archaeological sites. Horns were not used to sex sheep since a historic source claim that both males and females developed horns (Mentzel 1944: 211). Finally, spur growth on the tarsometatarsus can indicate the presence of male chickens (West 1982: 255), while medullary bone might indicate the presence of female chickens that were killed just before egg-laying (Driver 1982: 251).

Figure 2.1. Line drawing illustrating the medial acetabular wall of the Bos taurus pelvis (reproduced from Grigson 1982: 8).

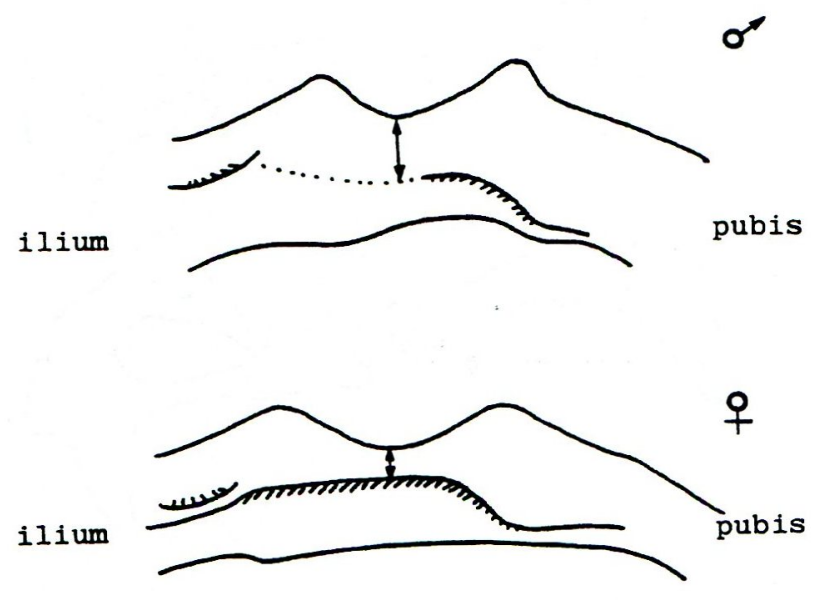


Figure 2.2. Placement of calipers measuring the medial acetabular wall (reproduced from Greenfield 2002: $\mathrm{np}$ ).

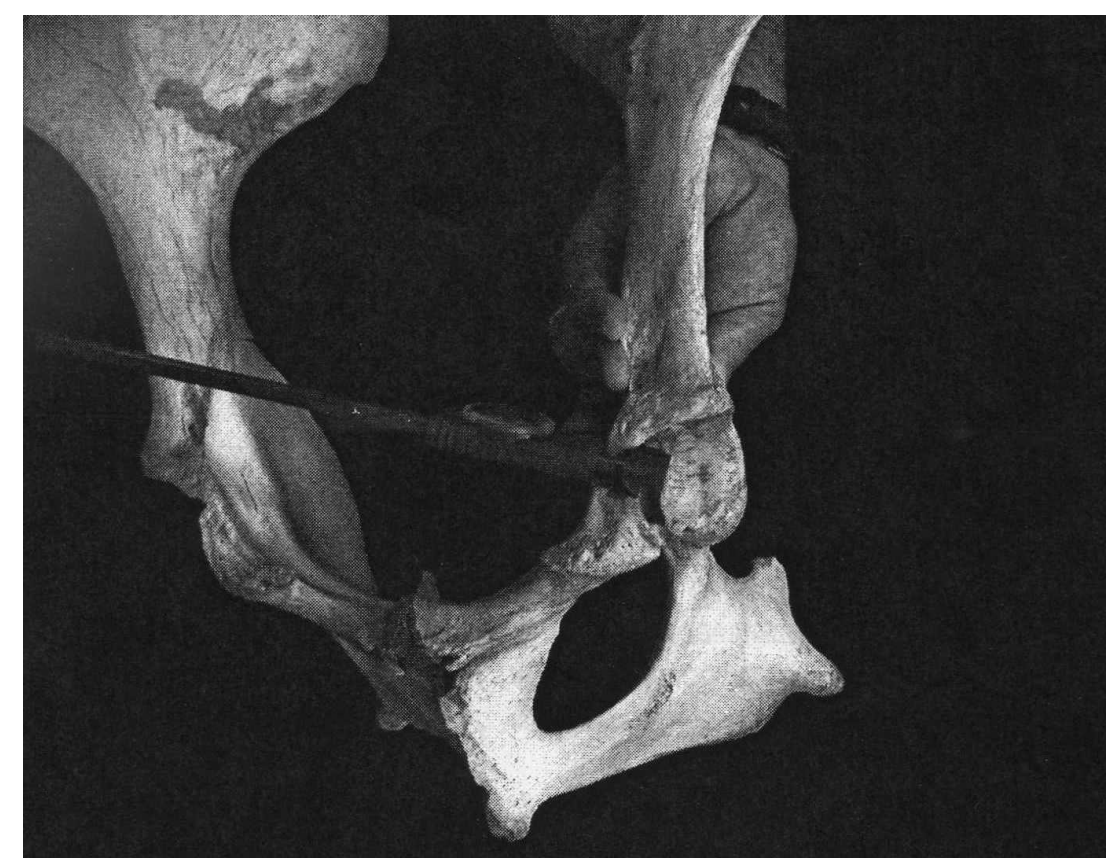

\section{BUTCHERY}

Butchery traces were investigated using the same microscopic analysis described for the identification of bone surface modifications (table 2.4). The type of mark was identified according to comparisons with actualistic studies of metal tool butchery for the categories of cut mark, scrape mark, chop mark, and saw mark, as well as personal experimentation and observation (Bello and Soligo 2008; Bromage and Boyd 1984; Greenfield 1999; Humphrey and Hutchinson 2001; Lewis 2008; Tucker et al. 2001). Additional notes were made describing the location of the mark on the bone as well as the quantity of marks present. In the historic context, burning is evidence of heating. Actualistic studies have shown that the burning of fresh bones or bones that contain grease and meat cause the bone to take on a bluish-gray discoloration instead of the gray and white coloring from calcination (David 1989: 74; Nicholson 1993: 427). 
Table 2.4. Criteria recorded to describe butchery related taphonomic traces observed on bone surfaces (adapted from Blumenschine 2003 with changes made to accommodate specific questions and qualities of the faunal collections).

\begin{tabular}{|c|c|}
\hline $\begin{array}{l}\text { Percussion } \\
\text { marks }\end{array}$ & $\begin{array}{l}0=\text { absent } \\
1=\text { present } \\
2=\text { present as isolated patches of } \\
\text { microstriations only } \\
3=\text { conspicuous battering fields of PMs } \\
4=\text { low confidence PM }\end{array}$ \\
\hline $\begin{array}{l}\text { PM } \\
\text { location }\end{array}$ & $\begin{array}{l}1=<2 \mathrm{~mm} \text { from fracture edge } \\
2=>2 \mathrm{~mm} \text { from fracture edge } \\
3=1 \& 2 \\
4=\text { on flake platform }\end{array}$ \\
\hline $\begin{array}{l}\text { KNIFE } \\
\text { MARKS } \\
\text { Chop } \\
\text { marks }\end{array}$ & $\begin{array}{l}0=\text { absent } \\
1=\text { present }\end{array}$ \\
\hline Cut marks & $\begin{array}{l}0=\text { absent } \\
1=\text { present }\end{array}$ \\
\hline $\begin{array}{l}\text { Scrape } \\
\text { marks }\end{array}$ & $\begin{array}{l}0=\text { absent } \\
1=\text { present }\end{array}$ \\
\hline Burning & $\begin{array}{l}0=\text { absent } \\
1=\text { charred black } \\
2=\text { burnt, calcined white } \\
3=1 \& 2\end{array}$ \\
\hline
\end{tabular}




\section{CHAPTER THREE: Castle of Good Hope's Moat}

\section{HISTORY}

The Moat at the Castle of Good Hope was considered an important but frustrating component of the Castle's geometric design. Georg Meister, visiting the Cape in 1677, described the Castle romantically though inaccurately as having "a good moat towards the Table Mountain and landward side..." (Hall et al: 1990: 26; Raven-Hart 1970a: 198199). It is unknown when the Moat was begun, but by 1677 , VOC officials still considered it unsuitably narrow and shallow (Fitchett 1996: 138-139; Johnson-Barker 2003: 33). The early period of the Moat's construction progressed sporadically due to unstable military pressures (Fitchett 1996: 139-140; Hall 1989: 5; Hall et al. 1990: 26; Johnson-Barker 2003: 33), and the Moat frequently experienced modifications to its original design due to underlying geological conditions (Fitchett 1996: 135-137, 141-143; Hall 1989: 5, 7; Hall et al. 1990: 27, 30; Raven-Hart 1970a: 189-190).

Governor Simon van der Stel was concerned that the original, seaward facing entrance was vulnerable to enemy fire from Table Bay and that the sand there was often saturated and difficult to transverse, which kept wagons from being able to enter the Castle. In 1682, the entranceway way was relocated to the curtain wall between the Leerdam and Buren bastions. This relocation included the construction of a triangular, cannoned ravelin and Moat extension (Fitchett 1996: 143-144; Hall 1989: 7). This ravelin was reported to be completed in 1707 , and is depicted accordingly on a map dated 1710 (figure 3.1) (Fitchett 1996: 147; M1/1103 Cape Archives). The 1710 map depicts a wooden walkway bridging the Moat to Van der Stel's relocated entranceway. The accuracy of this map may be questioned since it incorrectly depicts the Moat continuing 
along the seaward facing curtain wall. Contrary to these documents, Francois Valentyn recorded that the new entranceway with its ravelin and Moat were not yet completed in 1714 (Valentyn 1971: 83).

Though the documents do not reveal the exact date, this area was eventually filled and modified to an earthen pathway to the entrance during the first half of the eighteenth century. The final configuration for the Moat with the area behind the ravelin filled is depicted in a 1767 map (figure 3.2). This puts the most likely date of filling for the area posterior to the ravelin having occurred after 1710 and before mid-century. The artifacts, discussed below, help clarify when this area was filled. Ceramic manufacturing dates place the filling around 1720-1725 (Jordan 2005: 7; Klose 2005a: 1, 26). It is likely the filling occurred at this time because the great majority of the ceramic finds are at the end of their manufacturing period at this time, while no later ceramic types are present.

Figure 3.1. 1710 map of the Castle of Good Hope showing the Moat surrounding the ravelin with bridges to Van der Stel's relocated entranceway (Reorientated north, Cape Archives M1/1103 redrawn in Seemann 1997: 22).

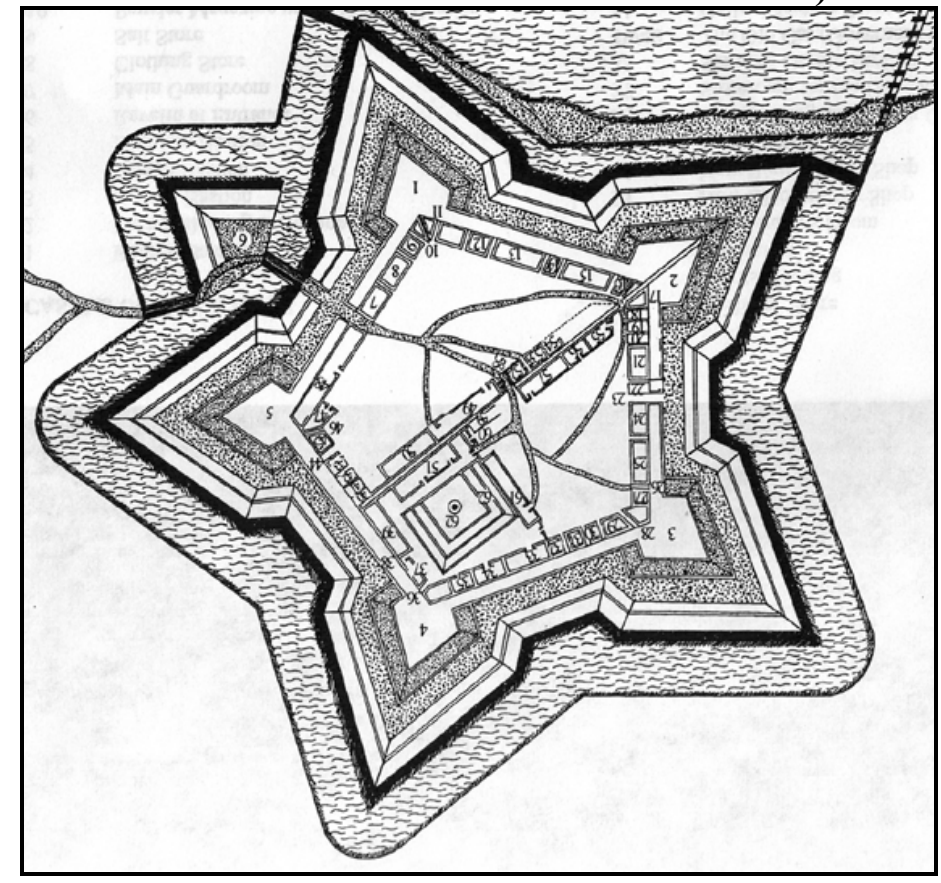


Figure 3.2. 1767 map of the Castle of Good Hope showing the final configuration of the Moat and jetty under the VOC (Cape Archives M1/377). The area behind the ravelin is now an earthen pathway. Also note that structure 7 is identified as a slaughterhouse.

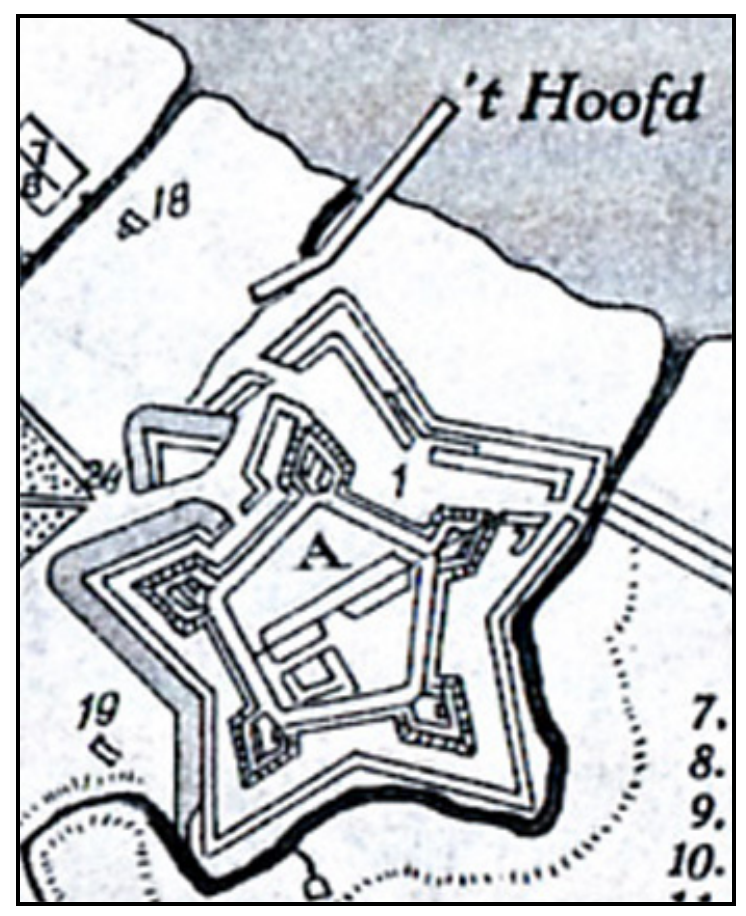

\section{ARCHAEOLOGY}

The Archaeology Contracts Office (ACO) of the University of Cape Town carried out two separate excavations in fill of the Moat. The investigations provided valuable information about the Moat's construction that was not presented in the documents.

\section{A. 1989 ACO Excavation Summary of the Darling Street Portion of the Moat: The}

first ACO archaeological excavation in 1989 expanded on Carmel Schrire's (Schrire and Jeppson 1987) tests in the areas of the Moat currently situated along Darling and Buitenkant Streets that were filled by the British in the mid-nineteenth century. This investigation determined that the Moat was not constructed according to the official documents. It was never excavated to the planned 150 feet width, and there was no evidence for the 60 feet wide trench at the base of the Moat. The Moat's final appearance 
was a 50 feet wide trench lined by a Malmesbury hornfels onderwal and

contrescarptalud (Hall 1989: 7, 10; Hall et al: 29). Water was likely present in the Moat as was suggested by the discovery of a relatively impermeable, gray clay lining at its base to limit water seepage into the sand. Water levels within the Moat could not be determined due to the stonework, though it likely originated from groundwater seepage, which was encountered during the excavations (Hall 1989: 7, 10). The base of the Moat was not excavated to a consistent gradient that would have facilitated the flow water if the Moat was to be filled by streams and since the base of the Moat is above the maximum high tide of Table Bay it could not have been filled by the tides (Hall 1989: 10; Hall et al. 1990: 29).

The lowest levels of the Darling Street Moat contained few late eighteenth century artifacts, and have been interpreted as incidental dumping while the Moat was still considered a part of the Castle's defenses under the VOC (Hall et al. 1990: 32). The bulk of the artifacts date to the early to mid nineteenth century and include ceramics, glass, faunal remains, and various metal objects. The thick, quickly accumulated nineteenth century deposits are interpreted as deliberate efforts to fill the Moat by the British who viewed it as a poorly drained "ditch" that posed health problems (Hall et al. 1990:32-33; Hall 1989: 15).

\section{B. 1990 ACO Excavation Summary of the Van der Stel Portion of the Moat: In} 1990, the ACO undertook an archaeological test before the onderwal to the left side of Simon van der Stel's relocated entranceway. This excavation consisted of a rough Lshaped layout of 2x1 meter units, which mirrored the angles of the onderwal instead of 
being oriented on a north-south axis (figures 3.3, 3.4, and 3.5) (ACO 1990: 50). The intact cultural layers were sieved through 3x3 millimeter mesh (ACO 1990: 8, 30). The excavations revealed a trench cut into the subsoil that was part of the Moat before it was detoured around the ravelin. This trench curved in line with the Malmesbury hornsfels onderwal above (ACO 1990: 46-48). The water table, which stopped further excavation, was often reached at 1300 millimeters below the surface (ACO 1990: 12-14). This excavation produced the rich faunal assemblage that is sampled here.

1. Stratigraphy: The collections were aggregated into five major Levels according to broader depositional episodes identified by the excavators. These Levels included many discrete strata and lenses containing various cultural materials such as tobacco pipes and ash (figure 3.6). Generally, the deposits were thickest towards the center of the Moat trench and tapered towards the edge. The excavators were able to identify the directions of dumping to have been from the southwest and from the east (ACO 1990: 21). The five Levels of the 1990 Moat excavation were defined as:

1. Surface Level (SF): The surface deposits were mainly gardening soils and hard sediments compacted by exposure and trampling (i.e. ACO 1990: 33, 41, 48, 49, 52). The surface deposits were not sieved, but visually inspected for artifacts during excavation (ACO 1990: 33, 49, 53). The artifacts were often significantly later in date than those in the lower levels (nineteenth century refined British earthenwares (Klose 2005b: 4) and also nineteenth century cylindrical glass bottles (Schrire pers. comm.)) (ACO 1990: 45). 
Figure 3.3. Aerial photograph of the Castle illustrating the location of the Moat excavation, plus the locations of the other Castle excavations presented in this thesis (Photograph by Hoberman 1997).

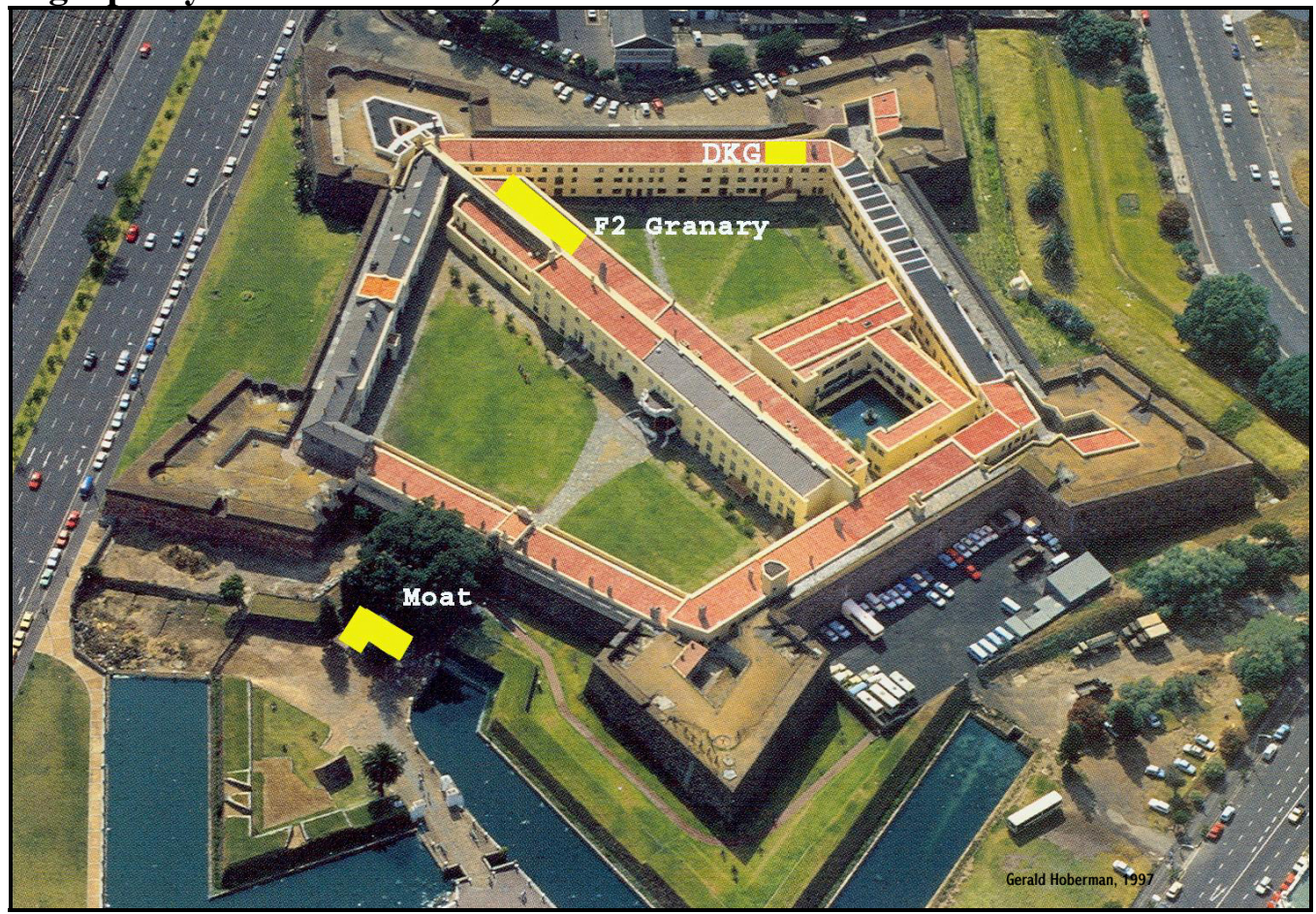

Figure 3.4. Photograph showing the excavation in relation to major architectural components of the Castle.

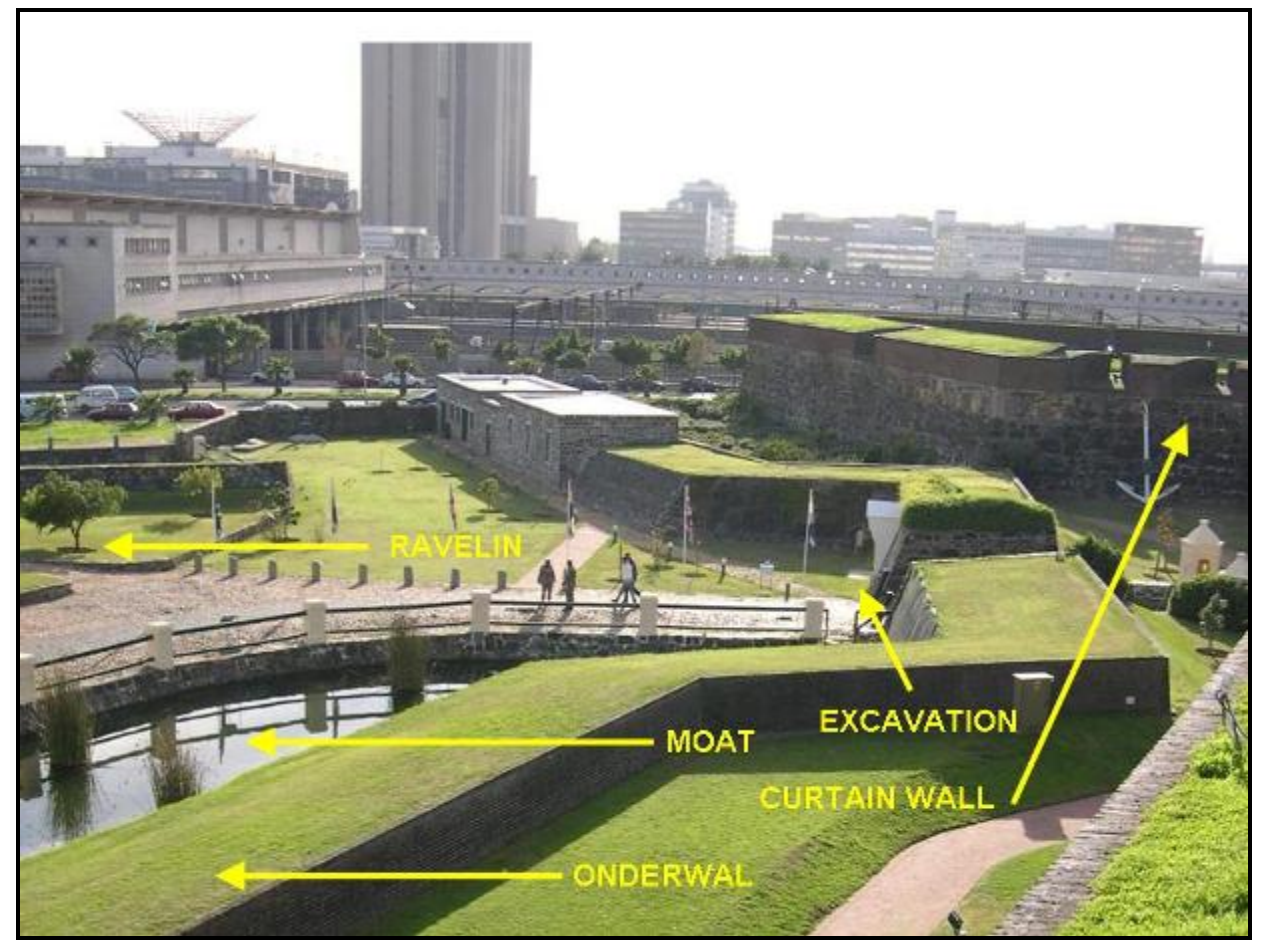


Figure 3.5. Photograph showing the area of the Moat excavation with the locations of the excavation units discussed in this chapter (outline reconstructed from field notes in ACO 1990).

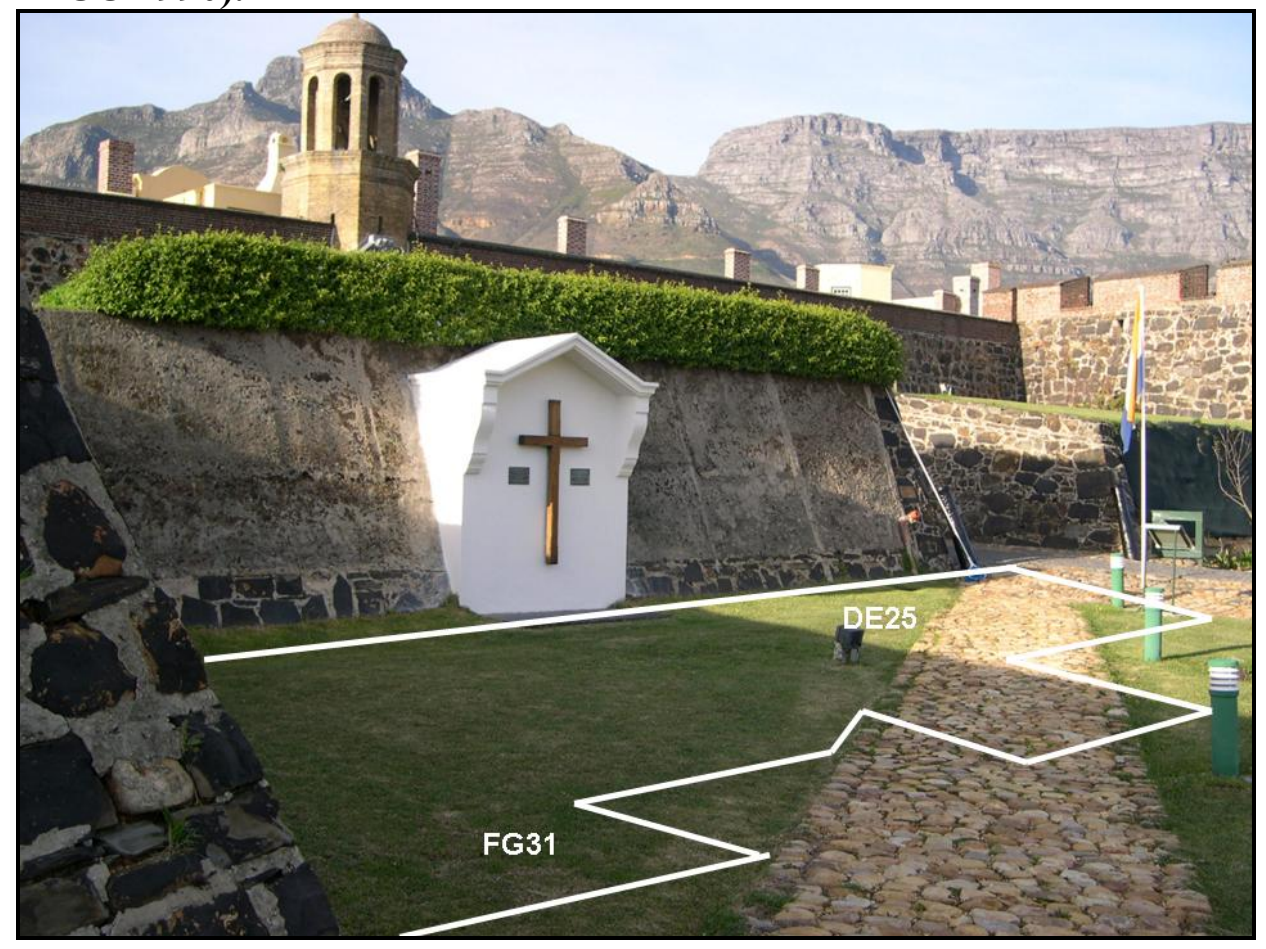

2. Level A-1: This Level contained an extensive "brick speckled" layer intermixed with discrete ash deposits and a lens of concentrated tobacco pipes.

The concentrations of ash and charcoal have been interpreted as isolated brazier cleanings (ACO 1990: 26). Level A-1 was also generally identified as the deposits above where the trench embankment was first noticed during excavation (ACO 1990: 28).

3. Level A-2: This Level was described as a looser brown soil with large quantities of brick rubble (ACO 1990: 28, 31). It showed sedimentary similarities to Level A-1, and they were likely continuous deposits. Level A-2 was mainly distinguished by the presence of the Moat embankment.

4. Level B: This Level was a uniform, relatively thick "granular brown soil" layer, which was extensive across all excavation units. It had been interpreted as 
a naturally deposited soil. Level B also included a "yellow-gray flecked soil" along with discrete lenses of ash (ACO 1990: 28).

5. Level C: This Level consisted mostly of "gray white sand," but also included charcoal lenses and a layer of "orange sand" (ACO 1990: 28, 30, 39, 40). Level C was often incompletely excavated due to the water table (ACO 1990: 12, 30, 40).

2. Material Culture: The artifactual material analyzed from the Moat includes a variety of ceramics, tobacco pipes, and glassware.

a. Ceramics: The stoneware ceramics were analyzed by Jordan (2005) and were mostly imported from German manufacturing centers. Each Level contained similar ware types and vessel forms with similar dates of manufacture. The stoneware was manufactured in the late seventeenth through the early eighteenth century. Level C contained English stoneware that determined a TPQ of 1725 (Jordan 2005: 7).

The porcelain was analyzed by Klose (2005a). Chinese export porcelains made up over $70 \%$ of the vessels of Asian origin in each Level below the surface (table 2 in Klose 2005a). The remainder of the Asian wares was provincial Chinese wares and a smaller proportion of Japanese export wares. Similar vessel forms and decorations, plus a high frequency of mends, were observed on many wares suggesting that they may have come from the same shipments, and that they may represent damaged supplies. Though tight dates were not often determined, the Moat's porcelain was manufactured between the later seventeenth century and the first quarter of the eighteenth century, while a few wares were manufactured into the second quarter of the eighteenth century. Levels A-1 and A-2 produced TPQs of 1720 (Klose 2005a: 1,26). Levels B and C also had early eighteenth century TPQs, while Level C contained a higher proportion of late seventeenth 
Figure 3.6. The Moat stratigraphy along the length of the excavation.

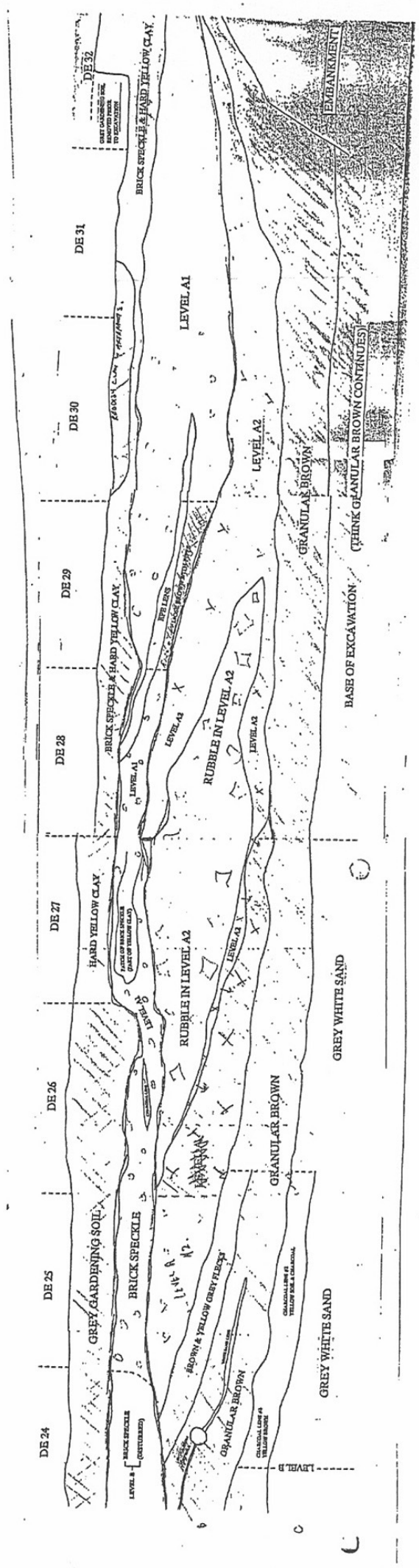


century wares compared to the upper Levels. The similarity of ware manufacturing dates, vessel forms, and decoration style suggests that the porcelains were dumped into the Moat quickly, and many may have derived from damaged shipments.

Though the coarse earthenwares could not provide tight dates, Jordan (1999) also analyzed the coarse earthenware ceramics from the Moat. Petrographic analyses of the Moat's coarse earthenwares were performed in order to identify the origin of their manufacture (Jordan 2000a: 239; Jordan et al. 1999: 1335). The thin sections revealed that many of these vessels were of local origin due to the use of local clays that contained unique mineral compositions.

Jordan also categorized the coarse earthenwares into a vessel form typology. The Moat assemblage contains a minimum of 218 coarse earthenware vessels, where $65.14 \%$ of these are related to food preparation. The remainder of the assemblage is food storage and serving vessels, with very few smoking/fuming related vessels (Jordan 2000: 128131). Levels A-1 and A-2 show a greater diversity of vessel forms compared to Levels B and $\mathrm{C}$, but this is clearly due to the higher number of fragments in the upper stratigraphic levels (Jordan 2000a: 128). The high proportion of cooking pots and hollow vessels suggests a diet of liquid based foods such as stews, which were carryovers from traditional northern European foodways (Coetzee 1977: 40; Jordan 2000a: 136). Documents record stews being common food items at the Cape during the early eighteenth century for soldiers and others such as the "kerri-kerri" stew served to the ill at the hospital (Jordan 2000a: 138; Mentzel: 1921: 112).

b. Tobacco Pipes: Yates et al. (n.d.: 23) measured the bores of the tobacco pipestems by using standardized drill bits according to the broad stratigraphic levels identified by the 
excavators (ACO 1990). The mean bore diameters became smaller up through the stratigraphic sequence with Level C showing the largest and Levels A-1 and A-2 showing the smallest mean bore diameters (table 3.1). This shows that the Levels were deposited quickly and in chronological superposition. Levels A-1 and A-2 provided similar mean bore diameters which suggest that they were deposited concurrently. The quick deposition of Levels A-1 and A-2 demonstrates that they were intended to rapidly fill the Moat. The mean bore diameters show that the Moat deposits occurred after the Granary fills and before the Dump at Elsenburg presented in other chapters of this thesis.

Table 3.1. Tobacco pipestem mean bore diameter according to Levels (mm) (Yates et al. n.d.: 23).

\begin{tabular}{|c|c|c|}
\hline Level & Mean bore diameter & $\begin{array}{l}\text { Sample size } \\
\text { (NISP) }\end{array}$ \\
\hline SF & Surface - Not tested & \\
\hline A-1 (2 samples) & \begin{tabular}{|l|l|}
$2.218 *$ & 2.158 \\
\end{tabular} & \begin{tabular}{l|l|l|}
177 & 1640
\end{tabular} \\
\hline A-2 (2 samples) & \begin{tabular}{l|l|}
2.167 & 2.155 \\
\end{tabular} & \begin{tabular}{l|l|l|}
890 & 1177
\end{tabular} \\
\hline $\mathrm{B}$ & 2.217 & 919 \\
\hline $\mathrm{C}$ & 2.275 & 1348 \\
\hline
\end{tabular}

* Greater mean bore diameter may be the product of a small sample size $(n<200)$.

Only the pipestems' bore diameters were analyzed systematically, but other information from the tobacco pipes can be gleaned from the excavation notes. A concentrated lens that contained hundreds of tobacco pipestems and bowls was found in Level A-1. The excavators noted that about $99 \%$ of the bowls have the same maker's marks, while none of the pipes show any evidence of smoking. They interpreted this deposit as a box of damaged pipes disposed of into the Moat (ACO 1990: 42).

\section{FAUNAL RESULTS}

The fauna from two excavation units were chosen for this analysis to provide samples from opposite ends of the 1990 excavation (refer back to figure 3.5). Excavation 
unit DE25 is from the southern end of the excavation, while FG31 is from the northern end of the excavation. DE25 is situated near the entranceway of the Castle, while FG31 is located closer to the location of the historical jetty. The Levels, as they were defined by the ACO (1990) and presented under "Stratigraphy," were analyzed individually.

Table 3.2: Sample sizes for respective columns and levels.

\begin{tabular}{|c|r|r|r|}
\hline $\begin{array}{c}\text { Column- } \\
\text { Level }\end{array}$ & $\begin{array}{c}\text { Bone } \\
\text { Sample } \\
\text { (NISP) }\end{array}$ & $\begin{array}{c}\text { Isolated } \\
\text { Teeth } \\
\text { (NISP) }\end{array}$ & $\begin{array}{c}\text { Total } \\
\text { Sample } \\
\text { (NISP) }\end{array}$ \\
\hline DE25-SF & 0 & 0 & 0 \\
\hline DE25-A-1 & 255 & 10 & 265 \\
\hline DE25-A-2 & 2373 & 148 & 2521 \\
\hline DE25-B & 484 & 14 & 498 \\
\hline DE25-C & 341 & 9 & 350 \\
\hline \multicolumn{5}{|r|}{} \\
\hline FG31-SF & 4 & 0 & 4 \\
\hline FG31-A-1 & Not in unit & Not in unit & Not in unit \\
\hline FG31-A-2 & 3186 & 231 & 3417 \\
\hline FG31-B & 707 & 29 & 736 \\
\hline FG31-C & water table & water table & water table \\
\hline
\end{tabular}

* Not included in this analysis due to later dates.

- Teeth contained in bone were not counted as isolated teeth.

A. Taphonomy: The overall impression of both Moat samples is that the bone fragments are very well preserved. Bone fragments are larger on average than comparative animal sizes from Elsenburg and the Granary where the assemblages were heavily modified by taphonomic factors such as trampling and carnivores (see figures 3.7 and 3.8). Mean dimensions of size 3 specimens show greater spread of measurements due to their small sample sizes present in the Moat samples. In addition to low degrees of fragmentation, bone surfaces are very well preserved. Table 3.3 shows that over $99 \%$ of the bone fragments retain pristine, original surface conditions, while concreted, ashy sediment matrix adhering to the bone surface is identified as the greatest factor affecting the quality of the bone surfaces. All Levels contain copper stained bone fragments. Copper oxide salts from a large quantity of copper artifacts, including buckles, cooking vessels, and 
scrap replaced organic bone material with inorganic minerals while also changing the bone color to green. FG31-A-2 with 3.04\% (n=97 NISP) and DE25-A-2 with $6.83 \%$ ( $n=162$ NISP) contain the most numerous chemically altered bone fragments.

Figure 3.7. Mean measures of size 2 bone fragments from all sites.

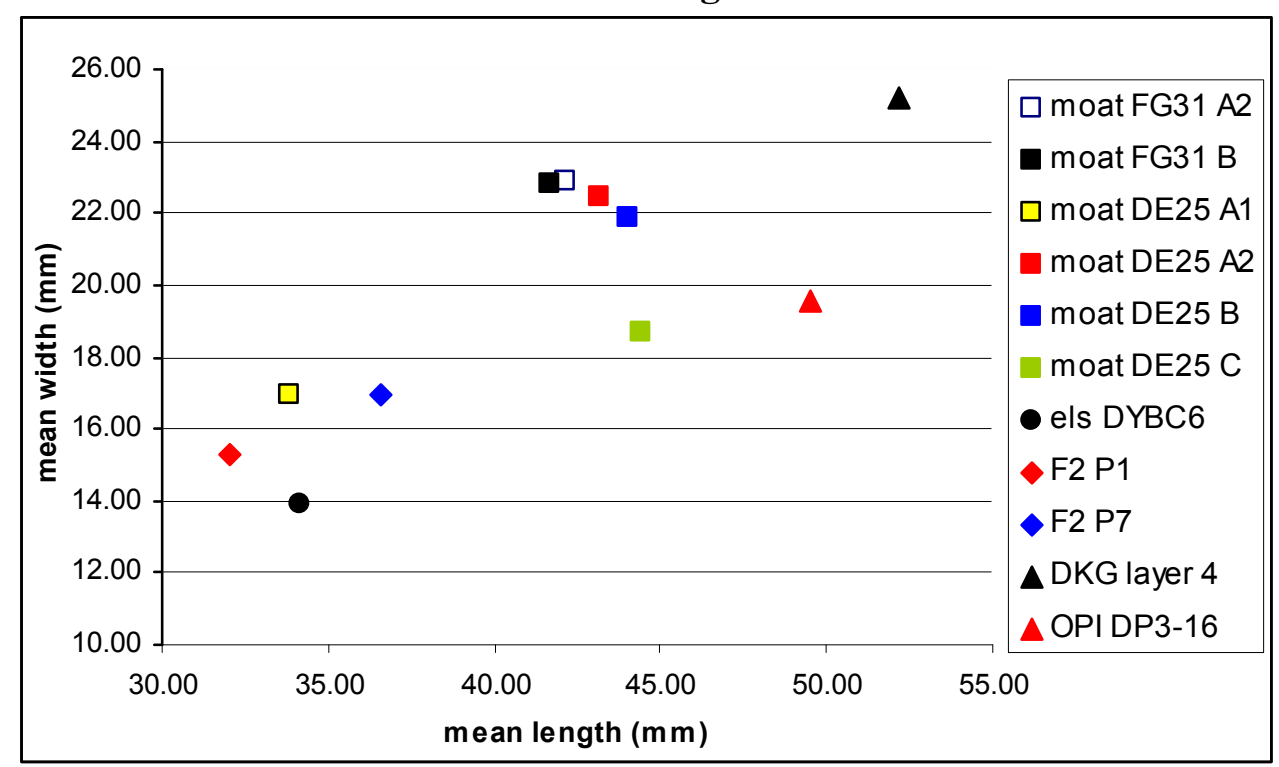

Figure 3.8. Mean measures of size 3 bone fragments from all sites.

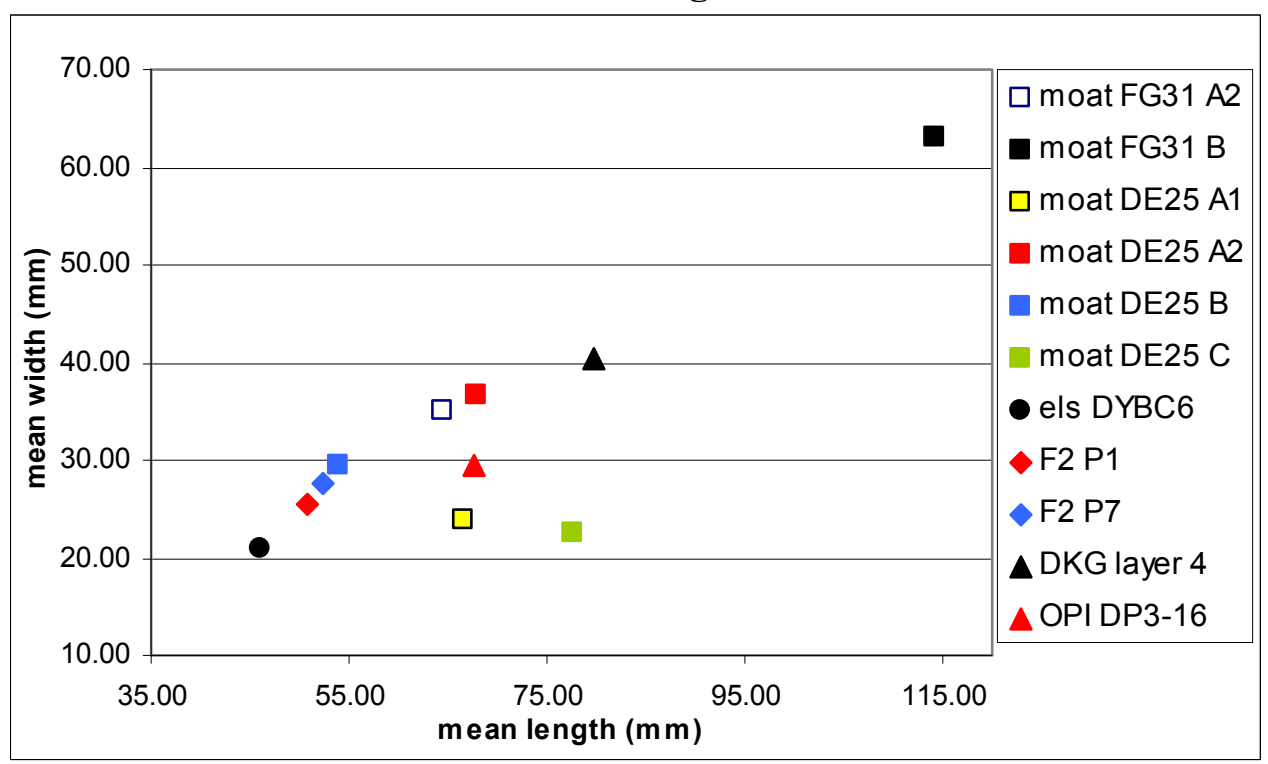


Table 3.3. Surface condition observed on all bone fragments.

\begin{tabular}{|c|c|c|c|c|c|c|c|c|c|c|}
\hline \multirow[t]{2}{*}{$\begin{array}{c}\text { surface } \\
\text { condition }\end{array}$} & \multicolumn{2}{|l|}{$\begin{array}{l}\text { pristine, } \\
\text { original }\end{array}$} & \multicolumn{2}{|l|}{$\begin{array}{c}\text { minor } \\
\text { exfoliation }\end{array}$} & \multicolumn{2}{|l|}{$\begin{array}{c}\text { minor } \\
\text { rounding }\end{array}$} & \multicolumn{2}{|l|}{$\begin{array}{c}\text { minor } \\
\text { adhering } \\
\text { matrix }\end{array}$} & \multicolumn{2}{|l|}{$\begin{array}{c}\text { major } \\
\text { adhering } \\
\text { matrix }\end{array}$} \\
\hline & NISP & $\%$ & NISP & $\%$ & NISP & $\%$ & NISP & $\%$ & NISP & $\%$ \\
\hline FG31 A-2 & 3158 & 99.12 & 1 & 0.03 & 5 & 0.16 & 19 & 0.60 & 3 & 0.09 \\
\hline FG31 B & 707 & 100.00 & 0 & 0.00 & 0 & 0.00 & 0 & 0.00 & 0 & 0.00 \\
\hline DE25 A-1 & 254 & 99.61 & 0 & 0.00 & 1 & 0.39 & 0 & 0.00 & 0 & 0.00 \\
\hline DE25 A-2 & 2373 & 100.00 & 0 & 0.00 & 0 & 0.00 & 0 & 0.00 & 0 & 0.00 \\
\hline DE25 B & 484 & 100.00 & 0 & 0.00 & 0 & 0.00 & 0 & 0.00 & 0 & 0.00 \\
\hline DE25 C & 341 & 100.00 & 0 & 0.00 & 0 & 0.00 & 0 & 0.00 & 0 & 0.00 \\
\hline
\end{tabular}

The well preserved bone surfaces allow for the observation of marks on bone

surfaces that can be used to infer depositional processes. Root etching is identified as the major biological modifier of the bone surfaces, and it rarely interferes with the investigation of other taphonomic traces (table 3.4). The proportion of root etched bone fragments decrease in the lower Levels, suggesting that the Moat area was not vegetated until after the filling episodes were completed. The Moat site was at one time converted to a garden with a large tree at the location of the southern end of the 1990 excavation (Hall et al. 1990: 34).

Table 3.4. The degree of root etching on the bone fragments.

\begin{tabular}{|c|c|c|c|c|c|c|c|c|}
\hline $\begin{array}{l}\text { degree of } \\
\text { etching }\end{array}$ & \begin{tabular}{|l} 
absent to \\
isolated \\
spots
\end{tabular} & & minor & & moderate & & major & \\
\hline & NISP & $\%$ & NISP & $\%$ & NISP & $\%$ & NISP & $\%$ \\
\hline FG31 A-2 & 2745 & 86.16 & 403 & 12.65 & 36 & 1.13 & 2 & 0.06 \\
\hline FG31 B & 706 & 99.86 & 1 & 0.14 & 0 & 0.00 & 0 & 0.00 \\
\hline DE25 A-1 & 197 & 77.25 & 50 & 19.61 & 8 & 3.14 & 0 & 0.00 \\
\hline DE25 A-2 & 2106 & 88.75 & 251 & 10.58 & 16 & 0.67 & 0 & 0.00 \\
\hline DE25 B & 475 & 98.14 & 9 & 1.86 & 0 & 0.00 & 0 & 0.00 \\
\hline DE25 C & 341 & 100.00 & 0 & 0.00 & 0 & 0.00 & 0 & 0.00 \\
\hline
\end{tabular}

Carnivore actions are very minor in the Moat samples (figure 3.9). Carnivore involvement is only observed on size 2 bone fragments, possibly because the smaller sized bones being more manageable to a domestic dog. Wild carnivores were not likely 
to be encountered in the urbanized Cape settlement since they were exterminated whenever encountered (Cruz-Uribe and Schrire 1991: 95; Mentzel 1944: 244-245; Skead 1980: 84-86, 123).

Figure 3.9. The frequencies (\% of NISP) of carnivore tooth mark damage to size 2 bone fragment surfaces.

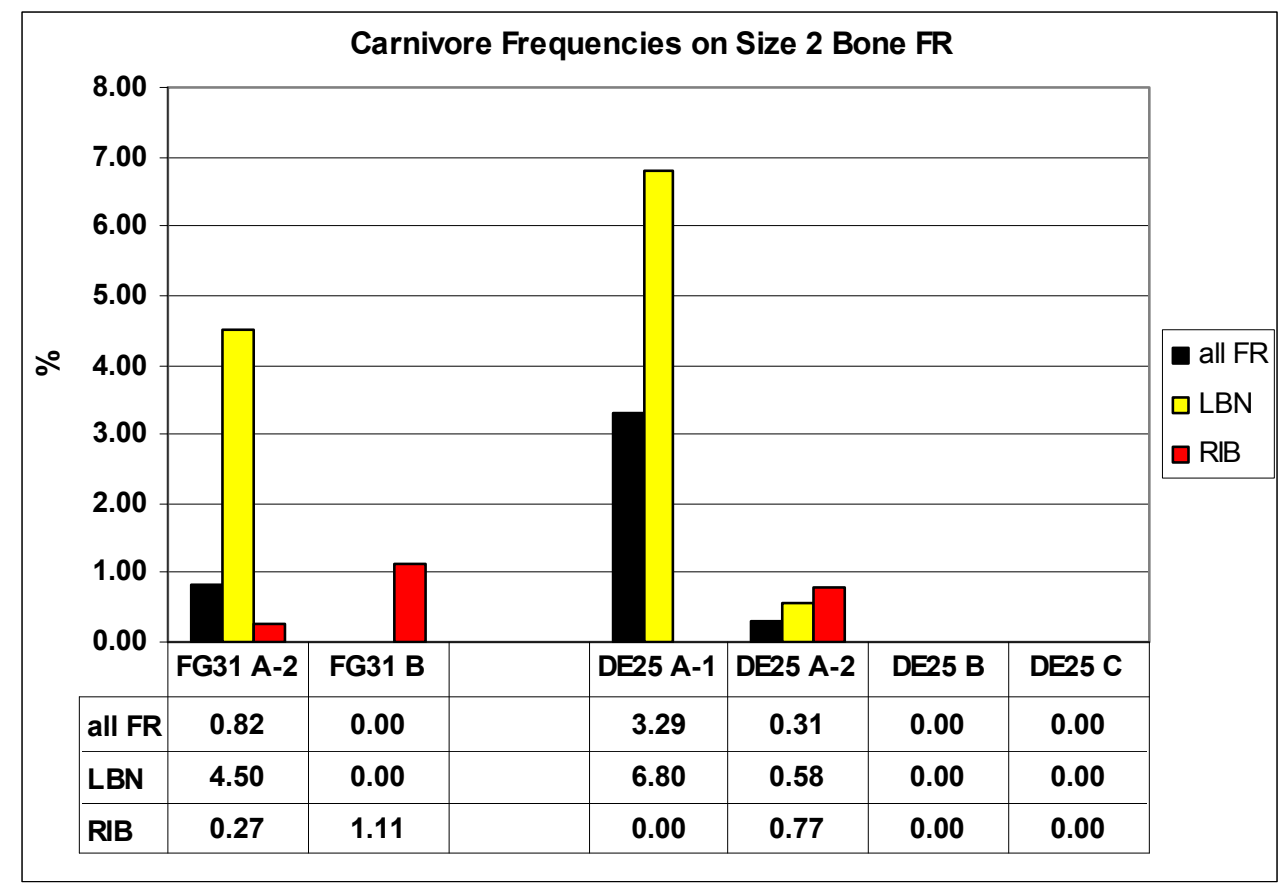

The completeness of the long bones shows that carnivores were not a major factor in bone fragmentation. Table 3.5 shows that the size 2 mammal long bone shafts are relatively complete where average shaft circumferences range between $31 \%$ and $49 \%$ complete for size 2 specimens. Size 3 mammal long bone shaft circumferences are less dependable due to small sample sizes. Both size 2 and 3 mammals are characterized by low epiphysis to shaft ratios showing that taphonomic processes such as carnivore consumption had not selectively deleted the spongy, grease laden articular ends.

Figures $3.10 \mathrm{a}-\mathrm{b}$ shows that abrasion damage is also rare, and except for a single example in FG31 A-2, all abrasion damage is observed on size 2 bone fragments. Often, the smooth surfaced long bones and ribs show greater frequencies of abrasion damage. 
Abrasion damage could have derived from the bone fragments either being trampled underfoot or scratched when deposited in the Moat alongside abrasive inclusions such as brick rubble. The low frequencies of abrasion marks suggest that the bones were moved to the Moat quickly after the animals were slaughtered and that the bones were not left exposed on the ground surface for extended periods of time to be trampled.

Table 3.5. Measures of long bone completeness, excluding the ulna due to its lack of a medullary cavity along with the shaft.

\begin{tabular}{|c|c|c|c|c|c|}
\hline & & $\begin{array}{c}\text { LBN } \\
\text { circum }\end{array}$ & $\begin{array}{c}\text { EPI } \\
\text { (NISP) }\end{array}$ & $\begin{array}{c}\text { shaft } \\
\text { (NISP) }\end{array}$ & $\begin{array}{c}\text { ratio } \\
\text { (shaft/EPI) }\end{array}$ \\
\hline \multirow[t]{6}{*}{ size 2} & FG31 A-2 & 0.43 & 90 & 298 & 3.31 \\
\hline & FG31 B & 0.35 & 24 & 49 & 2.04 \\
\hline & DE25 A-1 & 0.31 & 17 & 83 & 4.88 \\
\hline & DE25 A-2 & 0.49 & 204 & 444 & 2.18 \\
\hline & DE25 B & 0.49 & 33 & 80 & 2.42 \\
\hline & DE25 C & 0.40 & 25 & 95 & 4.75 \\
\hline \multirow[t]{6}{*}{ size 3} & FG31 A-2 & 0.54 & 2 & 11 & 5.50 \\
\hline & FG31 B & 0.80 & 2 & 2 & 1.00 \\
\hline & DE25 A-1 & 0.20 & 0 & 2 & 2.00 \\
\hline & DE25 A-2 & NA & 1 & 0 & NA \\
\hline & DE25 B & 0.20 & 0 & 2 & 2.00 \\
\hline & DE25 C & 0.20 & 0 & 1 & 1.00 \\
\hline
\end{tabular}

Articulated bones were identified in the excavation notes as well as still being present in the sorted faunal collection (ACO 1990: 15, 17). The articulated joints identified in the sorted collection are concreted together by hard, ashy sediments, and they derive from more tightly held articulations such as the ankle and vertebrae. These examples clearly demonstrate that many bones were disposed of quickly after slaughter into the Moat while they still contained soft tissue, without having been left exposed on the ground where they would have been exposed to taphonomic processes such as carnivore scavenging or trampling. Together, the finds of the articulated joints, along 
with the limited taphonomic damage, stratigraphy, tobacco pipes, ceramics, and glass, support the hypothesis that the deposit was aimed at quickly filling the Moat.

Figure 3.10a. Abrasion damage frequencies (\% of NISP) observed on size 2 bone fragments.

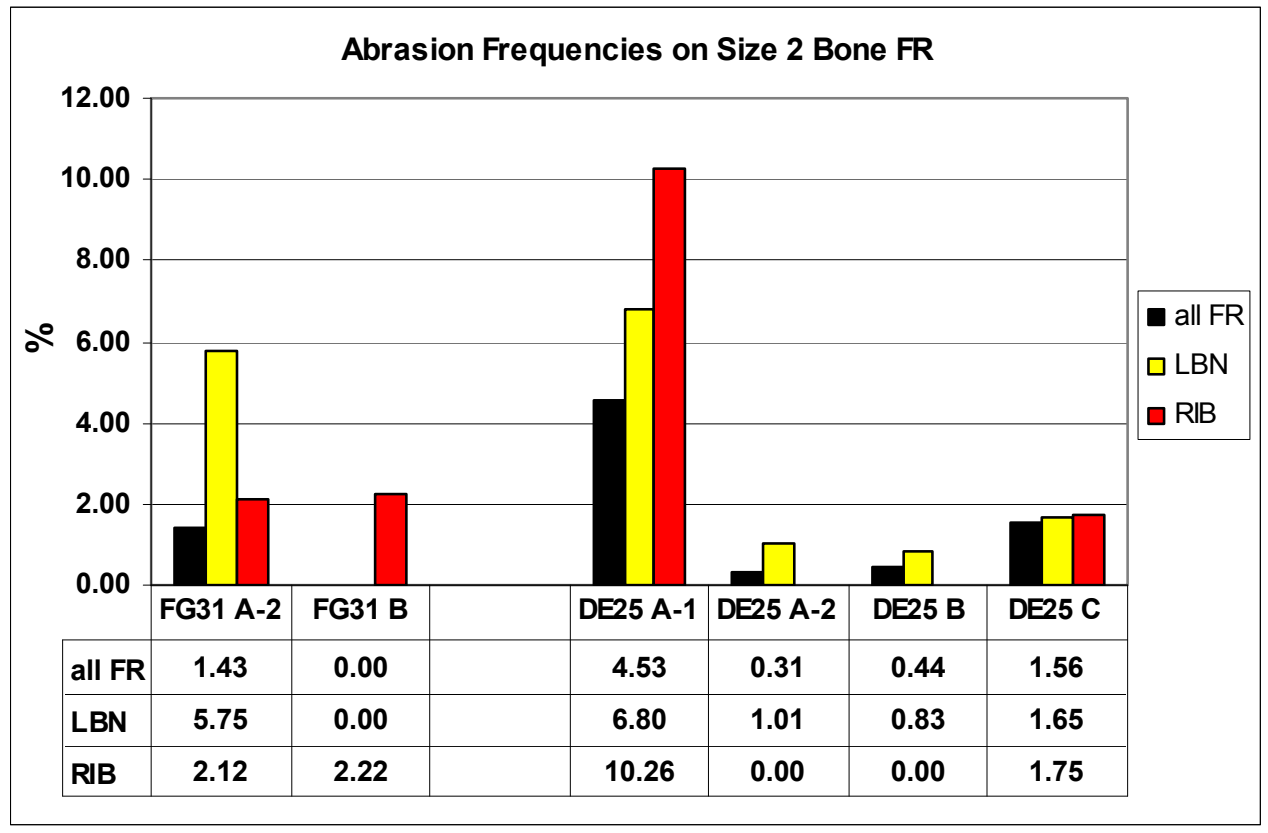

Figure 3.10b. Abrasion damage frequencies (\% of NISP) observed on size 3 bone fragments.

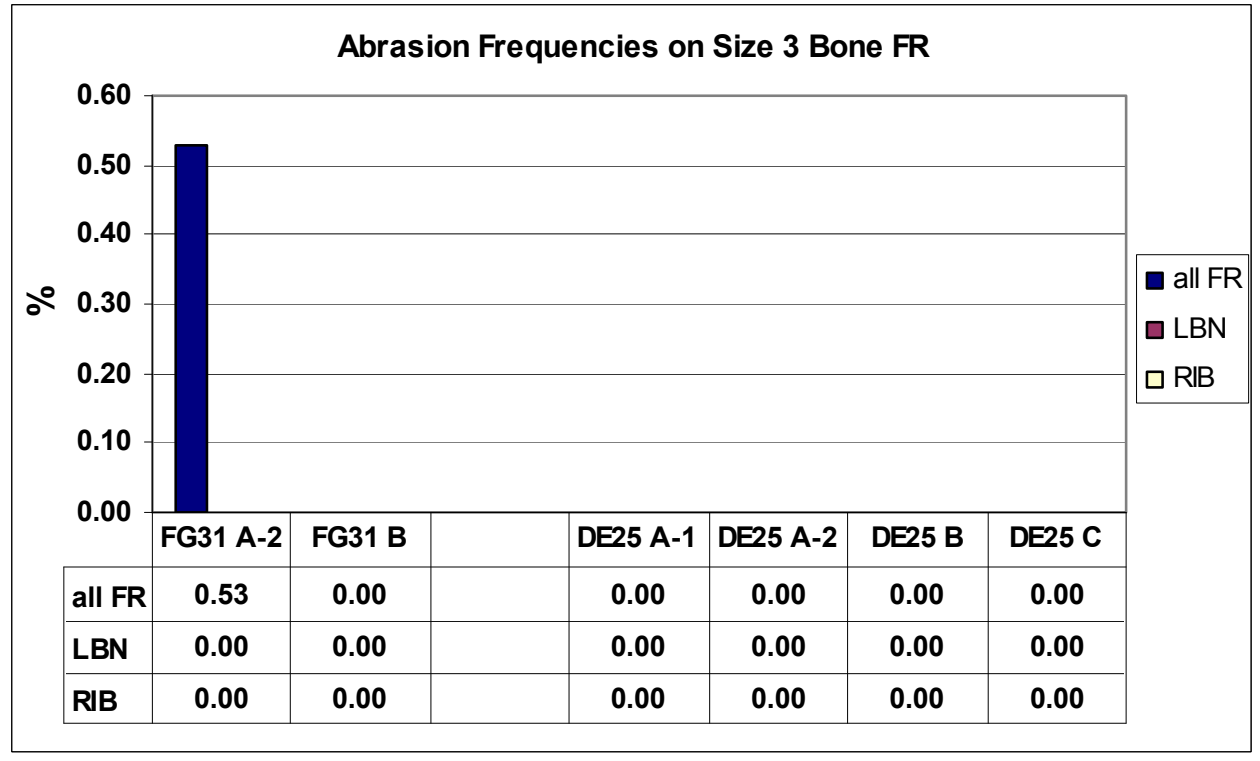


B. Taxonomic Representations: The Moat samples are dominated by domestic stock (table 3.6). Sheep (Ovis aries) outnumber cattle (Bos taurus) by MNI in each Column and all Levels in ratios ranging between $14: 1$ in FG31 B and 5:1 in DE25 C. DE25 A-1 contains an MNI of two sheep and no cattle remains. Pig (Sus scrofa) remains are present in every Level sampled, with one pig in each Level, except Level A-2 that has two in each excavation unit. Domesticated rabbits (Oryctolagus sp) are represented by one MNI in FG31 A-2, FG31 B, and DE25 A-2. Domestic dog (Canis familiaris) is only represented by isolated specimens in levels in Levels A-2 and C.

Wild mammals are mainly represented by the small bovids, and they are relatively rare compared to the domesticated species (table 3.6). The gray duiker (Sylvicapra grimmia) and steenbok (Raphicerus campestris) are the most common wild bovids, while only one grysbok (Raphicerus melanotis) is present in FG31 A-2. Other wild mammals include a porcupine (Hystrix africae-australis), a Cape fur seal (Arctocephalus pusillius), and a leopard (Panthera pardus). Elephant (Probiscidean sp) is only represented by sawn ivory from commercial processing.

Non-mammalian species make up a minor component of the Moat fauna (table 3.6). Birds include both domestic and wild species. Domestic fowl are the most numerous and include chicken (Gallus gallus) and the domestic duck (Anatidae dom). The wild fowl include birds from marine environments, such as the Jackass penguin (Spheniscus demersus), the Cape cormorant (Phacacrocorax capensis), and the yellowbilled duck (Anas erythrorhycha). The yellow-billed duck is the only wild bird represented by more than one individual. Lastly, an indeterminate pigeon or dove-like (Columbidae ind) specimen was recovered, though it could not be identified as a wild or 
domestic species. Carapace and plastron fragments of angulate tortoises (Chersina

angulata) are also present in each Level of the Moat.

Table 3.6. Taxonomic representations in the Moat samples.

\begin{tabular}{|c|c|c|c|c|c|c|c|c|c|c|c|c|}
\hline \multirow[b]{2}{*}{ TAXON } & \multicolumn{2}{|l|}{$\begin{array}{l}\text { FG31 } \\
\text { A-2 } \\
\end{array}$} & \multicolumn{2}{|l|}{$\begin{array}{l}\text { FG31 } \\
\text { B }\end{array}$} & \multicolumn{2}{|l|}{$\begin{array}{l}\text { DE25 } \\
\text { A-1 } \\
\end{array}$} & \multicolumn{2}{|l|}{$\begin{array}{l}\text { DE25 } \\
\text { A-2 }\end{array}$} & \multicolumn{2}{|l|}{$\begin{array}{l}\text { DE25 } \\
\text { B }\end{array}$} & \multicolumn{2}{|l|}{$\begin{array}{l}\text { DE25 } \\
\text { C }\end{array}$} \\
\hline & NISP & MNI & NISP & MNI & NISP & MNI & NISP & MNI & NISP & MNI & NISP & MNI \\
\hline Bos taurus, cow & 131 & 3 & 9 & 1 & & & 16 & 2 & 3 & 1 & 1 & 1 \\
\hline Ovis aries, sheep & 1432 & 38 & 281 & 14 & 100 & 2 & 1512 & 20 & 267 & 8 & 146 & 5 \\
\hline Sus scrofa, pig & 24 & 2 & 4 & 1 & 3 & 1 & 28 & 2 & 7 & 1 & 1 & 1 \\
\hline $\begin{array}{l}\text { Oryctolagus sp., } \\
\text { domestic rabbit }\end{array}$ & 9 & 1 & 2 & 1 & & & 6 & 1 & & & & \\
\hline $\begin{array}{l}\text { Sylvicapra grimmia, } \\
\text { gray duiker }\end{array}$ & 13 & 2 & 2 & 1 & & & & & 1 & 1 & 6 & 1 \\
\hline $\begin{array}{l}\text { Raphicerus } \\
\text { campestris, } \\
\text { steenbok }\end{array}$ & 13 & 1 & & & & & 10 & 1 & 2 & 1 & & \\
\hline $\begin{array}{l}\text { Raphicerus } \\
\text { melanotis, grysbok }\end{array}$ & 4 & 1 & & & & & & & & & & \\
\hline Raphicerus ind & 1 & 1 & 4 & 1 & & & & & & & & \\
\hline $\begin{array}{l}\text { Hystrix africae- } \\
\text { australis, porcupine }\end{array}$ & & & & & & & 4 & 1 & & & & \\
\hline $\begin{array}{l}\text { Panthera pardus, } \\
\text { leopard }\end{array}$ & 1 & 1 & & & & & & & & & & \\
\hline Probiscidean & 5 & 1 & & & & & & & & & & \\
\hline $\begin{array}{l}\text { Canis familiaris, } \\
\text { domestic dog }\end{array}$ & 1 & 1 & & & & & 1 & 1 & & & 1 & 1 \\
\hline indet carnivora & 1 & 1 & & & & & 1 & 1 & & & & \\
\hline indet mammal 1a & 1 & 1 & & & & & & & & & & \\
\hline indet mammal 2 & 439 & 1 & 168 & 1 & 37 & 1 & 254 & 1 & 65 & 1 & 34 & 1 \\
\hline indet mammal 3 & 1 & 1 & & & & & & & 6 & 1 & & \\
\hline indet artiodactyla 2 & 343 & 1 & 70 & 1 & 30 & 1 & 120 & 1 & 36 & 1 & 44 & 1 \\
\hline indet bovid $1 \mathrm{~b}$ & 5 & 1 & & & 3 & 2 & 4 & 1 & & & & \\
\hline indet bovid 2 & 809 & 20 & 177 & 6 & 82 & 1 & 513 & 5 & 93 & 1 & 104 & 1 \\
\hline $\begin{array}{l}\text { Chersina angulata, } \\
\text { angulate tortoise }\end{array}$ & 66 & 1 & 2 & 1 & 7 & 1 & 21 & 1 & 4 & 1 & 5 & 1 \\
\hline $\begin{array}{l}\text { Arctocephalus } \\
\text { pusillius, Cape fur } \\
\text { seal }\end{array}$ & & & & & & & 1 & 1 & & & & \\
\hline $\begin{array}{l}\text { Gallus gallus, } \\
\text { chicken }\end{array}$ & 63 & 7 & 9 & 2 & 2 & 1 & 12 & 2 & 9 & 1 & 7 & 1 \\
\hline $\begin{array}{l}\text { Spheniscus } \\
\text { demersus, Jackass } \\
\text { penguin }\end{array}$ & 3 & 1 & & & & & & & & & & \\
\hline $\begin{array}{l}\text { Phacacrocorax } \\
\text { capensis, Cape } \\
\text { cormorant }\end{array}$ & 1 & 1 & & & & & & & & & & \\
\hline $\begin{array}{l}\text { Anatidae dom, } \\
\text { domestic duck }\end{array}$ & 37 & 5 & 8 & 3 & 1 & 1 & 13 & 2 & & & 1 & 1 \\
\hline Columbidae ind & 1 & 1 & & & & & & & & & & \\
\hline $\begin{array}{l}\text { Anas } \\
\text { erythrorhyncha, } \\
\text { yellow-billed duck }\end{array}$ & 10 & 2 & & & & & 4 & 2 & 5 & 1 & & \\
\hline indet large bird & 3 & 1 & & & & & & & & & & \\
\hline TOTAL & 3417 & 98 & 736 & 33 & 265 & 11 & 2521 & 46 & 498 & 19 & 350 & 16 \\
\hline
\end{tabular}


Fish were analyzed by Cedric Poggenpoel of the University of Cape Town (1996) as an aggregated collection with an interior Castle site called F1. He concluded that the Moat fish were warmer-water, marine species that were likely obtained from False Bay (Poggenpoel 1996: 122, 130). These fish were often schooling species that were obtained by dragging large seine nets through the bays (Poggenpoel 1996: 123).

C. Ages of the Fauna: The sheep deposited the Moat were slaughtered at a relatively tight range of ages. Using Payne's (1973: 293-294) tooth wear stages, third molars show similar wear profiles for the sheep in each excavation unit and Level (figures 3.11a-d). The sheep were mainly slaughtered during the D through $\mathrm{G}$ wear stages, i.e. between 1.5 and six years old. The third molar data consistently fall between stages D and G, with the profiles from DE25 A-2 and DE25 B show greater proportions of older individuals in the F wear stage at three to four years of age. First and second molars are all in moderate wear stages, which support the data obtained from the third molars (Payne 1973: 293294). Likewise, deciduous incisors and premolars are present in highly advanced stages of wear when they would soon be shed. Epiphyseal fusion stages show that the majority of the sheep were slaughtered during the period represented by the third molars (Silver 1969: 285-286) (table 3.7). Additionally, postcranial epiphyses provide some data that was not revealed by the dentition. A small number of unfused first and second phalange epiphyses ( $\mathrm{n}=7$ total from all Levels) shows that some sheep were slaughtered before about 16 months of age (Silver 1969: 285-286). The rarer unfused distal humerus $(\mathrm{n}=2)$, proximal radius $(n=1)$, and acetabulum $(n=1)$ show that a minimum of two sheep were slaughtered before reaching 10 months of age (Silver 1969: 285). 
Figure 3.11a-d. Sheep M3 molar tooth wear profiles using Payne's (1973: 293-294) stages. DE25 A-1 and DE25 C were not graphed due to a lack of third molars that could provide ageing data.

3.11a).
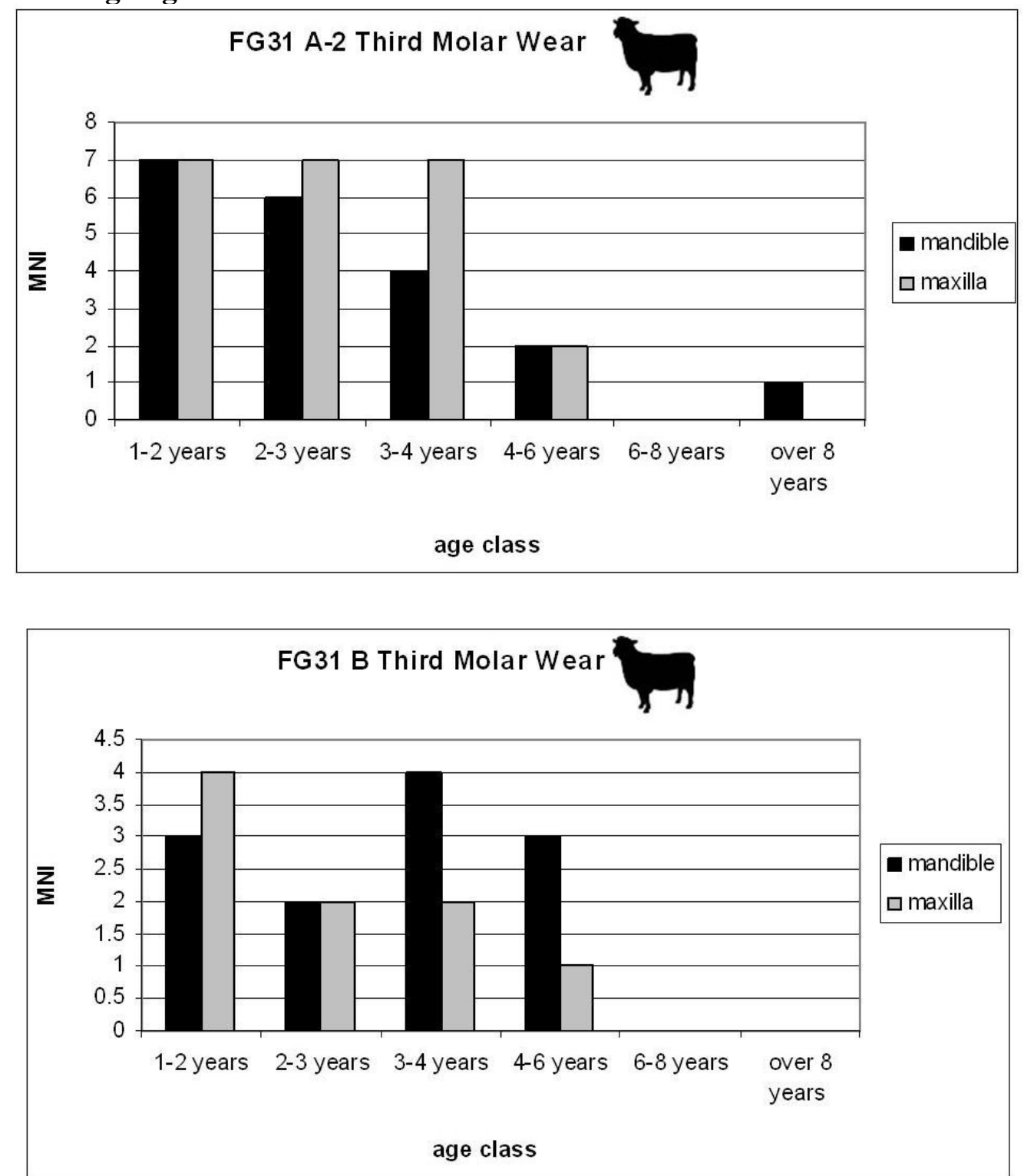

3.11b). 


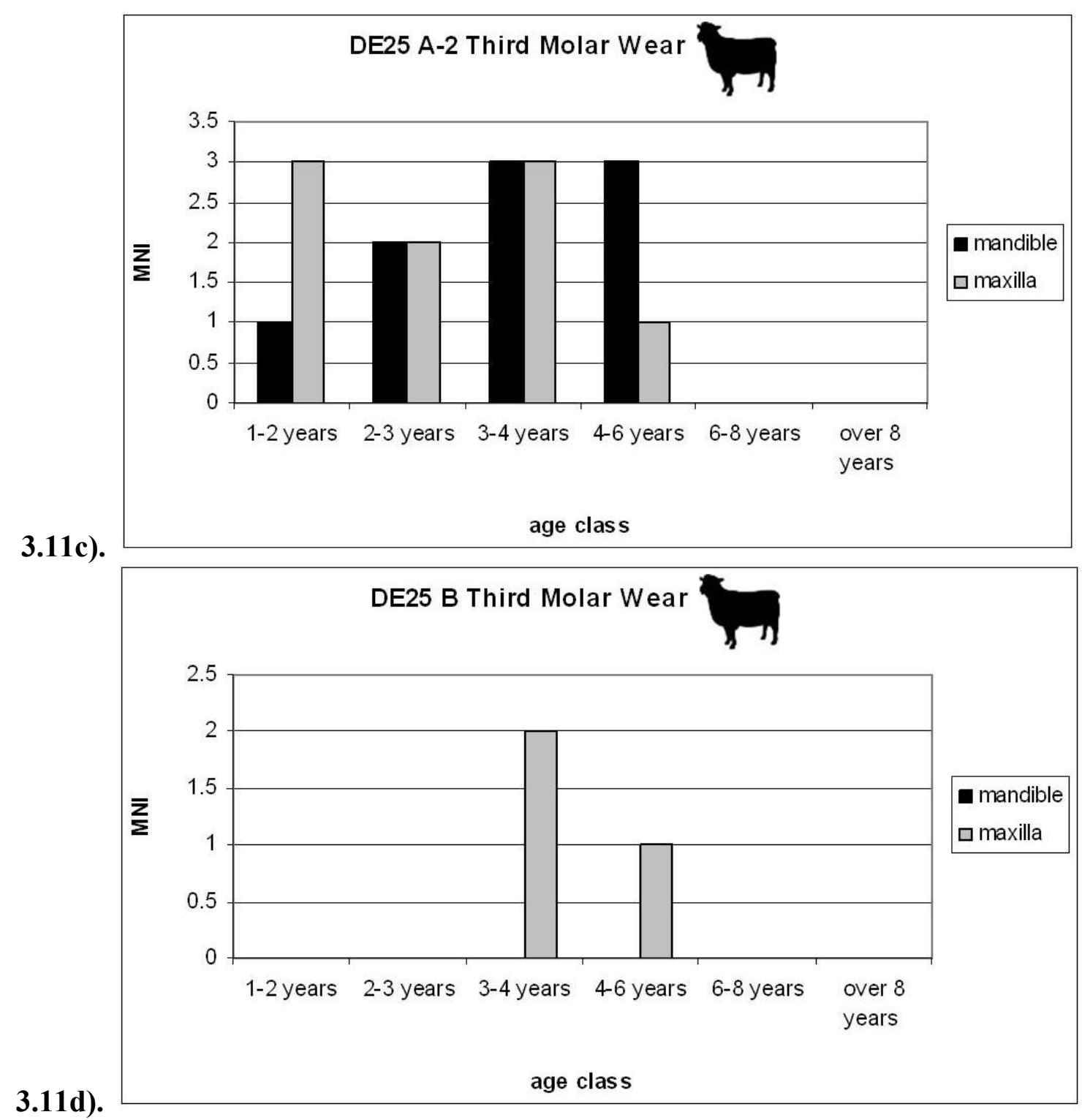

Table 3.7. Sheep postcranial epiphyseal fusion NISP.

\begin{tabular}{|c|c|c|c|c|c|c|c|}
\hline Column-Level & $\rightarrow \rightarrow \rightarrow \rightarrow$ & \begin{tabular}{|l|} 
FG31 \\
A-2
\end{tabular} & & & FG31 B & & \\
\hline Element & \begin{tabular}{|l} 
fusion age \\
(Silver 1969)
\end{tabular} & \begin{tabular}{|c|} 
subadult \\
NISP
\end{tabular} & $\begin{array}{l}\text { adult } \\
\text { NISP }\end{array}$ & $\begin{array}{l}\text { partial } \\
\text { NISP } \\
\end{array}$ & $\begin{array}{c}\text { subadult } \\
\text { NISP }\end{array}$ & $\begin{array}{l}\text { adult } \\
\text { NISP } \\
\end{array}$ & \begin{tabular}{|c} 
partial \\
NISP
\end{tabular} \\
\hline SCA & 6-8 mos. & 0 & 12 & 0 & 0 & 1 & 0 \\
\hline distal HUM & 10 mos. & 2 & 7 & 0 & 0 & 0 & 0 \\
\hline prox RAD & 10 mos. & 1 & 7 & 0 & 0 & 2 & 0 \\
\hline prox PHA1/2 & 13-16 mos. & 2 & 3 & 1 & 0 & 8 & 0 \\
\hline distal TIB & 18-24 mos. & 3 & 7 & 1 & 0 & 0 & 0 \\
\hline distal MTP & 18-28 mos. & 2 & 0 & 0 & 5 & 2 & 0 \\
\hline prox FEM & 30-36 mos. & 28 & 0 & 3 & 4 & 0 & 1 \\
\hline distal CAL & 30-36 mos. & 6 & 3 & 2 & 0 & 0 & 1 \\
\hline distal RAD & 36 mos. & 6 & 0 & 0 & 2 & 0 & 0 \\
\hline prox HUM & 36-42 mos. & 11 & 1 & 2 & 1 & 1 & 0 \\
\hline
\end{tabular}




\begin{tabular}{|c|c|c|c|c|c|c|c|}
\hline prox ULN & 36-42 mos. & 3 & 1 & 0 & 1 & 2 & \\
\hline distal FEM & 36-42 mos. & 9 & 0 & 4 & 2 & 1 & 0 \\
\hline prox TIB & 36-42 mos. & 13 & 1 & 1 & 1 & 0 & 1 \\
\hline Column-Level & $\rightarrow \rightarrow \rightarrow \rightarrow$ & \begin{tabular}{|l|} 
DE25 \\
A-1
\end{tabular} & & & \begin{tabular}{|l|} 
DE25 \\
A-2 \\
\end{tabular} & & \\
\hline Element & \begin{tabular}{|l} 
fusion age \\
(Silver 1969)
\end{tabular} & $\begin{array}{c}\text { subadult } \\
\text { NISP }\end{array}$ & $\begin{array}{l}\text { adult } \\
\text { NISP } \\
\end{array}$ & $\begin{array}{l}\text { partial } \\
\text { NISP }\end{array}$ & $\begin{array}{c}\text { subadult } \\
\text { NISP }\end{array}$ & $\begin{array}{l}\text { adult } \\
\text { NISP }\end{array}$ & \begin{tabular}{|c|} 
partial \\
NISP
\end{tabular} \\
\hline SCA & 6-8 mos. & 0 & 0 & 0 & 0 & 19 & 0 \\
\hline distal HUM & 10 mos. & 0 & 2 & 0 & 0 & 25 & 0 \\
\hline prox RAD & 10 mos. & 0 & 0 & 0 & 0 & 21 & 0 \\
\hline prox PHA1/2 & 13-16 mos. & 0 & 2 & 0 & 3 & 28 & 0 \\
\hline distal TIB & 18-24 mos. & 0 & 0 & 0 & 6 & 15 & 0 \\
\hline distal MTP & 18-28 mos. & 1 & 0 & 0 & 12 & 4 & 0 \\
\hline prox FEM & 30-36 mos. & 3 & 0 & 0 & 43 & 4 & 0 \\
\hline distal CAL & 30-36 mos. & 0 & 0 & 0 & 6 & 13 & 0 \\
\hline distal RAD & 36 mos. & 1 & 0 & 0 & 30 & 3 & 0 \\
\hline prox HUM & 36-42 mos. & 0 & 0 & 0 & 16 & 0 & 0 \\
\hline prox ULN & 36-42 mos. & 0 & 1 & 0 & 13 & 3 & 2 \\
\hline distal FEM & 36-42 mos. & 5 & 0 & 0 & 13 & 4 & 0 \\
\hline prox TIB & 36-42 mos. & 3 & 0 & 0 & 31 & 0 & 0 \\
\hline Column-Level & $\rightarrow \rightarrow \rightarrow \rightarrow$ & DE25 B & & & DE25 C & & \\
\hline Element & \begin{tabular}{|l} 
fusion age \\
(Silver 1969) \\
\end{tabular} & \begin{tabular}{|c|} 
subadult \\
NISP
\end{tabular} & $\begin{array}{l}\text { adult } \\
\text { NISP } \\
\end{array}$ & $\begin{array}{l}\text { partial } \\
\text { NISP }\end{array}$ & $\begin{array}{c}\text { subadult } \\
\text { NISP }\end{array}$ & $\begin{array}{l}\text { adult } \\
\text { NISP } \\
\end{array}$ & \begin{tabular}{|c|} 
partial \\
NISP \\
\end{tabular} \\
\hline SCA & 6-8 mos. & 0 & 4 & 0 & 0 & 0 & 0 \\
\hline distal HUM & 10 mos. & 0 & 4 & 0 & 0 & 1 & 0 \\
\hline prox RAD & 10 mos. & 0 & 4 & 0 & 0 & 2 & 0 \\
\hline prox PHA1/2 & 13-16 mos. & 1 & 8 & 0 & 1 & 13 & 0 \\
\hline distal TIB & 18-24 mos. & 1 & 0 & 0 & 0 & 2 & 0 \\
\hline distal MTP & 18-28 mos. & 0 & 1 & 0 & 1 & 4 & 0 \\
\hline prox FEM & 30-36 mos. & 5 & 0 & 0 & 0 & 0 & 0 \\
\hline distal CAL & 30-36 mos. & 1 & 2 & 0 & 0 & 0 & 0 \\
\hline distal RAD & 36 mos. & 6 & 2 & 0 & 4 & 0 & 0 \\
\hline prox HUM & 36-42 mos. & 2 & 0 & 1 & 0 & 0 & 0 \\
\hline prox ULN & 36-42 mos. & 0 & 0 & 0 & 0 & 1 & 0 \\
\hline distal FEM & 36-42 mos. & 5 & 0 & 1 & 2 & 1 & 0 \\
\hline prox TIB & 36-42 mos. & 5 & 0 & 0 & 1 & 0 & 0 \\
\hline
\end{tabular}

Turning to cattle, dental data show that those deposited in the Moat were

slaughtered after they were at least a few years old, some of which older individuals with moderately to heavily worn teeth. DE25 A-2 contains an isolated adult fourth premolar that was just erupting at slaughter, from an individual that was about two or three years of age (Silver 1969: 296). The postcranial data shows that a small number of cattle were 
Table 3.8. Cattle postcranial epiphyseal fusion NISP. No partially fused specimens were present. DE25 A-1 and DE25 C did not contain cattle specimens to provide ageing data.

\begin{tabular}{|c|c|c|c|c|c|}
\hline Column-Level & $\rightarrow \rightarrow \rightarrow \rightarrow$ & \begin{tabular}{|l} 
FG31 \\
A-2
\end{tabular} & & FG31 B & \\
\hline Element & \begin{tabular}{|l} 
fusion age \\
(Silver 1969)
\end{tabular} & $\begin{array}{c}\text { subadult } \\
\text { NISP }\end{array}$ & adult NISP & \begin{tabular}{|c|} 
subadult \\
NISP
\end{tabular} & $\begin{array}{l}\text { adult } \\
\text { NISP } \\
\end{array}$ \\
\hline SCA & 7-10 mos. & 0 & 0 & 0 & 0 \\
\hline Dist HUM & 12-18 mos. & 0 & 0 & 0 & 1 \\
\hline Prox RAD & 12-18 mos. & 0 & 0 & 0 & 0 \\
\hline Prox PHA1/2 & 18 mos. & 0 & 0 & 0 & 0 \\
\hline Dist TIB & 24-30 mos. & 0 & 0 & 0 & 1 \\
\hline Dist MTP & 27-36 mos. & 0 & 0 & 0 & 0 \\
\hline Prox FEM & 42 mos. & 0 & 0 & 0 & 0 \\
\hline Dist CAL & 36-42 mos. & 1 & 0 & 0 & 0 \\
\hline Dist RAD & 42-48 mos. & 0 & 1 & 0 & 0 \\
\hline Dist FEM & 42-48 mos. & 0 & 0 & 0 & 0 \\
\hline Prox TIB & 42-48 mos. & 0 & 1 & 0 & 0 \\
\hline Prox HUM & 42-48 mos. & 0 & 0 & 0 & 0 \\
\hline Prox ULN & 42-48 mos. & 0 & 0 & 0 & 0 \\
\hline CER CEN & 5 years & 1 & 0 & 0 & 0 \\
\hline THO CEN & 5 years & 0 & 0 & 0 & 0 \\
\hline LUM CEN & 5 years & 1 & 1 & 0 & 0 \\
\hline Prox RIB & indet & 1 & 2 & 0 & 0 \\
\hline Column-Level & $\rightarrow \rightarrow \rightarrow \rightarrow$ & \begin{tabular}{|l|} 
DE25 \\
A-2
\end{tabular} & & DE25 B & \\
\hline Element & \begin{tabular}{|l} 
fusion age \\
(Silver 1969)
\end{tabular} & $\begin{array}{c}\text { subadult } \\
\text { NISP }\end{array}$ & adult NISP & \begin{tabular}{|c|} 
subadult \\
NISP
\end{tabular} & $\begin{array}{l}\text { adult } \\
\text { NISP } \\
\end{array}$ \\
\hline SCA & 7-10 mos. & 0 & 0 & 0 & 0 \\
\hline Dist HUM & 12-18 mos. & 0 & 0 & 0 & 1 \\
\hline Prox RAD & 12-18 mos. & 0 & 0 & 0 & 0 \\
\hline Prox PHA1/2 & 18 mos. & 0 & 0 & 0 & 0 \\
\hline Dist TIB & 24-30 mos. & 0 & 0 & 0 & 1 \\
\hline Dist MTP & 27-36 mos. & 0 & 0 & 0 & 0 \\
\hline Prox FEM & 42 mos. & 0 & 0 & 0 & 0 \\
\hline Dist CAL & 36-42 mos. & 2 & 0 & 0 & 0 \\
\hline Dist RAD & 42-48 mos. & 0 & 0 & 0 & 0 \\
\hline Dist FEM & 42-48 mos. & 0 & 0 & 0 & 0 \\
\hline Prox TIB & 42-48 mos. & 0 & 0 & 0 & 0 \\
\hline Prox HUM & 42-48 mos. & 0 & 0 & 0 & 0 \\
\hline Prox ULN & 42-48 mos. & 0 & 0 & 0 & 0 \\
\hline CER CEN & 5 years & 1 & 0 & 0 & 1 \\
\hline THO CEN & 5 years & 0 & 1 & 0 & 0 \\
\hline LUM CEN & 5 years & 0 & 0 & 0 & 0 \\
\hline Prox RIB & indet & 1 & 0 & 0 & 0 \\
\hline
\end{tabular}

younger than three years of age, while others were older than four to five years of age at slaughter (Silver 1969: 285-286) (table 3.8). In all, although sample sizes are small, most 
cattle seem to have been slaughtered older than four or five years of age, while at least one was slaughtered about two years of age.

Pigs are rare, but they are present in both adult and subadult stages. There is only one erupted incisor in FG31 A-2, which ages that individual to older than one year of age when slaughtered (Bull and Payne 1982: 56).

D. Skeletal Element Frequencies: Sheep are the most numerous remains in the Moat and skeletal element profiles are able to be developed for all contexts except DE25 A-1, which rarely provides more than one MNI per element. Each end of the Moat produces a different profile. Levels A-2 and B of FG31, nearest to the jetty, have profiles heavily dominated by cranial elements (figures $3.12 \mathrm{a}-\mathrm{b}$ ). In contrast, DE25, which is nearest to the Van der Stel gate, has profiles that were more equally represented by all skeletal regions (figures 3.12c-e). Though each end of the Moat seems to demonstrate different skeletal representations, these differences are not statistically significant (Level A-2: Mann-Whitney $\mathrm{U}=629, P>0.05$; Level B: Mann-Whitney $\mathrm{U}=759.5, P>0.05)$. Cursory examinations were made of the excavation units between the northern and southern ends of the excavation. The units towards FG31 exhibited similar cranially-dominated profiles, and others, while still being heavily represented by cranial and axial bone fragments, graded towards the more evenly represented profiles observed in DE25. All contexts are consistently lacking in distal foot elements such as the metapodials and phalanges. Most of the metapodial fragments that are present consist of the proximal portions left behind from butchery and skinning (Diderot 1987: Plate 387; Landon 1996: 67; Reitz 1986a: 321-322; Shaw 1997: 93-96; Wood 1985 cited in Reitz 1986a: 327). 
Figure 3.12a-e: Sheep skeletal element profiles expressed as MNI represented by each element.
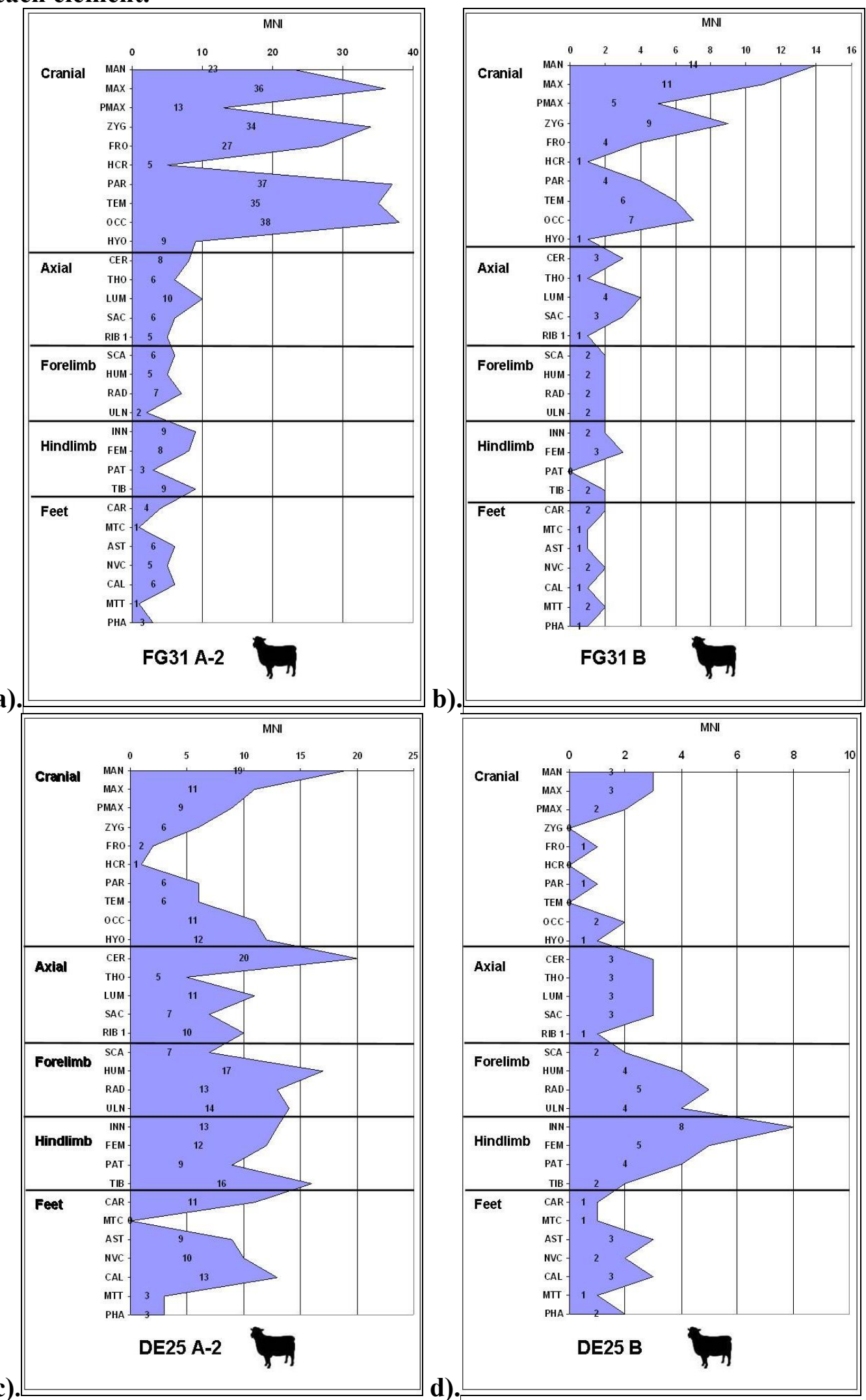

b).

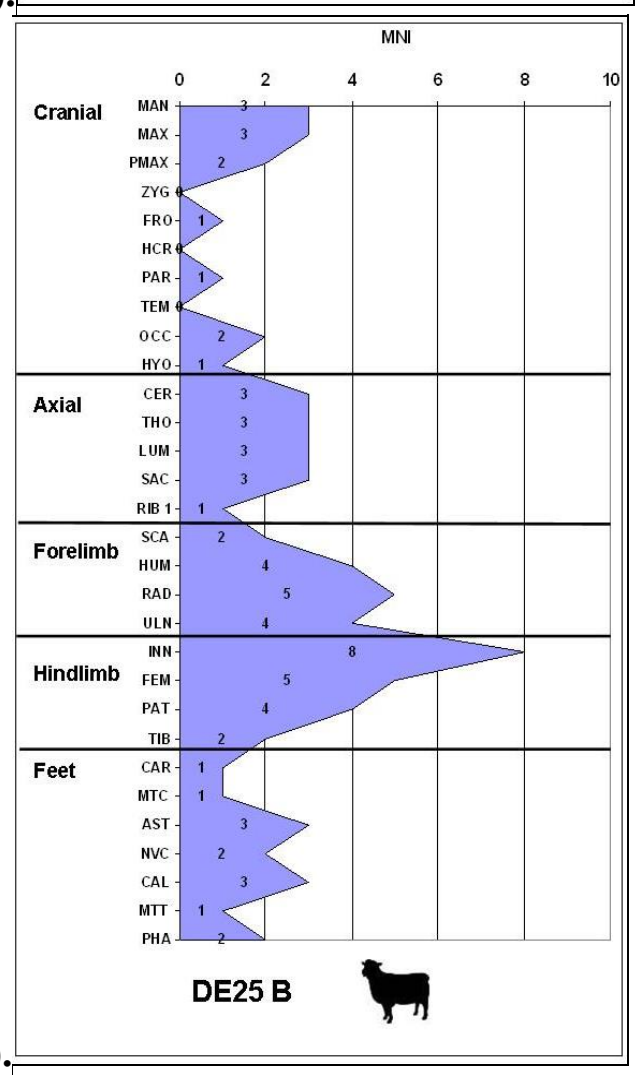




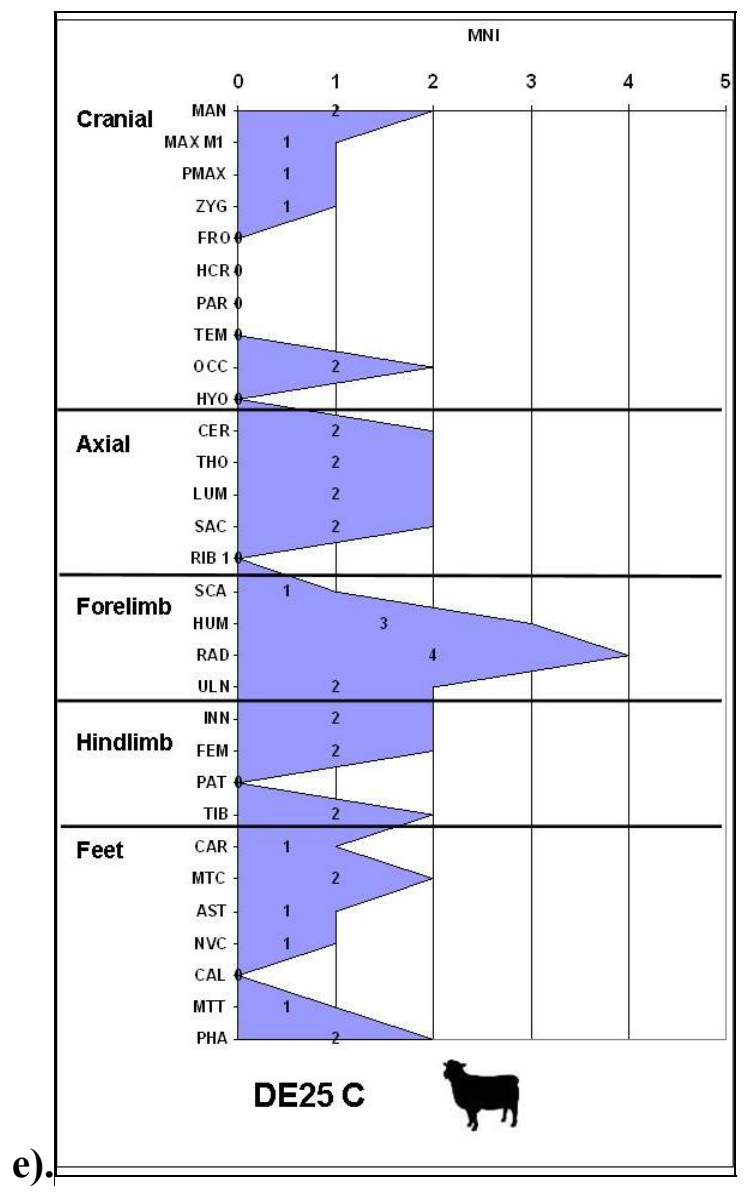

Despite small samples, cattle are represented by specimens from all skeletal regions, but they are slightly skewed towards cranial specimens. FG31 A-2 is the only context that contained a large sample size identified as cattle ( $\mathrm{n}=131$ NISP), and here a large proportion of the cattle remains from FG31 A-2 ( $n=68$ NISP, 51.90\%) are derived from a highly fragmented, very large horncore from one individual. Pigs remains are also rare, but they include specimens from most skeletal regions suggesting that full carcasses were deposited in the Moat.

Most of the wild mammals and birds are also represented by specimens from various skeletal regions. A pair of oddities included the Cape fur seal, which is 
represented by a lone penis bone, and the leopard, which is represented by a lone mandible fragment.

E. Fauna Sex: Horncores have often been used at pastoral sites to determine sheep sex, but they are not used in that capacity in this analysis (Albarella 1995: 700-701). A contemporary account from the Cape recorded that both male and female sheep contained horns, which would not allow sheep sexes to be inferred through their presence (Mentzel 1944: 211).

To provide a large sample size, all measurable acetabulae from the entire Moat were aggregated since no sex frequency differences were identified in individual excavation units or Levels. The fragmentary sheep acetabulae produce measurements ranging from smaller to larger sizes (figure 3.13). According to Greenfield (2005: np), the sheep that fall into the smaller end of the range correspond to measurements for females, while larger measurements correspond to male rams or wethers. The Moat sheep demonstrate a curve that stretches across the female and male ranges (comparison with Elsenburg $t=3.58, P=0.0008)$. Males and females could not be differentiated since their curves may overlap, but the peak in figure 3.13 is skewed towards the male end of the range, which would correspond to a higher proportion of wethers. Other animals present in the Moat samples do not provide sexing data with the exception of the male Cape fur seal's penis bone.

F. Butchery: Butchery marks are common on the Moat bone fragment, and frequencies exhibit similar proportions for the respective Levels in each excavation unit. It consists mainly of primary chops, made to divide the carcasses into manageable segments (table 3.9). Chop and cut marks are located in similar locations on the bone fragments 
regardless of the Column or Level from which they were recovered. Chop marks are found in predictable locations, at major limb joints, and on the vertebrae, the ribs, and the

Figure 3.13. Histogram illustrating the distribution of medial acetabular measurements for sheep in the Moat and how they compare to those from Elsenburg.

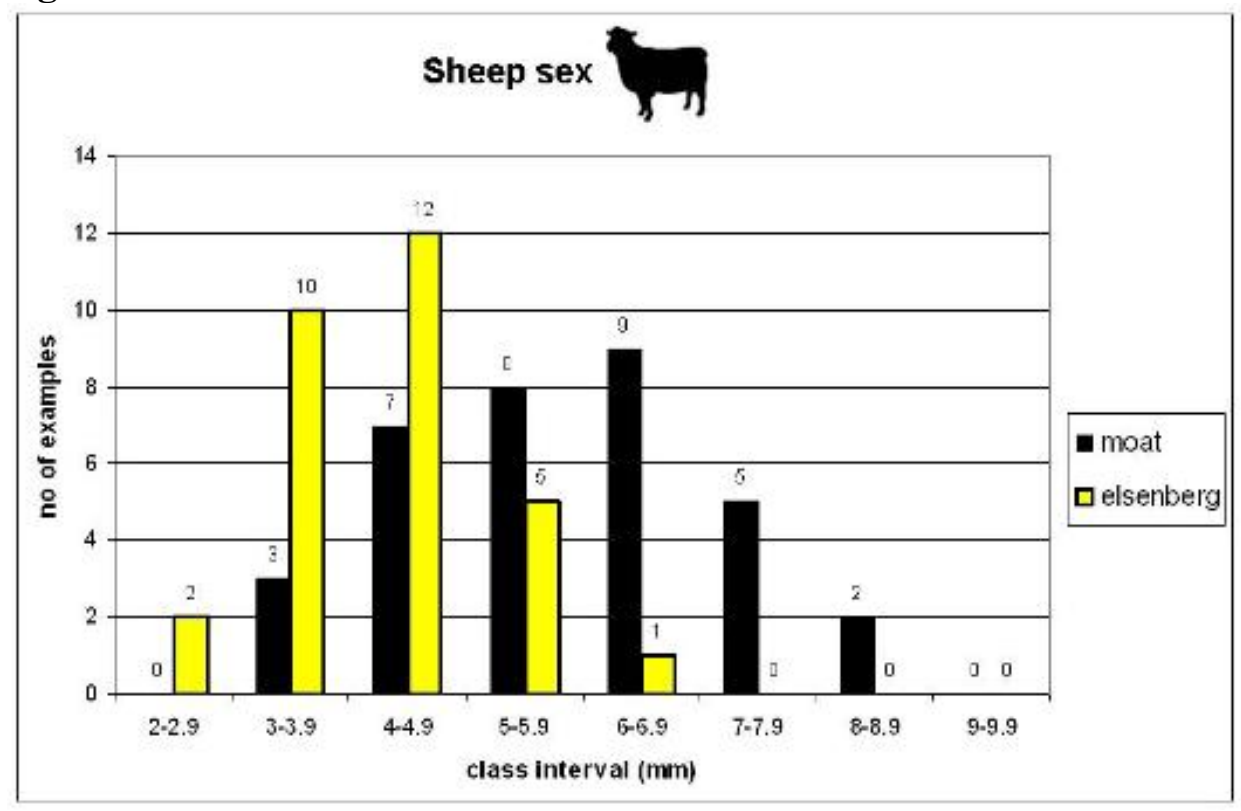

cranium (figures 3.14 and 3.15). Limb chops include those that removed the foot, those that separated upper and lower limb segments, and those that separated the limb from the axial portion of the carcass. Concerning vertebral columns, they were first separated into sections related to the different types of vertebrae, i.e. cervical from thoracic from lumbar. Next, they were then chopped sagittally to divide the carcass segments into halves. The vertebral halves could not be matched, suggesting that the other halves were deposited elsewhere or left in the meat when distributed through the various markets. Ribs were chopped in order to cut the rib bones down to smaller, regular sized pieces. The cranial chops divided the skull into sagittal halves, with these chop marks clearly observed on the occipital, parietal, and occasionally the frontal bones (figure 3.16a-b). 
Chops are also observed at the symphyses of the mandibles and premaxillae made during the division of the skull into halves (figures 3.14 and 15).

Cut and scrape marks are relatively rare compared to chops (table 3.9). They are most commonly found at the major muscle attachments on the femur, but are rare on other limb bones (figures 3.14 and 3.15). Cut marks present on the medial surface of the mandibles posterior to the symphysis and on hyoid bone fragments ( $\mathrm{n}=9$ NISP in N-3, $\mathrm{n}=7$ NISP in S-3) were aimed at tongue removal (figure 3.14 and 3.15) (Armitage 2004). Lower limb bones such as tibiae, radii, and metapodials have horizontal cut marks that indicate cutting the hide for skinning (Binford 1981: 136; Binford and Bertram 1977: 91; Diderot 1987: Plate 387; Landon 1996: 67; Shaw 1997: 93-96). Similar skinning marks are inferred from short cut marks located posterior to the orbits on the frontal bones (figure 3.16a-b) (Landon 1996: 67; The Hide, Leather and Allied Trades Improvement Society 1928: 7). The proportions of cut marks reflect a different usage of the knives as the two ends of the Moat produced different results. The northern end, near the historical jetty, showed cut marks present on $6.79-6.91 \%$ of the bone fragments. The southern end, closer to the Castle gateway, showed cut marks on $1.03-2.05 \%$ of the bone fragments. The greater proportion of cuts in the northern sample is the product of the skeletal element frequencies. The northern end is dominated by large-sized sheep cranial, hyoid, and mandibular fragments which contain $52.27 \%(n=115$ of 220 cut mark NISP) of the cut marks in the FG31 A-2 context, which suggests heavy skinning and tongue removal occurred within this sample.

Burning is extremely rare in the Moat samples. Those burnt bones present in the Moat are mainly calcined, while a few are charred (table 3.9). The burnt bone sample is 
highlighted by a charred duiker femur fragment in DE25 C, which shows that the wild game was roasted.

Table 3.9. The frequencies (\% of NISP) of butchery and burning in each Level.

\begin{tabular}{|l|c|c|c|c|c|c|c|c|}
\hline & \multicolumn{2}{|l|}{ burning } & \multicolumn{2}{l|}{ chop } & \multicolumn{2}{l|}{ cut } & \multicolumn{2}{l|}{ scrape } \\
\cline { 2 - 9 } & $\mathbf{n}$ & $\%$ & $\mathbf{n}$ & $\%$ & $\mathbf{n}$ & $\%$ & $\mathbf{n}$ & $\%$ \\
\hline FG31 A-2 & 10 & 0.31 & 468 & 14.69 & 220 & 6.91 & 27 & 0.85 \\
\hline FG31 B & 0 & 0.00 & 88 & 12.45 & 48 & 6.79 & 8 & 1.13 \\
\hline DE25 A-1 & 0 & 0.00 & 41 & 16.08 & 5 & 1.96 & 3 & 1.18 \\
\hline DE25 A-2 & 8 & 0.34 & 636 & 26.80 & 40 & 1.69 & 0 & 0.00 \\
\hline DE25 B & 3 & 0.62 & 133 & 27.48 & 5 & 1.03 & 1 & 0.21 \\
\hline DE25 C & 4 & 1.17 & 80 & 23.46 & 7 & 2.05 & 0 & 0.00 \\
\hline
\end{tabular}


Figure 3.14. Locations of chop, cut, and scrape marks for FG31 A-2. Butchery marks on the ribs are not illustrated (NISP for specimens identified as sheep with mark; red= chop mark, blue = cut mark). (template by Coutureau 1996)

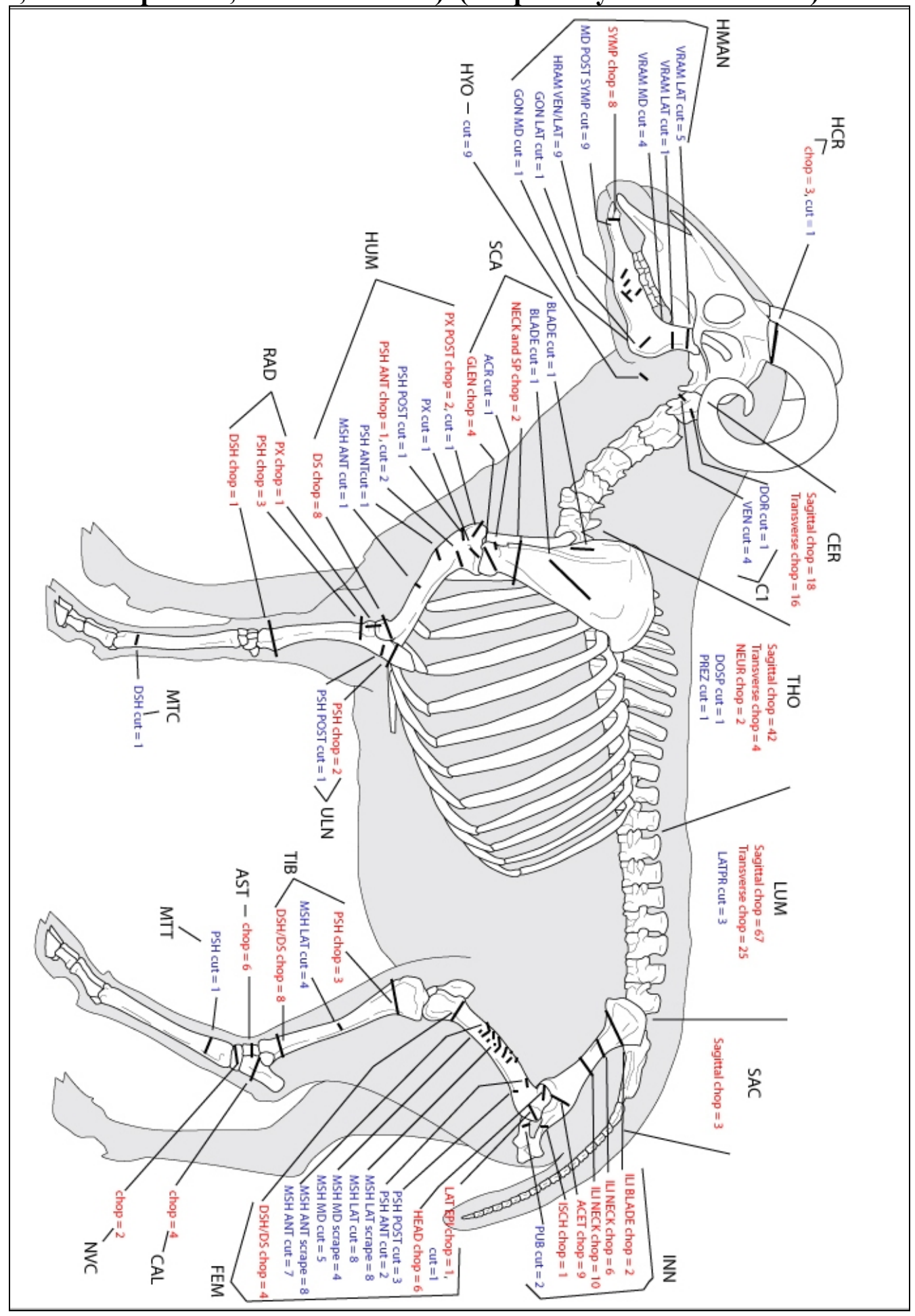


Figure 3.15. Locations of chop, cut, and scrape marks for DE25 A-2 (NISP for specimens identified as sheep with mark; red= chop mark, blue $=$ cut mark). Butchery marks on the ribs are not illustrated. (template by Coutureau 1996)

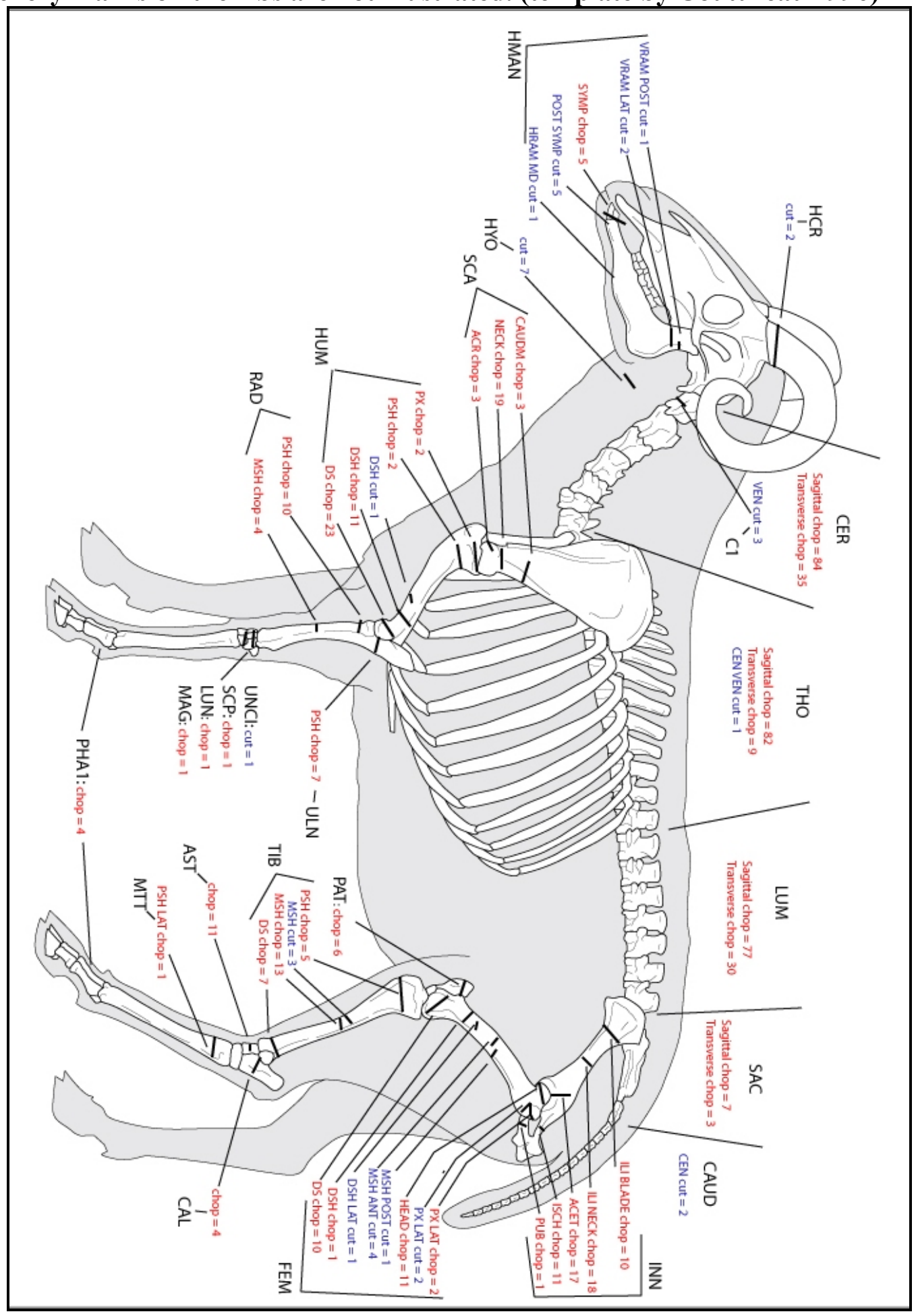


Figure 3.16a-b: Diagrams illustrating the relative locations of chop and cut marks on the dorsal (a) and ventral (b) sides of sheep crania from FG31 A-2 (NISP for specimens identified as sheep with mark). (template from Huxley 1864)

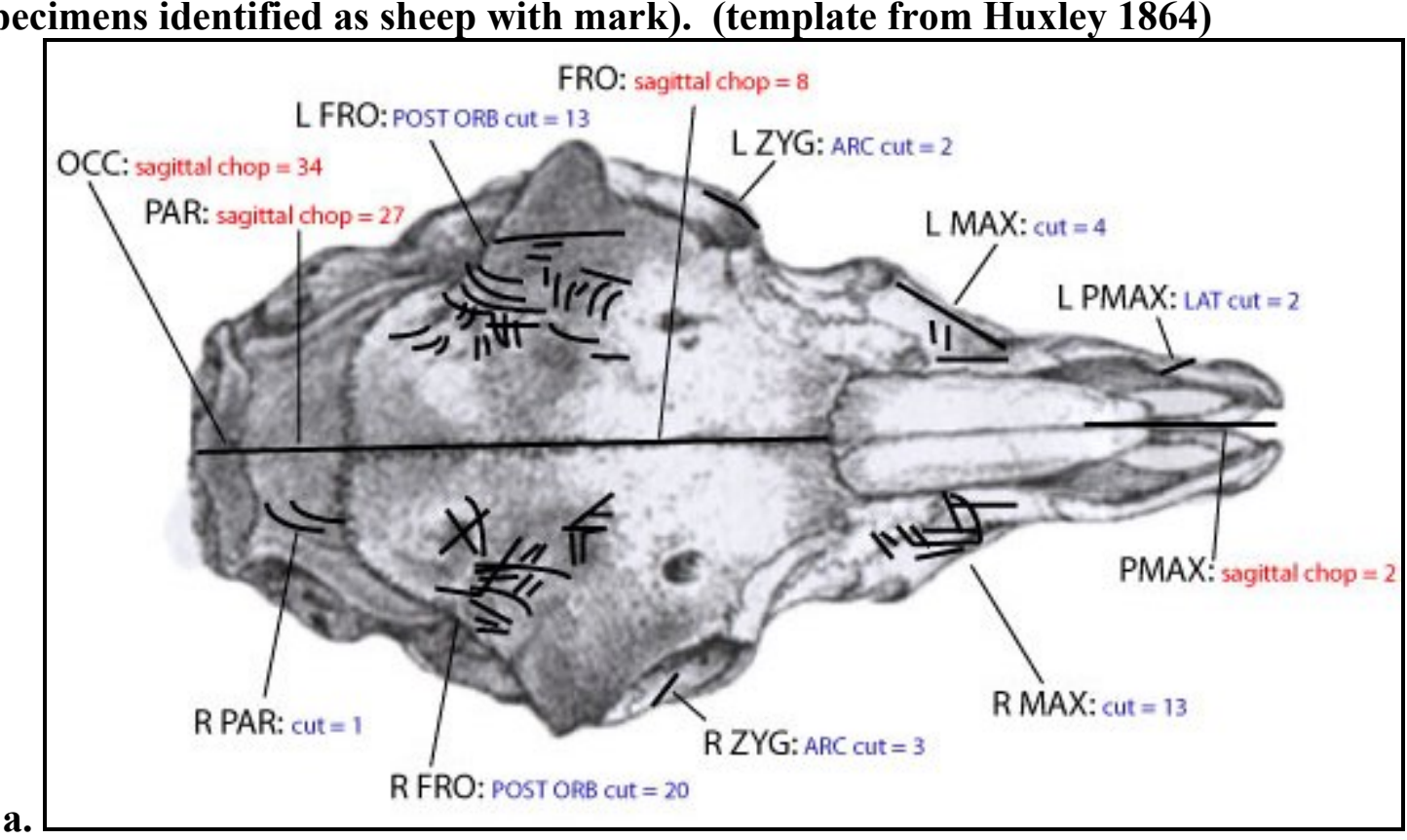

a.

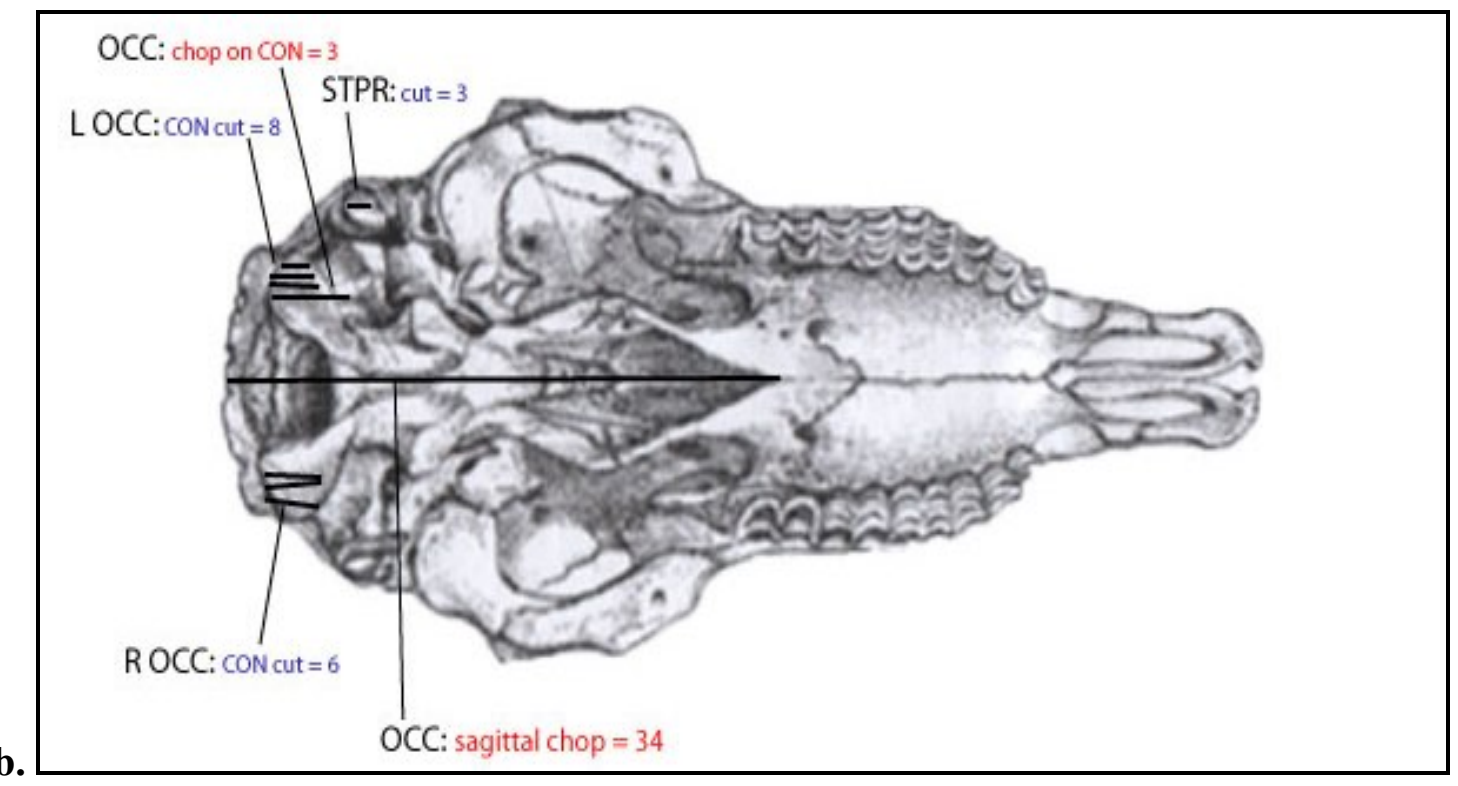

\section{DISCUSSION}

The Moat fauna reveals information about animal usage at the Castle and the wider Cape settlement as provisioning, kitchen, and herd management residues. The faunal residues were recovered from a well-protected deposit that was dumped there 
quickly after the animals were butchered, rather than after they were left other locations and then only moved to the Moat when fill was needed (Schiffer 1987: 199). The minimal taphonomic alteration to the Moat assemblage suggests that it is a confident representation of the animal remains slaughtered nearby and almost immediately deposited there in the second quarter of the eighteenth century.

A. Provisioning Residues: In the Moat, sheep dominated cattle in excess of the eighteenth century, archival "living ratio" of stock obtained through trade and breeding (Elphick 1985: 154-170; Elphick and Malherbe 1988: 21; Ross 1988: 251-253) and above the ratios reported from other VOC period archaeological sites (Avery 1989: 115; Avery 1992: 1; Cruz-Uribe and Schrire 1991: 96; Hart and Halkett 1993: 65; see Chapters 4, 5, $6,7)$. The highly skewed stock ratios from the Moat suggest that the sheep outnumber cattle in the meat provisioning business, whether for ship provisioning or local market distribution. At the founding of the Cape settlement, Jan van Riebeeck originally intended that each calling ship would receive 8 cattle and 8 sheep (Elphick 1985: 152), but since the Khoekhoe were more willing to trade sheep instead of cattle and the smaller bodied sheep bred faster than the larger bodied cattle, sheep were always more plentiful than cattle in the Dutch holdings (Elphick and Malherbe 1988: 21; Ross 1989: 251-254). Even when the stock trade with the Khoekhoe lessened over time, sheep always outnumbered cattle in the Dutch herds due to their faster rate of reproduction and growth. By the 1660s, only a decade after the first landing, the number of sheep slaughtered for the ships was nine times higher than that proposed by Van Riebeeck, and ship provisioning only became more heavily reliant on sheep into the later seventeenth century (Elphick 1985: 153). "By 1683 deliveries of sheep had risen to the point where many 
ships were given a hundred each, and few got less than thirty: the quota was now close to one sheep for every four to five sailors on board" (Elphick 1985: 153). These numbers were supported by contemporary Cape visitors such as Georg Meister in 1677 (RavenHart 1970a: 202). Mentzel (1925: 56) recorded that the VOC required a total of 390,000 pounds of slaughtered meat annually for the ships, with much of this being mutton.

Taphonomic and artifactual analyses show that the Moat had been filled rapidly after the new entranceway was built at the southern end of the 1990 excavation. Given the large amount of stock slaughtered en mass for ships or garrison, their remains could have served as a quick and available fill instead of their normal disposal into Table Bay. This would have solved two problems; the filling of an exposed, open hole and the burial of animal remains that could potentially rot as they washed upon the shore. Historic accounts recorded that stock destined for the calling ships were often butchered at the jetty just meters from the Buren bastion (refer back to figure 3.2). If we can recall from page 31 Georg Meister's 1688 account where he described the stock being slaughtered at this jetty along with the usual dumping of offal and unused bones into the Bay (RavenHart 1970b: 346).

The Moat fauna contained additional clues that suggest the sheep could be the remains of those butchered for ships' provisioning activities. Skeletal part frequencies showed a high proportion of cranial and postcranial axial elements, especially from the columns in the northern end of the excavations situated towards the jetty. Though very few shipwrecks have reported faunal remains, their recovered cargoes contain the inverse of that present in the Moat, namely high proportions of meatier elements such as the limbs and lumbar vertebrae (Armitage 2004: 6; English 1990; Green 1977: 244-246; 
Heinrich 2002: 262). Butchery patterns observed in the Moat faunal sample were mainly primary, intended to divide the carcasses into major anatomical segments. Limbs were chopped at the joints and vertebrae were chopped into shorter lengths according to their locations along the vertebral column, as well as split into halves. This primary butchery pattern was reported from the 1656 wreck of the VOC Vergulde Draeck, where bony remains of meat cuts were recovered from casks. These casks once contained salted or pickled meat obtained from the Cape Settlement where the ship took on provisions (Green 1977: 244-246). A seventeenth century Dutch outpost at Smeerenburg, Spitsbergen, in the Arctic Ocean off of Norway, also had imported, salted provisions that were dominated by upper limbs, ribs, and lumbar vertebrae; while head and feet elements were completely absent (Van Wijngaarden-Bakker 1984: 200-202). Provisioned cattle imported to the island of St. Kitts to feed slaves are represented by the high meat yielding limb bones, while the low utility portions are absent (Klippel 2001: 1193). Opposite of these provisioned sites, market sites in Charleston, South Carolina and Iowa City, Iowa have animal remains dominated by chop marks as well as skeletal element profiles that often show a preponderance of cranial and foot elements left behind after the meatier portions were sold (Calhoun et al. 1984 cited in Reitz 1986a: 327; Reitz 2007: 95, 98; Whittaker 1999: 51-54; Zierden and Reitz 2009: 347, 349). Finally, Armitage (2004: 6) reported hyoid bone fragments from historic shipwrecks, implying the presence of preserved tongues in the cargo. The Moat sample contained a number of cut marks representing the removal of the meaty tongue on several hyoid bone fragments as well as on several mandibles posterior to the symphyses. 
The primary butchery patterns observed in the Moat fauna suggest that most of the bones represent an early stage of processing before reaching the kitchen or table. The Moat fauna was dominated by chop marks, with relatively few cut and scrape marked fragments. Bone residues from locally consumed stews or roasts should contain a greater proportion of cut or scrape marks that would have been produced when the meat was removed from the bone (Cruz-Uribe and Schrire 1991: 100; see Chapter 4, 5, 6).

Interpreted as a combination of local consumption and provisioning debris, the terrestrial fauna sample from Oudepost I exhibited an equal number of cut and sawn bone fragments, where sawing was used for the same purpose as chopping in the Moat fauna (Cruz-Uribe and Schrire 1991: 100). Also, the incidence of knife cutting is much higher at Oudepost I than that observed in the Moat.

The lack of cooking evidence confirms that the Moat fauna represents residues from an early processing stage. Roasting was a common cooking method at the Cape where the meat was placed on the fire with the bone (Abrahams-Willis 1998: 25; Coetzee 1977: 92, 94, see Chapters 4, 5, 6). Burning was more frequent at Oudepost I than at the Moat, $2.60 \%(\mathrm{n}=180$, OPI aggregated terrestrial sample) to $0.34 \%(\mathrm{n}=25$, Moat bone sample aggregated) (Cruz-Uribe and Schrire 1991: 108). Processing meat for provisioning would not leave cooking residues on the bones since the meat would have been pickled or salted.

In other words, the greater representation of less meaty axial elements, the primary butchery, and the paucity of cooking evidence all suggest that most of the bones represent a stage of processing where the bones had not reached the markets or kitchens for further butchery or consumption. These details added to the highly skewed species 
ratios help suggest that the majority of the Moat fauna, specifically the sheep, derived from provisioning activities, where meaty elements were removed to other locations as supplies for ships or other markets.

B. Kitchen or Table Residues: Archaeological assemblages are often palimpsests, and it is necessary to tease out the various contributors. Associated elements of the Moat's collection, such as the porcelain and tobacco pipes, were derived from various sources not related to the meat supply of the garrison or provisioning. Likewise, together with the faunal remains, these clues suggest that the faunal residues may have also derived from a variety of sources. The presence of burned bones, though very few in number as compared with other sites, suggests a portion of the Moat fauna was derived from kitchen waste. When presented in site reports, burnt bone fragments make up a greater portion of the faunal assemblages that derive from kitchen waste at Cape archaeological sites (CruzUribe and Schrire 1991: 100; see Chapters 4, 5, 6).

There is also evidence of processing not intended for ships' provisioning. One example is sheep brain, where no documents or comparative archaeological sites were encountered that discussed provisioning with preserved brains. The sheep crania from the Moat were often chopped sagittally into halves through the occipital and parietal bones, and this chopping was occasionally observed continuing up through the frontal, premaxilla, and mandibular bones. This butchery was intended to access the brain. The consumption of brains was part of the European culinary tradition imported to the Cape (Beeton 1861, 877 in Mennell 1985, i; Coetzee 1977: 65-66). Heads could be boiled or roasted and that "the eyes, brains, and tongue were the choicest fare" Coetzee (1977: 66). It is possible that a similar preparation can be inferred here at the Castle. Though 
Mentzel (1925: 55) did not include brains in the description, he detailed the VOC meat contracts that stipulated "the pluck," such as the liver, heart, and lungs, were to be thrown in free of charge. The fate of these organs was not clear, though the contracts were for fresh meat provisioning to ships, the Governor, the hospital, and the slaves. Finally, postcranial elements of at least 2 lambs suggest local consumption, possibly served on the officers' tables.

Several other animal species present in the Moat do not fit within the ships' provisioning hypothesis. Birds, both domestic and wild, were probably eaten locally before being deposited in the Moat. Early in the Cape settlement's history, birds destined for ship supply were salted and placed in casks after only minor processing such as defeathering (Thom 1952: i.e. 59, 84, 229, 297, 303). It is unlikely that their bones would have been dumped into the Moat site since birds were not deboned before being placed in casks for preservation. Mentzel (1925: 101) also stressed that domestic poultry was difficult to obtain at the increasingly urbanized Cape settlement, which would make it unlikely that there was enough fowl to provision ships.

A similar argument can also be made for the fish remains. Fresh fish were salted or dried after minimal processing, leaving the bones in the meat and taking them away from the site. Poggenpoel (1996: 122) states that the Moat's fish are warmer water species and they were obtained locally. The fish were schooling species taken with large seine nets from False Bay, when later outposts were established there such as Posthuys (Poggenpoel 1996: 122, 130). Documents recorded that fish were common food sources for VOC servants, both soldiers and the enslaved (Armstrong and Worden 1988: 146; 
Dooling 1994: 23; Hall 1992: 394; Hall n.d.c.: 2, 17; Markell et al. 1995: 27; Sealy et al. 1993: 84, 89).

Wild mammals were also probably consumed locally, and the bovids could possibly be from the Governor's table (Cruz-Uribe and Schrire 1991: 95; Mentzel 1925:

101). By the time the Moat was filled in the second quarter of the eighteenth century, wild bovids were rare within 24 German or 120 English miles of the Cape settlement (Kolben 1731b: 34; Mentzel 1921: 61; 1925: 101; 1944: 102; Raven-Hart 1970b: 270; Skead 1987: 813-855). Though wild bovids were increasingly rare, the very small bovids persisted for some time and they were still present in the vicinity of the colonial settlements in throughout the eighteenth century (Skead 1980: 448-449, 456). The increasing rareness of wild bovids due to colonization and overhunting prompted the Governor to outlaw hunting, except by professional hunters who were contracted to hunt strictly for his table (Cruz-Uribe and Schrire 1991: 95; Mentzel 1925: 101). Wild bovids were considered a curiosity for visitors, and the animals were often presented during official dinners even though their meat was not described as having the most desirable flavor (Kolben 1731b: 116; Mentzel 1925: 100). DE25 C contains a charred duiker femur fragment that represents a roast of wild game. The wild bovids would likely be from official dinners since it may have been dangerous for illegal meat to have been brought so close to the Castle.

Other wild mammals were recorded as occasionally being eaten. Porcupine was present in the Moat (Kolben 1731b: 120; Mentzel 1944: 241). A fragment of a leopard mandible was recovered, and while it is possible that the leopard was eaten, since only mandible fragments were present may argue that it was more likely a trophy of its 
slaughter than as a food source. The large carnivores, such as the leopard, often harassed the settlements as they attacked and killed stock, fowl, and the occasional colonist. To eliminate these dangerous animals, the VOC administration offered financial reward to those who killed the dangerous carnivores that endangered the livestock and colonists (Cruz-Uribe and Schrire 1991: 95; Kolben 1731b: 41; Mentzel 1921: 60-61; 1944: 244; Skead 1980: 84-86, 123). Mentzel (1921: 61) actually stated that the shooter was required to present the head, claws, and pelt in order to receive the reward as a measure to prevent people from bartering with the Khoekhoe for the hides and then collecting the monetary rewards for themselves. The skins from such kills were often displayed in public places such as the Company Garden's zoo or the Castle entranceway (Valentyn 1973: 117). The meat from large carnivores was also described as a desirable food when available (Kolben 1731b: 41, 97; Valentyn 1973: 117).

An oddity present in the Moat was an isolated, unmodified Cape fur seal penis bone and may have also been a trophy since no other seal remains were encountered in the Moat. The Dutch frequently slaughtered seals in order to obtain train oil and skins, though the meat and skeletal remains were left behind (Cruz-Uribe and Schrire 1991: 100-101; Mentzel 1921: 179, 1925: 139; Skead 1980: 676-678; Thom 1952: i.e. 59, 81, 175, 177, 231, 287; Valentyn 1973: 125). Though the skin trade was stopped by Holland in 1657 , seals were still killed by the thousands for their large quantities of oil (CruzUribe and Schrire 1991: 100; Schrire 1984: 19). Seal meat was considered a last-resort type of food during the earliest days of the Settlement when fresh meat was continuously scarce due to the weak stock trade (Thom 1952: 231). The isolated curiosity in the Moat contrasts sharply with the samples from Oudepost I, where seal remains were numerous. 
The terrestrial assemblage from the outpost contains an MNI of 16 seals, nine of which came from around the Lodge structure (Cruz-Uribe and Schrire: 94). Cruz-Uribe and Schrire (1991: 101) have interpreted the presence of these seal bones at the living site as residues of seal meat consumption since oil would normally have been rendered at the hunting site due to the large quantity of animals slaughtered.

C. Herd Management: Herd management strategies can be discerned from the Moat faunal sample. Domestic stock was raised at the pastures along the Liesbeeck River or at the various frontier settlements and outposts before being delivered to the urbanized settlement, and the stock remains from the Moat deposit represent the end of the VOC meat production system.

The sheep deposited in the Moat were mainly slaughtered between 1.5 to six years of age when the animals would have been reaching their maximum meat yield. The Moat sheep were younger than those slaughtered at Elsenburg, a site of meat production where older animals were kept in order to obtain more lambs (see Chapter 6). The Moat age profiles also contrast with both the terrestrial and DP samples from Oudepost I where the sheep varied more widely in their ages at slaughter. At Oudepost I, about half of the sheep were younger than 18 to 24 months when they were slaughtered, while at least 21 individuals were slaughtered older than 18 to 24 months (Cruz-Uribe and Schrire 1991: 98).

The sheep from the Moat were slaughtered at similar ages as those identified from other archaeological sites around the settlement's urban center. The Parade site, an eighteenth century in-filled ditch near the Castle, produced a sheep age profile similar to the Moat's, where a minimum of 86 individuals were slaughtered older than 24 months of 
age, while only one was younger (Abrahams 1996: 244; Cruz-Uribe and Schrire 1991: 99). The outpost at Paradise outside the urban center contained sheep that were mainly slaughtered around two years of age (Avery 1989: 115; Hall et al. 1993: 52). Lastly, from within the Castle, DKG and Phase 7 from the Granary excavations also reveal slaughter ages similar to the Moat (Chapter 4, 5). The slaughter pattern identified in the sheep from eighteenth century contexts in the urban center suggests that the sheep were delivered to the settlement after the animals had reached optimal meat yields (Mentzel 1944: 212). The occasional lamb is identified in each of these sites suggesting that while the bulk of the meat was from prime aged animals, a very small portion was imported for taste.

The sex ratio of the Moat sheep shows that they were likely a mixture of wethers with some females. It is not possible to determine if the male sheep were wethers or rams, but since castration was commonly carried out by the Dutch herders they are likely to have been wethers (Mentzel 1944: 103). The unnecessary males would have been castrated in order to keep them as meat sources, while avoiding any unwanted breeding from less desirable individuals. When taken with the age data, the Moat sheep were probably a mixture of wethers with some females that were raised to their prime meat yield ages.

D. Secondary Products: The Moat fauna revealed very few details of the wider economy at the Cape settlement regarding secondary animal products. Animal slaughter profiles suggest that the sheep and cattle were brought into the settlement for meat, while milk would have been mainly available to the herders in the frontier (Abrahams 1996: 228; Coetzee 1977: 65; Mentzel 1921: 57; 1925: 101; 1944: 21, 206, 214; Valentyn 1973: 
121). Secondary products such as cow or ewe milk and eggs from poultry cannot be inferred here, and were not believed to be common items at the urban center. This inference is supported by the contemporary documents that state items such as milk and eggs were rare within the urban area unless a frontier settler brought these items in for barter (Abrahams 1996: 228; Mentzel 1925: 101; 1944: 21, 206, 214; Valentyn 1973: 121).

Hides were provided to the tanners free of charge from official provisioning slaughtering, and hide preparation can be inferred from the faunal residues (Mentzel 1925: 55; 1944: 202). The paucity of distal foot elements alongside cut marked distal limb and cranial bones are indicative of hide removal (Binford 1981: 136; Binford and Bertram 1977: 91; Diderot 1987: Plate 387; Landon 1996: 67; Reitz 1986a: 321-322; Shaw 1997: 93-96; Wood 1985 cited in Reitz 1986a: 327). Contrary to the hide processing evidence from Puerto Reale, Haiti (Reitz 1986a: 321-323), here at the Cape, the crania were not included with the hide for the tanning shop, instead, the hide was carefully removed from the skull so the brain could be used for food. Documents record that hide production was performed at the settlement near the shambles, at a tanning shop along the beach (figure 3.17), and smaller scale industries throughout the settlement such as the shoemaker's shop, which contained rawhides undergoing the tanning process when it burned in 1736 (Mentzel 1921: 135; Raven-Hart 1970a: 201).

Lastly, elephant ivory was present at the settlement for trade with passing ships (Green 1977: 241). Several elephant tusk ivory waste fragments were present in the faunal sample with clear sawing marks indicating that they were processed at the urban center. It is uncertain if this ivory was brought to the Castle by Dutch hunters or if they 
were obtained from the Khoekhoe in exchange for arrack, tobacco, beads, or copper

(Skead 1980: 236; Thom 1952: 78, 106, 110, 153).

Figure 3.17. A $1678 / 9$ map of the Cape Settlement illustrating a tannery on the beach near the Castle. The tannery is structure ' $N$ ' (Raven-Hart 1970a: 201). The jetty was moved closer to the Castle by the time of the Moat's deposition (see figure 3.2).

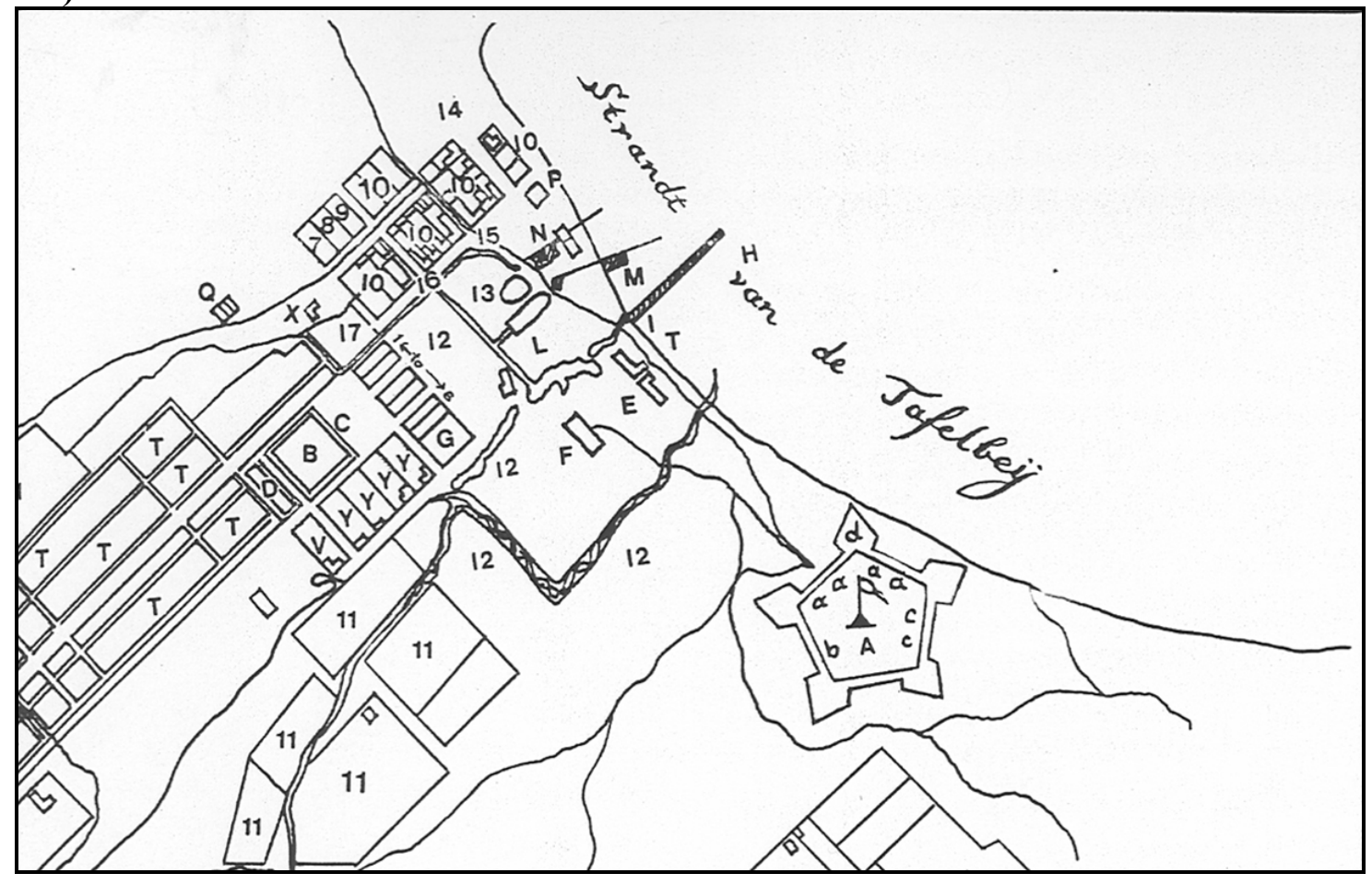




\section{CHAPTER FOUR: Donkergat (DKG)}

\section{HISTORY}

The Donkergat (DKG), or “dark hole," was a supposed torture chamber located along the curtain wall at the base of the Nassau Bastion in the rear courtyard of the Castle (figure 4.1). Though legal punishments were often public in order to provide lessons to the wider Cape population, torture was an accepted tool under the VOC at the Cape to extract information from suspected criminals, either indigenous, enslaved, or European, and the torture could have occurred in DKG (Johnson Barker 2003: 142-146; i.e. Moodie 1838: $311-317,380-385)$. DKG is currently a room subdivided in half with the only natural light coming into the room from a pair of small rectangular openings in the ceiling plus the doorway.

DKG was outfitted as a torture chamber in 1698 (Böeseken 1961: 140-145). It is unsure whether DKG served jointly as a prison and torture room, since a prison was constructed in the remodeled seaward entranceway when it was moved in 1682 (Böeseken 1961: 285-286). In 1786, another, more expansive prison was constructed above the Catzenellenbogen Bastion (Johnson Barker 2003: 136). DKG was no longer used as a torture chamber by the British after they took over the Cape in 1795 as was recorded by Lady Anne Barnard, who expressed disgust for such barbaric acts (Robinson 1994: 146-147). 
Figure 4.1. Aerial photograph of the Castle illustrating the location of the DKG excavation, plus the locations of the other Castle excavations presented in this thesis (Photograph by Hoberman 1997).

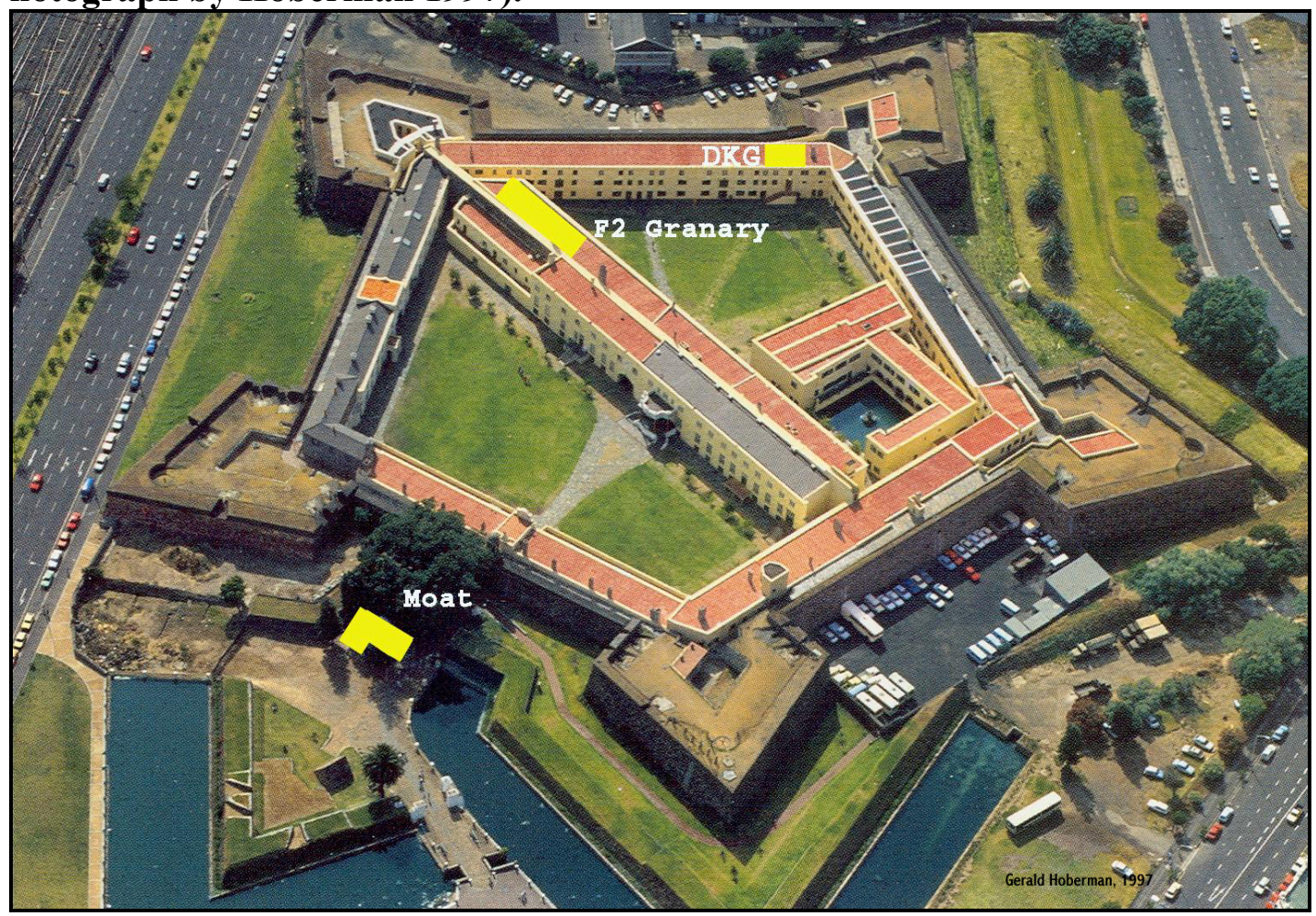

\section{ARCHAEOLOGY}

In 1988, the ACO (1988b: 1) undertook excavations in DKG after a contractor's trench during renovations revealed stratified fill deposits which included artifacts and bones.

DKG was excavated in two meter squares to a depth of about 40 centimeters (ACO 1988b: 1). The archaeological excavations revealed the foundation of a dividing wall within DKG, which had originally separated it into two rooms (ACO 1988b: 8-9). Each room exhibited differences in sediment layers (ACO 1988b: 2). Excavation unit AB1/2 from the northwest corner of Room 1 was chosen for the faunal sample.

A. Stratigraphy: The stratigraphy for AB $1 / 2$ is summarized as:

1. The DKG deposits were capped by a concrete floor, which was removed by the contractors. Immediately between the concrete floor and the consolidated 
archaeological deposits was a thin, loose sediment layer with mortar and brick fragments (ACO 1988b: 2).

2. Layer 1: A "brown clayey" fill that extended across Room 1. Portions of Layer 1, especially the areas against the walls, were disturbed by rodent burrows (ACO 1988b: 3, 5, 6).

3. Layer 2: A looser fill described as a "soft brown" fill, and it was also impacted by rodent burrows (ACO 1988b: 3, 5).

4. Layer 3: A rubble fill with many brick, mortar, and stone fragments (ACO 1988b: 12). At the base of the rubble layer, in situ cobbles and bricks were uncovered suggesting a floor that was mostly removed had once existed across the room (ACO 1988b: 12-13).

5. Layer 4: A "dark gray charcoal" fill and the deepest cultural layer in AB 1/2 (ACO 1988b: 14). Layer 4 was identified as a fill by the ACO (1988: 10) due to a large quantity of bone that was found arranged at a variety of angles. Into the subsoil, a pair of small pits was identified as scaffolding support holes (ACO 1988b: 47). These pits were filled by Layer 4, and were therefore included in the faunal sample from Layer 4.

B. Material Culture: The artifacts have not been analyzed systematically. Klose and Schrire (2005: pers. comm.) ascribed the ceramics to the end of the VOC occupation of the Cape in the late eighteenth century and into the early British period. 


\section{FAUNAL RESULTS}

As mentioned above, $\mathrm{AB} 1 / 2$ was randomly chosen for the faunal sample. The sample sizes for each Layer are very small except for Layer 4, and the results presented here are heavily based on the remains from Layer 4 (table 4.1).

Table 4.1. Sample sizes (NISP) for each Layer in AB 1/2 in DKG.

\begin{tabular}{|l|r|r|r|}
\hline & \multicolumn{1}{|c|}{$\begin{array}{c}\text { Bone } \\
\text { sample } \\
\text { (NISP) }\end{array}$} & $\begin{array}{c}\text { Isolated } \\
\text { teeth* } \\
\text { (NISP) }\end{array}$ & $\begin{array}{c}\text { Total } \\
\text { (NISP) }\end{array}$ \\
\hline Layer 1 & 17 & 0 & 17 \\
\hline Layer 2 & 14 & 0 & 14 \\
\hline Layer 3 & 33 & 0 & 33 \\
\hline Layer 4 & 806 & 4 & 810 \\
\hline
\end{tabular}

* Teeth present in bone were not counted as isolated teeth.

A. Taphonomy: Overall, the bone fragments from DKG are very well preserved. Bone fragment sizes are generally larger than fragments from comparable animal sizes from the other VOC period assemblages sampled in this thesis (see figures 4.2 and 4.3). Though sample sizes are small in the upper Layers of $\mathrm{AB} 1 / 2$, bone fragment sizes are relatively consistent throughout the Layers. Long bones also exhibit low degrees of fragmentation (table 4.2). Long bone shaft circumferences from size 2 mammals are about two-thirds complete on average, while size 3 mammal long bone shaft fragments are relatively rare and produce lower average shaft completeness than the size 2 long bones. High proportions of epiphyseal fragments are present for both size 2 and 3 mammals, suggesting that the less dense portions of bones were not selectively deleted. 
Figure 4.2. Mean measures of size 2 bone fragments from all sites.

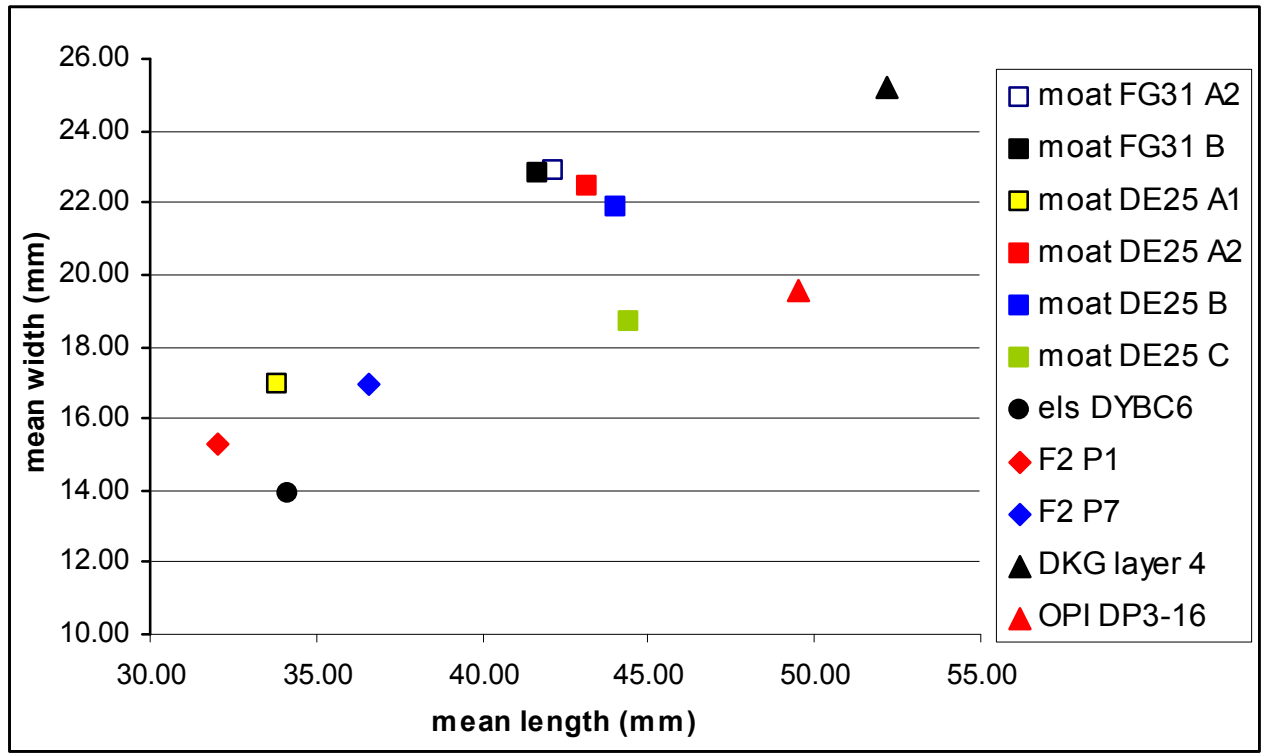

Figure 4.3. Mean measures of size 3 bone fragments from all sites.

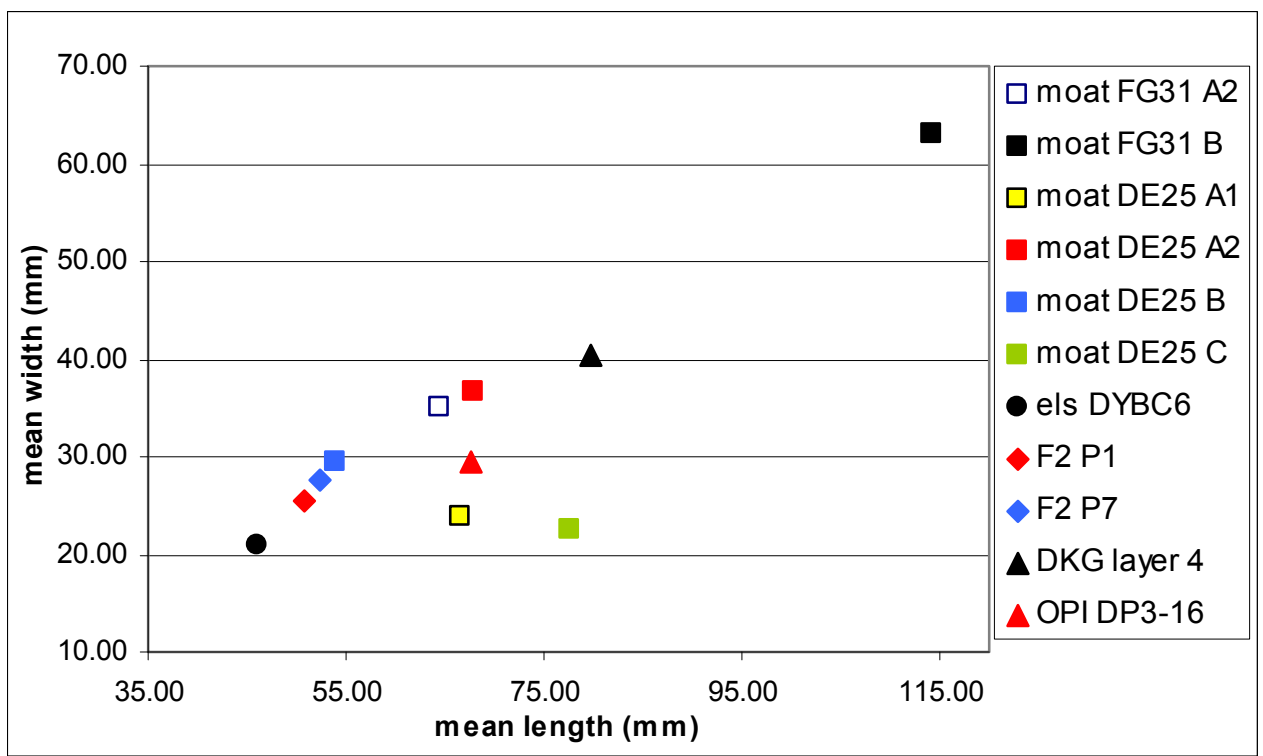

Table 4.2. Measures of long bone completeness, not including the ulna due to its lack of a medullary cavity along with the shaft.

\begin{tabular}{|l|l|r|r|r|r|}
\hline \multicolumn{2}{|c|}{} & $\begin{array}{l}\text { LBN } \\
\text { circum }\end{array}$ & $\begin{array}{l}\text { EPI } \\
\text { (NISP) }\end{array}$ & $\begin{array}{l}\text { shaft } \\
\text { (NISP) }\end{array}$ & $\begin{array}{l}\text { ratio } \\
\text { (shaft/EPI) }\end{array}$ \\
\hline \multirow{3}{*}{ size 2 } & Layer 1 & 0.1 & 0 & 2 & NA \\
\cline { 2 - 6 } & Layer 2 & 0.67 & 1 & 2 & 2 \\
\cline { 2 - 6 } & Layer 3 & 0.68 & 6 & 1 & 0.17 \\
\cline { 2 - 6 } & Layer 4 & 0.65 & 70 & 132 & 1.89 \\
\hline \multicolumn{6}{|c|}{} \\
\hline \multirow{3}{*}{ size 3 } & Layer 1 & 0.4 & 0 & 1 & NA \\
\cline { 2 - 6 } & Layer 2 & NA & 0 & 0 & NA \\
\cline { 2 - 6 } & Layer 3 & NA & 0 & 0 & NA \\
\cline { 2 - 6 } & Layer 4 & 0.24 & 11 & 39 & 3.55 \\
\hline
\end{tabular}


Carnivore damage was observed in moderate frequencies on the size 2 bones in the deeper Layers where the sample sizes were larger. Tooth mark frequencies were more common on the smaller, more manageable size 2 bones while they were rarely observed on the larger size 3 bone fragments (figure 4.4). Though carnivore traces were observed in moderate frequencies, the long bones shafts were relatively complete with high proportions of epiphyseal fragments suggesting that carnivores did not have a major affect in destroying portions of the assemblage.

Figure 4.4. Frequencies (\% of NISP) of carnivore tooth marks observed on bone surfaces.

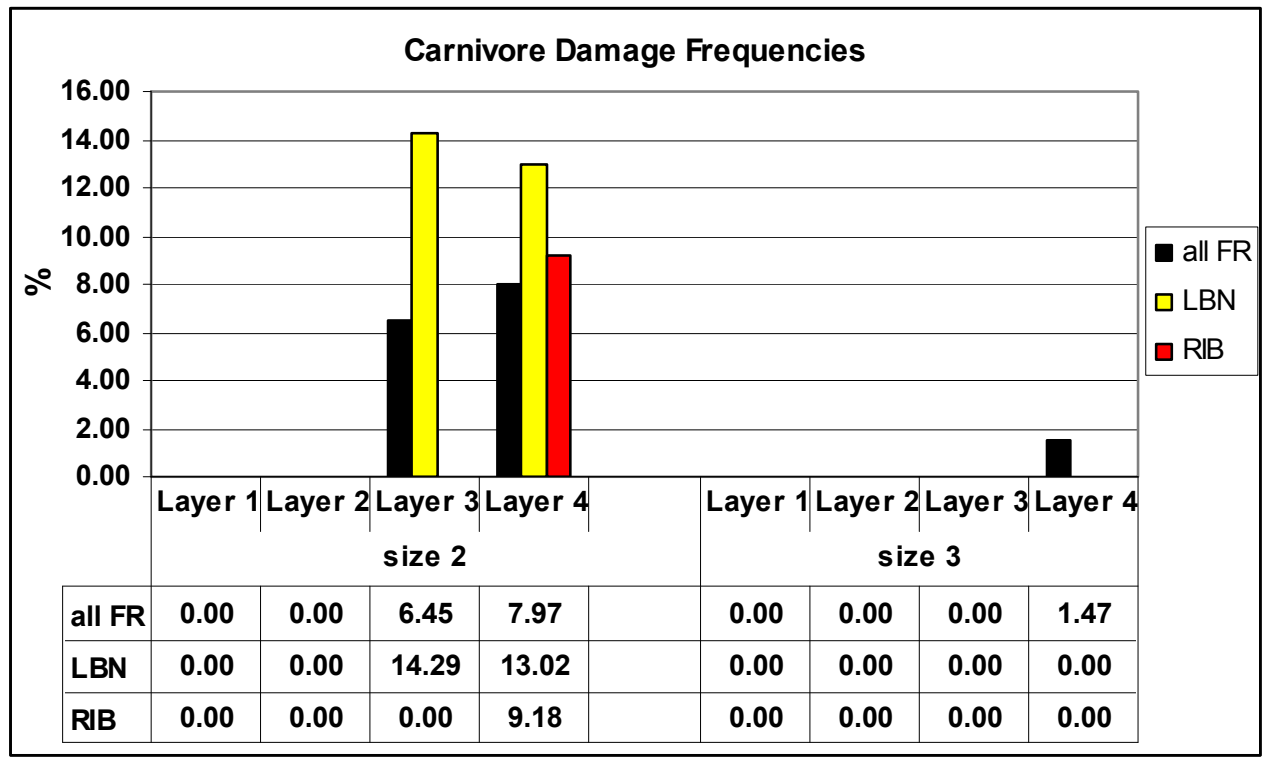

Abrasion damage is also observed in moderate frequencies on bones of both size 2 and 3 animals in the deepest Layer (figure 4.5). Abrasion damage frequencies are present in greater proportions on the denser, smoother surfaces of long bone and rib fragments. 
Figure 4.5. Frequencies (\% of NISP) of abrasion damage observed on bone surfaces.

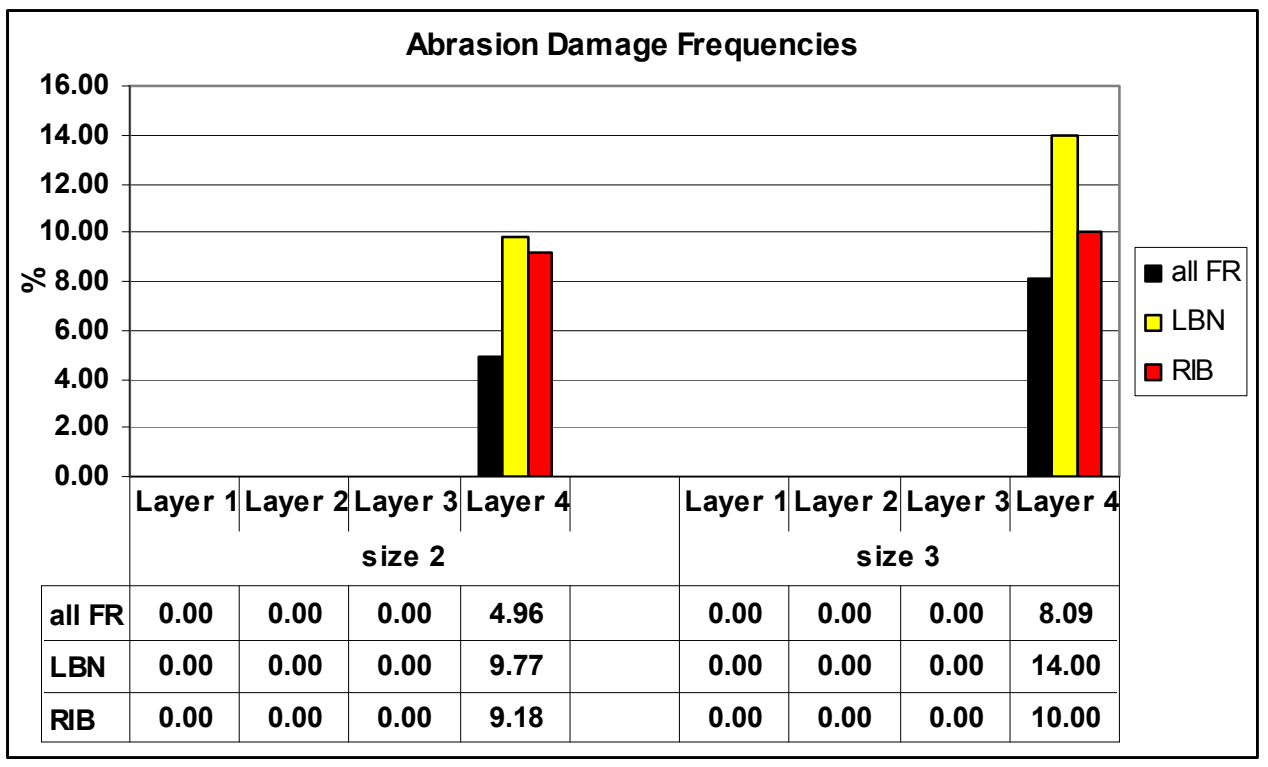

Rodents also contributed moderate damage to the bone surfaces, though they would not have consumed bones in the same manner as carnivores (figure 4.6). Rodent burrows were often identified in the archaeological deposits and these burrows were especially common in the upper Layers (ACO 1988b: 3, 5, 6). Though no rodent bones were identified in the sample, the small tooth mark size suggests they were mice or rats. Since they were smaller rodents, it is assumed that they modified the bones they encountered at the site and did not remove or import any fragments.

B. Taxonomic Representations: The taxa recovered from DKG are not very diverse and are dominated by domestic stock with only one wild species (table 4.3). Sheep (Ovis aries) is the most abundant species present, followed by cattle (Bos taurus) and pig (Sus scrofa). Sheep outnumber cattle in ratios of 2:1 in the upper Layers and 4:1 in Layer 4. Pigs are only identified in Layers 3 and 4. Pigs are equally represented with sheep in Layer 3 through MNI, though sheep are more heavily represented through NISP. Sheep outnumber pig in an MNI ratio of 4:1 in Layer 4. 
Figure 4.6. Frequencies (\% of NISP) of rodent damaged bones.

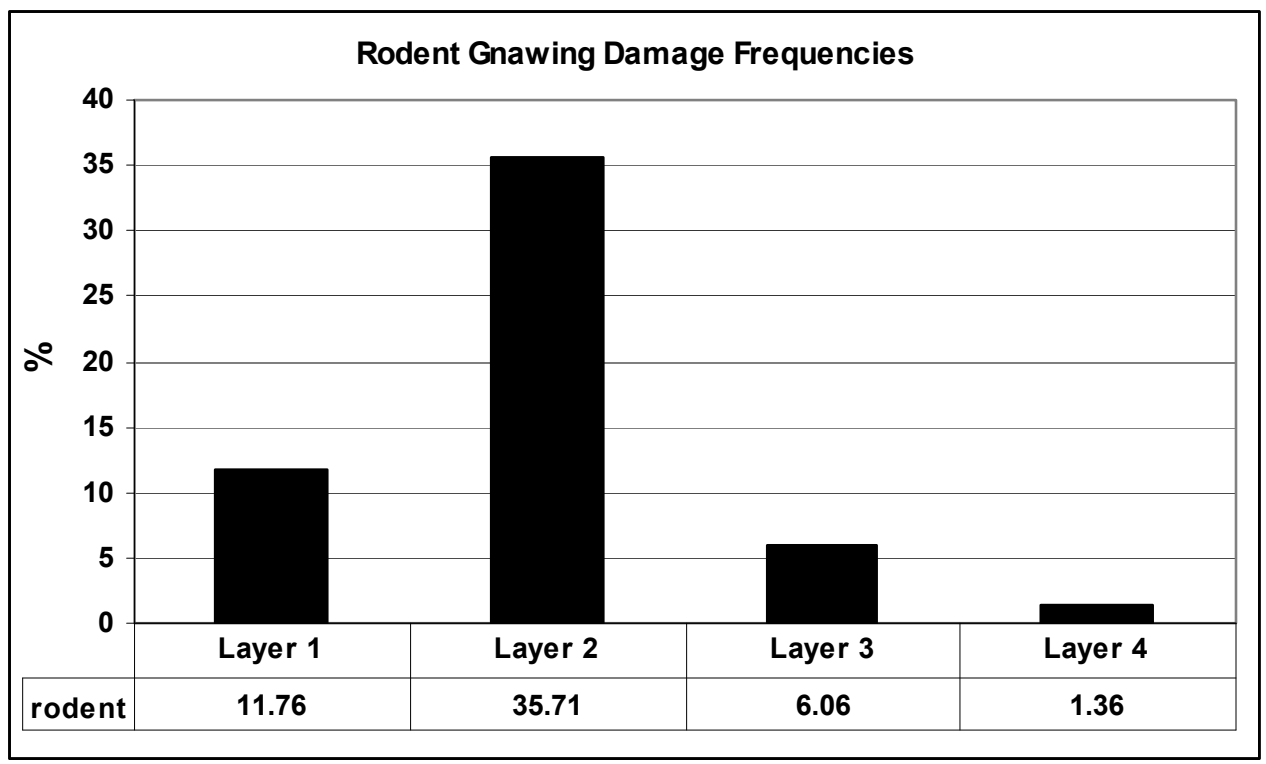

Though sheep outnumber the other domestic animals through NISP and MNI, meat yield calculations suggest that beef was an important meat source (table 4.4). Historical documents record the meat weight of the colonial sheep and cattle. The larger, meaty hybrid sheep carcass was estimated to weigh about 60 to 80 , and is averaged to 70 pounds here (Mentzel 1925: 56; Raven-Hart 1970b: 297). The indigenous cattle are recorded to have been smaller than their European counterparts, where an ox would rarely have provided more than 600 pounds of meat (Mentzel 1944: 202). Since an ox is a large male, meat yield for the indigenous cattle is estimated lower at 500 pounds per animal. Pig weights were not revealed through historical documents and since most are slaughtered young, they were minimal contributors to the diet. Table 4.4 illustrates that through meat yield, cattle provided most of the meat prepared by the Castle kitchens.

The only wild species identified in the DKG deposit is a steenbok (Raphicerus campestris), which is only represented by four specimens. The only bird specimen present is a chicken (Gallus gallus) (table 4.3). 
Table 4.3. Taxonomic representations in each respective Layer in DKG.

\begin{tabular}{|c|c|c|c|c|c|c|c|}
\hline & Layer 1 & Layer 2 & & Layer 3 & & Layer 4 & \\
\hline TAXON & NISP MNI & $\begin{array}{l}\text { I NISP MN } \\
\end{array}$ & MNI & NISP & MNI & NISP & MNI \\
\hline Bos taurus, cow & 1 & 2 & 1 & & & 44 & \\
\hline Ovis aries, sheep & 12 & 8 & 2 & 22 & 2 & 462 & 12 \\
\hline Sus scrofa, pig & & & & 4 & 2 & 22 & \\
\hline Raphicerus campestris, steenbok & & & & & & 4 & \\
\hline ind mammal 2 & & & & & & 37 & \\
\hline ind mammal 3 & & & & & & 11 & \\
\hline artiodactyla & & & & 4 & 1 & 95 & \\
\hline ind bovid 2 & 2 & 4 & 1 & 1 & 1 & 52 & \\
\hline ind bovid 3 & 2 & 1 & & 2 & 1 & 82 & \\
\hline Gallus gallus, chicken & & & & & & 1 & \\
\hline
\end{tabular}

Table 4.4. Estimated meat contributions from sheep and cattle in Layer 4.

\begin{tabular}{|l|r|r|r|}
\hline & MNI & Ibs/animal & $\begin{array}{c}\text { total } \\
\text { weight }\end{array}$ \\
\hline Ovis aries & 12 & 70 & 840 \\
\hline Bos taurus & 3 & 500 & 1500 \\
\hline
\end{tabular}

C. Ages of the Fauna: Teeth are rare in the DKG deposits so the ages at slaughter are mainly determined according to postcranial epiphyseal fusion stages. Layer 4 is presented here due to its larger sample size. The little information obtainable from Layers 1 through 3 is consistent with Layer 4.

The sheep deposited in DKG were mainly slaughtered between two and 3.5 years of age (table 4.5). An MNI of two sheep were slaughtered after three to 3.5 years of age. Also, an unfused distal humerus points to one lamb slaughtered before it was ten months of age (Silver 1969: 285). The postcranial ageing data is supported by the few teeth present in the sample. An MNI of two sheep are represented by dentition; one by adult fourth premolar and third molar, and the other by a well-worn deciduous fourth premolar. These teeth comfortably place these individuals within the main two to 3.5 years range for age at slaughter (Silver 1969: 297). 
Table 4.5. Sheep postcranial epiphyseal fusion stages for Layer 4 .

\begin{tabular}{|l|l|r|r|r|}
\hline & $\begin{array}{l}\text { fusion age } \\
\text { (Silver } \\
\mathbf{1 9 6 9 :} \mathbf{2 8 5})\end{array}$ & $\begin{array}{c}|c| \\
\text { subadult }\end{array}$ & $\begin{array}{c}\text { Nodult } \\
\text { NISP }\end{array}$ & $\begin{array}{l}\text { partial } \\
\text { NISP }\end{array}$ \\
\hline SCA & $\mathbf{6 - 8}$ mos. & 0 & 6 & 0 \\
\hline Dist HUM & $\mathbf{1 0}$ mos. & 1 & 12 & 0 \\
\hline Prox RAD & $\mathbf{1 0}$ mos. & 0 & 11 & 0 \\
\hline Prox PHA1/2 & $\mathbf{1 3 - 1 6}$ mos. & 2 & 2 & 0 \\
\hline Dist TIB & $\mathbf{1 8 - 2 4}$ mos. & 3 & 5 & 0 \\
\hline Dist MTP & $\mathbf{1 8 - 2 8}$ mos. & 0 & 0 & 0 \\
\hline Prox FEM & $\mathbf{3 0 - 3 6}$ mos. & 31 & 3 & 1 \\
\hline Dist CAL & $\mathbf{3 0 - 3 6}$ mos. & 8 & 5 & 0 \\
\hline Dist RAD & $\mathbf{3 6}$ mos. & 6 & 2 & 0 \\
\hline Dist FEM & $\mathbf{3 6 - 4 2}$ mos. & 18 & 1 & 1 \\
\hline Prox TIB & $\mathbf{3 6 - 4 2}$ mos. & 5 & 0 & 1 \\
\hline Prox HUM & $\mathbf{3 6 - 4 2}$ mos. & 5 & 0 & 0 \\
\hline Prox ULN & $\mathbf{3 6 - 4 2}$ mos. & 4 & 0 & 1 \\
\hline
\end{tabular}

Postcranial ageing data shows that the cattle were probably slaughtered when they were about four to five years of age (table 4.6). All epiphyses that fuse by four years of age are fully fused (Silver 1969: 285-286). Vertebral centrum epiphyses which fuse about five years of age are present in the subadult stage of development, while three specimens were in the process of fusion when the animal was slaughtered. Only one worn cattle incisor was recovered which simply indicates that individual was older than 14 months when slaughtered (Silver 1969: 296).

The pigs were mainly slaughtered between one and two years of age, though the sample size is extremely small (table 4.7). All epiphyses that fuse after two years of age are unfused. One pig was younger due to an unfused neural arch from a thoracic vertebra, not presented in table 4.7 , meaning that individual was slaughtered before six months of age (Silver 1969: 285). 
Table 4.6. Cattle postcranial epiphyseal fusion stages for Layer 4.

\begin{tabular}{|c|c|c|c|c|}
\hline Element & $\begin{array}{l}\text { fusion age } \\
\text { (Silver } \\
\text { 1969: 285) }\end{array}$ & $\begin{array}{c}\text { subadult } \\
\text { NISP }\end{array}$ & $\begin{array}{l}\text { adult } \\
\text { NISP }\end{array}$ & $\begin{array}{c}\text { partial } \\
\text { NISP }\end{array}$ \\
\hline SCA & 7-10 mos. & 0 & 1 & 0 \\
\hline Dist HUM & 12-18 mos. & 0 & 0 & 0 \\
\hline Prox RAD & 12-18 mos. & 0 & 2 & 0 \\
\hline Prox PHA1/2 & 18 mos. & 0 & 2 & 0 \\
\hline Dist TIB & 24-30 mos. & 0 & 1 & 0 \\
\hline Dist MTP & 27-36 mos. & 0 & 0 & 0 \\
\hline Prox FEM & 42 mos. & 0 & 2 & 0 \\
\hline Dist CAL & 36-42 mos. & 0 & 1 & 0 \\
\hline Dist RAD & 42-48 mos. & 0 & 3 & 0 \\
\hline Dist FEM & 42-48 mos. & 0 & 0 & 0 \\
\hline Prox TIB & 42-48 mos. & 0 & 0 & 0 \\
\hline Prox HUM & 42-48 mos. & 0 & 0 & 0 \\
\hline Prox ULN & 42-48 mos. & 0 & 0 & 0 \\
\hline CER CEN & 5 years & 1 & 0 & 1 \\
\hline THO CEN & 5 years & 0 & 0 & 2 \\
\hline LUM CEN & 5 years & 2 & 0 & 0 \\
\hline
\end{tabular}

Table 4.7. Pig postcranial epiphyseal fusion stages for Layer 4.

\begin{tabular}{|l|l|r|r|r|}
\hline & $\begin{array}{l}\text { fusion age } \\
\text { (Silver } \\
\text { 1969: 285) }\end{array}$ & $\begin{array}{c}\text { subadult } \\
\text { NISP }\end{array}$ & $\begin{array}{l}\text { adult } \\
\text { NISP }\end{array}$ & \multicolumn{1}{c|}{$\begin{array}{c}\text { partial } \\
\text { NISP }\end{array}$} \\
\hline SCA & $\mathbf{1 2}$ mos. & 0 & 1 & 0 \\
\hline Dist HUM & $\mathbf{1 2}$ mos. & 0 & 0 & 0 \\
\hline Prox RAD & $\mathbf{1 2}$ mos. & 0 & 0 & 0 \\
\hline Prox PHA1/2 & $\mathbf{1 8 - 2 4}$ mos. & 0 & 0 & 0 \\
\hline Dist TIB & $\mathbf{2 4}$ mos. & 2 & 0 & 0 \\
\hline Dist MTP & $\mathbf{2 4 - 2 7}$ mos. & 0 & 0 & 0 \\
\hline Prox FEM & $\mathbf{4 2}$ mos. & 1 & 0 & 0 \\
\hline Dist CAL & $\mathbf{2 4 - 3 0}$ mos. & 0 & 0 & 0 \\
\hline Dist RAD & $\mathbf{4 2}$ mos. & 1 & 0 & 0 \\
\hline Dist FEM & $\mathbf{4 2}$ mos. & 0 & 0 & 0 \\
\hline Prox TIB & $\mathbf{4 2}$ mos. & 1 & 0 & 0 \\
\hline Prox HUM & $\mathbf{4 2}$ mos. & 0 & 0 & 0 \\
\hline Prox FIB & $\mathbf{3 0 - 4 2}$ mos. & 1 & 0 & 0 \\
\hline
\end{tabular}

D. Skeletal Element Frequencies: The sheep remains from DKG are heavily dominated by vertebral and limb elements (figure 4.7). Mentioned to above regarding the lack of dentition for ageing, cranial elements are nearly invisible. When counted as MNI per element, each vertebral and limb element are relatively equally represented with the exception of femora and the distal foot elements such as metapodials and phalanges. 
Femora are twice as numerous as most other elements, which may suggest they were favored due to their greater meat yield than some other skeletal regions (Huelsbeck 1991: 66-69; Lyman 1977: 69, 1979: 536-541, 1987: 61-65; Schulz and Gust 1983: 48). A pattern observed in other Cape faunal samples, the metapodials were rare, because they were likely removed from the site during early stages of animal processing such as skinning (Binford 1981: 136; Binford and Bertram 1977: 91; Landon 1996: 67; Reitz 1986a: 325-327; Shaw 1997: 93-96; see Chapters 3, 5, 6, 7).

Figure 4.7. Sheep skeletal element profiles expressed as MNI represented by each element in Layer 4.

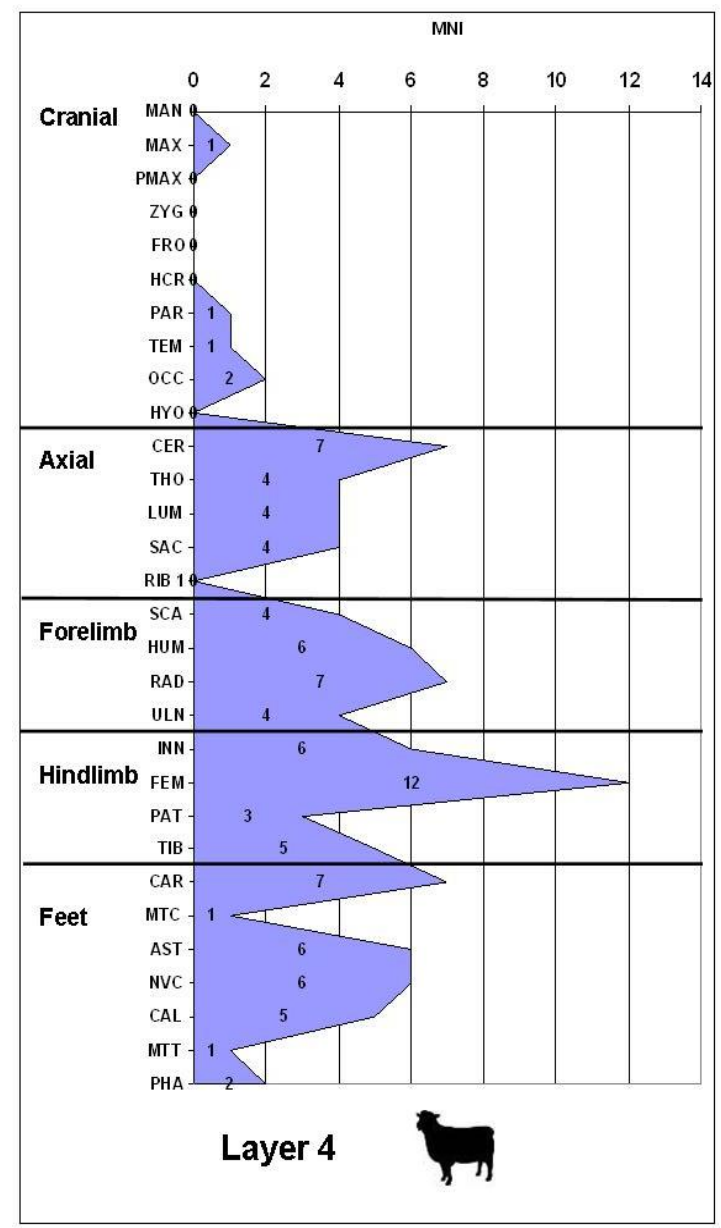

Cattle remains, like the sheep, are also dominated by postcranial elements (figure 4.8). The cattle are represented by smaller sample sizes and fragmentation may have 
affected the MNI counts of their relatively larger skeletal elements. Cattle are only represented by one MNI through the upper limb long bones, humeri and femora, which contrast with sheep that are heavily represented by all limb bones. In the cattle sample, the elements that articulate proximally and distally, being the girdles of the scapula and innominate, as well as the immediately distal bones of the radius and patella, are each represented by three MNI. Therefore, the lower representations of the long bones, the humerus and femur, may be a result of fragmentation and identifiability, and not differential deposition. Also, like the sheep, cattle metapodials are mostly absent, suggesting they were also removed with the hide during early butchery stages (Binford 1981: 136; Binford and Bertram 1977: 91; Landon 1996: 67; Shaw 1997: 93-96).

Figure 4.8. Cattle skeletal element profiles expressed as MNI represented by each element in Layer 4.

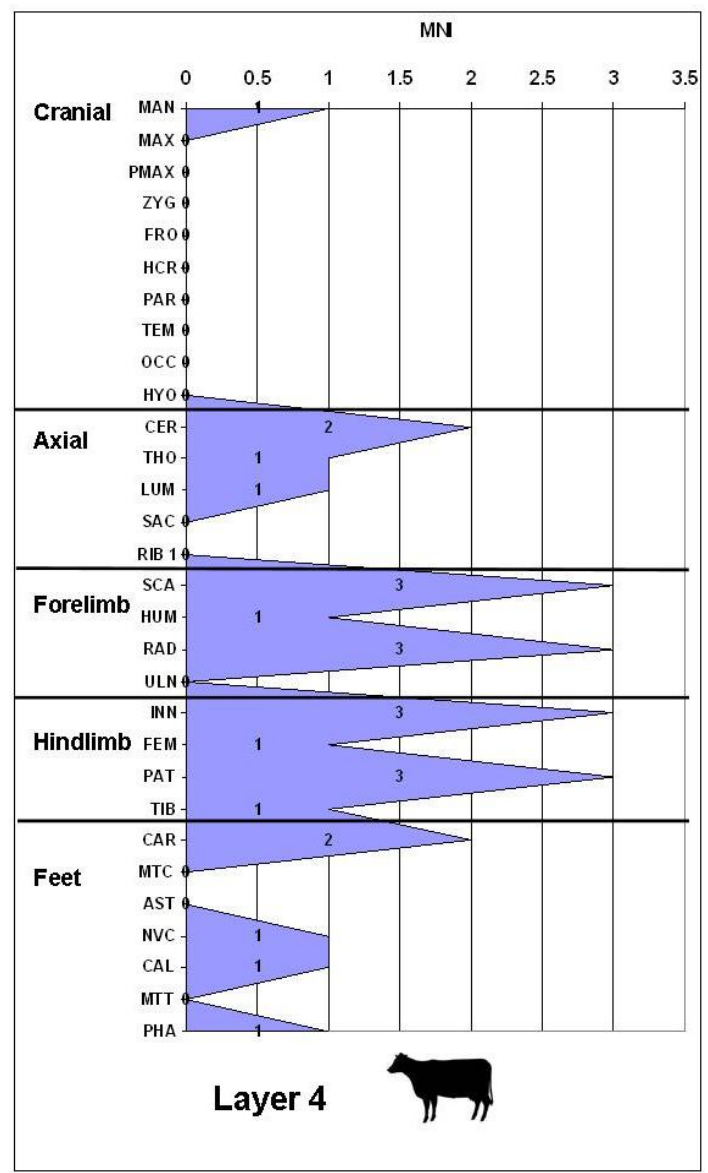


The remaining species in the DKG sample are represented by very small sample sizes and do not provide much data to identify consumption patterns. Pigs exhibit similar patterns to the sheep and cattle. The majority of the elements are from vertebral and appendicular regions, with only one cranial specimen represented by a premaxilla fragment. The lone bird specimen was a humerus fragment. The steenbok was represented by a variety of postcranial specimens suggesting that most if not all of the individual's carcass was brought to the Castle kitchen.

E. Sheep Sex: The DKG faunal sample does not provide any measurable acetabulae to determine sex.

F. Butchery: Layer 4 provides the best information concerning butchery at DKG. Chop and cut marks are present in moderate frequencies, and they are relatively equally represented (table 4.8). Scrape marks are very rare compared to chops and cuts.

Butchery marks are identified at regular, predictable locations on the bones (figure 4.9). Chopping was used as a primary processing stage to divide the carcass into manageable portions. Chops are aimed at separating the limbs from their girdles, as well as into upper and lower limb segments. They also divided the vertebral column transversely into shorter segments according to the specific vertebrae as well as sagitally into left and right halves. Cut marks are most commonly observed on the upper limb bones, the humeri and femora. The girdles, the scapulae and innominates, also contain cut marks, and may be related to cuts on the humeri or femora. Most of these cuts are found along major muscle attachments and are therefore aimed at removing these large portions of meat. 
Cooking evidence is also identified in moderate amounts (table 4.8). Burning is always present in isolated parts of the bones including chopped edges and do not incorporate the entire bone (figure 4.10). Burning is also commonly identified on the interior surfaces of long bone shaft cylinders while the exterior visually retained original bone conditions (figure 4.11). This suggests that the bones were chopped so that the internal marrow cavities were exposed to flame or high heat while the exterior was protected by meat. The burned portions are generally a gray-purple color that may fade to a white around the fringes. This purple color has been determined to be the result of burning fresh bones while the bones contained high amounts of grease or meat (David 1989: 74). Burning on exterior surfaces of the bones occurred in confined, isolated portions of the bone in locations where bone may have been exposed or the meat was thin enough not to provide protection to the bone. Long bones were burnt at fragment edges and internal medullary cavities suggesting that these portions were exposed to the flame or high heat.

Table 4.8. The frequencies of butchery and burning in each Layer.

\begin{tabular}{|l|c|c|c|c|c|c|c|c|c|c|}
\hline & \multicolumn{3}{|c|}{ burning } & \multicolumn{2}{c|}{ chop } & \multicolumn{2}{c|}{ scrape } & \multicolumn{2}{c|}{ sawn } \\
\cline { 2 - 12 } & $\mathbf{n}$ & $\mathbf{\%}$ & $\mathbf{n}$ & $\mathbf{\%}$ & $\mathbf{n}$ & $\mathbf{\%}$ & $\mathbf{n}$ & $\mathbf{\%}$ & $\mathbf{n}$ & $\mathbf{\%}$ \\
\hline Layer 1 & 2 & 11.76 & 2 & 11.76 & 0 & 0.00 & 0 & 0.00 & 0 & 0.00 \\
\hline Layer 2 & 1 & 7.14 & 4 & 28.57 & 0 & 0.00 & 0 & 0.00 & 1 & 7.14 \\
\hline Layer 3 & 2 & 6.06 & 7 & 21.21 & 1 & 3.03 & 0 & 0.00 & 1 & 3.03 \\
\hline Layer 4 & 55 & 6.82 & 89 & 11.04 & 69 & 8.56 & 3 & 0.37 & 0 & 0.00 \\
\hline
\end{tabular}


Figure 4.9. Locations of chop, cut, and scrape marks on sheep from DKG Layer 4. Butchery marks on the ribs are not illustrated (red = chops; blue = cut marks). (templates by Cutureau 1996).

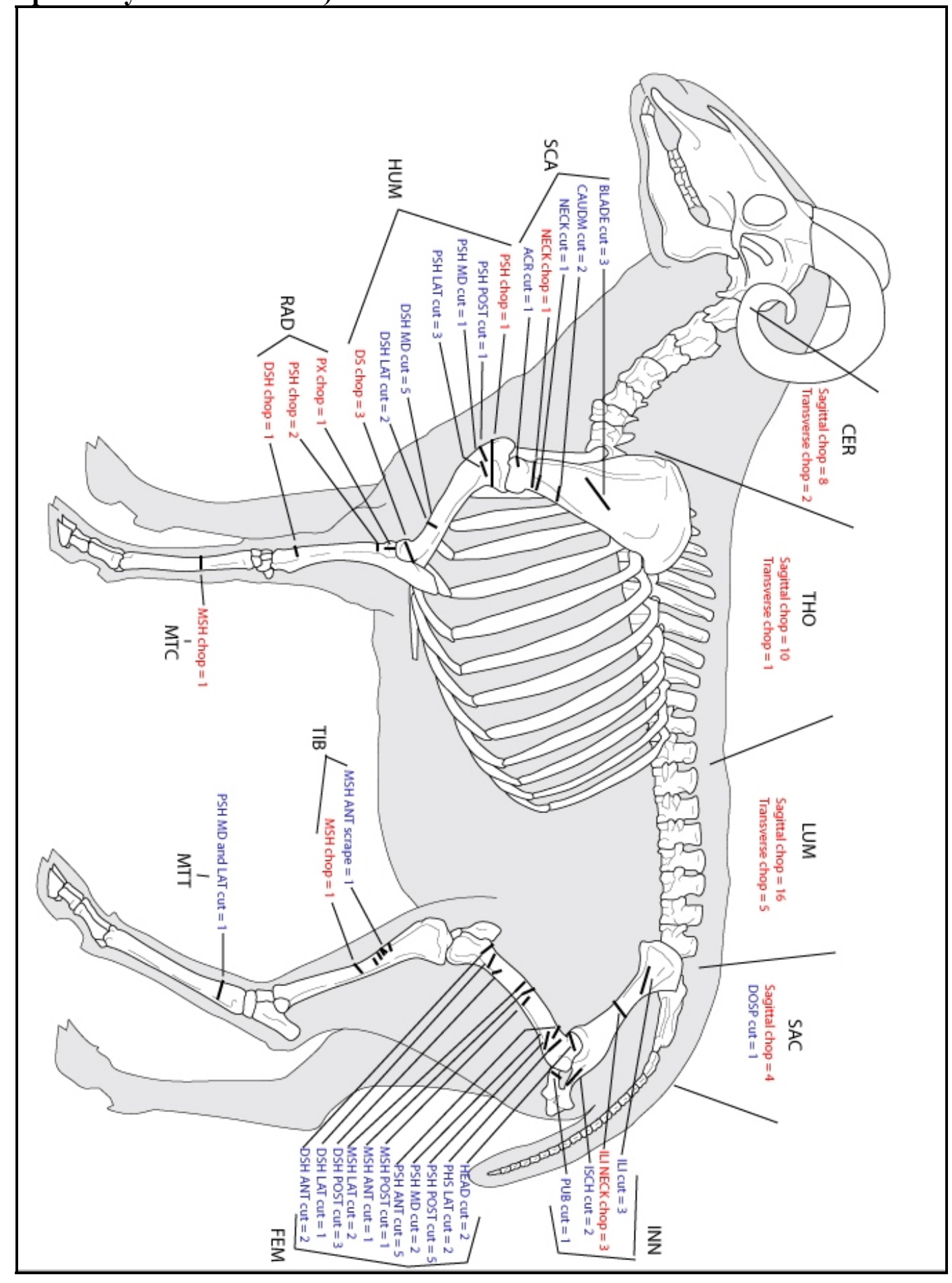


Figure 4.10. Sheep proximal femur showing localized burning.

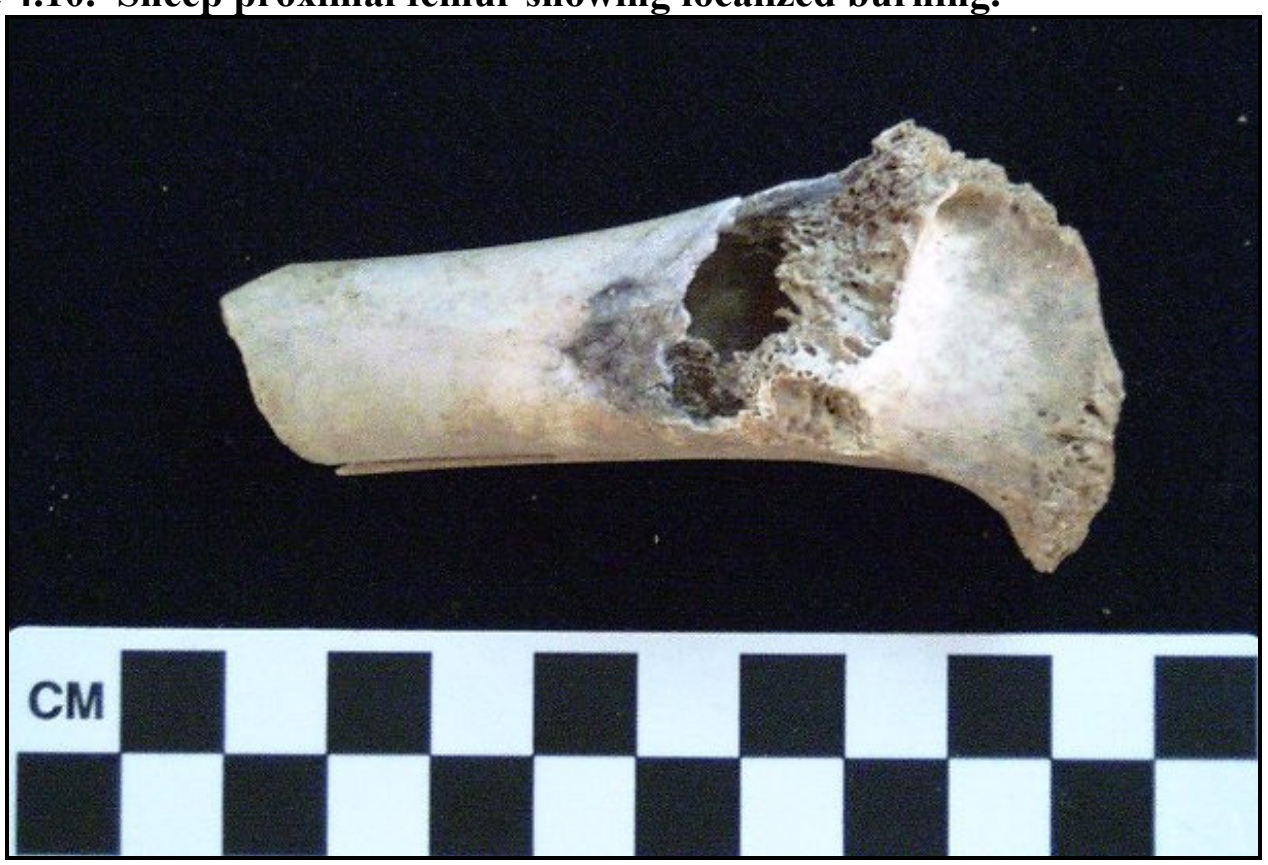

Figure 4.11. Cattle proximal tibia showing the burning on the interior shaft.

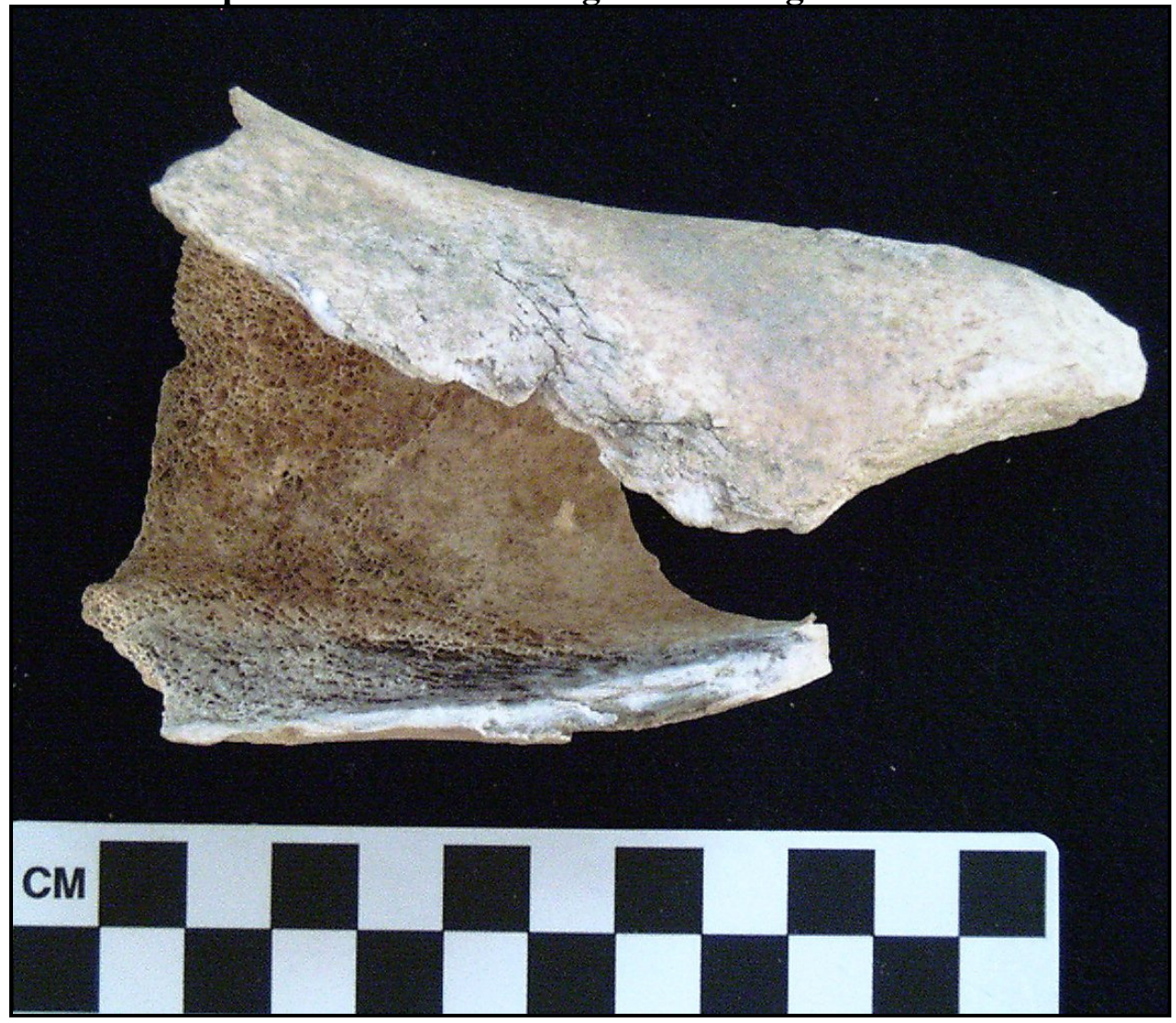




\section{DISCUSSION}

The DKG fauna comes from fills that probably include the residues of the meat prepared by the nearby kitchens (Mentzel 1921: 63-64, 104-106; 1925: 16). The fauna from DKG provides information about butchery, cooking, and portions of the carcasses that were utilized by the kitchens and consumed by the people within the Castle.

The DKG fauna reveals information about how the Castle kitchens prepared meat for the VOC servants. Though it is difficult to identify if certain body parts were preferred, skeletal element profiles from all species suggest that most of the carcasses, with exception of the head and feet, were prepared and ultimately deposited in DKG. This dominance of postcranial elements contrasts with the northern part of the Moat, which is heavily dominated by cranial elements (comparison with the Moat FG31 A-2: Mann-Whitney $\mathrm{U}=1049.0, P<0.001)$. Sheep remains suggest that the hind quarter, represented by the femora -- a high meat yield part, was possibly more favored, though small sample sizes make these interpretations tentative.

The completeness of the DKG bones and the high incidences of characteristic burning show that roasts were a common item in the cuisine. Burning has been determined to have occurred while the bones still contained meat (David 1989: 74). The bone fragments from DKG measure to be amongst the largest and most complete of all the Cape sites sampled (see Chapters 3, 5, 6, 7), and along with the high incidence of burning suggest that roasts were major components of the Castle population's diet.

Though sheep dominate the DKG fauna through MNI, cattle provided substantial amounts of meat with pigs providing smaller amounts. Skeletal element frequencies suggest that nearly complete carcasses were processed in the kitchens with exceptions of 
the crania and feet, which provide little meat in terms of poundage (Huelsbeck 1991: 6669; Lyman 1977: 69, 1979: 536-541, 1987: 61-65; Schulz and Gust 1983: 50). The importance of beef in the DKG fauna is contradictory to the historical documents which state that mutton is the mundane staple of the Cape diet, where Mentzel (1925: 101) states "mutton forms the staple diet; excellent mutton, undoubtedly, and made more appetizing by being prepared in a variety of ways, but - still mutton." Cape beef was considered to be of poor quality and was not in much demand by the wider community (Mentzel 1925: 84, 101). While beef was occasionally regarded as a break from the mundane mutton, but the DKG fauna suggest it was a predominant meat source within the Castle. It is possible that beef was reserved to provision the garrisons including the soldiers and other servants present in the Castle. 


\section{CHAPTER FIVE: The Granary (F2)}

\section{HISTORY}

The Castle of Good Hope, as it was originally designed, was potentially vulnerable to cannon fire if an enemy was able to position themselves on the slopes of Devil's Peak. This exposure was a constant concern, and in 1685, visiting Commissioner Hendrick Adriaen van Rheede ordered that a dividing wall be built in the courtyard of the pentagonal Castle (Fitchett 1996: 144; Johnson-Barker 2003: 34, 64). This dividing wall, known as the Kat wall, was extended from the Catzenellenbogen bastion to the middle of the curtain wall between the Leerdam and Oranje bastions. Constructed between 1685 and 1691, the wall was built perpendicular to firing positions on Devil's Peak and subsequently divided the Castle into two irregular courtyards (Fitchett 1996: 144).

The construction of the Kat wall accommodated more structures within the Castle interior. Among these was a long, vaulted Granary in the inner courtyard. In 1695, Simon van der Stel wrote to Batavia discussing his personal views on grain storage, where "it may be that wheat at the Cape will likewise be better preserved from destruction in vaults here, that on lofts, as in Surat and Bengal where it is customary to bury wheat in pits underground" (Fitchett 1996: 163). A letter sent by Van der Stel to Amsterdam stated that the Italian styled, vaulted grain cellars had already been erected along the Kat wall by 1694 and that they were air-tight (Fitchett 1996: 164).

After construction, the Granary on the Kat wall did not receive much attention in the documentary history. A letter in 1704 stated that the Granary was to be turned into a bombproof quarters for VOC soldiers due to a threat of conflict while temporary grain 
stores were to be built at this time (Fitchett 1996: 165). There is no evidence that these orders were carried out or that any VOC servants had ever inhabited the Granary.

\section{ARCHAEOLOGY}

The Granary was the second archaeological site identified by the ACO within the F Block (F2), and it was excavated during renovations to the Castle in the late 1980s (figure 5.1). After initial surface scrapings, a series of $1 \mathrm{x} 1$ meter units were excavated by trowel throughout the Granary. In addition, a deep trench and two smaller units were excavated in the eastern end of the vaulted room (Hall n.d.b.: 6). The names Granary and F2 are used synonymously by the archaeologists, but the deposits, as will be discussed below, extend deeper than the structures and therefore includes deposits older than those within the Granary.

Hall (n.d.a: 1, 4-5; n.d.b: 12; 1992: 390; 1999: 196) argued that slaves or possibly Khoekhoe servants inhabited secluded rooms such as the Granary before a formal slave quarters was constructed. He hypothesized these servants would have lived in these nearby corners in order to be available to serve the Company officials. This believed servant occupation within the Granary has not been substantiated by the documentary record. According to the field notes, the excavators seemed to have approached the excavation at the Granary with an agenda to find the material remains of slave occupation before a trowel was placed in the deposits. The notes from the early period of the Granary excavation repeatedly record interpretations of the recovery of mammal bones, fish bones, shell, and low quantities of porcelain as the possible residues of slaves or Khoekhoe (Gribble 1988: 5-6, 7-8, 11, 21; Woodborne 1988: 4-5). Later, Hall's agenda 
to identify slaves at the Cape influenced the resulting laboratory analyses of artifacts

(Klose 1993: 120) and fauna (Thackeray 1989).

Figure 5.1. Aerial photograph of the Castle illustrating the location of the F2 Granary excavation, plus the locations of the other Castle excavations presented in this thesis (Photograph by Hoberman 1997).

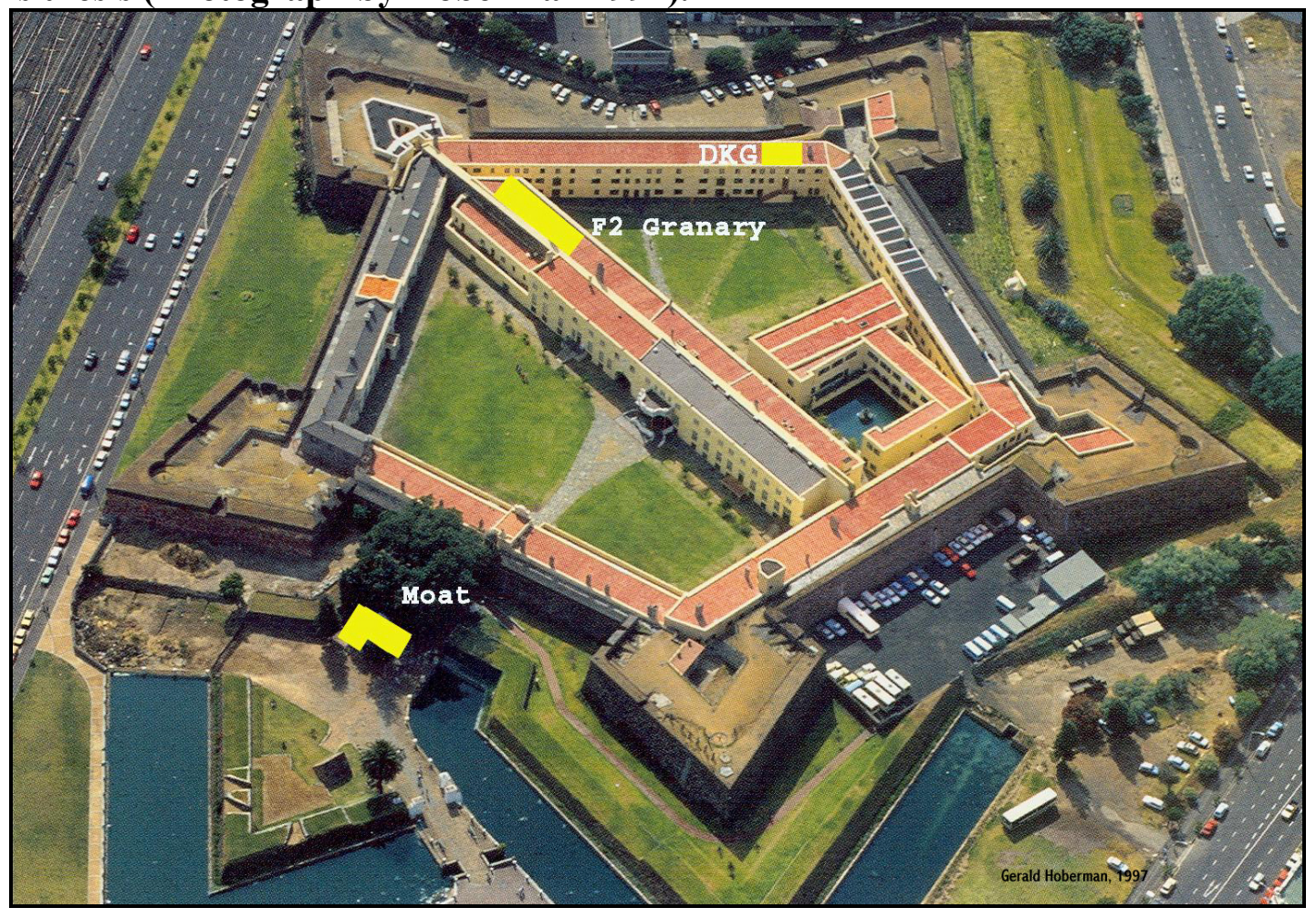

A. Stratigraphy: The Granary stratigraphy was presented as seven broader Phases

developed through the aggregation of the more discrete sediment units (Gribble 1988: 2936; Hall n.d.b: 7-8). This aggregation was used to form larger samples to better describe the overall sequence of events in the room as it was visible in the over 2 meters deep stratigraphy. Photographs suggest that the more discrete units were often platy, varying between parallel and slightly sub-parallel bedding planes (figure 5.2) (Waters 1992: 34). The units were generally of uniform depth across its extent suggesting they were placed as efforts to level the ground surface. Though the discrete stratigraphic units often 
extended across broad lengths, they were lens-like in the sense that they were rarely

continuous across the entire Granary structure, further suggesting that the

Figure 5.2. Section photograph illustrating the parallel, platy strata with abrupt stratigraphic breaks (Photograph by ACO).

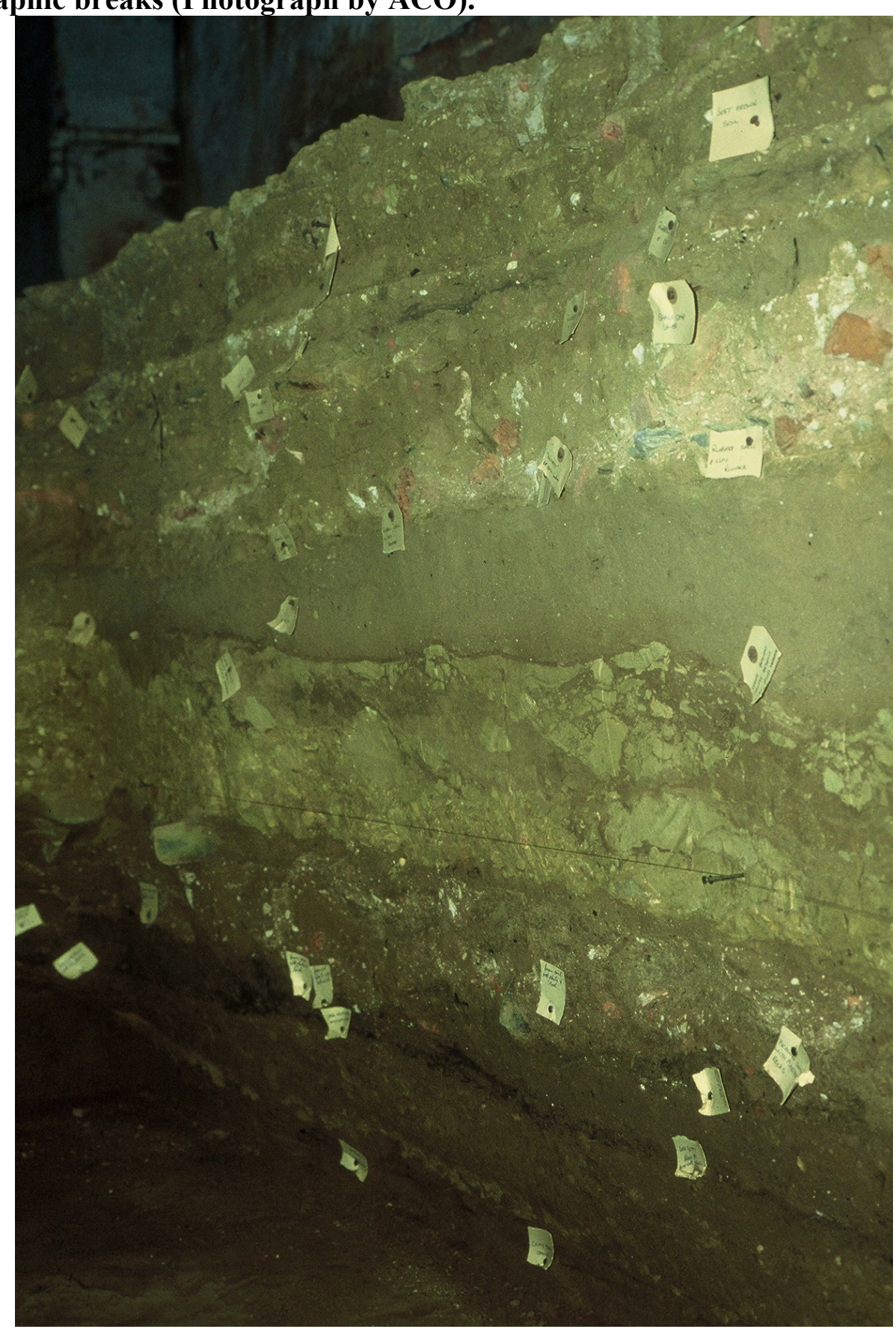

units were deposited as intermittent fills (Hall n.d.b: 3). Gleaned from the vague field notes and section photographs, the stratigraphic breaks were abrupt, where "abrupt 
contacts coincide with depositional bedding planes that formed as a result of changes in local depositional conditions" (Waters 1992: 70). This suggests that the sediment units were deposited and buried relatively quickly since they were not exposed long enough for characteristically gradated soil profiles to develop between depositional episodes (Schiffer 1987: 200-201; Waters 1992: 40). Successive sediment units were repeatedly reported to be variable in thickness, inclusions, and color, indicating that these units were fills brought into the Granary from various sources, and they are not the result of continuous use of the structure. Occasional compacted surfaces show that ground raisings were episodic so that the surface can be compacted by exposure (Peyddoke 1961: 112; Schiffer 1987: 205). After introduced fills were leveled, they would settle over time, which would have then required further dumping episodes to raise the ground levels. An overview of the material culture recovered from these fills further supports these interpretations.

The following are stratigraphic summaries of each phase as presented by Hall (n.d.b.: 7-8, 15) and the excavators (Gribble 1988: 29-36):

1. The Granary deposits were sealed off by a raised, wooden floor that Hall (n.d.b: 15) believed to be constructed about 1820. However, as presented below, the last fills in the Granary occur in the mid-eighteenth century. This would assume no artifactual incorporation or fillings for about 75 years.

2. Phase 7: The final period of fill in the Granary. This phase contained a total of 13 units. A rubble fill made up the base, while the upper sediment units included fills of various degrees of compaction. Phase 7 also contained a pair of 
depressions speculated to be "pits" and another ash scatter that Hall (n.d.b: 8; Gribble 1988: 35-36) together interpreted as habitation evidence.

3. Phase 6: Strictly designated as the construction of brick bin walls to subdivide the Granary, and it did not consist of any sediment units (Gribble 1988: 35; Hall n.d.b: 8$)$.

4. Phase 5: Consisted of five units and has been interpreted as reoccupation of the Granary after completed repairs to the Kat wall. Phase 5 included various rubble fills between hard brown occupation "floors" and another ash scatter “hearth” Hall (n.d.b: 7; Gribble 1988: 35) interpreted as living surfaces.

5. Phase 4: The re-excavation of the Kat wall for an undocumented repair. Phase 4 included 13 discrete units (Gribble 1988: 34; Hall n.d.b: 7).

6. Phase 3: Interpreted as occupation debris against the Kat wall after the Granary was completed, and the only deposits actually related to the Granary (Gribble 1988: 31; Hall n.d.b: 7). This phase included 27 individual units that were highlighted by repeated fills containing rubble, plaster, and clays. A pair of charcoal scatters was interpreted as hearths, though no heat altered soils were identified around the scatter suggesting the fires were not burnt in place (Gribble 1988: 20-21, 32-33; Hall n.d.b.: 7; Woodborne 1988: 23). Field notes often recorded common ash and charcoal deposits throughout the Granary as being inclusions within sediments, in contrast with isolated, in situ hearths (Gribble 1988: 22, 26, 27, 28; Jacky 1988: 5-9; Woodborne 1988: 10). Ash and charcoal dumps made up large proportions of the deposits from the Moat and DKG where no on-site habitation was inferred by the excavators. These were likely scatters of 
ash and charcoal from brazier and fireplace cleanings into the Granary as additional fills instead of $i n$ situ burning episodes.

7. Phase 2: The fill of the builder's trench dug for the Kat wall's construction and consisted of four units (Gribble 1988: 31; Hall n.d.b: 7). It dates between 1685 to1691 when the Kat wall was being erected, and this builder's trench would have been filled immediately when the wall's foundations were emplaced. These units in the Kat wall's trench would have been redeposited and were not the result of primary occupation (Gribble 1988: 31).

8. Phase 1: The lowermost and earliest level of the Granary deposits. It was cut into by the construction of the Kat wall and therefore predates the leveling of the ground for the Castle in 1665 and the wall's construction from 1685 to 1691. Phase 1 consisted of 18 discrete units that had high morphological variability. Various depositional processes were identified including units described as a stratum graded by water filtration, a gritty buried A horizon, thick fills with plaster concentrations, and an extensive yellow clay layer (Gribble 1988: 29-31; Hall n.d.b: 6-7).

The details of the stratigraphy reflect repeated filling and leveling episodes instead of accumulation from successive occupations. The need to keep the Granary dry would have been a priority since moisture would promote the decay of the valuable grains stored there, which was a relevant concern of Simon van der Stel when the Granary was designed (Fitchett 1996: 163). This may explain why the Granary fills are earlier than the deposits of other nearby sites such as the Toilet Block, F1, and F3 
excavations (Hall n.d.b: 9-10, 13). The Granary is located near the beach end of the Kat wall, meaning that the water table would have been shallower and more problematic than further inland as was encountered during the Moat's construction (Fitchett 1996: 143; Halkett 1991: no pg). These water table issues were also addressed by numerous drainages excavated by the ACO near the B Block, which is located at the opposite end of the Kat wall from the Granary (Halkett 1991: no pg).

B. Material Culture: The majority of the material recovered from the Granary was architectural residues consisting of brick, mortar, and plaster fragments. Tobacco pipes and ceramics were the only artifacts analyzed in detail, and they provided information about depositional processes in the Granary.

C. Tobacco Pipes: Tobacco pipes provided dating information for the Granary deposits. Mean bore diameters from the tobacco pipestems showed that the deposits were deposited sequentially with Phase 1 as the earliest fill and Phase 7 as the latest (Hall n.d.b: 9-13) (table 5.1). Tobacco pipebowl heelmarks provided additional dating information that supports the pipestem data. Phase 1 contained heelmarks that were all being manufactured before 1690, which supported the fact that Phase 1 was capped by the construction of the Kat wall. Phase 3 contained a high proportion of seventeenth century heelmarks with some that were also manufactured in the early eighteenth century. Phases 4,5 , and 7 contain heelmarks that show the deposits spanned the first half of the eighteenth century (Hall n.d.b: 13).

Yates et al. (n.d.:15-16, 21, 23, 26) also analyzed the Granary's pipestem bore diameters and their data can be used to test Hall's (n.d.b.: 9-13) results (table 5.1). Though Yates et al.'s mean diameters were slightly larger than those calculated by Hall, 
they still showed that each Phase was deposited in sequential order from oldest to most recent.

Table 5.1. Hall's (n.d.b.: 9) and Yates et al.'s (n.d.: 23) pipestem bore sample sizes and mean diameters.

\begin{tabular}{|l|c|c|c|c|}
\hline & \multicolumn{2}{|l|}{ Hall } & \multicolumn{2}{l|}{ Yates et al } \\
\hline PHASE & $\mathbf{n}$ & $\begin{array}{c}\text { mean } \\
(\mathbf{m m})\end{array}$ & $\mathbf{n}$ & $\begin{array}{c}\text { mean } \\
(\mathbf{m m})\end{array}$ \\
\hline Phase 7 & 339 & 2.25 & 340 & 2.38 \\
\hline Phase 5 & 197 & 2.28 & 203 & 2.44 \\
\hline Phase 4 & 169 & 2.38 & 173 & 2.53 \\
\hline Phase 3 & 214 & 2.51 & 215 & 2.65 \\
\hline Phase 1 & 168 & 2.56 & 161 & 2.70 \\
\hline
\end{tabular}

D. Ceramics: The Granary ceramic assemblage was analyzed by Klose (1993: 113), who described it as a complete unit and noted that there was little change in ware type, decoration, or manufacturing date throughout the entire sequence. The fragmentation was extremely high which hindered the identification of vessel types, but due to the small quantity of ceramics present in the deposits, individual fragments were often assessed as individual vessels by Klose $(1993: 113,115)$. Klose $(1993: 114,118)$ suggests that since all ceramic types were in production by the end of the seventeenth century, the fills could have been deposited in as little as 20 years. She was able to detect that the Granary fills were likely secondary deposits brought in from other locations around the Castle, where "it could be argued that the general characteristics of the ceramics in each phase, especially in the lower levels, indicate that all the sherds are in secondary context deposits, namely, high fragmentation, high [Minimum Numbers of Vessels] in relation to sherd count, few cross-mends and a low reconstruction of broken vessels" (Klose 1993: 120).

The ceramics were mainly imported from Europe, Far East Asia, India, and the Middle East, while a few of the vessels were made at the Cape (Jordan 2000: 145-151; 
Klose 1993: 114). Chinese export porcelain and European coarse earthenwares are the most common ware types, with each making up $23 \%$ of the vessels represented in the Granary (Klose 1993: 115-116). Asian wares are present in the Granary assemblage in ratios of 2:3 compared to European or locally produced wares, which is lower than the eighteenth century Cape site of Elsenburg at 4:1 (Klose 1993: 118). The Castle was a military and administrative site where greater proportions of utilitarian wares should be expected given that they were used in food storage and preparation for a large number of VOC employees.

The upper portion of Phase 7 included four fragments that represent four different nineteenth century British ceramic vessels, all which postdate the rest of the Granary ceramics by $100-120$ years. These very small examples of British ceramics are likely later intrusions that fell through gaps of the wooden floor (Klose 1993: 115, 118).

\section{THACKERAY'S FAUNAL RESULTS}

This chapter presents data from a reanalysis of the Granary fauna which was originally performed by Francis Thackeray (1989) and ultimately formed the foundation for Hall's (n.d.a: 3; 1992: 390; 1993: 188; 1999: 196) slave occupation interpretation. Though the fauna was initially analyzed as separate Phases, Thackeray's overall conclusions were based upon aggregating all of the fauna from the Granary (table 5.2). His aggregation of the entire Granary deposit assumed no changes in deposition or behavior through time from the second half of the seventeenth century Phase 1 through the mid-eighteenth century Phase 7. This is immediately problematic, since Phase 1 was deposited before the Kat wall and the Granary were constructed, and cannot represent 
slaves occupying the Granary. In addition, Thackeray (1989) and Hall (n.d.a: 3; 1992:

390; 1993: 188; 1999: 196), assumed that all the bones represented slave food waste dumped in a primary context and were therefore directly reflective of the animals consumed at the immediate site.

According to Thackeray (1989), domestic stock dominated the Granary fauna with sheep and cattle making up $60 \%$ of the NISP in the sample. Sheep outnumbered cattle in a ratio of $3: 1$ for the total sample. Phase 1 showed a ratio of $2: 1$, while Phase 7 showed a ratio of $2.5: 1.41 \%$ of the sheep postcranial specimens were juvenile, though this percentage is only from ageable bone fragments. Thackeray identified other taxa including domestic pig (Sus scrofa), an unidentified small bovid, an unidentified rabbit, Cape hyrax (Procavia capensis), an unidentified rodent, and some tortoise (see table 5.2).

Where skeletal part representation is concerned, high proportions of teeth and few hindlimb fragments suggested that the Granary occupants were lower class people with limited access to meaty portions of the carcass. He also reported that adult specimens were more heavily represented by forelimb elements, which could be accounted for by denser distal humeri and proximal radii fragments that would have expectedly survived many taphonomic processes. Juvenile specimens were most often represented by distal radii, a late fusing epiphysis (Thackeray 1989: 1-2). His MNI calculations do not consider staggered fusion ages for different epiphyses.

Thackeray presented little taphonomic information. The crania from sheep and cattle were described as being highly fragmented, and this fragmentation was explained as slaves breaking the skulls open for the brain. Additionally, Thackeray (1989: 2) 
estimated that less than $1 \%$ of the sample was burnt, though he stipulated that burning was not directly counted.

Table 5.2. Thackeray's (1989) MNI by Phase.

\begin{tabular}{|l|r|r|r|r|r|r|r|c|}
\hline & \multicolumn{1}{|c|}{ P7 } & \multicolumn{1}{|c|}{ 66 } & \multicolumn{1}{c|}{ 55 } & \multicolumn{1}{|c|}{ 4 } & \multicolumn{1}{c|}{ P3 } & \multicolumn{1}{c|}{ P2 } & \multicolumn{1}{c|}{ 11 } & P1-7 \\
\hline Sheep adult & 3 & 0 & 4 & 3 & 2 & 1 & 3 & $\mathbf{1 6}$ \\
\hline Sheep juv & 2 & 0 & 5 & 1 & 1 & 1 & 1 & $\mathbf{1 1}$ \\
\hline Cow adult & 2 & 0 & 1 & 1 & 1 & 1 & 1 & $\mathbf{7}$ \\
\hline Cow juv & 0 & 0 & 0 & 0 & 1 & 0 & 1 & $\mathbf{2}$ \\
\hline Pig & 1 & 0 & 1 & 0 & 1 & 0 & 0 & $\mathbf{3}$ \\
\hline Small bovid & 0 & 0 & 0 & 1 & 1 & 0 & 1 & $\mathbf{3}$ \\
\hline Lepus sp & 0 & 0 & 0 & 1 & 0 & 0 & 1 & $\mathbf{2}$ \\
\hline Cape hyrax & 0 & 0 & 0 & 0 & 0 & 1 & 1 & $\mathbf{2}$ \\
\hline Rodent & 1 & 0 & 0 & 0 & 0 & 0 & 1 & $\mathbf{2}$ \\
\hline Tortoise & 0 & 0 & 0 & 1 & 1 & 1 & 0 & $\mathbf{3}$ \\
\hline Total & $\mathbf{9}$ & $\mathbf{0}$ & $\mathbf{1 1}$ & $\mathbf{8}$ & $\mathbf{8}$ & $\mathbf{5}$ & $\mathbf{1 0}$ & $\mathbf{5 1}$ \\
\hline
\end{tabular}

\section{FAUNA RESULTS}

My analysis selected Phase 1 because it was the earliest deposit in the Castle (preKat wall 1665-1685/91), and Phase 7 because it was explicitly interpreted by Hall as in situ occupation debris of slaves. The sample sizes are presented in table 5.3.

Table 5.3. Sample sizes (NISP) for Phase 1 and Phase 7.

\begin{tabular}{|l|r|r|r|}
\hline & Bone (n) & $\begin{array}{c}\text { Isolated } \\
\text { Teeth*(n) }\end{array}$ & $\begin{array}{c}\text { Total } \\
\text { (n) }\end{array}$ \\
\hline Phase 7 & 2087 & 81 & 2168 \\
\hline Phase 1 & 883 & 43 & 926 \\
\hline
\end{tabular}

A. Taphonomy: The bones were modified by a variety of means. The bones were highly fragmented (figures 5.2 and 5.3), with average lengths and widths smaller than those from most units in the well-preserved Moat and DKG contexts. The average circumference of size 2 long bone shaft fragments from the Granary were only about 21\% to $26 \%$ complete for Phases 1 and 7, respectively (table 5.4), a much lower circumference completion than the long bones from well-protected contexts such as the Moat (see Chapter 3). The bone fragment sizes as well as long bone shaft completeness for size 2 
mammals in the Granary are more comparable to those from Elsenburg (see figures 5.3 and 5.4).

Figure 5.3. Mean measures of size 2 bone fragments from all sites.

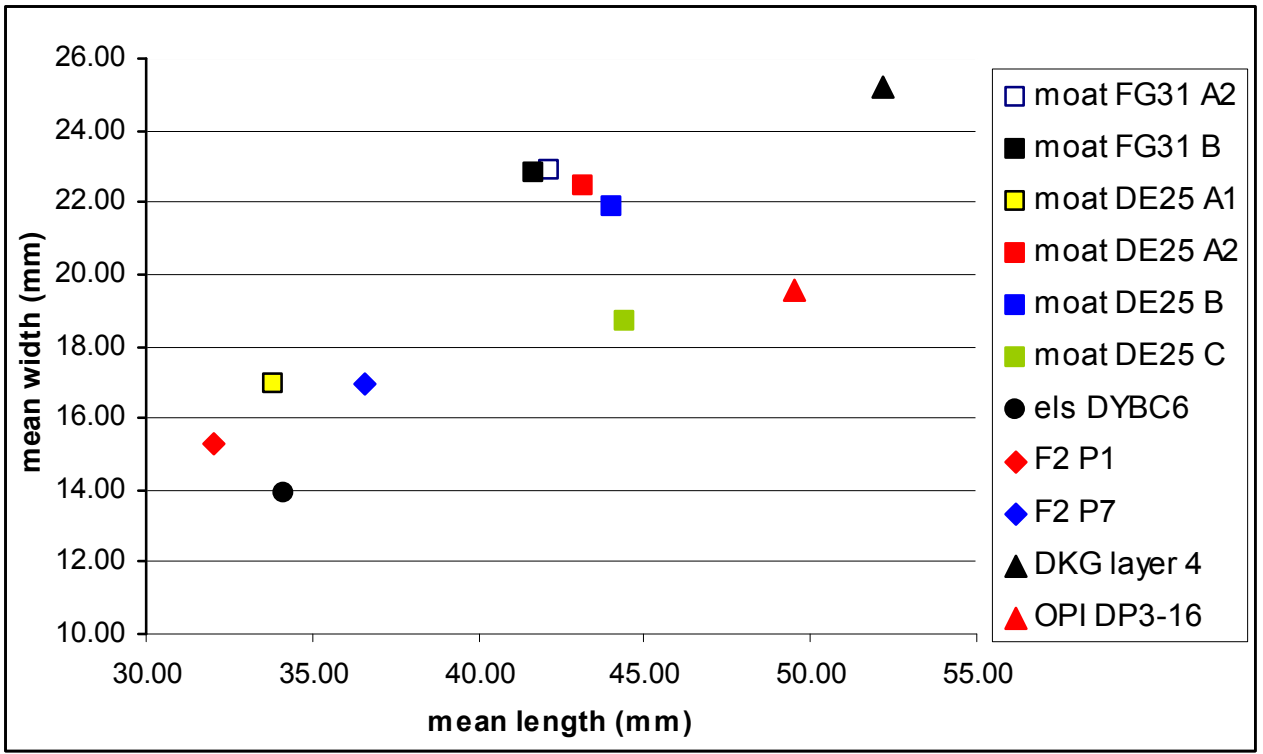

Figure 5.4. Mean measures of size 3 bone fragments from all sites.

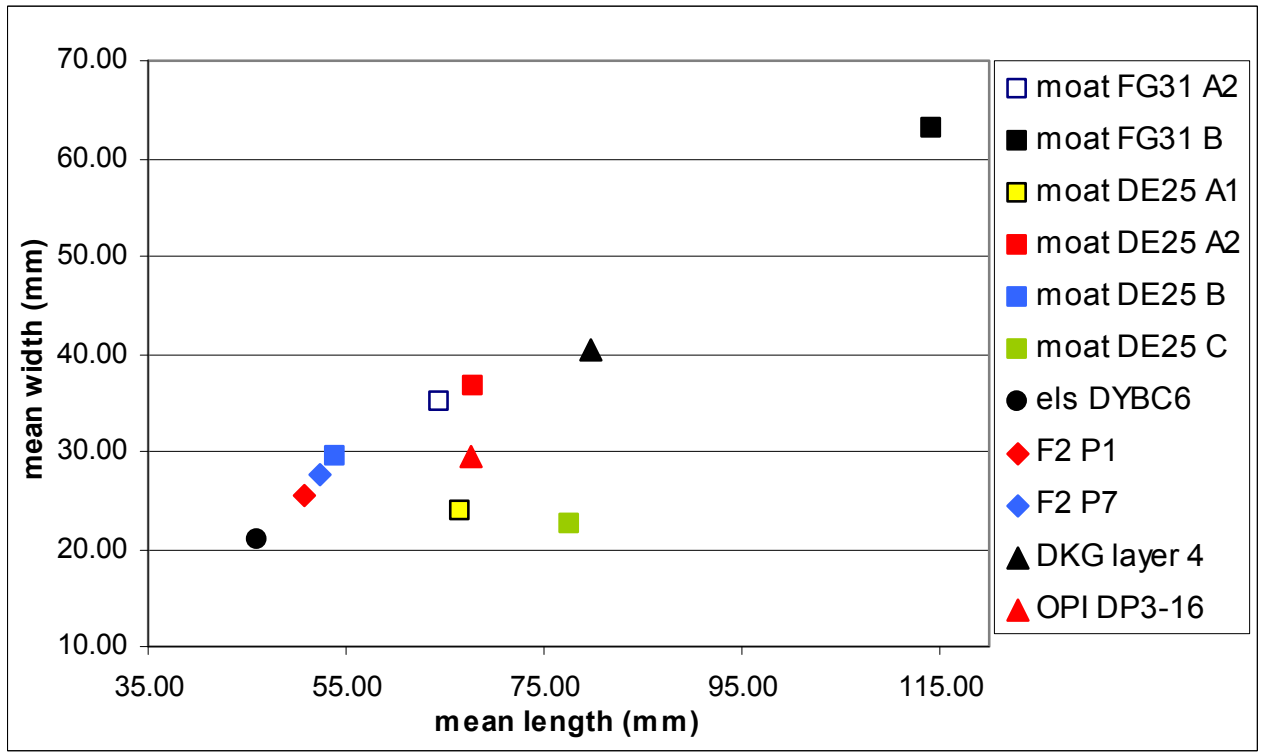


Table 5.4. Measures of long bone completeness, not including the ulna due to its lack of a medullary cavity along with the shaft.

\begin{tabular}{|l|l|r|r|r|r|}
\hline \multicolumn{2}{|l|}{} & $\begin{array}{c}\text { LBN } \\
\text { circum }\end{array}$ & \multicolumn{1}{c|}{$\begin{array}{c}\text { EPI } \\
\text { (NISP) }\end{array}$} & $\begin{array}{c}\text { shaft } \\
\text { (NISP) }\end{array}$ & $\begin{array}{c}\text { ratio } \\
\text { (shaft/EPI) }\end{array}$ \\
\hline size 2 & Phase 7 & 0.26 & 59 & 536 & 9.08 \\
\hline & Phase 1 & 0.21 & 31 & 218 & 7.03 \\
\hline \multicolumn{7}{|l|}{} \\
\hline size 3 & Phase 7 & 0.19 & 1 & 11 & 11.00 \\
\hline & Phase 1 & 0.17 & 4 & 37 & 9.25 \\
\hline
\end{tabular}

Both Thackeray (1989: 2) and Hall (1992: 392) speculated that the high degree of fragmentation in the Granary was related to heavy bone processing by low status people trying to extract as many nutrients as possible. Their interpretation did not include any analysis of marks on the bone surfaces to detect the possible agents of fragmentation. The present analysis identified two main actors that may have participated in fragmenting the bones after deposition; either at the primary dump location or after the fills were relocated to the Granary. Abrasion was identified as the major modifier to bone surfaces (table 5.5). Possible sources of the abrasion damage could be trampling and sediment movement and compaction around the bone fragments as they were moved and then redeposited in the Granary. Highly abrasive inclusions such as brick, mortar, plaster, and stones were common in the Granary fills. Abrasion marks were observed on $19.82 \%$ $(n=175)$ of the total bone sample from Phase 1 and $19.60 \%(n=409)$ from Phase 7 . Long bone and especially rib fragments of size 2 and 3 mammals showed the greatest proportion of abrasion marks, due to their smooth, dense outer surfaces that clearly display these marks.

Carnivores also modified the bone fragments, which denote exposure before being incorporated in the Granary fills (table 5.6). Their effects were relatively minor in Phase 1 with $3.51 \%(n=31)$ of all bone fragments exhibiting tooth marks. However, 
Table 5.5. Frequencies (\% of NISP) of abrasion damage observed on bone surfaces.

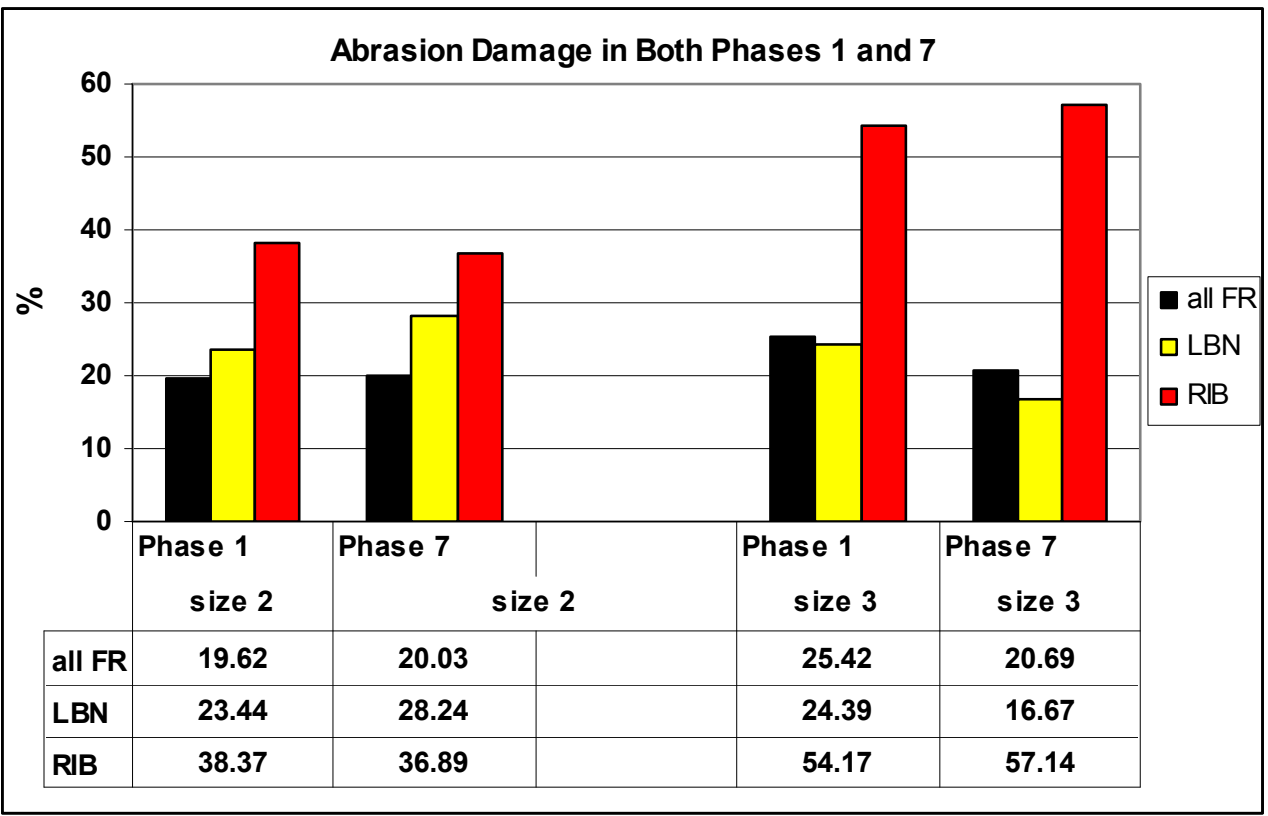

Phase 7 exhibited a greater carnivore involvement with $5.29 \%(n=106)$ of size 2 and $10.34 \%(\mathrm{n}=3)$ of size 3 bones fragments bearing tooth marks. When broken down to skeletal regions, long bones have even higher proportions of marks from carnivore scavenging. The less dense axial elements scavenged by carnivores may have been consumed completely and therefore do not provide comparable tooth mark frequencies (Bartram and Marean 1999: 25; Binford and Bertram 1977: 82; Blumenschine 1988: 498; Blumenschine and Madrigal 1993: 557; Blumenschine and Marean 1993: 282-289; Egeland et al. 2004: 349; Marean and Spencer 1991: 651-652; Marean et al. 1992: 106111; Munson and Garniewicz 2003: 411-412; Symmons 2005: 1697). Higher tooth mark proportions in more specific analytical categories might also be a product of smaller unidentifiable bone fragments deflating the percentages. In addition to the carnivore damage, rodent modification was observed on only one bone fragment from Phase 1 and 10 bone fragments from Phase 7. 
Table 5.6. Frequencies (\% of NISP) of carnivore damage observed on bone surfaces.

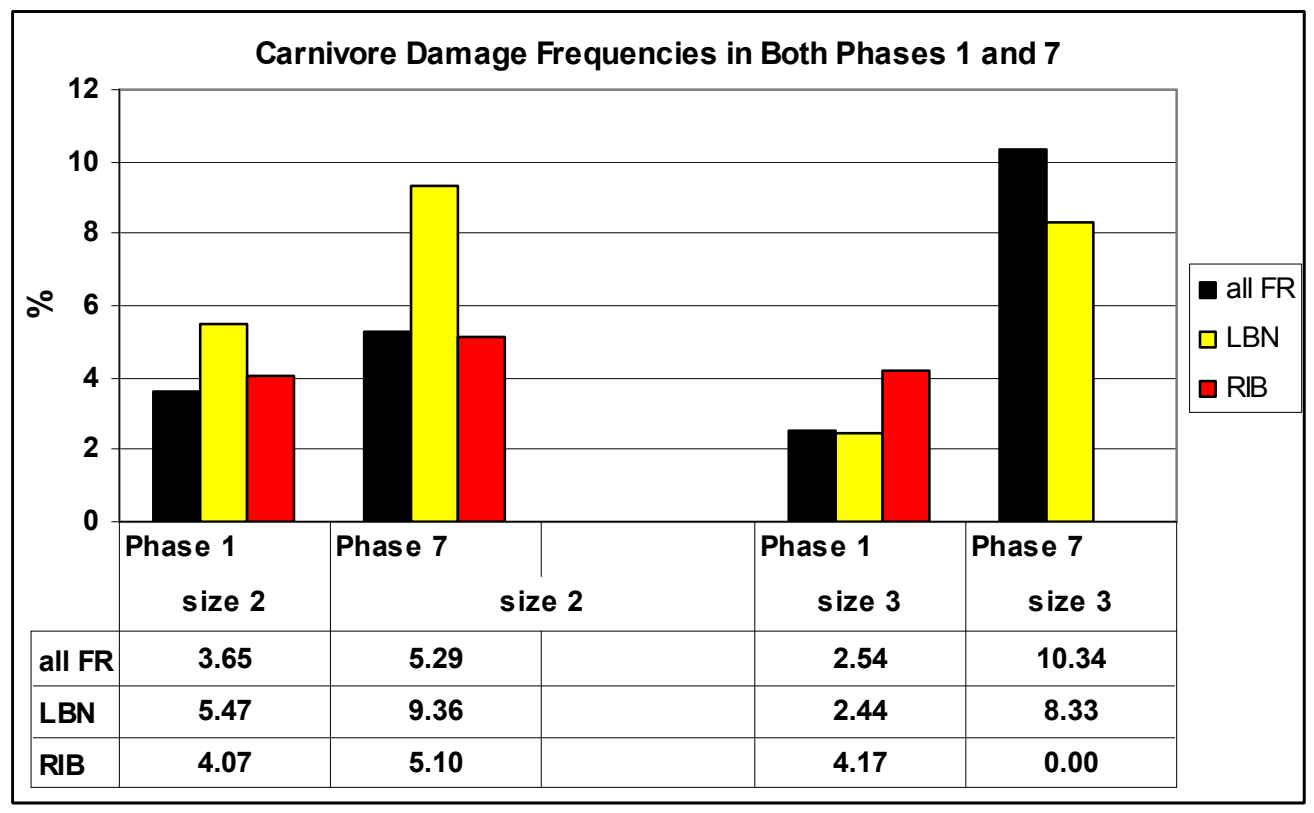

Butchery contributed to predepositional bone modification and fragmentation

(table 5.7). Chop marks were the most common butchery marks observed on $13.85 \%$ $(n=289)$ of the bone fragments in Phase 7 and $8.04 \%(n=71)$ of the bone fragments in

Phase 1. Phase 1 showed similar frequencies of chop and cut marks, while scrape marks were minimal in both Phases. Burning on these bones was limited to isolated spots at fragment ends or where meat may have been thin, exposing that part of the bone to the fire, while the remaining portions of the bone was protected. Interior shafts of long bones were often burnt, suggesting that the bones were chopped and then roasted with the marrow cavity exposed. Phase 1 contained burning traces on only $1.02 \%(n=9)$ of the bone fragments, as opposed to $5.80 \%(\mathrm{n}=121)$ of the Phase 7 bone fragments (table 5.7).

Table 5.7. Frequencies (\% of NISP) of butchery and cooking evidence.

\begin{tabular}{|l|r|c|c|c|c|c|c|c|c|c|}
\hline & \multicolumn{3}{|c|}{ burning } & \multicolumn{2}{c|}{ chop } & \multicolumn{2}{c|}{ cut } & \multicolumn{2}{c|}{ scrape } & \multicolumn{2}{c|}{ sawn } \\
\cline { 2 - 12 } & $\mathbf{n}$ & $\mathbf{\%}$ & $\mathbf{n}$ & $\mathbf{\%}$ & $\mathbf{n}$ & $\mathbf{\%}$ & $\mathbf{n}$ & $\mathbf{\%}$ & $\mathbf{n}$ & \% \\
\hline Phase 7 & 121 & 5.80 & 289 & 13.85 & 42 & 2.01 & 6 & 0.29 & 9 & 0.43 \\
\hline Phase 1 & 9 & 1.02 & 71 & 8.04 & 47 & 5.32 & 6 & 0.68 & 0 & 0.00 \\
\hline
\end{tabular}


The analysis of bone breakage patterns shows that while a majority of the bones were most likely broken relatively fresh, a large proportion show dry breaks (table 5.8). Both Phase 1 and Phase 7 exhibit similar depositional histories as shown through bone breakage patterns (Mann-Whitney $\mathrm{U}=43.0, P>0.05$ ). Though over $70 \%$ of the long bone fragments in each Phase show fresh, oblique fracture edges, the data also shows that a smaller portion $(14.82 \%)$ of the long bone fragmentation occurred after the bones were dry as shown by transverse or stepped fracture edges. Since no refits were possible, the bones were broken before they reached the Granary. Had the bones been fragmented by human smashing, trampling, or sediment compaction within the Granary, one would expect to have found higher proportions of dry bone fractures and refitted fragments.

B. Taxonomic Representations: The Granary deposits are dominated by sheep (Ovis aries) with smaller proportions of cattle (Bos taurus), pig (Sus scrofa), and wild species (table 5.9). The proportions of each species in the Phases 1 and 7 differ from those

\section{Table 5.8. Bone breakage patterns.}

\begin{tabular}{|c|c|c|c|c|c|c|c|c|}
\hline \multirow[b]{3}{*}{ Break type } & \multicolumn{4}{|l|}{ Phase 7} & \multicolumn{4}{|l|}{ Phase 1} \\
\hline & \multicolumn{2}{|l|}{ All FR } & \multicolumn{2}{|l|}{$\begin{array}{l}\text { LBN (size } \\
\text { 2/3) } \\
\text { breakage }\end{array}$} & \multicolumn{2}{|l|}{ All FR } & \multicolumn{2}{|l|}{$\begin{array}{l}\text { LBN } \\
\text { (size 2/3) } \\
\text { breakage }\end{array}$} \\
\hline & $\mathbf{n}$ & $\%$ & $\mathbf{n}$ & $\%$ & $\mathbf{n}$ & $\%$ & n & $\%$ \\
\hline 9-ind $\&$ axial & 1541 & 73.84 & 90 & 14.49 & 610 & 69.08 & 32 & 10.77 \\
\hline $8-1,2 \& 3$ & 0 & 0.00 & 0 & 0.00 & 0 & 0.00 & 0 & 0.00 \\
\hline 7-bone flake & 0 & 0.00 & 0 & 0.00 & 6 & 0.68 & 6 & 2.02 \\
\hline $6-2 \& 3$ & 0 & 0.00 & 0 & 0.00 & 0 & 0.00 & 0 & 0.00 \\
\hline $5-1 \& 3$ & 1 & 0.05 & 1 & 0.16 & 3 & 0.34 & 3 & 1.01 \\
\hline $4-1 \& 2$ & 8 & 0.38 & 7 & 1.13 & 6 & 0.68 & 6 & 2.02 \\
\hline 3-stepped & 6 & 0.29 & 5 & 0.81 & 10 & 1.13 & 10 & 3.38 \\
\hline 2-transverse & 82 & 3.93 & 79 & 12.72 & 26 & 2.94 & 25 & 8.41 \\
\hline 1-oblique & 449 & 21.51 & 439 & 70.69 & 222 & 25.14 & 215 & 72.39 \\
\hline total & 2087 & 100.00 & 621 & 100.00 & 883 & 100.00 & 297 & 100.00 \\
\hline
\end{tabular}

presented by Thackeray (1989). Sheep outnumber cattle by MNI ratios of 5:1 in Phase 1 and 3.5:1 in Phase 7, as opposed to Thackeray's (1989) 2:1 and 2.5:1 in Phase 1 and 7, respectively. The MNI of sheep increased in each Phase, while the MNI of cattle 
decreased in comparison to Thackeray's (1989) results. The decrease in cattle MNI is likely the result of accounting for staggered bone epiphyseal fusion ages. A partial skeleton of a domestic cat was identified in Phase 7 probably represents a natural death and not a meat source since it was a relatively complete carcass and did not exhibit butchery marks. This analysis identified several pig specimens in Phase 1 that were originally missed by Thackeray.

Table 5.9. Taxonomic representations in Phase 1 and Phase 7 of the Granary.

\begin{tabular}{|l|r|r|r|r|}
\hline & \multicolumn{2}{|c|}{ Phase 7 } & \multicolumn{2}{|c|}{ Phase 1 } \\
\hline TAXON & \multicolumn{1}{|c|}{ NISP } & MNI & \multicolumn{1}{|c|}{ NISP } & MNI \\
\hline Bos taurus, cow & 8 & 2 & 28 & 1 \\
Ovis aries, sheep & 497 & 7 & 175 & 5 \\
Sus scrofa, pig & 13 & 2 & 8 & 1 \\
indet Lagomorpha sp. & 1 & 1 & 1 & 1 \\
Sylvicapra grimmia, gray duiker & 3 & 1 & & \\
Raphicerus campestris, steenbok & 1 & 1 & 3 & 1 \\
Hystrix africae-australis, & & & & \\
porcupine & 15 & 1 & 6 & 1 \\
Felis catus, cat & 1 & 1 & 1 & \\
indet carnivore & 393 & 1 & 142 & 1 \\
indet mammal 2 & 1 & 1 & & \\
indet mammal 1a & 1 & 1 & & \\
indet mammal 1b & 2 & 1 & 19 & 1 \\
indet mammal 3 & 350 & 1 & 158 & 1 \\
indet artiodactyla 2 & 2 & 2 & & \\
indet bovid 1a & 28 & 1 & 4 & 1 \\
indet bovid 1b & 826 & 1 & 289 & 1 \\
indet bovid 2 & 21 & 1 & 78 & 1 \\
indet bovid 3 & & & & \\
Chersina angulata, angulate & 2 & 1 & 14 & 1 \\
tortoise & 1 & 1 & & \\
Gallus gallus, chicken & 1 & 1 & & \\
indet large bird & $\mathbf{2 1 6 8}$ & $\mathbf{2 9}$ & $\mathbf{9 2 6}$ & $\mathbf{1 8}$ \\
\hline TOTAL & & & \\
\hline
\end{tabular}

The wild species include the Cape hyrax (Procavia capensis), porcupine (Hystrix africae-australis), and small bovids such as the steenbok (Raphicerus campestris) and the gray duiker (Sylvicapra grimmia). Tortoise (Chersina angulata) was represented by a few fragments of the carapace, and each Phase also contained an MNI of one indeterminate domestic or wild rabbit. 
A preliminary unpublished analysis of birds from the Granary by Horwitz and Avery (1989) is summarized below (table 5.10). The Granary contained diverse avian species, where domestic fowl, including chicken (Gallus gallus) and domestic duck (Anatidae dom), were the most abundant. The MNI are very similar to the NISP for each species, which suggests few bird remains or low levels of identifiability since the number of unidentified bird bones was not presented. Encountered during this analysis, an additional chicken specimen and a distal foot phalanx from a large, unidentified ground bird are included here.

Table 5.10. Bird taxa identified in the various Phases of the Granary (Summary of table 7 from Horwitz and Hall 1989). No birds were identified in Phase 2.

\begin{tabular}{|c|c|c|c|c|c|c|c|c|c|c|}
\hline \multirow{2}{*}{ Phase $\rightarrow \rightarrow \rightarrow \rightarrow \rightarrow$} & \multicolumn{2}{|l|}{7} & \multicolumn{2}{|l|}{5} & \multicolumn{2}{|l|}{4} & \multicolumn{2}{|l|}{3} & \multicolumn{2}{|l|}{1} \\
\hline & NISP & MNI & NISP & MNI & NISP & MNI & NISP & MNI & NISP & MNI \\
\hline chicken & 7* & 2 & & & 3 & 2 & 2 & 1 & 2 & 2 \\
\hline domestic duck & 1 & 1 & & & & & 2 & 2 & & \\
\hline Cape teal & 1 & 1 & & & & & 6 & 1 & & \\
\hline Egyptian goose & 1 & 1 & & & & & & & & \\
\hline Cape francolin & 1 & 1 & & & & & 1 & 1 & & \\
\hline gray-wing francolin & 3 & 1 & & & & & 8 & 2 & & \\
\hline pigeon & 1 & 1 & & & & & 1 & 1 & & \\
\hline Cape raven & 1 & 1 & & & & & 1 & 1 & & \\
\hline pied crow & & & & & 1 & 1 & & & & \\
\hline Cape cormorant & & & 1 & 1 & & & & & & \\
\hline crowned cormorant & & & & & 2 & 1 & & & & \\
\hline greater flamingo & & & & & 1 & 1 & & & & \\
\hline penguin & 2 & 1 & & & & & & & & \\
\hline greenshank & & & & & 1 & 1 & & & & \\
\hline
\end{tabular}

Lastly, the fish were analyzed by Poggenpoel (1996: 122) who identified an abundance of fish (249 MNI) from 13 different taxa throughout the aggregated Granary sequence. The taxa present in the Granary did not include warmer water species from False Bay. Poggenpoel (1996: 122) suggested that the absence of warm water species suggests that the Granary deposits predate other Castle sites that contained these species, such as the Moat. The most abundant species in the Granary deposit was the southern 
mullet or haarder (Liza richardsoni) represented by a minimum of 128 individuals (Poggenpoel 1996: 122). Butchery marks showed that the fish were beheaded and filleted. Some haemal vertebral spines were removed suggesting that some fish were split to expose the meat for drying, smoking, or salting (Poggenpoel 1996: 125).

C. Ages of the Fauna: The sheep remains in the Granary derived from animals slaughtered at a wide range of ages. Unfortunately, few third molars were present to allow clear insights into slaughter practices through the use of Payne's (1973) tooth wear stages, but the third molar wear patterns from Phase 1 and 7 show similar profiles (figure 5.5). The third molars mainly exhibited wear from stage $F$ through $H$, which indicates that the sheep were slaughtered when they were relatively old, i.e. three to eight years of age. Each Phase included a third molar from one younger individual, less than 1.5 years of age. Though the third molars show similar profiles for each Phase, the wear data from first and second molars provides additional ageing data that was not able to be determined through the third molars. Phase 1 contained a well-developed, but unerupted second molar plus an additional second molar in very earliest stages of wear. These second molars show that two individuals were around one year of age at slaughter. In contrast, all isolated first and second molars from Phase 7 were in moderate to late stages of wear, which supports the information provided by the third molar wear stages. Each Phase contained few deciduous fourth premolars that were heavily worn, but consistent with the adult dentition patterns.

Sheep postcranial ageing data support the information obtained from the dentition in each Phase (table 5.11). The epiphyseal fusion data from Phase 1 show that roughly half of the sheep were slaughtered young before two years of age, and the rest when they 
were older than three years of age. Most Phase 7 sheep were slaughtered between two and four years of age, with a high proportion slaughtered older than three years of age. A small number of sheep were slaughtered younger than 1.5 to two years of age according to the presence of unfused phalangeal and distal metapodial epiphyses (Silver 1969: 285286).

Figure 5.5. Third molar wear stages for sheep from both Phases.

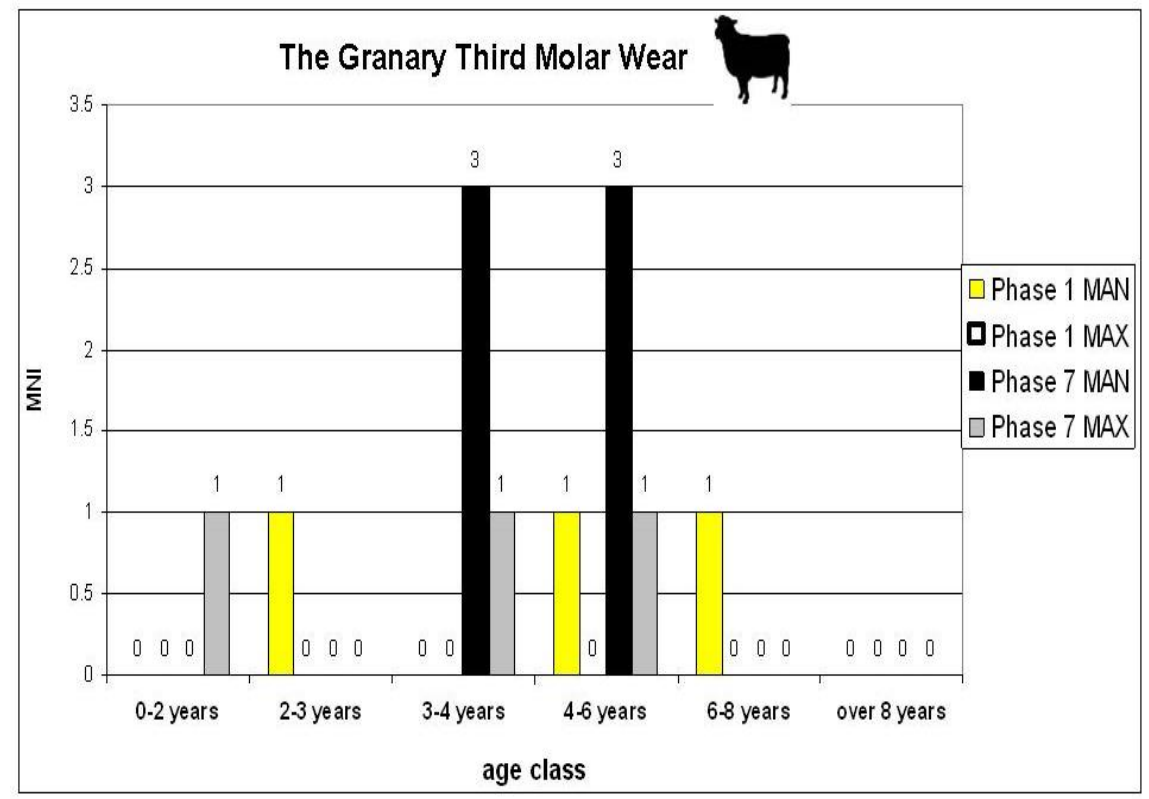

Though cattle are represented by a few NISP, their postcranial ageing data can provide some insights into the ages of those cattle that were eventually deposited in the Granary (table 5.12). An adult calcaneus from Phase 1 shows that one individual was slaughtered after three years of age. Phase 7 contained the remains of both a younger and an older individual. The presence of an unfused distal tibia indicates that one individual in Phase 7 was slaughtered before 2.5 years of age, while two fused distal metapodial fragments show that another individual was slaughtered after three years of age (Silver 1969: 285-286). 
Table 5.11. Sheep epiphyseal fusion frequencies.

\begin{tabular}{|c|c|c|c|c|c|c|c|}
\hline & \multirow[b]{2}{*}{$\begin{array}{c}\text { fusion age } \\
\text { (Silver 1969) }\end{array}$} & \multicolumn{3}{|l|}{ Phase 1} & \multicolumn{3}{|l|}{ Phase 7} \\
\hline & & $\begin{array}{c}\text { subadult } \\
\text { NISP }\end{array}$ & $\begin{array}{l}\text { adult } \\
\text { NISP }\end{array}$ & $\begin{array}{l}\text { partial } \\
\text { NISP }\end{array}$ & $\begin{array}{l}\text { subadult } \\
\text { NISP }\end{array}$ & $\begin{array}{l}\text { adult } \\
\text { NISP }\end{array}$ & $\begin{array}{l}\text { partial } \\
\text { NISP }\end{array}$ \\
\hline SCA & 6-8 mos. & 0 & 2 & 0 & 0 & 10 & 0 \\
\hline Dist HUM & 10 mos. & 0 & 7 & 0 & 0 & 9 & 0 \\
\hline Prox RAD & 10 mos. & 0 & 3 & 0 & 0 & 7 & 0 \\
\hline Prox PHA1/2 & 13-16 mos. & 2 & 0 & 0 & 2 & 6 & 0 \\
\hline Dist TIB & 18-24 mos. & 2 & 2 & 0 & 0 & 6 & 0 \\
\hline Dist MTP & 18-28 mos. & 3 & 0 & 0 & 2 & 2 & 0 \\
\hline Prox FEM & 30-36 mos. & 1 & 1 & 0 & 10 & 4 & 0 \\
\hline Dist CAL & 30-36 mos. & 0 & 0 & 0 & 0 & 5 & 0 \\
\hline Dist RAD & 36 mos. & 0 & 2 & 0 & 6 & 2 & 0 \\
\hline Dist FEM & 36-42 mos. & 0 & 1 & 0 & 7 & 2 & 0 \\
\hline Prox TIB & 36-42 mos. & 0 & 0 & 0 & 4 & 0 & 0 \\
\hline Prox HUM & 36-42 mos. & 0 & 0 & 0 & 2 & 1 & 0 \\
\hline Prox ULN & 36-42 mos. & 0 & 1 & 0 & 3 & 3 & 0 \\
\hline
\end{tabular}

Table 5.12. Cattle epiphyseal fusion frequencies.

\begin{tabular}{|c|c|c|c|c|c|c|c|}
\hline & \multirow[b]{2}{*}{$\begin{array}{c}\text { Fusion age } \\
\text { (Silver 1969) }\end{array}$} & \multicolumn{3}{|l|}{ Phase 1} & \multicolumn{3}{|l|}{ Phase 7} \\
\hline & & $\begin{array}{l}\text { subadult } \\
\text { NISP }\end{array}$ & $\begin{array}{l}\text { adult } \\
\text { NISP }\end{array}$ & $\begin{array}{l}\text { partial } \\
\text { NISP }\end{array}$ & $\begin{array}{c}\text { subadult } \\
\text { NISP }\end{array}$ & $\begin{array}{l}\text { adult } \\
\text { NISP }\end{array}$ & $\begin{array}{c}\text { partial } \\
\text { NISP }\end{array}$ \\
\hline SCA & 7-10 mos. & 0 & 0 & 0 & 0 & 0 & 0 \\
\hline Dist HUM & 12-18 mos. & 0 & 0 & 0 & 0 & 0 & 0 \\
\hline Prox RAD & 12-18 mos. & 0 & 0 & 0 & 0 & 0 & 0 \\
\hline Prox PHA1/2 & 18 mos. & 0 & 2 & 0 & 0 & 1 & 0 \\
\hline Dist TIB & 24-30 mos. & 0 & 0 & 0 & 1 & 0 & 0 \\
\hline Dist MTP & 27-36 mos. & 0 & 0 & 0 & 0 & 2 & 0 \\
\hline Prox FEM & 42 mos. & 0 & 0 & 0 & 0 & 0 & 0 \\
\hline Dist CAL & 36-42 mos. & 0 & 1 & 0 & 0 & 0 & 0 \\
\hline Dist RAD & 42-48 mos. & 0 & 0 & 0 & 0 & 0 & 0 \\
\hline Dist FEM & 42-48 mos. & 0 & 0 & 0 & 0 & 0 & 0 \\
\hline Prox TIB & 42-48 mos. & 0 & 0 & 0 & 0 & 0 & 0 \\
\hline Prox HUM & 42-48 mos. & 0 & 0 & 0 & 0 & 0 & 0 \\
\hline Prox ULN & 42-48 mos. & 0 & 0 & 0 & 0 & 0 & 0 \\
\hline
\end{tabular}

The pig from Phase 1 was represented by unfused distal tibia fragments and an adult second phalange showing that an individual was slaughtered around 2 years of age (Bull and Payne 1982: 66). Phase 7 contained the remains of a minimum of two pigs.

Proximal radius and metapodial fragments show that one individual was slaughtered after one year of age (Bull and Payne 1982: 66). An unerupted first molar, fourth premolar, and an incisor suggests that the other pig was younger than four to six months old when slaughtered (Bull and Payne 1982: 56). 
Only adult birds were reported (Horwitz and Avery 1989: 2), and this could be a factor of taphonomic processes selectively deleting juvenile bird bones or their undiagnostic morphologies inhibiting identification.

D. Skeletal Element Frequencies: The skeletal parts were organized by NISP in order to compare this reanalysis with Thackeray's results (table 5.13). Considering the heavy taphonomic interferences, for this analysis, table 5.13 presents the NISP of sheep combined with size 2 bovids, which are assumed to be sheep since no other size 2 bovid were present in the deposits. The results show that upper and middle limb elements are equally well represented as opposed to the more distal elements such as metapodials, carpals, tarsals, and phalanges. Distal limb elements such as metapodials, carpals, tarsals, and phalanges were underrepresented. Using a more inclusive taxonomic classification allows this analysis to take into account the taphonomic factors discussed above that could have deleted the species-level diagnostic portions of the bones. As a result, NISPs for Phase 7 alone outnumber those identified in all Phases combined by Thackeray (1989). The skeletal element frequencies suggest that all parts of the animals were deposited in the Granary fills except the feet, which were mostly likely removed from the carcasses before they were processed in the kitchens.

Cattle were represented by few NISP, and therefore any patterns in their skeletal part representations are uncertain. Cattle specimens $(n=28)$ from Phase 1 were heavily represented by cranial ( $n=14,50.00 \%$ NISP) and foot elements ( $n=12,42.86 \%$ NISP). Size 3 bovids, which are assumed to be cattle, evened out the representations since most 
Table 5.13. Skeletal part frequencies of Ovis aries/size 2 bovids by NISP and compared to Thackeray's (1989) sheep-only results. Arrows indicate direction of percentage change, $\mathrm{NC}=$ no change.

\begin{tabular}{|c|c|c|c|c|c|c|c|c|c|c|}
\hline \multirow[b]{2}{*}{ element } & \multicolumn{3}{|c|}{ Phase 1} & & \multicolumn{3}{|c|}{ Phase 7} & & \multicolumn{2}{|c|}{$\begin{array}{l}\text { Thackeray } \\
\text { All Phases }\end{array}$} \\
\hline & NISP & & $\%$ & & NISP & & $\%$ & & NISP & $\%$ \\
\hline lower premolars* & & 10 & 4.2 & $\nabla$ & & 23 & 2.8 & $\nabla$ & 72 & 6.4 \\
\hline lower molars* & & 10 & 4.2 & $\boldsymbol{\nabla}$ & & 23 & 2.8 & $\boldsymbol{\nabla}$ & 93 & 8.2 \\
\hline upper premolars* & & 3 & 1.3 & $\boldsymbol{\nabla}$ & & 6 & 0.7 & $\nabla$ & 54 & 4.8 \\
\hline upper molars* & & 4 & 1.7 & $\boldsymbol{\nabla}$ & & 7 & 0.9 & $\nabla$ & 80 & 7.1 \\
\hline incisors* & & 7 & 2.9 & $\boldsymbol{\nabla}$ & & 26 & 3.2 & $\nabla$ & 75 & 6.6 \\
\hline mandible* & & 20 & 8.4 & $\boldsymbol{\Delta}$ & & 23 & 2.8 & $\Delta$ & 5 & 0.4 \\
\hline maxilla* & & 2 & 0.8 & $\Delta$ & & 4 & 0.5 & $\Delta$ & 1 & 0.1 \\
\hline occipital & & 0 & 0.0 & $\nabla$ & & 4 & 0.5 & $\boldsymbol{\nabla}$ & 11 & 1.0 \\
\hline temporal ${ }^{\mathrm{n}}$ & 2 & & & & 4 & & & & & \\
\hline fronta $^{\mathrm{n}}$ & 2 & & & & 4 & & & & & \\
\hline premaxilla $^{\mathrm{n}}$ & 0 & & & & 5 & & & & & \\
\hline indet vault ${ }^{\mathrm{n}}$ & 8 & & & & 12 & & & & & \\
\hline parietal $^{\mathrm{n}}$ & 1 & & & & 4 & & & & & \\
\hline horncore $^{n}$ & 2 & & & & 2 & & & & & \\
\hline hyoid $^{\mathrm{n}}$ & 1 & & & & 2 & & & & & \\
\hline zygomatic $^{n}$ & 1 & & & & 3 & & & & & \\
\hline atlas & & 3 & 1.3 & $\Delta$ & & 3 & 0.4 & $\mathrm{NC}$ & 5 & 0.4 \\
\hline axis & & 3 & 1.3 & $\Delta$ & & 2 & 0.2 & $\boldsymbol{\nabla}$ & 8 & 0.7 \\
\hline cervical & & 12 & 5.0 & $\boldsymbol{\Delta}$ & & 55 & 6.7 & $\Delta$ & 24 & 2.1 \\
\hline thoracic & & 19 & 8.0 & $\nabla$ & & 120 & 14.7 & $\boldsymbol{\Delta}$ & 105 & 9.3 \\
\hline lumbar & & 20 & 8.4 & $\Delta$ & & 115 & 14.0 & $\Delta$ & 42 & 3.7 \\
\hline sacral $^{\text {n }}$ & 2 & & & & 9 & & & & & \\
\hline caudal & & 6 & 2.5 & $\boldsymbol{\nabla}$ & & 21 & 2.6 & $\nabla$ & 35 & 3.1 \\
\hline prox ribs & & 23 & 9.7 & $\boldsymbol{\nabla}$ & & 98 & 12.0 & $\nabla$ & 193 & 17.1 \\
\hline scapula & & 19 & 8.0 & $\Delta$ & & 43 & 5.3 & $\Delta$ & 27 & 2.4 \\
\hline prox humerus & & 0 & 0.0 & $\nabla$ & & 10 & 1.2 & $\Delta$ & 2 & 0.2 \\
\hline midshaft humerus ${ }^{\mathrm{n}}$ & 10 & & & & 19 & & & & & \\
\hline distal humerus & & 8 & 3.4 & $\boldsymbol{\Delta}$ & & 11 & 1.3 & $\boldsymbol{\nabla}$ & 18 & 1.6 \\
\hline prox radius & & 5 & 2.1 & $\boldsymbol{\Delta}$ & & 13 & 1.6 & $\Delta$ & 16 & 1.4 \\
\hline midshaft radius ${ }^{\mathrm{n}}$ & 4 & & & & 19 & & & & & \\
\hline distal radius & & 2 & 0.8 & $\nabla$ & & 12 & 1.5 & $\nabla$ & 29 & 2.6 \\
\hline prox ulna & & 5 & 2.1 & $\Delta$ & & 7 & 0.9 & $\nabla$ & 14 & 1.2 \\
\hline midshaft ulna & 0 & & & & 0 & & & & & \\
\hline $\begin{array}{l}\text { distal ulna } \\
\text { prox metacarnal }\end{array}$ & & 2 & $\begin{array}{l}0.8 \\
0.8\end{array}$ & $\mathbf{\Delta}$ & & $\begin{array}{l}7 \\
2\end{array}$ & $\begin{array}{l}0.9 \\
0.2\end{array}$ & $\vec{\nabla}$ & $\begin{array}{l}0 \\
8\end{array}$ & $\begin{array}{l}0.0 \\
0.7\end{array}$ \\
\hline $\begin{array}{l}\text { prox metacarpal } \\
\text { midshaft metacarpal }^{\mathrm{n}}\end{array}$ & 1 & 0 & 0.0 & $\mathbf{v}$ & 0 & 2 & 0.2 & & 8 & 0.7 \\
\hline distal metacarpal & & 1 & 0.4 & $\Delta$ & & 0 & 0.0 & $\nabla$ & 2 & 0.2 \\
\hline prox femur & & 4 & 1.7 & $\Delta$ & & 25 & 3.1 & $\Delta$ & 17 & 1.5 \\
\hline midshaft femur ${ }^{\mathrm{n}}$ & 10 & & & & 33 & & & & & \\
\hline $\begin{array}{l}\text { distal femur } \\
\text { prox tibia }\end{array}$ & & $\begin{array}{l}3 \\
3\end{array}$ & $\begin{array}{l}1.3 \\
1.3\end{array}$ & $\Delta$ & & $\begin{array}{l}24 \\
20\end{array}$ & $\begin{array}{l}2.9 \\
2.4\end{array}$ & $\dot{\Delta}$ & $\begin{array}{l}9 \\
3\end{array}$ & $\begin{array}{l}0.8 \\
0.3\end{array}$ \\
\hline $\begin{array}{l}\text { prox tibia } \\
\text { midshaft tibia }{ }^{\text {n }}\end{array}$ & 2 & 3 & 1.3 & $\boldsymbol{X}$ & 0 & 20 & & & & 0.3 \\
\hline distal tibia & & 6 & 2.5 & $\Delta$ & & 27 & 3.3 & $\Delta$ & 18 & 1.6 \\
\hline prox metatarsal & & 2 & 0.8 & $\boldsymbol{\Delta}$ & & 4 & 0.5 & $\boldsymbol{\Delta}$ & 3 & 0.3 \\
\hline $\begin{array}{l}\text { midshaft metatarsal }{ }^{\mathrm{n}} \\
\text { distal metatarsal }\end{array}$ & 1 & 3 & 1.3 & $\Delta$ & 7 & 2 & 0.2 & $\Delta$ & 1 & 0.1 \\
\hline
\end{tabular}




\begin{tabular}{|c|c|c|c|c|c|c|c|c|c|c|}
\hline prox metapodial & & 0 & 0.0 & $\nabla$ & & 0 & 0.0 & $\boldsymbol{\nabla}$ & 1 & 0.1 \\
\hline midshaft metapodial $^{\mathrm{n}}$ & 1 & & & & 0 & & & & & \\
\hline distal metapodial & & 2 & 0.8 & $\nabla$ & & 4 & 0.5 & $\boldsymbol{\nabla}$ & 15 & 1.3 \\
\hline indet long bone $\mathrm{FR}^{\mathrm{n}}$ & 168 & & & & 348 & & & & & \\
\hline 1st phalange & & 1 & 0.4 & $\boldsymbol{\nabla}$ & & 5 & 0.6 & $\boldsymbol{\nabla}$ & 10 & 0.9 \\
\hline 2nd phalange & & 2 & 0.8 & $\Delta$ & & 5 & 0.6 & $\mathrm{NC}$ & 7 & 0.6 \\
\hline 3rd phalange & & 1 & 0.4 & $\nabla$ & & 4 & 0.5 & $\boldsymbol{\nabla}$ & 7 & 0.6 \\
\hline pelvis & & 7 & 2.9 & $\Delta$ & & 20 & 2.4 & $\Delta$ & 25 & 2.2 \\
\hline carpals/tarsals & & 16 & 6.7 & $\Delta$ & & 20 & 2.4 & $\boldsymbol{\nabla}$ & 48 & 4.2 \\
\hline sesamoids & & 0 & 0.0 & $\boldsymbol{\nabla}$ & & 3 & 0.4 & $\Delta$ & 2 & 0.2 \\
\hline patella & & 1 & 0.4 & $\boldsymbol{\nabla}$ & & 3 & 0.4 & $\boldsymbol{\nabla}$ & 10 & 0.9 \\
\hline astragalus & & 3 & 1.3 & $\boldsymbol{\nabla}$ & & 11 & 1.3 & $\boldsymbol{\nabla}$ & 20 & 1.8 \\
\hline calcaneus & & 0 & 0.0 & $\nabla$ & & 7 & 0.9 & $\boldsymbol{\nabla}$ & 16 & 1.4 \\
\hline sternum $^{n}$ & 1 & & & & 5 & & & & & \\
\hline TOTAL & & 238 & 100.0 & & & 819 & 100.0 & & 1131 & 100.0 \\
\hline
\end{tabular}

* For the reanalysis, mandible or maxilla bone fragments that contained teeth were counted as the respective bone fragment as well as a count for each tooth contained. ${ }^{\mathrm{n}}$ Thackeray did not present these elements in his table, so they were not included in the percentage calculations.

-Tibiae were easier to identify as distal or proximal segments, so indeterminate midshaft fragments are rare.

limb and vertebral elements were unidentifiable at the species level (table 5.14). A similar pattern was observed in the cattle and size 3 bovid remains from Phase 7, which suggests that complete animals were originally brought to the Castle and their bone fragments were eventually dumped into the Granary deposits.

Pigs were also represented by few NISP, and are represented by specimens from a variety of skeletal regions in each Phase, again suggesting that complete animals were imported to the Castle and their fragments eventually dumped into the Granary deposits.

Table 5.14. Cattle NISP compared to size 3 bovid NISP.

\begin{tabular}{|l|r|r|r|r|}
\hline & \multicolumn{2}{|c|}{ Phase 1 } & \multicolumn{2}{c|}{ Phase 7 } \\
\hline element & $\begin{array}{c}\text { cattle } \\
\text { (NISP) }\end{array}$ & $\begin{array}{c}\text { size 3 } \\
\text { bovid } \\
\text { (NISP) }\end{array}$ & $\begin{array}{c}\text { cattle } \\
\text { (NISP) }\end{array}$ & $\begin{array}{c}\text { size 3 } \\
\text { bovid } \\
\text { (NISP) }\end{array}$ \\
\hline foot & 12 & 1 & 4 & 1 \\
limb & 1 & 36 & 1 & 9 \\
vertebral & 1 & 12 & 0 & 2 \\
rib/sternum & 0 & 24 & 0 & 5 \\
cranial & 14 & 5 & 3 & 4 \\
\hline TOTAL & 28 & 78 & 8 & 21 \\
\hline
\end{tabular}


E. Sheep Sex: Phase 1 provided the only two measurable sheep acetabulae $(\mathrm{H} 1=6.3 \mathrm{~mm}$ and $8.2 \mathrm{~mm}$ ), and these measured to likely be male (Greenfield 2002). Phase 7 did not contain any measurable acetabulae.

F. Butchery: Butchery mark and burning frequency was summarized in "Taphonomy." The Granary collection contained a few distal foot elements showing butchery suggesting that they were removed from the site during the skinning process: Phase 1 contained three cut and three chopped foot elements, including carpals, tarsals, and metapodials, and Phase 7 contained two cut and three chopped distal foot elements (Binford 1981: 136; Landon 1996: 67; Reitz 1986a: 325-327; Shaw 1997: 93-96).

\section{DISCUSSION}

A. The Granary Reanalysis as a Critique of Colonial-Period Slave Diet: Due to the subjugated nature of North American and South African slavery, researchers have often viewed slave diet in terms of limited access to preferred amounts and types of food. This perception has been partly disseminated by influential analyses from the 1980 s such as John Otto's (1984) at Cannon's Point and Diana Crader's $(1984 ; 1989 ; 1990)$ at Monticello that compared faunal residues from contexts associated with the different plantation social classes. Similar conclusions were made at both sites: Slaves had limited access to the meatiest parts of the domestic animals, slaves severely smashed bones to make stews and to extract as many nutrients as possible, and they ate older animals, while their owners predominately ate neatly proportioned roasts, they ate prime aged or younger animals, and they ate more sheep. These interpretations were directly transplanted to investigations into South African slave diet by Hall (n.d.a: 1; 1992: 384- 
386, 390; 1993: 187; 2000: 6; 2008: 129) at sites such as the Granary in the Castle of

Good Hope in Cape Town. More recently, Hall's discussions on slavery and underclass resistance have been taken up in studies of slave life outside the period of historical archaeology such as Jane Webster's (2008) discussion of using comparative archaeology to interpret Classical Roman slavery.

The slave diet interpretations by Otto, Crader, and Hall ultimately ignored the contexts from where the bones were recovered to see if the contexts may have played roles in the final appearance of the samples. The fauna from Cannon's Point were all recovered from refuse middens on the ground surface (summarized in table 5.15).

Table 5.15. Summary of Cannon's Point faunal samples.

\begin{tabular}{|c|c|}
\hline Slave Cabin \#3 & $\begin{array}{ll} & \text { Midden outside door (Otto 1984: 45) } \\
\text { - } & \text { 45.1\% un-ID mammal (Otto 1984: 50) } \\
\text { - } & \text { Animals represented by teeth, vertebrae, } \\
\text { ribs, scapula, pelvis, no limbs (Otto 1984: } \\
\text { 111) } \\
\text { - } & \text { Chop marks }\end{array}$ \\
\hline Overseer & $\begin{array}{ll}\text { - } & \text { Refuse midden off of the detached kitchen } \\
\text { (Otto 1984: 103) } \\
\text { - } \quad 50.9 \% \text { un-ID mammal (Otto 1984: 108) } \\
\text { - } \quad \text { Chop marks }\end{array}$ \\
\hline Planter & $\begin{array}{l}\text { Refuse midden behind the detached } \\
\text { kitchen next to the swamp (Otto 1984: } \\
137-138 \text { ) } \\
\text { - } 30.8 \% \text { un-ID mammal (Otto 1984: } 143 \text { ) } \\
\text { - } \quad \text { Saw marks }\end{array}$ \\
\hline
\end{tabular}

The slave cabin midden was directly outside the door where foot traffic and other activities occurred (Otto 1984: 45), while the middens at the overseer's and planter's houses were found behind the detached kitchen, meters away from the respective houses, and these were probably not in areas of high traffic and activity (Otto 1984: 103, 137138). High fragmentation correlates with low identifiability to the species level as well as identification of specific bone elements (i.e. Lyman 1994: 379). Generally, the diagnostic portions of bony elements are low density and susceptible to destruction 
through carnivore chewing and trampling, both of which are common actors on surface deposits. Characteristically, the elements left behind that are able to be identified to the skeletal and taxonomic levels are the hard teeth and the small, diagnostic foot elements, while the soft parts such as vertebrae and pelves are destroyed and long bones are reduced to undiagnostic midshaft fragments (Bartram and Marean 1999: 25; Binford and Bertram 1977: 82; Blumenschine 1988: 498; Blumenschine and Madrigal 1993: 557; Blumenschine and Marean 1993: 282-289; Egeland et al. 2004: 349; Faith et al. 2007: 2028; Marean and Spencer 1991: 651-652; Marean et al. 1992: 106-111; Munson and Garniewicz 2003: 411-412; Symmons 2005: 1697). At Cannon's Point, there is no discussion about these processes and how they could have affected the final appearance of the faunal collection. The pattern seen at the slave cabin with high numbers of teeth and foot elements along with low proportions of vertebrae and pelves and no identifiable long bones hint that the sample was severely affected by taphonomic processes. Otto (1984: 60, 111) interpreted the high degree of fragmentation at the slave and the overseer sites as a cuisine based on one-pot stews that could simmer for extended periods while attention was paid to other tasks. Without a more in-depth discussion of the fauna, it is difficult to explain why the planter's sample shows a lower proportion of unidentified fragments, but the distance from activity areas could be an explanation since the planter's midden is behind the kitchen at the edge of a marsh (see figure 5.1 in Otto 1984: 128).

At Monticello, the contexts show clearer connections to the conditions of the bones recovered at each site. Here, the Storehouse and Structure 'o' along the slave inhabited Mulberry Row, and the Dry Well behind Thomas Jefferson's house formed the main basis for Crader's Monticello dietary interpretations (summarized in table 5.16). 
The bones from the Storehouse were recovered from a broadcast deposit found outside the door (Crader 1984: 543). The Dry Well bones were recovered from a deep, wellprotected feature (Crader 1990: 693). The bones from Structure 'o,' which Crader (1990: 691-692) identifies as a higher status slave household, were recovered from both a broadcast deposit as well as a protected root cellar. Due to the combination of surface and protected contexts at Structure 'o', one should expect results somewhere between those seen at the Storehouse and the Dry Well. As one can see in table 5.16, the protected Dry Well shows significantly fewer unidentifiable bone fragments, while the slave sites show proportions comparable to the broadcast deposit at Cannon's Point's slave cabin.

Table 5.16. Summary of Monticello's faunal samples.

\begin{tabular}{|c|c|}
\hline Storehouse & $\begin{array}{ll} & \text { Broadcast out front door (Crader 1984: 543) } \\
- & 54.9 \% \text { un-ID (Crader 1984: 543; 1990: 692) } \\
- & 0.5 \% \text { of NISP are sheep (Crader 1990: 696) }\end{array}$ \\
\hline Structure 'o' & 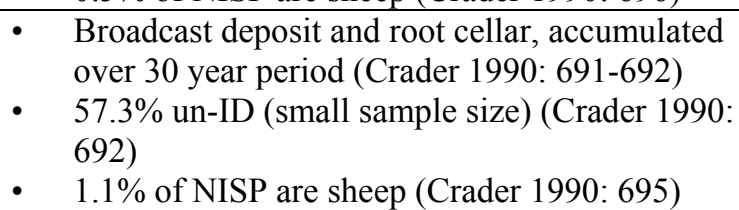 \\
\hline Dry Well & $\begin{array}{ll} & \text { Deep, protected feature, short duration fill } \\
\text { - } & 29.5 \% \text { un-ID (Crader 1990: 693) } \\
& 3.5 \% \text { of NISP are sheep (Crader 1990: 696) }\end{array}$ \\
\hline
\end{tabular}

The proportion of bones identified to the species level is tied closely to the degree of fragmentation, and here, Crader (1990: 695-696) partly uses proportions of sheep bones to infer status. As shown in table 5.16, the proportion of identifiable sheep remains are correlated with the context, where the Storehouse has the lowest amount of sheep NISP, the Dry Well has the most, while Structure 'o' falls in the middle. Looking at skeletal element frequencies of pigs, which were the most common bones identified by Crader, the Storehouse is dominated by teeth and feet (see table 2 in Crader 1984: 545). 
Though the Storehouse is nearly devoid of identifiable limb bones, a large number of limb bone shaft fragments were present, though only identified to the Artiodactyl size 2 classification, which is a less-diagnostic taxon and could be sheep, pigs, or possibly deer (see table 2 in Crader 1990: 697). Structure 'o' is also heavily represented by isolated teeth and feet, but meatier portions of limbs and vertebrae are represented. Structure 'o' also exhibits a very high number of long bone midshaft fragments (see table 4 in Crader 1984: 551). The Dry Well shows a distribution of pig elements more expected of a pig carcass, keeping in mind pigs' feet have relatively more bones than the feet of sheep or cattle.

The high number of unidentified fragments alongside the high number of isolated teeth and undiagnostic long bone midshaft fragments suggest that taphonomic processes may have been responsible for the patterns seen at the slave sites. The next question should be what caused the fragmentation and deletion of bones or the diagnostic portions of bones? At several moments, Crader (1984: 544, 548; 1990: 692) suggests that trampling may have affected the appearances of the Storehouse and Structure 'o' samples, but this suggestion is quickly ignored for the cultural explanation that the slaves chopped the bones into small fragments to extract grease in stews. Crader (1984: 548; 1990: 694,713 ) does present that dog chewing marks were presented on $2.6 \%$ of the Storehouse sample and about $3 \%$ of the Structure 'o' sample, which certainly altered the originally deposited fauna. Crader's (1984: 548, 554-556; 1990: 692, 706) stew interpretation was based on the fragmentation which she attributed to severe chopping to reduce the bones to small sizes. Her data from the Storehouse showed a moderate amount of butchery marks, but most of these marks were cut marks produced when meat 
was cut from the bone. Evidence for the chopping that supposedly reduced the bones was only identified as chop and sheer marks on about $2 \%$ of the collection or 29 individual bone fragments (Crader 1984: 547). There is little discussion about where the chop marks were located. In comparative contexts and historical accounts, chops are generally found in places that divide the carcass into manageable portions, while chops to support Crader's conclusions should hypothetically be all over the bones in order to render them into small bits. To close the discussion on the Monticello diets, Crader does not present quantifications of trampling damage or the timing of bone breakage to infer how much surface exposure could have affected the samples.

The aim of this Granary reanalysis was to analyze the oldest Castle deposits (from Phase 1) for comparison with the other Castle sites and also to examine Hall's (n.d.a: 3; 1992: 390; 1999: 196) and Thackeray's (1989) interpretation (from Phase 7) of the Granary's fauna as reflecting slave diet at the Cape. The findings here shows that the archaeology does not support an in situ occupation by any group of people. Phase 1 suggests a dump to raise and level the ground surface before the Kat wall was constructed. During subsequent Phases, keeping the grain dry would have been a primary function of the structure as was initially voiced in Van der Stel's 1695 letter to Batavia (Fitchett 1996: 163). Stratigraphic details show that the Granary deposits were episodic and secondary. A variety of inclusions suggests the fills were brought to the Granary from a range of sources within and around the Castle. Each successive layer was a separate depositional event and not the gradual accumulation of similar sediments (Waters 1992: 70). These layers also show that the fills were not exposed long enough for weathering to promote soil formation (Schiffer 1987: 200-201; Waters 1992: 40). 
Since the sediment layers were not continuous and their thicknesses were relatively uniform across their spans, these details suggest that they were purposefully placed for ground raising and leveling. If this was done to keep the floor dry, sediment compaction and later saturation would have required the introduction of more fills to raise the ground levels (Peyddoke 1961: 112; Schiffer 1982: 203-204).

The ceramic sample from the Granary supports this interpretation. The wares were highly fragmented with almost no refitting, and they were represented by very low sherd to vessel count ratios (Klose 1993: 120). Porcelain represented the most common ware type in the Granary deposits, but they were often individual fragments and not curated vessels by slaves (Klose 1993: 115-116). The isolated porcelain fragments do not support Hall's (n.d.a: 4; 1992: 390) insistence that they were symbols of slave resistance.

Thackeray's (1989) analysis only reports the fragments he was able to identify to the species level. By ignoring the bone fragments that he could not identify to the species level, Thackeray presents incomplete conclusions on the taxonomic and skeletal element frequencies in the deposits. He claimed that sheep hind limb fragments, a meaty portion of an animal, were scarce. He inferred that these portions of the animals were not available to the occupants, a pattern he then interpreted as reflective of a lower class or "slave" diet. This interpretation was taken by Hall (n.d.a: 1) and compared to American research such as Crader's $(1984 ; 1989 ; 1990)$ slave diet investigation at Monticello, Virginia. Neither Thackeray nor Crader presented conclusions with critical investigations into depositional contexts and taphonomic processes.

This reanalysis determined that more 'expected' numbers of fragments from relatively full carcasses were present in the Granary deposits (see table 5.13), which 
contrasts with Thackeray's (1989) and Hall's (n.d.a: 3; 1992: 390; 1999: 196) slave pattern. The evenness of the skeletal part frequencies shows that nearly complete carcasses of sheep, cattle, and pig were slaughtered at the Castle before ultimately ending up in the Granary fills. The only major gap in the skeletal part frequency profiles were foot elements, specifically metapodials and phalanges, which were scarce in both Phase 1 and 7. This pattern has been observed at the other Cape sites presented in this thesis such as Elsenburg, the Moat, and DKG, see Chapters 3, 4, 6). The lack of distal limb elements alongside characteristic skinning cutmarks has been interpreted as hide removal for the Cape tanning industry (Binford 1981: 136; Binford and Bertram 1977: 91; Landon 1996: 67; Mentzel 1921: 135, 1925: 55; Raven-Hart 1970a: 201; Reitz 1986a: 325-327; Shaw 1997: 93-96).

Other elements of the Granary fauna also do not fit an expected Cape slave diet (Armstrong and Worden 1988: 146; Markell et al. 1995: 84; Mentzel 1921: 56; Sealy et al. 1993: 84). Pig and chicken meat was considered difficult to acquire at the settlement unless a burgher brought these animals in from the frontier settlements for bartering purposes (Mentzel 1921: 101; 1944: 213). The wild mammals were not legal food items for any Cape inhabitant except the Governor and official visitors, and the wild bovids from the Granary could possibly be waste from the Governor's table (see Chapter 1 for a fuller discussion on wild fauna hunting, Cruz-Uribe and Schrire 1991: 95; Kolben 1731: 34; Mentzel 1921: 61; 1925: 101; 1944: 102; Raven-Hart 1970b: 270; Skead 1980: 448$449,456 ; 1987: 813-855)$. Therefore, difficult to acquire food sources such as chicken, pig, and wild game were not likely food items for any lower status VOC servants, either free or enslaved. 
B. Insights into Cape Faunal Consumption: Though the Granary deposits are secondary fills and therefore not immediately reflective of specific social class' diets, it reflects a mixture of residues from the Castle. Species representations with fish and the monotonous mutton suggest a common diet expected of a VOC servant, but due to their lowly status, a soldier's diet is expected to look similar and indistinguishable from a slave's (Hall n.d.a.: 3; n.d.c.: 2; Johnson-Barker 2003: 123). While previous arguments about the identity of the Granary bone accumulators focused on sheep and cattle part availability, this reanalysis demonstrates that these parts are well represented. The wild fauna is indicative of rare and privileged meat and therefore not intended for slaves or servants.

Burning is indicative of roasted meat, and the Granary's Phase 7 contains burning frequencies similar to that observed at Elsenburg, DKG, and even higher than that reported for Oudepost I's terrestrial fauna and therefore represents kitchen refuse (CruzUribe and Schrire 1991: 100; and Chapters 4, 6, 7). In both Phases, skeletal element frequencies show that the meatier elements were ultimately deposited in relatively equal proportions. Post-consumption residues from the Cape settlement would contain skeletal element frequencies that include high numbers of meat bearing limb and vertebrae bones, along with a moderate proportion of fragments exhibiting burning.

The Granary fauna provides a few clues to the organization of the wider Cape meat industry. As a comparison with other sites, the Granary fauna reflects the remains of animals after they had been consumed as opposed to the Moat fauna which is mainly animal waste from a primary butchery stage, and probably represents provisioning for either calling ships or local markets (see Chapter 3). As with the fauna from the Moat 
and DKG, the Granary's domestic faunal remains represent animals reared in the frontier or nearby farms and imported to the settlement when they had reached optimal slaughter size and age. Unfortunately, the high fragmentation of the Granary fauna did not preserve large sample sizes of suitable acetabulae to identify the sex of the sheep. Phase 1 contained only two measurable acetabulae which were determined to be male (Greenfield 2002). The male sheep in the Granary compare to the findings from the Moat, which suggests that the great majority of the sheep imported to the settlement were male, as either wethers or rams.

The age information from the Granary hints at a possible change in slaughter practices between the deposition of Phase 1 and Phase 7. Though sample sizes are small, Phase 1, c.1665-1691, showed that a high proportion of the sheep were slaughtered young, between one and three years of age, with a few older than three years of age. Phase 7, deposited about the mid-eighteenth century, shows that the majority of the sheep were slaughtered older, about two to four years of age, with a few even older as was suggested by M3 molar wear stages. The age profile developed for Phase 7 is similar to that developed for the Moat sheep, with the greatest proportion of sheep being slaughtered around their prime meat yield ages. The late seventeenth century Phase 1 age profile shows a similarity with the sheep remains from the terrestrial component of Oudepost I, where a high proportion of sheep slaughtered between one and two years of age, including a smaller number slaughtered before one year of age (Cruz-Uribe and Schrire 1991: 98). The lagoon Dump from Oudepost I further supports that sheep were slaughtered relatively young in the earlier years of the VOC's colonial endeavor (see Chapter 7). These results suggest that the VOC slaughtered their sheep younger during 
the late seventeenth century than in the eighteenth century. This may be because the VOC stock herds were not yet fully developed in the late seventeenth century so sheep had to be slaughtered when the meat was required instead of waiting until the sheep had reached their prime meat-yielding age. 


\section{CHAPTER SIX: Elsenburg}

\section{HISTORY}

Samuel Elsevier, Secunde to the Governor Willem Adriaan van der Stel, established Elsenburg as a private country estate. The land, granted on September 23, 1698 as a 110 morgen tract in the Bottelary section of Stellenbosch, was renowned as a fertile region with orchards, pastures, and cultivated fields (Fransen and Cook 1980: 166; Guelke 1987; Kolben 1731b: 43; Schutte 1989: 304). The landholdings of the Elsenburg farmstead expanded quickly when Elsevier incorporated a considerable portion of several neighboring VOC stock farms on Jossen Hill. These lands included a stream where he constructed a dam and mill to grind corn that would remain a focal point of the property throughout its history (Kolben 1731b: 43). Inappropriate use of VOC funds and resources by the Cape administration on lavish country estates, like Elsenburg and Van der Stel's own farm Vergelegen, caused unease amongst the burghers who successfully argued to have these officials recalled in 1707 (Fairbridge 1931: 138; Markell et al. 1995: 10; Mentzel 1921: 19; Valentyn 1971: 151).

The exact locations or appearances of the original Elsenburg manor house(s) (between 1698 and 1760) are unknown. Historians logically place them centered within the werf, a town-like farmstead, between the set of outbuildings along the stream near the mill (Fagan 1984: 34). Shortly after Elsevier's departure, Jan Jurgen Roos gained ownership of Elsenburg (1719 to 1722), and information gleaned from his probate inventory suggests that he may have inhabited a T-shaped house (Fagan 1984: 34; Hart and Halkett 1993: 24). In 1742, Jan Philip Geibelaar and his wife Anna Margaretha Hop, obtained ownership of the farm. Geibelaar's inventory taken after his death in 1747 
suggested a more complexly shaped house on the site (Fagan 1984: 35; Hart and Halkett 1993: 24). It is unknown whether Geibelaar's house may have been a completely different construction from his predecessors or just additions made to an existing structure (Hart and Halkett 1993: 24).

Anna Margaretha Hop was a constant figure at Elsenburg during the period when the main archaeological deposits accumulated. Hop's period at Elsenburg was initially as the wife of Geibelaar and then as his widow from 1747 till 1752 (J195 and J196 Cape Archives Census Records). In 1752, she married Martin Melck, a German VOC soldier who had become an accomplished burgher in Stellenbosch (De Bosdari 1953: 68; J198 Cape Archives Census Records). Melck and Hop resided at Elsenburg while accruing considerable wealth and standing in Cape society.

In 1761, major changes occurred at Elsenburg when significant building took place within the werf. The centerpiece was the construction of Melck's Herehuis, a Ushaped and gabled manor house centrally located between several outbuildings along the stream (figure 6.1). Additional developments at this time included the construction of several new outbuildings and the ornately walled sluice within the stream in front of the house (Fagan 1984: 35; Hart and Halkett 1993: 3; Walton 1974: 38). A visitor in 1774, Jan Splinter Stavorinus, described Melck's werf as appearing like a village with the main house surrounded by all of its outbuildings and workshops (De Bosdari 1953: 69; Fagan 1984: 35; Hart and Halkett 1993: 5; Walton 1974: 38). These outbuildings, which were the settings of Melck's many industries at Elsenburg, included wine cellars, stables, a wagon-making shop, slavehouses, smiths, and a school (Fagan 1984: 35; MOOC 7/1/25 Cape Archives Estate Papers). 
Figure 6.1. The U-shaped Herehuis is the centerpiece of Melck's werf surrounded by several outbuildings. This drawing reconstructs the werf at 1781 (from Fagan 1984).

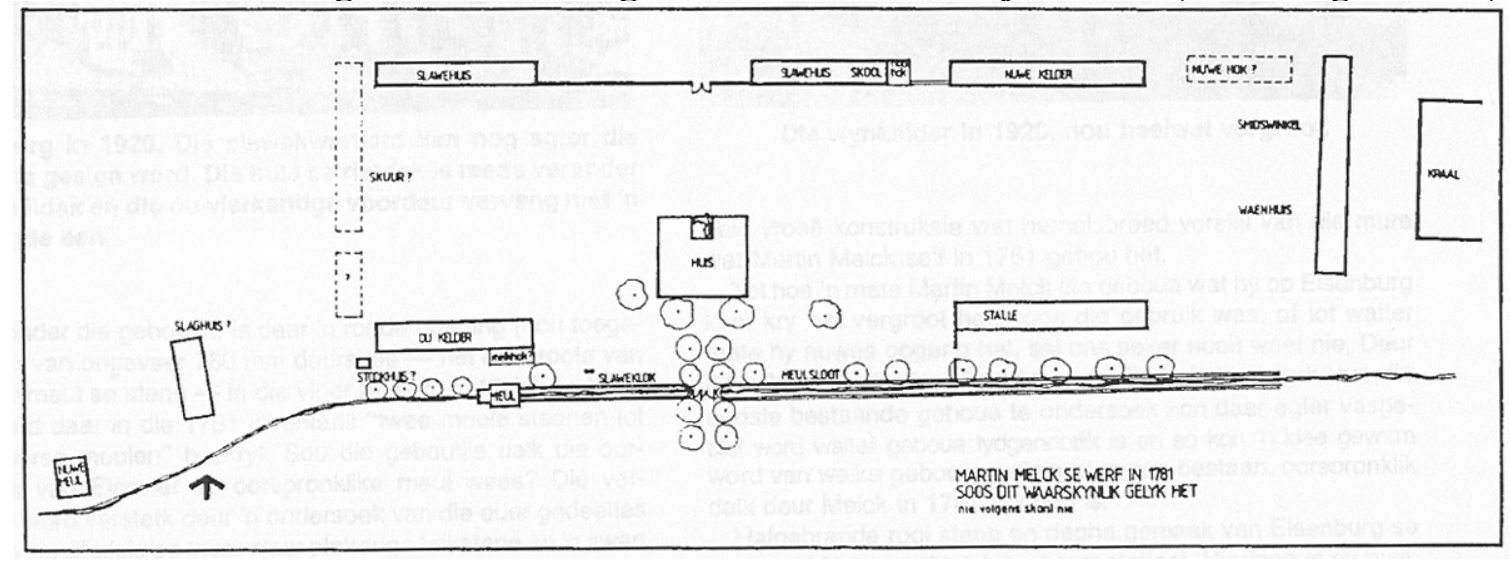

Melck's tenure was the golden period for Elsenburg, while the farmstead's later history saw numerous modifications that ruined "the integrity of the original werf which so impressed Stavorinus in 1774" (Hart and Halkett 1993: 5). After Melck died in 1781, Elsenburg remained in the family until his son-in-law, Gabriel Josua Rossouw, sold the property in 1811. The deed then passed through the hands of several unsuccessful real estate speculators until the Cape government purchased the property in 1898 to be used as an agricultural school of the University of Stellenbosch (De Bosdari 1953: 69). A fire gutted Melck's Herehuis in 1915/6, but it was restored with the original walls and a new tile roof to replace the original thatching (De Bosdari 1953: 69; Fransen and Cook 1980: 167; Hart and Halkett 1993: 3). A proposal in 1993 to restore the Herehuis back to its original appearance enabled the Archaeological Contracts Office of the University of Cape Town to explore and identify cultural remains related to the house and its inhabitants (Hart and Halkett 1993: 3). 


\section{ARCHAEOLOGY}

Archaeological investigations by the UCT Archaeological Contracts Office (ACO) in 1993 were performed in preparation for a restoration project at the Herehuis. The specific areas of interest were the grounds adjacent to and within the house since these areas held the potential to reveal information about the Herehuis's construction, inhabitants, and the location of original structures through features and broadcast deposits (Hart and Halkett 1993: 5-23).

The richest feature excavated was the Kitchen Dump (henceforth Dump) feature beneath the Herehuis's kitchen in the southeast corner of the house (figure 6.2). It is an expansive, lens-like fill dissected by foundation trenches and therefore predates the current Herehuis (Hart and Halkett 1993: 25-26). The deepest portion of the Dump was located in excavation units $1,2,5$, and 6 , while it thinned out towards the front of the house. A total of 15 square meters were excavated to an average depth of 1.2 meter (Hart and Halkett 1993: 9), and the deposit was interpreted as a fill used to level a natural depression in the land surface (Hart and Halkett 1993: 23).

A. Stratigraphy: The stratigraphy of the Dump beneath the Herehuis's kitchen consists of seven distinct stratigraphic contexts listed from top to bottom as follows (figure 6.3):

1. Layer 1: Ash and charcoal that resulted from the $1915 / 6$ fire that gutted the Herehuis (Hart and Halkett 1993: 13).

2. Layer 2: Relatively sterile soils that were used to level the ground beneath the Herehuis (Hart and Halkett 1993: 24). 
3. Layer 3: An expansive, dense accumulation of brick fragments that are the result of the wall construction for the Herehuis in 1761 (Hart and Halkett 1993: 25).

4. Layer 4: A yellowish clay "charcoal fleck" layer that is mainly the redeposited "Dump below yellow clay" layer. It seals the soils in the "Dump below yellow clay" and the builder's trenches (Hart and Halkett 1993: 25; Klose 1997: 126).

5. Layer 5: The filled-in builder's trenches for the 1761 Herehuis and its contemporary bakoond oven. This soil is a mixture of redeposited subsoil, topsoil, and the "Dump below yellow clay" layer (Hart and Halkett 1993: 11; Klose 1997: 126).

6. Layer 6: The "Dump below yellow clay" (DBYC) is a thick brownish-yellow clayey soil layer that contained a dense accumulation of cultural material (Hart and Halkett 1993: 11).

7. Layer 7: The "hard gritty clay" subsoil that did not contain any historical material (Hart and Halkett 1993: 11).

Layer six, DBYC, is an in situ deposit that is clearly bounded by tightly dated sediment layers. DBYC dates before 1761 as it was cut by the Herehuis's foundation trenches and capped by the brick debris from the wall construction. The presence of the house above the Dump protected the deposits from further disturbances.

The ACO investigated locations in the immediate area for architectural remains of an earlier house, but no earlier structures were found. The courtyard was tested specifically because Roos's probate inventory suggested a possible T-shaped house on the property (Fagan 1984: 34; Hart and Halkett 1993: 24). 
Figure 6.2. A plan view of the Herehuis excavations that shows the location of the kitchen Dump in the northeast corner. The detail below shows the layout of the units and the location of unit 6 (from Hart and Halkett 1993: 6).

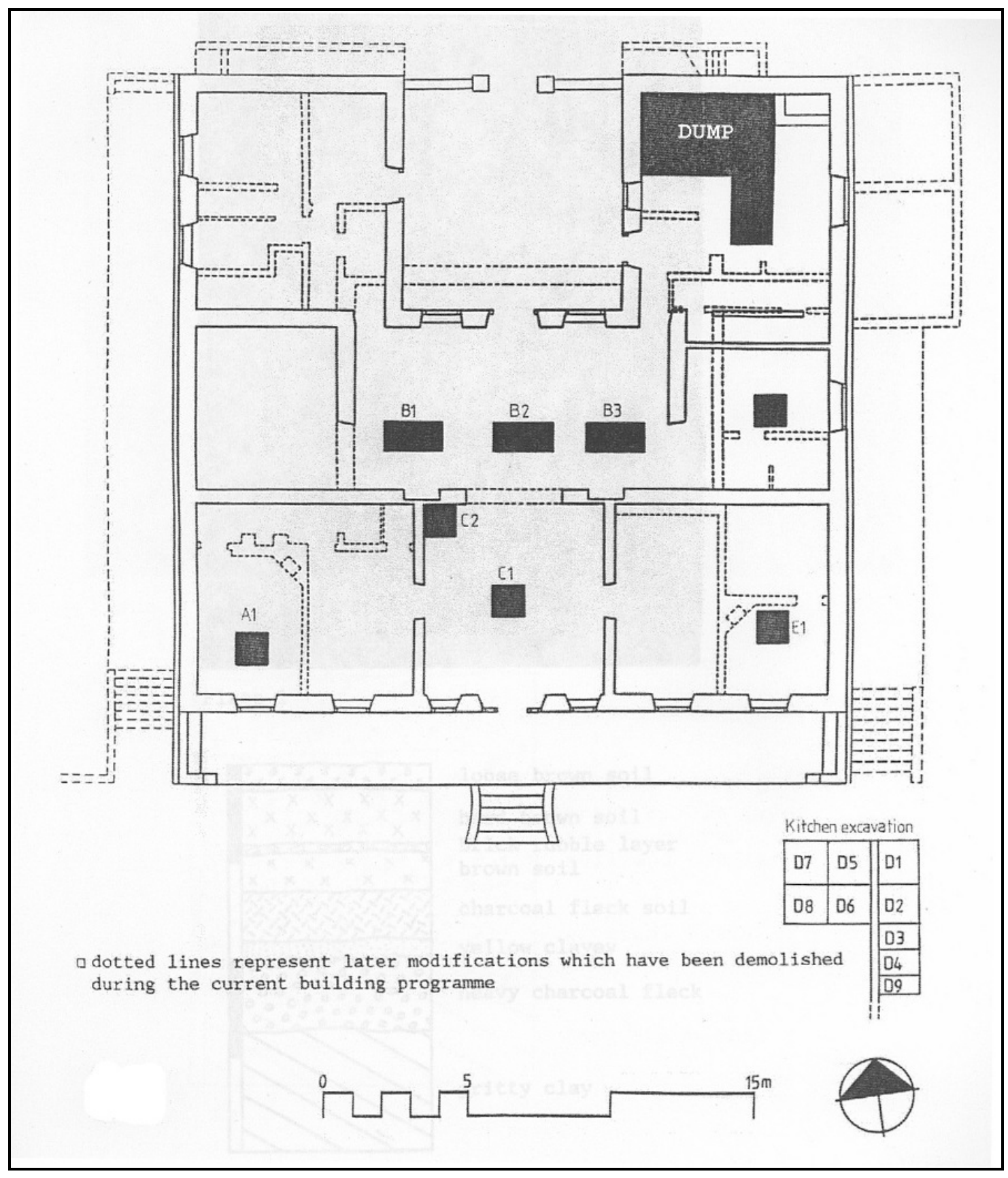


Figure 6.3. Profile drawing of the kitchen Dump illustrating the stratigraphy (from Hart and Halkett 1993: 11).

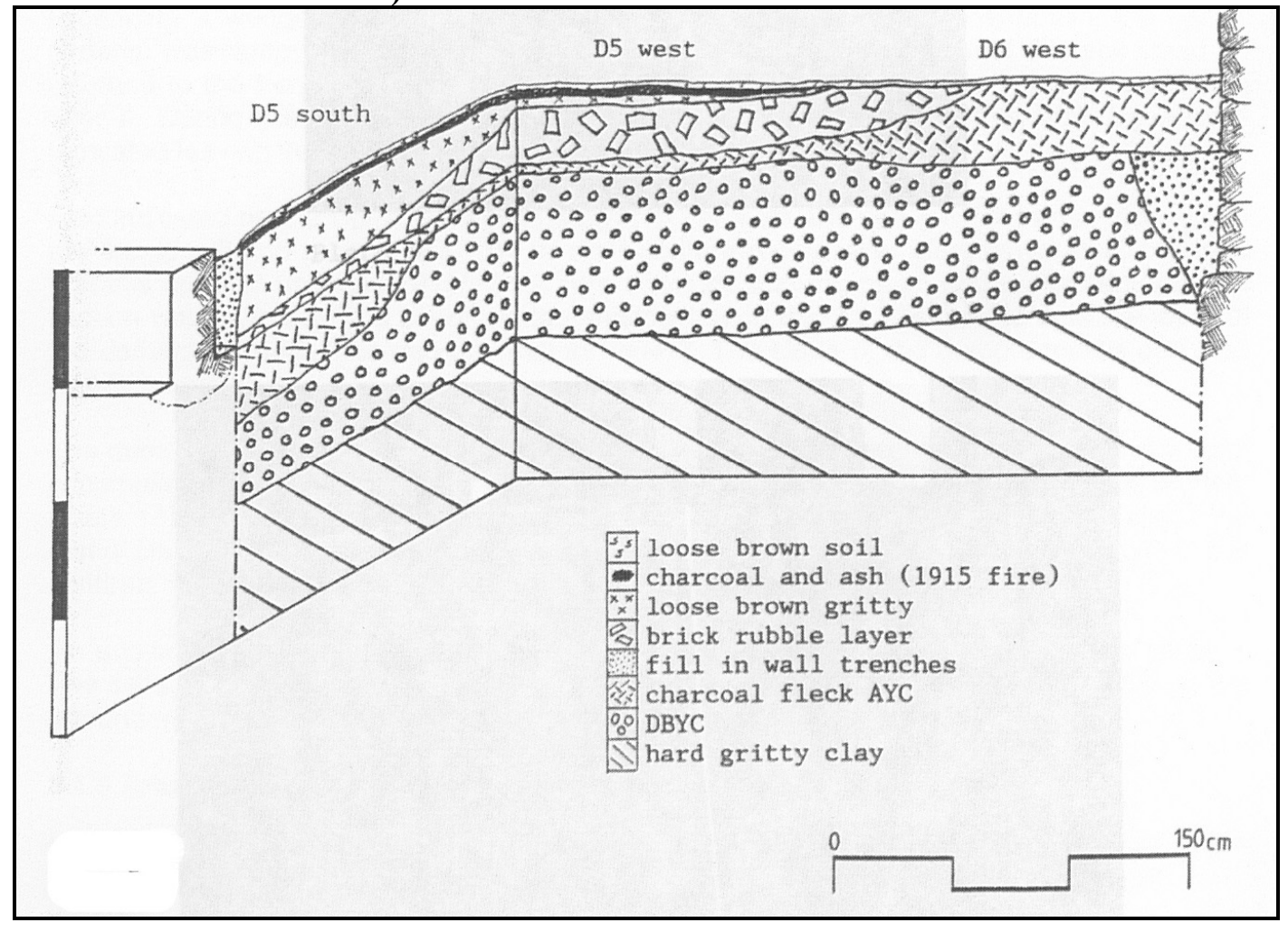

B. Material Remains from the Dump: The Dump contained a large quantity of cultural remains, which consisted mostly of tobacco pipes, ceramics, glass, and the fauna.

1. Tobacco Pipes: The tobacco pipes were analyzed by Otto Graff (Hart and Halkett 1993: 32-33) and others (Yates et al. n.d.). Graff aggregated the pipe material from the entire site, but he stated that since the Dump contained the majority of the material, his analysis focused on this deposit. He used electronic calipers and only measured decorated pipestems to ensure that he was only analyzing Dutch material. Dutch pipestem bore diameters have been debated to become smaller at a quicker rate than their English counterparts (Schrire et al. 1990: 277), so Graff might have been concerned with mixing pipe fragments from different origins of manufacture. His mean bore diameter calculated to $1.965 \mathrm{~mm}$ with a standard deviation of $0.178 \mathrm{~mm}(\mathrm{n}=501)$, placing the mean 
date at c.1740, and with the standard deviation, produces a date range of c.1725-1755 (Hart and Halkett 1993: 32). Graff stated that the use of decoration on pipestems was "most common during the second quarter of the eighteenth century (c.1725-1750) (Hart and Halkett 1993: 32).” Because of Graff's decision to only analyze decorated stem fragments, the date range of c.1725-1755 that he obtained could mean that his analysis only determined the mean date of decorated pipestems, already known to the archaeological community.

Yates et al. (n.d.: 25) reanalyzed the Dump pipestems from DBYC with standardized drill bits, suggesting that electronic calipers produce misleading measurements, about 0.2mm too large (Yates and Smith 1993: 52 from Ann Markell pers. com.). Yates et al. (n.d.) analyzed larger sample sizes and obtained mean bore diameters of $2.048 \mathrm{~mm}(\mathrm{n}=1372)$ and $2.053(\mathrm{n}=1246)$, which correspond to similar dates as those proposed by Graff.

The remaining portion of the tobacco pipe collection included the bowls and makers' marks, which could also be seriated through time (Duco 1982: 111; Mallios 2005: 92-103; Noel-Hume 1969: 302-304; Schrire et al. 1990: 297). Graff reported that the Elsenburg sample only contained bowl types of Duco's type F (1730-1740) and type G (1750-1775) (Duco 1982: 111). The majority of the maker's marks present on the Dump's pipe bowls were first manufactured in the late 1730s, but one mark of the letter "S" had a TPQ of March, 1740 (uncited from Duco 1982 in Hart and Halkett 1993: 33). The dating data from the tobacco pipestems, bowl shapes, and makers' marks brackets the period of the Dump's deposition to the two decades before Melck constructed his Herehuis in 1761. 
2. Ceramics, Glass, and Other Finds: The ceramics also provided important information about the deposition of the Dump. Analyses of ceramics confirmed that the “charcoal fleck layer" above the DBYC layer, was actually redeposited DBYC. The vessel forms and ware types exhibited identical profiles between the strata, and over $40 \%$ of the vessels in the "charcoal fleck layer" crossmended with those from the DBYC layer (Klose 1997: 126). The ceramics suggest that the deposition of the Dump probably began in the late 1730s, but occurred most heavily from c.1740-1750 (Klose 1997: 126). The ceramics support the dates determined from the tobacco pipe analyses.

In addition to dating information, the ceramics from the Dump have proven to be extremely valuable in revealing status and material consumption of Elsenburg's inhabitants during the mid-eighteenth century. Probate inventories that were taken after the deaths of Geibelaar and Hop, who lived at Elsenburg during the Dump period, revealed very lavish, though unspecified, possessions (Klose 1997: 133; MOOC 7/1/25 Cape Archives Estate Papers). The Elsenburg Dump contained a high quantity and variety of Asian porcelains, which dominated the ceramic profiles. The majority of the vessels (271 of 313 minimum vessels) in the DBYC layer were imported from Asia, and many were very rare and expensive pieces, including the first famille rose pattern on Chinese export porcelains found in an archaeological context at the Cape. The famille rose pattern was probably not part of official VOC cargoes, and were therefore privately ordered. Japanese export porcelain made up $9.6 \%$ of the minimum number of vessels. The presence and quantity of the Japanese wares were significant because official VOC trade with Japan had ceased in 1713. Klose (1997: 132) interprets the presence of these expensive and popular porcelains at the Cape as being the result of a private trade 
between Company representatives and Japan. About $48 \%$ of the vessels were in the form of tablewares used for food presentation and consumption (Klose 1997: 135). Another indicator of status in the ceramic assemblage was the large proportion of variously decorated, fragile teawares $(34.0 \%)$, enameled, and ornamental $(2.6 \%)$ porcelains, including porcelain utensil handles and figurines (Klose 1997: 132). The remaining portion of the assemblage consisted mainly of European or Cape manufactured coarse earthenwares and stonewares used for utilitarian purposes (Klose 1997: 130).

The glass consisted mostly of either onion or mallet shaped wine bottles. Other glass included engraved glassware and stemmed wineglasses. A moderate quantity of weaponry related items were recovered, including a moderate amount of "bird shot," plus musketballs and gunflints that suggests hunting. In addition, remaining artifacts consisted of household and personal items such as window glass, furniture hardware, and clothing accessories (Hart and Halkett 1993: 42-49).

The artifacts from the Dump provide insights into status and material consumption patterns before 1761 at the earlier Elsenburg manor house during the Hop tenure. The greater portion of the material remains certainly reflects a high status household, but any residues from the slaves and other farm workers may be left invisible in such a deposit, even though documents record them living in other sections of the werf a distance from the deposit (Fagan 1984: 35). The overwhelming proportion of expensive items suggests that underclass servant and slave residues here must be minimal. 


\section{FAUNAL RESULTS}

The DBYC layer in unit 6 (henceforth called DBYC 6) was selected for analysis as a large representative sample from an undisturbed context dated to c.1740-1761.

DBYC 6 was also chosen as a sample due to its large sample size and a cursory examination determined it to be representative of the rest of the Dump (table 6.1).

Table 6.1. Sample sizes of DBYC 6.

\begin{tabular}{|l|r|r|r|}
\hline & Bone & $\begin{array}{l}\text { Isolated } \\
\text { teeth* }\end{array}$ & Total \\
\hline DBYC 6 & 9762 & 270 & 10032 \\
\hline
\end{tabular}

*teeth present in bone were not counted as isolated teeth

A. Taphonomy: The bone fragments from DBYC 6 are in excellent condition and most of the fragments retain original surface conditions showing no effect from root etching or weathering (table 6.2). Though the bone fragments are in good condition, the collection is highly fragmented, with the bone fragments from size 2 and size 3 animals being amongst the smallest average sizes of all faunal samples analyzed in this thesis (figure 6.4 and figure 6.5 , respectively). Bone fragmentation has been determined to have mostly occurred while the bones were fresh, but a minor proportion $(11.27 \%$ of the long bone fragments) show dry bone breaks that occurred after the bones had experienced some decomposition (table 6.3).

Table 6.2. Surface condition observed on the bone fragments from DBYC 6.

\begin{tabular}{|c|c|c|c|c|c|}
\hline & $\mathrm{n}$ & $\%$ & & $\mathrm{n}$ & $\%$ \\
\hline $\begin{array}{l}\text { pristine, } \\
\text { original }\end{array}$ & 9642 & 98.77 & $\begin{array}{l}\text { major } \\
\text { exfoliaton }\end{array}$ & 6 & 0.06 \\
\hline $\begin{array}{l}\text { minor } \\
\text { exfoliation }\end{array}$ & 80 & 0.82 & $\begin{array}{l}\text { major } \\
\text { chemical } \\
\text { corrosion }\end{array}$ & 1 & 0.01 \\
\hline $\begin{array}{l}\text { minor } \\
\text { mechanical } \\
\text { rounding }\end{array}$ & 30 & 0.31 & $\begin{array}{l}\text { major } \\
\text { mechanical } \\
\text { rounding }\end{array}$ & 2 & 0.02 \\
\hline $\begin{array}{l}\text { minor } \\
\text { adhering } \\
\text { matrix }\end{array}$ & 1 & 0.01 & Total & 9762 & 100.00 \\
\hline
\end{tabular}


Figure 6.4. Mean measures of size 2 bone fragments from all sites.

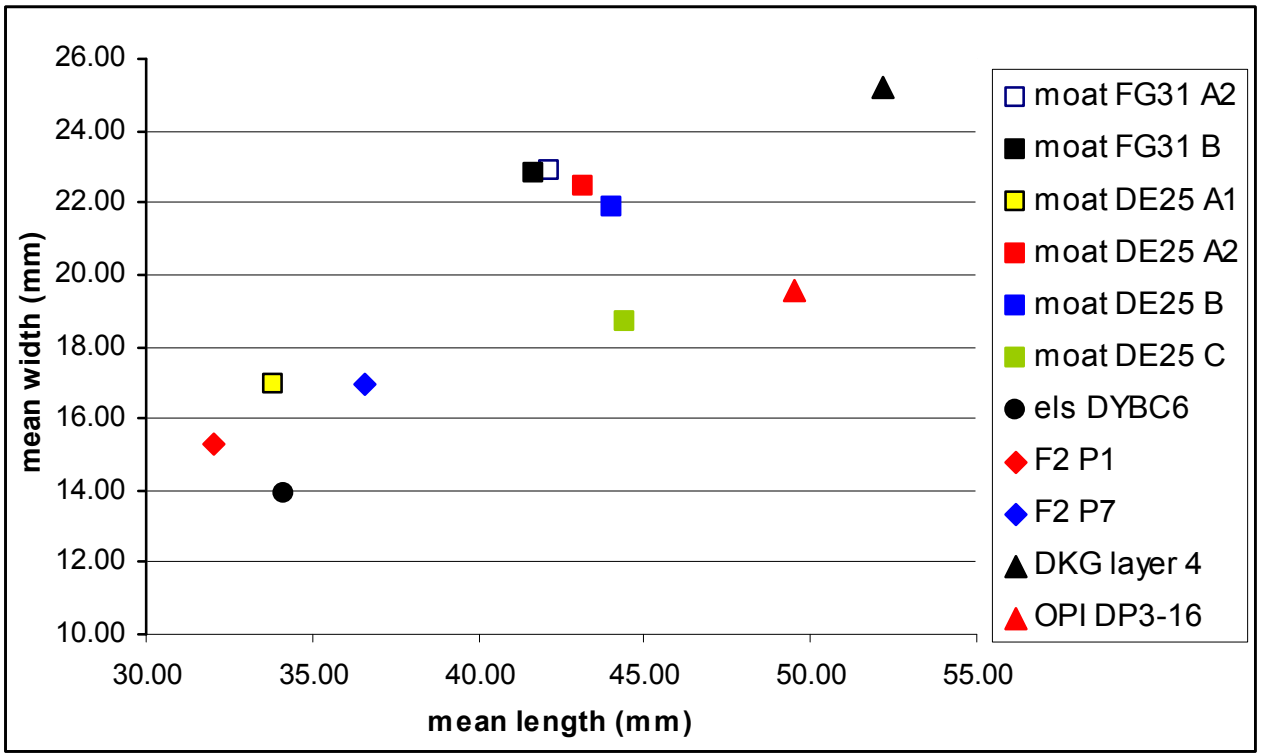

Figure 6.5. Mean measures of size 3 bone fragments from all sites.

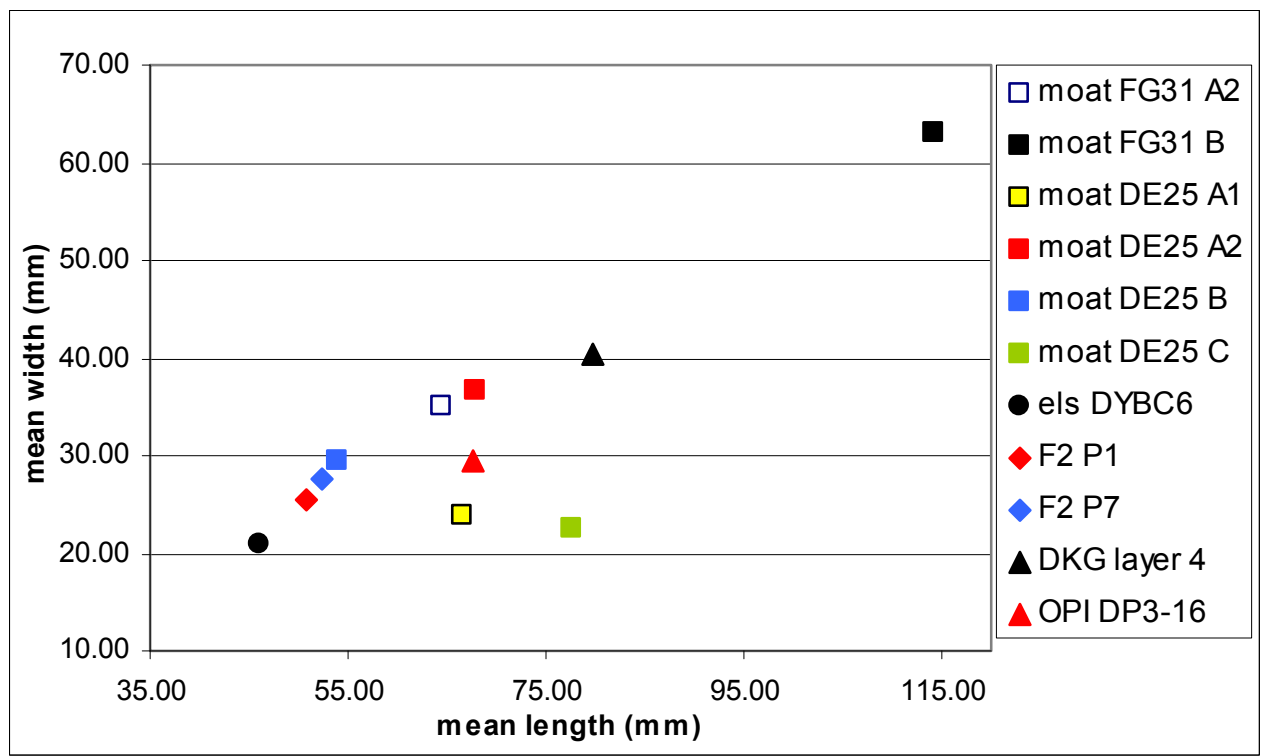

Since the archaeology determined that the Dump was deposited on the ground surface in a natural ground depression, it is expected that the bones might have been modified by several taphonomic agents. Observations of bone surfaces identify carnivores as having been significant modifiers of the DBYC 6 bone fragments (figure 6.6). Animal size is a factor in the frequency of tooth marked fragments with smaller 
Table 6.3. Bone breakage patterns.

\begin{tabular}{|l|r|r|r|r|}
\hline & \multicolumn{3}{|c|}{$\begin{array}{l}\text { LBN (size } \\
\text { 1/2/3) } \\
\text { breakage }\end{array}$} \\
\hline Break type & \multicolumn{1}{|c|}{$\mathbf{n}$} & \multicolumn{1}{c|}{$\%$} & \multicolumn{1}{c|}{$\mathbf{n}$} & \multicolumn{1}{c|}{$\%$} \\
\hline 9-ind \& axial & 5923 & 60.67 & 178 & 4.54 \\
\hline 8-1, 2 \& 3 & 0 & 0.00 & 0 & 0.00 \\
\hline 7-bone flake & 302 & 3.09 & 302 & 7.70 \\
\hline 6-2 \& 3 & 4 & 0.04 & 4 & 0.10 \\
\hline 5-1 \& 3 & 30 & 0.31 & 22 & 0.56 \\
\hline 4-1 \& 2 & 62 & 0.64 & 57 & 1.45 \\
\hline 3-stepped & 81 & 0.83 & 63 & 1.61 \\
\hline 2-transverse & 319 & 3.27 & 296 & 7.55 \\
\hline 1-oblique & 3041 & 31.15 & 3000 & 76.49 \\
\hline total & 9762 & 100.00 & 3922 & 100.00 \\
\hline
\end{tabular}

animals having higher proportions of tooth marked fragments than larger animals

(Binford 1981: 124). Long bone completion information also suggests that taphonomic factors such as the carnivores have selectively deleted portions such as the epiphyses as well as fragmenting the long bone shafts (table 6.4). The carnivore that interacted with these bone fragments was likely domestic dog, which has been identified through associated skeletal remains (table 6.5).

Figure 6.6. The frequencies of carnivore tooth mark damage to bone surfaces.

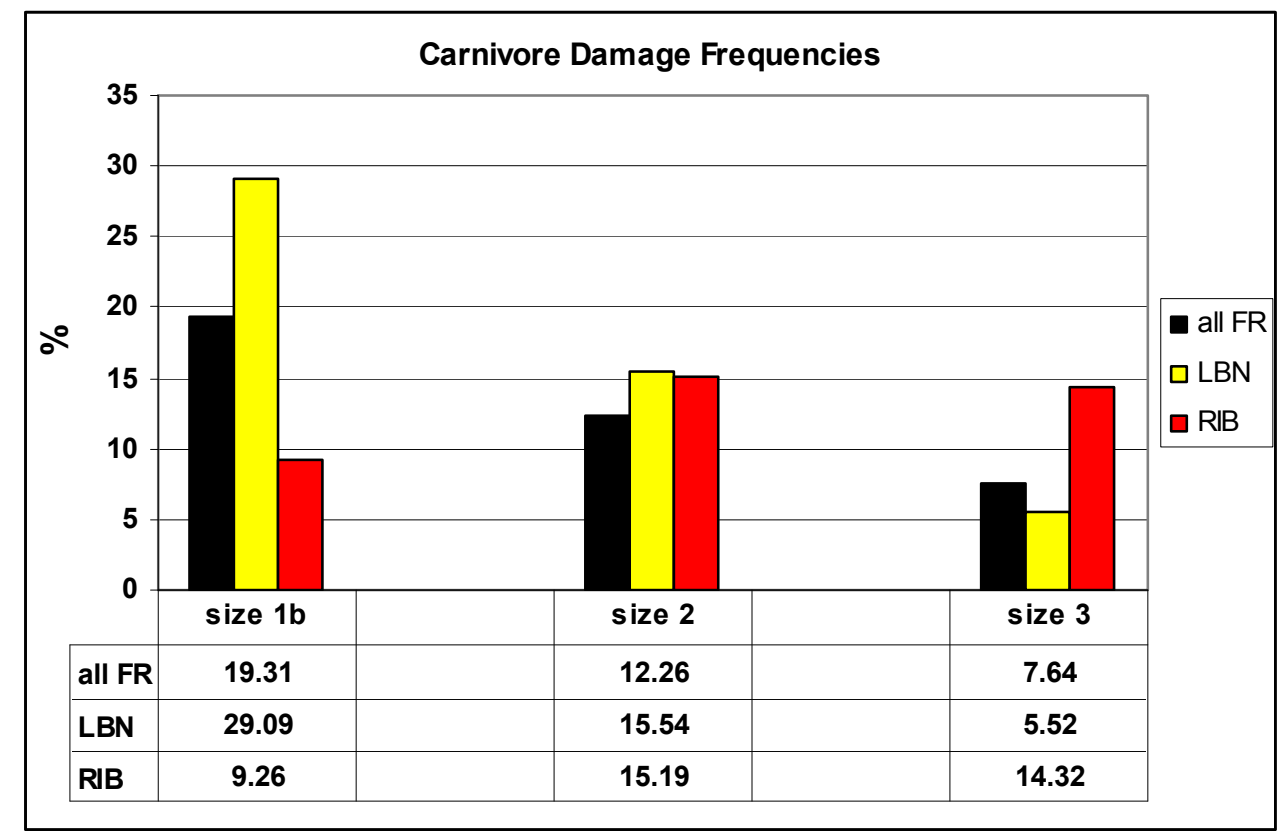


Table 6.4. Measures of long bone completion, excluding the ulna due to its lack of a medullary cavity.

\begin{tabular}{|c|r|r|r|r|}
\hline & $\begin{array}{c}\text { LBN } \\
\text { circum }\end{array}$ & $\begin{array}{c}\text { EPI } \\
\text { (n) }\end{array}$ & $\begin{array}{c}\text { shaft } \\
\text { (n) }\end{array}$ & $\begin{array}{c}\text { ratio } \\
\text { (shaft/EPI) }\end{array}$ \\
\hline size 1b & 0.36 & 11 & 208 & 18.91 \\
\hline \multicolumn{5}{|c}{} \\
\hline size 2 & 0.26 & 201 & 2921 & 14.53 \\
\hline \multicolumn{5}{|l}{} \\
\hline size 3 & 0.12 & 4 & 498 & 124.50 \\
\hline
\end{tabular}

Abrasion damage caused by trampling is present in moderate frequencies in all animal size classes and skeletal regions (figure 6.7). Generally, smaller animals show higher proportions of trampling damage as do dense, smoother surfaced bones such as long bones and ribs. Along with carnivore damage, the frequencies of trampling damage shows that the bone's exposure on the ground surface likely contributed to its postdepositional fragmentation.

Figure 6.7. The frequencies of abrasion damage observed on the bone surfaces.

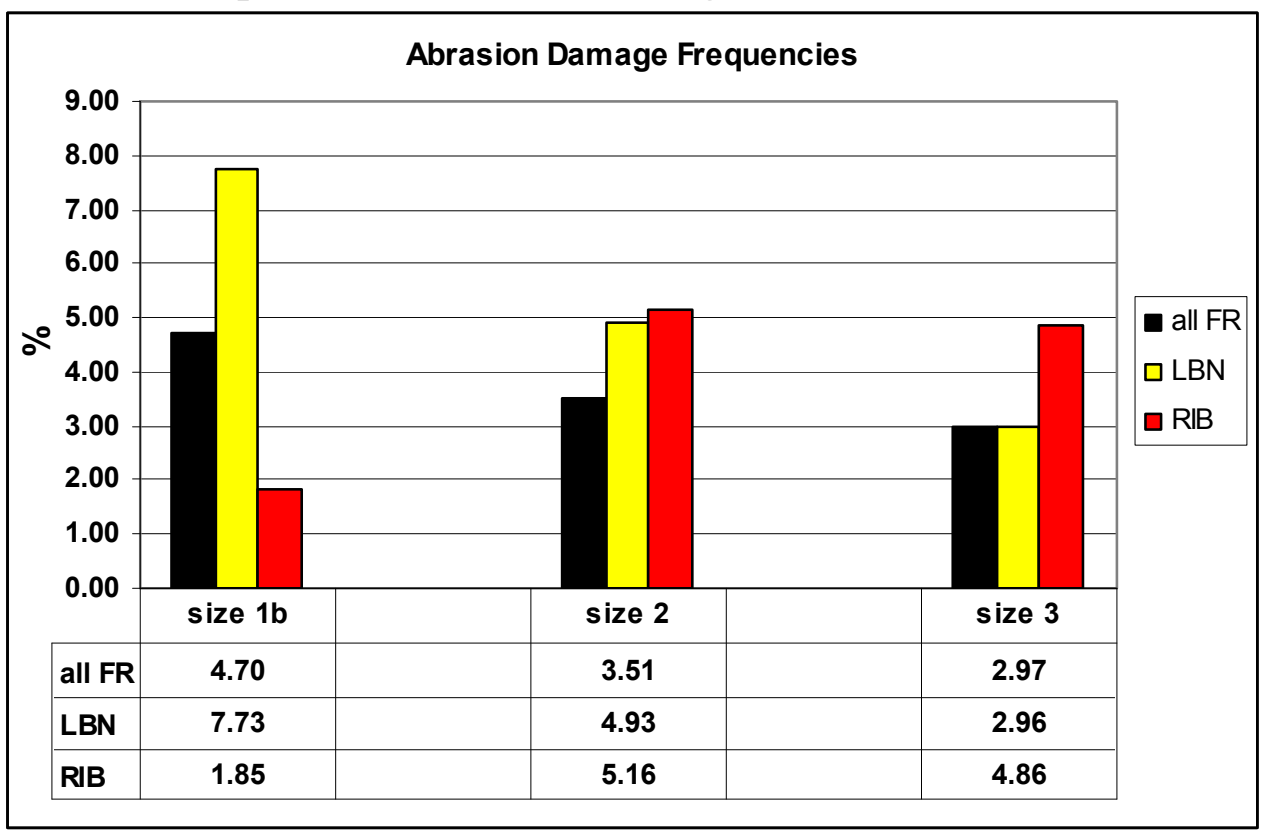

B. Taxonomic Representations: The mammalian fauna from DBYC 6 is dominated by domestic stock, with a small component of wild game (table 6.5). MNI counts show that 
sheep (Ovis aries) outnumber both cattle (Bos taurus) and pigs (Sus scrofa) in ratios of about $7: 1$. The high degree of fragmentation inhibited the ability to identify many bone fragments to specific taxonomic levels. Bone fragments only able to be identified to broader taxa such as mammal, artiodactyl, or bovid specimens greatly outnumber those bone fragments that were only able to be identified to the species level. The other domestic mammals identified in DBYC 6 are a cat (Felis catus) and a dog (Canis familiaris).

Though sheep outnumber cattle and pig through MNI, meat yield estimates show that cattle were significant contributors to the meat consumed by the inhabitants at Elsenburg (table 6.6). Though pigs and cattle are equally represented through MNI, the pigs only provided a small amount of meat due to their very young ages. It is assumed that the bone fragments that could not be identified to the species level would increase meat weight totals but would not change the meat yield ratios between sheep and cattle significantly. Due to the principles of calculating MNIs (Grayson 1984: 27-49; Klein and Cruz-Uribe 1984: 26-34), many of these fragments could not be assigned to additional individuals than those already identified to the species level.

The wild mammalian portion of the DBYC 6 suggests that the fauna around Elsenburg was still relatively diverse in the mid-eighteenth century (table 6.5). The wild fauna include the small bovids such as a gray duiker (Sylvicapra grimmia) and the steenbok (Raphicerus campestris). The rabbit specimens that are able to be identified to the species level are wild and belong to the Lepus capensis species. Other wild 
Table 6.5. Taxonomic representations in the DBYC 6 sample.

\begin{tabular}{|c|c|c|}
\hline TAXON & NISP & MNI \\
\hline Bos taurus, cow & 52 & 3 \\
\hline Ovis aries, sheep & 1014 & 20 \\
\hline Sus scrofa, pig & 21 & 3 \\
\hline Lepus capensis, Cape hare & 6 & 2 \\
\hline indet Lagomorpha & 3 & $\mathbf{1}$ \\
\hline Sylvicapra grimmia, gray duiker & 12 & 1 \\
\hline Raphicerus campestris, steenbok & 4 & 1 \\
\hline indet Raphicerus & 1 & $\mathbf{1}$ \\
\hline Orycteropus afer, aardvark & 1 & $\mathbf{1}$ \\
\hline Procavia capensis, Cape hyrax & 2 & 1 \\
\hline Canis familiaris, dog & 5 & 1 \\
\hline Felis catus, cat & 1 & 1 \\
\hline indet carnivora & 5 & 1 \\
\hline indet rodentia & 1 & 1 \\
\hline indet mammal 1a & 4 & 1 \\
\hline indet mammal $1 \mathrm{~b}$ & 27 & 1 \\
\hline indet mammal 2 & 1688 & 1 \\
\hline indet mammal 3 & 511 & 1 \\
\hline indet artiodactyla 2 & 1103 & 2 \\
\hline indet bovid $1 \mathrm{~b}$ & 356 & 4 \\
\hline indet bovid 2 & 3571 & 15 \\
\hline indet bovid 3 & 961 & 2 \\
\hline $\begin{array}{l}\text { Passer melanurus melanurus, } \\
\text { Cape sparrow }\end{array}$ & 3 & 1 \\
\hline $\begin{array}{l}\text { Ploceus capensis capensis, Cape } \\
\text { weaver }\end{array}$ & 5 & 2 \\
\hline indet Ploceidae & 1 & 1 \\
\hline Speo bicolor, starling & 18 & 3 \\
\hline indet Phasianidae, poss. peacock & 2 & 2 \\
\hline $\begin{array}{l}\text { Streptopelia capicola, Cape turtle } \\
\text { dove }\end{array}$ & 2 & 1 \\
\hline Colomba livea, pigeon & 11 & 4 \\
\hline Gallus gallus, chicken & 102 & 11 \\
\hline indet bird & 1 & 1 \\
\hline indet Anatidae & 18 & 4 \\
\hline $\begin{array}{l}\text { Anatidae dom, domestic duck } \\
\text { Anas erythrorhyncha, yellow- }\end{array}$ & 51 & 3 \\
\hline billed duck & 1 & 1 \\
\hline $\begin{array}{l}\text { Alopochen aegyptiacus, Egyptian } \\
\text { goose }\end{array}$ & 5 & 1 \\
\hline $\begin{array}{l}\text { Plectropterus gambensis, spur- } \\
\text { winged goose }\end{array}$ & 2 & $\mathbf{1}$ \\
\hline $\begin{array}{l}\text { Chersina angulata, angulate } \\
\text { tortoise }\end{array}$ & 409 & 11 \\
\hline $\begin{array}{l}\text { Pelomedusa subrufa, Cape } \\
\text { terrapin }\end{array}$ & 43 & 5 \\
\hline indet reptile & 8 & 1 \\
\hline indet Chiroptera & 1 & 1 \\
\hline TOTAL & 10032 & 119 \\
\hline
\end{tabular}


Table 6.6. Estimated meat contributions for the sheep and cattle from DBYC 6.

\begin{tabular}{|c|r|r|r|}
\hline & MNI & Ibs/animal & $\begin{array}{c}\text { total } \\
\text { weight(lb) }\end{array}$ \\
\hline Bos taurus & 3 & 500 & 1500 \\
\hline Ovis aries & 20 & 70 & 1400 \\
\hline
\end{tabular}

mammalian species present in the sample include the Cape hyrax (Procavia capensis), a bat (Chiroptera ind) and an aardvark (Orycteropus afer), which is represented by the presence of a single phalange.

The birds from DBYC 6 include both domestic and wild species (table 6.5). The domestic birds include chickens (Gallus gallus) and domestic duck (Anatidae dom). The wild birds are diverse and include small birds such as the Cape sparrow (Passer melanurus melanurus), the Cape turtle dove (Streptopelia capicola), the Cape weaver (Ploceus capensis capensis), and the starling (Speo bicolor), as well as water fowl such as the yellow-billed duck (Anas erythrorhyncha), the Egyptian goose (Alpochen aegyptiacus), and the spur-winged goose (Plectropterus gambensis). The wild birds are generally each represented by one individual except the starling (MNI of 3) and the weaver (MNI of 2). An MNI of 4 ducks are not able to be identified because the bones are subadult that had not yet developed sufficient morphology at the time of death to allow a more specific identification to domestic or wild taxa. In addition, two very large individuals of the Pheasantidae Family have been identified as possible peacocks.

Reptiles are relatively numerous and included the terrestrial angulate tortoise (Chersina angulata) and the freshwater Cape terrapin (Pelomedusa subrufa) (table 6.5). Tortoise outnumbers the terrapin in the DBYC 6 sample by a ratio of about 3:1 through MNI. Though they would not have been major sources of food, these reptiles were common introductions into the Dump deposit. 
Hart and Halkett (1993: 55) also identified other faunal resources found in the Dump that were not part of this analysis. Though not quantified, the predominant shellfish recovered from DBYC was reported to be the black mussel, white mussel, and the alikreukel. Other mollusks that were recovered include limpets and whelks, but in smaller amounts. These shellfish were harvested from both sandy and rocky marine substrates. Fresh and marine water fish species were also identified in the Dump (Hart and Halkett 1993: 65).

C. Ages of the Fauna: The sheep at Elsenburg were mostly slaughtered at relatively older ages. Payne's (1973: 293-294) M3 tooth wear stages show that the sheep were mainly slaughtered during stages $\mathrm{G}$, which corresponds to about four to six years of age (figure 6.8). Two mandibular M3 specimens in stages $\mathrm{H}$ and I denote that these sheep were slaughtered between six and 10 years of age. The remaining adult dentition supports the tooth wear data obtained from the M3s. The few deciduous teeth in DBYC 6 fall into the age ranges of the adult molar data except one mildly worn dP4, which suggests that one individual was probably less than one year of age when slaughtered (Silver 1969: 297). The dentition is considered a confident representation of the sheep deposited in the Dump, because actualistic studies show that the immature dentition from young animals fed to carnivores tend to be left behind compared to bones from scavenged carcasses (Munson and Garniewicz 2002: 410-415).

Sheep postcranial epiphyseal fusion data supports the dentition data (table 6.7). The great majority of the epiphyses are fused including most of the epiphyses that fuse around three to 3.5 years of age (Silver 1969: 285-286). The highest proportion of subadult specimens also come from the epiphyses that fuse between three and 3.5 years 
of age. One proximal radius fragment reveals that one lamb was slaughtered before 10 months of age. Although the high degree of fragmentation from taphonomic processes such as carnivore scavenging may have selectively deleted some of these subadult epiphyses suppressing their representation in the boney sample, the postcranial sample mirrors the dentition which shows that most sheep were slaughtered at relatively older ages.

Figure 6.8. Sheep M3 molar tooth wear profiles using Payne's (1973: 293-294) stages.

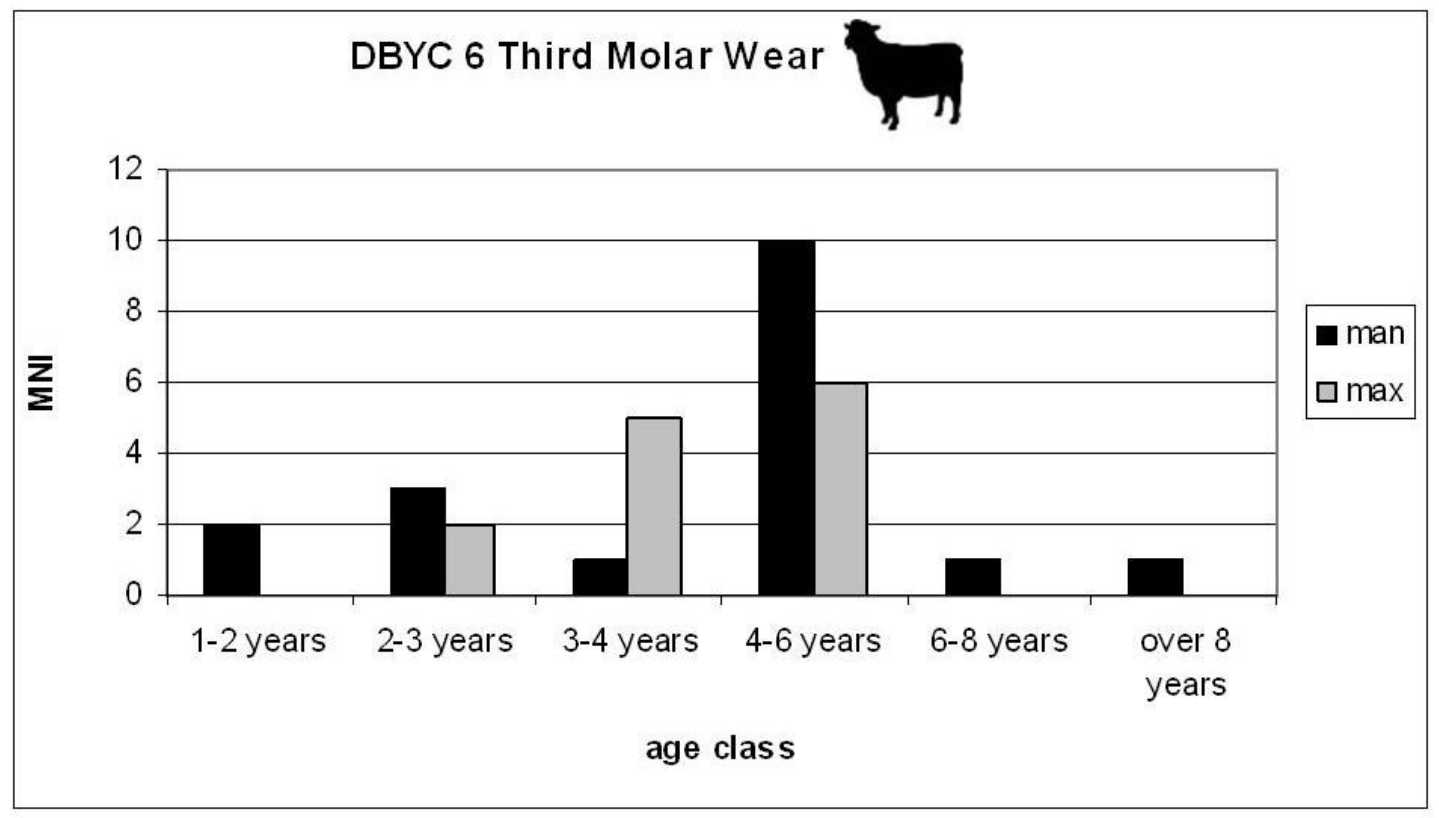

Table 6.7. Sheep postcranial epiphyseal fusion NISP.

\begin{tabular}{|l|c|r|r|}
\hline & $\begin{array}{r}\text { fusion age } \\
\text { (Silver 1969) }\end{array}$ & $\begin{array}{c}\text { subadult } \\
\text { N }\end{array}$ & \multicolumn{1}{c|}{$\begin{array}{c}\text { adult } \\
\text { N }\end{array}$} \\
\hline SCA & $\mathbf{6 - 8} \mathbf{~ m}$ & 0 & 24 \\
\hline Dist HUM & $\mathbf{1 0} \mathbf{~ m}$ & 0 & 26 \\
\hline Prox RAD & $\mathbf{1 0} \mathbf{~ m}$ & 1 & 28 \\
\hline Prox PHA1/2 & $\mathbf{1 3 - 1 6} \mathbf{~ m}$ & 0 & 10 \\
\hline Dist TIB & $\mathbf{1 8 - 2 4} \mathbf{~ m}$ & 1 & 29 \\
\hline Dist MTP & $\mathbf{1 8 - 2 8} \mathbf{~ m}$ & 1 & 6 \\
\hline Prox FEM & $\mathbf{3 0 - 3 6} \mathbf{~ m}$ & 6 & 9 \\
\hline Dist CAL & $\mathbf{3 0 - 3 6} \mathbf{~ m}$ & 6 & 9 \\
\hline Dist RAD & $\mathbf{3 6} \mathbf{~ m}$ & 2 & 10 \\
\hline Dist FEM & $\mathbf{3 6 - 4 2} \mathbf{~ m}$ & 0 & 1 \\
\hline Prox TIB & $\mathbf{3 6 - 4 2} \mathbf{~ m}$ & 5 & 2 \\
\hline Prox HUM & $\mathbf{3 6 - 4 2} \mathbf{~ m}$ & 4 & 0 \\
\hline Prox ULN & $\mathbf{3 6 - 4 2} \mathbf{~ m}$ & 2 & 8 \\
\hline
\end{tabular}


Cattle specimens are highly fragmented and ageing data was difficult to obtain from the DBYC 6 sample. An MNI of two individuals are represented by the dentition, and these are determined according to large disparities in the degrees of wear. One individual's teeth are extremely worn, probably near the point of having been ineffective tools for processing food. The second individual is represented by worn molar fragments and a dP4 that is in a very advanced degree of wear, which places the individual at about three years of age at slaughter (Silver 1969: 296). The only postcranial specimens that could provide ageing data fuse at very young ages and only show that those cattle were slaughtered after one year of age (table 6.8) (Silver 1969: 285-286).

Table 6.8. Cattle postcranial epiphyseal fusion NISP.

\begin{tabular}{|c|c|c|c|}
\hline & $\begin{array}{r}\text { fusion age } \\
\text { (Silver 1969) }\end{array}$ & $\begin{array}{c}\text { subadult } \\
\mathbf{N}\end{array}$ & $\begin{array}{c}\text { adult } \\
\text { N }\end{array}$ \\
\hline SCA & $7-10 \mathrm{~m}$ & 0 & 1 \\
\hline Dist HUM & $12-18 \mathrm{~m}$ & 0 & 2 \\
\hline Prox RAD & $12-18 \mathrm{~m}$ & 0 & 0 \\
\hline Prox PHA1/2 & $18 \mathrm{~m}$ & 0 & 0 \\
\hline Dist TIB & 24-30 m & 0 & 0 \\
\hline Dist MTP & $27-36 \mathrm{~m}$ & 0 & 0 \\
\hline Prox FEM & $42 \mathrm{~m}$ & 0 & 0 \\
\hline Dist CAL & 36-42 m & 0 & 0 \\
\hline Dist RAD & $42-48 \mathrm{~m}$ & 0 & 0 \\
\hline Dist FEM & $42-48 \mathrm{~m}$ & 0 & 0 \\
\hline Prox TIB & $42-48 \mathrm{~m}$ & 0 & 0 \\
\hline Prox HUM & $42-48 \mathrm{~m}$ & 0 & 0 \\
\hline Prox ULN & $42-48 \mathrm{~m}$ & 0 & 0 \\
\hline
\end{tabular}

Pig remains dumped into DBYC were generally very young. One pig is represented by a series of unerupted teeth including a $\mathrm{dP} 4$, which show that this pig was slaughtered before one year of age (Bull and Payne 1982: 56). The rare postcranial pig remains support the dental information where one unfused distal humerus shows that this pig was younger than one year of age (table 6.9) (Bull and Payne 1982: 66; Silver 1969: 285). In addition, a pair of vertebral fragments has unfused neural arches showing that 
this individual was younger than three to six months of age at death (Silver 1969: 285). In contrast to the dental and epiphyseal data, relative bone size and texture suggests that some older pigs are present in DBYC 6.

The non-mammalian fauna is also aged to identify collecting, hunting, or slaughter preferences. The bird and reptile samples are only able to be aged according to Table 6.9. Pig postcranial epiphyseal fusion NISP.

\begin{tabular}{|l|l|r|r|}
\hline & $\begin{array}{c}\text { fusion age } \\
\text { (Silver 1969) }\end{array}$ & $\begin{array}{c}\text { subadult } \\
\text { N }\end{array}$ & $\begin{array}{c}\text { adult } \\
\text { N }\end{array}$ \\
\hline SCA & $12 \mathrm{~m}$ & 0 & 0 \\
\hline Dist HUM & $12 \mathrm{~m}$ & 1 & 0 \\
\hline Prox RAD & $\mathbf{1 2} \mathrm{m}$ & 0 & 0 \\
\hline Prox PHA1/2 & $\mathbf{1 8 - 2 4} \mathrm{m}$ & 0 & 0 \\
\hline Dist TIB & $\mathbf{2 4} \mathrm{m}$ & 0 & 0 \\
\hline Dist MTP & $\mathbf{2 4 - 2 7} \mathrm{m}$ & 0 & 0 \\
\hline Prox FEM & $\mathbf{4 2} \mathrm{m}$ & 0 & 0 \\
\hline Dist CAL & $\mathbf{2 4 - 3 0 ~} \mathrm{m}$ & 0 & 0 \\
\hline Dist RAD & $\mathbf{4 2} \mathrm{m}$ & 0 & 0 \\
\hline Dist FEM & $\mathbf{4 2} \mathrm{m}$ & 0 & 0 \\
\hline Prox TIB & $\mathbf{4 2} \mathrm{m}$ & 0 & 0 \\
\hline Prox HUM & $\mathbf{4 2} \mathrm{m}$ & 0 & 0 \\
\hline Prox FIB & $\mathbf{3 0 - 4 2 ~} \mathrm{m}$ & 0 & 0 \\
\hline
\end{tabular}

coarse subadult or adult age classes through bone development. The chickens include eight adult and three subadult individuals. The domestic duck is represented by three adult individuals. The four indeterminate duck individuals are all subadults, and they were not able to be distinguished from wild ducks due to underdeveloped morphologies. The possible peacocks are present as both adult and subadult individuals. Except the turtledove, which is present as both adult and subadult individuals, all the wild birds are adults. The turtles and tortoises were found as subadults and adults. Tortoises are well represented by carapaces and plastrons of variable sizes, which may suggest tortoises of a variety of ages were collected (figure 6.9). 
Figure 6.9. Angulate tortoise marginal xiphiplastron fragments illustrating the size variability present in DBYC 6. Seven lefts and eight rights are shown.

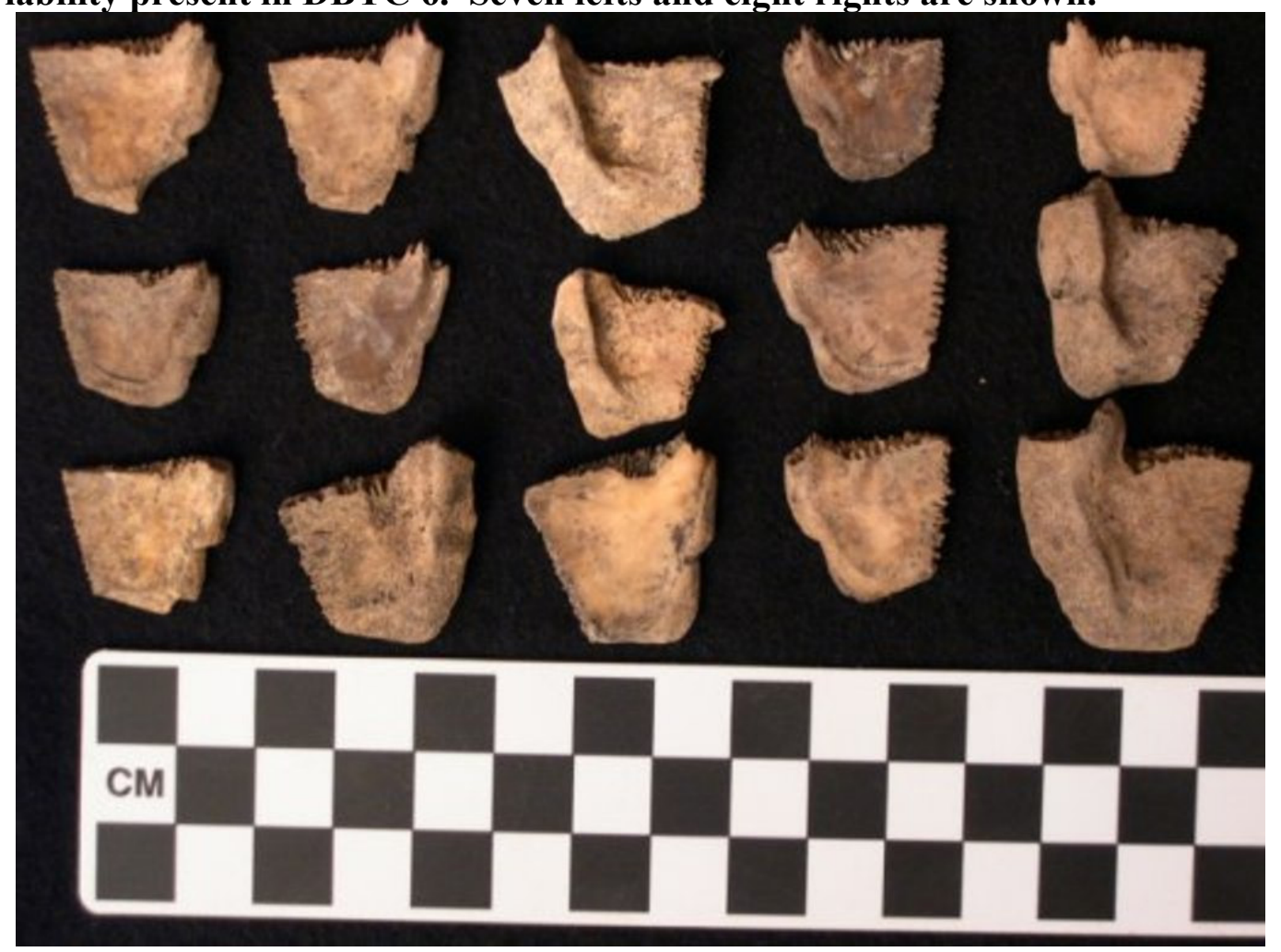

D. Skeletal Element Frequencies: Sheep are well represented by teeth and long bones from both the fore and hind limbs (figure 6.10). Softer and smaller bones such as the cranial vault, vertebrae, and most foot bones are relatively less well represented, probably due to the carnivore scavenging and trampling that had selectively deleted these portions of the skeleton or rendered them unidentifiable since they are softer and easier to ingest. The high representation of some softer bones such as the diagnostic hyoid, second cervical (axis) vertebrae, and innominates suggests that the other softer bones should have been more equally represented if taphonomic processes did not interfere with the deposit. Metapodials and foot elements are also rare, but are likely the product of a cultural practice such as skinning. One detail of the Elsenburg werf was the development a large amount of industries to work the farm, and hide processing and leather 
manufacture could have taken place at one of the outbuildings away from the Herehuis (De Bosdari 1953: 69; Fagan 1984: 35; Hart and Halkett 1993: 5; Walton 1974: 38).

Figure 6.10. Sheep skeletal element profiles expressed as MNI represented by each element.

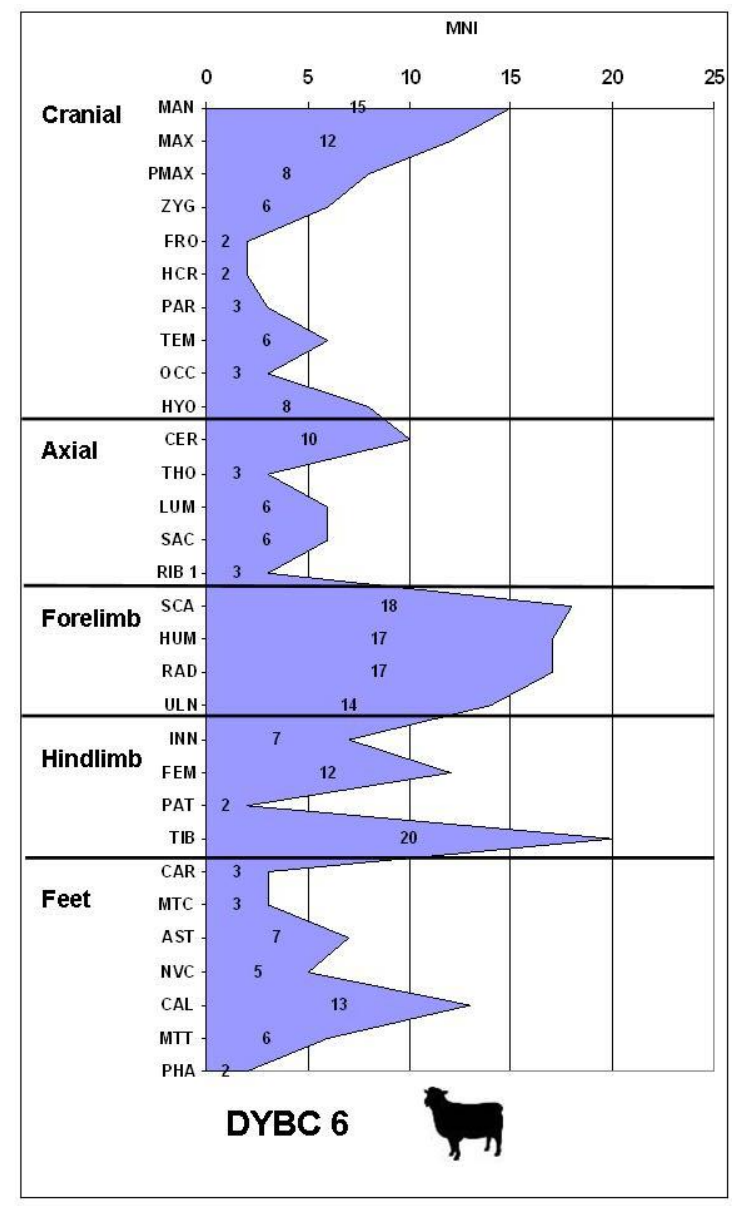

Both cattle and pigs are represented by too few identifiable specimens to allow any definitive statements to be made on skeletal element frequencies. Specimens from most skeletal regions are identified in DBYC, and it is assumed that nearly complete carcasses were deposited there after processing like the sheep.

E. Sheep Sex: Medial acetabular measurements of the sheep at Elsenburg show that they were relatively smaller than the sheep recovered from the Moat (figure 6.11). According to Greenfield (2005, np), the sheep that fall into the smaller medial acetabular 
measurements correspond to those for female sheep. The Elsenburg sheep produce a curve that peaks in the female end of the range, but also contains some that overlap into the male portion of the range (comparison with the Moat $t=3.58, P=0.0008$ ). Without control data from the historic sheep population, one cannot determine if the larger sheep are simply larger females or if they may be males. It has been documented that castration was practiced by the Cape Dutch during the eighteenth century (Mentzel 1944: 103), and it is very likely that wethers and a smaller amount of breeding rams were present at Elsenburg, which was a site of meat production. Horncores are often used at pastoral sites to determine sheep sex, but they were not used in that capacity in this analysis (Albarella 1995: 700-701). A contemporary account from the Cape recorded that both male and female sheep contained horns, which would not allow sheep sexes to be inferred through their presence (Mentzel 1944: 211).

Figure 6.11. Histogram illustrating the distribution of medial acetabular measurements for sheep in Elsenburg and how they compare to those from the Moat at the Castle of Good Hope.

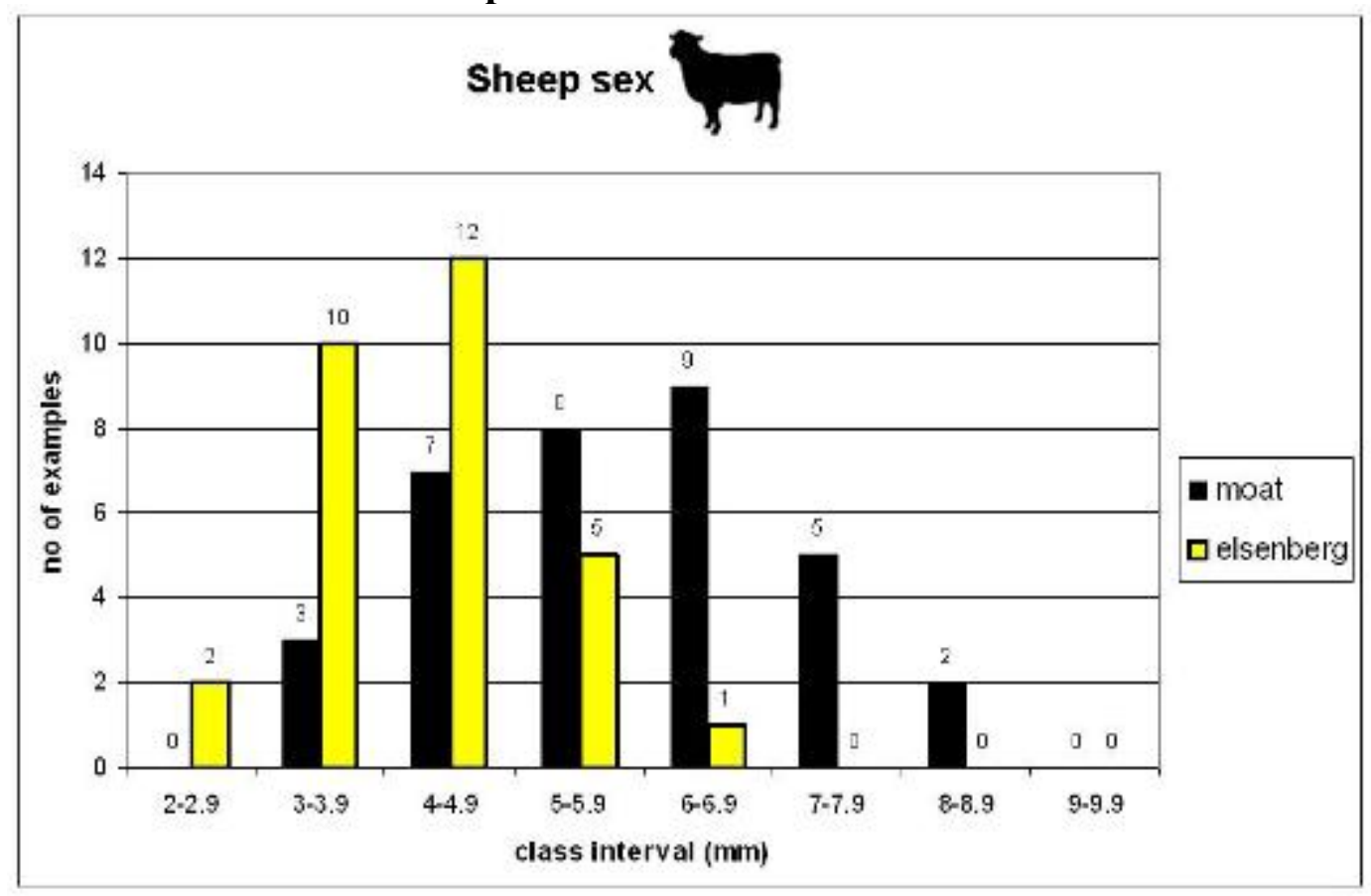


G. Butchery: Chop marks dominate cuts and scrapes marks in the Elsenburg faunal sample (figures 6.12 and 6.13 , table 6.10). The chops were aimed at dividing the carcasses into smaller segments and these are observed at major anatomical joints, such as where appendicular elements articulate with the girdles, where upper and lower limb segments meet, and near locations of foot removal. Cranial elements also exhibit heavy sagittal chops that divided the cranium into halves, likely to access the brain. These chops are most often observed on occipital and parietal bones, but are sometimes found on the frontal bone and also the premaxillary and mandibular symphyses. Additional chop marks are observed along the vertebral column. These vertebral chops accomplished two goals, which were to split the vertebral column into sagittal halves and also transversely at natural anatomical segments along the column. Chop marks are also commonly observed on rib fragments at regular locations such as at the rib head or proximal shaft near the tubercle and also the midshaft. These chops separated the ribs from the vertebrae and also divided the ribs into regular short segments.

Butchery is also observed at other important locations on the skeleton. Cuts and scrapes are common on upper limb bones to remove meat masses from the bone (figures 6.12 and 6.13). Additional knife-related butchery is observed on the cranium which includes cut marks posterior to the orbits and vertically on the premaxillae. These cranial cuts are likely the result of skinning around the head aimed at releasing the tightly adhering skin around the orbits. The hyoid bone was a focus of knife cuts to separate the tongue from its anchor. Ten of the $23(43.48 \%)$ hyoid fragments contain cut marks. Six mandible fragments also contain cuts medially posterior to the mandibular symphysis to further separate the tongue from any bony attachments. Two $\mathrm{C} 1$ (atlas) vertebrae contain 
transverse cut marks across their ventral surface, which may be evidence for slicing of the throat during slaughter (Shaw 1997: 93).

Table 6.10. The frequencies of butchery and burning in DBYC 6.

\begin{tabular}{|c|c|c|c|c|c|c|c|}
\hline burning & \multicolumn{2}{|c|}{ chop } & \multicolumn{1}{c|}{ cut } & \multicolumn{3}{c|}{ scrape } \\
\hline $\mathbf{n}$ & $\%$ & $\mathbf{n}$ & $\%$ & $\mathbf{n}$ & $\%$ & $\mathbf{n}$ & $\%$ \\
\hline 884 & 9.06 & 1067 & 10.93 & 366 & 3.75 & 31 & 0.32 \\
\hline
\end{tabular}

Burning is observed in moderate frequencies in DBYC 6 (table 6.10). Fire altered bone fragments range from being charred to being fully calcined. A number of fragments are only partially calcined, being burnt on the exterior and charred on the interior surface. The color of these fragments was modified to a grayish white color, which has been demonstrated to be the result of a fire having burnt a bone that contained meat or a large quantity of grease (David 1991: 74). Burning is most common on long bone fragments, suggesting that roasts were common components of the cuisine at Elsenburg. It is unknown if roasts included meat from the axial portions of the carcass since they are underrepresented due to various taphonomic processes mentioned above.

H. Pathologies: The DBYC 6 faunal sample contains some evidence of trauma that has not been observed in the other Cape sites. The lateral process of a lumbar vertebrae and the caudal margin of a scapula from size 2 bovids exhibit breaks that were in the process of healing with porous bony cysts. One cow maxilla contains a circular hole just anterior to the infraorbital foramen suggesting that the cow suffered from an abscess. Lastly, one sheep metacarpal contains an osteochondritis dissecan on the proximal articular surface, where an osteochondritis dissecan is a hole that is "result from the herniation of small portions of the joint cartilage through the articular surface of the bone" (Dobney et al. 1996: 38). The exact causes of this trauma are not fully understood but they are suspected to result from sudden physical stress or impact trauma. 
Figure 6.12. Locations of chop, cut, and scrape marks on sheep from DBYC6. Butchery marks on the ribs are not illustrated. (templates by Cutureau 1996).

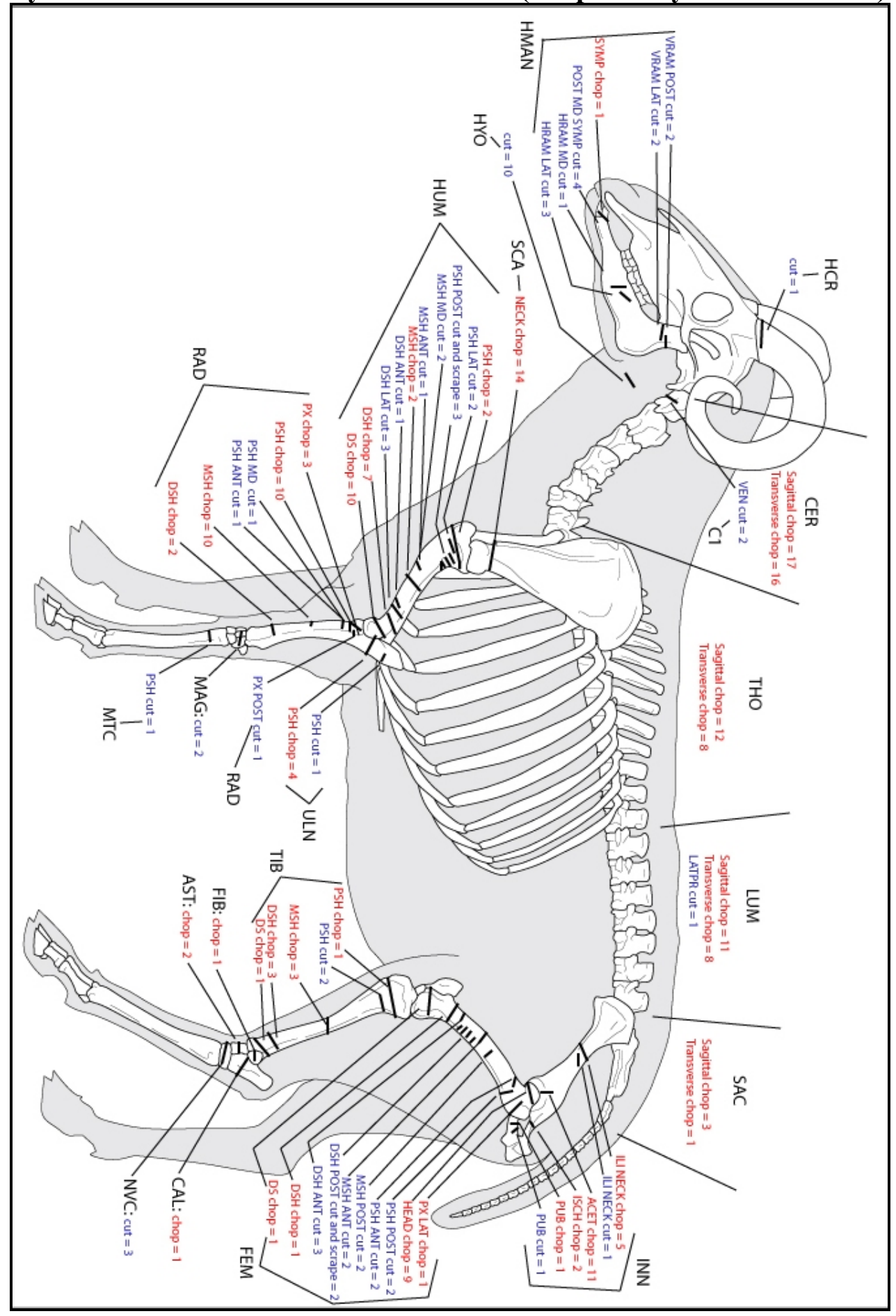


Figure 6.13. Locations of chop, cut, and scrape marks on cattle from DBYC6. Butchery marks on the ribs are not illustrated. (templates by Cutureau 1996).

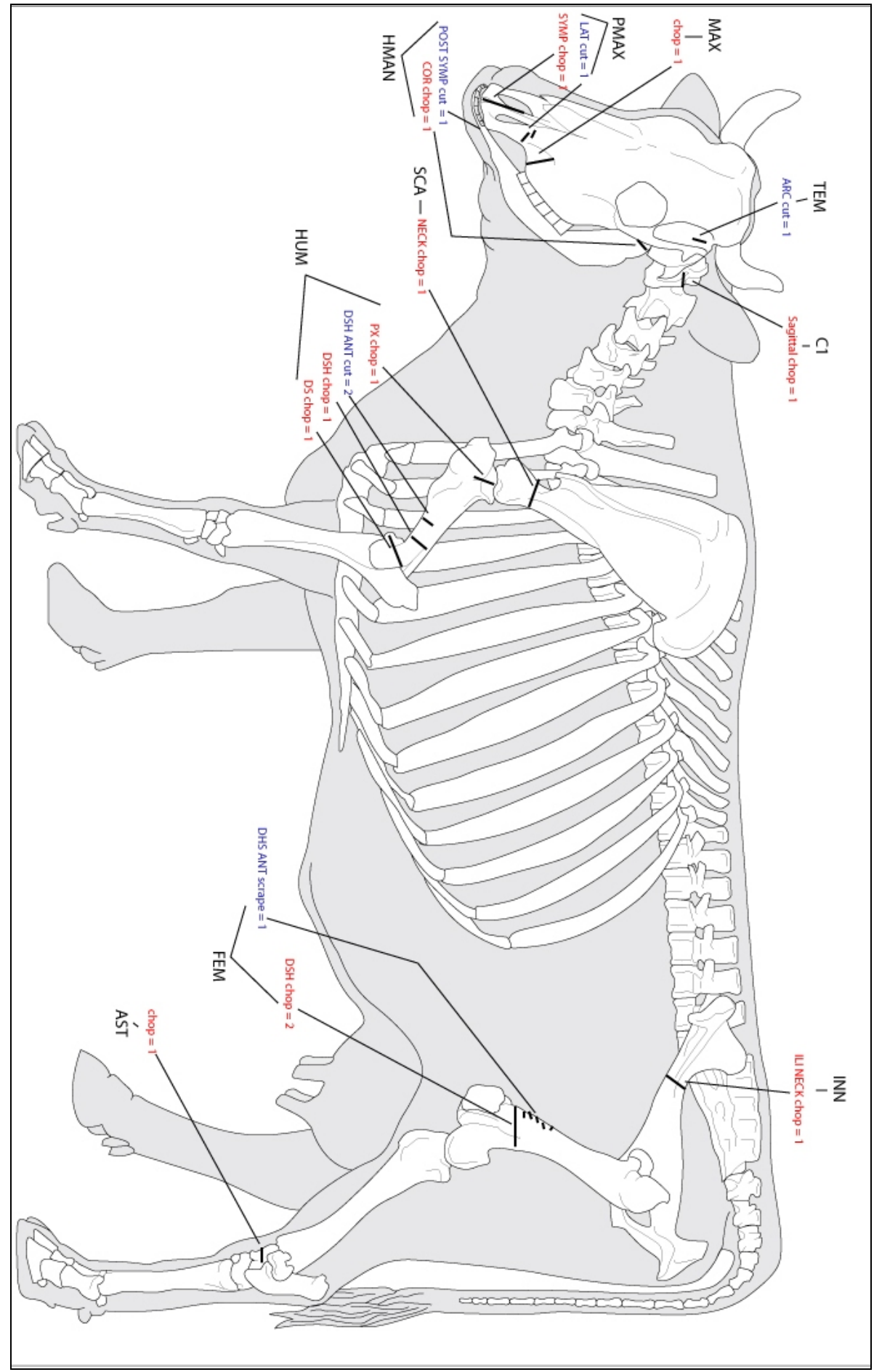




\section{DISCUSSION}

The fauna from the Dump at Elsenburg provides details about the various aspects of animal use from local meat consumption to herd management practices designed to provide meat for $\mathrm{VOC}$ requirements during the mid-eighteenth century.

A. Meat Consumption and Herd Management at Elsenburg: The archaeological and documentary records clearly demonstrate that sheep were important components in the Cape diet, outnumbering other domestic fauna (i.e. Cruz-Uribe and Schrire 1991: 96; Elphick 1985: 160; Hall et al. 1993: 52; Mentzel 1925: 101; Ross 1988: 253). In accord with this, the DBYC 6 sample shows that sheep outnumber both cattle and pigs in a ratio of about 7:1 MNI. This is within the "living ratio" of sheep and cattle recorded at Elsenburg in the Stellenbosch census records where these documents show sheep outnumbering cattle in ratios from 4:1 to 9:1 MNI (J188, J189, J193- J200 Cape Archives Census Records).

The butchery and cooking observed in the Dump fauna reflect a diet that mainly consisted of roasts of mutton, beef, and some wild game. Butchery is dominated by axe chopping located at the joint articulations and other anatomical segments to divide the carcass. The frequency of charring and burning in the sample demonstrates that the bones were in direct contact with high heat or the fire itself. As described above, the whitish gray color, partially calcined characteristic of many bone fragments indicates burning of bones containing meat or high quantities of grease. In addition, fully calcined bone has been demonstrated to be the result of intense heating from direct, prolonged contact with fire (David 1991: 74). In addition to roasts, sections of ribs were prepared by chopping at proximal and midshaft areas of the rib shafts. Knife cuts and scraping on 
limb and vertebral elements appear to have been aimed at removing meat at muscle attachments. It cannot be determined if the meat was removed before roasting as fillets, or afterwards to cut the meat to facilitate consumption. There is no conclusive evidence in the sample to conclude that pork was roasted, though pig butchery patterns are similar to that of other animals.

Besides the consumption of major meat yielding portions of the carcass, lower yielding parts, especially the skull, were also utilized. Sheep and cattle hyoid and medial mandible fragments exhibited cutting indicative of tongue removal (Armitage 2004: 6; Landon 1996: 69). Though only observed on sheep specimens, the cranium was cut on the muzzle and the posterior of the orbits to remove the skin. In addition, the crania were often sagittally chopped into halves through the occipital and parietal bones, and this midsagittal chopping was occasionally observed continuing up through the frontal, premaxilla and mandibular bones to access the brain. Traditional recipes describe preparing boiled calves' and sheeps' heads as a whole or as halves after they had been skinned, while using the brain and tongue together in a separate dish (Beeton 1861: 877 in Mennell 1985: i; Coetzee 1977: 66). A similar boiled dish may be inferred here at Elsenburg since no cranial fragments show any burning.

Skeletal element frequencies and butchery suggest that hides were used from the sheep as a secondary product to the meat. Skinning marks were identified as cuts and chops around the shafts of the distal limb bones such as the radius, tibia, and metapodials, plus across the nonarticular sides of the carpals and tarsals (Binford 1981: 136; Binford and Bertram 1977: 91; Landon 1996: 67; Reitz 1986a: 325-327; Shaw 1997: 93-96). The skeletal part frequencies for sheep illustrate a low proportion of foot elements, suggesting 
that these bones were removed along with the hide to a location away from the rest of the carcass. Archaeological precedence from a Late Medieval/Early Modern tannery in England shows that the tanning industry is associated with a preponderance of foot elements at the site that were brought in with the skins (Shaw 1997: 92-93). Further evidence for the removal of foot elements is the presence of burnt or charred ends of the distal limb bones exposed through the removal of more distal metapodials and other foot elements. These bones contained little or no tissue to protect the bone from heat. Thirteen of the total $65(20.00 \%)$ bovid metapodial fragments show evidence of burning.

The age and sex data present an interesting picture of sheep management practices at Elsenburg as they portray the farm as a site of meat production. The sheep recovered from the Dump were relatively old at the time of their slaughter having been slaughtered mainly between four to six years of age, as well as some up to 10 years of age. Only a few were slaughtered younger than three years of age, and one lamb was slaughtered before 10 months of age. The Elsenburg sheep are therefore, on average, older than the sheep deposited in the Moat, Oudepost I, F2, DKG, Parade, or Paradise sites (Abrahams 1996: 244; Avery 1989: 115; Cruz-Uribe and Schrire 1991: 99; Hall et al. 1993: 52; and see chapters 3, 4, 5, 7). Sex ratios demonstrate a high representation of ewes in the Dump deposit. Though most sheep seem to have been ewes, wethers or rams may be present since the medial acetabular measurement curve extends into the larger male portion of the range. A farm focused on meat production would be expected to retain a larger proportion of reproductive females in their flock, while reproductive males could be kept in smaller numbers since one male is capable of impregnating many females (Dobney et al. 1996: 30-31, 39-40; Payne 1973: 281-282). Combining the age and sex 
data shows that the Dump deposit contains older ewes, which were slaughtered after their reproductive prime, but before they lost any substantial meat yield efficiency. This accords with the practice of letting the reproductive ewes grow old enough to obtain the maximum number of lambs without endangering the physical qualities of the lambs or the ewes (see Mentzel 1921: 56). This inference fills the gap in the archival documents that simply counted the quantities of sheep present at Elsenburg without any information about flock demographics (J188-J200 Cape Archives Census Records; MOOC 7/1/25 Cape Archives Estate Papers).

Archaeological information on the cattle at Elsenburg is minimal due to a small sample size and the high degree of fragmentation. The age data from the bone and dentition shows that the few cattle were relatively old with one about three years of age, and another near the end of its productive life. No acetabulae were present to determine the sex of the cattle. If the cattle are assumed to be female, the presence of the older individuals would allow the development of an interpretation similar to the sheep, with older females being been used for reproduction, meat, and probably milk. The more calves produced by each cow would increase the availability of milk. If the cattle are assumed to be male, it might indicate that they were used for an extended period as draught oxen, reproduction, or simply meat. Epiphyses are lacking, so the identification of arthritis that is commonly associated with aged, hard-labor animals could not be determined to infer any cattle usage at Elsenburg. Contrasting with the sheep, the documents related to Elsenburg actually provide information about cattle demographics. A variety of cattle were described. Though it was compiled after the Dump was deposited, Hop's Staat end Inventaris recorded after her death on 25-26, January 1776, 
describes a variety of cattle. Included in this inventory are quantities of "trekoysen" or "trekbeesten" used as draught oxen and "koeyen en kalveren door malkederen" which are female cows with calves for milking. The milk cows and calves (recorded together) are recorded in a ratio of 2:1 to draught oxen. Relevant to the old cattle individual in the archaeological deposit, the inventory did record "10 oude trekoysen", old draught oxen (MOOC 7/1/25 Cape Archives Estate Papers).

Sheep outnumber pigs in the Dump in a ratio of about 7:1 MNI, which is higher than the "living ratio" recorded in the documents. The "living ratio" was never closer than 18 sheep to one pig for any one year during the Dump's period (J196 Cape Archives Census Records). Pigs held particular importance at Elsenburg, and their presence in the Dump supports the interpretation that it was deposited during Hop's occupation (Hart and Halkett 1993: 25; Klose 1997: 123). Pigs only appear in large numbers in the archival record at Elsenburg beginning in 1742 when Geibelaar and Hop gained control of the farm (J194-J196 Cape Archives Census Records). After Hop remarried to Melck in 1752, pigs were remained present in the Elsenburg records (J198-J200 Cape Archives Census Records). The pigs were probably present through the personal choice of Hop, because other than for personal use, there was little market for local pork (Mentzel 1944: 101). The ages at which the pigs were slaughtered at Elsenburg shows that they were for personal use. Mentzel (1944: 101) states that pigs were often slaughtered at six to eight weeks and then pickled. Though absolute ages were often not able to be determined, the archaeological pigs were clearly very young; where one was determined to have been younger than three to six months of age at slaughter. Hop's Staat end Inventaris recorded information about these pigs at Elsenburg. One place in the inventory records " 16 
varkens, "general pigs. Later, at another location on the farmstead, the inventory describes "90 verkens grood en kleyn," or pigs great and small (MOOC 7/1/25 Cape Archives Estate Papers). The Dump's pigs can be interpreted as the young pigs described by Mentzel (1944: 101, 213-214) which were slaughtered young and suitable for pickling. The presence, number, and butchery of the pigs present in the archaeological deposit support the documents and the interpretation that the pigs were primarily for personal consumption during Hop's period instead of being raised for the local market.

Except for one specimen identified during the cursory analysis of the entire Dump deposit, horses are nearly invisible in the archaeological record. This contrasts greatly with the historical documents that record great numbers of horses at Elsenburg throughout the period represented by the Dump. In 1749 (an arbitrarily chosen midpoint of the Dump deposit) there were 50 horses at Elsenburg, which was $5.0 \%$ of the total number of horses on 110 farms in all of Stellenbosch (n=1000 horses) (J196 Cape Archive Census Records). Though this percentage is relatively low, it must be noted that 80 of these 110 farms with horses had 10 or fewer horses per farm (J196 Cape Archive Census Records). Hop's Staat end Inventaris provides a more detailed description of the horses kept at Elsenburg during the Dump deposit. The different types of horses recorded include "wagen paarden," or wagon horses, "ryd paarden," or riding horses, and "paarden in zood," or general horses kept outside. These details are informative when taken alongside information about the workshops at the farmstead. The inventory includes a wagonmaker's shop, possibly inferring an industry where horses were raised for the wagons or carriages produced on site (MOOC 7/1/25 Cape Archives Estate Papers). It is therefore understandable that horses were not food sources, and their virtual 
absence in the archaeological record is expected. Contemporary accounts imply that horse farming was not a very lucrative business during the early eighteenth century. Kolben (1731b: 8) stated that in 1712 the Persian horses, originally imported in the seventeenth century, increased so much that they sold for only 18 Dutch schillings. Mentzel (1921: 57-58) supports Kolben stating that the market was glutted by the overstock of horses, but a good riding horse would earn the seller 40 to 60 rixdollars, while a cart with four horses would earn $3331 / 3$ rixdollars. It is likely that the Elsenburg occupants, especially Melck, participated in these industries due to the large numbers of riding and wagon horses alongside the existence of a wagonmaker's workshop.

Though Elsenburg was situated in the relatively sparsely settled frontier, away from the more urbanized Cape settlement, wild mammals only formed a minor proportion of the faunal sample. This contrasts sharply with Oudepost I, the VOC frontier outpost even more distant into the frontier along the western coast where wild fauna made up about 50 percent of the MNI in the terrestrial faunal assemblage (Cruz-Uribe and Schrire 1991: 96). Increased colonial settlement was recognized to have severely diminished the numbers of wild bovids through habitat modification and overhunting (Mentzel 1921: 61; 1925: 101; 1944: 102; Raven-Hart 1970: 270; Skead 1987: 813-855), but the very small bovids persisted for some time as they were still present in the vicinity of the colonial settlements in the early eighteenth century (Skead 1980: 448-449, 456). Since Elsenburg was a self-sufficient farmstead, where meat mostly came from the domestic stock, wild fauna was more likely a novelty to be eaten only occasionally (Kolben 1731b: 116).

The wild fauna, especially the steenbok and duiker present in the Dump sample, were probably acquired on the property. The small bovids were popular food choices 
when they were able to be acquired, even though their meat was described as white, tough, and often of a high odor (Kolben 1731b: 116), and these small bovids were consumed at Elsenburg as is evident through butchery and burning. Though the other wild mammals in the Dump do not show direct evidence for consumption, contemporary accounts often described eating these animals. Kolben (1731b: 118) described the aardvark as a "desirable food." Hares, either domestic or wild, were said to cure scurvy if eaten with the imported porcellan herb (Kolben 1731b: 83). Artifacts such as gun flints and lead shot, which may possibly be related to hunting, were also recovered from the Dump (Hart and Halkett 1993: 42-49).

Early country farmsteads often had their own menageries to raise chickens and domestic ducks (Mentzel 1925: 101). The large presence of domestic fowl at Elsenburg supports Mentzel's (1925: 101) statement that fowl was usually only kept by those people on country farms since they had the available space. Though no menagerie structure was identified at Elsenburg, the domestic fowl were likely obtained from personal stocks. Chickens were the most commonly consumed poultry in the Dump, and they were slaughtered as adults and occasionally as older subadults. Domestic ducks were only able to be positively identified when in the adult stage of development, but the four subadult individuals were likely domestic ducks. The wild birds, especially the ducks, would have been acquired through hunting. The smaller birds like the starling, weaver, dove, and sparrow; cannot be confidently identified as food sources or as incidental inclusions into the Dump. Hart and Halkett (1993: 42-49) identified a moderate quantity of bird shot in the Dump, which they state may have been pulled from the hunted meat as in the modern analogy of a hunter and a shotgun. Kolben (1731b: 157) stated that the starling was a 
serious pest to wine producers, because large flocks would consume the valuable grapes on the vines. Being the most common wild bird in the Dump on a major wine producing farm, the starlings might have been incorporated into the archaeological deposit through pest control measures and/or consumption.

Reptiles were common inclusions into the Dump deposit, and while several burnt specimens suggest that they were food items, they would not have provided large amounts of meat. Both the turtles and tortoises were collected in subadult and adult stages of development, and size did not seem to be a factor during the collection of tortoises since limb bones and carapace fragments exhibit a wide variety of sizes (figure 4.9).

B. Status: Although the history and the ceramic analysis clearly identify Elsenburg as a high status household, the fauna does not conspicuously support this interpretation. Elsenburg is dominated by older animals and very little lamb, which is often considered a hallmark of a high status diets (Hall n.d.a.: 3; 1992: 389-390; Thackeray 1989: 1). Supporting this interpretation is a contemporary account that states "old ewes suffice for slaves" (Mentzel 1921: 56). There exists the possibility that the Elsenburg inhabitants were business conscious, and they retained their animals for fulfilling VOC requirements instead of consuming meat according to social hierarchical norms in a market economy (i.e. Jones 2002: 132; Miller 1979: 174; Reitz 1987: 110). It may have been more important to keep their animals longer for breeding purposes and meat production. Unlike other "high status" diets which have been argued to be dominated by meaty appendicular elements (e.g. Crader 1984; 1989; 1990; Lev-Tov 1998; Lyman 1987a; 
Reitz 1987; Schulz and Gust 1983; Scott 1996), all skeletal elements in the Dump are well represented when taphonomic processes are considered.

The difference in recognizing status in the Elsenburg fauna from that interpreted at other historic period contexts could be due to inconsistencies in investigating, reporting, or understanding taphonomic processes. Reitz (1987) points out that social or economic status may not necessarily be represented in the faunal remains from a large number of American sites along the Atlantic coastal plain, which is stressed through a lack of methodological uniformity that makes inter-site comparisons difficult. A piece of research considered to be one of the influential works on plantation status in the faunal record is by Diana Crader at Thomas Jefferson's Monticello (1984; 1989; 1990). Monticello could have been a suitable comparison with Elsenburg since they were both self-sustaining farmsteads in rural settings, but there the comparisons end, because taphonomic issues were not integrated into the cultural interpretations at Monticello. There, the master's diet was heavily represented by meaty limb bones from animals of young through prime ages. The slave, or underclass diet, was heavily represented by fragmentary bones of less meaty elements and older individuals. Little concern is paid to the fact that the high status diet was recovered from a deep, protected dry-well, while the underclass diet was mostly recovered from a scatter within and around a structure susceptible to weathering, carnivore, and trampling damage (refer back to critique in Chapter 5).

The routine, everyday diet on high status and self-sufficient country farms may not be consistent with the stereotypical high status diet. High status in the diet may only be expressed during specific, finite moments in time, such as dinner parties, banquets, or 
holidays when social standing needed to be demonstrated to guests. These isolated, special events could easily be masked by normal everyday consumption patterns. Everyday meals may look like the diet of a stereotypical lower class household, especially on distant country farms removed from the more socially integrated urban households where meat was purchased from local markets.

The Elsenburg faunal sample does contain some elements that could be considered aspects of higher status. Tortoises and turtles, especially their livers, were considered fine and delicate, but their ubiquitous presence in the local environment would have made them common food items (Kolben 1731b: 214). Wild bovids were generally rare, and restrictions against their hunting were enforced (Cruz-Uribe and Schrire 1991: 95; Mentzel 1925: 101; Van der Merwe 1995: 29). Their increasing rarity made them curiosities and therefore desirable even though the meat was not considered the finest (Kolben 1731b: 116). And lastly, the pig was able to be consumed at very young age out of taste preference instead of meat yield purposes.

C. Elsenburg's Position in the Cape Meat Industry: Elsenburg may have served as a receiving point for livestock obtained from the indigenous Khoekhoe. The nearby Klapmuts farm was a VOC frontier outpost where indigenous livestock were obtained through trading and military seizure, and these animals would have been distributed throughout the neighboring farms to be hybridized, bred, and pastured (Schulz 2005: pers. com).

Though no VOC meat contract was discovered for the inhabitants of Elsenburg (Schulz 2005: pers. com.), contemporary taxation and census inventories record cattle and sheep number far in excess of what would be necessary for local market demands. 
Elsenburg regularly ranked amongst the largest stock holding farms in Stellenbosch during the 1740s and 1750s (J188-J200 Cape Archives Census Records). In fact, while at most only six official contracts were awarded for meat provisioning in six year intervals, the other burghers would also produce products for sale to the VOC including wine, meat, and wheat (Fouche 1914: xix; Mentzel 1921: 171; 1925: 55-56; Ross 1988: 247; Van der Merwe 1995: 1).

The archaeological record reveals that Elsenburg was a center of meat production, while other sites such as the Castle Moat and DKG were receptacles for the sheep remains obtained from these VOC meat orders (see Chapters 3, 4). The hypothesis that the prime aged individuals, wethers, rams, or females unnecessary for reproduction, were sent off to fulfill meat requirements is supported by the data from the two sites. At Elsenburg, the ewes were kept older, till four to six years of age or even older, in order to obtain a maximal amount of lambs. This contrasts with the Moat where age profiles show that slightly younger sheep between 1.5 to four years of age were slaughtered along the beachfront. Elsenburg's ewes were then slaughtered at the point where further reproduction may have endangered the physical qualities of the ewe or the lamb. The Dump deposit contained a low proportion of wethers or rams, as they would have likely been sent off to fulfill the annual meat quotas. While Elsenburg was dominated by females, the Moat sheep fall across the range of medial acetabular measurements from smaller to quite large. This would correspond to the presence of some female individuals, but a majority fall into the male end of the distribution.

Another note on the fauna is the presence of a few pathologies, where Elsenburg is the only site from the analyses presented in this thesis that contained any identifiable 
pathologies in the domestic stock. Two size 2 bovid elements, a transverse process of a lumbar vertebrae and the caudal margin of a scapula, were in the process of healing from a fracture. These were probably not serious health endangering injuries, which did not necessitate the early slaughter of the individuals, allowing them to undergo the healing process. The osteochondritis dissecan lesion on the sheep metacarpal was the result of trauma to the joint (Dobney et al. 1996: 38). A cattle maxilla also contained a lesion of an unknown cause that was still in the process of bone absorption. Several factors may be responsible but can only be speculations such as older animals being more susceptible to injuries, inter-individual competition, or rough animal handling. The fact that these pathologies are present and that some had the opportunity to heal may go along with the maintenance of older animals as seen in Elsenburg stock. 


\section{CHAPTER SEVEN: Oudepost I Dump}

\section{HISTORY}

Oudepost I was a VOC frontier outpost with a fort, a lodge, and an unattributed structure called GCL, built on the shore of Langebaan Lagoon of Saldanha Bay up the Atlantic coast about $120 \mathrm{~km}$ north of the main Cape settlement (figure 7.1). The outpost was initially established 1669 as an effort to protect the Bay from a French territorial claim. After this threat passed, the post continued as a small provisioning post for calling ships and as a trading post with the indigenous Khoekhoe groups. Except for a period between 1673 to $1684 / 6$ when the post was abandoned after an attack by some of the indigenous people, Oudepost I was manned by a small contingent of four to 10 VOC soldiers until 1732 when a new outpost was built closer to a better water source (CruzUribe and Schrire 1991: 92; Schrire 1988: 218; 1990: 12-13; 1992: 362-363; 1995: 77-78, 87; Schrire et al. 1993: 21). Two fauna-rich contexts were identified at Oudepost I, which have been separated into the land-based, "terrestrial" collection and the Dump (DP) from the intertidal zone between the fort and the lagoon.

\section{TERRESTRIAL FAUNA SUMMARY}

The terrestrial fauna was recovered from the sandy deposits scattered around the three stone structures as well as a burial. In total, 7229 NISP of mammal and 174 NISP of tortoise were reported with great densities of fauna recovered from within and around the once-occupied structures of the lodge and fort (for full report see Cruz-Uribe and Schrire 1991). 
Figure 7.1. Map locating Oudepost I within the Western Cape including a plan of the three stone structures and DP on the shore of Langebaan Lagoon (adapted from Schrire et al. 1993: 21 showing a more accurate location of DP).

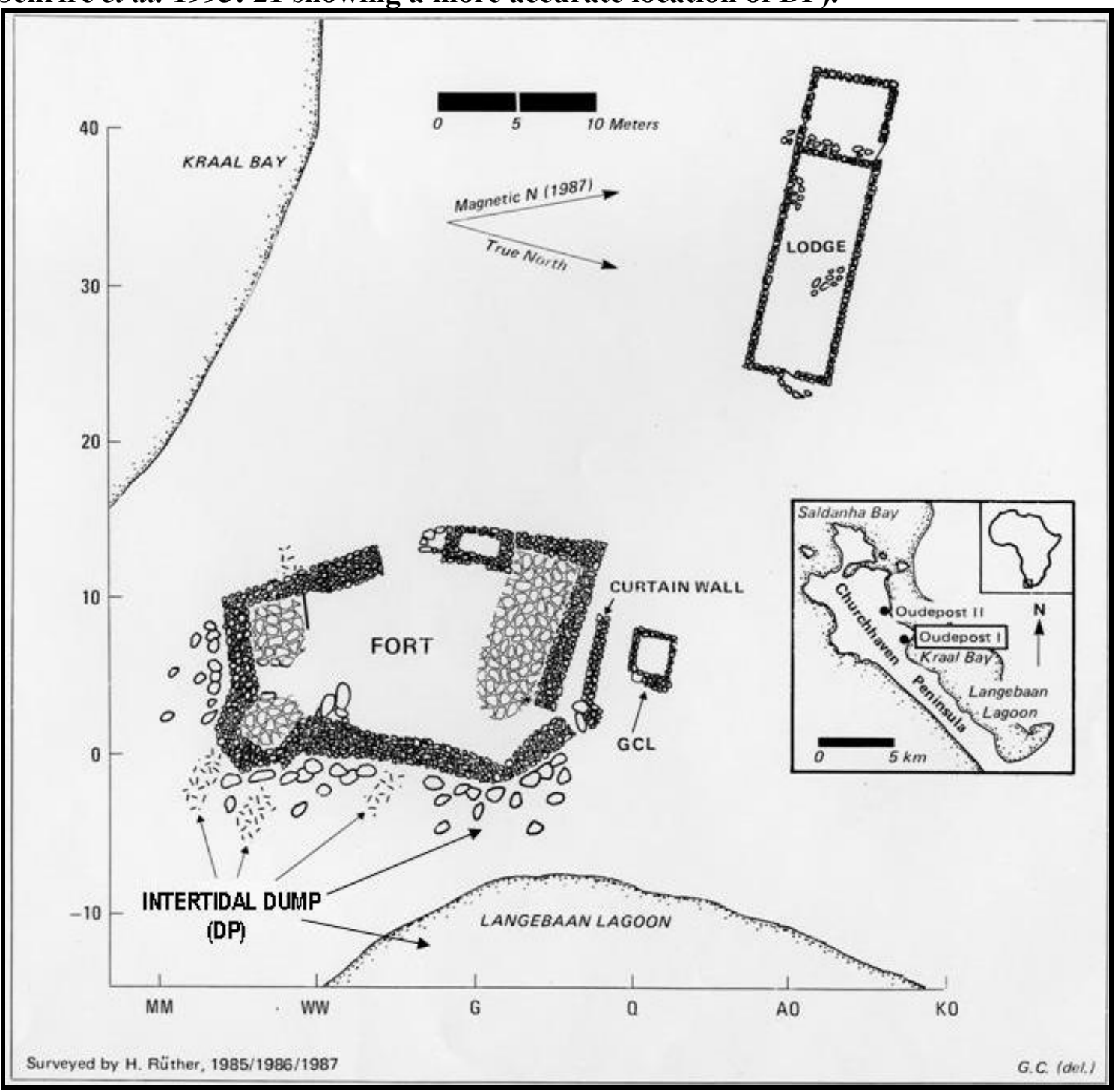

The animals present in the Oudepost I faunal sample include a wide variety of wild herbivores and carnivores along with the domestic stock of sheep, cow, and pig expected from an historic archaeological site. The high proportion of wild taxa at Oudepost I is remarkable and their inclusion in the historical deposits speaks to two different factors at the outpost. Cruz-Uribe and Schrire (1991: 96) interpret the high proportion of wild fauna as the result of the VOC soldiers supplementing their rations 
with wild game. The high proportion of wild game also speaks to the efficiency that the soldiers were able to acquire these animals with their superior technology which included horses, boats, and most importantly guns.

The domestic stock portion of the sample is dominated by sheep which may include both the indigenous as well as the hybrid form developed by the VOC (see Chapter 8 for a fuller discussion on the different breeds). The indigenous sheep were brought to the outpost through trade with Khoekhoe herders, while a possible mix of indigenous and hybrid sheep were delivered from VOC farmers and the abattoir at Mamre (Cruz-Uribe and Schrire 1991: 97). Analysis of the terrestrial faunal sample shows that a large proportion of the sheep was slaughtered between 18 and 24 months old with a second peak of slaughter older than two years of age. A number of lambs were also slaughtered before six weeks of age (NISP of 3 unerupted dP4s) (Cruz-Uribe and Schrire 1991: 98). Though cattle were numerous in the VOC holdings throughout the Cape, they are under-represented in the Oudepost I terrestrial fauna, this may be the result of taphonomic processes that caused the cattle to be less identifiable or differential deposition that removed the cattle remains from the settlement area. Pigs were also present at Oudepost I in small numbers, and their remains have been interpreted as the residues of live, on-site butchery instead of the importation of salted pig heads (CruzUribe and Schrire 1991: 96).

\section{ARCHAEOLOGICAL SUMMARY OF THE DUMP DEPOSIT}

Excavations at Oudepost I revealed a number of faunal remains and artifacts, but researchers felt that the quantities were much less than they expected for a site occupied 
by several men over a period of 50 years. Artifacts came from scatters within and around the fort and lodge, while no in-filled garbage pits were found (Schrire et al. 1993: 28). After the main excavations were completed, artifactual material was noticed eroding from between rocks in the inter-tidal zone of Langebaan Lagoon (refer back to figure 7.1). Finds within this zone, named the Dump (DP), included more fauna and artifacts similar to those found around the structures. Conjoins were able to be made between ceramics from the terrestrial and DP deposits, confirming this inference (Schrire et al. 1993: 29). Tobacco pipe stems produced a tight, unimodal distribution that dates DP earlier than the 1695 mean date pipe stems produced for the terrestrial deposits (Schrire et al. 1993: 30). The faunal sample from units 1 and 2 from DP includes a large amount of domestic animals. In contrast, DP contained a greater proportion of cattle post cranial material which was under-represented in the other assemblage. Speaking of one particular concentration, Schrire et al. (1993: 30) suggest that, in an effort to clean around the fort and lodge, DP "represents an early event of garbage disposal in the colonial occupation of Oudepost I that took place shortly after a major episode of butchery of domestic animals on the site."

\section{FAUNAL RESULTS FROM DP}

The fauna from the Oudepost I DP was analyzed in its entirety. Cruz-Uribe (n.d.; Schrire et al.: 1993: 30) previously analyzed and published the faunal analysis from the units DP 1 and DP 2. Cruz-Uribe (n.d.) counted about 1700 bone fragments from DP 1 and DP2, but only 227 diagnostic bone fragments have been reported (table 7.1). My analysis adds the sample from units DP3 through DP 16 excavated in 1995. The bones from DP were aggregated since they were from a continuous, unstratified midden. 
Where noted, calculations and descriptions were only made from DP 3 through DP 16 due to the additional data recorded from these faunal remains in my analysis. No faunal specimens were recovered from DP 15.

Table 7.1. Sample sizes (NISP) for both DP analyses.

\begin{tabular}{|c|r|r|r|}
\hline & $\begin{array}{c}\text { Bone } \\
\text { (NISP) }\end{array}$ & $\begin{array}{c}\text { Isolated } \\
\text { Teeth * } \\
\text { (NISP) }\end{array}$ & $\begin{array}{c}\text { Total } \\
\text { (NISP) }\end{array}$ \\
\hline DP 1-2 & $\mathbf{1 7 1}$ & $\mathbf{5 6}$ & $\mathbf{2 2 7 / 1 7 0 0}$ \\
\hline DP3-16 & $\mathbf{1 0 5 7}$ & $\mathbf{2 2 0}$ & $\mathbf{1 2 7 7}$ \\
\hline
\end{tabular}

* Teeth present in bone were not counted as isolated teeth.

A. Taphonomy: The bone fragments from DP were in poor condition due to their burial in a brackish lagoon environment. The DP was in a tidal zone so the bones would have been repeatedly submerged and dried, which contributed to their deteriorated condition. Only four $(0.38 \%)$ bone fragments retained a pristine, original surface condition and they were recovered from the units more distant from the intertidal zone (table 7.2). Most of the fragments exhibited severe rounding and cortical surface exfoliation with a powdery texture, which obscured any observation of surface modifications from biological or human taphonomic processes (figure 7.2). The brackish environment also caused the bone fragments to develop an orange-white or white bleached bone color.

Table 7.2. Bone fragment surface condition for DP 3-16.

\begin{tabular}{|c|c|c|c|c|c|c|c|c|c|c|c|c|}
\hline \multirow[t]{2}{*}{$\begin{array}{l}\text { surface } \\
\text { condition }\end{array}$} & \multicolumn{2}{|l|}{ pristine } & \multicolumn{2}{|l|}{$\begin{array}{l}\text { minor } \\
\text { rounding }\end{array}$} & \multicolumn{2}{|l|}{$\begin{array}{l}\text { major } \\
\text { rounding }\end{array}$} & \multicolumn{2}{|l|}{$\begin{array}{l}\text { major } \\
\text { exfoliation }\end{array}$} & \multicolumn{2}{|l|}{$\begin{array}{l}\text { minor } \\
\text { rounding } \\
\text { and major } \\
\text { exfoliation }\end{array}$} & \multicolumn{2}{|l|}{$\begin{array}{l}\text { major } \\
\text { exfoliation } \\
\text { and major } \\
\text { rounding }\end{array}$} \\
\hline & NISP & $\%$ & NISP & $\%$ & NISP & $\%$ & NISP & $\%$ & NISP & $\%$ & NISP & $\%$ \\
\hline DP 3-16 & 4 & 0.38 & 45 & 4.26 & 826 & 78.15 & 5 & 0.47 & 7 & 0.66 & 170 & 16.08 \\
\hline
\end{tabular}

Though the bone fragments show evidence of damage due to the depositional context, the bone fragment sizes were relatively large for both size 2 and size 3 mammal classes (figures 7.3 and 7.4). Two possible reasons for this large fragment size in DP could be that the bones were not severely broken by cultural or natural processes, or that the smaller bone fragments were selectively dissolved or winnowed away by tidal action. 
Bone breakage patterns show that the bones were broken in moderate frequencies after being deposited in DP (table 7.3). 23.15\% $(n=169)$ of the long bone fragments exhibited dry bone breaks that would have occurred after the bones had already been dumped into the lagoon. High long bone midshaft to epiphyses fragment ratios suggest that the less dense, and probably smaller, bone fragments were selectively deleted from the faunal sample (table 7.4). Discussion on skeletal part frequencies below will provide further insights into the taphonomic history of DP.

Figure 7.2. Illustrating flakey, powdery surface and rounding common on the bone fragments from DP.

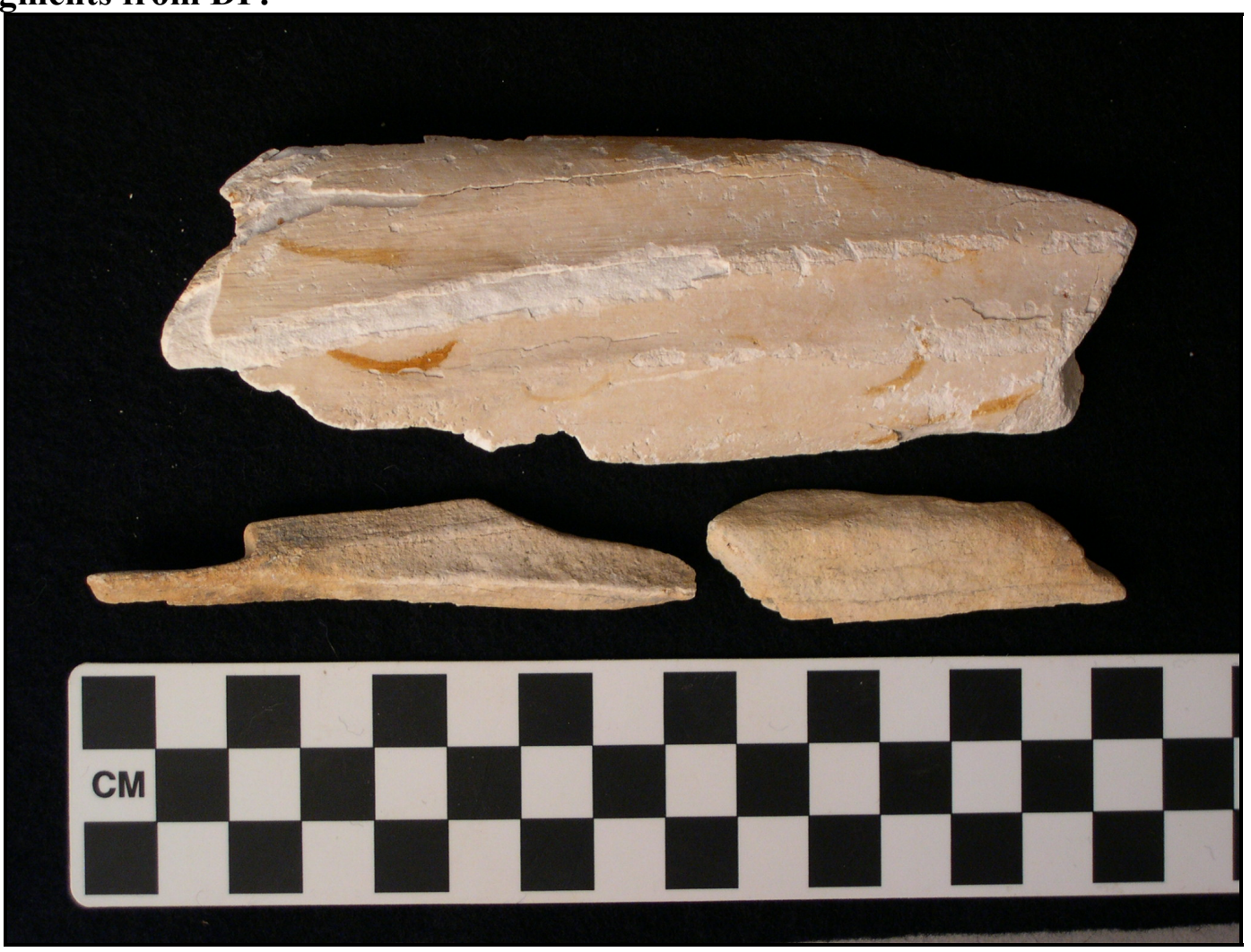


Figure 7.3. Mean measures of size 2 bone fragments from all sites.

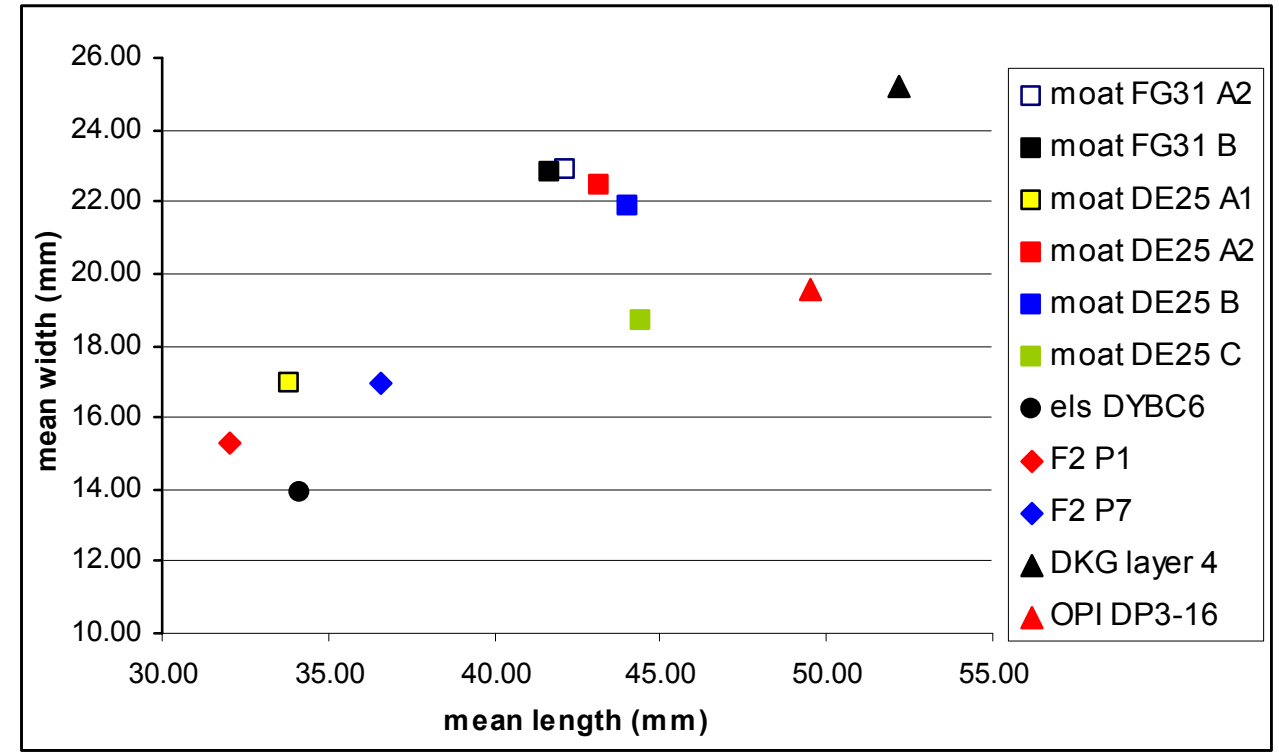

Figure 7.4. Mean measures of size 3 bone fragments from all sites.

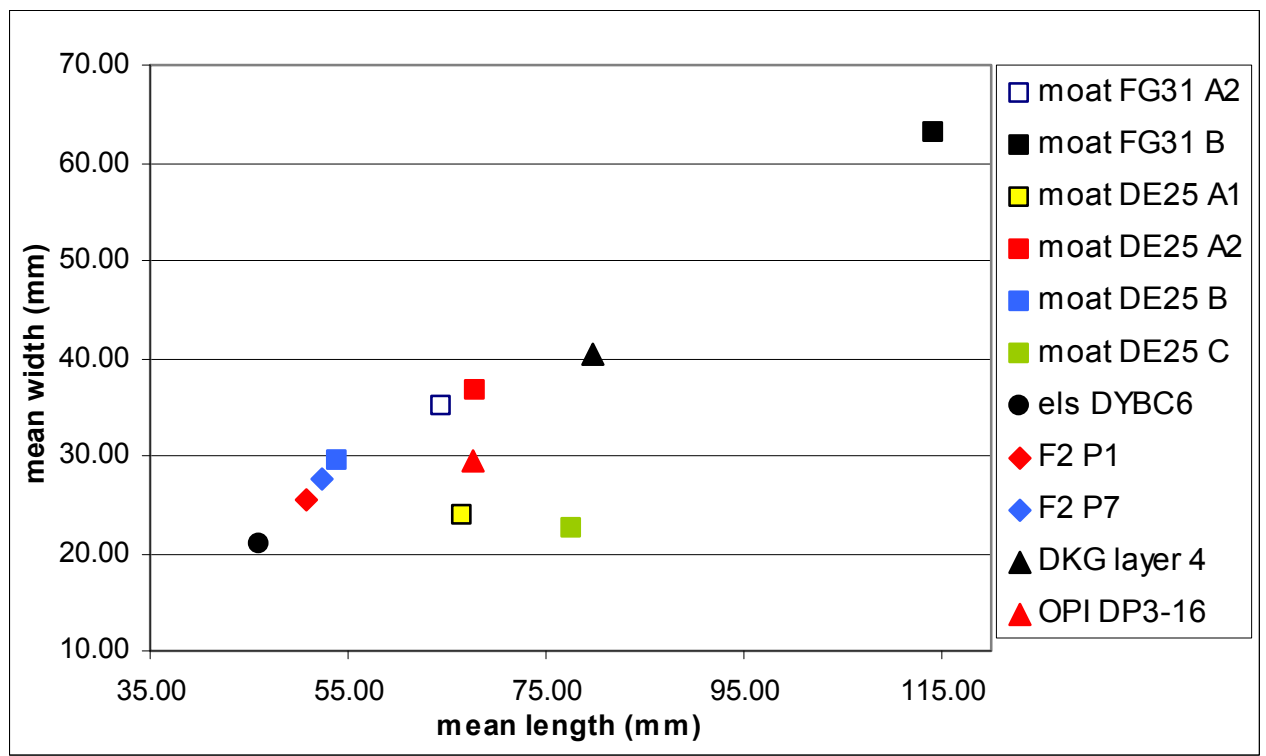

B. Taxonomic Representations: The DP fauna was dominated by domestic stock including sheep (Ovis aries), cattle (Bos taurus), and pig (Sus scrofa) (table 7.5). Sheep outnumbered cattle by a ratio of 4.67:1 MNI. Sheep outnumbered pig by a ratio of 14:1 MNI. One horse (Equus sp) phalange specimen represented an animal that was only 
Table 7.3. Bone breakage patterns from DP 3-16.

\begin{tabular}{|c|c|c|c|c|}
\hline \multirow[t]{2}{*}{ Break type } & \multicolumn{2}{|l|}{ All FR } & \multicolumn{2}{|c|}{ Long bone FR } \\
\hline & NISP & $\%$ & NISP & $\%$ \\
\hline 9-ind \& axial & 325 & 30.75 & 30 & 4.11 \\
\hline $8-1,2 \& 3$ & 0 & 0.00 & 0 & 0.00 \\
\hline 7-bone flake & 0 & 0.00 & 0 & 0.00 \\
\hline $6-2 \& 3$ & 1 & 0.09 & 1 & 0.14 \\
\hline $5-1 \& 3$ & 15 & 1.42 & 15 & 2.05 \\
\hline $4-1 \& 2$ & 67 & 6.34 & 67 & 9.18 \\
\hline 3-stepped & 45 & 4.35 & 43 & 5.89 \\
\hline 2-transverse & 43 & 4.07 & 43 & 5.89 \\
\hline 1-oblique & 561 & 53.07 & 531 & 72.74 \\
\hline total & 1057 & 100.00 & 730 & 100.00 \\
\hline
\end{tabular}

Table 7.4. Measures of long bone completion.

\begin{tabular}{|l|r|r|r|r|}
\hline & \multicolumn{1}{|l|}{$\begin{array}{l}\text { LBN } \\
\text { circum }\end{array}$} & $\begin{array}{l}\text { EPI } \\
\text { (NISP) }\end{array}$ & $\begin{array}{l}\text { shaft } \\
\text { (NISP) }\end{array}$ & $\begin{array}{l}\text { ratio } \\
\text { (shaft/EPI) }\end{array}$ \\
\hline size 2 & 0.34 & 10 & 195 & 19.5 \\
\hline & & & & \\
\hline size 3 & 0.21 & 47 & 457 & 9.73 \\
\hline
\end{tabular}

previously identified in the archaeological record through the discovery of a lead spur (Cruz-Uribe and Schrire 1991: 96)

The condition and fragmentation of the DP bones affected their ability to be identified, and this can be seen in the proportions of NISP compared to MNI (table 7.5). Though sheep outnumber cattle through MNI, the NISP of size 3 specimens, most not able to be identified to the species level, shows that they outnumber the size 2 specimens by a ratio of $818: 561$ or $1.46: 1$. Size 3 specimens may be underrepresented through MNI due to fragmentation and taphonomic damage, but NISP shows that the large animals were important allometric components of the DP fauna.

Wild fauna was relatively rare in DP compared to the findings from the terrestrial sample where they made up to $49.31 \%$ of NISP or $71.43 \%$ of MNI if carnivores are included in the calculations (Cruz-Uribe and Schrire 1991: 96). The largest portion of the wild fauna consisted of the wild bovids which included hartebeest (Alcelaphus 
buselaphus), steenbok (Raphicerus campestris), and duiker (Sylvicapra grimmia) (table 7.5). The other herbivores present in the DP sample include the hippopotamus (Hippopotamus amphibius), elephant (Probiscidean sp), and the angulate tortoise (Chersina angulata), the lone reptile that was identified by carapace fragments. The elephant was identified through the presence of ivory. The only carnivore identified in DP was the Cape fur seal (Arctocephalus pusillius). The rabbit specimens could not be identified to any domestic or wild species.

Table 7.5. Taxonomic representations in DP.

\begin{tabular}{|c|c|c|c|c|c|c|}
\hline \multirow[b]{2}{*}{ TAXON } & \multicolumn{2}{|c|}{ OP1 DP 3-16 } & \multicolumn{2}{|c|}{ Cruz-Uribe DP 1-2 } & \multicolumn{2}{|c|}{ TOTAL } \\
\hline & NISP & MNI & NISP & MNI & NISP & MNI \\
\hline Bos taurus, cow & 120 & 5 & 120 & 5 & 240 & 6 \\
\hline Ovis aries, sheep & 252 & 25 & 69 & 6 & 321 & 28 \\
\hline Sus scrofa, pig & 7 & 2 & 1 & 1 & 8 & 2 \\
\hline Equus ind, horse & 1 & 1 & & & 1 & 1 \\
\hline Sylvicapra grimmia, gray duiker & 2 & 1 & & & 2 & 1 \\
\hline Raphicerus campestris, steenbok & 11 & 2 & & & 11 & 2 \\
\hline $\begin{array}{l}\text { Raphicerus spp. } \\
\text { Alcelaphus buselaphus, }\end{array}$ & & & 16 & 3 & 16 & 3 \\
\hline hartebeest & 3 & 1 & 4 & 1 & 7 & 1 \\
\hline $\begin{array}{l}\text { Lagomorpha ind, rabbit } \\
\text { Hippopotamus amphibius, }\end{array}$ & & & 3 & 1 & 3 & 1 \\
\hline $\begin{array}{l}\text { hippopotamus } \\
\text { Probiscidean, elephant }\end{array}$ & 2 & 1 & 7 & 1 & $\begin{array}{l}7 \\
2\end{array}$ & $\begin{array}{l}1 \\
1\end{array}$ \\
\hline ind mammal 2 & 16 & 1 & & & 16 & 1 \\
\hline ind mammal 3 & 77 & 1 & & & 77 & 1 \\
\hline artiodactyla & 49 & 1 & & & 49 & 1 \\
\hline ind bovid $1 \mathrm{~b}$ & 15 & 1 & & & 15 & 1 \\
\hline ind bovid 2 & 183 & 1 & & & 183 & 1 \\
\hline ind bovid 3 & 501 & 1 & & & 501 & 1 \\
\hline $\begin{array}{l}\text { Chersina angulata, angulate } \\
\text { tortoise } \\
\text { Arctocephalus pusillius, Cape }\end{array}$ & 34 & 1 & & & 34 & 1 \\
\hline $\begin{array}{l}\text { Arctocephalus pusillius, Cape } \\
\text { fur seal }\end{array}$ & 5 & 2 & 7 & 3 & 12 & 4 \\
\hline TOTAL & 1278 & 53 & 227 & 21 & 1505 & 58 \\
\hline
\end{tabular}

C. Ages of the Domestic Fauna: Sheep were represented by a large quantity of isolated teeth. The ages for sheep were determined by using Payne's (1973) tooth wear stages as well as Silver's (1969) tooth eruption data; though absolute ages for individual specimens were rarely able to be determined. Through tooth wear stages, the sheep were determined 
to have been slaughtered at a relatively broad range of ages. First molars show that the sheep were slaughtered relatively old since the teeth were moderately worn (figure 7.5). One first molar, which erupts at five months of age, was only mildly worn (stage 3) which identifies the presence of a younger individual. Second molars show more clearly that the sheep were slaughtered at a wider range of ages and can provide the younger boundary for the slaughter age bracket (figure 7.6). The second molars at stage 1 were unworn meaning that some of the sheep were as young as nine months to one year of age at slaughter (Silver 1969: 297). The bulk of the second molars were in moderate wear (stages 4 to 8 ) showing that most of the sheep were slaughtered after 1.5 years of age (Payne 1973: 288, 293). The third molars provide a maximum age for the bracket the DP sheep were slaughtered. An MNI of three sheep had third molars in the G wear stage, which corresponded to about four to six years of age (figure 7.7). Taken together, the DP sheep were slaughtered between nine months to about six years of age, with the majority of the sheep being slaughtered about two to three years of age (stage E) (Payne 1973: 293).

Though they were common through NISP, cattle were not well represented by specimens that provided ageing data. Postcranial remains show that most cattle deposited in DP were older individuals since most epiphyseal fragments were in the adult stage of development (table 7.6). Proximal tibia, proximal humerus, and distal radius fragments show that at least one individual was slaughtered older than 3.5 to four years of age. At least one individual was younger than three years of age due to the presence of a pair of unfused distal metapodial fragments (Silver 1969: 286). The dentition was mostly 
moderately worn adult teeth that support the data obtained from the postcranial epiphyseal fusion stages.

Figure 7.5. Sheep first molar wear stages according to Payne (1973: 288).

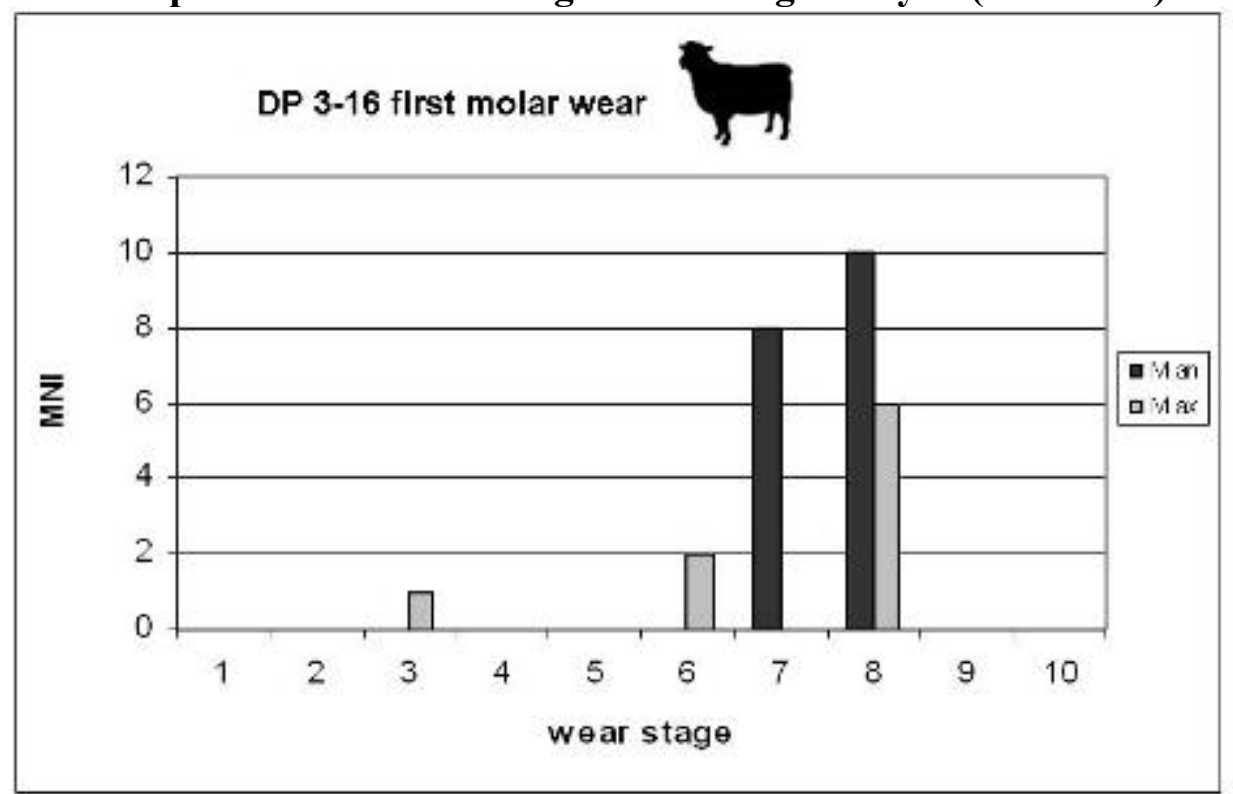

Figure 7.6. Sheep second molar wear stages according to Payne (1973: 288).

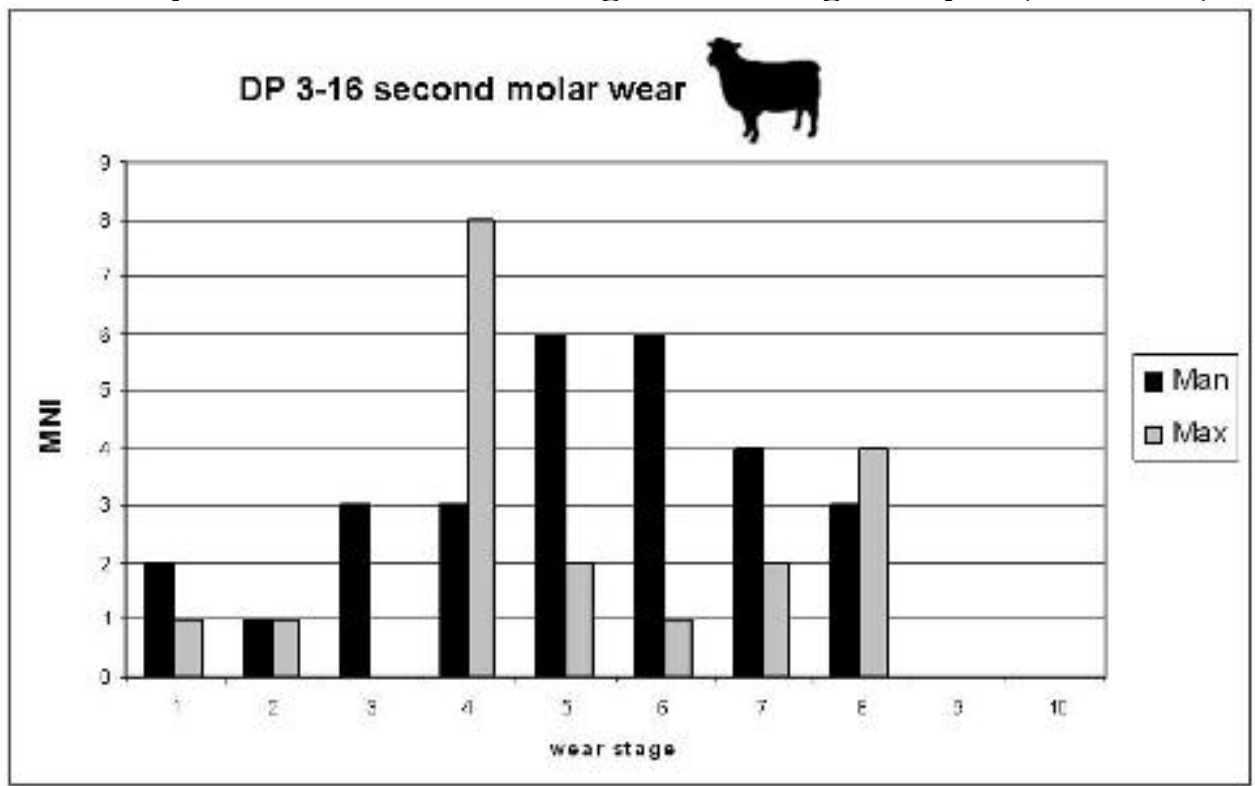


Figure 7.7. Sheep third molar wear stages according to Payne (1973: 293). Because the teeth were isolated, the age classes $A$ through $D$ could not be discerned because the associated second molar was needed to determine the third molar wear stage.

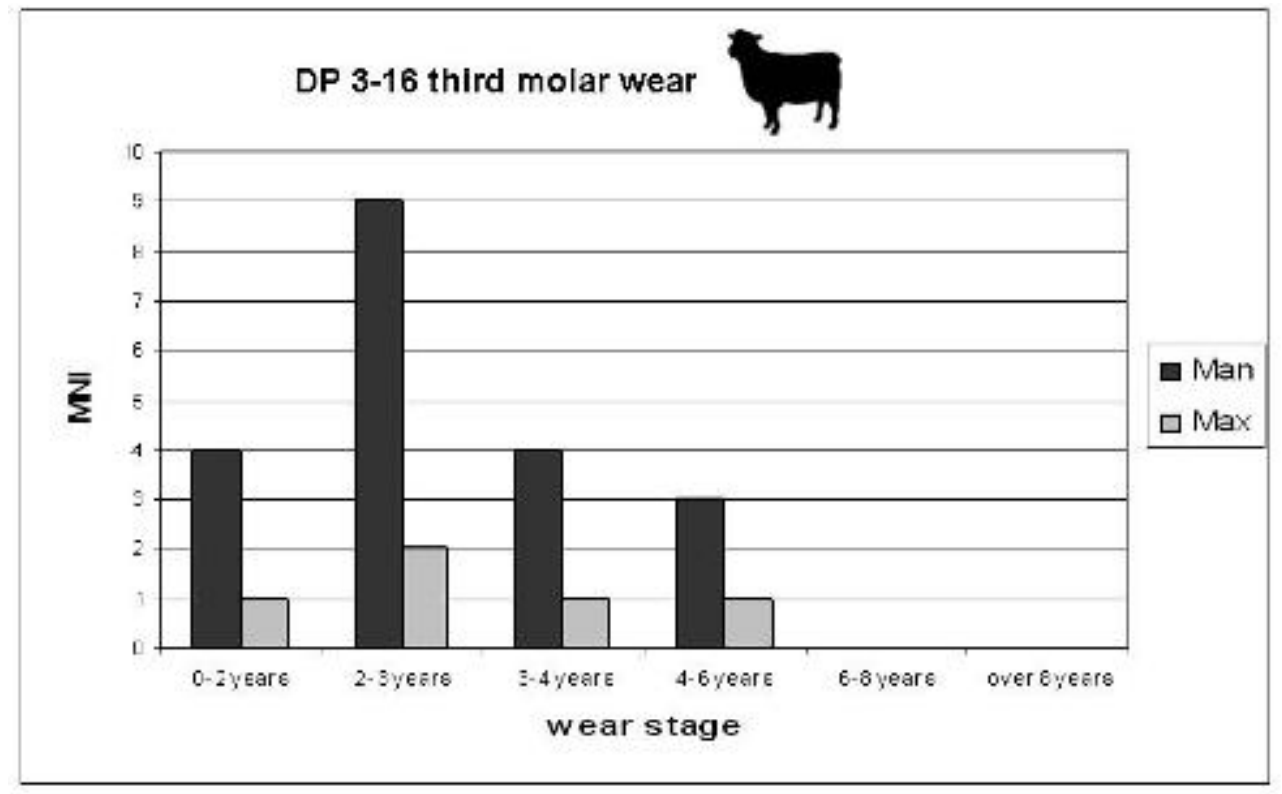

Table 7.6. Cattle postcranial epiphyseal fusion stages from DP 3-16.

\begin{tabular}{|l|l|r|r|r|}
\hline Element & $\begin{array}{l}\text { fusion age } \\
\text { (Silver } \\
\text { 1969) }\end{array}$ & \multicolumn{1}{|c|}{$\begin{array}{c}\text { subadult } \\
\text { (NISP) }\end{array}$} & $\begin{array}{c}\text { adult } \\
\text { (NISP) }\end{array}$ & $\begin{array}{r}\text { partial } \\
\text { (NISP) }\end{array}$ \\
\hline SCA & $\mathbf{7 - 1 0}$ mos. & 0 & 1 & 0 \\
\hline Dist HUM & $\mathbf{1 2 - 1 8}$ mos. & 0 & 6 & 0 \\
\hline Prox RAD & $\mathbf{1 2 - 1 8}$ mos. & 0 & 5 & 0 \\
\hline Prox PHA1/2 & $\mathbf{1 8}$ mos. & 0 & 4 & 0 \\
\hline Dist TIB & $\mathbf{2 4 - 3 0}$ mos. & 0 & 5 & 1 \\
\hline Dist MTP & $\mathbf{2 7 - 3 6}$ mos. & 2 & 6 & 0 \\
\hline Prox FEM & $\mathbf{4 2}$ mos. & 0 & 0 & 0 \\
\hline Dist CAL & $\mathbf{3 6 - 4 2}$ mos. & 0 & 0 & 0 \\
\hline Dist RAD & $\mathbf{4 2 - 4 8 ~ m o s . ~}$ & 0 & 1 & 0 \\
\hline Dist FEM & $\mathbf{4 2 - 4 8}$ mos. & 0 & 0 & 0 \\
\hline Prox TIB & $\mathbf{4 2 - 4 8 ~ m o s . ~}$ & 0 & 1 & 0 \\
\hline Prox HUM & $\mathbf{4 2 - 4 8 ~ m o s . ~}$ & 0 & 1 & 0 \\
\hline Prox ULN & $\mathbf{4 2 - 4 8 ~ m o s . ~}$ & 0 & 0 & 0 \\
\hline
\end{tabular}

Pigs were rarely represented by specimens that can provide ageing data (table 7.7). Fused phalange and distal tibia and an unfused calcaneus shows that at least one individual was between two and three years of age (Silver 1969: 285). Pigs were not represented by any dentition. 
Table 7.7. Pig postcranial epiphyseal fusion stages from DP 3-16.

\begin{tabular}{|c|c|c|c|c|}
\hline & $\begin{array}{l}\text { fusion age } \\
\text { (Silver } \\
\text { 1969: 285) }\end{array}$ & $\begin{array}{l}\text { subadult } \\
\text { (NISP) }\end{array}$ & $\begin{array}{c}\text { adult } \\
\text { (NISP) } \\
\end{array}$ & $\begin{array}{l}\text { partial } \\
\text { (NISP) } \\
\end{array}$ \\
\hline SCA & 12 mos. & 0 & 0 & 0 \\
\hline Dist HUM & 12 mos. & 0 & 0 & 0 \\
\hline Prox RAD & 12 mos. & 0 & 0 & 0 \\
\hline Prox PHA1/2 & 18-24 mos. & 0 & 1 & 0 \\
\hline Dist TIB & 24 mos. & 0 & 1 & 0 \\
\hline Dist MTP & 24-27 mos. & 0 & 0 & 0 \\
\hline Prox FEM & 42 mos. & 0 & 0 & 0 \\
\hline Dist CAL & 24-30 mos. & 1 & 0 & 0 \\
\hline Dist RAD & 42 mos. & 0 & 0 & 0 \\
\hline Dist FEM & 42 mos. & 0 & 0 & 0 \\
\hline Prox TIB & 42 mos. & 0 & 0 & 0 \\
\hline Prox HUM & 42 mos. & 0 & 0 & 0 \\
\hline Prox FIB & 30-42 mos. & 0 & 0 & 0 \\
\hline
\end{tabular}

D. Skeletal Element Frequencies: Skeletal element frequencies provide more

information about the depositional environment than they do about garbage disposal.

Sheep were heavily represented by teeth (especially molars) which were recovered loose and isolated from their maxillae or mandibles (figure 7.8). Winnowing, dissolution, or breakage of the low density cranial elements seemed to have caused the heavier, dense molars to be incorporated into the DP deposit as pebble-like sediments. High numbers of isolated teeth were also reported for DP 1 and DP 2 (Cruz-Uribe n.d.; Schrire et al. 1993: 30). Boney remains were rarely identified to the species level, and those that could be identified were from most often from denser diagnostic portions of bones such as the radii, humeri, and tibiae. Size 2 mammal remains that were not able to be identified to the species level were also dominated by dense portions of bones such as long bone midshaft fragments $(69.51 \%, \mathrm{n}=171$ of total size 2 mammal/artiodactyla/bovid sample from DP 3-16 were long bone shaft fragments). If one assumes that the vast majority of size 2 specimens were sheep, the heavy representation of long bone fragments should 
produce a more even skeletal element profile for the appendicular segments, though axial elements were still absent. This suggests that more complete sheep carcasses were originally deposited in DP, and that taphonomic processes biased the recovered sample by destroying most bone fragments or rendering them unidentifiable to a more specific element or taxon.

Figure 7.8. Skeletal element frequencies represented by MNI for sheep from DP 116.

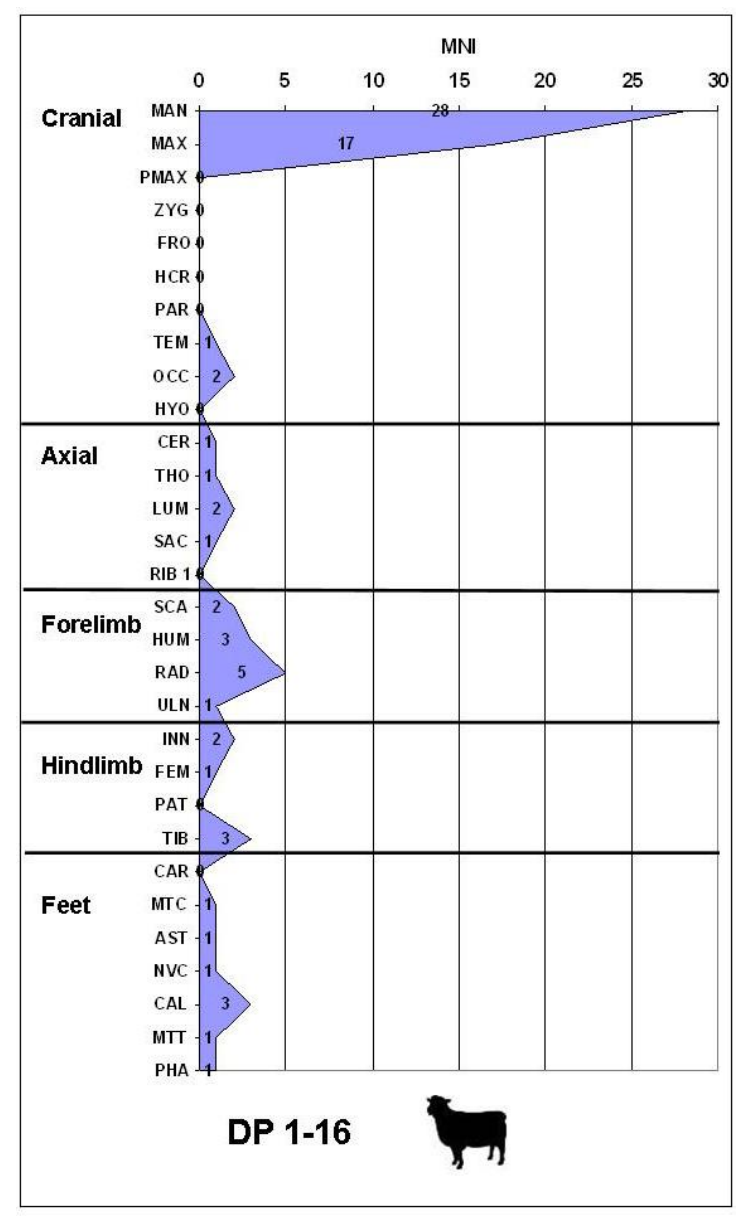

Cattle remains produced a different skeletal element frequency profile than that for the sheep (figure 7.9). Teeth were again found isolated from their boney anchors, but they did not make up a large percentage of the remains. Cattle were most heavily represented by appendicular elements. Higher proportions of postcranial bones from 
cattle were also reported for DP 1 and DP 2 (Cruz-Uribe n.d.; Schrire et al. 1993: 30). As with the sheep, boney remains were rarely able to be identified to the species level. Size 3 remains only able to be identified to the mammal and bovid taxonomic levels were dominated by limb element fragments $(76.25 \%, \mathrm{n}=456$ of total size $3 \mathrm{mammal} / \mathrm{bovid}$ sample from DP 3-16 were long bone fragments). Unlike the sheep where the unidentified bones could even out the element frequency profile, the cattle element frequency profile would be further skewed by limb elements.

Pigs and wild mammals were represented by very small sample sizes. These animals were mainly represented by postcranial specimens.

Figure 7.9. Skeletal element frequencies represented by MNI for cattle from DP 116.

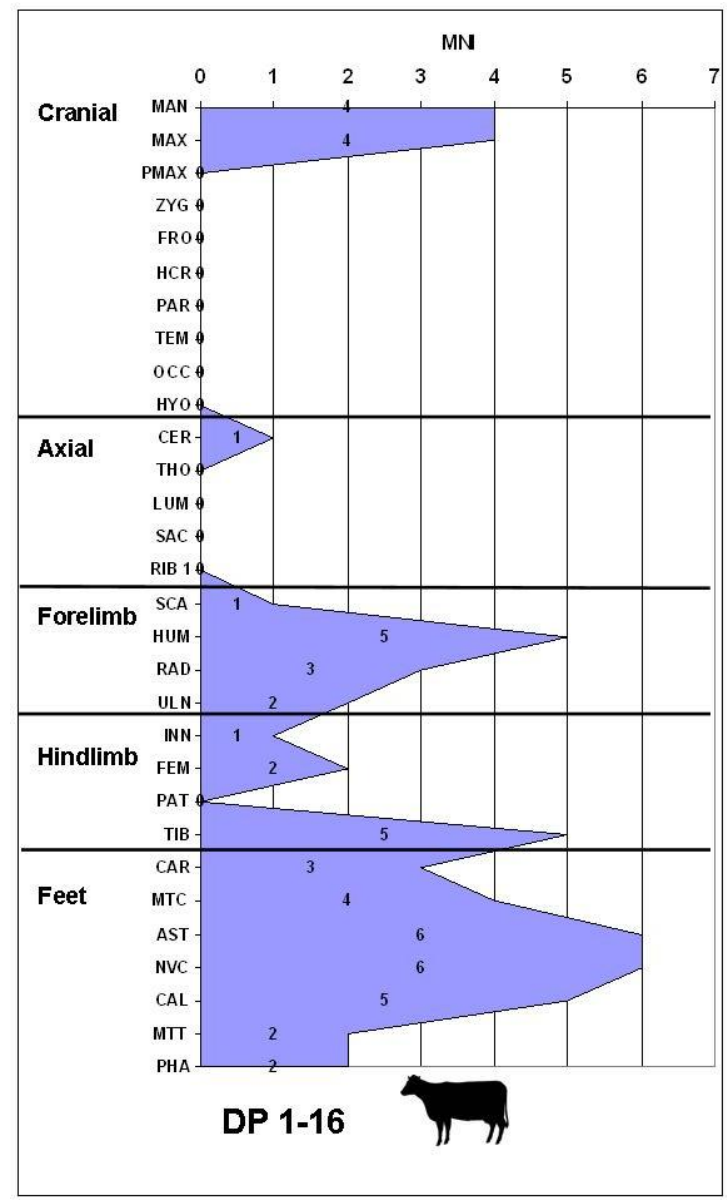


E. Sex: Data was not available to identify sex in the DP sample.

F. Sheep Size: Data was not available to determine sheep size in the DP sample.

G. Butchery: Butchery and cooking evidence is nearly invisible in the DP sample because of the severe damage caused by the brackish depositional environment. This is especially true of cuts and scrapes that require observations of the bone surfaces and these surfaces were severely eroded in the DP sample. Chops were most heavily represented due to the larger, more conspicuous trace this butchery technique left on the bone (table 7.8). Chops were located in skeletal regions such as joints aimed at dividing the carcasses into smaller segments such as the elbows and ankles. Cooking residues were rare, which is likely also due to the taphonomic damage.

Table 7.8. Frequencies (\% of NISP) of processing damage on the bone fragments from DP 3-16.

\begin{tabular}{|c|c|c|c|c|c|c|c|}
\hline burning & \multicolumn{2}{|l|}{ chop } & \multicolumn{2}{l|}{ cut } & \multicolumn{2}{l|}{ scrape } \\
\hline NISP & $\%$ & NISP & $\%$ & NISP & $\%$ & NISP & $\%$ \\
\hline 3 & 0.28 & 42 & 3.97 & 2 & 0.19 & 0 & 0.00 \\
\hline
\end{tabular}

\section{DISCUSSION}

DP has been interpreted as a quick dump used to dispose of a large quantities of domestic stock from periodic slaughter episodes that occurred when meat was needed to supply a calling ship (Schrire 1995: 99; Schrire et al. 1993: 30). The DP faunal sample provides information about disposal patterns at Oudepost I that were not able to be answered by the terrestrial excavations. With no trash pits discovered, the watery, tidal lagoon seemed to have been a natural, attractive location to dump rotting animal residues in hopes of them being washed away (Schrire et al. 1993: 28). A similar sea dumping was reported from Table Bay when large numbers of animals were slaughtered en mass (Raven-Hart 1970b: 346, see chapter 3). The archaeological residues in DP are 
dominated by faunal remains, showing that this deposit was likely a purposeful dump of faunal residues instead of the less noxious ceramic, glass, and metal artifacts. This seemed to have been especially true of larger animal parts such as cattle postcranial bones and sheep crania which would have been less easily trampled into the outpost's sand (Schrire 1995: 99; Schrire et al. 1993: 30).

The taphonomic history of the DP fauna was complicated by the tidal, brackish lagoon environment. A major concern is that portions of the recovered faunal sample were winnowed away by the lagoon environment, either by being washed away or dissolved through repeated saturation and drying for a few centuries. Skeletal element frequencies make the strongest argument that lower density skeletal parts were deleted. Softer axial bones associated with the vertebral column and cranium were almost nonexistant for both size 2 and size 3 mammals. The selective deletion of softer elements can be extended to those elements that were present in DP, specifically the limb bones. Long bones specimens consist of two main portions, one being the very dense shaft segment and the other being the softer, trabecular, epiphyseal ends. The DP faunal sample is overwhelmingly dominated by the dense midshaft portions, meaning the spongy epiphyseal ends were removed from the site. In addition, a large proportion of the limb bone fragments contained breakages that occured after the bones were dried out or the collagen component was deteriorated. The paucity of lower density bone portions along with post-depositional breakages and severe bone damage show that the faunal sample had been compromised between deposition and recovery. The taphonomic affects on the DP fauna means that conclusions about skeletal element frequencies and 
taxonomic representations may not be confidently made and it may therefore it may be difficult to determine cultural patterns in animal usage through the remains from DP.

One conclusion is of importance. Cattle remains were scarce in the terrestrial fauna, where sheep outnumbered cattle in much higher ratios than the stock ratios reportedly owned by the indigenous populations (Cruz-Uribe and Schrire 1991: 96; Schrire 1995: 109; Schrire et al. 1993: 30). The scarcity of cattle specimens in the terrestrial sample was initially interpreted to reflect the cattle-poor trade experienced by the Dutch with the indigenous peoples. Instead of relying on domestic stock to feed the outpost's garrison, it was determined that the soldiers relied on wild meat due to the high percentages of wild fauna in the terrestrial fauna (Schrire 1995: 108). The DP fauna decreases this ratio where cattle are only outnumbered by about $4.67: 1$ by sheep. It is possible that cattle were better represented in the DP fauna through MNI, but postdepositional damage and fragmentation caused many cattle-sized specimens to not be identified to the species level or specific skeletal element. A raw count of sheep-sized and cattle-sized specimens suggests that cattle were more important allometric resources at Oudepost than previously determined from the terrestrial fauna. If the DP fauna mainly reflects provisioning residues, the cattle seem to have been reserved mainly for the provisioning episodes mentioned above.

If cattle were mainly used for provisioning, wild fauna was determined to have supported the garrison. Documents recorded that Oudepost I received the least amount of meat from the VOC stock holdings for garrison consumption (Cruz-Uribe and Schrire 1991: 96; Schrire 1990: 15-17; 1995: 106). The terrestrial fauna which was dominated by wild fauna clearly showed that hunting, fishing, and possibly trapping were important 
subsistence methods to compensate for low meat provisions for garrison supply (CruzUribe and Schrire 1991: 93-96; Schrire 1995: 106-109; Schrire et al. 1993: 30). Though, the wild species present in the terrestrial fauna were generally smaller sized animals, which would have been easily destroyed and removed from the DP deposit. The DP faunal sample contained only a fraction of the wild faunal abundances and diversity identified in the terrestrial fauna, which could suggest that DP could have served a different depositional purpose than the terrestrial sample.

One fortunate aspect of the DP fauna is the presence of numerous isolated sheep teeth. Ideally, teeth present in mandible or maxilla anchors with neighboring in situ teeth would have provided more absolute ages than isolated molars. Gleaned from the isolated molars, the sheep were slaughtered at a wide range of ages between about nine months and six years of age, while the bulk of the sheep were slaughtered about two to three years of age when meat yield would have been at its maximum efficiency (Mentzel 1944: 212). The ageing data from DP supports the sheep ageing data previously determined for the terrestrial fauna (Cruz-Uribe and Schrire 1991: 98). The similar age profiles for the terrestrial and the DP sheep show that they were probably from a common stock and that they were slaughtered following the same protocol. Though there was a preponderance of prime aged animals, not all animals were treated equally. Some were slaughtered relatively young while others were kept much older. Similar slaughter strategies seemed to have been followed for both cattle and sheep. 


\section{CHAPTER EIGHT: Determining Breed Differences}

\section{INTRODUCTION}

One application of bone measurements of sheep remains from South African archaeological fauna is as an attempt to determine the presence of different sheep breeds (Cruz-Uribe and Schrire 1991: 97; Klein and Cruz-Uribe 1989: 90-91). This chapter investigates the idea that the differences identified in the archaeological sheep could be the result of sexual dimorphism instead of different breeds. Measurements were taken of known-sex bovids from different body size classes to identify sexual dimorphism at the distal humerus, the distal tibia, and various tooth row segments. The findings are then applied to archaeological material from South Africa. Lastly, the affect of age on tooth row lengths is investigated.

In 1652, the Dutch East India Company (VOC) established a refreshment station at the Cape of Good Hope, South Africa in order to provision their passing trade ships with fresh vegetables, water, and meat. The Dutch partly chose the Cape for the likely trade opportunities with the indigenous Khoekhoe pastoralists who migrated throughout the Cape with immense herds of cattle and sheep. The Dutch hoped to develop their own herds of cattle and sheep that could sustain the provisioning of their shipping network to Asia. While the trade for cattle was slow and usually resulted in the acquisition of less-fit animals, the sheep trade was more successful. The Dutch soon learned that a hybrid between imported European, Persian, and Bengali breeds and indigenous sheep produced a larger, meatier product that was both well suited for the Cape environment and also a great boon for their provisioning aspirations (Cruz-Uribe and Schrire 1991: 97; Guelke 1988: 71; Mentzel 1921: 56; 1944: 210; Raven-Hart 1970b: 381; Thom 1936: 246, 249). 
The VOC period archaeological sheep samples potentially include indigenous sheep which were obtained from the indigenous Khoekhoe pastoralists through trade and capture throughout the seventeenth and early eighteenth centuries. Currently, the identification of these hybrid sheep in the archaeological record relies on measurements of the distal humeri (Cruz-Uribe and Schrire 1991: 97; Klein and Cruz-Uribe 1989: 9091). Though this method has produced promising results that show a clear size dimorphism, the method does not rule out other factors that can produce equifinalities such as better historic feeding techniques or the greater representation of larger males/wethers in the historic VOC period collections (1652-1795). A potential method to identify different breeds could be through the measurements of tooth rows. This idea stems from Grigson's (1982: 7) statement that "[in cattle] there is no sexual difference in tooth row length or indeed in the size of individual teeth." Though her statement refers specifically to cattle, tooth rows may be an osteometric measurement that could bypass problems caused sexual dimorphism when trying to identify different breeds of domestic bovids through postcranial bone measurements. The implication of Grigson's statement is that tooth row lengths could serve as an osteometric marker of breed differences that could circumvent sexually dimorphic traits as well as destructive and expensive genetic testing. This chapter tests the idea that if tooth rows are not sexually dimorphic through measurements of known-sex individuals of wild and domestic bovids, they might be used to identify the improved hybrid sheep. Since bovid teeth change due to wear down due to grazing throughout the age of the animal, this chapter also investigates any possible agedependent changes in tooth row lengths to avoid equifinality. 


\section{SEXUAL DIMORPHISM}

In terrestrial mammals, sexual dimorphism has been most closely correlated with sexual polygyny, where males would have access to and mate with multiple females. The larger body size of the males would allow for improved sexual competition with other male individuals for the opportunity to mate with as many females as possible by defending home ranges or establishing a hierarchy within a herd where the reproductively available females are present (Clutton-Brock 1991: 231; Estes 1991: 11; Loison et al. 1999: 622-624; Weckerly 1998: 39; Willner and Martin 1985: 1-2). Males in polygynous systems tend to have a restricted period of mating success during a peak of physical fitness that wanes with age and competition from younger, stronger males (Alexander et al. 1979: 402; Clutton-Brock 1991: 231-234). Males in the more dimorphic taxa grow more quickly than females (Clutton-Brock 1991: 236; Glucksmann 1978: 80; Willner and Martin 1985: 34) or mature later than their female counterparts, which allows for a greater ultimate body size (Alexander et al. 1979: 414; Estes 1991: 11; Weckerly 1998: 33; Willner and Martin 1985: 34). The degree of sexual dimorphism also increases positively with body size as long as environmental conditions can supply enough nutrition (Loison et al. 1999: 622-624; Weckerly 1998: 33; Willner and Martin 1985: 13). Other sexually dimorphic traits such as secondary sex characteristics generally develop after maturity and these can include horns, hair growth, and scent glands (Estes 1991: 1112). In contrast, mammalian taxa that are more monogamous exhibit minimally dimorphic body forms between the sexes including some cases where the females may be only slightly larger than the male (Estes 1991: 11, 44; Weckerly 1998: 38). The polygyny-dimorphism correlation has been described across a wide variety of 
mammalian taxa including carnivores (Grandal-D'Anglade and Lopez-Gonzalez 2005; Szuma 2007), primates (Alexander et al. 1979; Clutton-Brock 1991; Clutton-Brock et al. 1977; Martin et al. 1994), and ungulates (Alexander et al. 1979; Loison et al. 1999; Perez-Barberia and Gordon 1999; Perez-Barberia et al. 2002; Weckerly 1998).

A. Sex Differences in Oral Morphology: The brief statement by Grigson (1982: 7) which states that tooth rows may not be sexually dimorphic needs to be further investigated. Biologists interested in differential feeding behavior between the sexes have investigated sex-related differences in oral morphology. Discussions about differences in oral morphology have fallen under the topic of sexual size dimorphism in terms of sexual segregation and niche-partitioning during feeding since larger bodied ungulate males require more bulk diet while females require higher energy intake (Clutton-Brock 1991: 238-239; Willner and Martin 1985: 7-10). Males and females would avoid inter-sexual competition by feeding on different resources, or different parts of the same resource. Various feeding behaviors have been investigated between the sexes such as feed intake through the study of incisor breadth, food selection ability through the study of incisor protrusion and muzzle width, and chewing effectiveness and rate through occlusal surface size and mandible length (Gross et al. 1995: 387; PerezBarberia and Gordon 1998: 362-365; Perez-Barberia and Gordon 1999: 259-265; PerezBarberia and Gordon 2000: 668; Szuma 2007: 78). Some sex differences have been identified. For an example, "polygynous ungulate females ... have narrower muzzles which enable them to access smaller discrete high energy items of food from intimate mixtures of herbage (Perez-Barberia and Gordon 1998: 362).” But, after controlling for 
body size, researchers have not identified morphological dimorphism between the sexes in regards to dental morphologies, and the identified morphological differences of size between the sexes allow for differential usage of resources (Perez-Barberia and Gordon 1998: 365; Perez-Barberia and Gordon 2000: 674).

Regarding the archaeological application of dimorphic oral morphology, if the controlling for body size shows no oral sexual dimorphism between the sexes, the absolute sizes or shapes could potentially be used to differentiate sexes. A case study of the red fox (Vulpes vulpes) shows that male tooth size is larger than females. While canine size was the most dimorphic for purposes of sexual selection and male-male competition, weak dimorphism also was identified in the carnassials of the fourth premolar and first molar (Szuma 2007: 78). For the identification of sex in South African Zulu human forensic cases, various mandibular bone measurements exhibit strong size dimorphism between the sexes (Franklin et al. 2008: 84.e3). Unfortunately, these examples do not include the ungulates recovered from archaeological sites. The size and shape dimorphisms identified in ungulate dental morphology such as muzzle widths and incisor arcades are also not often preserved in archaeological collections. The possibility of absolute size differences might be used to differentiate sexes through tooth row lengths.

B. Archaeological Application of Sexual Dimorphism: The determination of sex in the zooarchaeological record holds importance when trying to reconstruct herd demographics, slaughter preferences, and domestication. Sexual dimorphism has been studied in archaeological cattle since cattle are highly dimorphic and the sexes are easier 
to distinguish based on osteological measurements. Cattle studies have often focused on metatarsals and metacarpals that are often preserved in complete conditions in European archaeological sites. Research has shown that epiphyseal breadths as well as bone lengths and bivariate analyses of various metapodial measurements can effectively distinguish male bulls and/or oxen from female cows, while they can occasionally tease out the presence of the castrated oxen (Fock 1966; Grigson 1982; Higham 1968; Jewell 1963; Thomas 1988; Zalkin 1960). These studies also determined that the metacarpal at the fore end (the greater weight bearing end) of the animal exhibits greater dimorphism than the hind situated metatarsal (Jewell 1963: 81; Svensson et al. 2008: 942; Thomas 1988: 87; Zalkin 1960: 123). Osteological measurements of cattle dimorphism using the metacarpal's distal epiphysis have been confirmed through DNA tests (Svensson et al. 2008).

Investigations into sexual dimorphism have also been undertaken on other ungulates. Davis $(1996 ; 2000)$ performed a variety of measurements on males, castrates, and females from samples of unimproved Shetland sheep. His findings show that pubic shaft thickness as well as long bone lengths are the best indicators of sex, but these elements are seldom recovered complete in archaeological deposits (Davis 2000: 384385). Greenfield (2002) has developed an effective method of sexing ungulates, including the important domestic stock of cattle, sheep, and pigs, through a measurement in the medial acetabular wall at the ilio-pubic juncture of the innominate.

C. Sex and Breed Differences: Bone measurements have been applied to archaeological collections to understand the effects of domestication through time. In general, the 
average domestic animal size decreased from their wild forms since the development of domestication in the Stone Age up through the Medieval Period. This pattern has been demonstrated in Denmark through the lengths of the lower third molar and metacarpals of domestic cattle (Degerbol 1963: 70-77). Size decrease has also been demonstrated for domestic cattle in Britain through the measurements of length and width of metacarpals, the width of the distal humerus, and the length of the astragalus (Jewell 1963: 81-84). Size decrease of sheep and goats, especially males, has also been used as a marker for the beginning of domestication in the Middle East (i.e. Arbuckle 2008; Ducos 1968; Flannery 1983; Helmer 1992; Meadow 1989; Peters et al. 1999; Uerpmann 1978), but recent work by Zeder (2008: 77) suggests that this conclusion could arise from ancient people selecting from smaller wild caprine populations or by scientists only measuring the females that may have been kept to adulthood while the males were slaughtered younger.

At the beginning of the Modern Period in the late fifteenth and sixteenth centuries, increased meat demands from growing urban markets caused changes in the management of domestic stock (Davis 1997: 416; Pennington 1989: 61; Trow-Smith 1957: 172-173). With changing strategies from the production of secondary products to meat, animals began to be slaughtered younger in their prime ages (Albarella 1997: 22; Allison 1958: 101-102; Fehring 1991: 176; Landon 1997: 57; Sykes 2006a: 62-63; TrowSmith 1957: 239, 244; 1959: 23, 199). Part of this new focus towards greater meat production was the improvement of the animal breeds. One method used to identify improved breeds in the English archaeological record is that larger skeletal measurements would indicate greater meat producing animals (Albarella 1997: 19-23; Davis 2008: 9961008; Davis and Beckett 1999: 4; Thomas 2005: 74). Using the width of various 
elements to judge animal size, researchers identify steady increases in mean size of the stock, including fowl, from as early as the fifteenth century (Albarella 1997: 19-26; Davis 1997: 418-427; Davis and Beckett 1999: 11-14; Dobney et al. 1996: 33; Fussell and Atwater 1933: 381; Outhwaite 1986: 3-4; Thomas 2005: 77-82). Though breed improvement occurred early, cattle were improved the earliest, while sheep, pigs, and fowl were improved later (Albarella 1997: 21; Davis and Beckett 1999: 11-14).

\section{METHODOLOGY AND MATERIALS}

This chapter aims to identify sexual dimorphism through the measurements of potentially dimorphic bone portions of known-sex individuals from four bovid species: domestic sheep (Ovis aries), steenbok (Raphicerus campestris), springbok (Antidorcas marsupialis), and eland (Taurotragus oryx). The skeletal portions measured include the distal humerus (Von den Dreisch $1976=$ Bd), the distal tibia (Von den Dreisch $1976=$ Bd), as well as tooth rows in order to test Grigson's (1982: 7) statement. The Bd measurement was recorded on the humerus because it has been used by the South African studies of the different breeds. The Shetland sheep data uses Von den Dreisch's Bt measurement (Davis 1996: 594-595; 2000: 376-377). Mandibular and maxillary tooth rows were measured as complete rows as well as in their components such as premolar rows (P2-P4 or P3-P4 in the case of the springbok) and molar rows (M1-M3). These element portions were selected since they are robust and they are often present in the archaeological samples. The length of the tooth row from M1 to M2 was also measured since this was a common configuration present in the archaeological samples presented in this thesis. Tooth row measurements were taken at the junction between the teeth and 
their bone anchors. Only specimens that had reached the adult stage of development were measured. Tooth row portions had to be represented by adult dentition and the distal humerus and tibia epiphyses had to be fused. In the case of tooth rows, the right side of mandibles and maxillae were measured since there was close symmetry identified between halves. Left halves were measured in the cases of pathologies or damages. Both the left and right distal humeri and tibiae were measured and then averaged for each animal specimen. Other elements usually used to indicate sexual dimorphism such as metapodials were not measured sine they are not well-represented in the archaeological samples. The measurements presented here were performed with a vernier caliper (in tenths of mm) and they follow the guidelines put forth by Von den Dreisch (1976), which are commonly used by zooarchaeologists.

A. The Animals: Measurements were taken of known-sex individuals from four bovid species: domestic sheep (Ovis aries), steenbok (Raphicerus campestris), springbok (Antidorcas marsupialis), and eland (Taurotragus oryx). The sheep was chosen because sheep remains are at question from the South African material. Since sheep carry the added question of domestication, the three wild species of different size classes were measured to attempt to control for domestication-related variables such as trait selection and differential feeding by people. The three wild species were selected because the steenbok is a very small, relatively unimorphic bovid, the springbok is a wild, sheepsized bovid, and the eland is a wild, cattle-sized bovid.

The specimens are housed in reference collections at the IZIKO: South African Museum (SAM) in Cape Town and the American Museum of Natural History (AMNH) 
in New York. Most of the specimens were collected in the late nineteenth century through the early twentieth century during hunting expeditions throughout southern Africa. The museum collections contained an even mixture of adult aged specimens for both sexes of the wild bovids. The post-cranial sheep measurements used here come from the data published by Davis $(1996 ; 2000)$ and derive from a pair of flocks of unimproved Shetland sheep from Orkney, Scotland.

B. Animal Behavior: Sexual dimorphism is positively correlated with a greater degree of polygyny as well as larger body size. Therefore, some basic information is presented about the animals in this study.

1. Domestic sheep (Ovis aries): Today, the domestic sheep comes in many different breeds across the globe so making a broad statement is difficult. It is generally accepted that its wild progenitor was the mouflon sheep (Ovis orientalis) of Europe and Asia (Hiendleder et al. 2002). Today, mouflons are dimorphic with males weighing on average $50 \mathrm{~kg}$ to the female's $35 \mathrm{~kg}$ though their sizes do vary according to climatic conditions (Uerpmann 1978: 42). Domestic sheep sizes vary widely and depend on the breed, but males generally weigh between $45-160 \mathrm{~kg}$ while females range from $45-100 \mathrm{~kg}$ (Burrill 2004). Rams have been observed to display aggressive behavior with other males who have similar horn size to establish dominance, but males with different horns tend to be less inclined to fight (Budiansky 1999: 78). Today, extreme polygyny is imposed on domestic sheep since the farmer controls breeding with a small number of selected rams to pass on specific qualities. 
Predictions: Due to dimorphic body sizes and weights of wild mouflons and domestic sheep, significant sexual dimorphism is expected to be identified in the distal tibiae and humeri measurements. No sexual dimorphism is expected in the tooth row measurements.

2. Steenbok (Raphicerus campestris): Steenbok are very small bovids that are monogamous and territorial in patchy open areas across southern Africa. Though they are often observed individually, it is likely that monogamous pairs inhabit and defend the same territory while foraging and hiding apart. Both sexes of the steenbok average in height about $50 \mathrm{~cm}$ (range from $45-60 \mathrm{~cm}$ ). Males weigh on average $10.9 \mathrm{~kg}$, while females are slightly heavier at $11.3 \mathrm{~kg}$ (Estes 1991: 44-47).

Predictions: Due to the monogamous nature of the steenbok and the similar body size ranges for males and females, no significant sexual dimorphism is expected to be identified in the distal tibiae and humeri measurements. No sexual dimorphism is expected in the tooth row measurements.

3. Springbok (Antidorcas marsupialis): Springbok are a medium-sized bovid that tolerates a wide variety of habitats but they are generally found in the dry, arid areas of southern Africa and up the western Atlantic coast. Springbok social organization is more fluid with varying herd sizes that are dependant on sex, climate, and age. Sexually mature males will defend territories from other sexually mature males during periods of 
migration, congregation, and when smaller herds fragment during dry seasons. Females are described as having no home territory and they probably travel more widely and move between herds more freely than males. The springbok is slightly dimorphic with males averaging $73 \mathrm{~cm}$ in height and $30.6 \mathrm{~kg}$ in weight to the females' averages of $69 \mathrm{~cm}$ and $26.7 \mathrm{~kg}$, respectively. Springboks are slightly larger in the dryer areas of Botswana and Namibia. Horn size differs slightly between the sexes with the males' being larger (Estes 1991: 80-84).

Predictions: Due to weakly dimorphic body sizes and the polygynous behavior of the springbok, significant sexual dimorphism is expected to be identified in the distal tibiae and humeri measurements. No sexual dimorphism is expected in the tooth row measurements.

4. Eland (Taurotragus oryx): Eland are the largest antelope and their ranges spread through a wide variety of habitats across southern Africa and up the Indian Ocean coast. Eland form large, mixed-sex herds that may change with season and food availability. As males age, they become less social and can become aggressive when approached too closely by other mature males. The most dominant male in the herd most successfully attains the opportunity to mate with available females. The eland is highly dimorphic with males ranging from $151-183 \mathrm{~cm}$ in height with females ranging from $125-153 \mathrm{~cm}$. Males weight from 450-942 kg while the smaller female weighs between $317-470 \mathrm{~kg}$. Eland are also dimorphic in several secondary sex characteristics such as tufts of hair, a 
dewlap, and neck mane in the males who also have shorter, thicker spiraled horns compared to the female (Estes 1991: 188-192).

Predictions: Due to dimorphic body sizes and the polygynous behavior of the eland, significant sexual dimorphism is expected to be identified in the distal tibiae and humeri measurements. No sexual dimorphism is expected in the tooth row measurements.

C. The Archaeological Material: The prehistoric sheep samples derive from the Later Stone Age sites of Nelson Bay Cave (c. 1100 BP), Die Kelders I (c. 2000-1500 BP), and two components of the Kasteelberg site, A and B (c. 1860-300 BP). These prehistoric sites were occupied by the ancestors of the historically-known, seasonally-nomadic Khoekhoe pastoralists. No sex data was available, but the prehistoric sheep at Die Kelders and Kasteelberg B were mainly slaughtered very young with a small proportion of sheep slaughtered at "post-prime" ages. The sheep from Kasteelberg A were also slaughtered very young with some at "post-prime" ages, but this site also contained a larger proportion of prime aged sheep which may be the result of a lengthier, less seasonal occupation of the site compared to Kasteelberg B (Klein and Cruz-Uribe 1989: 91-92). VOC period sheep were measured from the frontier sites of Oudepost I (1669$1732 \mathrm{CE}$ ) and Elsenburg (c. 1740-1761 CE), both of which are interpreted as being depots for indigenous and hybridized sheep distributed by VOC trading posts (CruzUribe and Schrire 1991; Schrire 1995; Schulz 2005: pers. com.). These frontier sites are contrasted with the more urban site of the Castle of Good Hope's Moat where a large amount of provisioning refuse was discarded (c. 1720-1730 CE). Oudepost I and 
Elsenburg contain sheep of a wide range of sizes, while the more urban Cape center is dominated by large sheep (Cruz-Uribe and Schrire 1991: 97; Klein and Cruz-Uribe 1989: 90-91; and see Chapters 6 and 7 in this thesis). Though the size contrast with the prehistoric sites is clear, this study raises the possibility that the measurements could reflect sexual dimorphism instead of two different breeds. Age and sex data from the archaeological remains shows that the Elsenburg sample is heavily represented by older females, while the urban-situated Moat sample is heavily represented by prime-aged males or castrated wethers. This pattern of females kept on the farm and non-breeding males sent off to slaughter is a common practice in a market economy (Allison 1958: 101-102; Harrison et al. 2008: 10-109; Landon 1997: 57; Sykes 2006a: 62). Sex data is not available for Oudepost I, but the sheep were slaughtered in two general age class, very young or prime aged (Cruz-Uribe and Schrire 1991: 98).

Predictions: The sheep recovered from the historic sites will be larger than their prehistoric counterparts due to the fact that they are hybrids. Failing this, if any of the historic sheep are indigenous, they cannot be differentiated by osteological measurements due to better historic husbandry practices. Assuming sexual dimorphism in the postcranial measurements of the distal humerus and tibia, the sheep from the Moat, which are interpreted to be mostly male, are expected to be significantly larger than the sheep from the historic sites of Elsenburg and Oudepost. Elsenburg and Oudepost are expected to look similar due to the higher proportion of smaller sheep which are assumed to be female. Due to hybridization and husbandry practices, all of the historic sites are 
expected to be significantly larger than the prehistoric sheep which are the fully indigenous breed.

D. Hypothesis: The hypothesis tested with the known-sex specimens is:

$H_{o}$ : There is no sexual dimorphism at the osteometric measurement.

$H_{i}$ : There is significant sexual dimorphism at the osteometric measurement.

$\alpha<0.05$

\section{KNOWN-SEX RESULTS}

Table 8.1 provides some statistical descriptions for the known-sex bovid samples and their distribution curves. Table 8.2 presents the Mann-Whitney comparisons between the sexes for each osteometric measurement discussed below.

Table 8.1. Sample sizes (NISP), means, standard deviation (SD), normality, skewness, and skewness standard deviation (SES) for each sample of the known-sex bovids.

\begin{tabular}{|c|c|c|c|c|c|c|c|c|}
\hline Element & Animal & Sex & $\mathbf{N}$ & $\begin{array}{l}\text { Mean } \\
(\mathrm{mm})\end{array}$ & SD & Distribution & Skew & SES \\
\hline \multirow[t]{9}{*}{ Humerus } & \multirow[t]{3}{*}{ Sheep } & Male & 12 & 28.62 & 1.25 & norm & 0.628 & 1.414 \\
\hline & & Castrate & 30 & 28.57 & 1.14 & norm & 0.095 & 0.894 \\
\hline & & Female & 26 & 26.83 & 0.96 & norm & -0.374 & 0.961 \\
\hline & \multirow[t]{2}{*}{ Steenbok } & Male & 7 & 19.49 & 1.01 & norm & -0.443 & 1.852 \\
\hline & & Female & 6 & 19.68 & 0.75 & norm & 0.709 & 2.000 \\
\hline & \multirow[t]{2}{*}{ Springbok } & Male & 7 & 32.09 & 2.07 & norm & 0.124 & 1.852 \\
\hline & & Female & 7 & 29.51 & 2.11 & norm & 0.053 & 1.852 \\
\hline & \multirow[t]{2}{*}{ Eland } & Male & 14 & 101.41 & 8.64 & norm & 0.339 & 1.633 \\
\hline & & Female & 9 & 88.38 & 3.95 & norm & -0.544 & 1.309 \\
\hline \multirow[t]{9}{*}{ Tibia } & \multirow[t]{3}{*}{ Sheep } & Male & 12 & 26.22 & 1.06 & norm & 0.318 & 1.414 \\
\hline & & Castrate & 30 & 25.47 & 0.98 & norm & -0.412 & 0.894 \\
\hline & & Female & 26 & 25.13 & 1.00 & norm & 0.304 & 0.961 \\
\hline & \multirow[t]{2}{*}{ Steenbok } & Male & 7 & 19.04 & 0.86 & norm & -0.822 & 1.852 \\
\hline & & Female & 5 & 19.42 & 0.61 & norm & -0.539 & 2.191 \\
\hline & \multirow[t]{2}{*}{ Springbok } & Male & 7 & 28.57 & 1.33 & norm & 0.730 & 1.852 \\
\hline & & Female & 7 & 26.90 & 1.73 & norm & 0.014 & 1.852 \\
\hline & \multirow[t]{2}{*}{ Eland } & Male & 15 & 70.55 & 3.34 & norm & 0.264 & 1.265 \\
\hline & & Female & 9 & 63.69 & 2.63 & norm & 0.164 & 1.309 \\
\hline Mandible & Steenbok & Male & 11 & 17.05 & 1.15 & norm & 1.230 & 1.477 \\
\hline
\end{tabular}




\begin{tabular}{|c|c|c|c|c|c|c|c|c|}
\hline \multirow[t]{5}{*}{ Premolars } & \multirow{3}{*}{ Springbok } & Female & 8 & 18.57 & 1.40 & norm & 1.232 & 1.732 \\
\hline & & Male & 9 & 12.70 & 1.23 & norm & 0.375 & 1.633 \\
\hline & & Female & 8 & 12.13 & 0.92 & norm & 0.306 & 1.732 \\
\hline & \multirow[t]{2}{*}{ Eland } & Male & 6 & 55.28 & 1.99 & norm & 0.107 & 2.000 \\
\hline & & Female & 6 & 54.18 & 2.87 & norm & -0.423 & 2.000 \\
\hline \multirow{6}{*}{$\begin{array}{l}\text { Mandible } \\
\text { M1-2 }\end{array}$} & \multirow[t]{2}{*}{ Steenbok } & Male & 15 & 16.79 & 0.64 & norm & -0.708 & 1.265 \\
\hline & & Female & 14 & 18.08 & 1.13 & weakly norm & -0.765 & 1.309 \\
\hline & \multirow[t]{2}{*}{ Springbok } & Male & 30 & 29.13 & 1.91 & norm & -0.017 & 0.894 \\
\hline & & Female & 23 & 27.45 & 2.23 & norm & -0.139 & 1.022 \\
\hline & \multirow[t]{2}{*}{ Eland } & Male & 6 & 54.22 & 3.60 & norm & 0.008 & 2.000 \\
\hline & & Female & 7 & 52.83 & 4.31 & norm & -0.899 & 1.852 \\
\hline \multirow{6}{*}{$\begin{array}{l}\text { Mandible } \\
\text { M1-3 }\end{array}$} & \multirow[t]{2}{*}{ Steenbok } & Male & 14 & 29.82 & 1.22 & norm & -0.401 & 1.309 \\
\hline & & Female & 9 & 30.69 & 1.71 & norm & -0.489 & 1.633 \\
\hline & \multirow[t]{2}{*}{ Springbok } & Male & 23 & 52.87 & 3.65 & norm & 0.023 & 1.022 \\
\hline & & Female & 20 & 50.99 & 2.86 & norm & 0.715 & 1.095 \\
\hline & \multirow[t]{2}{*}{ Eland } & Male & 5 & 102.58 & 5.14 & norm & 0.211 & 2.191 \\
\hline & & Female & 5 & 96.98 & 5.43 & norm & -1.345 & 2.191 \\
\hline \multirow{6}{*}{$\begin{array}{l}\text { Mandible } \\
\text { Full Row }\end{array}$} & \multirow[t]{2}{*}{ Steenbok } & Male & 8 & 47.64 & 2.14 & norm & 0.279 & 1.732 \\
\hline & & Female & 5 & 51.00 & 2.91 & norm & -1.205 & 2.191 \\
\hline & \multirow[t]{2}{*}{ Springbok } & Male & 9 & 67.28 & 2.22 & norm & 0.313 & 1.633 \\
\hline & & Female & 8 & 64.09 & 1.98 & norm & 0.073 & 1.732 \\
\hline & \multirow[t]{2}{*}{ Eland } & Male & 3 & na & na & na & na & na \\
\hline & & Female & 2 & na & na & na & na & na \\
\hline \multirow{6}{*}{$\begin{array}{l}\text { Maxilla } \\
\text { Premolars }\end{array}$} & \multirow[t]{2}{*}{ Steenbok } & Male & 15 & 18.69 & 1.72 & norm & 0.250 & 1.265 \\
\hline & & Female & 11 & 18.69 & 1.29 & norm & 0.839 & 1.477 \\
\hline & \multirow[t]{2}{*}{ Springbok } & Male & 8 & 16.75 & 1.39 & norm & 0.375 & 1.732 \\
\hline & & Female & 8 & 16.38 & 1.20 & norm & 0.093 & 1.732 \\
\hline & \multirow[t]{2}{*}{ Eland } & Male & 11 & 57.65 & 1.49 & norm & -0.619 & 1.477 \\
\hline & & Female & 7 & 55.80 & 3.80 & norm & -0.793 & 1.852 \\
\hline \multirow{6}{*}{$\begin{array}{l}\text { Maxilla } \\
\text { M1-2 }\end{array}$} & \multirow[t]{2}{*}{ Steenbok } & Male & 24 & 16.56 & 0.71 & norm & 0.107 & 1.000 \\
\hline & & Female & 18 & 17.38 & 1.54 & norm & -0.064 & 1.155 \\
\hline & Springbok & Male & 26 & 29.02 & 2.36 & norm & -0.300 & 0.961 \\
\hline & & Female & 25 & 27.79 & 2.27 & norm & 0.278 & 0.980 \\
\hline & Eland & Male & 12 & 53.13 & 3.55 & norm & 0.822 & 1.414 \\
\hline & & Female & 8 & 55.15 & 3.85 & norm & -0.936 & 1.732 \\
\hline Maxilla & Steenbok & Male & 23 & 26.54 & 0.82 & norm & -0.431 & 1.022 \\
\hline M1-3 & & Female & 13 & 27.35 & 1.60 & norm & 1.024 & 1.359 \\
\hline & Springbok & Male & 23 & 47.38 & 2.97 & norm & 0.193 & 1.022 \\
\hline & & Female & 22 & 45.29 & 2.34 & norm & 0.149 & 1.044 \\
\hline & Eland & Male & 12 & 88.63 & 5.15 & norm & 0.862 & 1.414 \\
\hline & & Female & 8 & 88.99 & 4.64 & norm & -0.417 & 1.732 \\
\hline Maxilla & Steenbok & Male & 8 & 44.86 & 1.96 & norm & 0.379 & 1.732 \\
\hline Full Row & & Female & 5 & 48.78 & 3.55 & norm & -0.315 & 2.191 \\
\hline & Springbok & Male & 8 & 64.38 & 2.30 & norm & 1.216 & 1.732 \\
\hline & & Female & 8 & 61.35 & 2.76 & norm & 0.123 & 1.732 \\
\hline & Eland & Male & 7 & 142.56 & 4.43 & norm & -0.142 & 1.852 \\
\hline & & Female & 5 & 148.36 & 5.10 & norm & -0.327 & 2.191 \\
\hline
\end{tabular}


Table 8.2. Mann-Whitney comparisons of the measurements for the known-sex bovid samples.

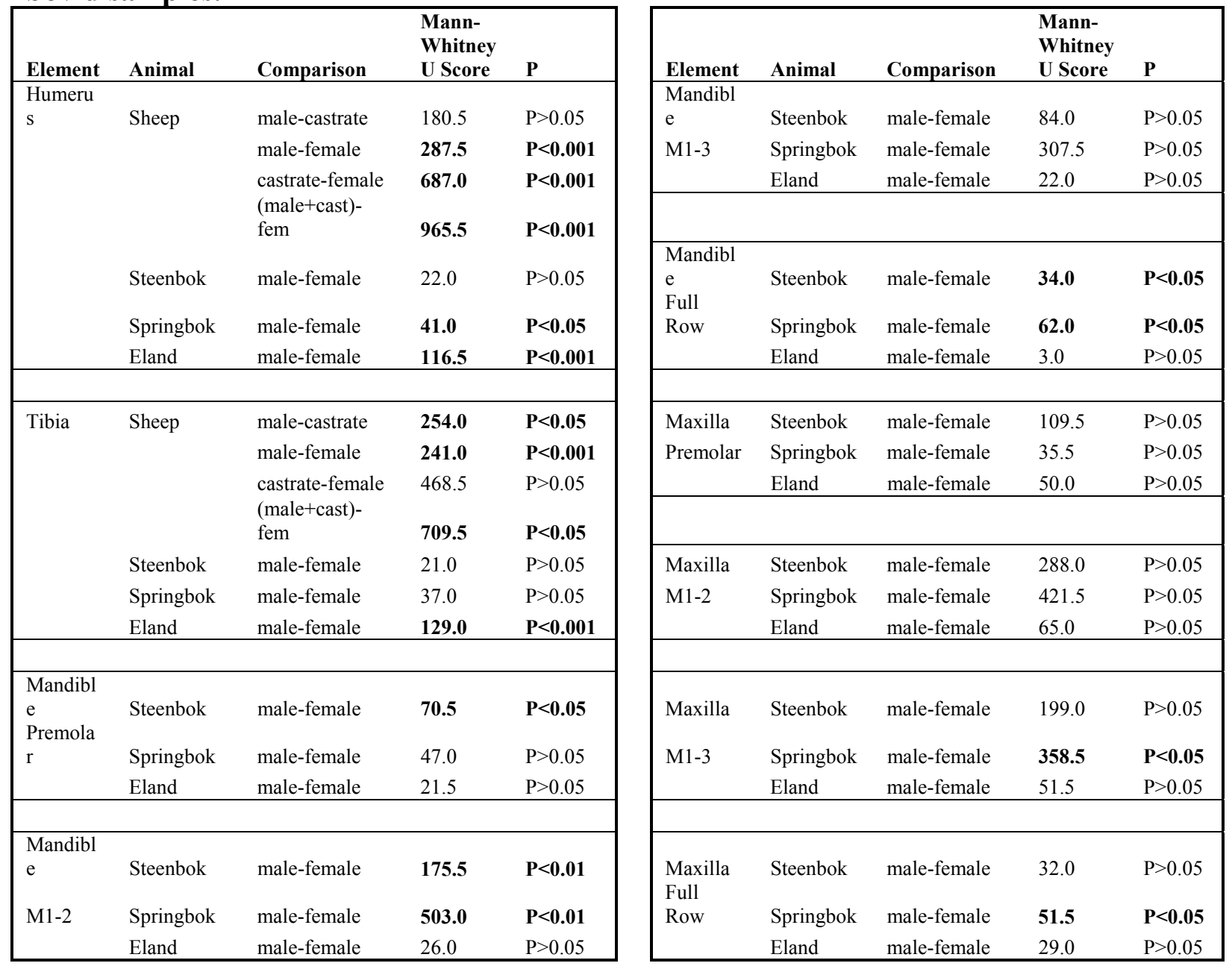

A. Distal Humerus Breadth: Using Davis' (1996; 2000) data, there is no significant dimorphism between rams and wethers at the distal humerus articulation (Bt). Instead, Davis' data clearly demonstrates a significant sexual dimorphism between the male and female Shetland sheep. As expected in the wild bovids, the monogamous steenbok showed no sexual dimorphism, while the larger bodied, polygynous springbok and eland did exhibit significant differences between the sexes.

B. Distal Tibia Breadth: In contrast to the distal humerus measurement, the distal tibia breadth (Bd) exhibits significant dimorphism between rams and wethers. Here, the 
wethers resemble the ewes with no significant dimorphism being demonstrated between them. Steenbok and springbok do not exhibit any significant sexual dimorphism at the distal tibia, but the larger bodied eland did produce a significant result.

\section{Mandibular Tooth Rows:}

1. Premolars: A significant length difference between the sexes was only identified in the steenbok.

2. $\mathbf{M}_{1}-\mathbf{M}_{2}$ : The steenbok and the springbok exhibited significant differences between the sexes at the $\mathrm{M}_{1}-\mathrm{M}_{2}$ tooth row. The eland did not show any significant differences.

3. $\mathbf{M}_{1}-\mathbf{M}_{3}$ : None of the wild bovids exhibited significant differences for the entire molar row.

4. Full Rows: The full mandibular tooth row produced similar results to the $\mathrm{M}_{1}-\mathrm{M}_{2}$ segment where the steenbok and the springbok exhibited significant differences between the sexes, while the eland did not.

\section{Maxillary Tooth Rows:}

1. Premolars: Regardless of body size, maxillary premolar tooth rows did not exhibit statistically significant dimorphism between the sexes.

2. $\mathbf{M}^{1}-\mathbf{M}^{2}$ : Like the premolar rows, the maxillary $\mathrm{M}^{1}-\mathrm{M}^{2}$ rows did not exhibit significant dimorphism in the three wild bovids.

3. $\mathbf{M}^{\mathbf{1}}-\mathbf{M}^{\mathbf{3}}$ : The springbok exhibited a significant result for sexual dimorphism at the full maxillary molar row. The small, monogamous steenbok and the large, polygynous eland did not show any significant differences between the sexes. 
4. Full Rows: Only the springbok exhibited any significant sexual dimorphism in the full maxillary tooth row.

E. Known-Sex Discussion: The distal humerus and tibia measurements produced expected results. The smallest, monogamous steenbok showed that females' mean widths were slightly larger than their male counterparts, but they are statistically indistinguishable. Increased body size from sheep and springbok to eland exhibited statistically significant dimorphism in the distal humerus, while only the sheep and eland exhibited significant dimorphism at the distal tibia. Since the springbok is not a highly dimorphic bovid (Estes 1991: 80-84), it is understandable that the lesser weight bearing hind limb would not exhibit a significant difference between the sexes.

In the case of the domestic sheep, human involvement in the practice of castration produces a mixed result. The fore end of the castrated wether continued to resemble a normal ram, while the hind end is more gracile than a normal ram. As speculation, Davis (1996; 2000) used the humerus measurement "Bt" which is a direct measurement of the trochlea and since this part is directly involved in joint motion, perhaps trochlea size is less affected by a loss of testosterone. On the other hand, the tibia measurements for the wethers more closely resembled the ewes, which may be a result of the distal tibia measurement which included some nonarticular bone where muscles attach. Decreased testosterone results in lessened muscle mass, and the lesser amount of muscle would not develop the distal tibia muscle attachments as fully as it would in a normal ram (Lawrence and Fowler 2002: 138; Purchas 1991: 217-218). Davis (2000: 384, 386-387) reported minor epiphyseal fusion delays in those epiphyses that fuse in the second and 
third years of life, and this is used to explain the increased length of wether long bones. Davis' (2000: 378) Shetland sheep were castrated within the first seven days of age, which is well ahead of the epiphyseal fusion ages for the distal humerus and distal tibia. While the distal humerus and distal tibia fuse at about seven-10 months and 18-24 months, respectively (Davis 2000: 381; Silver 1969: 285-286), the earlier fusion of the distal humerus trochlea may cause it to be less affected by the lack of testosterone than the distal tibia. As mentioned earlier, the humerus is at the greater weight bearing end of the animal and it would exhibit greater dimorphism than the hind limbs, especially in males which carry more weight whether or not they are castrated (Jewell 1963: 81; Svensson et al. 2008: 942; Thomas 1988: 87; Zalkin 1960: 123). Davis (2000: 383-384) continued to say that the humerus trochlea continues some width-directional growth after its fusion while the distal tibia does not exhibit significant increased widening with age. So, while the distal humerus measurement is age-dependent and could reflect older versus younger individuals of the same sex, sexual dimorphism is more clearly expressed in distal humeri widths (Davis 2000: 384).

Tooth row measurements produced inconsistent results. No statistically significant dimorphism was identified in the mandibular $\mathrm{M}_{1}-\mathrm{M}_{3}$ as well as the maxillary premolar and $\mathrm{M}^{1}-\mathrm{M}^{2}$ rows for any of the known-sex bovids, which suggests that these could be useful osteometric points to distinguish different breeds that had significantly different body sizes. The steenbok and springbok often exhibited significant sexual dimorphism at other tooth row segments. Interestingly, the largest bodied and most polygynous bovid, the eland exhibited no significant dimorphism in any tooth row 
measurement which could support Grigson's (1982: 7) claim that there is no sexual dimorphism in cattle tooth rows.

\section{ARCHAEOLOGICAL RESULTS}

Table 8.3 provides some statistical descriptions for the archaeological sheep samples and their distribution curves. Table 8.4 presents the Mann-Whitney comparisons between each site.

Table 8.3. Sample sizes (NISP), means, standard deviation (SD), normality, skewness, and skewness standard deviation (SES) for each sample of each archaeological sheep sample.

\begin{tabular}{|c|c|c|c|c|c|c|c|}
\hline Element & Site & $\mathbf{N}$ & $\begin{array}{l}\text { Mean } \\
(\mathrm{mm})\end{array}$ & SD & Distribution & Skew & SES \\
\hline \multirow[t]{4}{*}{ Humerus } & Moat & 64 & 36.08 & 1.90 & norm & -0.055 & 0.612 \\
\hline & Elsenburg & 50 & 33.73 & 2.57 & norm & 0.011 & 0.693 \\
\hline & Oudepost & 18 & 34.77 & 1.87 & norm & 0.331 & 1.155 \\
\hline & Prehistoric & 76 & 31.00 & 1.46 & not norm & -0.479 & 0.562 \\
\hline \multirow[t]{4}{*}{ Tibia } & Moat & 53 & 31.56 & 1.52 & norm & -0.185 & 0.673 \\
\hline & Elsenburg & 44 & 29.58 & 1.50 & norm & -0.447 & 0.739 \\
\hline & Oudepost & 12 & 29.22 & 1.72 & norm & -0.048 & 1.414 \\
\hline & Prehistoric & 10 & 27.22 & 1.28 & norm & -1.002 & 1.549 \\
\hline \multirow{4}{*}{$\begin{array}{l}\text { Mandible } \\
\text { Premolars }\end{array}$} & Moat & 77 & 25.01 & 1.82 & norm & 0.237 & 0.558 \\
\hline & Elsenburg & 29 & 23.61 & 1.45 & norm & 0.329 & 0.091 \\
\hline & Oudepost & 10 & 23.99 & 2.51 & norm & -0.134 & 1.549 \\
\hline & Prehistoric & 24 & 22.72 & 2.56 & weakly norm & 0.845 & 1.000 \\
\hline \multirow{4}{*}{$\begin{array}{l}\text { Mandible } \\
\text { M1-2 }\end{array}$} & Moat & 105 & 30.14 & 2.18 & not norm & 0.142 & 0.478 \\
\hline & Elsenburg & 39 & 28.21 & 1.60 & weakly norm & 0.859 & 0.784 \\
\hline & Oudepost & 18 & 30.08 & 3.44 & norm & -1.057 & 1.155 \\
\hline & Prehistoric & 29 & 27.42 & 3.90 & norm & -2.028 & 0.910 \\
\hline \multirow{4}{*}{$\begin{array}{l}\text { Mandible } \\
\text { M1-3 }\end{array}$} & Moat & 56 & 52.89 & 1.95 & norm & -0.043 & 0.655 \\
\hline & Elsenburg & 30 & 53.08 & 1.43 & weakly norm & 0.658 & 0.894 \\
\hline & Oudepost & 7 & 52.64 & 2.96 & norm & -1.518 & 1.852 \\
\hline & Prehistoric & 14 & 49.99 & 1.92 & norm & 0.105 & 1.309 \\
\hline \multirow{4}{*}{$\begin{array}{l}\text { Maxilla } \\
\text { Premolars }\end{array}$} & Moat & 32 & 26.80 & 1.88 & norm & -0.261 & 0.866 \\
\hline & Elsenburg & 2 & 24.60 & 2.12 & na & na & na \\
\hline & Oudepost & 4 & 26.65 & 0.88 & norm & 0.175 & 2.449 \\
\hline & Prehistoric & 7 & 23.56 & 2.21 & norm & -0.574 & 1.852 \\
\hline
\end{tabular}




\begin{tabular}{|llllllll|}
\hline Maxilla & Moat & 60 & 31.94 & 2.09 & norm & -0.198 & 0.632 \\
M1-2 & Elsenburg & 10 & 30.43 & 1.61 & norm & 1.426 & 1.549 \\
& Oudepost & 11 & 32.18 & 3.50 & norm & -0.992 & 1.477 \\
& Prehistoric & 17 & 29.33 & 3.03 & norm & 0.083 & 1.188 \\
\hline \multirow{2}{*}{ Maxilla } & Moat & 15 & 50.27 & 2.42 & norm & 0.739 & 1.265 \\
M1-3 & Elsenburg & 4 & 50.60 & 1.60 & norm & 0.671 & 2.449 \\
& Oudepost & 4 & 48.03 & 3.53 & norm & -1.855 & 2.449 \\
& Prehistoric & 6 & 46.97 & 1.89 & norm & -0.471 & 2.000 \\
\hline
\end{tabular}

Table 8.4. Mann-Whitney comparisons of the measurements for the archaeological sheep samples.

\begin{tabular}{|c|c|c|c|}
\hline Element & Comparison & $\begin{array}{l}\text { Mann- } \\
\text { Whitney } \\
\text { U Score }\end{array}$ & $\mathbf{P}$ \\
\hline \multirow[t]{6}{*}{ Humerus } & $\begin{array}{l}\text { Elsenburg- } \\
\text { Oudepost }\end{array}$ & 565.5 & $\mathrm{P}>0.05$ \\
\hline & Moat-Prehistoric & 4794.0 & $\mathrm{P}<\mathbf{0 . 0 0 1}$ \\
\hline & Elsenburg-Moat & 2447.0 & $\mathrm{P}<0.001$ \\
\hline & $\begin{array}{l}\text { Moat-Oudepost } \\
\text { Oudepost- }\end{array}$ & 796.0 & $\mathrm{P}<0.05$ \\
\hline & Prehistoric & 1308.0 & $\mathrm{P}<0.001$ \\
\hline & $\begin{array}{l}\text { Elsenburg- } \\
\text { Prehistoric }\end{array}$ & 3071.5 & \\
\hline \multirow[t]{6}{*}{ Tibia } & $\begin{array}{l}\text { Elsenburg- } \\
\text { Oudepost }\end{array}$ & 297.0 & $\mathrm{P}>0.05$ \\
\hline & Moat-Prehistoric & 523.5 & $\mathrm{P}<0.001$ \\
\hline & Elsenburg-Moat & 1931.5 & $P<0.001$ \\
\hline & $\begin{array}{l}\text { Moat-Oudepost } \\
\text { Oudepost- }\end{array}$ & 540.5 & $\mathrm{P}<\mathbf{0 . 0 0 1}$ \\
\hline & Prehistoric & 95.5 & $\mathrm{P}<0.05$ \\
\hline & Elsenburg- & 3050 & \\
\hline & & & \\
\hline \multirow{6}{*}{$\begin{array}{l}\text { Mandible } \\
\text { Premolars }\end{array}$} & $\begin{array}{l}\text { Elsenburg- } \\
\text { Oudepost }\end{array}$ & 164.5 & $\mathrm{P}>0.05$ \\
\hline & Moat-Prehistoric & 1450.5 & $P<0.001$ \\
\hline & Elsenburg-Moat & 1609.5 & $\mathrm{P}<0.001$ \\
\hline & $\begin{array}{l}\text { Moat-Oudepost } \\
\text { Oudepost- }\end{array}$ & 476.5 & $\mathrm{P}>0.05$ \\
\hline & Prehistoric & 161.0 & $\mathrm{P}>0.05$ \\
\hline & $\begin{array}{l}\text { Elsenburg- } \\
\text { Prehistoric }\end{array}$ & 477.5 & $\mathrm{P}<0.05$ \\
\hline \multirow{7}{*}{$\begin{array}{l}\text { Mandible } \\
\text { M1-2 }\end{array}$} & Elsenburg- & & \\
\hline & Oudepost & 532.5 & $\mathrm{P}<0.01$ \\
\hline & Moat-Prehistoric & 2169.5 & $\mathrm{P}<0.001$ \\
\hline & Elsenburg-Moat & 3193.5 & $\mathrm{P}<0.001$ \\
\hline & $\begin{array}{l}\text { Moat-Oudepost } \\
\text { Oudepost- }\end{array}$ & 1062.5 & $\mathrm{P}>0.05$ \\
\hline & Prehistoric & 362.5 & $\mathrm{P}<0.05$ \\
\hline & $\begin{array}{l}\text { Elsenburg- } \\
\text { Prehistoric }\end{array}$ & 672.0 & $\mathrm{P}>0.05$ \\
\hline
\end{tabular}

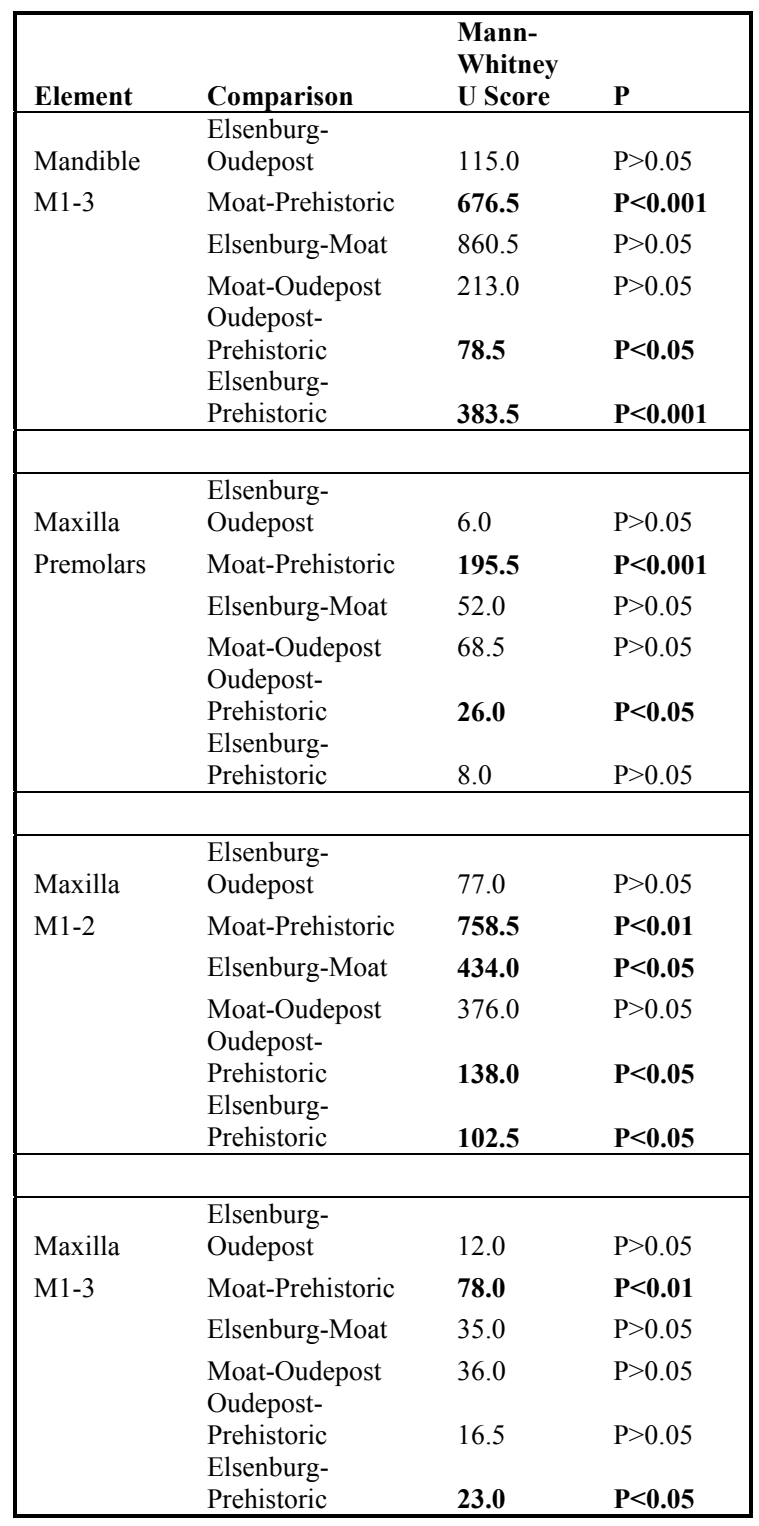

A. Distal Humerus Breadth: As expected, all historic samples were significantly larger than the prehistoric samples. Also, Oudepost and Elsenburg were not statistically 
distinguishable and this was expected due to the full overlap of their bimodal histograms (figure 8.1). The Moat sample was also significantly larger than all other historic sites sampled here. The Moat's distribution presents a slight peak (at about 31.0-33.9 mm) which falls within the lower peak of the Oudepost and Elsenburg distributions.

B. Distal Tibia Breadth: The distal tibia breadth produced the same expected results as the distal humerus. All historic samples were significantly larger than the prehistoric samples, and the Moat was significantly larger than the other historic sites. Again, Elsenburg and Oudepost sheep samples were not statistically distinguishable at the distal tibia breadth. The distal tibiae histograms do not exhibit a clear bimodality like the humeri histograms (figure 8.2). The low end of the Moat (at 30.0-30.4 mm) exhibits a slight peak coinciding with the peak of the Elsenburg distribution. The Elsenburg curve also exhibits a small secondary peak (at 32.0-32.9 mm) which matches the main peak for the Moat's distribution. These secondary peaks are not expected to be clearly separated from the main peak since the distal tibia was not as dimorphic between females and wethers as discussed above.

\section{Mandibular Tooth Rows:}

1. Premolars: Interestingly, Oudepost did not exhibit statistically significant premolar row length differences with any other sample. In contrast, significant differences were identified between the Moat, Elsenburg, and prehistoric samples. The histograms show relatively broad distributions with the Moat being, on average, slightly larger than the 
other sites (figure 8.3). Elsenburg and Oudepost exhibit similar peaks around 23.0-23.9 $\mathrm{mm}$, while the prehistoric sheep peak was smaller between $21.0-23.4 \mathrm{~mm}$.

2. $\mathbf{M}_{1}-\mathbf{M}_{2}$ : Significant differences in the $\mathrm{M}_{1}-\mathrm{M}_{2}$ segment were identified in all comparisons except Moat-Oudepost and Elsenburg-Prehistoric. Here, the histograms show very broad distributions for Oudepost and the prehistoric sheep with possible peaks at the upper and lower ends of their distributions (figure 8.4). The Moat distribution peaks slightly larger than Elsenburg.

3. $\mathbf{M}_{1}-\mathbf{M}_{3}$ : Significant differences were only identified at the $\mathrm{M}_{1}-\mathrm{M}_{3}$ segment between the historic and prehistoric samples. While the three historic sites measure larger, Oudepost's small sample extended into the lower end of the prehistoric distribution at $46.5 \mathrm{~mm}$ (figure 8.5).

\section{Maxillary Tooth Rows:}

1. Premolars: The Oudepost-Prehistoric and Moat-Prehistoric comparisons produced significantly different results. The histograms show that the historic sites are relatively larger than the prehistoric maxillary premolar segments (figure 8.6). Elsenburg's sample size did not allow it to be meaningfully compared with the other samples.

2. $\mathbf{M}^{1}-\mathbf{M}^{2}$ : The maxillary $\mathrm{M}^{1}-\mathrm{M}^{2}$ segment produced a mixed result. The Moat distribution was significantly different than Elsenburg and prehistoric samples. Oudepost also exhibited a significant difference with the prehistoric sample. Similar to the mandible, the maxillary $\mathrm{M}^{1}-\mathrm{M}^{2}$ segment shows broad distributions for Oudepost and the prehistoric sheep (figure 8.7). The Elsenburg peak matches up with the lower Moat peak between 29.0-30.9 mm. 
3. $\mathbf{M}^{1}-\mathbf{M}^{3}$ : The only significant differences identified at the maxillary $M^{1}-M^{3}$ segment were between the Moat and Elsenburg samples with the prehistoric sample. Sample sizes were small, but the Oudepost and prehistoric sheep histograms continue to show relatively broad distributions while the Moat and Elsenburg distributions are more condensed (figure 8.8).

E. Archaeological Discussion: The postcranial measurements at the distal humerus and distal tibia produced expected results. As per Davis' (2000) known-sex results indicating significant sexual dimorphism in these postcranial parts, the Moat sheep support the prediction that they would be the largest since they are predominately male. Elsenburg and Oudepost did not exhibit significant differences from each other. The Elsenburg sample is dominated by female sheep, and the clear bimodality produced by the Oudepost sample suggests that this site also contains a large proportion of female sheep.

Oudepost's smaller sample size may have produced a lucky result that does not contain larger females or smaller males that would blur the two peaks of the distribution, thus facilitating the past interpretation of two clearly different sized breeds. The humeri and tibiae from the Moat exhibit minor peaks at the lower ends of the respective distributions that match the main peak from Elsenburg and the lower peak from Oudepost, suggesting that the Moat sample also contains a small number of female sheep. Conversely, the upper ends of the Elsenburg distributions produce a secondary peak at the larger end of the scale which suggests that the Elsenburg sample contains some male sheep.

Though there is a large amount of overlap between the prehistoric sheep and historic sheep from Elsenburg and Oudepost, the prehistoric sheep were significantly 
smaller than those from the historic sites. Interestingly, the prehistoric sheep humeri do not show the bimodal distribution one would expect if the samples contained both males and females (the tibia sample size is much smaller and sexual dimorphism is also less pronounced in this bone portion). This result could support Zeder's (2008: 77) concern that the current methodology may only measure females which were kept to adulthood, while ignoring the males that were likely slaughtered younger. An additional explanation for the unimodality in prehistoric samples could be that the prehistoric sheep were not sexually dimorphic, but this explanation is unlikely since both wild and domesticated sheep are sexually dimorphic (Uerpmann 1978: 42; Burrill 2004).

Like the known-sex results, the archaeological tooth rows do not produce clear results. In general, the Moat and Elsenburg samples produce more compact distributions. Oudepost and the prehistoric sheep samples exhibit relatively broad distributions and they both contain specimens that are amongst the smallest tooth row segment lengths recorded from the archaeological sites. While Oudepost and the prehistoric sheep share similarities in their broad distributions, the two samples were often significantly different. The Moat and Oudepost did not show any statistically significant differences at any tooth row segments. Also, with only one exception at the mandibular $\mathrm{M}_{1}-\mathrm{M}_{2}$ segment, Elsenburg and Oudepost did not show statistically significant differences in tooth row lengths. These results suggest some similarities are shared with the sheep from these sites. If sexual differences are demonstrated through some tooth rows in sheep-sized bovids as discussed above, one might expect that a portion of the Oudepost sample would look like the Moat since both sites contain a large proportion of males. In addition, Oudepost would look like Elsenburg since both sites contain a large proportion of 
females. The comparisons between Elsenburg and the Moat produce evenly mixed results with three segments demonstrating significant differences while three did not.

Postcranial measurements show that the historic sheep are on-average larger than their prehistoric relatives. If one assumes the prehistoric sheep sampled were female, they are still smaller than the sheep which may be interpreted as female from Oudepost and Elsenburg, though there is size overlap in the distributions between the two time periods. Tooth rows have these same characteristics. With the best sex data coming from the Moat and Elsenburg samples, the tooth row comparisons between these sites do not match the results obtained for the bovids in the known-sex investigation in that no clear pattern can be identified. Due to the mixed results of the archaeological and the known-sex investigations, the question still remains whether these tooth row measurements reflect sexual differences or if the smaller prehistoric size could be used to identify different breeds and this will be explored below. 
Figure 8.1. Distal humerus distributions.

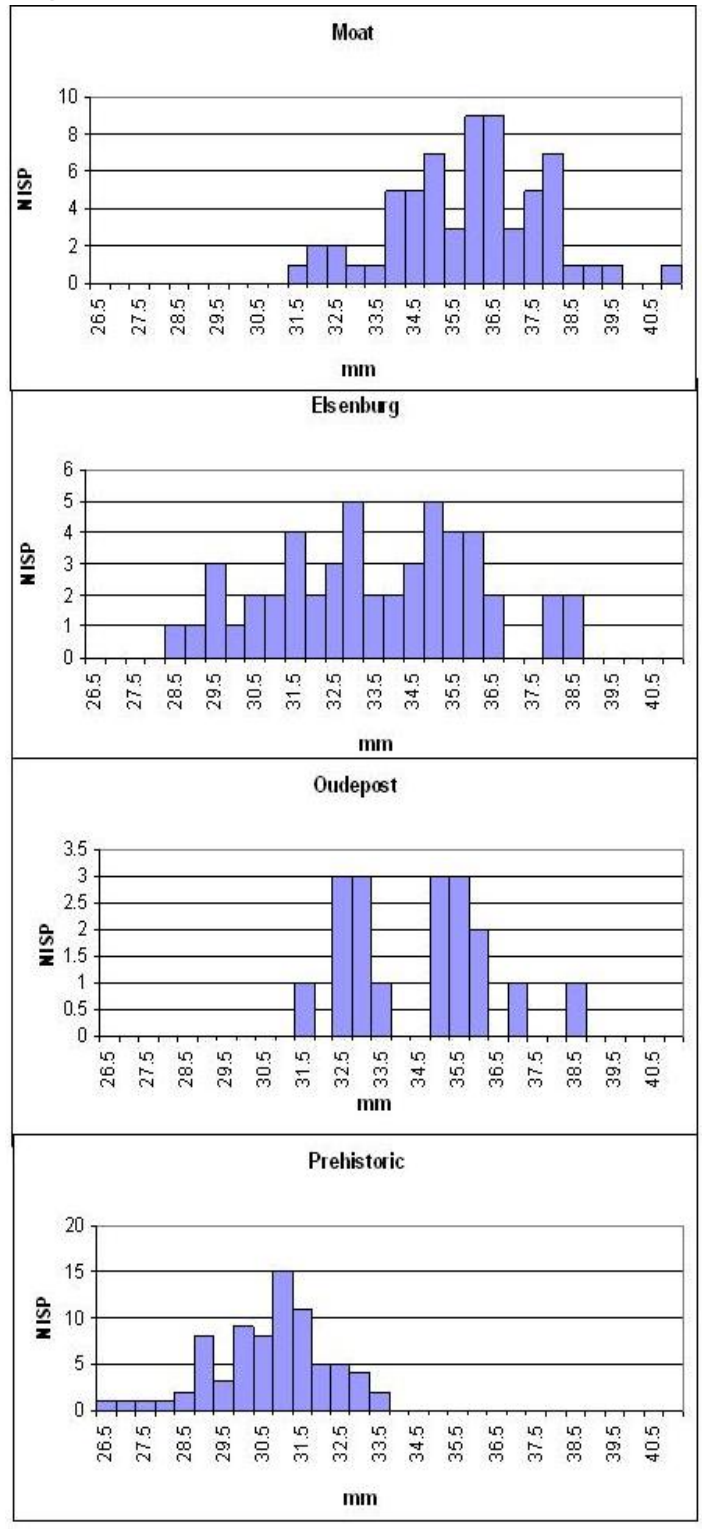

Figure 8.2. Distal tibia distributions.

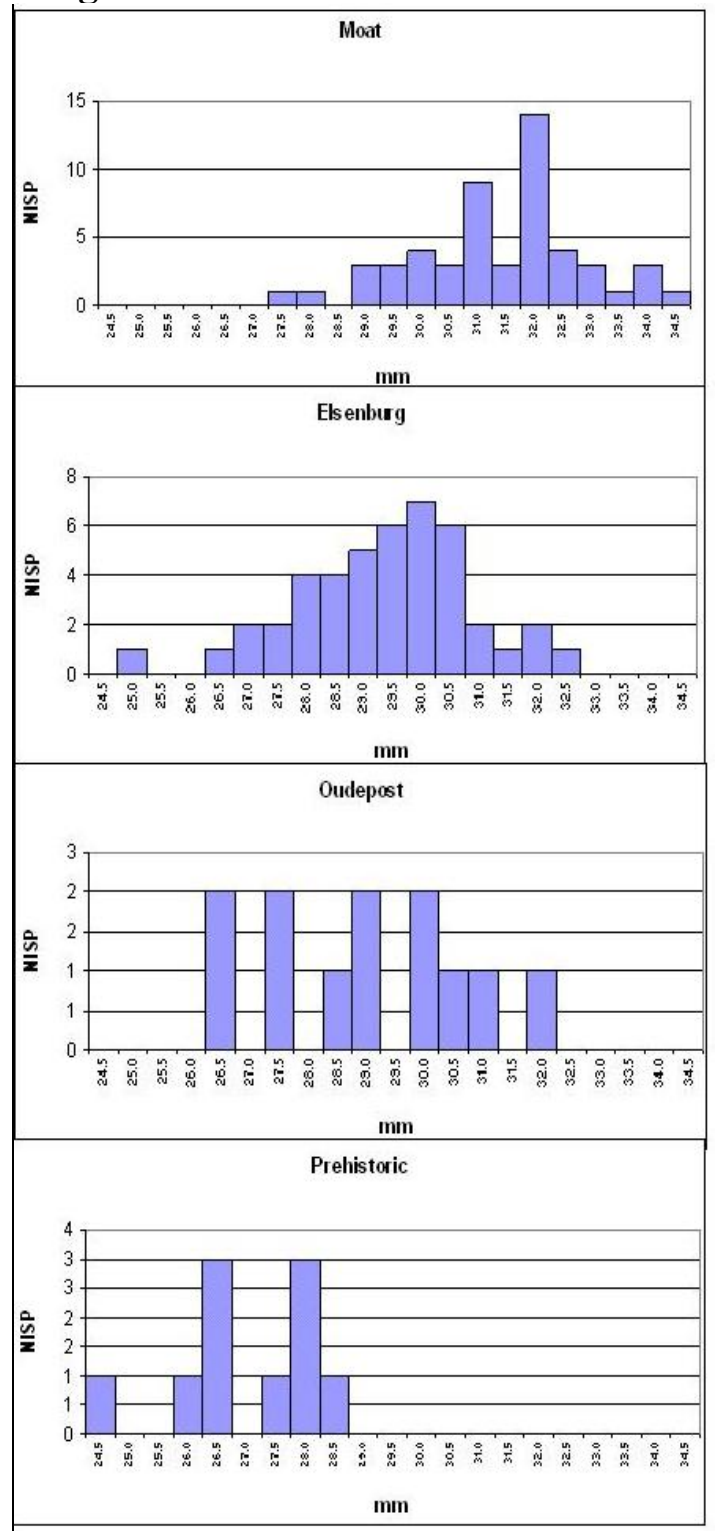


Figure 8.3. Mandibular premolar distributions.

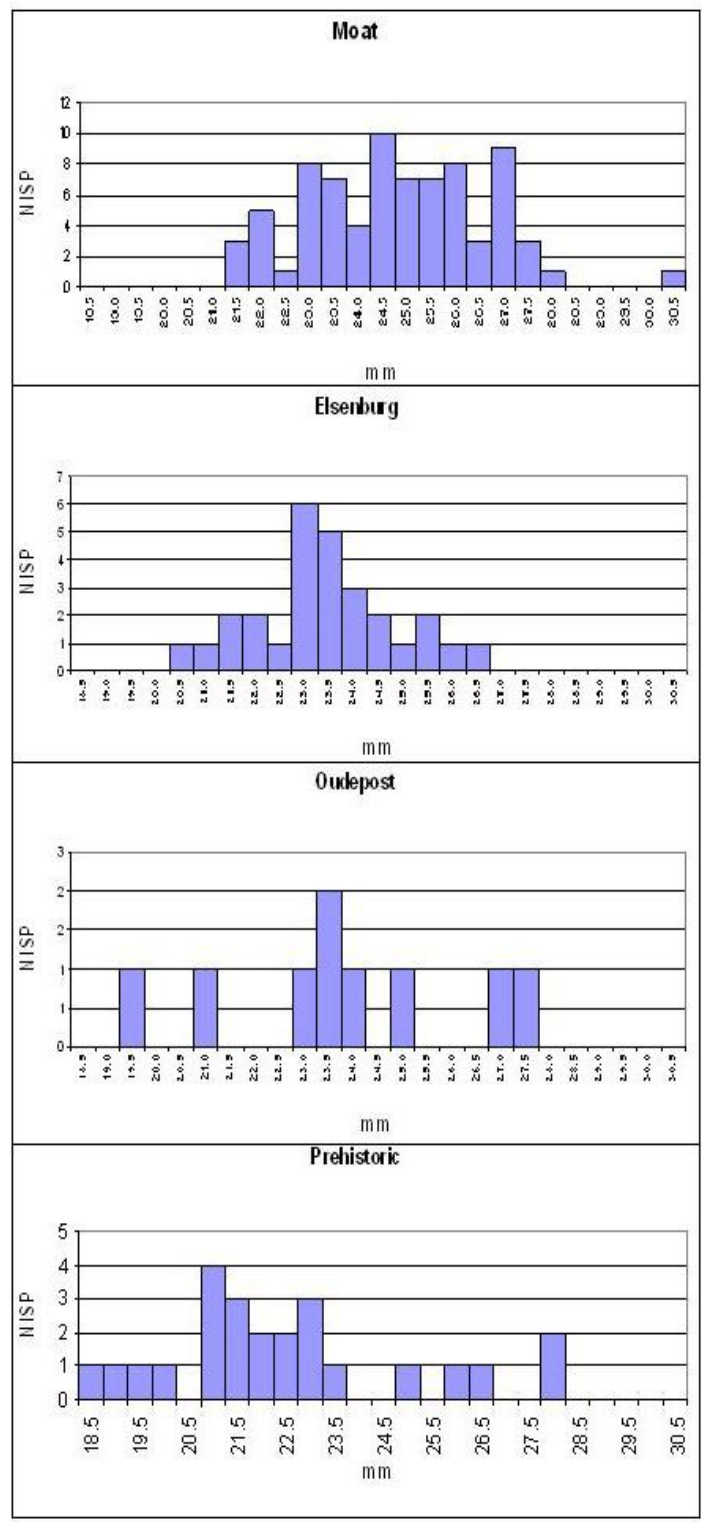

Figure 8.4. Mandibular $M_{1}-M_{2}$ distributions.

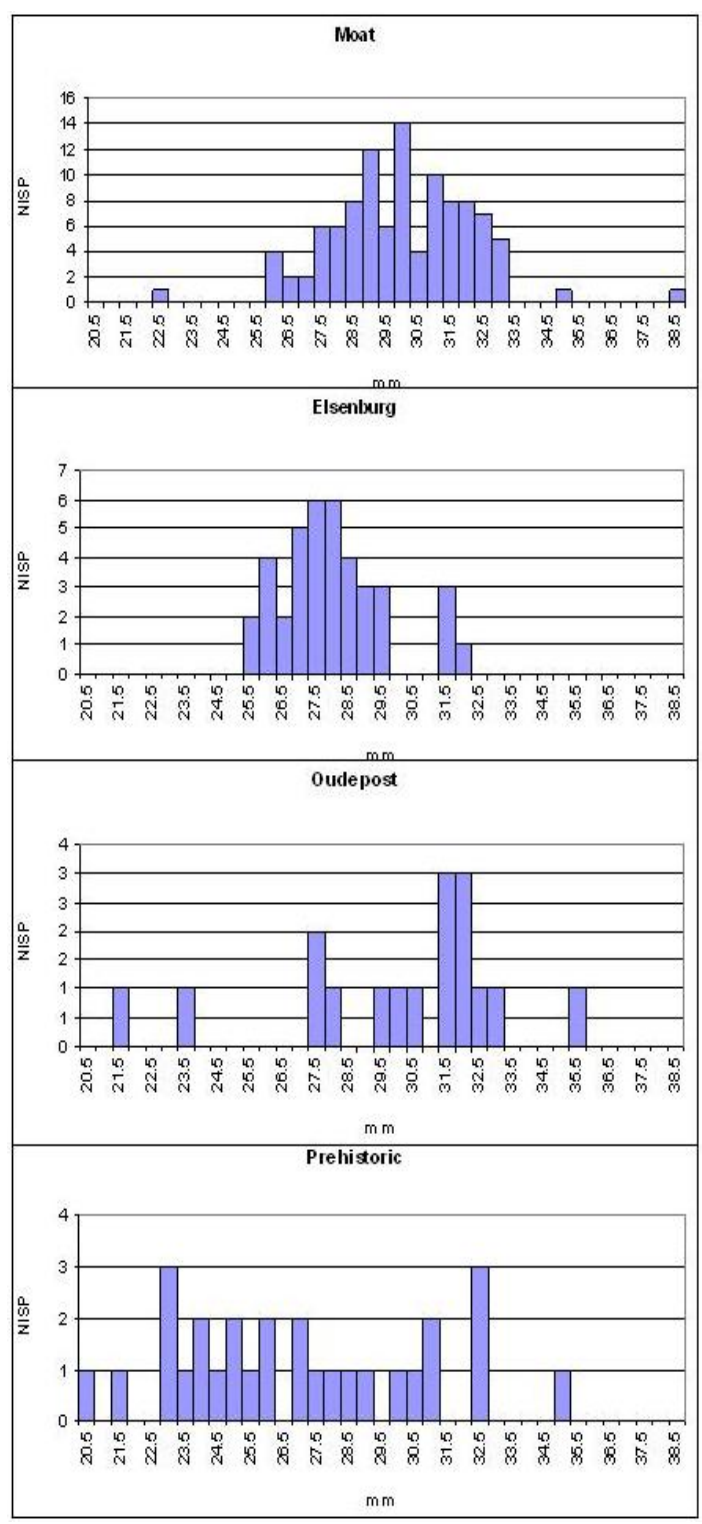


Figure 8.5. Mandibular $M_{1}-M_{3}$ distributions.

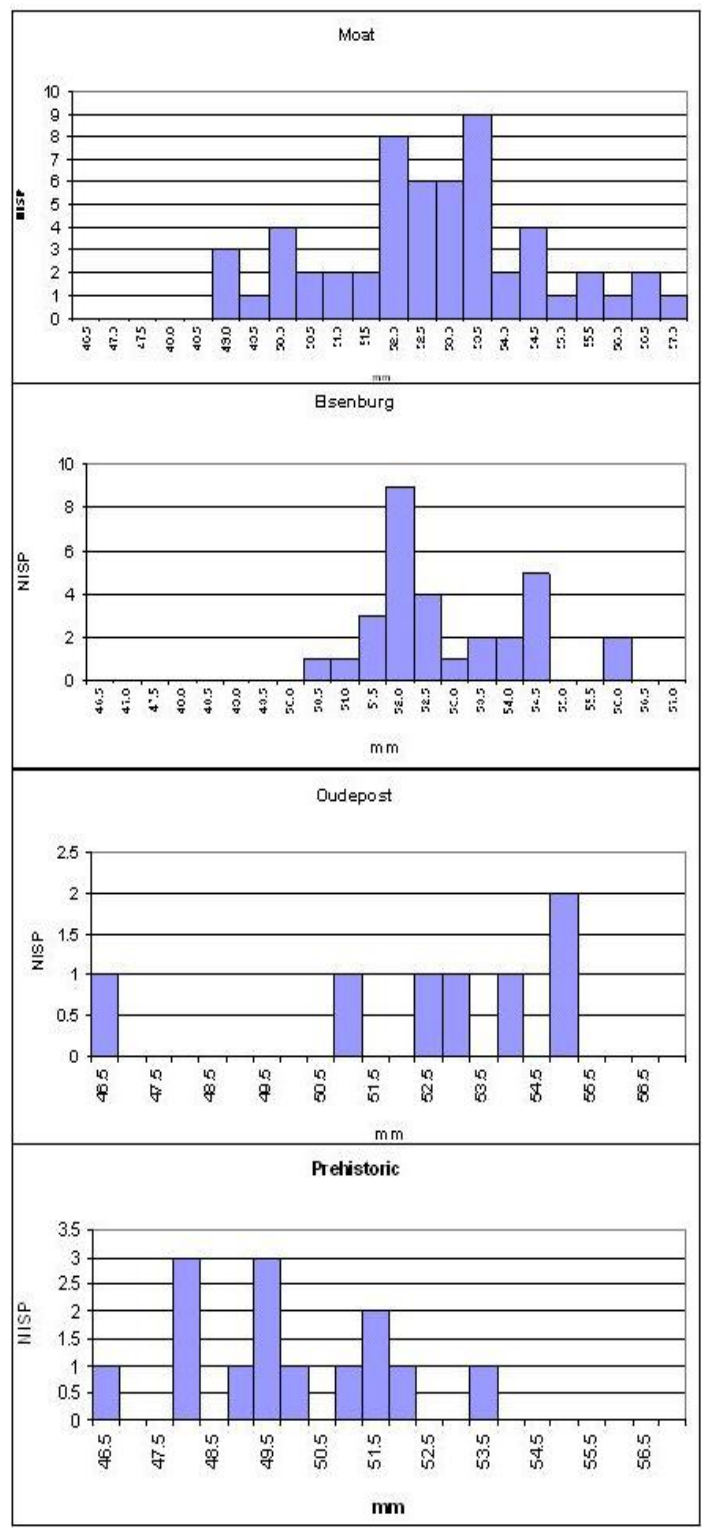

Figure 8.6. Maxillary premolar distributions.

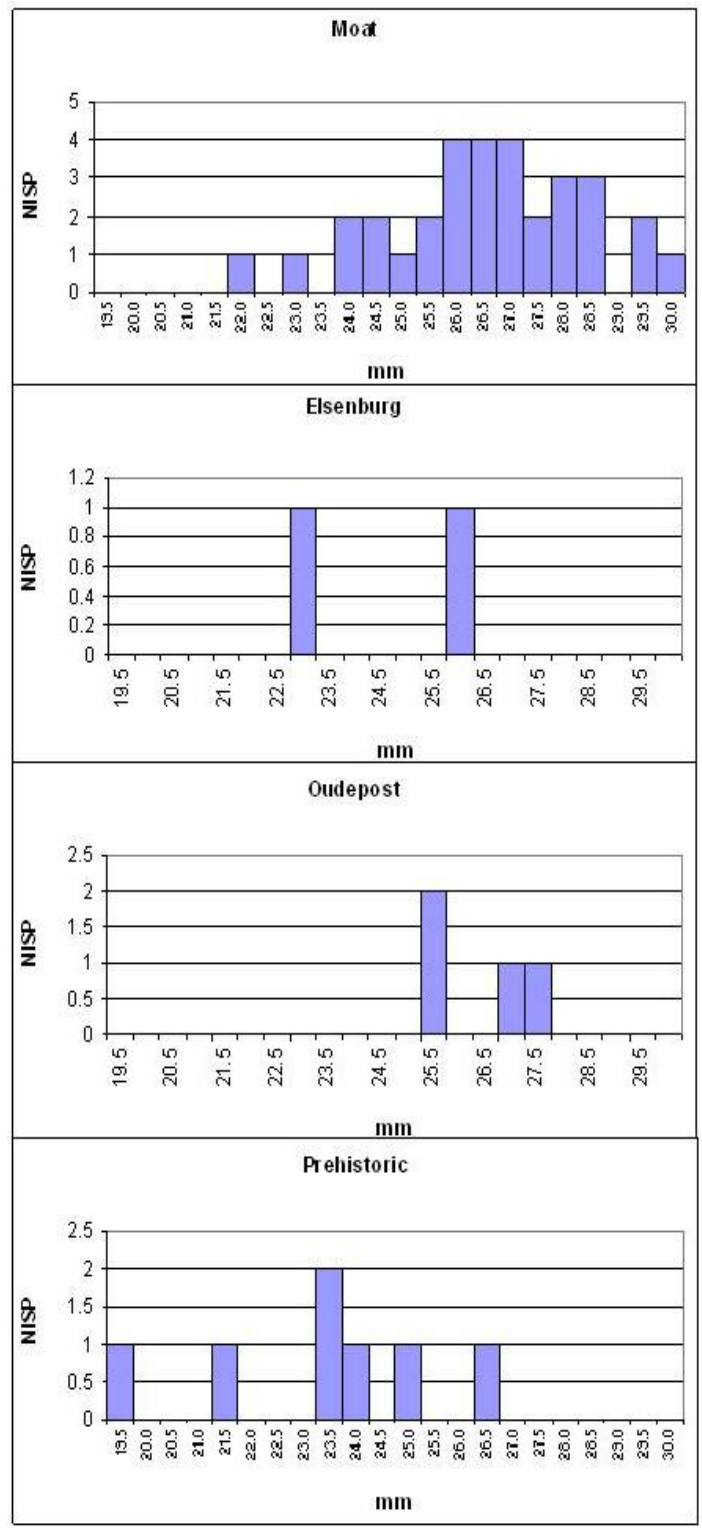


Figure 8.7. Maxillary $\mathbf{M}^{1}-M^{2}$

distributions.

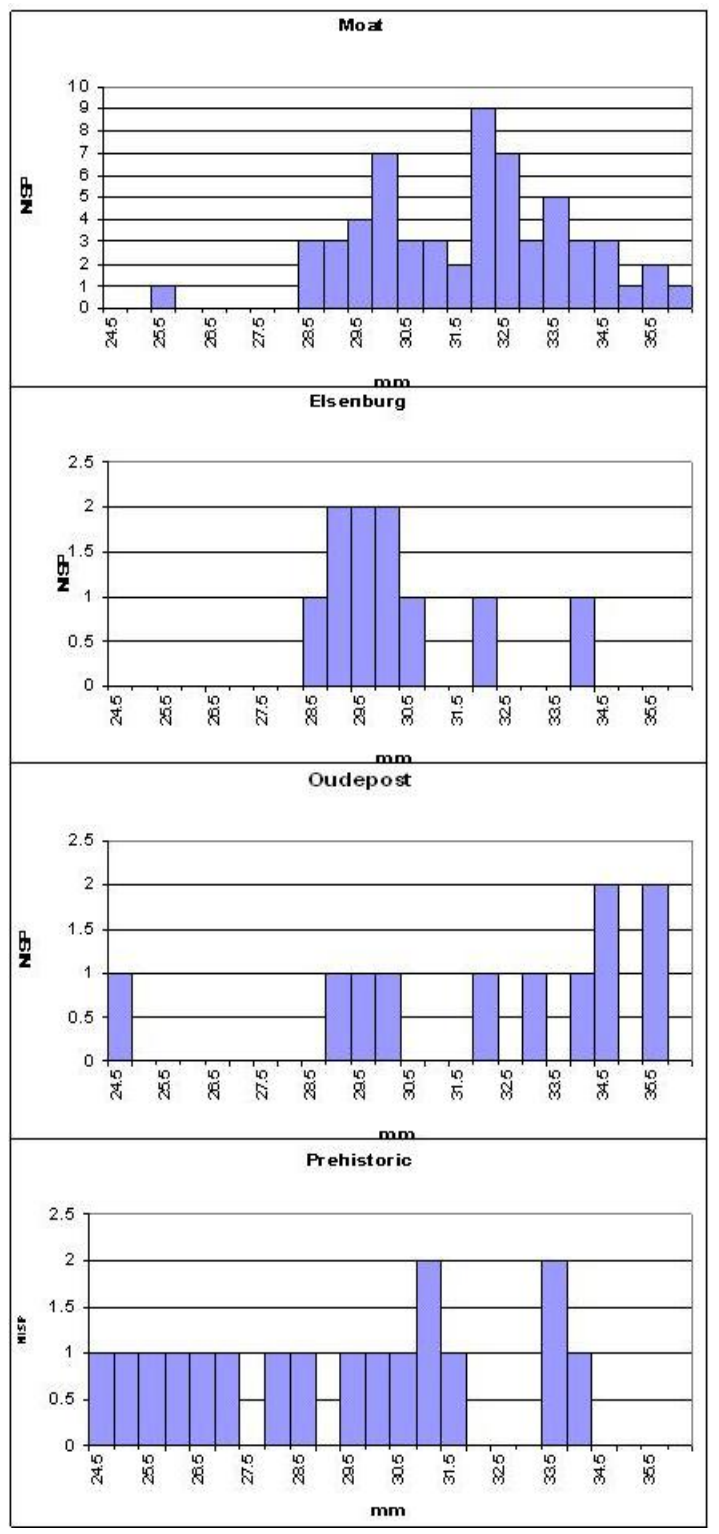

Figure 8.8. Maxillary $M^{1}-M^{3}$ distributions.

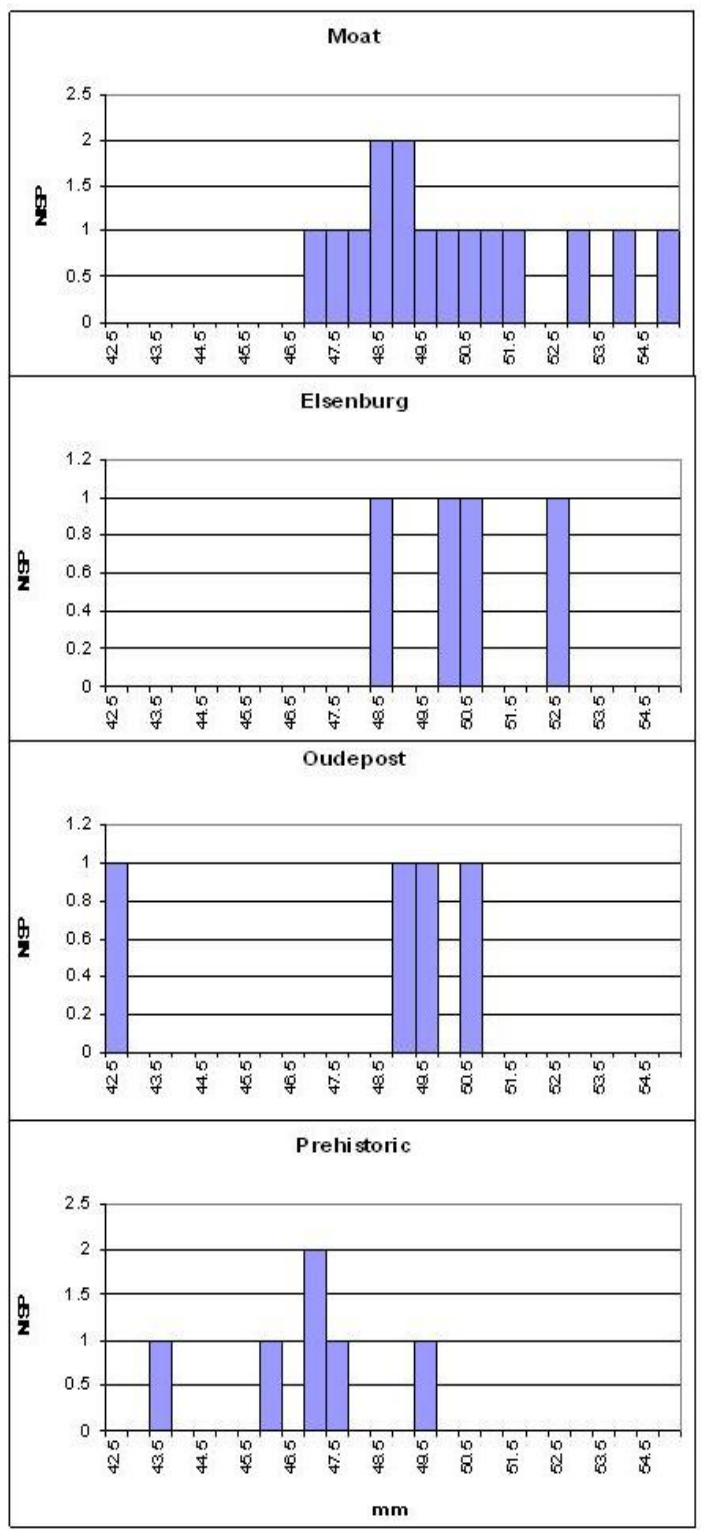




\section{AGE-RELATED VARIATION IN TOOTH ROW LENGTHS}

The archaeological comparisons suggest that there are similarities as well as significant differences between the sites. While the distal humeri and distal tibiae data show that sex is reflected in these particular distributions, the tooth row segments are not explained. A concern was raised when the smallest measurement from the Moat's mandibular $\mathrm{M}_{1}-\mathrm{M}_{2}$ segment at $22.8 \mathrm{~mm}$ represents the oldest individual present in the sample (see figure 8.4). This specimen raises the following question: is tooth row length affected by age; or stated another way, is a shorter tooth row representing an older animal?

Since a large number of complete mandibular tooth rows were preserved in the Moat, tooth row length can be tested against age using Payne's (1973) tooth wear stages. With this method, the smallest mandibular specimen from the Moat was aged at stage I, which shows that this individual was older than eight years of age when it was slaughtered. Regarding age, this specimen was much older than all the other sheep, which were mainly slaughtered between stages D and G, or between 1.5 and six years of age. This age pattern mimicked the histogram where most of the specimens fit within a relatively concise distribution curve, while the specimen in question fell as an outlier. This raised a concern that tooth row length could be dependent on animal age (figure 8.9). 
Figure 8.9. Contrasting lengths between the molar tooth row segments of two different aged sheep mandible specimens (examples from a Medieval/Early Modern Period site in York, England).

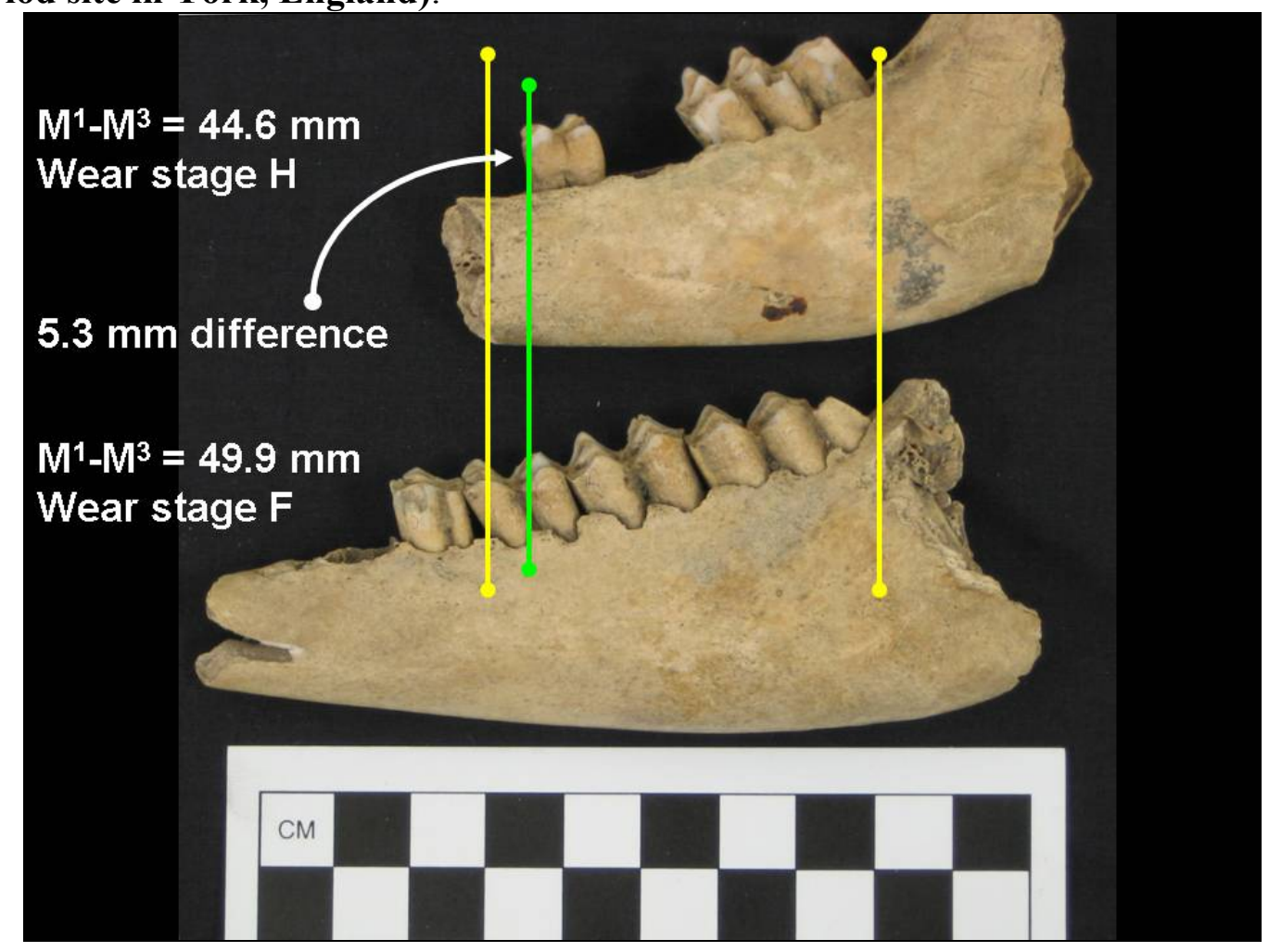

A. Mandibular Tooth Rows and Age: Figures 8.10, 8.11, and 8.12 show the tooth row segments for aged sheep mandibles from the Moat. It is clear that each tooth row segment is affected by advancing age. While tooth rows clearly get smaller with age, the trend is most clear in the premolar and $\mathrm{M}_{1}-\mathrm{M}_{2}$ segments. While the full molar segment seems to get slightly larger around three to four years of age (stage F), the length begins to decrease when the sheep get older. The less marked change in the full molar row is likely a result of the uniquely shaped $\mathrm{M}_{3}$ which is actually smaller at the top than it is at mid-crown in the vertical dimension (figure 8.13). So as the $\mathrm{M}_{3}$ wears down, the mesialdistal length of the crown increases. At these later ages, the increasingly narrower $\mathrm{M}_{1}$ and $\mathrm{M}_{2}$ may compensate for the slight increase of the early-wear $\mathrm{M}_{3}$ occlusal length. 
Figure 8.10. Mandibular premolar tooth row length decreases with advancing age.

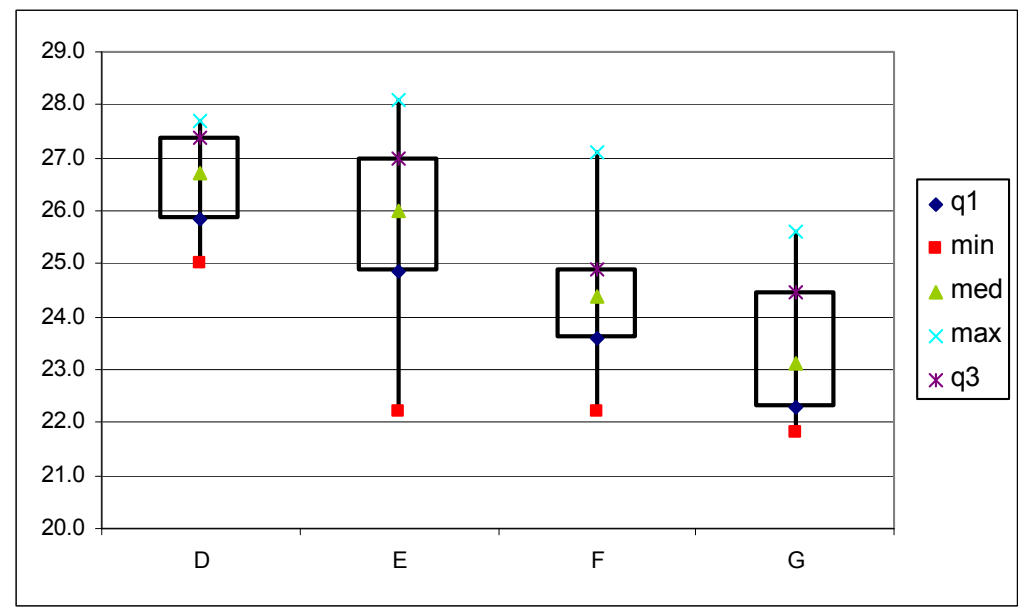

Figure 8.11. Mandibular $M_{1}-M_{2}$ row length decreases with advancing age.

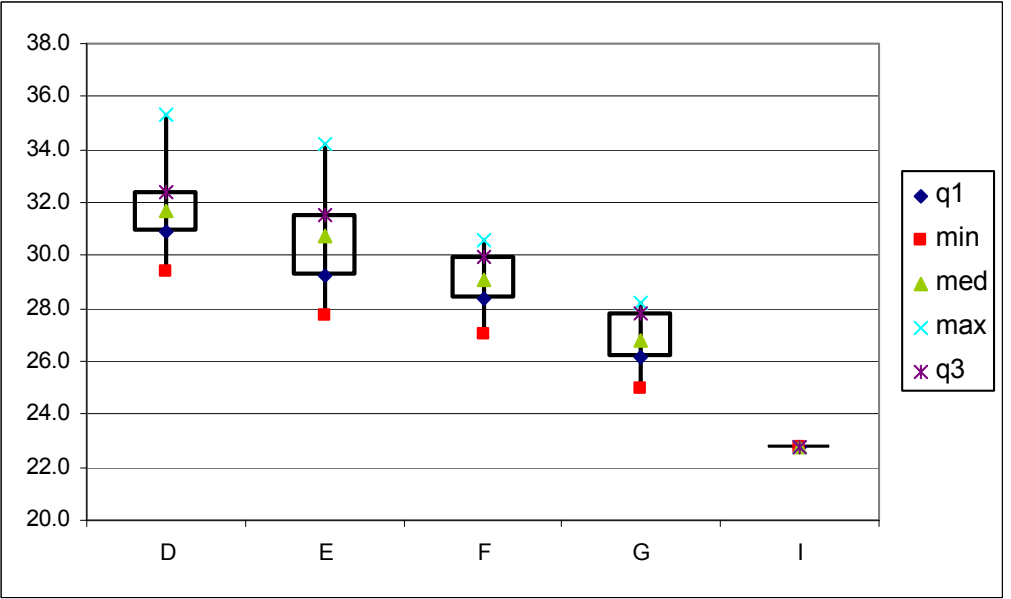

Figure 8.12. Mandibular $M_{1}-M_{3}$ row length slightly increases and then may decrease with advancing age.

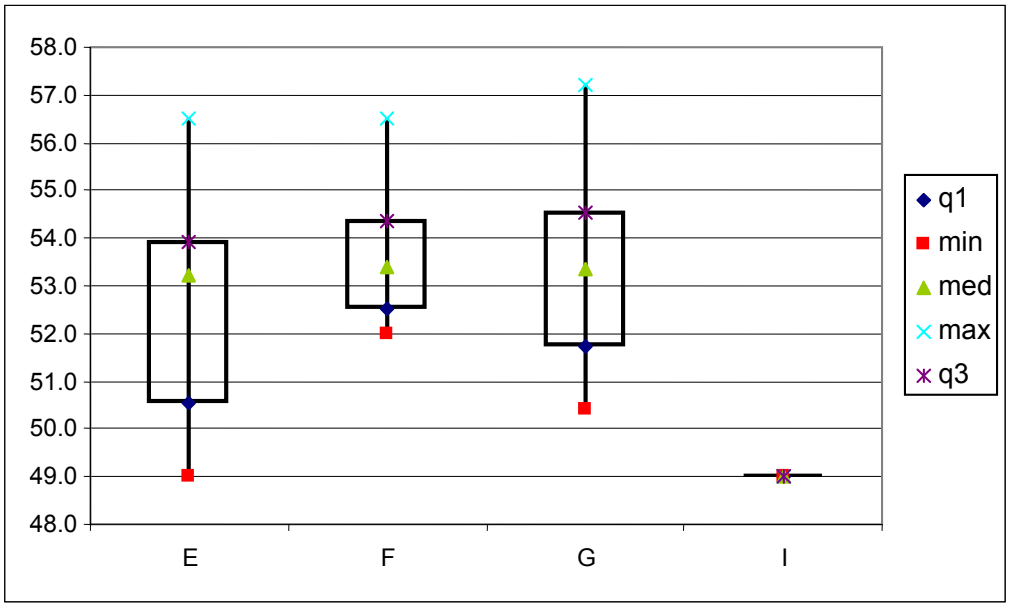


Figure 8.13. The mandibular molars showing the trapezoidal crown shape of the $M_{1}$ and $M_{2}$, and the increasing mesio-distal length of the $M_{3}$ down the tooth crown's height (examples from a Medieval/Early Modern Period site in York, England).

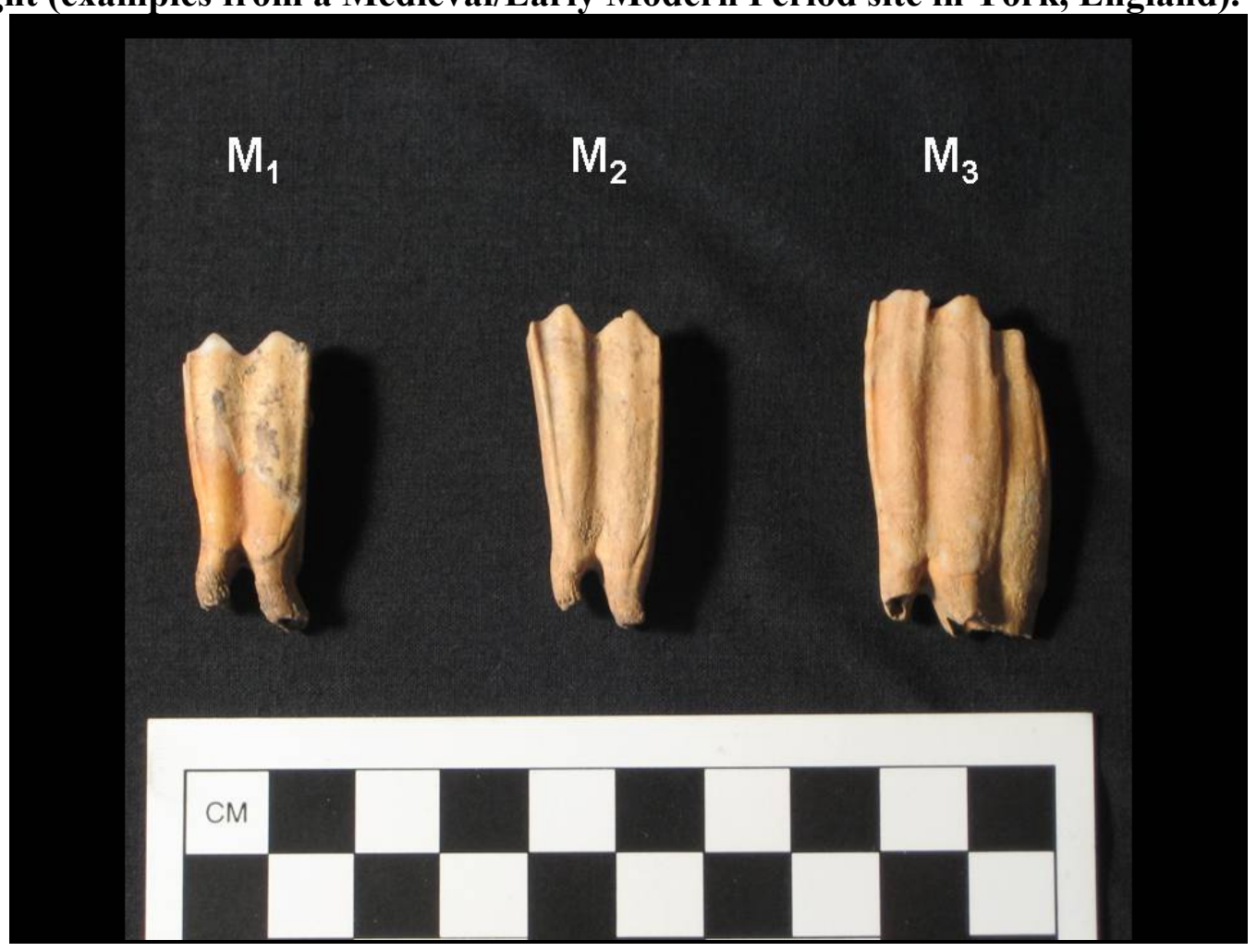

B. Maxillary Tooth Rows and Age: In the known-sex comparisons, the maxillary tooth row segments only showed significant differences in the springbok. The archaeological comparisons mainly showed significant differences between historic and prehistoric sheep maxillary tooth rows. The Moat-Elsenburg $\mathrm{M}^{1}-\mathrm{M}^{2}$ segment comparison produced a statistically significant difference, which does not clarify whether sex and/or age may be affecting the tooth row length. Premolars are late erupting teeth, and the small sample size in the younger, 18-24 months age class does not show if increasing age affects the premolar row length (Mann-Whitney $U=59.5, P>0.05$ ) (figure 8.14). In the Moat, the $\mathrm{M}^{1}-\mathrm{M}^{2}$ segment specimens can be broken into three age classes, and increasing age shows a clear decrease in the segment's length (figure 8.15). While a clear downward trend is present in Figure 8.14, the difference between the 12-18 months and the 18-24 
months age classes is not statistically significant (Mann-Whitney $U=53.0, P>0.05$ ), but the difference between the $18-24$ months and the $24-48$ months age class is marginally significant (Mann-Whitney $U=311.5, P<0.05$ ). In fact, during the early wear period of the maxillary $\mathrm{M}^{1}$ and $\mathrm{M}^{2}$, the tooth crown starts off more parallel and then becomes more triangular towards the root (figure 8.17). Like in the mandible, the $\mathrm{M}^{1}-\mathrm{M}^{3}$ segment seems to get larger after the $\mathrm{M}^{3}$ erupts and begins to wear, but the two age classes are not significantly different (Mann-Whitney $U=39.0, P>0.05$ ) (figure 8.17 and 8.16).

Figure 8.14. Maxillary premolar tooth row length shows no clear change through these two age brackets.

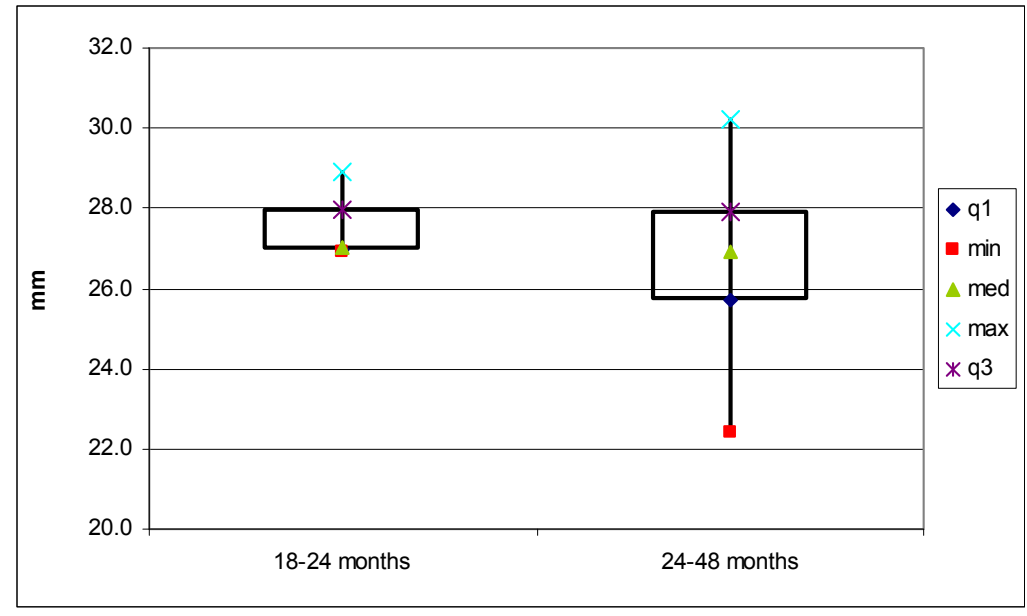

Figure 8.15. The maxillary $M^{1}-M^{2}$ tooth row segment decreases slightly through advancing age.

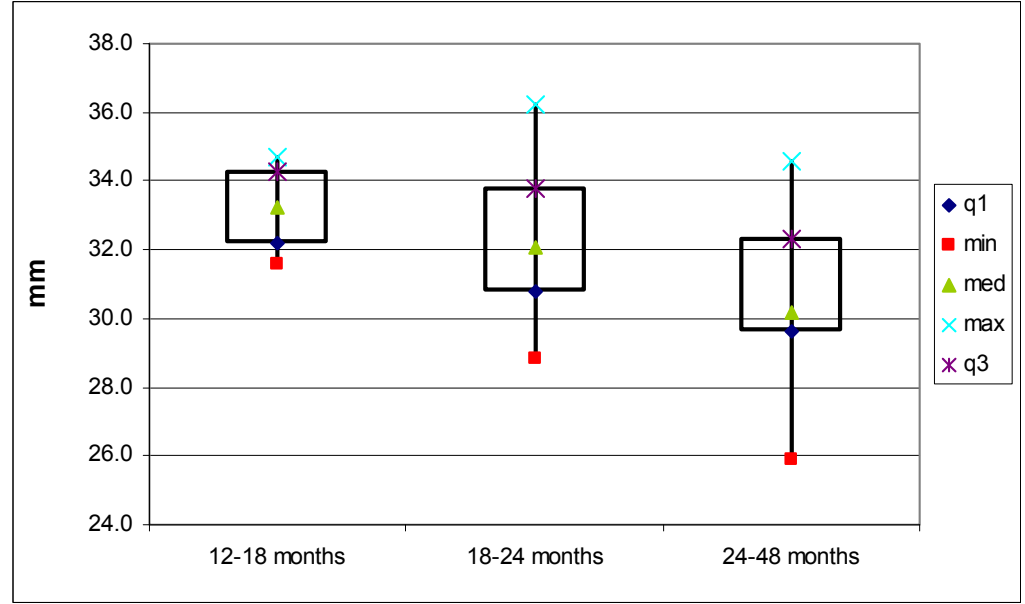


Figure 8.16. The mean maxillary $M^{1}-M^{3}$ tooth row segment may increase with advancing age.

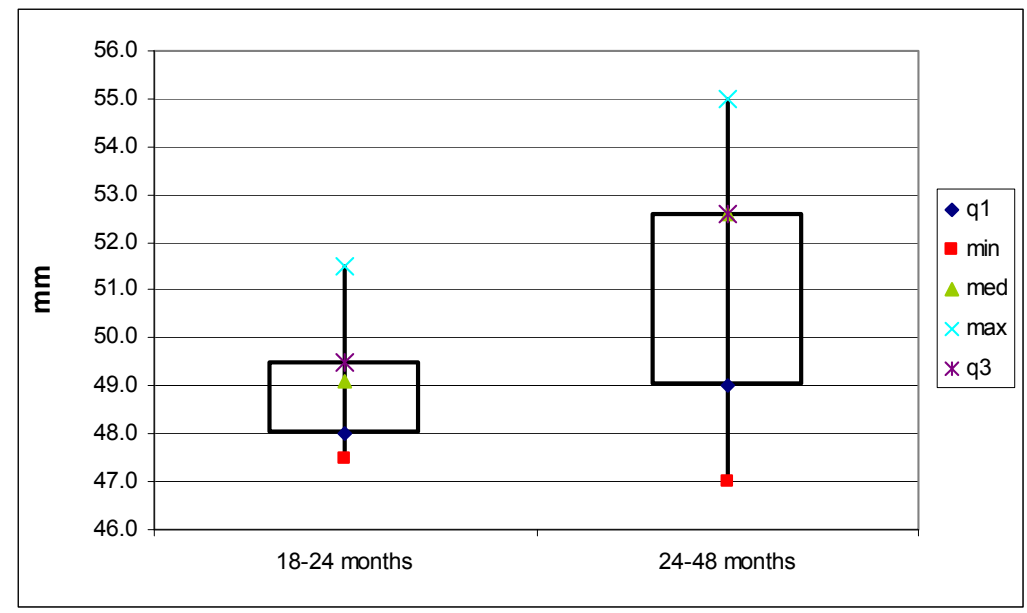

Figure 8.17. Maxillary molar examples showing the variably shaped crown of the $M^{1}$ and $M^{2}$ that start more parallel-sided (yellow) but become more trapezoidal (green) as these molars wear down. Like the mandible, the $\mathbf{M}^{3}$ shows increasing mesio-distal length down the tooth crown's height (examples from a Medieval/Early Modern Period site in York, England).

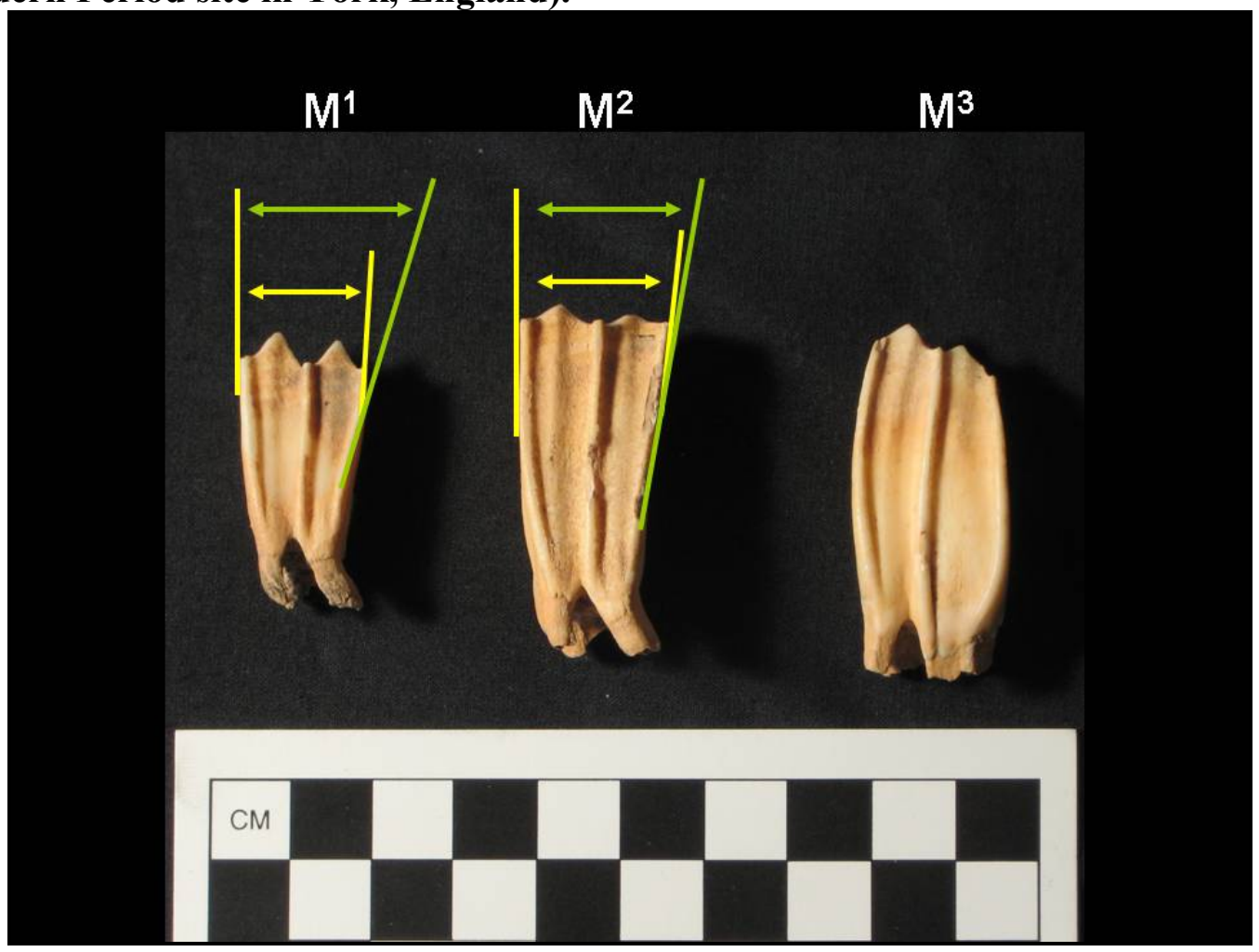




\section{AGE VARIATION DISCUSSION}

Since the Moat collection is heavily dominated by males, the variation in tooth row lengths is confidently attributed to age. While the decreasing length is most clearly observed in the mandible, the maxillary dentition also follows this pattern. Sheep maxillary teeth are more pillar-like with more parallel-sided crowns than the teeth in the mandible. This is similar to the maxillary and mandibular dentition of the largest bovids who have very pillar-like teeth. The less dramatic decrease in maxillary tooth row length could explain why the eland and possibly cows, according to Grigson's (1982: 7) statement, do not exhibit significant variation between sexes, or possibly even ages.

The implication of age-affected tooth row lengths is that tooth rows will not allow for the identification of different breeds if different management strategies were practiced at the compared sites. Measuring tooth rows at the tooth-bone juncture hoped to avoid any possible age-dependent problems that would be expected when measuring the mesial-distal length of the occlusal surface of teeth that are generally trapezoidal in shape. Due to the function and shape of bovid teeth, an individual tooth becomes narrower as it wears down with use through advancing age.

This affect of age on the tooth row length allows one to reinterpret the comparisons between the archaeological sites. Tooth rows from Elsenburg, which contained the highest proportion of older sheep, were significantly smaller than the Moat ones in all mandibular and the maxillary $\mathrm{M}^{1}-\mathrm{M}^{2}$ segments. The known-age study showed these tooth row segments to be the most significantly affected by age. Interestingly, the mandibular and the maxillary M1-M2 tooth row segments did not demonstrate any statistically significant differences between Elsenburg and the prehistoric sites which also 
contained a high proportion of "post-prime" sheep. Though Oudepost's distributions were often spread, they were never significantly different than the Moat. From the age data for these two sites, both samples contain a high proportion of prime aged sheep. Instead of reflecting sex or breed dimorphism, tooth row lengths reflect husbandry practices in regards to the age at which the sheep were slaughtered.

\section{CONCLUSION}

Since tooth rows diminish throughout the life of the sheep, Grigson's (1982) statement about cattle can probably not be applied to sheep when attempting to identify different breeds unless the sample is of uniform age at slaughter or can be separated into age classes. Though, exact ages were not able to be determined for the wild steenbok, springbok, and eland specimens, there was a similar mix of adult ages based on tooth wear for both females and males, which suggests that the data could be reflecting sexual dimorphism in the tooth rows lengths for steenbok and springbok.

The historic period archaeological data seems to be reflecting age and sex differences due to different sheep management strategies at each site. Elsenburg which is dominated by older females regularly shows significantly smaller postcranial and tooth row measurements than the Moat which is dominated by prime aged males, which are likely castrated males. Oudepost produces varying results with several measurements falling between the Moat and Elsenburg samples. The sheep distal humeri widths at Oudepost I exhibit a clear bimodal distribution, which were originally interpreted as the presence of indigenous and hybrid sheep in the sample (Cruz-Uribe and Schrire 1991: 97; Klein and Cruz-Uribe 1989: 90-91). With this new data, the original interpretation of 
indigenous and hybrid breeds being represented can no longer be considered a valid explanation. The distal humeri and tibiae measurements show that the Oudepost I sheep are a mix of males and females, while the tooth row data is showing the older and younger individuals already identified through tooth wear and eruption (Cruz-Uribe and Schrire 1991: 98). The Oudepost I sample contains a greater proportion of males than Elsenburg.

Prehistoric sheep are, on average, significantly smaller than any historic period sheep sample. This supports the contemporary accounts which stated that the VOC's hybrid was larger and meatier than the indigenous sheep (Cruz-Uribe and Schrire 1991: 97; Guelke 1988: 71; Mentzel 1921: 56; 1944: 210; Raven-Hart 1970b: 381; Thom 1936: 246, 249). Reiterating Zeder (2001: 77), these results must be taken with reservation since early pastoralist systems may have slaughtered or culled most of the males at young ages, and archaeological investigations may be disproportionately measuring females who were kept until adult ages. With this in mind, the postcranial measurements of the prehistoric sheep at the Cape are still smaller than the assumed females of the historic period samples at Elsenburg and Oudepost I. Since the historic sites exhibit some degree of bimodality in the post cranial measurements, they support Zeder's concerns that they reflect sexual differences and not different sheep breeds.

In closing, Grigson's (1982: 7) claim that cattle are not sexually dimorphic in the lengths of tooth rows can not be applied to domestic sheep in order to identify different breeds. Using known-sex wild bovids, sexual dimorphism seems to be noted in the smaller steenbok and springbok mandibular tooth rows, while the large-bodied eland did not exhibit dimorphism in any tooth rows. While the archaeological data often showed 
promising differences between the historic and prehistoric sheep samples, the likeliness of sexual dimorphism and the age-dependent variation in tooth row lengths means that this data can indicate different sheep management strategies. Assuming that the adult prehistoric sheep are females, and since these sheep are only slightly smaller than their historic female counterparts, the hybrid sheep may not be much larger than the purely indigenous sheep in terms of osteological measurements. Since the sheep were used for meat production, husbandry would have favored greater meat and fat development instead of bone growth. The slight increase in female size in the VOC flocks might be better explained as a product of feeding strategies. The indigenous Khoekhoe pastoralists were highly mobile where they led their stock along a seasonal route around the Western Cape. The VOC stock keepers practiced a relatively more sedentary herding practice which would allow the sheep to convert feed into muscle and fat development. The stress of Khoekhoe migration could have caused the sheep to convert a lot of feed into energy for migration instead of muscle, bone, and fat. In the end, these examinations hoped to establish an inexpensive, non-destructive methodology to identify different sheep breeds in Cape historic sites, but genetic testing would be the clearest method to identify the different breeds. 


\section{CHAPTER NINE: Conclusions}

\section{SCOPE OF THE THESIS}

This dissertation emplaces the Cape settlement in its historical setting at a time when the Netherlands was becoming a titan in the emerging network of mercantile capitalism. For the Dutch, this was a dynamic, golden age built on the foundations of centuries of innovations in the fields of shipping, military, diversifying social structures, and even food production, which allowed great numbers of skilled laborers and merchants to aggregate in the towns and cities to develop local markets for foreign products and luxury goods.

This dissertation combines various zooarchaeological methodologies based on actualistic taphonomic research with historical accounts in order to identify the various components of the meat industry that was established at the Cape under the VOC rule. The comparison of taphonomic traces allows the five faunal samples from the Castle Moat, Elsenburg, DKG, the Old Granary, and the Oudepost Dump to form a picture of the wider meat industry that helped sustain the colonial settlement from the late seventeenth through eighteenth centuries. The combined analyses are then integrated into the documentary record of observers, travelers, and officials at the Cape. Finally, the details of this industry can help speak to the practice of animal husbandry as well as the power relations of the early colonial Cape.

Figure 9.1 summarizes the taphonomic details of the major samples discussed in this dissertation. This figure shows that taphonomic investigations are important in historic period contexts. Although their age and time depth is much less than that of prehistoric contexts, similar destructive forces have operated in both (see the citations in 
the discussion on Taphonomy in Chapter 2). Moreover, taphonomic processes did not affect each sample equally, which adds additional emphasis of the need for an understanding of the destructive processes (figure 9.1). These processes revealed important information about responsible for the nature of the faunal collections we have for analysis today (cf. Behrensmeyer 1991: 326-327).

Figure 9.1. Diagram summarizing and comparing the taphonomic details of the major faunal samples discussed in this dissertation.

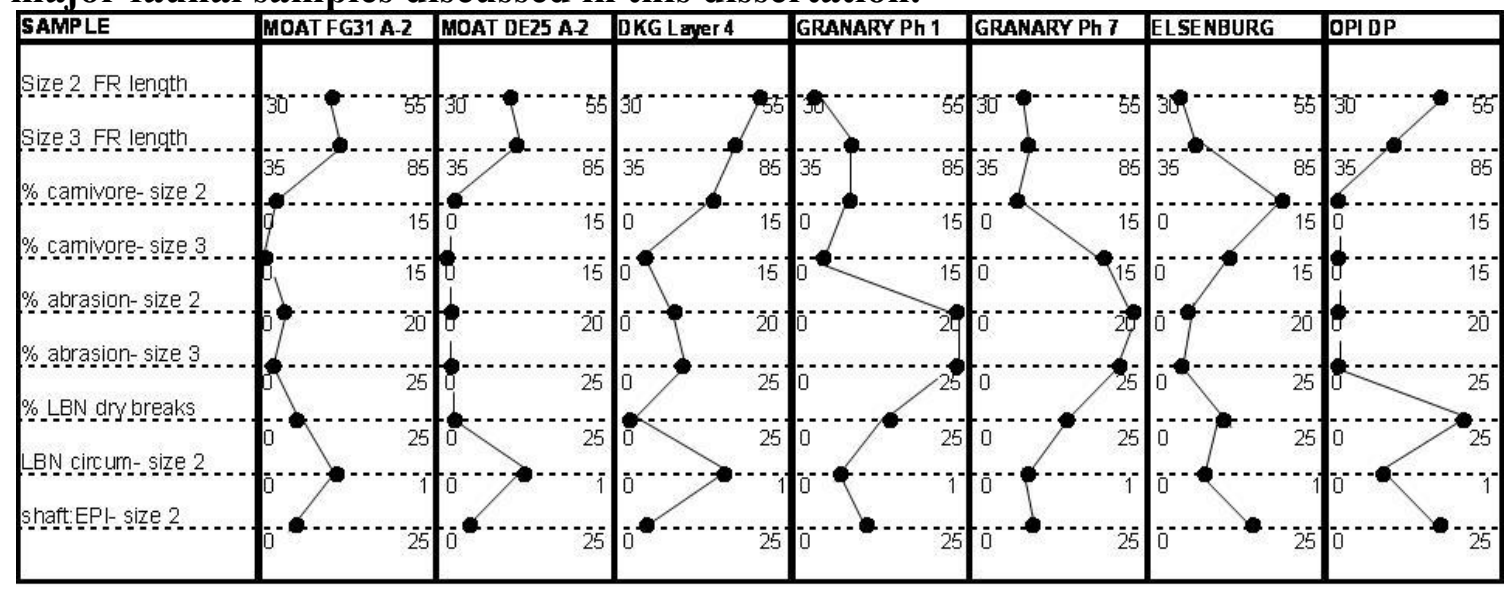

\section{CHARACTERISTICS OF THE VOC MEAT INDUSTRY}

A biological or economic system incorporates a variety of individual units that must work together (Bertalanffy: 54-56; 1969; Braudel 1979: 138-230; Johnson 1999: 220-226; Orser 2005: 77-80; Wallerstein 1980: 38-39). In the case of the VOC meat industry, these units include livestock acquisitionists (through trading or seizure), producers, slaughterers, and consumers. Figure 9.2 summarizes the main analytical categories of the major faunal samples presented in this dissertation.

Figure 9.2. Diagram summarizing and comparing the main characteristics of the major faunal samples discussed in this dissertation. 


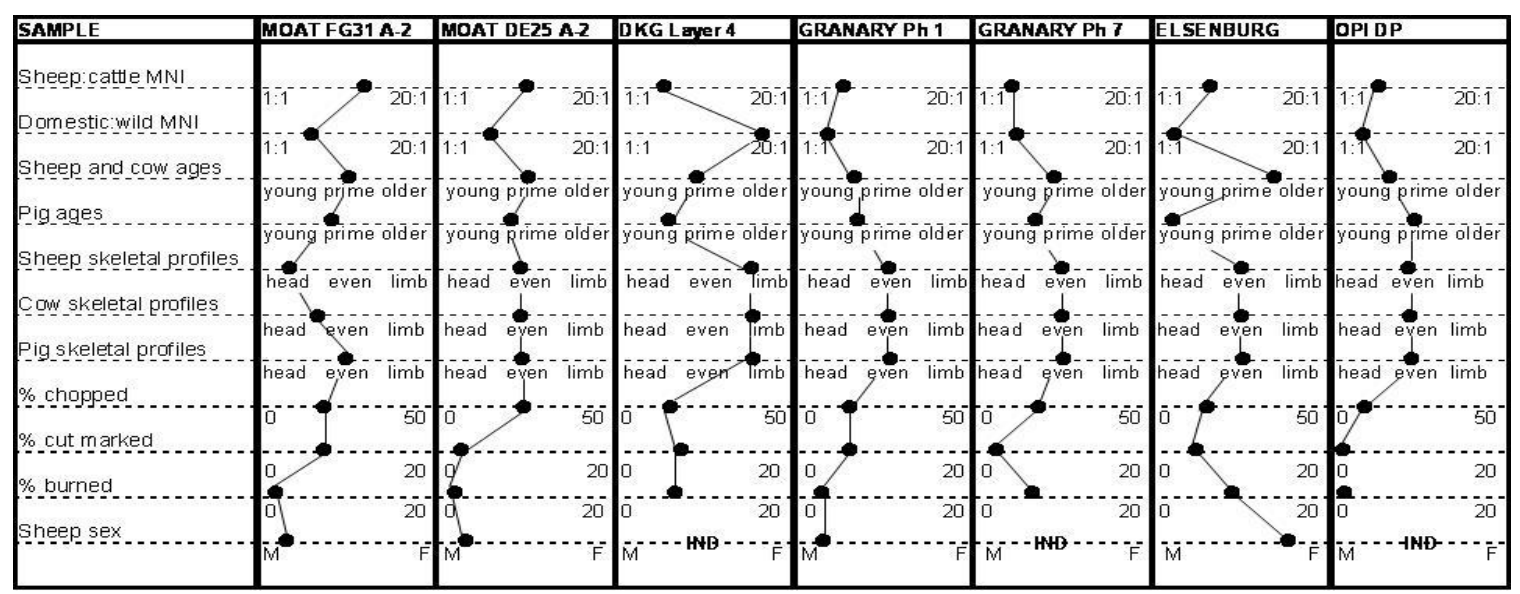

A. Livestock Acquisition: This dissertation argues that there is no unequivocal evidence of Khoekhoe stock traded to the VOC at the Cape. Starting with sheep, I argue against the belief that two different sized sheep reflect indigenous and hybridized sheep at Oudepost I (Cruz-Uribe and Schrire 1991:97; Klein and Cruz-Uribe 1989:90-91). Instead, using sexual dimorphism in known-sex bovids and the effect of age on sheep tooth row lengths, I argue that tooth row and postcranial measurements are likely attributed to colonial sheep management practices.

Turning to cattle, it is assumed that cows from these VOC sites are purely indigenous since hybridization was not put into practice until the 1780s (Cruz-Uribe and Schrire 1991: 96; Thom 1942: 103-105). Both prehistoric and colonial cattle samples are very few in numbers and they rarely provide measurable samples. The colonial attributions are entirely dependent on the documentary evidence. Pending genetic analysis one cannot be sure if any of the cattle individuals were from the Khoekhoe or if they were products of the burghers' own Khoekhoe-descendant stock. A forthcoming genetic analysis of cattle specimens from Oudepost I by K. Ann Horsburgh (pers. comm.) hopes to contribute to this question. 
B. Livestock Production: Whether the archaeological site was at the consumption or the production end of the system, each faunal sample provides clues about how the stock was raised for the market. For the most part, these clues are the demographic categories of age and sex.

Regarding age, while a large proportion of the sheep were slaughtered in their prime (three- six years of age), age at slaughter became older over time. Relatively more younger sheep (nine months to three years of age) were slaughtered in the late seventeenth and earliest part of the eighteenth centuries (Phase 1 in the Granary, the terrestrial sample and DP from Oudepost I). Specifically, the small sample from the Granary Phase 1 contains two sheep that were slaughtered at about one year of age, while another was slaughtered at about 1.5 years of age. Similarly, a large proportion of the sheep from the terrestrial sample from Oudepost I were slaughtered between six weeks and two years of age, while some sheep were even younger than six weeks of age (CruzUribe and Schrire 1991: 98). Although deciduous teeth may have been lost through winnowing and not available in Oudepost's DP sample, the available molars show that a larger proportion of sheep younger than 1.5 years of age were slaughtered at the site. The postcranial specimens from these three contexts confirm these findings with a large proportion of unfused elements that typically fuse around one to three years old. In contrast, sheep from more recent sites, dating from the mid- to later eighteenth century, (the Moat, Elsenburg, DKG and Phase 7 from the Granary), together with the published data from the ditch in the Grand Parade (Abrahams 1996) and Paradise (Avery 1989), show that almost all sheep were slaughtered at prime or older ages (1.5 - four years) with a few individuals even older. 
In contrast to the urban situation, most of the sheep from the farm Elsenburg were slaughtered after four years of age. Cattle, though relatively rare, conform to the patterns seen with the sheep, with urban slaughter at prime ages, and farm ones beyond their prime. These findings contradict the documentary sources, namely Mentzel (1921: 56; 1944: 212), specifically between 1733-41 after the Moat was filled, who described sheep slaughter during the later period, and said wethers were slaughtered between one and two years of age.

Turning from age to sex, the two largest samples (Moat and Elsenburg) provided measurable acetabulae, which are among the best indicators of sex in osteological materials (Greenfield 2002). The Moat was dominated by larger sheep, most likely male wethers (Leibbrandt 1905: 130-131; Mentzel 1921: 56; 1944: 212), while Elsenburg was dominated by smaller sheep, or females. Measurements of distal humeri and tibiae, though less pronounced, support this finding. Though the sample size is smaller and no acetabulae were available, humeri and tibiae from the terrestrial sample from Oudepost I show a more even split between male and female sheep.

Ages at death provide some idea about meat production strategies at the Cape. The samples from the seventeenth and early eighteenth centuries show that sheep were often slaughtered younger than what seemed to be ideal in the mid to later eighteenth century. In addition, the sex data gleaned from Oudepost I also suggests that a higher proportion of females were being slaughtered alongside males during this earlier period. In contrast, the better established herds drawn on for the Elsenburg, Moat, DKG, Granary, and the Grand Parade samples show that prime-aged, males/wethers were preferred for slaughter, while useful females were kept on the farms until they exceeded 
their reproductively fit ages. Together, the age and sex information from these earlier contexts could speak to the difficulties that stock holders may have had filling VOC meat orders. When VOC meat contracts required regular shipments of pre-specified pounds of meat to be supplied to the official slaughterers (Elphick and Malherbe 1988: 11; Fouche 1914: xix; Mentzel 1921: 171; 1925: 55-56; Ross 1988: 247; Robertson 1945b: 79-80; Van der Merwe 1995: 1), the stock holders may have had to supply animals they would have normally kept to increase their own herd numbers. History have shown that the VOC had difficulties keeping up with the demands for meat during the first 50-75 years of the settlement's establishment, which required continual trading expeditions into the interior to obtain more stock from the Khoekhoe (Elphick 1985: 151, 154; Penn 2005: 29).

A similar pattern may be found in the Chesapeake, where English colonists experienced similar initial difficulties in establishing their herds. Cattle and pigs were slaughtered younger in the $1620-1660$ period than during the $1660-1700$ period when the stock was slaughtered at prime ages from better established herds (Bowen 1999: 362363). Likewise, Spanish colonists in Florida and Dutch colonists in New Amsterdam, initially slaughtered their cattle younger than what was typical in later periods, and they had to more heavily rely on indigenous resources until their domestic stocks were established (Cantwell and DiZerega Wall 2001: 179; Janowitz 1993: 16; Reitz 1991a: 65, 69; Reitz and Scarry 1985: 80, 96-97).

Once the Cape meat system was established, the husbandry practices took shape like those seen in other colonial period meat production systems. Urban sites generally exhibit an incomplete demographic since the breeding portion of the herd would have 
remained at the production sites, like that seen at Elsenburg, until they were no longer useful (Allison 1958: 101-102; Landon 1996: 8, 123; 1997: 57, 61; Sykes 2006: 62; Zeder 1984: 285). Sites at the consumption end of the system, like the Granary, DKG, the Moat, Paradise, and the Grand Parade from the Cape, are dominated by prime-aged animals that are usually male (Abrahams 1996: 244-245; Avery 1989: 115; Landon 1996: 8, 123; Zeder 1984: 285). This contrast between the rural producers and urban consumers is a product of animal husbandry focused on large scale meat production for a high-demand system like seen for a large urban center, exports, or ship provisioning instead of diversified products such as dairy, draught, and wool (Davis 1997: 416; Landon 1996: 114, 123; Pennington 1989: 61; Sykes 2006: 63; Trow-Smith 1957: 172173, 239; 1959: 199; Wilson 1994: 111).

C. Livestock Slaughter: Butchery marks help interpret consumption and marketing practices. The samples from all sites were dominated by chop marks to dismember the carcass for further chopping or cutting. Initial chops were in predictable locales such as near major joints and distal limb midshafts above the foot. Secondary chopping divided the vertebral columns into sagittal halves as well as into smaller segments near the natural division of the column (i.e. between lumbar and thoracic vertebrae). Extra chopping on ribs separated them from thoracic vertebrae and produced smaller segments. Evidence for cranial chopping that split the crania into sagittal halves was well-represented in the Moat and Elsenburg samples. All animals were initially reduced in similar manners before the portions were sent onto ships, to markets, or to kitchens for further processing. 
Knife processing, seen as cut or scrape marks, was less common than chop marks. Knife processing was observed on limb shafts where muscle was removed, or near joints where ligaments, tendons, and meat were severed. More cut marks were found on food consumption residues from DKG, both Phases of the Granary, Elsenburg, and the terrestrial sample from Oudepost I (Cruz-Uribe and Schrire 1991: 100). The Moat samples have fewer knife marks, suggesting that most of these bones derive from an early stage of butchery. This is similar to bones recovered from the colonial Beef Market in Charleston, South Carolina which show low frequencies of cut marked bone, especially in comparison to households which were recipients of the butchered meat (Reitz 2007: 98; Zierden and Reitz 2009: 346, 349). Samples from both ends of the Moat excavation produced different proportions of knife cut marks: The northern end, near the historical jetty, shows relatively moderate amounts while the southern end, closer to the Castle gateway, is comparatively deficient in cut marks. The greater numbers of cut marks in the northern sample is a product of the large numbers of sheep cranial, hyoid, and mandibular fragments which contain over half of the observed cut marks, suggesting heavy skinning and tongue removal from these bones (Landon 1996: 67; The Hide, Leather, and Allied Trades Improvement Society 1928: 7).

D. Meat Consumption: What can these bones tell us about the Cape diasporic European diet and the creolization of foodways by Malay slaves?

Evidence of table refuse can be identified in the Moat, DKG, the Granary, and Elsenburg. Roasts were allegedly common in the Cape diet and they often appear in historical documents (Abrahams 1996: 226-227; Botha 1970: 57; Coetzee 1977: 87; 89, 
91, 92, 94; Fouche 1914: 75; Gerber 1959: 65; Robinson 1994: 181). Burned bone confirms the presence of meat roasted on the bone in these contained, historical contexts. DKG shows the clearest evidence for kitchen/table refuse due to the large bone fragments from meat-bearing elements and high incidence of burning. The burning on the DKG bones strongly suggests the consumption of roasted meat due to the characteristic color of the burnt bones, as well as the location of the burning in isolated spots or internal long bone shafts that were exposed to flame or very high heat while the exteriors were not modified by heat probably due to meat covering those portions. The characteristic burning on the DKG bones derived from the burning of bones that contain a large quantity of grease and or meat and not after deposition (David 1989: 74). Burning is moderate and comparable in frequencies to that from Elsenburg, Phase 7 from the Granary, and higher than that found in the terrestrial sample from Oudepost I. These frequencies contrast with the Moat where burning is rare. This partly suggests again that the Moat was not a major deposit for kitchen refuse, at least not roasts. The Moat's associated collection of cooking vessels is made up of coarse earthenwares, dominated by food preparation vessels, most of which would have been used to make stews, not roasts (Jordan 2000a: 136; in press: 13). Along with the moderate burning frequency, ceramic and utensil finds further suggest that roasts were popular at the upper-class Elsenburg due to the large proportion of flat, porcelain dishes and forks (Hart and Halkett 1993: 29-30, 37; Klose 1997: 130-1, 133, 135).

Stews are not readily identifiable in these faunal samples. It is believed that meat prepared for stews are customarily chopped into small pieces with the bones so the most grease can be extracted through boiling or simmering (i.e. Baker 1980: 34; Crader 1984: 
548; 1989: 230-231; 1990: 710; Otto 1984: 172). Actualistic studies have shown that this severe chopping is not necessary for optimal grease extraction, but the idea may have persisted through tradition (Church and Lyman 2003). Documentary sources do record the popularity of stews made by Malay and Asian cooks in the mid-eighteenth century (Abrahams 1998: 6-8; Botha 1970: 49; Coetzee 1977: 28, 44-47; Elphick and Malherbe 1988: 28-35; Elphick and Shell 1988: 225; Gerber 1959: 10; Mentzel 1921: 112). Hall (n.d.a: 3; 1992: 390; 1999: 196) and Thackerey (1989) interpreted the highly fragmented bones in the Granary deposits as evidence of stews made by slaves who had tried to extract as much nutrition as possible from the bones. However, the investigations into bone breakage show that the Granary deposits happened after they were dry and had undergone some breakdown of the organic collagen. Though stews, or wet dishes, were an important component of the evolving Cape diet, the evidence is not available on the bones. In the Dutch and the Cape cuisine, boiled meats were generally removed from the bone and cut into manageable sizes before being placed in the pot (Gerber 1959; Rose 1989). Some of this meat may be represented by the cut marks identified on the bones such as the femur or humerus, though these marks cannot be confidently attributed to the filleting of meat for stews or for roasts, with the possibility that not all roasted meat may have been on the bone (Gerber 1959; Rose 1989).

The types of animals present in the deposits also speak to diet. The Moat contrasts with the other sites due to the fact most of the sample strongly represents primary, en mass slaughter for calling ships or other markets before reaching a kitchen, but portions of the Moat collection do not fit the expected provisioning model. There is a small amount of burnt bones derived from kitchen refuse, probably from inside the 
adjacent Castle. In addition, animals that would not fit provisioning needs include lamb, wild animals, and birds. These animals represent a diet of elevated status, where the people ate according to their taste for more tender lamb or their privilege to acquire exotic wild animals (i.e. Cruz-Uribe and Schrire 1991: 95; Hall n.d.a.: 3; 1992: 389-390; Mentzel 1925: 101; Thackeray 1989: 1). While wild birds were originally important for feeding garrisons and ships when the settlement faced starvation during its infancy, domestic fowl was later kept for personal consumption and was not farmed on a large scale (Mentzel 1925: 101; Thom 1952: 59, 297, 303). Birds used for provisioning were minimally processed and were sent nearly complete and therefore the bones would have been removed away from the sites.

In sixteenth century Spanish Florida, where diverse fauna was available, a low diversity of taxa was characteristic of military diets. In military contexts, rations were normally derived from meat that could be regularly supplied, i.e. domestic meat (Reitz and Scarry 1985: 88). At the Cape, this pattern is evident at DKG and Phase 7 of the Granary. Here, only one or two wild mammal individuals are present in the samples. These sites inside the Castle contrast markedly with the terrestrial sample from the distant, and earlier dated Oudepost I where hunting supplemented the meat rations and where the domestic sheep, cow, and pig only make up $25-29 \%$ of the individuals (CruzUribe and Schrire 1991: 96-97; Schrire 1990: 15).

Some elements of status have been mentioned, such as lambs for taste instead of meat quantity and the wild fauna (in the later eighteenth century and urban contexts especially) which was supposedly illegal and reserved for the Governor's table (Mentzel 1925: 101). In the case of Elsenburg, high status is signified through documents, the 
constructed werf landscape, and associated expensive porcelains (De Bosdari 1953: 69; Fagan 1984: 35; Hart and Halkett 1993: 3, 5, 29-30; Klose 1997: 132; Walton 1974: 38; MOOC 7/1/25 Cape Archives Estate Papers; J188-J200 Census Records). Though the material remains of Elsenburg represent a lavish setting, the fauna does not. There are some elements that might connote high status (the single lamb, young pigs, wild mammals and birds), but their numbers are small and they were likely immediately available on the farm. A large number of tortoises and turtles are present, and their livers were considered fine and delicate, though their presence in the local environment probably made them commonly accessible food items (Kolben 1731: 214). Instead, the bulk of the meat, and hence the everyday diet, consumed at Elsenburg was from old, female sheep and old cattle, which were likely stock that have outlived their usefulness for breeding or draught. Being a frontier farm, Elsenburg's inhabitants could have distinguished between the daily "meal" and the special "feast" where dietary markers of status were likely reserved for those holidays and occasions when visitors needed to be entertained (i.e. Jones 2002: 132; Miller 1979: 174; Reitz 1987: 109-110; Rose 1989: 28).

Though the bones from the Cape discussed in this thesis are from land-based processes, the research exposes a glaring and frustrating deficiency in the archaeological literature of nautical archaeology. The Oudepost I DP sample shows that salt water environments are destructive to bones, especially if not properly treated after recovery (Schrire pers. comm.). Hints of well-preserved faunal remains have been mentioned in association with shipwrecks, though minimal reporting has been done (Armitage 2004; English 1990; Green 1977; Hall 2002; Heinrich 2002). With the comparison with the Dutch provisioned whaling post at Smeerenburg, Spitsbergen (Van Wijngaarden-Bakker 
1984), the residues of the Moat help infer what types of meat cuts were sent to provisioned contexts such as ships.

\section{THE IMPACT OF THE VOC MEAT INDUSTRY ON THE CAPE LANDSCAPE}

While the decision for the Cape VOC venture was initially predicated on the testimonies of shipwrecked sailors on the fertile soil, availability of fresh water, and bright trading prospects with the Khoekhoe pastoralists, the fates of the meat industry and the indigenous societies were tied to the constraints of the arid South African climate and landscape. The faunal analyses presented in this thesis provide details overlooked in the wider history of the colonial Cape.

The meat trade was of prime importance in order for the Cape settlement to function as a successful refreshment station. The settlement also strove to be selfsufficient and to provision vegetables and grain, and, in 1657, the Heeren XVII and Van Riebeeck decided to contract free burgher farmers along the Liesbeek River to establish large scale, labor-intensive grain production. This initiative was repeatedly frustrated by strong seasonal winds that destroyed crops before they were able to be harvested. With this destruction along and the low grain prices set by the Company, the burghers found it hard to repay the debts they shouldered to establish their farms. In contrast, stock farming required less financial output and management was less intensive, while meat was continually in demand and earned rewarding profits (Fisher 1969: 9; Geulke 1988: 70-71, 80, 86; Giliomee 2003: 7; Katzen 1969: 209; Schutte 1988: 288-291; Templin 1984: 18-19; Van der Merwe 1995: 1-11, 14, 19). 
Stock farming became economically more attractive to the burghers, but during the first 50-75 years of the Cape settlement, meat was in greater demand that its supply. With the limited supply, the acquisition of stock from the Company or other burghers was difficult and expensive (Elphick 1985: 151-161; Penn 2005: 29; Templin 1984: 19). With the expense and difficulty of obtaining stock through the Company suppliers, the Khoekhoe posed as an opportunity and as an obstacle to stock farming. The low prices paid for stock purchased from the Khoekhoe was a delicate balance that the Company tried to tightly control. Due to years of trading and strained relations from conflict, the indigenous markets were becoming glutted with the trinkets the Company used for barter and stock was becoming increasingly difficult to obtain during trading expeditions. VOC officials feared that the delicate stock markets could be disrupted by unregulated freelance burghers paying better prices or committing violent theft while trying to acquire their own stock privately, and these fears were quickly realized when the burghers' mistreatment of the Khoekhoe led to retaliation and restricted markets (Guelke 1988: 77; Katzen 1969: 209-212, 234; Legassick 1988: 359-363; Penn 1986: 66; 2005: 38-39, 41, 52-55; Schrire 1990: 17-18; Van der Merwe 1995: 25). Governor Simon van der Stel's legislative and judicial attempts to control the frontiers were ineffectual, and were shortlived because his successor, Willem Adriaan van der Stel, promoted frontier settlement and opened free trade with the Khoekhoe in 1700 (Elphick 1985: 155-161; Guelke 1988: 79; Penn 2005: 27-30, Van der Merwe 1995: 21-22, 35-38). In the period from 1700 to 1708, just after when Willem Adriaan van der Stel was removed from his position, the open trade devastated Khoekhoe herds when burghers took a documented 35,562 sheep and 8,871 cattle, probably under recorded figures (Elphick and Malherbe 1988: 21). 
Whether through trade, theft, or natural breeding, the VOC herds increased. To avoid over-grazing, burghers spread inland into arid areas where the stock required large tracts of land around suitable water sources. The dry South African climate required many of the frontier burghers to adopt a Khoekhoe-like lifestyle of seasonally migratory pastoralism, and the inland frontier supplied the land that they needed. The interior frontiers had become ever more sparsely populated through the degradation of the Khoekhoe societies who were tied together through the identity of stock ownership. The increasing loss of stock through trading as well as inter-Khoekhoe conflict and stock theft, where "the disappearance of livestock must be counted the prime feature of the erosion of traditional Khoikhoi society," left groups impoverished and fractured (Elphick 1977: 164). When the small pox outbreak of 1713 further decimated the Khoekhoe groups to about $1 / 10^{\text {th }}$ of their already diminished strength, there was little to impede the burghers from inhabiting the grazing lands and water sources that were so important to the Khoekhoe (Elphick 1977: 229-233; 1985: 233; Elphick and Malherbe 1988: 21-22; Guelke and Shell 1992: 823-824; Mentzel 1925: 36; Penn 1986: 65; 2005: 42; Ross 1998: 307). Further degradation of the Khoekhoe identity continued when the desperate and dispossessed had to become servants of the burghers in order to survive (Elphick 1985: 217-219; Penn 1986: 66; Ross 1998: 308-311).

The tentative inference made from the two earliest Cape faunal samples, from Oudepost I and Phase 1 from the Granary, speaks to the struggles faced by the burghers who had to meet the demands of the calling ships, which required their sheep to be slaughtered at younger ages than what was seen as ideal in the mid to later eighteenth century. This stress to meet provisioning demands required continual accumulation of 
stock through trade and capture from the ever dwindling Khoekhoe holdings. The success of this strategy is seen in the later collections from the Moat, Phase 7 from the Granary, Elsenburg, and DKG, where there were self-replenishing herds, large enough for sheep to be slaughtered in their prime. This achievement is also seen in the collections from Oudepost I and the Moat, where sheep and sometimes cattle were slaughtered in great numbers to meet demands which had multiplied significantly since Van Riebeeck's original mid-seventeenth century plan for eight sheep and eight cattle per ship (Elphick 1985: 152).

The dispossession of indigenous peoples is just one pattern that followed European colonial ventures in their new worlds (Wolf 1997). The European presence also modified the ecology of the land (Crosby 1986: 275; Grove 1995: 126). In the case of the Southwest Cape, prehistoric hunter-gatherers, foragers, and pastoralists lived in low density groups that moved with the availability of resources. When the VOC settlement was established in 1652 an estimated 50,000 Khoekhoe including about 8000 Peninsular Khoekhoe lived in the Western Cape (Elphick 1985: 23, 92; Theal 1897: 126), which was one of the most diverse and richest ecozones (Avery and Underhill 1986; Cruz-Uribe 1988: 184; Cruz-Uribe and Schrire 1991: 93, 96; Skead 1980, 1987: 813855). By the mid-eighteenth century, a European population that slowly increased to a maximum of about 5000 settlers had so markedly modified the landscape that wild fauna was rare within 24 German (120 English) miles of the Castle (Guelke 1988: 66; RavenHart 1970b: 270; Mentzel 1925: 101; 1944: 77, 102; Skead 1987: 813-855; Spilhaus 1966: 99). The faunal collection from Oudepost I illustrates the hunting effectiveness of a small garrison with European technology where a large proportion of wild mammals 
and birds were hunted, shot and trapped, and where seals were obtained from offshore islands with boats, guns and knives (Cruz-Uribe and Schrire 1991: 96: Schrire 1990: 1517; 1995: 107). The depletion of wild fauna speaks to the lack of ecological balance maintained by the European colonists who wiped the animals off the landscape for food and sport, as well as to clear grazing lands for their own stock herds.

Archaeological data from the sites presented in this thesis support the historic accounts of depletion of wild fauna. Wild fauna is rare in all the urban sites not necessarily because it was illegal and reserved for official meals, but because it had all been hunted out! Mid-eighteenth century Elsenburg, situated further into the inland frontier, included a greater amount and diversity of wild fauna compared to the urban sites, but these pale in comparison to the earlier Oudepost I terrestrial fauna collection. Oudepost I relied on the wild fauna to supplement rations (Cruz-Uribe and Schrire 1991: 96; Schrire 1995: 107); Elsenburg was a well established stock farm where wild fauna would have served as a dietary change. While most of the wild fauna are birds, the bovids found in these archaeological sites are the smallest steenbok and duikers which being relatively solitary, survived in settled areas even until the present day (Estes 1991; Skead 1980: 448-449, 456). Beyond the depletion of indigenous fauna, European penetration into the Cape frontier modified the vegetation through overgrazing by the burghers' large herds. The Roggeveld Escarpment in the northern frontier, which was originally a mixed grassveld when the burghers arrived, was changed through overgrazing between 1740 and 1800 to a Karoo-type veld that was suitable for sheep, but was no longer able to support cattle (Penn 1986: 63-65; 2005: 86). 


\section{THE VOC MEAT INDUSTRY'S IMPACT ON THE CAPE CULTURE}

Though the settlement was established at the furthest tip of Africa, it was never completely cut off from the settlers' European fatherlands due to immigration, news, material goods, and sometimes devastating germs. While the socially minded urbandwellers would continually crave the latest European fashions, over time, through successive, native-born generations with the distance and conditions of the Cape, the frontier burghers of the Cape transformed their Dutch culture into a distinct form they would come to call "Afrikaner" (Botha 1970: 53; Giliomee 2003: 22-23; Guelke 1988: 87; Idenburg 1963: 12, 16-17; Ross 1988: 270-271; 1998: 306; 1999: 11; Schutte 1988: 301-302). Livestock farming provided means for the burghers to distance themselves from VOC and the later British government interferences. When the VOC was declining in power and as the Cape Colony expanded beyond its function as a refreshment station, officials sent to the Cape viewed this cultural transformation as a crisis. Some, for example, Admiral Johan Splinter Stavorinus, who visited between 1768 and 1771, drew distinctions between the classy, connected urban folk and the free burghers who were becoming un-European "according to the customs of the East Indies" (quoted in Idenburg

1963: 12). Most others, such as Captain Scipio Cornelius de Jong who visited between 1791 and 1797, were more critical. De Jong stressed that the outward appearance of European fashion did little to distinguish the urban dweller and the frontier farmers whom he considered all to be:

...Ignorant, proud, haughty, conceited, full of himself, empty-headed, knows little and despises what he does not know, has rather crude morals... He is proud of the name Afrikander; Citizen of the Cape seems to him a great title. This excessive pride results in laziness. (quoted in Idenburg 1963: 15) 
De Jong and Commissioner Jacob Abraham de Mist, who came to the Cape in the early nineteenth century, agreed that the transformation from the Dutch to the Afrikaner was due to a lack of education (Idenburg 1963: 14-18; Spilhaus 1966: 318-319). This was especially true of the burghers who were far removed from the urban areas and lived in small family-sized farmsteads.

While a lack of education might have contributed to the colonists' ignorance of their ancestral fatherlands, the ignorance does not really explain what Afrikaner culture became. Good evidence of the change from the Dutch culture could be food, an often conservative and traditional marker of culture. Creolization of diet would occur in the face of newly discovered food items, the importation of exotic spices and vegetables, and new preparation styles from peoples of other cultures. At the Cape, the incorporation of East African and Malay slaves started within a year of settlement and they would number about 2300 by the mid-eighteenth century (Armstrong and Worden 1988: 112). The settlers' reliance on Malay and also Khoekhoe servants caused a transformation in the diet to one that would be heavily based on Asian stews, spices, and vegetables (Abrahams 1998: 6-8; Botha 1970: 49; Coetzee 1977: 28, 44-47; Elphick and Malherbe 1988: 28-35; Elphick and Shell 1988: 225; Gerber 1959: 10). The exact moment when one can point out that the diet had become more Malay or Afrikaner than Dutch might be difficult, but the seeds of dietary change were planted very early on when the settlement was established.

Clear creolization of the Cape diet was somewhat slow and really took form in the mid-eighteenth century. During her visit in 1709, Van Riebeeck's granddaughter, who was Batavian-born into an Eastern creolized diet, retained her slave to cook palatable, 
Indonesian-influenced food since the Cape diet was still too Dutch-like for her tastes (Gerber 1959: 10). Kolben and Valentyn, who covered the second quarter of the eighteenth century, remark that the Eastern ingredients were mostly reserved for the slaves (cited in Gerber 1959: 10). These three accounts most likely describe the urban diet and not that of the burghers in the interior. It must be noted that there was no frontier burgher fauna available to contrast with the sites presented in this thesis to see if there was a marked difference with the distant frontier. Frontier burghers were generally poorer and did not have slaves, though Khoekhoe servants often worked for them as cattle herders and house servants for meager wages (Elphick and Malherbe 1988: 16-17, 28-31). An incidence of creolized diet within the urban center was at the hospital where the ill were fed Eastern-influenced curry stews of mutton and beef by this period (Mentzel 1921: 112). .

The main differentiator between Dutch and Cape diet in the earlier years was the amount of meat consumed and the diminished importance of dairy. Due to the availability of meat and the Cape's warmer climate dairy no longer held the importance that it had in the temperate Northern European areas where dairy was a necessary supplement for the poor who could not afford regular meat (Adamson 2004: 45-47, 134; Mennell 1985: 42-43, 46; Norman 1972: 120; Schaefer 1994: 140-141). In addition, indigenous Cape stock was not suited for milk production and the little milk that could be obtained was restricted to the breeding season and was considered to be of inferior quality to that made in Europe (Mentzel 1944: 203, 213; Raven-Hart 1976: 30-31; Robertson 1945b: 75; Thom 1942: 103; 1952: 359; Wilkens 1901: 74). Accounts do tell us that dairy was produced for local consumption and also available for purchase at the 
settlement's market, though it was relatively expensive (Coetzee 1977: 33; Leibbrandt 1905: 135; Thom 1942: 111). The near absence of milk pans in the archaeological record speaks to the diminished importance of dairy in the Cape diet (Abrahams 1996: 228; Jordan 2000a: 175).

After the initial shipment of Dutch cattle failed, the VOC and its burghers relied solely on the indigenous cattle since their draught ability was superior and important to travelers into the frontier. Sheep cross-breeding was more successful and the hybridized breed proved to be a great boon for the meat industry, but not for the wool one, because the VOC denied the burghers' petition to import wooly sheep to start a wool industry at the Cape in 1782 (Boxer 1965: 252). Where cattle breeding was concerned, a series of questionnaires was given to local farmers in the early nineteenth century when the Fiscal Willem Stephanus van Ryneveld asked why the VOC did not try to improve the poor milk producing indigenous cattle? The conclusions included first, that the Cape settlement was supposed to be a complimentary node in the mercantile world trade network where the VOC did not want to expend too much capital to expand the settlement and to develop industries that would compete with other Dutch production centers. Second, in the early years of VOC settlement, burghers may not have been financially capable of importing animals (Elphick 1985: 151-161; Guelke 1974: 262; Penn 2005: 29; Ross 1988: 254; 1998: 311; Schutte 1988: 301; Thom 1942: 49, 79). This is confirmed by the fact that only the wealthiest stock holders imported different breeds to improve their herds, including Governor Willem Adriaan van der Stel who brought English sheep to the Cape between 1699 and 1707 (Mentzel 1944: 210), Governor Joachim Ammena van Plettenberg who brought the Friesland cattle in the 1780s (Thom 
1942: 105), and the Commander of the Cape garrison Colonel Gordon who brought some Spanish Merino rams in 1789-1790 (Lydekker 1912: 180; McKee 1913: 2; Mentzel 1944: 211; Thom 1942: 57). It may also be worth mentioning that these officials were foreignborn and retained close connections to their mother culture.

While working on behalf of the British to improve the economic conditions at the Cape, Van Ryneveld states:

As soon as one contemplates the improvement of the country's products, one meets insurmountable difficulties on all sides; shortages of hands, lack of requisites locally for the furtherance of agriculture, absence of inland navigation, so serviceable for easy transport, are all like so many immovable stones perpetually obstructive. Should one think of making good the deficiency by pinning one's hope to the foreign trade of Cape Town, one would, I believe, be seriously deceived; for wherein should we trade, what produce and wherewith make payment. (Thom 1942: 49-51)

While Van Ryneveld lists some geographic obstacles, the major impediment to economic improvement was the demographics of the Colony. The nature of the meat industry in the arid Cape caused the burghers to scatter loosely across the frontier and live relatively isolated, minimalist, self-sufficient lifestyles, which did not allow for the development of strong markets feeding demands for meat and other products. Though the frequency of urban contact depended on the distance and travel routes from the Cape, the burghers did retain some connection with the urban markets to sell products and obtain necessary material goods such as guns (Guelke 1988: 84-91; Ross 1998: 311; Schutte 1988: 301$302)$.

The staunchest "Afrikaners" were those burghers living on the Cape frontier who were conservative, stubborn, and strove for freedom from government interference in their movements and acquisition of stock (Fisher 1969: 9; Idenburg 1963: 15, 105; Schutte 1988: 288). They were what De Mist described as, “...the traditional, 
impenetrable resistance of the Afrikaner to interference with his personal predilections" (quoted in Spilhaus 1966: 320). Van Ryneveld encountered the burgher's desire to continue in the traditional ways of the Cape-settled ancestors when he tries to convince a wealthy burgher named Jacob Laubscher to improve his sheep for wool and his cattle for dairy (Thom 1942: 77-81, 111-113). Laubscher remained inflexible about changing his stock and cited excuses like the European stock being ugly, lazy, or spiritless compared to his Cape stock (Thom 1942: 73, 79, 111). Though presented with evidence that new cross-bred stock would produce an economic windfall in regards to the amount of wool and milk, Laubscher "...would not hear of ever crossing his cattle; they were of the same stock as his father had owned to his profit and been blessed with for such a length of time, and he disliked all foreign things..." (Thom 1942: 111). The Laubscher example illustrates the conservative mindset of the burghers in regards to their stock.

Colonialism is seen as a process of bringing in old customs while modifying them or adopting new customs to fit the local conditions (Bowen and Andrews 2000), and creolized colonial cultures can vary from being minimally changed to resembling little of the homeland's culture (Gabaccia 2005: 85). The archaeological faunal samples here do not speak much to changes in dietary culture at the Cape. At most, the Cape diet was heavily reliant on meat, especially mutton which Mentzel (1925: 102) described as a monotonous staple. While sheep dominate the archaeological samples in absolute numbers of individuals slaughtered, beef was a significant portion of the diet at consumption sites like DKG and Elsenburg since one full cow could provide the amount of meat that could be taken from seven to ten sheep. Though a small number of pigs were recovered from all sites, a deviation from the typical mutton diet was evident at 
Elsenburg where a greater incorporation of pork can be inferred through the archaeology and the documents (MOOC 7/1/25 Cape Archives Estate Papers; J188-J200 Census Records). The treatment of the meat does not change noticeably through time in the samples available for this thesis. In the later eighteenth century when the Afrikaner culture was firmly developed on the frontier, the cooking evident at DKG shows a dominance of roasts and not the stews that are more typical of Malay cuisine. As mentioned earlier, it must be remembered that DKG represents garrison residues and the VOC garrison was typically new soldiers from Europe and not composed of rooted Afrikaner burghers.

While history shows that the Cape diet eventually became creolized through the incorporation of spices and preparation methods, the faunal residues do not speak to a significant departure from the original European meat components through the eighteenth century. Cape stock did not have to be slaughtered seasonally for winter culling so fresh meat was continually available and dairy was limited beyond the localized farm (Schrire 1995: 107). These experiences differed from the New Netherland Dutch colonists who immigrated to a highly seasonal climate similar to that in the homeland. Traveler accounts describe that the colonists were able to transport and successfully cultivate almost all the ingredients from the homeland (Danckaerts 1913: 44, 51, 70; Janowitz 1993: 15-21; Rose 1989: 14, 24-25; Van der Donk 1968: 24, 41, 43). Archaeology at Fort Orange, Albany and other Dutch sites show that wild deer, birds, and fish were commonly eaten in the earliest frontier sites though the urban center focused more on domesticates (Cantwell and DiZerega Wall 2001: 178-180; Huey 1991: 58; Janowitz 1993: 12-16; Rose 1989: 26). Though American animals, fruits, and vegetables were 
added to the imported Dutch cuisine or eaten in indigenous recipes such as the corn meal mush sappaen (Grider 1888: 73; Rose 1989: 27-34), the New Netherland Dutch maintained foodways that were distinctively Dutch for centuries even though the colony was governed by Dutch hands for only 50 years (Cantwell and DiZerega Wall 2001: 178187; Grant 1972: 113; Irving 1964: 138-139; Janowitz 1993: 15-21; Kalm 1966: 347; Rose 1989: 27-35). While the introduction of new ingredients is enough for some to label a diet as creolized (i.e. Gabaccia 2005; Janowitz 1993; Sunseri and GiffordGonzalez 2002), the North American Dutch colonists were able to maintain distinctively Dutch foodways. While the fauna suggests that the Cape Dutch also maintained a European meat-focused diet apart from the diminished dairy and seasonal culling, the European-descendent burghers would come to identify themselves as a unique and distinct on social and political grounds, and ultimately through uniquely South African dishes (i.e. Fisher 1969; Giliomee 2003; Guelke 1988; Moodie 1975; Templin 1984).

\section{CONTRIBUTIONS TO SLAVE ZOOARCHAEOLOGY}

The New Archaeology pioneer, Lewis Binford (1977; 1978; 1981; Binford and Binford 1968; Binford and Bertram 1977) advocated the benefits of working in more recent time periods where one might be able to more immediately infer cultural and natural processes. Binford (1977: 13) believed that historical archaeology could be at the forefront of archaeological theory due to its close relationship with documentation to help connect what is found in the ground with the culture responsible for the residues. Part of this was to apply "Middle Range Theory," or actualistic studies of modern processes, to make archaeology into a scientific discipline. This was slow to be realized in historical 
archaeology, where Stanley South (1977: 23) criticized that, "[the historical archaeologist] is interested in contributing to classificatory, descriptive, documentary research oriented around a priori beliefs about the past." This means that historical archaeology was mainly focused on finding objects that uncritically support the predetermined conclusions or desires of the groups supporting the research. Historical period zooarchaeology has lagged even further in attempts to perform empirical investigations of diet and husbandry issues by avoiding investigating taphonomic interferences with the archaeological materials (Jolley 1983: 67; Landon 2005: 6; Piper 1989: 152; Reitz 1987: 116).

Since Otto's $(1977 ; 1984)$ influential work at Cannon's Point Plantation where he tried to identify status differences in ceramic and food artifacts between slave, overseer, and planter sites, researchers have tried to give voice to those not well represented in the documents (Hodder 1986). Out of these ideas came a series of papers describing slave diet throughout the American South, including Crader's $(1984 ; 1989 ; 1990)$ Monticello research that has been the direct model for slave diet investigations at the Cape (Hall n.d.a: np; 1992: 392-396; 1999: 196; 2000: 6; 2008: 128-130). In this thesis, the reanalysis of the Granary fauna is important because it challenges the previous, influential writings on slavery and underclass resistance, which today still shape research that is based on the uncritical use of comparative archaeology (Hall 2008; Webster 2008). Here, the Granary sedimentology is taken into consideration alongside taphonomic investigations of the bones to understand how they were treated before being deposited in the room, which ultimately led to a conclusion that the Granary represents secondary fills with bones from typical garrison residues and not from slaves. This investigation was 
then applied to the published analyses by Otto and Crader which challenges the accuracy of their slave diet conclusions.

The critique of slave diet in Chapter 5 shows that depositional histories and faunal residues must be carefully analyzed and considered together. Underclass deposits were often broadcast at places where several activities occurred sequentially and repeatedly, and they frequently include mixed finds of bones, buttons, pins, ceramics, and pipes (i.e. Crader 1990: 691-692; Deetz 1993: 139; Grzymala-Jordan 2005: 66-92; Kelso 1997: 8890; Klippel 2001: 1192; McKee 1999: 228-229; Otto 1984: 45, 128; Scott 2001: 673-674; Tuma 2006). Though the site may be identified as underclass, artifacts from various social classes could have been intermixed such as when washerwomen lost and broke buttons from their clients' or masters' clothing during routinely aggressive washing (Grzymala-Jordan 2005: 65, 67-92; Grzymala-Jordan and Schrire 2004: 51-53). These deposits were subsequently trampled underfoot, confusing their origins and original representations. They contrast with residues generated by the elite which were routinely removed away from residential activity areas or into taphonomically-protected pits (i.e. Barber 1976: 68; Crader 1990: 693; Kelso 1997: 85-87; Lev-Tov 1998: 123; Miller 1979: 161; Otto 1984: 103, 137-138; Scott 2001: 674).

Discussions of slavery at the Cape have changed over time in accord with the varied political and racial agendas (i.e. Malan 2008; Meskell 2002: 284; Shepherd 2002). This was seen at Vergelegen, where the history of the farm's slaves was minimized through the removal of exhibits commemorating slave life, poorly signed slave quarters, and a size-reduced slave roster display (Malan 2008: 6). With the end of apartheid, the focus of slavery research has been to provide voices and a history to the enslaved and 
underclass around the Cape. A few robust examples of underclass archaeology include studies of washerwomen in the Platteklip Stream (Grzymala-Jordan 2005; GrzymalaJordan Schrire 2004), Vergelegen (Markell et al. 1995; Sealy et al. 1993), and burials at Prestwich and Coburn Streets (Cox and Sealy 1997; Cox et al. 2001; Malan 2008). Less successful, motivated efforts to identify slaves at the Cape stem from sites with mixed residues that cannot be confidently assigned to any specific group such as was done at the Granary (see Chapter 5), in town house yards (Hall n.d.c; Hall and Markell 1993: 4), and on a glass sherd painted with the image of a slave woman (Abrahams-Willis 2002; Malan 2008: 5; Malan and Schrire 2000: 16-19). The reanalysis of the Granary fauna shows how its depositional history excludes weighty conclusions of underclass subjugation.

\section{IN CLOSING}

Napoleon Bonaparte is credited with saying, "History is the version of past events that people have decided to agree upon." Relying on history to understand the past means relying on the official story of the past as portrayed through the historical documents which were generally recorded by the powerful and the literate, and throughout most of history, this means white, elite males with agendas (Bowen 1975; Jordan 2000: 240). The VOC were master recorders who insisted on meticulous accounts in order to maintain an efficient mercantile company. In spite of the impressive documentary record of the Cape settlement, details of their meat industry were not fully recorded for posterity, possibly because it was a mundane aspect of their overall workings maintained, in part, in the private and distant sectors. This thesis shows how the meat trade of the VOC at the Cape helped sustain their expanding global mercantile 
trade networks, while at the same time, disempowering the indigenous groups and promoting the evolution of the creolized Cape population.

This thesis can serve as a foundation for further work in the historical archaeology of the Cape. This investigation into the VOC meat industry also exposes some glaring missing information. It opens avenues of future research that are needed to fill the gaps before, between, and after the temporal and geographic data points presented here. Specifically, seventeenth century sites can further contribute to understanding the struggles faced during the development of the meat industry. Synchronic sites across the Cape can potentially fill gaps about any differences between social classes and geographic locales. Frontier sites at outposts and farms could further our knowledge of changing European colonial culture away from the urban center as well as the depletion of the indigenous fauna. Shipwrecks can contribute greatly to understanding the types of provisioned meat taken from the Cape. Lastly, this thesis exposes the need for microscopic sciences such as genetics and stable isotopes which can answer the toughest questions about stock hybridization and animal movement from the frontier to the colonial holdings. Microscopic tooth structures can be examined to verify the en mass slaughter of stock as well as the lack of seasonal culling (i.e. Landon 1993). Significant archaeological residues of VOC-period colonization and establishment are expected to be preserved throughout the Western Cape due to the relatively rural nature of the country and the growing preservation mindset embodied by some South Africans. 


\section{APPENDIX 1: Coding Conventions}

FIELD

Sample \#

Taxon

Animal size

Skeletal part

Skeletal portion

Skeletal part segment

\section{CODE}

By context and bone specimen number

Most specific identifiable taxon

Relative size, for mammals according to Bunn 1982

$\backslash$

| After Blumenschine 2003; 070: 392 (attached APP 2) 
Long bone shaft circumference

Maximum length

Maximum width

Allometry

Relative age

Tooth eruption age

Side

Bone measurements

BIOGENIC MARKS

Tooth Mark

TM location A

TM location B

TM location $\mathrm{C}$

Rodent

Root etching
0.1-1.0, shafts divided by tenths to assess completeness

$\mathrm{mm}$

$\mathrm{mm}$

Greenfield 2002 sex measurements, mm

$\mathrm{A}=$ adult

$\mathrm{S}=$ subadult

$\mathrm{P}=$ subadult, but partially fused

$\mathrm{I}=$ indeterminate

Age of eruption according to Bull and Payne 1982; Silver 1969

$\mathrm{R}=$ right

$\mathrm{L}=$ left

$\mathrm{I}=$ indeterminate

According to Von den Driesch 1976

$0=\mathrm{absent}$

$1=$ present as isolated marks

$2=$ present as punctures

$3=$ present as gross gnawing

$4=$ low confidence tooth marks

$1=$ cortical only

$2=$ medullary only

$3=1 \& 2$

$4=$ thickness only

$5=1,2 \& 3$

$6=1 \& 3$

$7=2 \& 3$

$9=$ cannot see thickness or medullary surface

$1=<2 \mathrm{~mm}$ from fracture edge

$2=>2 \mathrm{~mm}$ from fracture edge

$3=1 \& 2$

$4=$ on flake platform

$1=$ on or towards epiphyseal and NEFs, respectively

$2=$ on or towards midshaft end for epiphyseal and NEFs

$3=1 \& 2$

$4=$ indeterminate, on midshaft fragment

$0=$ absent

$1=$ present, minor

$2=$ present, major

$1=$ absent to isolated spots

$2=$ minor 
$3=$ moderate

$4=$ severe, obscuring marks

HUMAN MADE MARKS

Percussion marks

$0=$ absent

$1=$ present

$2=$ present as isolated patches of microstriations only

$3=$ conspicuous battering fields of PMs

4= low confidence PM

PM location

$1=<2 \mathrm{~mm}$ from fracture edge

$2=>2 \mathrm{~mm}$ from fracture edge

$3=1 \& 2$

$4=$ on flake platform

KNIFE MARKS

Chop marks

$0=$ absent

$1=$ present

Cut marks

$0=$ absent

$1=$ present

Scrape marks

$0=$ absent

$1=$ present

Burning

$0=$ absent

$1=$ charred black

$2=$ burnt, calcined white

$3=1 \& 2$

Trampling

$0=$ absent

$1=$ present

BONE CONDITION

Surface color

Specific to specimen

Surface condition

$1=$ pristine, original surface

$2=$ minor exfoliation or flaking

$3=$ minor chemical erosion

$4=$ minor mechanical rounding

$5=$ minor adhering matrix

$6=$ major exfoliation or flaking that obscures marks

$3=$ major chemical erosion that obscures marks

$4=$ major mechanical rounding that obscures marks

$5=$ major adhering matrix that obscures marks

Weathering

0-5, according to Behrensmeyer 1978

Recent breakage

$0=$ none

$1=$ yes, but with less than $10 \%$ missing

$2=$ yes, with more than $10 \%$ missing

$3=$ modern breaks, but fragments can mend

$9=$ indeterminate

General breakage

$1=$ spiral, oblique

$2=$ transverse 
Notching

Notch associates

Multiple notches

Copper stain

Notes

Tooth row

Crown height

Crown breadth

Payne 1973

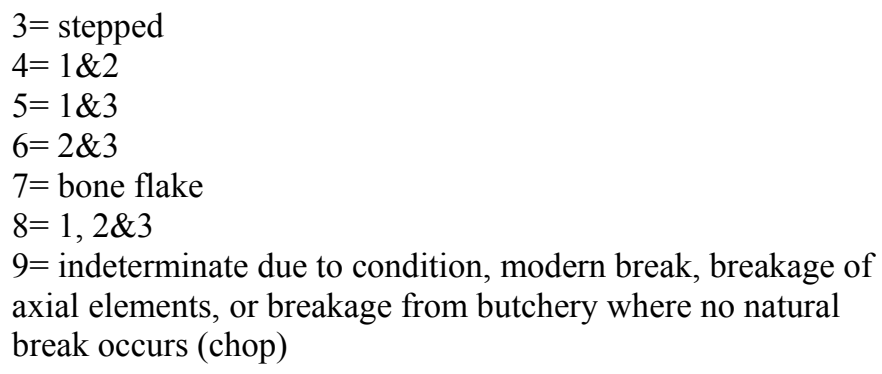

$0=$ absent

$1=$ percussion mark

$2=$ tooth notch

$3=$ uncertain

$0=$ no mark

$1=$ tooth mark at notch

$2=$ tooth mark opposite notch

$3=$ percussion mark at notch

$4=$ percussion mark opposite notch

$0=$ none $($ only 1$)$

$1=$ on same edge

$2=$ on opposite edge

$3=$ on both edges

$0=$ absent

$1=$ present

Details relevant about specimen not covered above

Measurements of tooth rows (mm)

Height of tooth crown (mm)

Breadth of tooth crown (mm)

Tooth wear stage of specific tooth if isolated

\section{APPENDIX 2: Osteological Coding Conventions (Blumenschine 2003)}

\section{SKELETAL PART}

NID- not identified

AX- axial skeleton

CRA-cranium

MAND- mandible

HMAN- hemi-mandible

TOOTH- isolated tooth (defined by MAX or HMAN for upper of lower and followed by tooth number) 


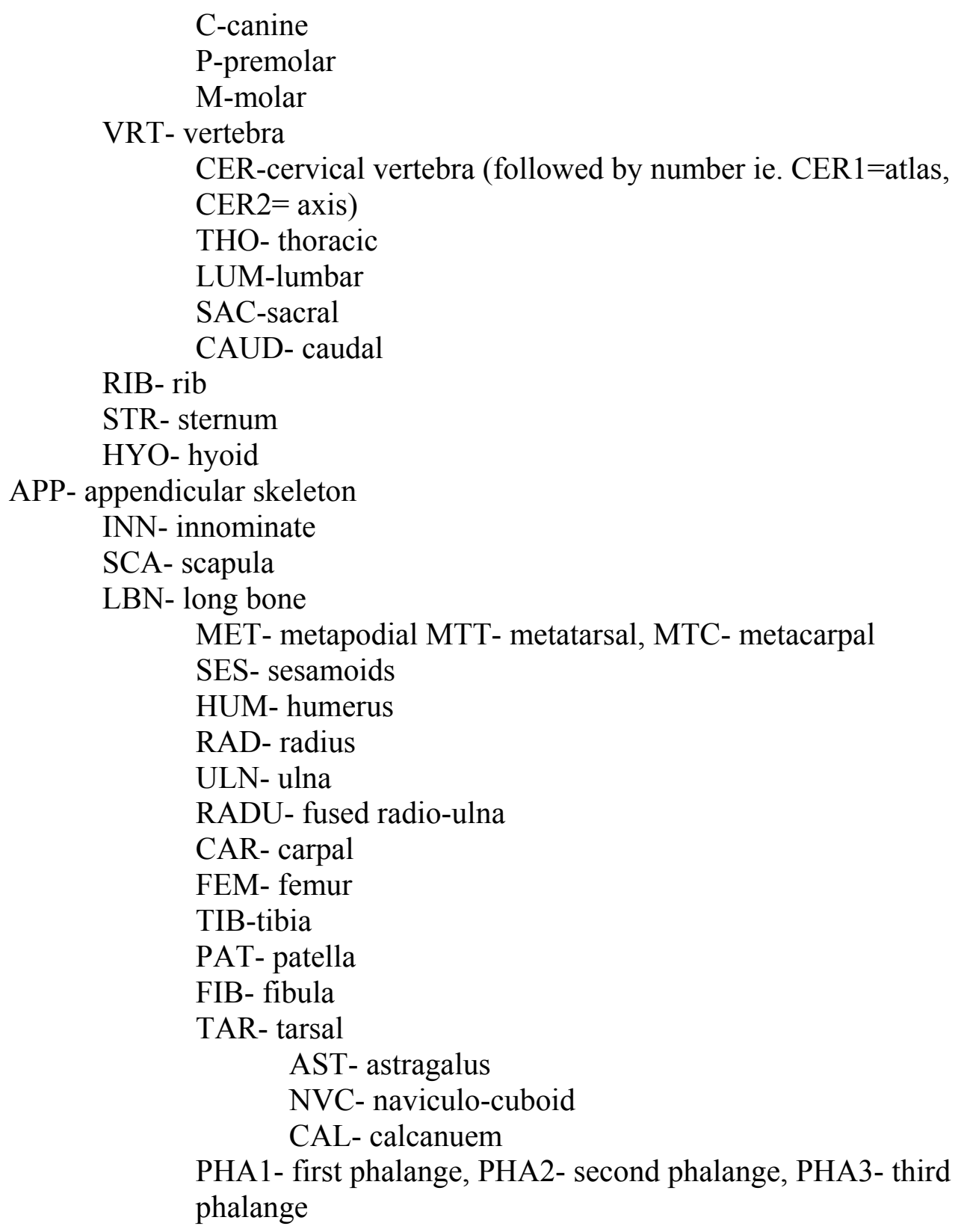

\section{SKELETAL PART PORTION}

CO- complete

FOR LONG BONES AND RIBS

EPI- epiphyseal fragment

PX- proximal

DS- distal

NEF- near epiphyseal fragment

PSH- proximal

DSH-distal

MSH- midshaft

FOR CRANIUM 
HCR- horncore

FRO- frontal

OCC- occipital

TEM-temporal

ZYG-zygomatic

NAS-nasal

MAX-maxilla

PMAX-premaxilla

LAC-lacrimal

PAR-parietal

FOR MANDIBLE

HRAM-horizontal ramus

VRAM-vertical ramus

CON-condyle

COR-coranoid process

GON-gonial angle

SYMP-symphysis

FOR VERTEBRAE

PREZ-prezygopophysis, POSZ-postzygopophysis

DOSP-dorsal spine

NEUR-neural arch

LATPR- lateral process

CEN-centrum

FOR INNOMINATE

ILI-ilium

ISCH-ischium

PUB-pubis

ACET- acetabulum

FOR SCAPULA

GLEN-glenoid fossa

SP-spine

ACR-acromion

BLADE-blade

CAUDM-caudal margin

\section{SKELETAL PART SEGMENT}

FR-fragment

ANT- anterior

POST-posterior

SUP-superior

VEN-ventral

MD-medial

LAT-lateral

DOR-dorsal

INF-inferior

HF-half 
ORB-at orbit

ARC-at TEM arch

PP-petrous pyramid of TEM

ALV-alveoli of MAX or HMAN

CS-complete shaft cylinder

CO-complete

\section{WORKS CITED}

Abrahams, Gabeba. 1994. Coarse Earthenwares of the VOC Period: $18^{\text {th }}$ Century Pottery Excavated from the Grand Parade at the Cape. Annals of the South African Cultural History Museum. Volume 6.

Abrahams, Gabeba. 1996. Foodways of the Mid-18 ${ }^{\text {th }}$ Century Cape: Archaeological Ceramics from the Grand Parade in Central Cape Town. Unpublished Ph.D. thesis submitted to the Department of Archaeology, University of Cape Town.

Abrahams-Willis, Gabeba. 1998. Archaeology and Local Cuisine: Signatures of the 
Cape Around 1750. Annals of the South African Cultural History Museum. Volume 10.

Abrahams-Willis, Gabeba. 2002. The Slave Lodge: Excavations in 2000. The Heritage of Slavery in South Africa: The Slave Lodge. Iziko Museums of Cape Town. http://www.iziko.org.za/sh/resources/slavery/slavelodge_excavations.html

Adamson, Melitta Weiss. 2004. Food Through History: Food in Medieval Times. Connecticut: Greenwood Press.

Albala, Ken. 2003. Food in Early Modern Europe. Connecticut: Greenwood Press.

Albarella, Umberto. 1995. Depressions in Sheep Horncores. Journal of Archeological Science. Vol. 22. 699-704.

Albarella, Umberto. 1997. Size, Power, Wool, and Veal: Zooarchaeological Evidence for Late Medieval Innovations. In Environment and Subsistence in Medieval Europe- Papers of the 'Medieval Europe Brugge 1997' Conference. Edited by Guy de Boe and Frans Verhaeghe. Zellik: I.A.P. Rapporten 9. 19-30.

Alexander, Richard, John Hoogland, Richard Howard, Katharine Noonan, and Paul Sherman. 1979. Sexual Dimorphisms and Breeding Systems in Pinnipeds, Ungulates, Primates, and Humans. In Evolutionary Biology and Human Social Behavior: An Anthropological Perspective. Edited by Napoleon Chagnon and William Irons. Massachusetts: Duxbury Press. 402-435.

Allison, K. J. 1958. Flock Management in the Sixteenth and Seventeenth Centuries. The Economic History Review. Vol. 11. 98-112.

Andrews, P. 1990. Owls, Caves, and Fossils. Chicago: University of Chicago Press.

Anonymous. 1650. A Book of Cookery, and the Order of Meates to be Served to the Table, Both for Flesh and Fish Days. With many Excellent Wayes for the Dressing of all Sorts of Meats, Both Bak'd, Boyld, or Rosted of Flesh, Fish, Fowle, or Others, With Their Appropriate Sawes. As Also Many rare Inventions in Cookery for Made Dishes: With Most Notable Preserves of Sundry Sorts of Fruits. Likewise for making many Precious Waters With Divers Approved Medicines for Grievous Diseases. With Certaine Points of Husbandry how to Order Oxen, Horses, Sheep, Hogges \& With many Other Necessary Points for Husbandmen to Know. London: Printed by James Bell.

Arbuckle, Benjamin. 2008. Revisiting Caprine Exploitation at Suberde, Turkey. Journal of Field Archaeology. Vol. 33. 219-236.

Archaeological Contracts Office. 1988. Unpublished field notes from the DKG excavations. University of Cape Town. 
Archaeological Contracts Office. 1990. Unpublished field notes from the Van der Stel Gateway Moat excavations. University of Cape Town.

Armitage, Philip. 2004. The Study of Six Artifact Categories from the Wreck Site of the Earl of Abergavenny: Study of the Animal Bones- Section 1. www.weymouthdiving.co.uk/research.htm\#Section1.

Armstrong, Douglas. 1990. Subsistence Activities and Dietary Practices. In The Old Village and the Great House: An Archaeological and Historical Examinations of Drax Hall Plantation St. Ann's Bay, Jamaica. Chicago: University of Illinois Press. 209-250.

Armstrong, James and Nigel Worden. 1988. The Slaves, 1652-1834. In Shaping of South African Society, 1652-1840. Edited by Richard Elphick and Herman Giliomee. Middletown, Connecticut: Wesleyan University Press. 109- 181.

Avery, D. Margaret. 1989. Remarks Concerning Vertebrate Faunal Remains from the Main House at Paradise. South African Archaeological Bulletin. Vol. 44. 114116.

Avery, Graham. 1992. Preliminary Report on Faunal material from Excavations at the Slave Lodge, Cape Town. Unpublished report.

Avery, Graham and L. G. Underhill. 1986. "Seasonal Exploitation of Seabirds by Late Holocene Coastal Foragers: Analysis of Modern and Archaeological data from the Western Cape, South Africa." Journal of Archaeological Science. Vol. 13. 339360 .

Baker, Vernon G. 1980. Afro-American Culture History. In Archaeological Perspectives on Ethnicity in America. Edited by Robert Schulyer. New York: Baywood Publishing Company. 29-37.

Balasse, Marie and Stanley Ambrose. 2002. The Seasonality Mobility Model for Prehistoric Herders in the South-western Cape of South Africa Assessed by Isotopic Analysis of Sheep Tooth Enamel. Journal of Archaeological Science. Vol. 29. 917-932.

Balasse, Marie, Andrew Smith, Stanly Ambrose, and Steven Leigh. 2003. "Determining Sheep Birth Seasonality by Analysis of Tooth Enamel Oxygen Isotope Ratios: The Late Stone Age Site of Kasteelberg (South Africa)." Journal of Archaeological Science. Vol. 30. 205-215.

Barber, Michael. 1976. The Vertebrate Fauna from a Late Eighteenth Century Well: The Bray Plantation. Kingsmill, Virginia. Historical Archaeology. Vol. 10. $68-71$. 
Beaudry, Mary, J. Long, H. M. Miller, Frasier Nieman, and G. W. Stone. 1983. A Vessel Typology for Early Chesapeake Ceramics. Historical Archaeology. Vol. 17. 18-43.

Behrensmeyer, Ann. 1978. Taphonomic and Ecological Information from Bone Weathering. Paleobiology. Vol. 4. 150-162.

Behrensmeyer, Ann. 1991. Terrestrial Vertebrate Accumulations. In Taphonomy: Releasing the Data Locked in the Fossil Record, Volume 9; Topics in Geobiology. Edited by Peter Allison and Derek Briggs. New York: Plenum Press. 291-334.

Behrensmeyer, Ann, Kathleen Gordon, and Glenn Yanagi. 1986. Trampling as a Cause of Bone Surface Damage and Pseudo-Cutmarks. Nature. Vol. 319. 768-771.

Bello, Silvia and Christophe Soligo. 2008. A New Method for the Quantitative Analysis of Cutmark Micromorphology. Journal of Archaeological Science. Vol. 35. $1542-1552$.

Bertalanffy, Ludwig von. 1968. General System Theory: Foundations, Development, Applications. New York: George Braziller.

Binford, Lewis. 1977. Historical Archaeology: Is It Historical or Is It Archaeological? In Historical Archaeology and the Importance of Material Things: Papers of the Thematic Symposium, Eighth Annual Meeting of the Society for Historical Archaeology, Charleston, South Carolina, January 7-11, 1975. Edited by Leland Ferguson. Michigan: Society for Historical Archaeology.

Binford, Lewis. 1978. Nunamiut Ethnoarchaeology. New York: Academic Press.

Binford, Lewis. 1981. Ancient Men and Modern Myths. New York: Academic Press.

Binford, Lewis and Jack Bertram. 1977. Bone Frequencies - And Attritional Processes. In For Theory Building in Archaeology: Essays on Faunal Remains, Aquatic Resources, Spatial Analysis, and Systemic Modeling. Edited by Lewis Binford. New York: Academic Press. 77-153.

Binford, Lewis and Sally Binford, editors. 1968. New Perspectives in Archeology. Chicago: Aldine Publishing Company.

Bleek, D. F. 1929. Comparative Vocabularies and Bushman Languages. Cambridge: Cambridge University Press.

Blumenschine, Robert. 1988. An Experimental Model of the Timing of Hominid and Carnivore Influence on Archaeological Bone Assemblages. Journal of Archaeological Science. Vol. 15. 483-502. 
Blumenschine, Robert. 1995. Percussion marks, Tooth Marks, and Experimental Determinations of the Timing of Hominid and Carnivore Access to Long Bones at FLK Zinjanthropus, Olduvai Gorge, Tanzania. Journal of Human Evolution. Vol. 29. 21-51.

Blumenschine, Robert. 2003. 070:392 Faunal Analysis: Recording criteria. Rutgers University.

Blumenschine, Robert and T. Cregg Madrigal. 1993. Variability in Long Bone Marrow Yields of East African Ungulates and its Zooarchaeological Implications. Journal of Archaeological Science. Vol. 20. 555-587.

Blumenschine, Robert and Curtis Marean. 1993. A Carnivore's View of Archaeological Bone Assemblages. In From Bones to Behavior. Edited by J. Hudson. Carbondale, Illinois: Center for Archaeological Investigations, Southern Illinois University. 273-300.

Blumenschine, Robert and Marie Selvaggio. 1988. Percussion Marks on Bone Surfaces as a New Diagnostic of Hominid Behavior. Nature. Vol. 333. 763-765.

Blumenschine, Robert, Curtis Marean, and Salvatore Capaldo. 1996. Blind Tests of Inter-analyst Correspondence and Accuracy in the Identification of Cut Marks, Percussion Marks, and Carnivore Tooth Marks on Bone Surfaces. Journal of Archaeological Science. Vol. 23. 493-507.

Blusse, Leonard. 1996. No Boats to China. The Dutch East India Company and the Changing Pattern of the China Sea Trade, 1635-1690. Modern Asian Studies. Vol. 30. 51-76.

Böeseken, A. J. 1961. Resoluties van die Politieke Raad. Deel III: 1681-1707. SuidAfrikaanse Argiefstukke, Kaap No. III. Cape Town: Nasionale Handelsdrukkery BPK.

Boessneck, Jaochim. 1970. Osteological Differences Between Sheep (Ovis aries Linné) and Goat (Capra hircus Linné). In Science in Archaeology. Edited by Don Brothwell and Eric Higgs. New York: Thames and Hudson. 331-358.

Bokonyi, Sandor. 1971. The Development and History of Domestic Animals in Hungary: The Neolithic Through the Middle Ages. American Anthropologist. Vol. 73. 640-674.

Bonnichsen, Robson and Marcella Sorg, editors. 1989. Bone Modification. Orono, Maine: Center for the Study of the First Americans, Institute of Quaternary Studies, University of Maine. 
Boonzaier, Emile, Candy Malherbe, Andy Smith, and Penny Berens. 1996. The Cape Herders: A History of the Khoikhoi of South Africa. Cape Town: David Philip.

Bostwick, John. 1980. The Plaza II Site Excavation of a Colonial Spanish Well in St. Augustine, Florida. Historical Archaeology. Vol. 14. 73-81.

Botha, C. Graham. 1928. The Public Archives of South Africa. Cape Town: Cape Times Ltd.

Botha, C. Graham. 1970. Social Life at the Cape Colony with "Social Customs in South Africa" in the $18^{\text {th }}$ Century. Cape Town: C. Struik Ltd.

Bousman, C. Britt. 1998. The Chronological Evidence for the Introduction of Domestic Stock into Southern Africa. African Archaeological Review. Vol. 15. 133-150.

Bowen, Joanne. 1975. Probate Inventories: An Evaluation from the Perspective of Zooarchaeology and Agricultural History at Mott Farm. Historical Archaeology. Vol. 9. 11-25.

Bowen, Joanne. 1992. Faunal Remains and Urban Household Subsistence in New England. In The Art and Mystery of Historical Archaeology: Essays in Honor of James Deetz. Edited by Anne Yentsch and Mary Beaudry. Florida: CRC Press. 267-281.

Bowen, Joanne. 1994. A Comparative Analysis of the New England and Chesapeake Herding Systems. In Historical Archaeology of the Chesapeake. Edited by Paul Shackel and Barbara Little. Washington: Smithsonian Institution Press. 155-167.

Bowen, Joanne. 1999. The Chesapeake Landscape and the Ecology of Animal Husbandry. In Old and New Worlds: Historical/Post Medieval Archaeology Papers from the Societies' Joint Conferences at Williamsburg and London 1997 to Mark Thirty Years of Work and Achievement. Edited by Geoff Egan and R. L. Michael. Oxford: Oxbow Books. 358-367.

Bowen, Joanne and Susan Andrews. 2000. The Starving Time at Jamestown. Unpublished report to the Association for the Preservation of Virginian Antiquities, Jamestown Rediscovery.

Boxer, C. R. 1965. The Dutch Seaborne Empire: 1600-1800. New York: Alfred A. Knopf.

Brain, C. K. 1967. Bone Weathering and the Problem of Bone Pseudo-tools. South African Journal of Science. Vol. 63. 97-99.

Brain. C. K. 1975. An Introduction to the South African Australopithecine Bone 
Accumulations. In Archaeozoological Studies. Edited by A. T. Clason. New York: Elsevier Press. 109-119.

Brain, C. K. 1981. The Hunters or the Hunted: An Introduction to African Cave Taphonomy. Chicago: University of Chicago Press.

Bromage, T. and A. Boyd. 1984. Microscopic Criteria for the Determination of Directionality of Cut Marks on Bone. American Journal of Physical Anthropology. Vol. 65. 359-366.

Brown, Gregory. 1989. Food and Foodways in an Urban Context: The Diet of an Eighteenth-Century Williamsburg Craftsman. Paper presented at the First Joint Archaeological Congress, Baltimore, Maryland, January 8, 1989.

Budiansky, Stephen. 1999. The Covenant of the Wild: Why Animals Chose Domestication. Connecticut: Yale University Press.

Bull, Gail and Sebastian Payne. 1982. Tooth Eruption and Epiphyseal Fusion in Pigs and Wild Boar. In Ageing and Sexing Animal Bones from Archaeological Sites. Edited by Bob Wilson, Caroline Grigson, and Sebastian Payne. BAR British Series 109. 55-71.

Bult, Epko and Henk Robbers. 1992. Animal Bones. In IHE Delft Prospers on a Cesspit: Archaeological Research Between Oude Delft and Westvest. Edited by Bult et al. Netherlands: IHE Delft. 135-149.

Bunn, Henry. 1981. Archaeological Evidence for Meat Eating by Plio-Pleistocene Hominids from Koobi Fora and Olduvai Gorge. Nature. Vol. 291. 574-577.

Bunn, Henry. 1982. Meat Eating and Human Evolution: Studies on the Diet and Subsistence Patterns of Plio-Pleistocene Hominids in East Africa. Ph. D. Dissertation, University of California, Berkeley.

Burrill, Melinda. 2004. Sheep. World Book. Department of Animal and Veterinary Sciences, California State Polytechnic University.

Calhoun, J. A., Elizabeth Reitz, M. B. Trnkley, and Martha A. Zierden. 1984. Meat in Due Season: Preliminary Investigations of Marketing Practices in Colonial Charleston. Archaeological Contributions 9. Charleston: The Charleston Museum.

Cantwell, Anne-Marie and Diana DiZerega Wall. 2001. Unearthing Gotham: The Archaeology of New York City. New Haven: Yale University Press.

Capaldo, Salvatore and Robert Blumenschine. 1994. A Quantitative Diagnosis of 
Notches made by Hammerstone Percussion and Carnivore Gnawing on Bovid Long Bones. American Antiquity. Vol. 59. 724-748.

Chaplin, R. E. 1968. The Use of Non-Morphological Criteria in the Study of Animal Domestication from Bones Found in Archaeological Sites. In The Domestication and Exploitation of Plants and Animals. Edited by P. J. Ucko and G. W. Dimbleby. London: Duckworth Press. 231-245.

Cheek, Charles. 1998. Massachusetts Bay Foodways: Regional and Class Influences. Historical Archaeology. Vol. 32. 153-172.

Church, Robert and R. Lee Lyman. 2003. Small Fragments Make Small Difference in Efficiency When Rendering Grease from Fractured Artiodactyla Bones by Boiling. Journal of Archaeological Science. Vol. 30. 1077-1084.

Clutton-Brock, Juliet. 2000. Cattle, Sheep, and Goats South of the Sahara: An Archaeozoological Perspective. In The Origins and Development of African Livestock: Archaeology, Genetics, Linguistics, and Ethnography. Edited by Roger Blench and Kevin MacDonald. London: UCL Press. 30-37.

Clutton-Brock, T. H. 1991. The Evolution of Sex Differences and the Consequences of Polygany in Mammals. In The Development and Integration of Behaviour: Essays in Honour of Robert Hinde. Edited by Patrick Bateson. New York: Cambridge University Press. 229-253.

Clutton-Brock, T. H., P. H. Harvey, and B. Rudder. 1977. Sexual Dimorphism, Socionomic Sex Ration and Body Weight in Primates. Nature. Vol. 269. 797800 .

Coetzee, Renata. 1977. The South African Culinary Tradition: The Origin of South Africa's Culinary Arts during the $17^{\text {th }}$ and $18^{\text {th }}$ Centuries, and 167 Authentic Recipes of this Period. Cape Town: C. Struik Publishers.

Cohen, Alan and Dale Serjeantson. 1996. A Manual for the Identification of Bird Bones from Archaeological Sites. London: Archetype Publications.

Cossette, Evelyne and Marie-Pierre Horard-Herbin. 2003. A Contribution to the Morphometrical Study of Cattle in Colonial North America. Journal of Archaeological Science. Vol. 30. 263-274.

Coutureau, M. 1996. Osteological templates hosted on http://www.archeozoo.org/frarticle 50.html.

Cox, Glenda and Judith Sealy. 1997. Investigating Identity and Life Histories: Isotopic 
Analysis and Historical Documentation of Slave Skeletons Found on the Cape Town Foreshore, South Africa. International Journal of Historical Archaeology. Vol. 1. 207-224.

Cox, Glenda, Judith Sealy, Carmel Schrire, and Alan Morris. 2001. Stable Carbon and Nitrogen Isotopic Analyses of the Underclass at the Colonial Cape of Good Hope in the Eighteenth and Nineteenth Centuries. World Archaeology. Vol. 33. 73-97.

Crabtree, Pam. 1989. Sheep, Horses, Swine, and Kine: A Zooarchaeological Perspective on the Anglo-Saxon Settlement of England. Journal of Field Archaeology. Vol. 16. 205-213.

Crabtree, Pam. 1990. Zooarchaeology and Complex Societies: Some Uses of Faunal Analysis for the Study of Trade, Social Status, and Ethnicity. In Archaeological Method and Theory, Volume 2. Edited by Michael Schiffer. Tuscon: University of Arizona Press. 155-206.

Crabtree, Pam. 1996. Production and Consumption in an Early Complex Society: Animal Use in Middle Saxon East Anglia. World Archaeology. Vol. 28. 58-75.

Crader, Diana. 1984. The Zooarchaeology of the Storehouse and the Dry Well at Monticello. American Antiquity. Vol. 49. 542-558.

Crader, Diana. 1989. Faunal Remains from Slave Quarter Sites at Monticello, Charlottesville, Virginia. Archaeozoologia. Vol. III/1,2. 229-236.

Crader, Diana. 1990. Slave Diet at Monticello. American Antiquity. Vol. 55. 690-717.

Crosby, Alfred. 1987. Ecological Imperialism. The Biological Expansion of Europe, 900-1900. Cambridge: Cambridge University Press.

Crossley-Holland, Nicole. 1996. Living and Dining in Medieval Paris: The Household of a Fourteenth Century Knight. Cardiff: University of Wales Press.

Cruz-Uribe, Kathryn. N.d. Unpublished notes of Oudepost I DP 1 and 2 fauna.

Cruz-Uribe, Kathryn. 1988. “The Use and Meaning of Species Diversity and Richness in Archaeological Faunas.” Journal of Archaeological Science. Vol. 15. 179196.

Cruz-Uribe, Kathryn and Carmel Schrire. 1991. Analysis of Faunal Remains from Oudepost I, an Early Outpost of the Dutch East India Company, Cape Province. South African Archaeological Bulletin. Vol. 46. 92-106.

Dankaerts, Jasper. 1913. Journal of Jaspar Dankaerts, 1679-1680. Edited by Bartlett Burleigh James and J. Franklin Jameson. New York: Charles Scribner's Sons. 
David, Bruno. 1989. How Was This Bone Burnt? In Problem Solving in Taphonomy: Archaeological and Paleontological Studies from Europe, Africa, and Oceania. Edited by Su Solomon, Iain Davidson, and Di Watson. Queensland: Anthropology Museum, the University of Queensland.

Davis, K. L. 1985. A Taphonomic Approach to Experimental Bone Fracturing and Applications to Several South African Pleistocene Sites. Unpublished Ph. D. Dissertation, State University of New York, Binghamton.

Davis, Simon. 1987. The Archaeology of Animals. Connecticut: Yale University Press.

Davis, Simon. 1996. Measurements of a Group of Adult Female Shetland Sheep Skeletons from a Single Flock: a Baseline for Zooarchaeologists. Journal of Archaeological Science. Vol. 23. 593-612.

Davis, Simon. 1997. The Agricultural Revolution in England: Some Zooarchaeological Evidence. Anthropozoologica. Vol. 25/26. 413-428.

Davis, Simon. 2000. The Effect of Castration and Age on the Development of Shetland Sheep Skeleton and a Metric Comparison Between Bones of Males, Females, and Castrates. Journal of Archaeological Science. Vol. 27. 373-390.

Davis, Simon. 2008. Zooarchaeological Evidence for Moslem and Christian Improvements of Sheep and Cattle in Portugal. Journal of Archaeological Science. Vol. 35. 991-1010.

Davis, Simon and John Beckett. 1999. Animal Husbandry and Agricultural Improvement: The Archaeological Evidence from Animal Bones and Teeth. Rural History. Vol. 10. 1-17.

Deacon, Hillary and Janette Deacon. 1999. Human Beginnings in South Africa: Uncovering the Secrets of the Stone Age. Walnut Creek, CA: Altamira Press.

Deacon, Hillary, Janette Deacon, M. Brooker, and M. L. Wilson. 1978. The Evidence for Herding at Boomplaas Cave in the Southern Cape, South Africa. South African Archaeological Bulletin. Vol. 33. 39-65.

De Bosdari, C. 1953. Cape Dutch Houses and Farms: Their Architecture and History, Together with a Note on the Role of Cecil John Rhodes in Their Preservation. Cape Town: A A Balkema Press.

Deetz, James. 1968. The Inference of Residence and Decent Rules from Archaeological Data. In New Perspectives in Archaeology. Edited by Lewis Binford and Sally Binford. Chicago: Aldine Publishing Company. 41-48. 
Deetz, James. 1993. Flowerdew Hundred: The Archaeology of a Virginia Plantation, 1619-1864. Charlottesville: University Press of Virginia.

Deetz, James. 1996. In Small Things Forgotten: An Archaeology of Early American Life. New York: Anchor Books.

Degerbol, Magnus. 1963. Prehistoric Cattle in Denmark and Adjacent Areas. In Man and Cattle. Edited by A. E. Mourant and F. E. Zeuner. Great Britain: Royal Anthropological Institute of Great Britain and Ireland. 68-79.

Deniz, E. and Sebastian Payne. 1978. Eruption and Wear in the Mandibular Dentition of Turkish Angora goats in Relation to Ageing Sheep/Goat Mandibles from Archaeological Sites. Paper presented at ICAZ conference, Szczecin, Poland.

Denys, C. 2002. Taphonomy and Experimentation. Archaeometry. Vol. 44. 469-484.

DeVries, Jan and Ad van der Woude. 1997. The First Modern Economy: Success, Failure, and Perseverance of the Dutch Economy, 1500-1815. UK: Cambridge University Press.

Diderot, Denis. 1987. A Diderot Pictoral Encyclopedia of Trades and Industry: Manufacturing and the Technical Arts in Plates Selected from "L'Encyclopédie, ou Dictionnaire Rasionné des Sciences, des Arts et des Métiers, Volume 2" Edited by Charles C. Gillispie. New York: Dover Publications, Inc.

Dobney, K. M., S. D. Jacques, and B. G. Irving. 1996. Of Butchers and Breeds: Report on Vertebrate Remains from Various Sites in the City of Lincoln. Lincoln Archaeological Studies Vol. 5.

Dominguez-Rodrigo, Manuel and Ana Piqueras. 2003. The Use of Tooth Pits to Identify Carnivore Taxa in Tooth-marked Archaeofaunas and Their Relevance to Reconstruct Hominid Carcass Processing Behaviours. Journal of Archaeological Science. Vol. 30. 1385-1391.

Dooling, Wayne. 1994. The Castle: Its Place in the History of Cape Town in the VOC Period. In Studies in the History of Cape Town, Volume 7. Edited by Elizabeth van Heyningen. Cape Town: University of Cape Town Press. 11-31.

Driver, Jonathan. 1982. Medullary Bone as an Indicator of Sex in Bird Remains from Archaeological Sites. In Ageing and Sexing Bones from Archaeological Sites. Edited by Bob Wilson, Caroline Grigson, and Sebastian Payne. London: BAR British Series 109. 251-254.

Duco, D. H. 1982. Merken van Goudse Pijpenmakers 1660-1960. Poperinge: Uitgeversmaatschappij De Tijdstroom B. V. Lochem. 
Ducos, Pierre. 1968. L'origine des Animaux Domestique en Palestine. Publications de Prehistoire de l'Universite de Bordeaux 6. Bordeaux: University of Bordeaux.

Dyer, C. C. 2006. Seasonal Patterns in Food Consumption in the Later Middle Ages. In Food in Medieval England. Edited by C. M Woolgar, D Sarjeantson, and T. Waldron. Oxford: Oxford University Press. 27-40.

Egeland. Charles, Travis Pickering, Manuel Dominguez-Rodrigo, C. K. Brain. 2004. Disentangling Early Stone Age Palimpsests: Determining the Functional Independence of Hominid- and Carnivore-derived Portions of Archaeofaunas. Journal of Human Evolution. Vol. 47. 343-357.

Elphick, Richard. 1977. Kraal and Castle. New Haven, CT: Yale University Press.

Elphick, Richard. 1985. Khoikhoi and the Founding of White South Africa. Johannesburg: Ravan Press.

Elphick, Richard and Hermann Giliomee, editors. 1988. The Shaping of South African Society, 1652-1840. Middletown, Connecticut: Wesleyan University Press.

Elphick, Richard and V. C. Malherbe. 1988. The Khoisan to 1828. In The Shaping of South African Society, 1652-1840. Edited by Richard Elphick and Hermann Giliomee. Middletown, Connecticut: Wesleyan University Press. 3-65.

Elphick, Richard and Robert Shell. 1988. Intergroup Relations: Khoikhoi, Settlers, Slaves, and Free Blacks, 1652-1795. In The Shaping of South African Society, 1652-1840. Edited by Richard Elphick and Hermann Giliomee. Middletown, Connecticut: Wesleyan University Press. 184-242.

English, A. J. 1990. Salted Meats from the Wreck of the William Salthouse: Archaeological Analysis of Nineteenth Century Butchering Patterns. Australian Historical Archaeology. Vol. 8. 63-69.

Epstein, H. 1971. The Origin of the Domestic Animals of Africa. London: Africana Publishing Corporation.

Ervynck, Anton. 2005. Detecting Seasonal Slaughtering of Domestic Mammals: Inferences from the Detailed Recording of Tooth Eruption and Wear. Environmental Archaeology: The Journal of Human Paleoecology. Vol. 10. 153169.

Ervynck, Anton, Win Van Neer, Heide Huster-Plogmann, and Jorg Schibler. 2003. Beyond Affluence: The Zooarchaeology of Luxury. World Archaeology. Vol. 34. $428-441$.

Estes, Richard Despard. 1991. The Behavior Guide to African Mammals. Berkely: The 
University of California Press.

Ewen, Charles. 1986. Fur Trade Archaeology: A Study of Frontier Hierarchies. Historical Archaeology. Vol. 20. 15-28.

Fagan, Gwen. 1984. Die Werf by Elsenburg. Restorica. Vol. 16. 34-38.

Fairbridge, Dorothea, editor. 1927. Letters from the Cape by Lady Duff Gordon. London: Oxford University Press.

Fairbridge, Dorothea. 1931. Historic Farms of South Africa: The Wool, the Wheat, and the Wine of the $17^{\text {th }}$ and $18^{\text {th }}$ Centuries. London: Oxford University Press

Faith, J. Tyler, Curtis Marean, and Anna Behrensmeyer. 2007. Carnivore Competition, Bone Destruction, and Bone Density. Journal of Archaeological Science. Vol. 34. 2025-2034.

Fehring, Gunter. 1991. The Archaeology of Medieval Germany: An Introduction. Translated by Ross Samson. New York: Routledge Press.

Fessell, G. E. 1972. The Classic Tradition in Western European Farming. Rutherford: Farleigh Dickinson University Press.

Fiorillo, Anthony. 1989. An Experimental Study of Trampling: Implications for the Fossil Record. In Bone Modification. Edited by Bonnichsen, Robson and Marcella Sorg. Orono, Maine: Center for the Study of the First Americans, Institute of Quaternary Studies, University of Maine. 61-71.

Fisher, John. 1969. The Afrikaners. London: Cassell and Company Limited.

Fisher, John W. 1995. Bone Surface Modifications in Zooarchaeology. Journal of Anthropological Method and Theory. Vol. 2. 7-68.

Fitchett, Rowallan Hugh. 1996. Early Architecture at the Cape under the VOC (16521710): The Characteristics and Influence of the Proto-Cape Dutch Period. Unpublished $\mathrm{PhD}$. thesis at the University of Witswatersrand.

Flannery, Kent. 1983. Early Pig Domestication in the Fertile Crescent: A Retrospective Look. In The Hilly Flanks: Essays on the Prehistory of Southwestern Asia Presented to Robert J. Braidwood November 15, 1982, Studies in Ancient Oriental Civilization 36. Edited by P. Mortensen. Chicago: Oriental Institute, University of Chicago. 163-188.

Fock, J. 1966. Metrische Untersuchungen an Metapodien einiger europaeischer Rinderrassen. Unpublished dissertation, University of Munich. 
Fouche, Leo. 1914. The Diary of Adam Tas: With an Enquiry Into the Complaints of the Colonists Against the Governor Wilem Adriaan van der Stel. Translated by A. C. Paterson. London: Longmans, Green and Co.

Franklin, Daniel, Paul Higgins, Charles Oxnard, and Ian Dadour. 2008. Discriminant Function Sexing of the Mandible of Indigenous South Africans. Forensic Science International. Vol. 179. 84.e1-84.e5.

Fransen, Hans and Mary Alexander Cook. 1980. The Old Buildings of the Cape: A Survey and Description of Old Buildings in the Western Province Extending from Cape Town to Calvania in the North and to Graaff-Reinet, Colesburg and Uitenhage in the East; Covering Substantially the $18^{\text {th }}$ and $19^{\text {th }}$ Century Styles: Cape Dutch, Cape Regency, Georgian and Victorian. Cape Town: A A Balkema Press.

Fussell, G. E. and V. G. B. Atwater. 1933. Agriculture of Rural England in the Seventeenth Century. Economic Geography. Vol. 9. 379-394.

Gabaccia, Donna. 2005. Colonial Creoles: The Formation of Tastes in Early America. In Taste Culture Reader: Experiencing Food and Drink. Edited by Carolyn Korsmeyer. Oxford: Berg Publishers. 79-85.

Gerber, Hilda. 1959. Traditional Cookery of the Cape Malays: Food Customs and 200 Old Cape Recipes. Cape Town: A. A. Balkema.

Gifford, Diane. 1989. Taphonomy and Paleoecology: A Critical Review of Archaeology's Sister Disciplines. In Advances in Archaeological Method and Theory, Vol. 4. Edited by Michael Schiffer. New York: Academic Press. 365438.

Gifford-Gonzalez, Diane. 1991. Examining and Refining the Quadratic Crown Height Method of Age Estimation. In Human Predators and Prey Mortality. Edited by Mary Stiner. San Francisco: Westview Press. 41-77.

Giliomee, Hermann. 2003. The Afrikaners: Biography of a People. London: Hurst and Company.

Glucksmann, Alfred. 1978. Sex Determination and Sexual Dimorphism in Mammals. New York: Crane, Russak, and Company, Inc.

Grandal-D'Anglade, Aurora and Fernando Lopez-Gonzalez. 2005. Sexual Dimorphism and Ontogenetic Variation in the Skull of the Cave Bear (Ursus spelaeus Rosenmueller) of the European Upper Pleistocene. Geobios. Vol. 38. 325-337.

Grant, Anne. 1972. Memoirs of an American Lady. Freeport, NY: Books for Libraries Press. 
Grant, Annie. 1982. The Use of Tooth Wear as a Guide to the Age of Domestic Ungulates. In Ageing and Sexing Animal Bones from Archaeological Sites. Edited by Bob Wilson, Caroline Grigson, and Sebastian Payne. Oxford: BAR British Series 109. 91-108.

Grant, Annie. 2002. Food, Status, and Social Hierarchy. In Consuming Passions and Patterns of Consumption. Edited by PrestonMiracle and Nicky Milner. UK: Oxbow Books. 17-23.

Grayson, Donald. 1973. On the Methodology of Faunal Analysis. American Antiquity. Vol. 39. 432-438.

Grayson, Donald. 1978. Minimum Numbers and Sample Size in Vertebrate Faunal Analysis. American Antiquity. Vol. 43. 53-65.

Grayson, Donald. 1981. The Effects of Sample Size on Some Derived Measures in Vertebrate Faunal Analysis. Journal of Archaeological Science. Vol. 8. 77-88.

Grayson, Donald. 1984. Quantitative Zooarchaeology: Topics in the Analysis of Archaeological Fauna. New York: Academic Press.

Grayson, Donald. 1989. Sample Size and Relative Abundance in Archaeological Analysis: Illustration from Spiral Fractures and Seriation. In Quantifying Diversity in Archaeology. Edited by Robert D. Leonard and George T. Jones. Cambridge: Cambridge University Press. 79-84.

Green, Jeremy. 1977. The Loss of the Verenigde Oostindische Compagnie Jacht VERGULDE DRAECK, Western Australia 1656: An Historical background and Excavation Report with an Appendix on Similar Loss of the Fluit LAST DRAGER. BAR Supplementary Series 36.

Greenfield, Haskel. 1989. From Pork to Mutton: A Zooarchaeological Perspective on Colonial New Amsterdam and Early New York City. Northeast Historical Archaeology. Vol. 18. 85-110.

Greenfield, Haskel. 1999. The origins of Metallurgy: Distinguishing Stone from Metal Cut-marks on Bones from Archaeological Sites. Journal of Archaeological Science. Vol. 26. 797-808.

Greenfield, Haskel. 2002. Sexing Fragmentary Ungulate Acetabulae. Unpublished paper presented at International Congress of Archaeozoology, Durham, UK.

Greenfield, Haskel and Elizabeth Arnold. 2008. Absolute Age and Tooth Eruption and 
Wear Sequences in Sheep and Goat: Determining Age-at-Death in Zooarchaeology Using a Modern Control Sample. Journal of Archaeological Science. Vol. 35. 836-849.

Gribble, John. 1988. Unpublished field notes from the F2 Granary excavations. Archaeological Contracts Office, University of Cape Town.

Grider, Rufus A. 1888. Volume 8, Rufus A. Grider Collection. Albany: New York State Library.

Grigson, Caroline. 1982. Sex and Age Determination of Some Bones and Teeth of Domestic Cattle: A Review of the Literature. In Ageing and Sexing Animal Bones from Archaeological Sites. Edited by Bob Wilson, Caroline Grigson, and Sebastian Payne. Oxford: BAR British Series 109.

Gross, J. E., M. W. Demment, P. U. Alkon, and M. Kotzman. 2005. Feeding and Chewing Behaviours of Nubain Ibex: Compensation for Sex-Related Differences in Body Size. Functional Ecology. Vol. 9. 385-393.

Grove, Richard. 1997. Green Imperialism. Colonial Expansion, Tropical Island Edens and the Origin of Environmentalism, 1600-1860. Cambridge: Cambridge University Press.

Grzymala-Jordan, Elizabeth. 2005. "From Time Immemorial.” Washerwomen, Culture, and Community in Cape Town, South Africa. Ph.D. at Rutgers University.

Grzymala-Jordan, Elizabeth and Carmel Schrire. 2004. The Historical Archaeology of Cape Town's Washerwomen: Preliminary Findings. Quarterly Bulletin of the National Library of South Africa. Vol. 58. 47-58.

Guelke, Leonard. 1974. The Early European Settlement in South Africa. Ph.D. thesis at University of Toronto.

Guelke, Leonard. 1987. The Southwestern Cape Colony 1657-1750, Freehold Land Grants. Department of Geography Publication Series, Occasional Paper Number 5. University of Waterloo.

Guelke, Leonard. 1988. "Freehold Farmers and Frontier Settlers, 1657-1780." In The Shaping of South African Society, 1652-1840. Edited by R. Elphick and H. Giliomee. Middletown, Connecticut: Wesleyan University Press. 66-108.

Guelke, Leonard and Robert Shell. 1992. Landscape of Conquest: Frontier Water Alienation and Khoikhoi Strategies of Survival, 1652-1780. Journal of Southern African Studies. Vol. 18. 803-824.

Gumerman IV, George. 1997. Food and Complex Societies. Journal of Archaeological 
Method and Theory. Vol. 4. 105-139.

Habermehl, K. H. 1975. Die Altersbestimmung bei Haus- und Labortieren. Berlin: Auflage, Verlag Paul Parey.

Halkett, Dave. 1991. Report on Archaeological Excavations at the Castle 18-29 November 1991. Unpublished report for Gabriel Fagan Architects. Archaeology Contracts Office, University of Cape Town.

Hall, Jerome Lynn. 2002. Monti Cristi Shipwreck Project: The 2001 Excavation. http://ina.tamu.edu/monticristi.htm

Hall, Martin. n.d.a. Towards an Archaeology of Slavery in the Cape: The Castle- Cape Town. Unpublished manuscript. Historical Archaeology Research Group, University of Cape Town.

Hall, Martin. n.d.b. Establishing Sequences and Chronology. Unpublished report on the excavations for F1, F2, F3 and TB. Archaeological Contracts Office, University of Cape Town.

Hall, Martin. n.d.c. "Fish and Fisherman: Art, Text, and Archeology." Unpublished report. Historical Archaeology Research Group, Department of Archaeology, University of Cape Town.

Hall, Martin. 1989. The Castle Moat: A Report. Unpublished report. Archaeological Contracts Office, University of Cape Town.

Hall, Martin. 1992. Small Things and the Mobile, Conflictual Fusion of Power, Fear, and Desire. In The Art and Mystery of Historical Archaeology: Essays in Honor of James Deetz. Edited by Anne Yentsch and Mary Beaudry. London: CRC Press. 373-399.

Hall, Martin. 1993. The Archaeology of Colonial Settlement in Southern Africa. Annual Review of Anthropology. Vol. 22. 177-200.

Hall, Martin. 1999. Subaltern Voices? Finding the Spaces Between Things and Words. In Historical Archaeology: Back from the Edge. Edited by Pedro Paulo A, Funari, Martin Hall, and Sian Jones. New York: Routledge Press.

Hall, Martin. 2000. Archaeology and the Modern World. Colonial Transcripts in South Africa and the Chesapeake. London: Routledge Press.

Hall, Martin. 2008. Ambiguity and contradiction in the archaeology of slavery. Archaeological Dialogues. Vol. 15. 128-130.

Hall, Martin and Ann Markell. 1993. Introduction: Historical Archaeology in the 
Western Cape. South African Archaeological Bulletin; Goodwin Series 7. 3-7.

Hall, Martin, David Halkett, Pieta Huigen van Beek, and Jane Klose. 1990. 'A Stone Wall Out of the Earth that Thundering Cannon Cannot Destroy'? Bastion and Moat at the Castle, Cape Town. Social Dynamics. Vol. 16. 22-37.

Halstead, P., P. Collins, and V. Isaakidou. 2002. Sorting the Sheep from the Goats: Morphological Distinctions Between the Mandibles and Mandibular Teeth of Adult Ovis and Capra. Journal of Archaeological Science. Vol. 29. 545-553.

Hamerow, Helena. 2002. Early Medieval Settlements: The Archaeology of Rural Communities in Northwest Europe 400-900. UK: Oxford University Press.

Hanotte, Oliver, Daniel Bradley, Joel Ochieng, Yasmin Verjee, Emmeline Hill, and Edward Rege. 2002. African Pastoralism: Genetic Imprints of Origins and Migrations. Nature. Vol. 296. 336-339.

Harrison, Ramona, Howell Roberts, and W. Paul Adderley. 2008. Gasir in Eljafjordur: International Exchange and Local Economy in Medieval Iceland. Journal of the North Atlantic. Vol. 1. 99-119.

Hart, Timothy and Dave Halkett. 1993. An Archaeological Investigation of the Elsenburg Herehuis. Unpublished report prepared for the Department of Local Government, Housing and Works. Archaeology Contracts Office, University of Cape Town.

Haynes, Gary. 1983. Frequencies of Spiral and Green-Bone Fractures on Ungulate Limb Bones in Modern Surface Assemblages. American Antiquity. Vol. 48. 102-114.

Haynes, Gary. 1991. Mammoths, Mastodons, and Elephants: Biology, Behavior, and the Fossil Record. Cambridge: Cambridge University Press.

Heinrich, Dirk. 2002. A Comparison of Animal Bones from Two Wrecks of Ships $\left(17^{\text {th }}\right.$ and $18^{\text {th }}$ Century) Stranded on the North Sea Coast of Schleswig-Holstein. Bonner Zoologische Beitrage. Vol. 50. 259-267.

Helmer, Daniel. 1992. La Domestication des Animaux Par les Hommes Prehistoriques. Paris: Masson.

Henn, Brenna, Christopher Genoux, Alice Lin, Peter Oefner, Peidong Shen, Rosaria Scozzari, Fulvio Cruciani, Sarah Tishkoff, Joanna Mountain, and Peter Underhill. 2008. Y-chromosomal Evidence of a Pastoralist Migration Through Tanzania to Southern Africa. PNAS. Vol. 105. 10693-10698.

Henn, Roselle. 1985. Reconstructing the Urban Foodchain: Advances and Problems in 
Interpreting Faunal Remains Recovered from Household Deposits. American Archaeology. Vol. 5. 202-209.

Henshilwood, C. 1996. Arevised Chronology for Pastoralism in Southernmost Africa: New Evidence of Sheep at c. 2000 BP from Blombos Cave, South Africa. Antiquity. Vol. 70. 945-949.

Hiendleder, S., B. Kaupe, R. Wassmuth, and A. Janke. 2002. Molecular Analysis of Wild and Domestic Sheep Questions Current Nomenclature and Provides Evidence for Domestication from Two Different Subspecies. Proceedings. Biological Sciences, The Royal Society of London. Vol. 269. 893-904.

Highman, C. F. W. 1968. The Metrical Attributes of Two Samples of Modern Bovine Bones. Journal of Zoology. Vol. 157. 63-74.

Hillson, Simon. 1992. Mammal Bones and Teeth: An Introductory Guide to Methods of Identification. London: Institute of Archaeology, University College.

Hodder, Ian. 1986. Reading the Past. Cambridge: Cambridge University Press.

Holl, Augustin. 1998. The Dawn of African Pastoralisms: An Introductory Note. Journal of Anthropological Archaeology. Vol. 17. 81-96.

Horsburgh, Ann. Origin and Spread of Pastoralism in South Africa. Presentation to Rutgers University, New Brunswick, New Jersey, 24 November 2008.

Horwitz, Liora and Graham Avery. 1989. A Preliminary Report on the Bird Remains from the Castle (July, 1989). Unpublished report.

Houston, R. A. 1999. Colonial Enterprises and Wealth: The Economies of Europe and the Wider World in the Seventeenth Century. In Early Modern Europe. Edited by Evan Cameron. UK: Oxford University Press. 137-170.

Huelsbeck, David. 1987. Zooarchaeological Measures Revisited. Historical Archaeology. Vol. 23. 113-117.

Huelsbeck, David. 1991. Faunal Remains and Consumer Behavior: What Is Being Measured? Historical Archaeology. Vol. 25. 62-76.

Huey, Paul. 1991. The Dutch at Fort Orange. In Historical Archaeology in a Global Perspective. Edited by Lisa Falk. Washington: Smithsonian Institution Press. 21-68.

Humphrey, J. H. and D. L. Hutchinson. 2001. Macroscopic Characteristics of Hacking Trauma. Journal of Forensic Science. Vol. 46. 228-233. 
Huxley, F. R. S. 1864. Huxley and Hawkins' Atlas of Comparative Osteology. London: William and Nargate.

Idenburg, P. J. 1963. The Cape of Good Hope at the Turn of the Eighteenth Century. Netherlands: University of Leiden.

Ijzereef, Gerard. 1988. Animal Bones and Social Stratification. A Preliminary Analysis of the Faunal Remains from Cess-Pits in Amsterdam (1600-1850). Archaeozoologia. Vol. II/1,2. 283-292.

Irving, Washington. 1964. A History of New York. Edited by Edwin Bowden. New York: Twayne Publishers.

Israel, Jonathan. 1998. The Dutch Republic: Its Rise, Greatness and Fall, 1477-1806. Oxford: Claredon Press.

Janowitz, Meta. 1993. Indian Corn and Dutch Pots: Seventeenth-Century Foodways in New Amsterdam/New York. Historical Archaeology. Vol. 27. 6-24.

Jayasena, Ranjith. 2006. The Historical Archaeology of Katuwana, a Dutch East India Company Fort in Srilanka. Post-Medieval Archaeology. Vol. 40. 111-128.

Jeffreys, M. K. 1944. Kaapse Argiefstukke: Kaapse Plakkaatboek. Deel I (1652-1707). Cape Town: Cape Times.

Jerardino, Antonieta. 1999. A First Account of Fat-Tailed Sheep in the Rock Paintings of the Western Cape Coast. South African Archaeological Bulletin. Vol. 54. 6466.

Jewell, Peter. 1963. Cattle from British Archaeological Sites. In Man and Cattle. Edited by A. E. Mourant and F. E. Zeuner. Great Britain: Royal Anthropological Institute of Great Britain and Ireland. 80-101.

Lawrence, T. and V. R. Fowler. 2002. Growth in Farm Animals. New York: CABI Publishing.

Johnson, Eileen. 1985. Current Developments in Bone Technology. In Advances in Archaeological Method and Theory, Vol. 8. Edited by Michael Schiffer. New York: Academic Press. 157-235.

Johnson Barker, B. 2003. The Castle of Good Hope from 1666. Cape Town: Castle Military Museum.

Johnson, Matthew. 1999. Historical, Archaeology, Capitalism. In Historical Archaeologies of Capitalism. Edited by Mark Leone and Parker Potter. New York: Kluwer Academic Plenum Publishers. 219-232. 
Jolley, Robert. 1983. Historical Sites Zooarchaeology. Historical Archaeology. Vol. 17. 64-79.

Jones, J. R. 1967. Britain and Europe in the Seventeenth Century. New York: W. W. Norton and Company, Inc.

Jones, Martin. 2002. Eating for Calories or for Company? Concluding Remarks on Consuming Passions. In Consuming Passions and Patterns of Consumption. Edited by Preston Miracle and Nicky Milner. Cambridge: McDonald Institute for Archaeological Research. 131-136.

Jordan, Stacey. 2000a. The 'Utility' of Coarse Earthenware: Potters, Pottery Production and Identity at the Dutch Colonial Cape of Good Hope, South Africa (1652-1795). Unpublished Ph.D. thesis at Rutgers University.

Jordan, Stacey. 2000b. Coarse Earthenware at the Dutch Colonial Cape of Good Hope, South Africa: A History of Local Production and Typology of Products. International Journal of Historical Archaeology. Vol. 4. 113-143.

Jordon, Stacey. 2005. Castle Moat M90: Stoneware. Unpublished catalogue.

Jordan, Stacey. In press.

Jordan, Stacey, Carmel Schrire, and Duncan Miller. 1999. Petrography of Locally Produced Pottery from the Dutch Colonial Cape of Good Hope, South Africa. Journal of Archaeological Science. Vol. 26. 1327-1337.

Kalm, Peter. 1966. Travels in North America: The English Version of 1770. Edited by Adolph Benson. New York: Dover Press.

Kelso, William. 1997. Archaeology at Monticello. Virginia: Thomas Jefferson Memorial Foundation, Monticello Monograph Series.

Kintigh, Keith W. 1989. Sample Size, Significance, and Measures of Diversity. In Quantifying Diversity in Archaeology. Edited by Robert D. Leonard and George T. Jones. Cambridge: Cambridge University Press. 25-36.

Klein, Richard. 1982. Age (Mortality) Profiles as a Means of Distinguishing Hunted Species from Scavenged Ones in Stone Age Archaeological Sites. Paleobiology. Vol 8. 151-158.

Klein, Richard. 1986. The Prehistory of Stone Age Herders in the Cape Province of South Africa. South African Archaeological Society Goodwin Series 5. 5-12.

Klein, Richard and Kathryn Cruz-Uribe. 1983. The Computation of Ungulate Age (Mortality) Profiles from Dental Crown Heights. Paleobiology. Vol. 9. 70-78. 
Klein, Richard and Kathryn Cruz-Uribe. 1984. The Analysis of Animal Bones from Archaeological Sites. Chicago: The University of Chicago Press.

Klein, Richard and Kathryn Cruz-Uribe. 1989. Faunal Evidence for Prehistoric HerderForager Activities at Kasteelberg, Western Cape Province, South Africa. South African Archaeological Bulletin. Vol. 44. 82-97.

Klein, Richard, K. Allwarden, and C. Wolf. 1983. The Calculation and Interpretation of Ungulate Age Profiles from Dental Crown Heights. In Hunter-Gatherer Economy in Prehistory: A European Perspective. Edited by G. Bailey. Cambridge: University of Cambridge Press. 47-57.

Klippel, Walter E. 2001. Sugar Monoculture, Bovid Skeletal Part Frequencies, and Stable Carbon Isotopes: Interpreting Enslaved African Diet at Brimstone Hill, St. Kitts, West Indies. Journal of Archaeological Science. Vol. 28. 1191-1198.

Klose, Jane. 1997. Analysis of Ceramics Assemblages from Four Cape Historical Sites Dating from the Late Seventeenth Century to the Mid-Nineteenth Century. Unpublished MA thesis at the University of Cape Town.

Klose, Jane. 2005a. Castle Moat M90: Asian Wares. Unpublished catalogue.

Klose, Jane. 2005b. Castle Moat M90: Non-Asian Wares. Unpublished catalogue.

Klose, Jane and Carmel Schrire. 2005. Personal communication concerning DKG ceramic dating.

Kolben, Peter. 1731a. The Present State of the Cape of Good Hope: Volume I, Containing the Natural History of the Cape. Translated by Mr. Medley. Reprinted by Johnson Reprint Corporation, New York.

Kolben, Peter. 1731b. The Present State of the Cape of Good Hope: Volume II, Containing the Natural History of the Cape. Translated by Mr. Medley. Reprinted by Johnson Reprint Corporation, New York.

Landon, David. 1993. Testing a Seasonal Slaughter Model for Colonial New England Using Tooth Cementum Increment Analysis. Journal of Archaeological Science. Vol. 20. 439-455.

Landon, David. 1996. Feeding Colonial Boston: A Zooarchaeological Study. Historical Archaeology. Vol. 30. 1-153.

Landon, David. 1997. Interpreting Urban Food Supply and Distribution Systems from the Faunal Assemblages: An Example from Colonial Massachusetts. International Journal of Osteoarchaeology. Vol. 7. 51-64. 
Landon, David. 2005. Zooarchaeology and Historical Archaeology: Progress and Prospects. Journal of Archaeological Method and Theory. Vol. 12. 1-36.

Landon, David. 2008. Seasonal Slaughter Cycles and Urban Food Supply in the Colonial Chesapeake. In Case Studies in Environmental Archaeology, Second Edition. Edited by Elizabeth Reitz, Margaret Scarry, and Sylvia Scudder. New York: Springer Science. 375-390.

Legassick, Martin. 1988. The Northern Frontier to c.1840: The Rise and Decline of the Griqua People. In The Shaping of South African Society, 1652-1840. Edited by Richard Elphick and Hermann Giliomee. Middletown, Connecticut: Wesleyan University Press. 358-420.

Leibbrandt, H. C. V. 1896. Precis of the Archives of the Cape of Good Hope. Letter Received, 1695-1708. Cape Town: W. A. Richards and Sons.

Leibbrandt, H. C. V. 1905. Precis of the Archives of the Cape of Good Hope. Letter Requestum (Memorials); 1715-1806. Cape Town: Cape Time Limited, Government Printers.

Leonard, Tony John Lawrence and V. R. Fowler. 2002. Growth in Farm Animals. Oxford: CABI Publishing.

Leone, Mark editor. 1972. Contemporary Archaeology: A Guide to Theory and Contributions. Illinois: Southern Illinois University Press.

Lev-Tov, Justin S. E. 1998. Zooarchaeology and Social Relations in Annapolis, Maryland. In Annapolis Pasts: Historical Archaeology in Annapolis, Maryland. Edited by Paul Schackel, Paul Mullins, and Mark Warner. Knoxville: University of Tennessee Press. 119-146.

Lewis, Jason. 2008. Identifying Sword Marks on Bone: Criteria for Distinguishing Between Cut Marks Made by Different Classes of Bladed Weapons. Journal of Archaeological Science. Vol. 35. 2001-2008.

Lodewijcksz, W. 1597. 't Eerste boek. Historie van Indien waer inne verhealt is de avonturen die de Hollantse schepen bejegent zijn... Amsterdamn: Michiel Colijn.

Loison, Anne, Jean-Michael Gaillard, Cristophe Pelabon, and Nigel Gilles Yoccoz. 1999. What factors Shape Sexual Size Dimorphism in Ungulates? Evolutionary Ecology Research. Vol. 1. 611-633.

Lydekker, R. 1912. The Sheep and Its Cousins. London: George Allen and Co., Ltd.

Lyman, R. Lee. 1977. Analysis of Historic Faunal Remains. Historical Archaeology. 
Vol. 11. 67-73.

Lyman, R. Lee. 1979. Available Meat from Faunal Remains: A Consideration of Techniques. American Antiquity. Vol. 44. 536-545.

Lyman, R. Lee. 1987a. On Zooarchaeological Measures of Socioeconomic Position and Cost-Efficient Meat Purchases. Historical Archaeology. Vol. 21. 58-66.

Lyman, R. Lee. 1987b. On the Analysis of Vertebrate Mortality Profiles: Sample Size, Mortality Type, and Hunting Pressure. American Antiquity. Vol. 52. 125-142.

Lyman, R. Lee. 1994. Vertebrate Taphonomy. United Kingdom: Cambridge University Press.

Lyman, R. Lee and Kenneth Ames. 2004. Sampling to Redundancy in Zooarchaeology: Lessons from the Portland Basin, Northwestern Oregon and Southwestern Washington. Journal of Ethnobiology. Vol. 24. 329-346.

Lyman, R. Lee and Kenneth Ames. 2007. On the Use of Species-Area Curves to Detect the Effects of Sample Size. Journal of Archaeological Science. Vol. 34. 19851990.

Lyman, R. Lee and Gregory Fox. 1989. A Critical Evaluation of Bone Weathering as an Indication of Bone Assemblage Formation. Journal of Archaeological Science. Vol. 16. 293-317.

Malan, Antonia. 1993. Households of the Cape 1750-1850: Inventories and the Archaeological Record. Unpublished Ph. D. thesis, Department of Archaeology, University of Cape Town.

Malan, Antonia. 2008. Unearthing Slavery: The Complex Role of Archaeology. Iziko Museums Freedom Day Lecture Series.

Malan, Antonia and Carmel Schrire. 2000. 'Milking the system: the identification of the 'Painted Slave Lady' at the Slave Lodge, Cape Town'. Quarterly Bulletin of the National Library of South Africa. Vol. 55:1. 16-19.

Mallios, Seth. 2005. Back to the Bowl: Using English Tobacco Pipebowls to Calculate Mean Site-Occupation Dates. Historical Archaeology. Vol. 39. 89-104.

Manhire, A. H., John Parkington, A. D. Mazel, and T. M. O’C. Maggs. 1986. Cattle, Sheep, and Horses: A Review of Domestic Animals in the Rock Art of Southern Africa. South African Archaeological Society Goodwin Series 5. 22-30.

Marean, Curtis and Lillian Spencer. 1991. Impact of Carnivore Ravaging on 
Zooarchaeological Measures of Element Abundance. American Antiquity. Vol. 56. 645-658.

Marean, Curtis, Lilian Spencer, Robert Blumenschine, and Salvatore Capaldo. 1992. Captive Hyaena Bone Choice and Destruction, the Schlepp Effect and Olduvai Archaeofaunas. Journal of Archaeological Science. Vol. 19. 101-121.

Markell, Ann, Martin Hall, and Carmel Schrire. 1995. The Historical Archaeology of Vergelegen, an Early Farmstead at the Cape of Good Hope. Historical Archaeology. Vol. 29. 10-34.

Marshall, Larry. 1989. Bone Modification and "The Law of Burial." In Bone Modification. Edited by Robson Bonnichsen and Marcella Sorg. Orono, Maine: Center for the Study of the First Americans, Institute of Quaternary Studies, University of Maine. 7-24.

Martin, R. D., L. A. Willner, and A. Dettling. 1994. The Evolution of Sexual Size Dimorphism in Primates. In The Differences Between the Sexes. Edited by R. V. Short and E. Balaban. Cambridge: Cambridge University Press. 159-200.

Martin, Terrance. 1991. An Archaeological Perspective on Animal Exploitation Patterns at French Colonial Sites in the Illinois Country. In French Colonial Archaeology: The Illinois Country and the Western Great Lakes. Edited by John Walthall. Chicago: University of Illinois Press. 189-200.

McKee, Larry. 1987. Delineating Ethnicity from the Garbage of Early Virginians: Faunal Remains from Kingsmill Plantation Slave Quarter. American Archaeology. Vol. 6. 31-39.

McKee, Larry. 1988. Plantation Food Supply in Nineteenth-Century Tidewater Virginia. Ph. D. thesis submitted to The College of William and Mary.

McKee, Larry. 1999. Food Supply and Plantation Social Order: An Archaeological Perspective. In "I, Too, Am America," Archaeological Studies of AfricanAmerican Life. Edited by Theresa Singleton. Charlottesville: University Press of Virginia. 218-232.

Meadow, Richard. 1978. Effects of Context on the Interpretation of Faunal Remains: A Case Study. In Approaches to Faunal Analysis in the Middle East. Edited by Richard Meadow and Melinda Zeder. Massachusetts: Peabody Museum of Archaeology and Ethnology. 15-22.

Meadow, R. 1989. Osteological Evidence for the Process of Animal Domestication. In The Walking Larder: Patterns of Domestication, Pastoralism, and Predation. Edited by T. H. Clutton-Brock. London: Unwin Hyman. 80-90. 
Mennell, Stephen. 1985. All Manners of Food: Eating and Taste in England and France from the Middle Ages to the Present. England: Basil Blackwell.

Mentzel, Otto. F. 1921. A Geographical and Topographical Description of the Cape of Good Hope, Part One. Translated by H. J. Mandelbrote. Cape Town: Van Riebeeck Society.

Mentzel, Otto. F. 1925. A Geographical and Topographical Description of the Cape of Good Hope, Part Two. Translated by H. J. Mandelbrote. Cape Town: Van Riebeeck Society.

Mentzel, Otto. F. 1944. A Geographical and Topographical Description of the Cape of Good Hope, Part Three. Translated by G. V. Marias, J. Hoge, and H. J. Mandelbrote. Cape Town: Van Riebeeck Society.

Meskell, Lynn. 2002. The Intersections of Identity and Politics in Archaeology. Annual Review of Anthropology. Vol. 31. 279-301.

Micozzi, Marc. 1991. Postmortem Change in Human and Animal Remains: A Systematic Approach. Illinois: Charles C. Thomas, Pub.

Miller, Henry. 1979. Pettus and Utopia: A Comparison of the Faunal Remains from Two Late Seventeenth-Century Virginia Households. The Conference on Historic Sites Archaeology Papers 1978. Vol. 13. 158-175.

Monk, Gregory. 1981. Seasonality Studies. In Advances in Archaeological Method and Theory, Vol. 4. Edited by Michael Schiffer. New York: Academic Press. 177240.

Moodie, Donald editor. 1838. The Record; or, a Series of Official Papers Relative to the Condition and Treatment of the Native Tribes of South Africa: Part 1 1649-1720. Cape Town: A. S. Robertson.

Moodie, T. Dunbar. 1975. The Rise of Afrikanerdom: Power, Apartheid, and the Afrikaner Civil Religion. Berkeley: University of California Press.

Morlan, Richard. 1984. Towards the Definition of Criteria for the Recognition of Artificial Bone Alterations. Quaternary Research. Vol. 22. 160-171.

Munson, Patrick. 2000. Age-correlated Differential Destruction of Bones and its Effect on Archaeological Mortality Profiles of Domestic Sheep and Goats. Journal of Archaeological Science. Vol. 27. 391-407.

Munson, Patrick and Rexford Garniewicz. 2003. Age-mediated Survivorship of Ungulate Mandibles and Teeth in Canid-ravaged Faunal Assemblages. Journal of Archaeological Science. Vol. 30. 405-416. 
Museum Boymans-van Beuningen Rotterdam. 1991. Pre-industriele Gebruiksvoowerpen (Pre-industrial Utensils): 1150-1800. Rotterdam: Museum Boymans-van Beuningen Rotterdam, Department of Applied Arts and Design.

Myers, Thomas, Michael Voorhies, and R. George Corner. 1980. Spiral Fractures and Bone Pseudotools at Paleontological Sites. American Antiquity. Vol. 45. 483490.

Newton-King, Susan. 1999. Masters and Servants on the Cape Eastern Frontier: 17601803. Cambridge: Cambridge University Press.

Nicholson, Rebecca. 1992. Bone Survival: The Effects of Sedimentary Abrasion and Trampling on Fresh and Cooked Bone. International Journal of Osteoarchaeology. Vol. 2. 79-90.

Nicholson, Rebecca. 1993. A Morphological Investigation of Burnt Animal Bone and an Evaluation of its Utility in Archaeology. Journal of Archaeological Science. Vol. 20. 411-428.

Noel-Hume, Ivor. 1969. A Guide to Artifacts of Colonial America. Philadelphia: University of Pennsylvania Press.

Norman, Barbara. 1972. Tales of the Table: A History of Western Cuisine. New Jersey: Prentice Hall, Inc.

Nyerges, Eva Agnes. 2002. Ethnic Traditions in Meat Consumption and Herding at a $16^{\text {th }}$ Century Cumanian Settlement in the Great Hungarian Plain. In. Behaviour behind Bones: The Zooarchaeology of Ritual, Religion, Status, and Identity. Edited by Sharyn Jones O'Day, Wim van Neer, and Anton Ervynck. London: Oxbow Books. 262-270.

O'Brien, Michael, R. Lee Lyman, and Michael Schiffer. 2007. Archaeology as a Process: Processualism and Its Progeny. Salt Lake City: The University of Utah Press.

O’Connor, Terry. 2000. The Archaeology of Animal Bones. Texas: Texas A\&M University Press.

Orser, Charles E. 2005. Network Theory and the Archaeology of Modern History. In Global Archaeological Theory: Contextual Voices and Contemporary Thoughts. Edted by Pedro Paulo Funari, Andres Zarankin, and Emily Stovel. New York: Kluwer Academic Plenum Publishers. 77-96.

Otto, John Solomon. 1977. Artifacts and Status Differences - A Comparison of 
Ceramics from Planter, Overseer, and Slave Sites on an Antebellum Plantation. In Research Strategies in Historical Archaeology. Edited by Stanley South. New York: Academic Press. 91-118.

Otto, John Solomon. 1984. Cannon's Point Plantation, 1794-1860; Living Conditions and Status Patterns in the Old South. New York: Academic Press.

Outhwaite, R. B. 1986. Progress and Backwardness in English Agriculture, 1500-1650. The Economic History Review. Vol. 39. 1-18.

Paine, Thomas. 1995. Common Sense. New York: Barnes and Noble Books.

Parkington, John. 1984. Soqua and Bushmen: Hunters and Robbers. In Past and Present in Hunter-Gatherer Studies. Edited by Carmel Schrire. New York: Academic Press. 151-174.

Payne, Sebastian. 1973. Kill-off Patterns in Sheep and Goats: The Mandibles from Asvan Kale. Anatolian Studies. Vol. 23. 281-303.

Payne, Sebastian. 1985. Morphological Distinctions Between the Mandibular Teeth of Young Sheep, Ovis, and Goats, Capra. Journal of Archaeological Science. Vol. 12. 139-147.

Pearson, A. M. and T. R. Dutson. 1991. Growth Regulation in Farm Animals. New York: Elsevier Science Publication Company.

Pendery, Steven R. 1984. The Archaeology of Urban Foodways in Portsmouth, New Hampshire. In Foodways in the Northeast; The Dublin Seminar for New England Folklife: Annual Proceedings June 25 Through 27, 1982. Edited by Peter Benes. Boston: Boston University Press. 9-27.

Penn, Nigel G. 1986. Pastoralists and Pastoralism in the Northern Cape Frontier Zone During the Eighteenth Century. South African Archaeological Society Goodwin Series 5. 62-68.

Penn, Nigel G. 2005. The Forgotten Frontier: Colonist and Khoisan on the Cape's Northern Frontier in the $18^{\text {th }}$ Century. Athens: Ohio University Press.

Pennington, D. H. 1989. Europe in the Seventeenth Century. New York: Longman.

Perez-Barberia, F. Javier and Iain Gordon. 1998. The Influence of Sexual Dimorphism in Body Size and Mouth Morphology on Diet Selection and Sexual Segregation in Cervids. Acta Veterinaria Hungarica. Vol. 46. 357-367.

Perez-Barberia, F. Javier and Iain Gordon. 1999. Body Size Dimorphism and Sexual 
Segregation in Polgynous Ungulates: An Experimental Test with Soay Sheep. Oecologia. Vol. 120. 258-267.

Perez-Barberia, F. Javier and Iain Gordon. 2000. Differences in Body Mass and Oral Morphology Between the Sexes in the Artiodactyla: Evolutionary Relationships with Sexual Segregation. Evolutionary Ecology Research. 667-684.

Perez-Barberia, F. Javier, Iain Gordon, and M. Pagel. 2002. The Origins of Sexual Dimorphism in Body Size in Ungulates. Evolution. Vol. 56. 1276-1285.

Peters, Joris, Daniel Helmer, Angela von den Driesch, and Maria Sana Sagui. 1999. Early Animal Husbandry in the Northern Levant. Paleorient. Vol. 25. 27-47.

Picardie, Hymen W. J. 1968. Gentleman's Walk: The Romantic Story of Cape Town's Oldest Streets, Lanes, and Squares. Cape Town: C. Struik Ltd.

Pigiere, Fabienne, Ides Boone, Mircea Udrescu, Wim van Neer, and Sofie Vanpoucke. 2002. Status as Reflected in Food Refuse of Late Medieval Noble and Urban Households at Narmur, Belgium. In Behaviour Behind Bones: The Zooarchaeology of Ritual, Religion, Status, and Identity. Edited by Sharyn Jones O’Day, Wim van Neer, and Anton Ervynck. London: Oxbow Books. 233-243.

Pike-Tay, Anne, C. Andrew Morcomb, and Magen O'Farrell. 2000. Reconsidering the Quadratic Crown Height Method of Age Estimation for Rangifer from Archaeological Sites. Archaeozoologia. Vol. XI. 145-174.

Piper, Andrew. 1989. Can Taphonomy Aid in the Analysis of Faunal Material from Historical Archaeological Sites? In Problem Solving in Taphonomy: Archaeological and Paleontological Studies from Europe, Africa, and Oceania. Edited by Su Solomon, Iain Davidson, and Di Watson. Queensland: The University of Queensland. 149-157.

Plumb, J. H. 1952. Sir Robert Walpole and Norfolk Husbandry. Economic History Review. Vol. 5. 86-89.

Poggenpoel, Cedric Alan. 1996. The Exploitation of Fish During the Holocene in the South-Western Cape, South Africa. Unpublished MA thesis at the University of Cape Town.

Potts, Richard and Pat Shipman. 1981. Cutmarks Made by Stone Tools on Bones from Olduvai Gorge, Tanzania. Nature. Vol. 291. 577-580.

Prummel, Wietske. and Hans-Jorg Frisch. 1986. A Guide for the Distinction of Species, Sex, and Body Side in Bones of Sheep and Goats. Journal of Archaeological Science. Vol. 13. 567-577. 
Purchas, R. W. 1991. Effect of Sex and Castration on Growth and Composition. Growth Regulation in Farm Animals: Advances in Meat Research, Vol 7. Edited by A. M. Pearson and T. R. Dutson. London: Elsevier. 203-254.

Pyddoke, Edward. 1961. Stratification for the Archaeologist. London: Phoenix House.

Raven-Hart, Rowland. 1967. Before van Riebeeck: Callers at South Africa from 1488 to 1652. Cape Town: C. Struik.

Raven-Hart, Rowland. 1970a. Cape Good Hope 1652-1702: The First Fifty Years of Dutch Colonization as Seen by Callers, Volume I. Cape Town: Balkema.

Raven-Hart, Rowland. 1970b. Cape Good Hope 1652-1702: The First Fifty Years of Dutch Colonization as Seen by Callers, Volume II. Cape Town: Balkema.

Raven-Hart, Rowland. 1976. Nicolas Louis de la Caille: Travels at the Cape 1751-53. Cape Town: A. A. Balkema.

Reiland, S. 1978. Growth and Skeletal Development of the Pig. Acta Radiologica, Supplement. Vol. 358. 15-22.

Reitz, Elizabeth. 1986a. Vertebrate Fauna from Locus 39, Puerto Real, Haiti. Journal of Field Archaeology. Vol. 13. 317-328.

Reitz, Elizabeth. 1986b. Urban/Rural Contrasts in Vertebrate Fauna from the Southern Atlantic Coastal Plain. Historical Archaeology. Vol. 20. 47-58.

Reitz, Elizabeth. 1987. Vertebrate Fauna and Socioeconomic Status. In Consumer Choice in Historical Archaeology. Edited by Suzanne Spencer-Wood. New York: Plenum Press. 101-119.

Reitz, Elizabeth. 1991a. Animal Use and Culture Change in Spanish Florida. In MASCA Research Papers in Science and Archaeology; Supplement to Volume 8, 1991: Animal Use and Culture Change. Edited by Pam Crabtree and Kathleen Ryan. Philadelphia: University of Pennsylvania. 63-77.

Reitz, Elizabeth. 1991b. Evidence for Animal Use at the Missions of Spanish Florida. The Florida Anthropologist; Special Issue: The Missions of Spanish Florida. Vol. 44. 295-306.

Reitz, Elizabeth. 1992a. The Spanish Colonial Experience and Domestic Animals. Historical Archaeology. Vol. 26. 84-91.

Reitz, Elizabeth. 1992b. Vertebrate Fauna from Seventeenth-Century St. Augustine. Southeastern Archaeology. Vol. 11. 79-94. 
Reitz, Elizabeth. 1994. Zooarchaeological Analysis of a Free African Community: Gracia Real de Santa Teresa de Mose. Historical Archaeology. Vol. 28. 23-40.

Reitz, Elizabeth. 2007. Animal Remains from the Eighteenth-Century Charleston Beef Market. South Carolina Antiquities. Vol. 39. 87-103.

Reitz, Elizabeth and Nicholas Honerkamp. 1983. British Colonial Subsistence Strategy on the Southeastern Coastal Plain. Historical Archaeology. Vol. 17. 4-26.

Reitz, Elizabeth and Barbara Ruff. 1994. Morphometric Data for Cattle from North America and the Caribbean Prior to the 1850s. Journal of Archaeological Science. Vol. 21. 699-713.

Reitz, Elizabeth and Margaret Scarry. 1985. Reconstructing Historic Subsistence with an Example from Sixteenth-Century Spanish Florida, Special Publication Series, Number 3. The Society for Historical Archaeology.

Reitz, Elizabeth and Elizabeth Wing. 1999. Zooarchaeology. United Kingdom: Cambridge University Press.

Reitz, Elizabeth, Tyson Gibbs, and Ted Rathbun. 1985. Archaeological Evidence for Subsistence on Coastal Plantations. In The Archaeology of Slavery and Plantation Life. Edited by Theresa Singleton. New York: Academic Press. 163191.

Reitz, Elizabeth, Lee Newsom, and Sylvia Scudder, editors. 1996. Case Studies in Environmental Archaeology. New York: Plenum Press.

Reitz, Elizabeth, Barbara Ruff, and Martha Zierden. 2006. Pigs in Charleston, South Carolina: Using Specimen Counts to Consider Status. Historical Archaeology. Vol. 40. 104-124.

Robertshaw, P. T. 1979. Coastal Settlement, Freshwater Fishing and Pastoralism in the Later Prehistory of the Western Cape, South Africa. Doctoral Dissertation, University of Cambridge.

Robertson, H. M. 1945a. The Economic Development of the Cape under Van Riebeek. The South African Journal of Economics. Vol. 13. 1-17.

Robertson, H. M. 1945b. The Economic Development of the Cape under Van Riebeek. The South African Journal of Economics. Vol. 13. 75-90.

Robertson, H. M. 1945c. The Economic Development of the Cape under Van Riebeek. The South African Journal of Economics. Vol. 13. 170-184.

Robertson, H. M. 1945d. The Economic Development of the Cape under Van Riebeek. 
The South African Journal of Economics. Vol. 13. 245-262.

Robinson, A. M. Lewin editor. 1973. The Letters of Lady Anne Barnard to Henry

Dundas from the Cape and Elsewhere, 1793-1803, Together with Her Journal of a Tour Into the Interior and Certain Other Letters. Cape Town: A. A. Balkema.

Robinson, A. M. Lewin editor. 1994. The Cape journals of Lady Anne Barnard, 17971798. Cape Town: Van Riebeeck Society.

Rose, Peter G. editor. 1989. The Sensible Cook: Dutch Foodways in the Old and New Worlds. Syracuse: Syracuse University Press.

Ross, Robert. 1988. The Cape of Good Hope and the World Economy, 1652-1835. In The Shaping of South African Society, 1652-1840. Edited by Richard Elphick and Hermann Giliomee. Middletown, Connecticut: Wesleyan University Press. 243280.

Ross, Robert. 1998. The First Two Centuries of Colonial Agriculture in the Cape Colony: A HIstoriographical Review. In Settlement Patterns in Early Modern Colonization, $16^{\text {th }}-18^{\text {th }}$ Centuries. Edited by Joyce Lorimer. Brookfield: Ashgate. 301-316.

Ross, Robert. 1999. Status and Respectability in the Cape Colony, 1750-1870. Cambridge: Cambridge University Press.

Ross, Robert. 2005. Email correspondence with Carmel Schrire.

Roux, A. P. 1975. Die Geskiedenis van Saldanhabaai, St. Helenabaai en Dasseneiland 1652-1806. Unpublished MA Dissertation. Department of History, University of Stellenbosch.

Sadr, Karim. 1998. The First Herders at the Cape of Good Hope. African Archaeological Review. Vol. 15. 101-132.

Schaeffer, Richard. 1994. A Typology of Seventeenth-Century Dutch Ceramics and Its Implications for American Historical Archaeology. Ph. D. dissertation, University of Pennsylvania. Michigan: U. M. I Dissertation Services.

Schama, Simon. 1987. The Embarassment of Riches: An Interpretation of Dutch Culture in the Golden Age. New York: Vintage Books.

Schiffer, Michael. 1987. Formation Processes of the Archaeological Record. Salt Lake City: University of Utah Press.

Schmid, Elizabeth. 1972. An Atlas of Animal Bones. Amsterdam: Elsevier.

Schmitt, Dave and Charles Zeier. 1993. Not by Bones Alone: Exploring Household 
Composition and Socio-Economic Status in an Isolated Historic Mining Community. Historical Archaeology. Vol. 27. 20-38.

Schrire, Carmel. 1984. Wild Surmises on Savage Thought. In Past and Present in Hunter Gatherer Studies. Edited by Carmel Schrire. New York: Academic Press. $1-25$.

Schrire, Carmel. 1988. The Historical Archaeology of the Impact of Colonialism in $17^{\text {th }}$ century South Africa. Antiquity. Vol. 62. 214-225.

Schrire, Carmel. 1990. Excavating Archives at Oudepost I, Cape. Social Dynamics. Vol. 16. 11-21.

Schrire, Carmel. 1992. Digging Archives at Oudepost I, Cape, South Africa. In The Art and Mystery of Historical Archaeology. Edited by Anne Yentsch and Mary Beaudry. Ann Arbor: CRC Press. 361-372.

Schrire, Carmel. 1995. Digging through Darkness: Chronicles of an Archaeologist. Charlottesville, Virginia: University of Virginia Press.

Schrire, Carmel, Kathryn Cruz-Uribe, and Jane Klose. 1993. The Site History of the Historical Site at Oudepost I, Cape. South African Archaeological Society Goodwin Series 7. 21-32.

Schrire, Carmel and P. Jeppson. 1987. Report on Test Excavations at the Castle of Good Hope, Cape Town. Unpublished report to the National Monuments Council.

Schrire, Carmel, James Fanto Deetz, David Lubinsky, and Cedric Poggenpoel. 1990. The Chronology of Oudepost I, Cape, as Inferred from an Analysis of Clay Pipes. Journal of Archaeological Science. Vol. 17. 269-300.

Schulz, Kathy. 2005. Personal communication of her research for the Archaeology Contracts Office of the University of Cape Town.

Schulz, Peter and Sherri Gust. 1983. Faunal Remains and Social Status in $19^{\text {th }}$ Century Sacramento. Historical Archaeology. Vol. 17. 44-53.

Schutte, Gerrit. 1989. Company and Colonists at the Cape, 1652-1795. In The Shaping of South African Society. Edited by Richard Elphick and Hermann Giliomee. Middletown, CT: Wesleyan University Press.

Schweitzer, Franz. 1979. Excavations at Die Kelders, Cape Province, South Africa: The Holocene Deposits. Annals of the South African Museum. Vol. 78. 101-223.

Schweitzer, Franz and Katharine Scott. 1973. Early Occurrence of Domestic Sheep in Sub-Saharan Africa. Nature. Vol. 241. 547. 
Scott, Elizabeth. 1996. Who Ate What? Archaeological Food Remains and Cultural Diversity. In Case Studies in Environmental Archaeology. Edited by Elizabeth Reitz, Lee Newsom, and Sylvia Scudder. New York: Plenum Press. 339-356.

Scott, Elizabeth. 2001. Food and Social Relations at Nina Plantation. American Anthropologist. Vol. 103. 671-691.

Sealy, Judith and Royden Yates. 1994. The Chronology of the Introduction of Pastoralism to the Cape, South Africa. Antiquity. Vol. 68. 58-67.

Sealy, Judith and Royden Yates. 1996. Direct Radiocarbon Dating of Early Sheep Bones: Two Further Results. South African Archaeological Bulletin. Vol. 51. 109-110.

Sealy, Judith, A. Morris, Richard Armstrong, Ann Markell, and Carmel Schrire. 1993. Archaeological, Biological, and Isotopic Observations on a Historic Skeleton from the Slave Lodge at Vergelegen. South African Archaeological Society, Goodwin Series 7. 84-91.

Selveggio, Marie and Joseph Wilder. 2001. Identifying the Involvement of Multiple Carnivore Taxa with Archaeological Bone Assemblages. Journal of Archaeological Science. Vol. 28. 465-470.

Shaw, Michael. 1997. The Excavation of a Late $15^{\text {th }}$ to $17^{\text {th }}$ Century Tanning Complex at the Green, Northhampton. Post-Medieval Archaeology. Vol. 30. 63-127.

Shepherd, Nick. 2002. The Politics of Archaeology in Africa. Annual Review of Anthropology. Vol. 31. 189-209.

Shipman, Pat. 1981. Applications of Scanning Electron Microscopy to Taphonomic Problems. In The Research Potential of Anthropological Museum Collections. Edited by A. Cantwell, J. Griffen, and N. Rothschild. New York: New York Academy of Science. 357-385.

Silver, I. A. 1969. The Ageing of Domestic Animals. Science in Archaeology: A Survey in Archaeology. Edited by Don Brothwell and Eric Higgs. Great Britain: Thames and Hudson. 283-302.

Singer, David. 1985. The Use of Fish Remains as a Socio-Economic Measure: An Example from $19^{\text {th }}$ Century New England. Historical Archaeology. Vol. 19. 110113.

Skead, C. J. 1980. Historical Mammal Incidence in the Cape Province Volume 1. Cape Town: The Department of Nature and Environmental Conservation of the Provincial Administration of the Cape of Good Hope. 
Skead, C. J. 1987. Historical Mammal Incidences in the Cape Province Volume 2; The Eastern Half of the Cape Province, Including the Ciskei, Traskei, and East Griqualand. Cape Town: The Chief Directorate Nature and Environmental Conservation of the Provincial Administration of the Cape of Good Hope.

Sleigh, Dan. 1980. Jan Compagnie: The World of the Dutch East India Company. Cape Town: Tafelberg Press.

Sleigh, Dan. 1987. Die Buiteposte in die Ekonomie van die Kaapse Ververingstasie 1652-1795. Unpublished Ph. D. thesis, University of Stellenbosch.

Smith, Andrew. 1983. Prehistoric Pastoralism in the Southwestern Cape, South Africa. World Archaeology. Vol. 15. 79-89.

Smith, Andrew. 1992. Pastoralism in Africa: Origins and Development Ecology. London: Hurst Press.

Smith, Andrew. 1997. Southern African Pastoralists. In Encyclopedia of Precolonial Africa. Edited by J. O. Vogel. Walnut Creek, CA: Altamira Press. 210-213.

Smith, Andrew. 1998. Early Domestic Stock in Southern Africa: A Commentary. African Archaeological Review. Vol. 15. 151-156.

Smith, Andrew. 2000. The Origin of Domestic Animals of Southern Africa. In The Origins and Development of African Livestock: Archaeology, Genetics, Linguistics, and Ethnography. Edited by Roger Blench and Kevin MacDonald. London: UCL Press. 222-238.

Smith, Andrew. 2006. Excavations at Kasteelberg and the Origins of the Khoekhoen in the Western Cape, South Africa. Cambridge Monographs in African Archaeology 66. BAR International Series 1537.

Smith, Andrew and Roy Pheiffer. 1993. The Khoikhoi at the Cape of Good Hope: Seventeenth-century drawings in the South African Library. Cape Town: South African Library.

South, Stanley. 1977. Method and Theory in Historical Archaeology. New York: Percheron Press.

Spilhaus, M. Whiting. 1966. South Africa in the Making, 1652-1806. Cape Town: Juta and Company, Limited.

Stein, Julie. 1987. Deposits for Archaeologists. In Advances in Archaeological Method and Theory, Volume 11. Edited by Michael Schiffer. New York: Academic Press. 337-395. 
Stone, David. 2005. Decision making in Medieval Agriculture. UK: Oxford University Press.

Stow, G. W. 1905. The Native races of South Africa: A History of the Intrusion of the Hottentots and Vantu into the Hunting Grounds of the Bushmen, the Aborigines of the Country. London: Swan Sonnenschein.

Strangman, Edward. 1936. Early French Callers at the Cape. Cape Town: Juta and Co. Ltd.

Stynder, Deano. 2009. Craniometric Evidence for South African Later Stone Age Herders and Hunter-Gatherers Being a Single Biological Population. Journal of Archaeological Science. Vol. 36. 798-806.

Sunseri, Jun Ueno and Diane Gifford-Gonzalez. 2002. The Paa-ko Archaeofauna: Evidence for Creolization in Animal Use. Poster presented at Society for American Archaeology, Denver, Colorado.

Svensson, Emma, Anders Gotherstrom, and Maria Vretemark. 2008. A DNA Test for Sex Identification in Cattle Confirms Osteometric Results. Journal of Archaeological Science. Vol. 35. 942-946.

Sykes, N. J. 2006a. From $\mathrm{Cu}$ and Sceap to Beffe and Motton: The management, Distribution, and Consumption of Cattle and Sheep in Medieval England. In Food in Medieval England. Edited by C. M Woolgar, D Sarjeantson, and T. Waldron. Oxford: Oxford University Press. 56-71.

Sykes, N. J. 2006b. The Impact of the Normans on Hunting Practices in England. In Food in Medieval England. Edited by C. M Woolgar, D Sarjeantson, and T. Waldron. Oxford: Oxford University Press. 162-175.

Symmons, Robert. 2005. New Density Data for Unfused and Fused Sheep Bones, and a Preliminary Discussion on the Modelling of Taphonomic Bias in Archaeofaunal Age Profiles. Journal of Archaeological Science. Vol. 32. 1691-1698.

Szuma, E. 2007. Geography of Sexual Dimorphism in the Tooth Size of the Red Fox Vulpes vulpes (Mammalia, Carnivora). Journal of Zoological Systematics and Evolutionary Resources. Vol. 46. 73-81.

Tannahill, Reay. 1973. Food in History. New York: Stein and Day Publishers.

Templin, J. Alton. 1984. Ideology on a Frontier: The Theological Foundation of Afrikaner Nationalism, 1652-1910. Westport, Connecticut: Greenwood Press.

Teuteberg, Hans J. 1986. Periods and Turning-Points in the History of European Diet: A 
Preliminary Outline of Problems and Methods. In Food in Change: Eating Habits from the Middle Ages to the Present Day. Edited by Alexander Fenton and Eszter Kisban. Scotland: John Donald Publishers.

Thackeray, Francis. 1989. "Report on Analysis of Mammalian Fauna from Excavations at the Cape Castle (CA88, F1 and F2)." Unpublished report to Martin Hall. University of Cape Town.

Theal, George McCall. 1897. History of South Africa Under the Dutch East India Company, 1652-1795. London: Swan Sonnenschein and Company.

Theal, George McCall. 1910. History of South Africa, Volume 1: Ethnography and Condition of South Africa Before AD 1505. London: George Allen and Unwin.

Thirsk, Joan. 2007. Food in Early Modern England: Phases, Fads, Fashions 1500-1760. Great Britain: Hambledom Continuum.

Thom, Hendrik Bernardus. 1936. Die Geskiedenis van die Skaapsboerdery in SudAfrika. Amsterdam: Swets and Zeitlinger.

Thom, Hendrik Bernardus, Editor. 1942. Willem Stephanus van Ryneveld se Aanmerkingen over de Verbetering van het Vee aan de Kaap de Goede Hoop, 1804. Cape Town: Van Riebeeck Society 23.

Thom, Hendrik Bernardus, Editor. 1952. Journal of Jan van Riebeeck Volume I: 16511655. Cape Town: A. A. Balkema.

Thomas, Richard. 2005. Zooarchaeology and the British Agricultural Revolution. International Journal of Historical Archaeology. Vol. 9. 71-88.

Thomas, Robin. 1988. A Statistical Evaluation of Criteria Used in Sexing Cattle Metapodials. Archaeozoologia. Vol. II/1,2. 83-92.

Trow-Smith, Robert. 1951. English Husbandry: From the Earliest Times to the Present. London: Faber and Faber, Ltd.

Trow-Smith, Robert. 1957. A History of British Livestock Husbandry to 1700. London: Routledge and Kegan Paul.

Trow-Smith, Robert. 1959. A History of British Livestock Husbandry 1700-1900. London: Routledge and Kegan Paul.

Tucker, B. K., D. L. Hutchinson, M. F. G Gilliland, T. M Charles, H. J. Daniel, and L. D. Wolfe. 2001. Microscopic Characteristics of Hacking Trauma. Journal of Forensic Science. Vol. 46. 234-240. 
Tuma, Michael. 2006. Ethnoarchaeology of Subsistence Behaviors within a Rural African American Community: Implications for Interpreting Vertebrate Faunal Data from Slave Quarter Areas of Antebellum Plantation Sites. Historical Archaeology. Vol. 40. 1-26.

Uerpmann, Hans-Peter. 1978. Metrical Analysis of Faunal Remains from the Middle East. In Approaches to Faunal Analysis in the Middle East. Edited by Richard Meadow and Melinda Zeder. Massachusetts: Peabody Museum of Archaeology and Ethnology, Harvard University. 41-45.

Unger, Richard. 1980. Dutch Herring, Technology, and International Trade in the Seventeenth Century. The Journal of Economic History. Vol. 40. 253-280.

Valentyn, Francois. 1971. Description of the Cape of Good Hope with the Maters Concerning It: Amsterdam 1726, Part I. Edited by P. Serton, R. Raven-Hart, and W. J. de Kock. Translated by R. Raven-Hart. Cape Town: Van Riebeeck Society.

Valentyn, Francois. 1973. Description of the Cape of Good Hope with the Maters Concerning It: Amsterdam 1726, Part II. Edited by E. H. Raidt. Translated by R. Raven-Hart. Cape Town: Van Riebeeck Society.

Van der Merwe, P. J. 1995. The Migrant Farmer in the History of the Cape Colony; 1657-1842. Translated by Roger Beck. Athens, Ohio: Ohio University Press.

Van Wijngaarden-Bakker, Louise. 1984. Faunal Analysis and Historical Record: Meat Preservation and the Faunal Remains at Smeerenburg, Spitsbergen. In Animals and Archaeology: 4. Husbandry in Europe. Edited by Caroline Grigson and Juliet Clutton-Brock. BAR International Series 227.

Villa, P. and E. Malhieu. 1991. Breakage Patterns of Human Long Bones. Journal of Human Evolution. Vol. 21. 27-48.

Von den Driesch, Angela. 1976. A Guide to the Measurement of Animal Bones from Archaeological Sites. Cambridge, Mass.: Peabody Museum of Archaeology and Ethnology, Harvard University.

Von der Donk, Adriaen. 1968. A Description of the New Netherland. Edited by Thomas F. O’Donnell. Syracuse: Syracuse University Press.

Wade, Nicholas. 2006. Study Detects Recent Instance of Human Evolution. New York Times. December 10, 2006. http://www.nytimes.com/2006/12/10/science/10cndevolve.html?ei=5090\&en=6576a01albb4ce31\&ex=1323406800\&partner=rssuser land\&emc $=$ rss\&pagewanted $=$ print.

Wallerstein, Immanuel. 1980. The Modern World-System II: Mercantilism and the 
Consolidation of the European World-Economy, 1600-1750. New York: Academic Press.

Walton, James. 1974. Water-mills, Windmills and Horse-mills of South Africa. Cape Town: C. Struik Publishers.

Waters, Michael. 1992. Principles of Geoarchaeology: A North American Perspective. Tucson: University of Arizona Press.

Watson, J. P. N. 1978. The Interpretation of Epiphyseal Fusion Data. In Research Problems in Archaeology. Edited by Don Brothwell, K. D. Thomas, and Juliet Clutton-Brock. London: University of London, Institute of Archaeology, Occasional Publication No. 3. 97-101.

Watson, Patty Jo. 2007. The New Archaeology and After. In Archaeological Anthropology: Perspectives on Method and Theory. Edited by James Skibo, Michael Graves, and Miriam Stark. Tucson: The University of Arizona Press. vii-x.

Watson, Patty Jo, Steven LeBlanc, Charles Redman. 1984. Archaeological Explanation: The Scientific Method in Archeology. New York: Columbia University Press.

Webster, Jane. 2008. Less Beloved. Roman Archaeology, Slavery and the Failure to Compare. Archaeological Dialogues. Vol. 15. 103-123.

Weckerly, Floyd. 1998. Sexual Size Dimorphism: Influence of Mass and Mating Systems in the Most Dimorphic Mammals. Journal of Mammalogy. Vol. 79. 3352.

West, Barabara. 1982. Spur Development: Recognizing Caponized Fowl in Archaeological Material. In Ageing and Sexing Bones from Archaeological Sites. Edited by Bob Wilson, Caroline Grigson, and Sebastian Payne. London: BAR British Series 109. 255-261.

Whestphal, E. O. J. 1963. The Linguistic Prehistory of Southern Africa. Africa. Vol. 33. $237-264$.

White, E. M. and L. A. Hannus. 1983. Chemical Weathering of Bone in Archaeological Soils. American Antiquity. Vol. 48. 316-322.

Whittaker, William E. 1999. Production of Animal Commodities at Plum Grove, Iowa City. Historical Archaeology. Vol. 33. 44-57.

Wilkens, W. H., editor. 1901. South Africa a Century Ago: Letter Written from the Cape of Good Hope (1797-1801). New York: Dodd, Mead, and Co. 
Willner, L. A. and R. D. Martin. 1985. Some Basic Principles of Mammalian Sexual Dimorphism. In Human Sexual Dimorphism. Edited by J. Ghesquiere, R. D. Martin, and F. Newcombe. Philadelphia: Taylor and Francis. 1-42.

Wilmsen, E. N. 1989. Land Filled with Flies: A Political Economy of the Kalahari: 65. Chicago: Chicago University Press.

Wilson, Bob. 1994. Mortality Patterns, Animal Husbandry, and Marketing in and Around Medieval and Post-Medieval Oxford. In Urban and Rural Connexions: Perspectives from Environmental Archaeology: Symposia of the Association for Environmental Archaeology No. 12. Edited by A. R. Hall and H. K. Kenward. Oxford: Oxbow Books. 103-116.

Wolf, Eric. 1997. Europe and the People Without History. Berkeley: University of California Press.

Wood, K. G. 1985. Life in New Leeds: Archaeological and Historical Investigations at the Fahm Street Extension Site 9 CH703 (FS), Savannah, Georgia. Report submitted to the City of Savannah, Georgia by Southeastern Archaeological Services, Athens, Georgia.

Wood, Raymond and Donald Johnson. 1978. A Survey of Disturbance Processes in Archaeological Site Formation. In Advances in Archaeological Method and Theory, Vol. 1. Edited by Michael Schiffer. New York: Academic Press. 315381.

Woodborne, Stefan. 1988. Unpublished field notes from the F2 Granary excavations. Archaeological Contracts Office, University of Cape Town.

Woolgar, C. M. 2006. Meat and Dairy Products in Late Medieval England. In Food in Medieval England. Edited by C. M Woolgar, D Sarjeantson, and T. Waldron. Oxford: Oxford University Press. 102-130.

Woolgar, C. M., D. Serjeantson, and T. Waldron. 2006. Conclusion. In Food in Medieval England. Edited by C. M Woolgar, D Sarjeantson, and T. Waldron. Oxford: Oxford University Press. 267-280.

Yates, Royden and Andrew Smith. 1993. A Reevaluation of the Chronology of Oudepost: A Reply in Part to Schrire. South African Archaeological Bulletin. Vol. 48. 52-53.

Yates, Royden, Stefan Woodborne, and Martin Hall. n.d. The Chronology of Colonial Settlement at the Cape of Good Hope: Clay Tobacco Pipes. Unpublished manuscript for the Department of Archaeology, University of Cape Town.

Yellen, John. 1991. Small Mammals: Post-discard Patterning of !Kung San Faunal 
Remains. Journal of Anthropological Archaeology. Vol. 10. 1-26.

Yentsch, Ann. 1994. A Chesapeake Family and Their Slaves: A Study in Historical Archaeology. New York: Cambridge University Press.

Zalkin, V. I. 1960. Metapodialia Variation and its Significance for the Study of Antient Horned Cattle. Biulleten Moskovskoe Obschhesto Ispytatelei Pirody Otdel Denii Biologicheskei. Vol. 65. 109-126.

Zeder, Melinda. 1984. Meat Distribution at the Highland Iranian Urban Center of Tal-E Malyan. In Animals and Archaeology: Early Herders and Their Flocks. Edited by Juliet Clutton-Brock and Caroline Grigson. Oxford: BAR International Series, British Archaeological Reports. 279-307.

Zeder, Melinda. 2008. A Metrical Analysis of a Collection of Modern Goats (Capra hircus aegargus and $C . h$. hircus) from Iran and Iraq: Implications for the Study of Caprine Domestication. Journal of Archaeological Science. Vol. 28. 61-79.

Zierden, Martha and Elizabeth Reitz. 2009. Animal Use and the Urban Landscape in Colonial Chalreston, South Carolina, USA. International Journal of Historical Archaeology. Vol. 13. 327-365.

\section{Unpublished Cape Archives}

J188 Census Records

J189 Census Records

J193 Census Records

J194 Census Records

J195 Census Records

J196 Census Records

J197 Census Records

J198 Census Records

J199 Census Records

J200 Census Records

MOOC 7/1/25 Cape Archives Estate Papers 
M1/377 Maps

M1/1103 Maps

\section{Unpublished Algemeen Rijksarchief, The Hague}

VOC 4004. Overgekomen brieven en papieren van Kaap de Goede Hoop 1669. Folio 591-633, 893-894. Journal en grootboeck van de winckel.

VOC 4008. Overgekomen brieven en papieren van Kaap de Goede Hoop 1672. Folio 453. Journal en grootboeck van de winckel.

VOC 4010. Overgekomen brieven en papieren van Kaap de Goede Hoop 1673. Folio 547-625. Journal en grootboeck van de winckel.

VOC 4047. Overgekomen brieven en papieren van Kaap de Goede Hoop 1700-1701. Folio 533, 547, 554, 571, 583, 589. Journal en grootboeck van de winckel.

\section{CURRICULUM VITA}

\section{Adam Robert Heinrich}

\section{Education}

2010 Ph.D. in Anthropology, Rutgers University 
2005 M.A. in Anthropology, Rutgers University

2000 B.Sc. in Evolutionary Anthropology, Rutgers University

\section{Academic and Related Positions}

2010 spring: Instructor, 355:302:05 Scientific and Technical Writing, Rutgers University 2010 spring: Instructor, 355:302:06 Scientific and Technical Writing, Rutgers University 2009-present: Field Assistant, Richard Hunter and Associates, Trenton, New Jersey 2002-2009: Field and lab Assistant, Cultural Resources Consulting Group, Highland

Park, New Jersey

2009 fall: Instructor, 355:302:06 Scientific and Technical Writing, Rutgers University 2009 fall: Instructor, 355:302:07 Scientific and Technical Writing, Rutgers University 2009 fall: Teaching Assistant, 070:333 Colonial Archaeology, Rutgers University 2007-2008: Field and lab Assistant, Richard Grubb and Associates, Cranbury, New Jersey

2008 fall: Instructor, 355:302:08 Scientific and Technical Writing, Rutgers University 2008 fall: Instructor, 355:302:09 Scientific and Technical Writing, Rutgers University 2008 summer: Supervisor, Undergraduate and Graduate Joint Archaeological Field

School, Joseph Bonaparte House, Monmouth University

2008 spring: Teaching Assistant, 070:333 Colonial Archaeology Lab, Rutgers University

2007 fall: Instructor, 355:101:MK Expository Writing, Rutgers University

2007 fall: Instructor, 355:101:ND Expository Writing, Rutgers University

2007 summer: Supervisor, Undergraduate and Graduate Joint Archaeological Field

School, Joseph Bonaparte House, Monmouth University

2007 spring: Instructor, 070:105 Introduction to Archaeology lecture and lab, Rutgers University

2006 fall: Instructor, 070:105 Introduction to Archaeology lecture and lab, Rutgers University

2006 summer: Supervisor, Undergraduate Archeological Field School, Abraham Staats House/Joseph Bonaparte House, Monmouth University

2006 spring: Teaching Assistant, 070:105 Introduction to Archaeology and lab, Rutgers University

2005 fall: Teaching Assistant, 070:358/359 Human Osteology lecture and lab, Rutgers University

2004 fall: Teaching Assistant, 070:105 Introduction to Archaeology and lab, Rutgers University

2004 summer: Teaching Assistant, 070:334 Archaeological Field School, John Henry House 28-ME-300 site, Rutgers University

2004 summer: Supervisor, Undergraduate Archeological Field School, Merchants and Drovers Tavern, Monmouth University

2004 summer: Supervisor, Graduate Archaeological Field School, Merchants and Drovers Tavern, Monmouth University

2004 spring: Teaching Assistant, 070:105 Introduction to Archaeology and lab, Rutgers University, Head Teaching Assistant

2003 fall: Teaching Assistant, 070:105 Introduction to Archaeology and lab, Rutgers University

2003 spring: Teaching Assistant, 070:230 Indians of North America, Rutgers University 
2002 fall: Teaching Assistant, 070:330 Archaeology of Australasia, Rutgers University

2002 fall: Teaching Assistant, 070:208 Survey of Historical Archaeology, Rutgers University

2002 summer: Teaching Assistant, 070:334 Archaeological Field School, 28-ME-127 prehistoric site, Rutgers University

2002 spring: Teaching Assistant, 070:330 Archaeology of Australasia, Rutgers University

2002 spring: Teaching Assistant, 070:333 Colonial Archaeology Lab, Rutgers University

2001 fall: Teaching Assistant, 070:208 Survey of Historical Archaeology, Rutgers University

2001 summer: Supervisor, James Fort site, APVA Jamestown Rediscovery/University of Virginia

2000 summer: Supervisor, James Fort site, APVA Jamestown Rediscovery/University of Virginia

2000-2001: Field and lab Assistant, James Fort Site, APVA Jamestown Rediscovery, Jamestown, Virginia

\section{Presentations:}

2002: "Remember Me..." but "Be Mindfull of Death": The Art of Commemoration in Eighteenth Century Monmouth County, New Jersey." Rutgers University Anthropology Department Second Year Graduate Student Retreat.

2003: "Remember Me..." but "Be Mindfull of Death": The Art of Commemoration in Eighteenth Century Monmouth County, New Jersey." Society of Historical Archaeology Conference, Providence, Rhode Island.

2006: “A Zooarchaeological Investigation of the Dutch East India Company's Meat Industry at the Cape of Good Hope During the Late Seventeenth and Eighteenth Centuries." Society of Historical Archaeology Conference, Sacramento, California.

2010 "Critiquing Slave Diet: The Importance of Taphonomy to Zooarchaeological Interpretations." Society of Historical Archaeology Conference, Amelia Island, Florida. 